UNIVERSIDAD POLITÉCNICA DE MADRID

ESCUELA TÉCNICA SUPERIOR DE ARQUITECTURA DE MADRID

\title{
El Llibre de traces de biaix y montea de Joseph Ribes
}



Departamento de Patrimonio Arquitectónico

Escuela Técnica Superior de Arquitectura de Madrid

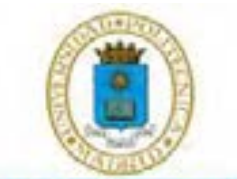

POLITÉCNICA

\section{El Llibre de traces de biaix y montea de Joseph Ribes}

Tesis Doctoral presentada por el arquitecto D. Fabio Tellia bajo la dirección del doctor arquitecto D. Jose Carlos Palacios Gonzalo 

Tribunal nombrado por el Sr. Rector Magfco. De la Universidad Politécnica de Madrid, el día. de...... de $20 \ldots$.

Presidente:

Vocal:

Vocal:

Vocal:

Secretario:

Suplente:

Suplente:

Realizado el acto de defensa y lectura de la Tesis el día de. de $20 \ldots$. en la E.T.S.I. / Facultad

Calificación

EL PRESIDENTE

LOS VOCALES

EL SECRETARIO 



\section{Índice}

Resumen

Abstract

\section{Introducción y objetivos}

1.1 Importancia del manuscrito

1.2 Ámbito geográfico y temporal

1.3 Implicaciones históricas del documento: la extensión del Tardo gótico,

El Gótico de Después: Nach Gotik

1.4 Estructura tesis

1.5 Objetivos

\section{Estado del arte}

2.1 Estereotomía de la piedra

2.1.1 Conceptos

2.1.2 Definición

2.1.3 El despiece

2.1.4 La montea

2.1.5 Los métodos de talla

2.1.6 Las herramientas del cantero $\quad 30$

2.1.7 La organización de la obra 31

2.1.8 La Piedra

2.2 Manuscritos de estereotomía antiguos

2.2.1 La codifica de la estereotomía 32

2.2.2 Manuscritos Góticos y Tardogóticos centroeuropeos 34

2.2.2 Los tratados de estereotomía en España 36

2.3 Otros manuscritos catalanes $\quad 39$

2.4 Autores Contemporáneos $\quad 40$

2.5 Contexto histórico $\quad 44$

2.6 Trasmisión del saber $\quad 48$

2.6.1 Antes de la llustración $\quad 48$

$\begin{array}{ll}\text { 2.6.2 Llegada de la llustración } & 49\end{array}$

$\begin{array}{ll}\text { 3. Metodología } & 51\end{array}$

3.1 El Manuscrito $\quad 52$

3.2 Contenido y estructura del manuscrito $\quad 54$

3.3 Elenco trazas $\quad 56$

3.4 El papel y la marca de agua $\quad 59$

$\begin{array}{ll}3.5 \text { Léxico } & 60\end{array}$

$\begin{array}{ll}3.6 \mathrm{El} \text { Autor } & 62\end{array}$

\section{Arcos}

4.1 Primer bloque: arcos rectos, arcos elípticos, arcos en esquina o rincón, arcos cóncavos y convexos, arcos en talud y arcos avanzados 
4.3 Tercer bloque: arcos en viaje con superficie de intradós no cilíndrica

4.3.1 Notas históricas sobre los arcos oblicuos

5. Bóvedas y bóvedas compuestas 103

5.1 Bóvedas de arista $\quad 103$

5.2 Bóvedas en rincón de claustro 105

5.3 Bóvedas en vuelta de horno (esféricas y de directriz curva) 110

$\begin{array}{ll}\text { 5.3.1 Bóvedas esféricas } & 110\end{array}$

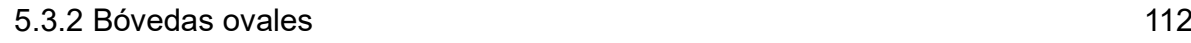

5.3.3 Trompas esféricas $\quad 113$

5.3.4 Volta ab sub biño - Bóveda en patio redondo (anular) 118

5.3.5 Bolta per aresta que las filadas rrodan - Bóveda de arista por hiladas redondas 120

5.4 Bóvedas compuestas $\quad 124$

$\begin{array}{lr}\text { 6. Bóvedas de crucería } & 127\end{array}$

6.1 Descripción tipológica elemento y características geométricas $\quad 130$

6.2 La persistencia del gótico en el siglo XVIII, el gótico de después 132

6.3 Clasificación geométrica de las bóvedas de Ribes $\quad 132$

6.3.1 Bóvedas en planta cuadrada y rectangular $\quad 132$

6.3.2 Bóvedas estrelladas $\quad 133$

6.3.3 Bóvedas en red 136

6.3.4 Bóvedas en planta triangular, redonda y octagonal 144

6.4 Otros elementos compositivos de la bóveda: plementería, enjarjes, claves 150

6.4.1 Plementería y jarjas $\quad 150$

6.4.2 Claves $\quad 150$

6.4.3 Las claves verticales $\quad 152$

6.4.4 Las claves inclinadas $\quad 154$

6.4.5 El dibujo de las claves inclinadas $\quad 154$

$\begin{array}{lr}\text { 7. Capialzados } & 159\end{array}$

7.1 Rrebolcura de marcella - Capialzado de Marsella $\quad 160$

7.2 Rropolt de mercella, anell y rrevol - Capialzado de Marsella, anillo y revuelto 163

7.3 Rravol ascasa - Capialzado de Marsella escarzano $\quad 165$

7.4 Anell y rravol ascasa - Capialzado de Marsella escarzano anillo y revuelto 165

7.5 Rravol ab canto - Capialzado de Marsella en esquina 166

7.6 Anell y rravol tot en una pesa ab canto - Capialzado de Marsella en esquina todo $\begin{array}{ll}\text { de una pieza } & 168\end{array}$

7.7 Rravol ab talus y canto - Capialzado de Marsella en esquina y talud 168

7.8 Rravol ab raco - Capialzado de Marsella en rincón $\quad 170$

7.9 Anell y rravol ab raco - Capialzado de Marsella en rincón anillo y revuelto 170

7.10 Rravol ab talus y rraco - Capialzado de Marsella en rincón y talud 172

7.11 Rravol biax - Capialzado de Marsella en viaje 173

7.12 sin nombre - Capialzado de Marsella en viaje (en paso oblicuo) 174

7.13 Rravol ab torra rrodona - Capialzado de Marsella en torre redonda 176

7.14 Rravol ab talus y torra rrodona - Capialzado de Marsella en torre redonda y talud 178

7.15 Anell y rravol ab torra rrodona - Capialzado de Marsella en torre redonda (sic) anillo y revuelto 178

7.16 Rravol ab talus y torra rrodona - Capialzado de Marsella torre redonda y talud 178

7.17 Rrabol ab torra acabada - Capialzado de Marsella en torre cava 179

7.18 Rravol ab talus y torra acabada - Capialzado de Marsella en torre cava y talud $\quad 179$

7.19 Rravol ab torra acabada y torra rrodona - Capialzado de Marsella torre cava y redonda 179

7.20 Rravol ab talus torra cavada. torra rodona, per dins - Capialzado de Marsella en torre

cava y talud, en torre redonda hacia adentro 
7.21 Rravol ab canto y torra acabada - Capialzado de Marsella en esquina y torre cava 181

7.22 Rravol ab talus y canto y torra acabada - Capialzado de Marsella en talud en esquina

y torre cava $\quad 181$

7.23 Rravol ab rraco y ab torra cabada - Capialzado de Marsella en rincón y torre cava 181

7.24 Rravol rodo - Capialzado redondo 184

7.25 Rravol rodo anell y rravol - Capialzado redondo anillo y revuelto 184

7.26 Rravol rracole - Capialzado en puerta cuadrada 186

7.27 Rravol rracole, anell y rrevoll - Capialzado en puerta cuadrada anillo y revuelto 186

\section{Trompas}

8.1 Patxina ab canto - Trompa en esquina con trompillón en diente de sierra 196

8.2 Patxina ab canto - Trompa en esquina 202

8.3 Patxina ab canto (escasana) - Trompa en esquina de arco escarzado 202

8.4 Patxina dela primera planta - Trompa de medio punto 204

8.5 Patxina dela primera planta - Trompa de medio punto 206

8.6 Patxina apañada - Trompa de medio punto de tres paños (poligonal) 206

8.7 Patxina ab torra rrodona - Trompa en torre redonda 210

$\begin{array}{lr}\text { 9. Escaleras } & 217\end{array}$

9.1 Caragol - Escalera de caracol de husillo 218

9.2 Caracol de Mallorca $\quad 221$

9.3 Escala ab dos rraplans - Escalera de dos rampantes 224

9.4 Vis de Saint Gilles $\quad 230$

10. Capiteles pinjantes $\quad 235$

10.1 Clasificación geométrica 238

10.2 Capitel pinjante entre arcos sucesivos 238

10.3 Capitel pinjante entre arcos perpendiculares 244

10.3.1 Palau de la Generalitat $\quad 245$

$\begin{array}{ll}\text { 10.3.2 Palau Mercader } & 248\end{array}$

10.3.3 Ca la Mercè y Casa Amatller $\quad 251$

10.4 Un episodio catalán 251

11. Construcción de una bóveda de crucería del Llibre de trasas 255

11.1 Influencias del gótico alemán $\quad 255$

11.2 Hipótesis de trazado $\quad 255$

11.3 Método de dibujo alemán: El Prinzipalbogen 257

$\begin{array}{ll}11.4 \text { La Montea } & 259\end{array}$

11.5 La labra de los nervios $\quad 261$

$\begin{array}{ll}11.6 \text { Las jarjas } & 261\end{array}$

11.7 Las claves $\quad 262$

11.8 Las cimbras $\quad 262$

11.9 La construcción y el descimbrado 263

11.10 Estudio paramétrico de la volta ab dotsa claus 266

12. Conclusiones 269

12.1 Análisis del Llibre de trasas de viax y muntea 269

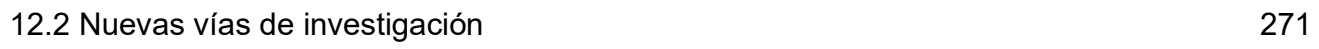

$\begin{array}{ll}\text { 13. Bibliografía } & 275\end{array}$

13.1 Bibliografía de referencia $\quad 276$ 


\section{Resumen}

El Llibre de trasas de viax y muntea (1708) es un extraordinario manuscrito sobre cantería y estereotomía redactado a principios de siglo XVIII en Barcelona por Joseph Ribes, un mestre de obras del cual sabemos muy poco. Contiene 135 modelos de trazas de cantería, algunas de ellas de origen clásico y, otras, de inspiración gótica. Su contenido abarca la construcción en piedra de cantería de arcos, trompas, capialzados, escaleras, así como un extraordinario repertorio de bóvedas de crucería y adoveladas. Algunas de estas trazas son conocidas por estar presentes en anteriores tratados, otras son originales y totalmente inéditas. El tratado carece de un texto que describa el procedimiento empleado para llevar a cabo la construcción geométrica expuesta, afortunadamente, las trazas están meticulosamente dibujadas lo cual hace innecesarias mayores explicaciones a un lector familiarizado en el arte de la cantería. Sólo al final el manuscrito consta de un apartado de pocas páginas que instruyen cómo enlucir paramentos de piedra y fabricar morteros.

La fecha de redacción de este manuscrito, 1708, le añade un indudable valor, ya que constituye una excelente fuente documental para el conocimiento del arte de la cantería en la Barcelona del siglo XVII, previa al profundo cambio que se iba a producir en la estructura política e institucional de Cataluña como consecuencia del cambio dinástico del reino de España. Venimos introducidos en un momento histórico en que la transmisión del arte de la cantería se producía o por vía oral, o se limitaba a manuscritos de escasa difusión. En España, al contrario de lo que sucedía en Francia, antes de la llustración, los tratados de cantería no fueron nunca publicados, sólo algunos fueron reproducidos y muchos otros se perdieron. El Llibre de Trasas, a día de hoy, es el único manuscrito de cantería de procedencia catalana que ha sobrevivido.

Una característica notable de esta obra es el extenso capítulo dedicado a las bóvedas de crucería góticas. El peculiar interés que Ribes manifiesta por ellas no es en realidad anacrónico, se inscribe en una innegable prolongación del gótico a lo largo de los siglos XVII y XVIII. Este gótico de después, escasamente conocido, está reclamando un estudio profundo que haga aflorar una arquitectura cuya existencia contradice la cronología de la historiografía más ortodoxa. Su desarrollo, paralelo al Barroco y Neoclásico, nos habla de perennidad de un estilo que termina por conectarse con el gótico romántico del siglo XIX.

Otra característica singular de las bóvedas de Ribes es que todas ellas tienen sus claves inclinadas; son claves en el que el eje del cilindro central se orienta hacia el centro de la bóveda. Esta particularidad constructiva, escasamente señalada, hace su aparición en las bóvedas de crucería construidas a partir del siglo XVI en España y Portugal. La talla de una clave inclinada, con sus correspondientes brazos de conexión, implica pasar de la proyección vertical de las claves tradicionales, a la proyección sobre el plano tangente; 
todo un logro geométrico de la cantería gótica. La clave inclinada, contrariamente a lo que sucede con la clave vertical que se talla con ayuda de su proyección horizontal, se talla a partir de su proyección sobre el plano tangente.

En la Escuela Técnica Superior de Arquitectura de Madrid, hemos tenido la oportunidad de construir una de las bóvedas de red de inspiración germánica descrita en el Llibre de Trasas, que nos ha permitido lograr un conocimiento más profundo de las geometrías de estas bóvedas y de la construcción de las claves inclinadas.

Los capiteles pinjantes son elementos arquitectónicos de complicada estereotomía que tienen una presencia importante en el repertorio estilístico catalán. Al momento este tema es carente de bibliografía y aunque no venga tratado en el manuscrito de Ribes, se ha considerado oportuno estudiar en esta tesis.

Palabras claves: Joseph Ribes, Llibre de Trasas de viax and muntea, estereotomía, bóvedas de crucería, claves inclinadas, cantería, traza, geometría, Barcelona, Cataluña, Historia de la Construcción, gótico, tardogótico, gótico de después, taller de cantería, capiteles pinjantes, prinzipalbogen. 


\section{Abstract}

The Llibre de trasas de viax y muntea (1708) is an extraordinary manuscript on stonework and stereotomy written at the beginning of the 18th century in Barcelona by Joseph Ribes, a stonemason of which we know very little. It contains 135 models of stone-cutting tracings, some of them of classical origin and others of Gothic inspiration. Its content comprises the construction in ashlar stone of arches, trompes (conical vaults), doorways, stairs, as well as an extraordinary repertoire of ribbed and ashlar vaults. Some of these traces are known to be present in previous treaties, others are original and never published before. The treaty lacks a text that describes the procedure used to carry out the exposed geometric construction, fortunately, the traces are meticulously drawn which makes further explanations unnecessary to a reader familiar in the art of stone-cutting. Only at the end the manuscript consists of a section of few pages that instruct how to plaster stone walls and make mortars.

The date of writing of this manuscript, 1708, adds an undoubted value, since it constitutes an excellent documentary source for the knowledge of the art of stonework in the 17thcentury Barcelona, prior to the profound change that would take place in the political and institutional structure of Catalonia as a result of the dynastic change of the kingdom of Spain. We have been introduced in an historical moment in which the transmission of the art of stereotomy occurred either orally or was constricted to manuscripts of limited distribution. In Spain, contrary to what happened in France, before the Enlightenment, the stereotomy treatises were never published, only some were reproduced, and many others were lost. The Llibre de Trasas, today, is the only stone manuscript of Catalan origin that has survived.

A notable feature of this treatise is the extensive chapter dedicated to Gothic ribbed vaults. The peculiar interest that Ribes expresses for them is not anachronistic, it is part of an undeniable prolongation of the Gothic throughout the 17th and 18th centuries. This latter gothic, barely known, is demanding an in-depth study that brings out an architecture whose existence contradicts the chronology of the most orthodox historiography. Its development, parallel to the Baroque and Neoclassical, tells us about the persistency of a style that ends up connecting with the romantic Gothic of the 19th century.

Another unique feature of Ribes' ribbed vaults is that they all have inclined keystones; they are keystones in which the axis of the central cylinder is oriented towards the center of the vault. This constructive peculiarity, scarcely indicated, makes its appearance in the ribbed vaults built from the 16th century in Spain and Portugal. The cutting of an inclined keystone, with its corresponding connecting arms, implies moving from the vertical projection of the traditional keystones, to the projection on the tangent plane; a geometric achievement of the Gothic stone-cutting. The inclined keystone is carved from its projection on the tangent 
plane, contrary to what happens with the vertical keystone that is carved with the help of its horizontal projection.

At the Superior Technical School of Architecture of Madrid (ETSAM), we have had the opportunity to build one of the Germanic-inspired network vaults described in the Llibre de Trasas, which has allowed us to gain a deeper understanding of the geometries of these vaults and the construction of the inclined keystones.

The suspended capitels are architectural elements of complicated stereotomy that have an important presence in the Catalan stylistic repertoire. Nowadays this topic is devoid of bibliography and although it is not treated in the Ribes' manuscript, it has been considered appropriate to study in this thesis.

Keywords: Joseph Ribes, Llibre de Trasas de viax and muntea, stereotomy, ribbed vaults, inclined keystone, stone-cutting, tracing, geometry, Barcelona, Catalonia, History of Construction, Gothic, Late gothic, stonemasonry workshop, suspended capitels, prinzipalbogen. 


\section{Agradecimientos}

El estudio del tratado de Ribes se ha convertido en una tesis doctoral gracias a la invaluable enseñanza y al entusiasmo del profesor José Carlos Palacios Gonzalo, al quien quiero expresar mi más grande reconocimiento.

He apreciado mucho los diálogos, sugerencias y tiempo que me han dedicado los profesores Enrique Rabasa Diaz y Giuseppe Fallacara.

También se querría recordar a la Biblioteca de Cataluña por permitir la consulta del Llibre de Trasas y la amabilidad de sus bibliotecarios. 


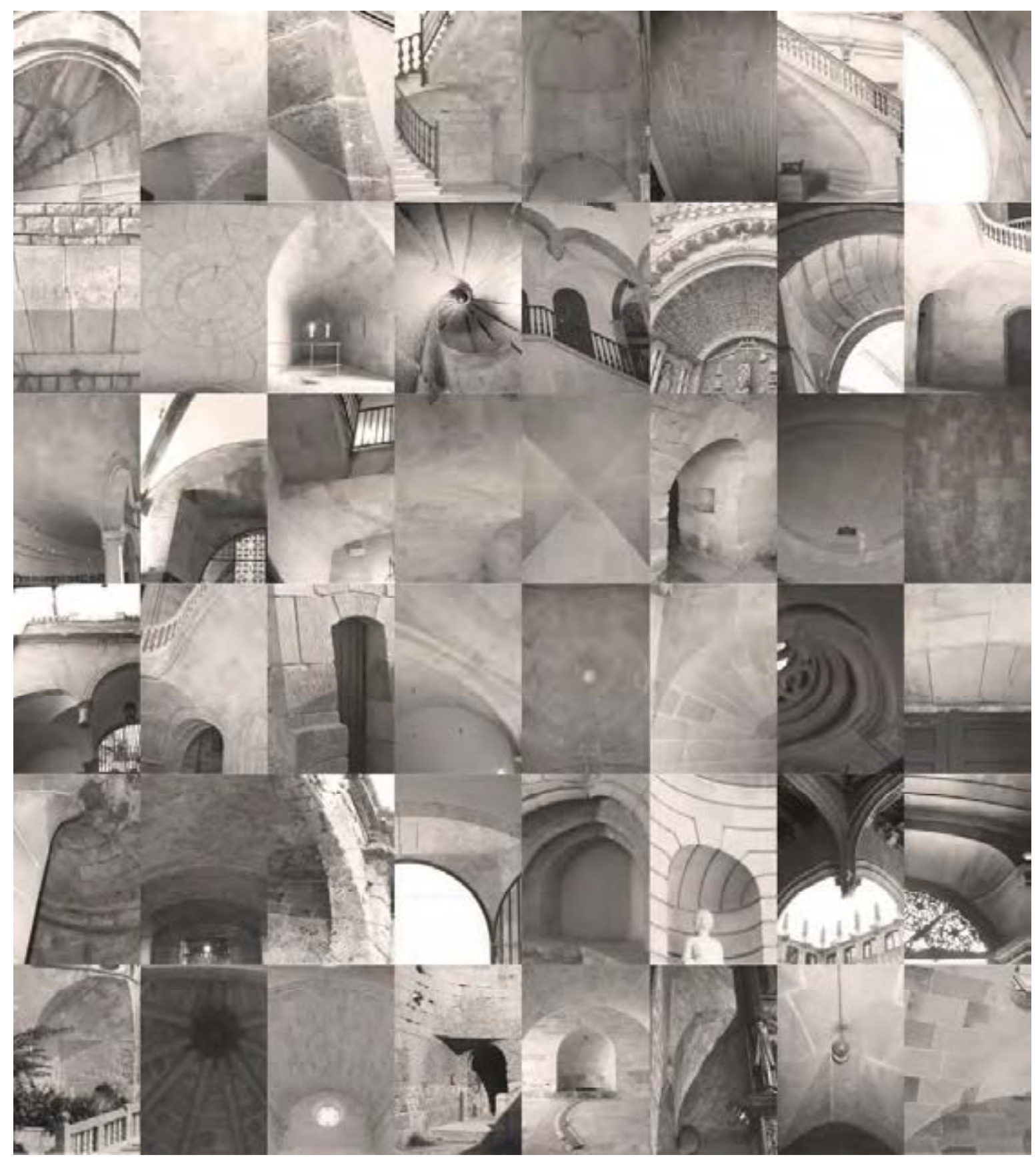

Fig. 0.1. Estereotomia en Cataluña 
El Llibre de traces de biaix y montea de Joseph Ribes 


\section{Introducción y objetivos}

En esta tesis se quiere estudiar el desconocido tratado de estereotomía del catalán Joseph Ribes: el Llibre de traces de biaix y montea, redactado a Barcelona en 1708. Al mismo tiempo se quiere poner de relieve la tradición y persistencia de la estereotomía en Cataluña y, en mesura más contenida, en los territorios del Mediterráneo a ella relacionados políticamente, en particular las Islas Baleares, abarcando un arco temporal que va desde los primeros aparejos de época románica hasta las obras de estampo neoclásico del principio del siglo $\mathrm{XX}$.

El manuscrito de Ribes es un exhaustivo tratado de estereotomía datado 1708 que incorpora trazas de montea de arcos, trompas, capialzados, escaleras, así como un amplio repertorio de bóvedas de crucería y adoveladas.

Este tratado, contiene una interesante recopilación de elementos de estereotomía, ya presente en anteriores tratados de herencia española y francesa, junto a algunos nuevos e insólitos cortes de cantería totalmente originales. Se piensa que este manuscrito es la conexión entre el conocimiento práctico de la cantería de tradición gótica de las tierras catalanas y las fecundas tradiciones estereotómicas del Levante, del Languedoc y de las Islas Baleares.

El estudio de sus trazas va a permitir poner de relieve la complejidad de dibujos, registrar sus singulares correspondencias con otros tratados y apreciar plenamente algunos de los originalísimos ejemplos que Ribes propone.

Este manuscrito ha sido estudiado por primera vez en esta tesis y hasta mis primeras publicaciones era casi desconocido en el ámbito de la historia de la construcción, sin embargo, una publicación anterior de historiadores del arte mencionaba su existencia sin ser objeto de particulares análisis ${ }^{1}$, y ha sido la fuente documental que me ha permitido conocer de la existencia del manuscrito. Guiado por la curiosidad, he podido consultar en la Biblioteca Nacional de Catalunya el documento original.

1 La bibliografía completa vendrá explicada en esta tesis en los capítulos a seguir 


\subsection{Importancia del manuscrito}

El Llibre de trasas es un documento extraordinario para una multitud de razones:

1. Unicidad. Se trata del único manuscrito catalán de estereotomía que al momento conocemos, aunque no se puede excluir la existencia de otros manuscritos.

2. Contenido. Es original en el contexto español. En particular el capítulo de las bóvedas de crucería, que es un tema que no ha sido desarrollado en manera tan extensiva en los otros tratados españoles y franceses.

3. Fecha. La fecha de compilación, 1708, testimonia los todavía existentes conocimientos gremiales en Barcelona. Se coloca en el momento de transición del periodo en el cual la transmisión de los conocimientos era por vía oral, al periodo de la llustración en el cual los conocimientos eran regulados por el poder estatal. Esta fue una fase compleja e importante por los profundos cambios que la caracterizaron.

4. Pervivencia del interés en el Gótico en el siglo XVIII. El extenso capítulo de bóvedas de crucería, único en los tratados de estereotomía, suporta la tesis que el gótico no se termina en el siglo XVI, sino continua vivo hasta enlazarse con las obras de concepción neogóticas del siglo XX.

5. Contexto. Representa elementos de la arquitectura en piedra de cantería presentes en Cataluña antes de la llegada de las academias.

6. Tazas inéditas. Las originalidades de las trazas presentadas representan soluciones inéditas que no aparecen en otros tratados de estereotomía.

Hace falta poner de relieve que el Llibre de trasas es el único manuscrito catalán conocido de estereotomía. No sabemos si directamente o indirectamente, el saber contenido en el tratado ha tenido influencia en ejemplos de arquitectura posterior a su fecha (como los arcos del Palau de la Virreina u otros ejemplos de arcos en esviaje en Barcelona). Quizás el tratado no era conocido a todos los maestros de obra que han producido elementos estereotómicos, pero ciertamente hacía referencia a un saber común que sobrevivía la arquitectura del estado central, cuales los arcos en esviaje que eran una reminiscencia de la arquitectura local

Los conocimientos se quedaban dentro de las estructuras gremiales, o mejor dicho dentro de las confrarias hasta la imposición del saber borbónico actuado a través de las Academias y de las instituciones estatales.

Por esta razón, el hecho que sea fechado a 1708 (Fig. 1.1) da al manuscrito más valor de fuente documental que testimonie los conocimientos del lugar.

La fecha de redacción de este manuscrito le añade un indudable valor, ya que constituye una excelente fuente documental para el conocimiento del arte de los maestros de cantería en la Barcelona del siglo XVII, previa al profundo cambio que se iba a producir en la estructura política e institucional de Cataluña como consecuencia del cambio dinástico del reino de 
España ${ }^{2}$. El libro de Ribes nos introduce en un momento histórico en que la transmisión del arte de la cantería se producía o por vía oral, o se limitaba a manuscritos de escasa difusión. En España antes de la llustración, al contrario de lo que sucedía en Francia, los tratados de cantería no fueron nunca publicados, sólo algunos fueron reproducidos y muchos otros se perdieron.

El manuscrito presenta algunas trazas inéditas y otras comunes en Francia, pero muy infrecuentes en España, como los capialzados de Marsella.

El gran número de bóvedas de crucería contribuye a documentar la tesis de pervivencia del gótico más allá de los límites temporales tradicionalmente determinados.

Impone además una revisión de lugares comunes de la historia de la arquitectura en Cataluña que no le reconoce, o quizás solo de forma limitada, la contribución al desarrollo de la estereotomía.

Por terminar, este manuscrito representa la correlación entre teoría y actividad constructiva y nos proporciona valiosas informaciones sobre la arquitectura de Barcelona. Muchos aparejos descritos en el tratado se encuentran en la ciudad.

Hace falta señalar que como consecuencia a particulares eventos históricos y a necesidades urbanísticas, algunas obras estereotómicas, de las cuales tenemos evidencia documental, han sido destruidas. Podemos recordar por ejemplo las destrucciones efectuadas por los Borbones a su llegada de todas las edificaciones de defensa que no eran propiedad real a través del Decreto de Nueva Planta, las destrucciones de la Ciudadela, los derribos del barrio de la Ribera consecuencia de la abertura de la vía Layetana, la construcción de la Plaza Reyal.

Otras veces es difícil encontrar referencias concretas de los elementos que se han destruidos; será oportuno recordar las destrucciones de la Setmana Tràgica de 1909, en la cual solo en Barcelona se incendiaron nada menos que ochenta edificios religiosos.

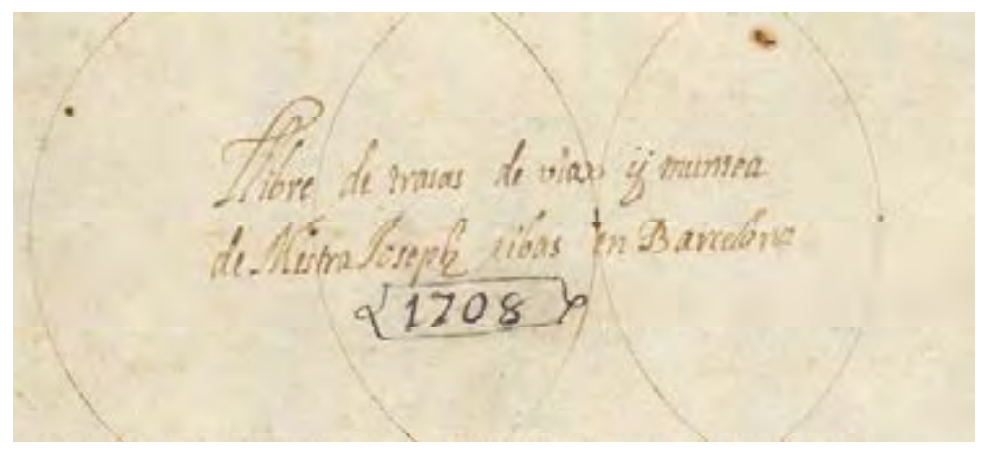

Fig. 1.1. Fecha en la portada del Llibre de trasas

\footnotetext{
2 Josep Maria Montaner, La Modernització de l'utillatge Mental de l'arquitectura a Catalunya (1714-1859) (Barcelona: Institut D'estudis Catalans, 1990). Describe la evolución del saber arquitectónico en Cataluña en la época de la llustración, detallando el pasaje de la cultura practica de los mestres de casas gremial a la cultura más técnica y científica, típica del siglo XVIII, que fue transmitida a los técnicos de la construcción principalmente por los cuerpos de Ingenieros y por las Academias. Anteriormente la Confraria dels Mestres de Cases i Molers tutelaba la actividad y enseñanza profesional.
} 


\section{2 Ámbito geográfico y temporal}

Esta tesis, a sus comienzos, se propuso de estudiar la estereotomía en Cataluña e Islas Baleares, de hecho, su título inicial era El arte de la estereotomía en Cataluña e Islas Baleares. Sucesivamente, por la gran cantidad de material encontrado y por su extensión relevante, ha sido necesario acotar el tema y enfocar el estudio en particular al tratado de Ribes y sus referencias más directas.

Sin embargo, se harán referencias a los territorios de influencia catalana como el Levante, Valencia, Perpiñán, Cerdeña y Sicilia; se citarán también ejemplos más tardíos de estereotomía de las Baleares, aunque, temporalmente e históricamente, ya no sean directamente bajo la influencia cultural y política de Cataluña. Se piensa que la cultura constructiva y el gusto arquitectónico implantado en los siglos del alto y bajo medioevo hayan pervivido y perdurado a través de los estilos arquitectónicos sucesivos.

En este contexto se quiere conectar a la cultura constructiva del Gótico Mediterráneo que ha sido exhaustivamente discutida por otros historiadores.

Se excluirán de esta tesis las obras con elementos estereotómicos del Modernismo Catalán y mallorquín que por su extraordinario interés y extensión necesitarían un estudio dedicado.

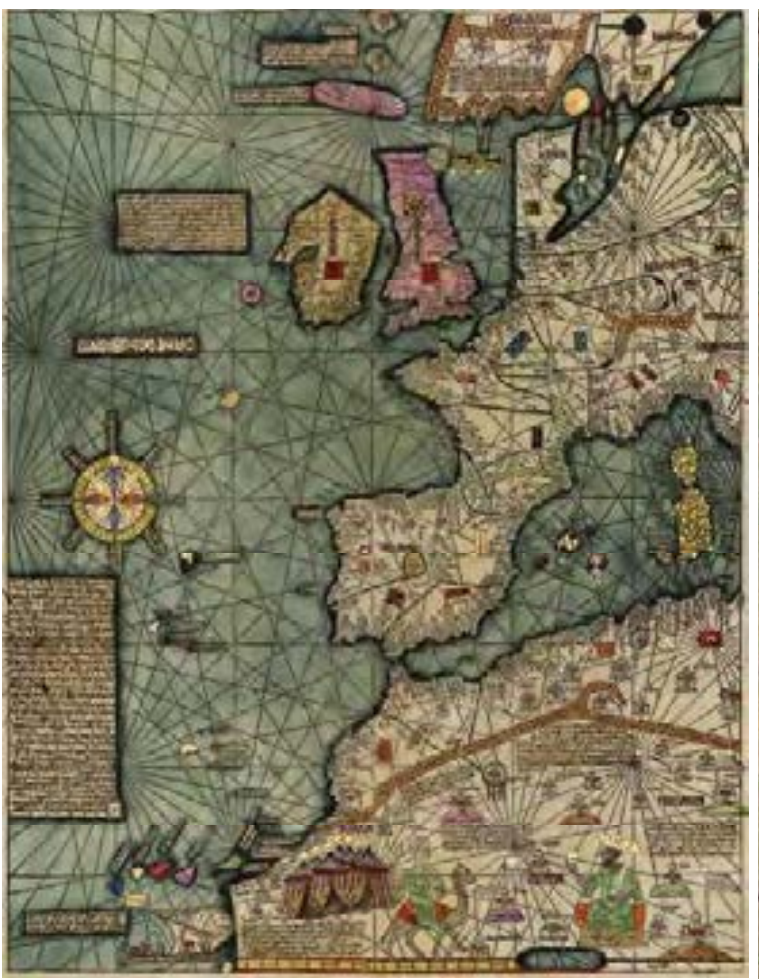

Fig. 1.2. Atles català, 1375. Atribuido a Cresques Abraham

Fig. 1.2. Atles català, 1375. Atribuido a Cresques Abraham

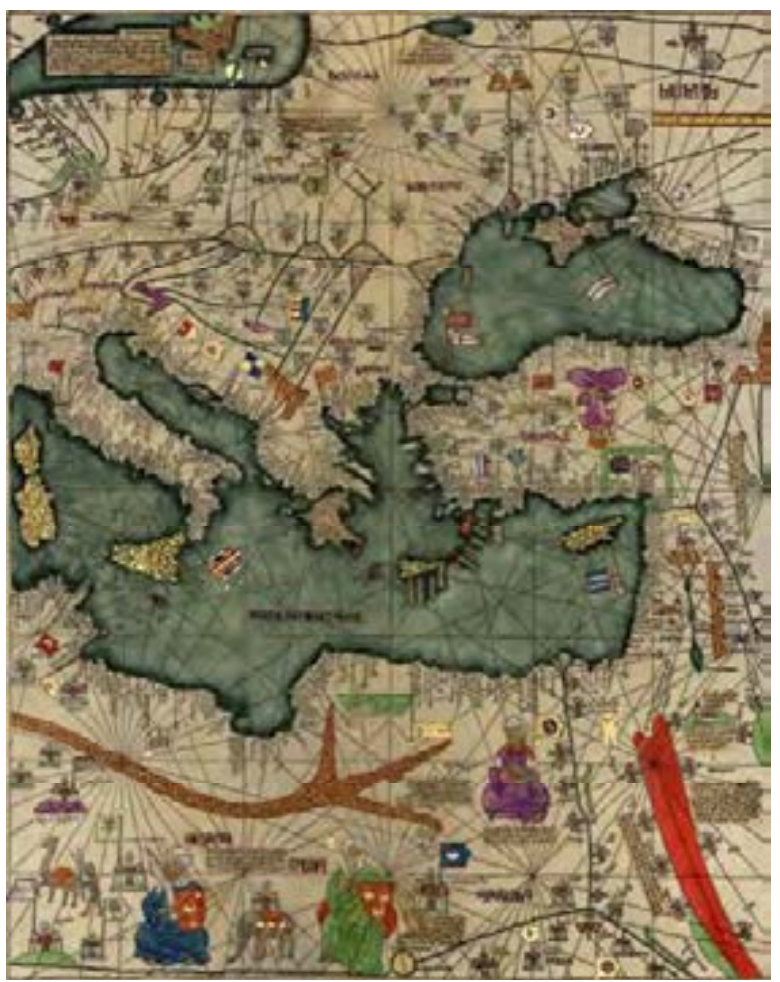




\subsection{Implicaciones históricas del documento: la extensión del Tardo gótico, El Gótico de Después: Nach Gotik}

El gótico tardío español, es decir aquel que se produce en el siglo $\mathrm{XVI}$, un siglo en el que el Renacimiento español alcanza su cenit, era escasamente apreciado hasta no hace demasiados años.

Quizás influido por la historiografía francesa que situaba en el siglo XIII francés, el siglo de las catedrales, el momento culminante del gótico europeo, el gótico fuera de Francia adquiría tientes provincianos y localistas. Este gótico, cuando además se producía fuera de su época, es decir, en pleno Renacimiento, constituía ya una anomalía histórica que sólo se podía explicar por la resistencia de gremios y talleres de origen medieval a desaparecer.

Afortunadamente esta situación ha cambiado radicalmente y ahora somos capaces de aceptar y valorar este gótico, el Tardogótico, como una brillante página de la arquitectura europea que coexiste y resiste con gallardía al deslumbrante despliegue de la arquitectura clásica.

Sin embargo, el tratado de Ribes y su interés por el gótico a comienzos del siglo XVIII, nos interpela de nuevo sobre la vitalidad de este estilo que, definitivamente, se resiste a desaparecer.

El tratado de Ribes no es un hecho aislado y periférico en el conjunto de España, sino que se ve acompañado por un buen número de construcciones que hacen de la bóveda de crucería su razón de ser. Sólo por poner un ejemplo, recordemos al respecto la formidable cabecera y las nuevas sacristías de la catedral de Salamanca, terminándose de construir en tiempos de Ribes.

Esta tesis, aparte de ocuparse del estudio del singular tratado de Ribes tiene un horizonte más amplio y quiere llamar la atención sobre el gótico de después del Tardogótico, o sea todo el gótico disperso y poco conocido que durante dos siglos y medios se extiende desde finales del XVI hasta la aparición de los historicismos del XIX; porque, forzoso es reconocerlo, el gótico tampoco se extingue con el Tardogótico.

Una vez más, como sucedió en Castilla en la segunda mitad del siglo XV, como le sucedió a Ribes con su bóveda en red, Alemania puede ayudarnos ahora, el Nach Gotik, el Gótico de Después, es ya un paradigma arquitectónico perfectamente establecido en ese país. 


\subsection{Estructura tesis}

Esta tesis se divide en dos partes, en la primera se describe el manuscrito y lo se coloca en la historia de la estereotomía con particular referencia a Cataluña, relacionando los factores políticos y culturales al periodo histórico al cual pertenece.

A seguir, en la segunda parte, para comprender el significado y la importancia del manuscrito, se analiza y descifra el contenido grafico que viene a su vez interpretado con dibujos originales y fotos que documentan los artefactos arquitectónicos de Cataluña y en los territorios del dominio catalán.

\subsection{Objetivos}

Sin lugar a dudas, esta investigación viene a rellenar un vacío documental de la historia de la estereotomía española del XVIII por la originalidad del tema: el Llibre de traces es un manuscrito de grandísimo interés y totalmente olvidado por los historiadores de la construcción; Cataluña es un territorio generalmente recordado por técnicas de construcción ligadas a la albañilería pero que, en el campo de la cantería estereotómica, también alcanzó niveles de extraordinaria calidad e interés; el estudio del Gótico Catalán, aunque rico en cuanto a textos que describen la historia y sus aspectos formales, carece de estudios sobre la geometría y la estereotomía de las bóvedas ${ }^{3}$; las relaciones artísticas entre Cataluña y los territorios mediterráneos con los cuales desarrolla relaciones culturales y políticas son riquísimas en cantidad y calidad e incluyen una multitud de obras de estereotomía.

Los objetivos que se quieren alcanzar en esta tesis son variados:

1. Contribuir a llenar en parte el vacío documental y la falta de estudios sobre la estereotomía catalana y el reducido número de estudios sobre el tardo gótico catalán.

2. Dar a conocer la obra de Ribes en primer lugar al ambiente académico y profesional, pero también hacer llegar al público catalán esta valiosa obra.

3. Estudiar el contenido de sus aspectos técnicos y analizar las relaciones con el contexto arquitectónico y con los factores socio-culturales.

4. Evidenciar las implicaciones que la fecha del manuscrito tiene en el contexto de la historia de la construcción. Por las implicaciones de la fecha tardía, verificar con el análisis del papel la fiabilidad y exactitud de la fecha mostrada en el texto.

5. Por último, empezar un inventario de arquitecturas estereotómicas en Cataluña de soporte a la tesis y de base para estudios futuros.

\footnotetext{
3 Marià Carbonell i Buades, "De Marc Safont a Antoni Carbonell: La Pervivencia de La Arquitectura Gótica En Cataluña," Artigrama, no. 23 (2008): 98.
} 


\section{Estado del arte}

\subsection{Estereotomía de la piedra}

\subsubsection{Conceptos}

Una de las primeras cualidades constructivas que caracterizan las edificaciones en piedra se puede identificar en la geometría de las piezas unitarias que constituyen los sillares o el dovelaje de la obra, que, según su tamaño y precisión del corte, permite distinguir una obra de cantería de una construcción en piedra más convencional ligada a técnicas de albañilería ${ }^{1}$. De hecho, una obra en piedra no es necesariamente una obra de estereotomía: es suficiente que la dovela sea simplemente desbastada y puesta en obra con la ayuda de mortero para que conforme el muro de fabrica o la cubierta deseada, como es el caso, por ejemplo, de las plementerías medievales y de las construcciones rusticas.

En cantería, una dovela, como fragmento más pequeño del conjunto, tiene un tamaño relativamente grande, que obliga que sea perfectamente diseñada y cortada para encajar en la posición correcta y garantizar en su conjunto la estabilidad del edificio.

Es necesario entonces conocer a priori sus dimensiones a través del dibujo previo de la pieza, proceso que en general es relativamente sencillo y que puede revelarse extremadamente complicado cuando se producen proyecciones y cortes afuera del plano horizontal o vertical. El cenit de este procedimiento se alcanza en la llamada "cantería de gran talla", cuando las dovelas, alcanzando dimensiones muy notables, necesitan de una gran precisión ejecutiva para la realización de las mismas al fin de asegurar la resistencia de la obra.

Las implicaciones en cuanto a técnica constructiva entre la "cantería de gran talla" y la albañilería son radicalmente distintas, así como la expresión figurativa de su autor y el poder económico del comitente.

Las condiciones de existencia que caracterizan una arquitectura estereotómica con respecto a una genérica obra en piedra se basan sobre tres principios determinantes²:

1. Aparejo. La voluntad estética en el corte y disposición de las dovelas

2. Técnica Proyectiva. La capacidad de definición puntual del elemento dovela

3. Estática. Capacidad de asegurar el equilibrio al conjunto arquitectónico juntado en seco

\footnotetext{
1 José Carlos Palacios Gonzalo, Trazas y Cortes de Canteria En El Renacimiento Español (Madrid: Ministerio De Cultura, Instituto De Conservación Y Restauración De Bienes Culturales, 1990): 13-21.

2 Giuseppe Fallacara, en: II paradigma stereotomico nell'arte del costruire (tesis doctoral, 2003): 43-44, ha identificado estos puntos interpretando el texto de Charles-Félix-Augustin Leroy, Traité de stéréotomie.
} 


\subsubsection{Definición}

La estereotomía ${ }^{3}$ es el arte de cortar sólidos para que sus piezas adhieran perfectamente una a la otra y garanticen la estabilidad del artefacto arquitectónico. Generalmente se refiere al corte de la piedra y tiene por objeto la división o despiezo más conveniente de una obra en porciones de tamaño tal que sean fáciles de obtener y manejar, determinando sus formas para que, una vez colocadas en obra, exista la trabazón y enlace suficientes que garanticen la necesaria estabilidad y resistencia del conjunto.

El proceso de construcción de una obra estereotómica necesita resolver tres operaciones necesarias:

1. despiece de la obra: el propósito estético para organizar las juntas de piedra de una manera que cumpla con los requisitos estructural-geométricos.

2. montea y determinación de las plantillas: la capacidad de describir geométricamente, mediante técnicas proyectivas, cualquier punto de un bloque para producir las plantillas requeridas (en escala 1:1) con un conjunto de reglas coherente y repetible.

3. labra de los sillares: el protocolo de corte de piedra que apunta a la creación eficiente y estandarizada de cualquier dovela, incluso con caras curvas y no ortogonales.

\subsubsection{El despiece}

Después haber determinado el tamaño del dovelaje que se va a utilizar en la obra, se plantea el problema fundamental de la estereotomía: la definición de la forma y de las dimensiones de cada una de las dovelas del elemento arquitectónico que pretendemos ejecutar ${ }^{4}$. En esta fase hay que atender dos criterios fundamentales, el invariante estático y la facilidad de ejecución.

La estabilidad de la fábrica es garantizada por la geometría y la masa resistente de los elementos estructurales en piedra. La estereotomía debe garantizar que el despiezo de la obra de fabrica haga posible que las tensiones que se producen en la obra misma puedan ser absorbidas sin inducir desplazamientos relativos entre las dovelas o rupturas de algunas de ellas.

La solidez mecánica tiene que satisfacer también el objetivo estético, considerar la facilidad y economía de ejecución, y tener en cuenta del poder económico del comitente que decretará la factibilidad de un especifico proyecto de dovelaje ${ }^{5}$.

El despiece se realiza a través de operaciones geométricas que pueden alcanzar niveles

\footnotetext{
3 El origen del término stéréotomie fue utilizado por primera vez por Jacques Curabelle en Examen des oeuvres du Sieur Desargues, su texto del 1644 dirigido contra Desargues, procede del griego stereos, sólido, y tomé, sección.

4 José Carlos Palacios Gonzalo, La Estereotomía En Las Construcciones Abovedadas (Madrid: Cuaderno del Instituto Juan de Herrera de la ETSAM, 1999): 4.

5 Proyectos demasiados ambiciosos en cuanto a virtuosidad estereotómica tuvieron repercusiones muy negativas sobre el presupuesto de la obra. A este propósito se quiere recordar la construcción de la Mola de Menorca que se quedó por terminar.
} 
de gran levadura y elegancia, dependiendo de la complejidad del aparejo y de la manera en que se resuelve la definición espacial de las dovelas. Mediante las proyecciones geométricas se determinan las verdaderas dimensiones de las caras y los ángulos que se crean entre ellas. Es posible entonces obtener las informaciones necesarias para conformar esas dovelas que no tienen caras que reposan directamente en el plano de horizonte. La sofisticación de los métodos de traza de los talleres de cantería medievales y renacentistas han desarrollado las técnicas para resolver estas cuestiones prácticas.

\subsubsection{La montea}

La montea, desarrollada en las grandes obras del medioevo, consistía en la reproducción a tamaño natural, mediante las técnicas de proyecciones, de los elementos en piedra del conjunto arquitectónico, con el fin de determinar las medidas reales de las varias piezas que la iban a conformar. El vehículo de transmisión de la forma y medida de las dovelas eran los patrones a tamaño natural ${ }^{6}$, plantillas de madera o papel que se aplicaban sobre el bloque de piedra a tallar para que sirvieran como guías para el proceso de labrado.

Se podía entonces trazar directamente sobre las piedras los contornos de las caras de las distintas piezas, las medidas lineales de las aristas y los ángulos que se producían entre las caras de las dovelas.

Las plantillas se sacaban directamente del trazado de la montea y su uso era imprescindible en toda la obra de cantería debido a la complejidad de las piezas a tallar.

La montea se ejecutaba sobre un tendido de yeso ${ }^{7}$ en el suelo o en la pared, en el lugar en que se iba a ejecutar el elemento arquitectónico o en las llamadas "salas de trazas", lugares específicamente dedicados a tal fin ya desde la edad media ${ }^{8}$.

La montea, o su equivalente francés art du trait, se avale de ingeniosos sistemas de construcción geométrica y de sistemas de proyecciones que eran guardados celosamente por los gremios medievales y preservados en el perpetuo silencio ${ }^{9}$. Solo la llegada del Renacimiento produjo la aparición de tratados sobre estereotomía de libre circulación que describían las formas constructivas de la cantería, desvelando Los secrets del' Architecteure $^{10}$, los métodos de proyección geométrica y los protocolos de talla de la piedra, fruto de la herencia del medioevo tardío.

\footnotetext{
6 Palacios Gonzalo, 1990; 16

7 Ricardo Boguerín, Ingeniero Jefe de Caminos, Canales y Puertos, y Profesor de la Escuela Especial del Cuerpo, en Lecciones de Estereotomía (Imprenta y fototipia de J. Lacoste. 1908 Madrid): 7, describe las superficies sobre las que se realiza la montea:

"Para hacer el trazado de la montea hay que preparar previamente una superficie a propósito. Si en las proximidades de la obra existiese un muro de bastante extensión y plano, bastará cubrirlo con un enlucido de cal. Si no se dispusiera de ningún muro, o fuese necesario representar más de una proyección, será preciso preparar en el suelo una superficie plana, para lo cual, después de bien igualado y apisonado el terreno, se colocarán una o dos capas de ladrillo puesto de plano, y sobre ellas el enlucido de cal.."

8 Alain Erlande-Brandenburg, Quand Les Cathédrales Étaient Peintes (Paris: Gallimard, 2009).

9 Gines Martínez de Aranda, Cerramientos y Trazas de Montea, Facsimilar (Madrid: CEHOPU, 1986).

10 Mathurin Jousse, Le Secret d'architecture... (La Fleche: Georges Griveau, 1642).
} 


\subsubsection{Los métodos de talla}

Después haber calculado los patrones se puede proceder al labrado de las correspondientes dovelas, operación que constituye fundamentalmente el oficio del cantero.

La estereotomía Renacentista y el desarrollo de la geometría permitió superar el método arcaico para la talla de esas dovelas conformadas afuera de los planos ortogonales, que Sakarovitvh ${ }^{11}$ define como talla por ravalement y consiste en aproximarse al volumen final después haber posicionado la dovela en obra. Las piedras vienen desbastadas lo suficiente para que quepan en su lugar y sucesivamente las caras vienen descantilladas y alisadas aproximándose por tanteos a la superficie deseada.

Existen dos procedimientos generales contemplados en la estereotomía Renacentista (Fig. 2.1 y 2.2): el método por robos y el método a baivel ${ }^{12}$, que responden a técnicas y aproches distintos y se colocan uno a los polos opuesto del otro, sin embargo, es posible identificar métodos híbridos a mitad de camino entre ambos procedimientos. No todas las dovelas pueden ser talladas indiferentemente con uno u el otro método: las dovelas de una bóveda de canon, por ejemplo, pueden ser talladas en ambas maneras, mientras que las dovelas de una cúpula de media naranja pueden ser labradas solo a través del método por baivel.

El método de corte por robos se basa en proyecciones y sólidos capaces. Requiere obtener el sólido capaz ${ }^{13}$ con forma de prisma recto de la pieza a labrar, obtener las proyecciones ortogonales de las caras de la pieza sobre la cara correspondiente del sólido capaz y, "robando" al prisma contenedor de la dovela, ir quitando material hasta conformar la pieza. Esta labra es el procedimiento más sencillo, sin embargo, puede ser muy laboriosa y poco económica porque puede necesitar de un sólido capaz de volumen varias veces superior a la dovela.

El otro procedimiento, el método de corte a baivel, se revela más difícil a ejecutar porque necesita canteros más hábiles y porque puede producir errores durante las mediciones de los patrones y de las saltarreglas. El volumen de cada dovela es determinado por las superficies de cada una de las caras, obtenidas mediante el dibujo de las plantillas. En este caso se utilizan abatimientos más complejos y se exige construir más plantillas, necesitando así de métodos de traza más sofisticados. Sin embargo, se revela más rápido a ejecutar y el sólido capaz se reduce al mínimo.

En la mayoría de los casos, los dos métodos se pueden combinar en el tallado de una misma pieza generando métodos de Labra por robos y saltarreglas. Existen numerosas variantes intermedias, una de ellas prevé utilizar un sólido capaz que se acerque lo más posible a la forma final de la dovela y sucesivamente definir los derrames a través de baiveles y saltarreglas.

\footnotetext{
11 Joel Sakarovitch, "Gèomètrie Practique, Gèomètrie Savante. Du Trait Des Tailleurs de Pierre à La Gèomètrie Descriptive," in Géométrie, Mesure Du Monde, ed. Thierry Paquot (Paris: La Découverte, 2005): 48

12 Fue Derand en " $L$ ' architecture des voùtes" en 1643 el que clarificó y diferenció los dos procedimientos, llamándoles "panneaux" (por caras) y "equarissement" (por robos).

13 El prisma con volumen de medida más pequeña dentro de la cual se encuentran todos los puntos de la dovela a cortar.
} 
Cualquiera sea el método de talla, se han identificado unos principios constructivos generales para el corte de las piedras ${ }^{14}$ :

1. La dimensión de las piedras no sea excesiva para facilitar el trasporto, salvo que venga requerido en algunas partes de la obra.

2. Es mejor si los bloques tienen proporciones tendencialmente cúbicas.

3. No hay que tener grandes diferencias en el tamaño de las piedras para no crear esfuerzos tensionales non optímales.

4. Las caras paralelas a las superficies de separación de la piedra (lechos de cantera) tienen que ser colocados perpendicularmente a la dirección de los esfuerzos mayores.

5. La superficie de separación entre dovela y dovela (cara de lechos) deben ser perpendiculares la una a la otra.

6. La superficie de separación entre dovela y dovela (cara de lechos), si son perpendiculares a la dirección de las fuerzas, pueden ser continuas; si son paralelas a las fuerzas deben ser discontinuas o despiezadas, para no dividir el sólido en porciones independientes que resistan independientemente.
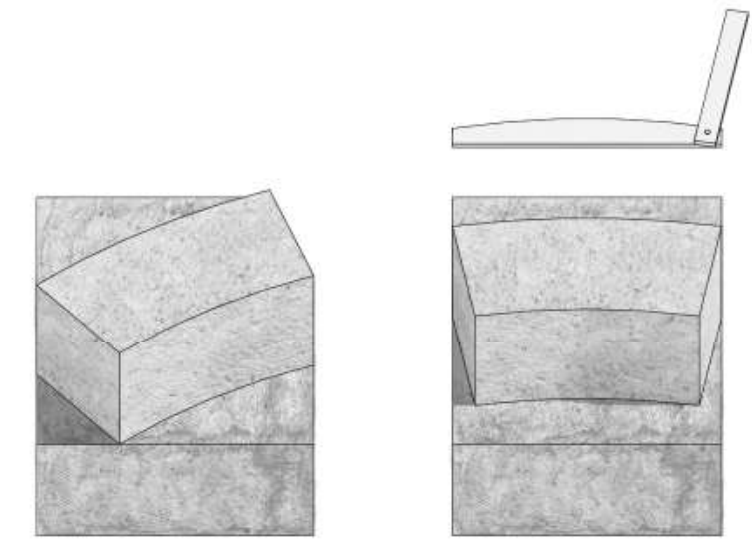

Fig. 2.1. Metodo de talla de un bloque de piedra por robos y a baibel

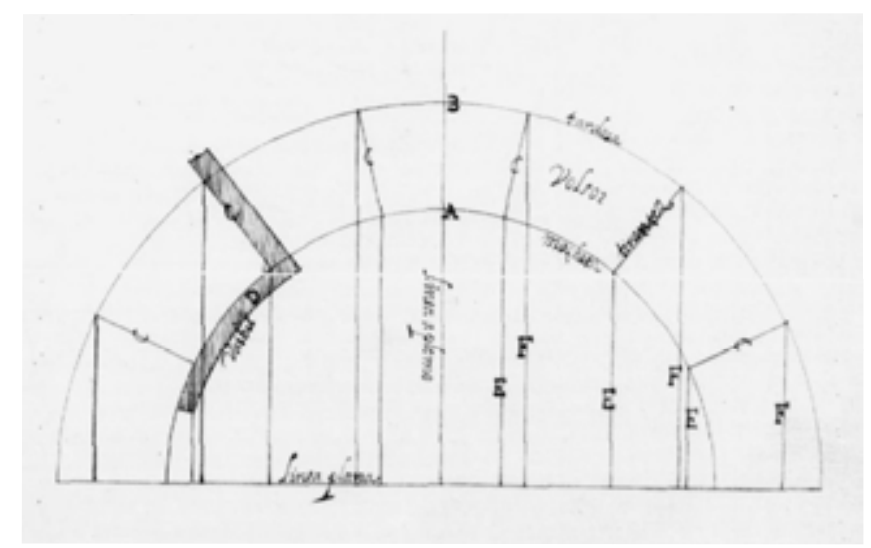

Fig. 2.2. Metodo de talla por baibel segun Vandelvira

14 Eduardo Mojados Ramos, Nociones de Estereotomia (Madrid: Libr. Impr. Y Bibliot. Militar, 1883). 


\subsubsection{Las herramientas del cantero}

Las plantillas a tamaño natural, la saltarregla y el baivel son los instrumentos que permiten transportar los datos geométricos y dimensionales obtenidos con la montea y proceder a la talla de la piedra (Fig. 2.3).

Las plantillas, una vez dibujados sobre el bloque de piedra, permiten definir la cantidad de material a remover, operación que se efectúa mediante la maceta y el cincel.

Si es necesario transportar ángulos o perfiles que puedan trasladar sobre la superficie del bloque de piedra conformado, el cantero utiliza la saltarregla y el baivel, ambos dibujados y fabricados a partir de la montea.

La saltarregla, necesaria para transportar el ángulo entre dos planos, es una falsa escuadra articulada con las caras interiores de sus brazos planas, que permite, por ejemplos, cortar las testas de las dovelas de las trompas trayendo del dibujo de la montea al bloque de piedra el ángulo entre paramento vertical y plano de intradós.

El baivel, herramienta imprescindible para controlar la talla de las dovelas, es una escuadra de dos brazos no articulados o móviles, pero que vienen fijados en la posición que marca el ángulo resultante entre dos caras. Uno de los brazos es recto y el otro conformado con la superficie curva de la dovela. Para construir un nervio de una bóveda de crucería, por ejemplo, se corta uno de los brazos del baivel con la curvatura del intradós del arco y el otro recto, orientado hacia el centro geométrico del arco y se procede a tallar las dovelas con la certeza que su curvatura interior y la inclinación de sus lechos de apoyos se atienen con total precisión a la montea.

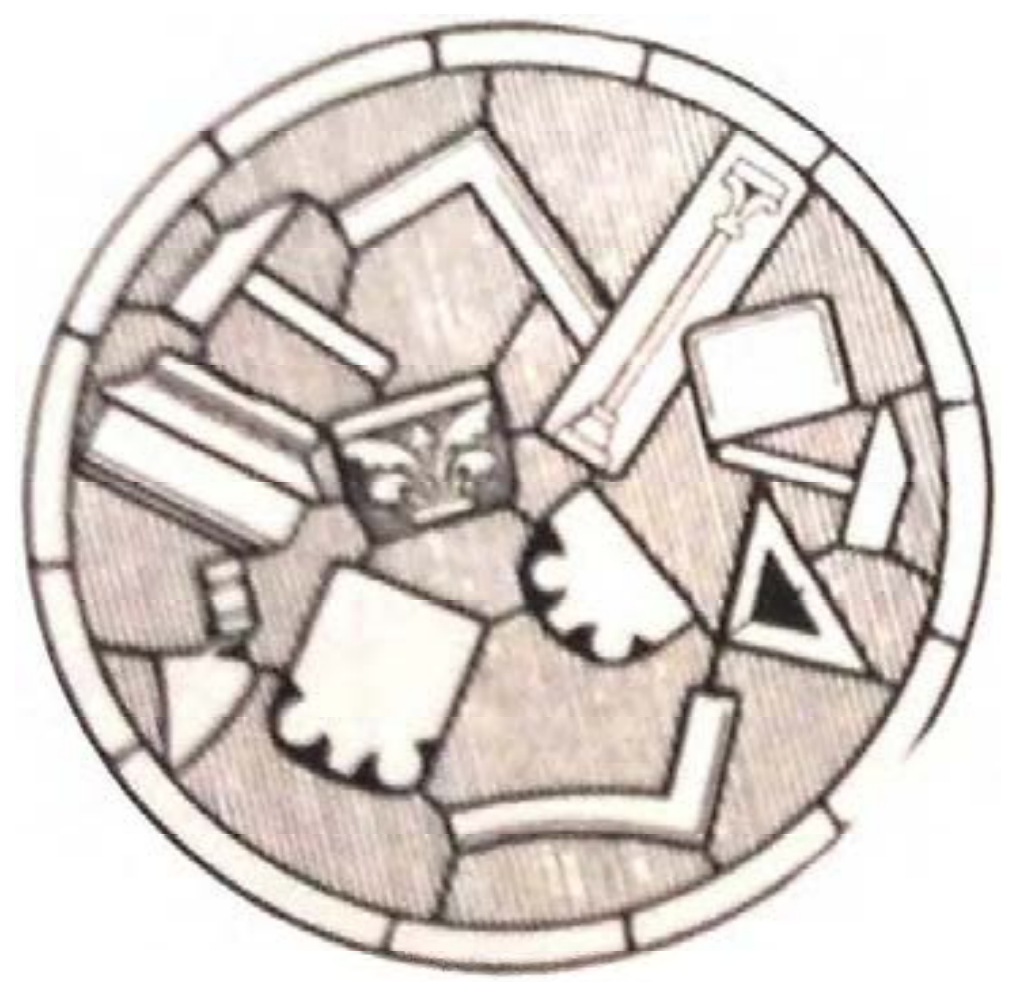

Fig. 2.3. Herramientas del cantero en los vidriales de la Catedral de Chartres, vidrial de San Silvestro. 


\subsubsection{La organización de la obra}

El proceso de construcción guiado por los principios estereotómicos y por el uso de la montea produjo también notables ventajas en la organización de la obra en temas de logística y de temporización de las tareas. Cuando se había previamente descompuesto el edificio en partes que iban a encajar perfectamente la una en la otra, era posible conformar las piezas, por lo menos cuando era conveniente, directamente en la cantera y entonces transportar solo el volumen y consecuentemente el peso mínimo necesario para una determinada obra ${ }^{15}$. Conociendo de antemano el tamaño y la geometría de las dovelas que iban a conformar el edificio, era también posible organizar las tareas a lo largo del año entero, y dedicar los meses invernales a tallar las dovelas que, en primavera, podían ser colocadas en obra.

\subsubsection{La Piedra}

La piedra es el medio con el cual se manifiesta la estereotomía, el material al que se confía la respuesta resistente de la obra y su expresión artística.

En su superficie se ostenta la habilidad de los constructores, se reconoce la calidad y el valor del material, y consecuentemente se manifiesta el prestigio y el poder económico del comitente. En el contexto de la arquitectura estereotómica entonces, más piedra sale a la superficie, más alto es el resultado que se ha alcanzado.

En realidad, en la praxis constructiva, no todas las obras de cantería están construidas totalmente en piedra porque sujetas a principios estilísticos y de economía.

Se preferían evidenciar todos los elementos que contribuían a dar un aspecto más solemne al edificio: cuales arcos, ventanas, capialzados y escaleras, vienen ejecutan con elementos en piedra de cantería; mientras que otras partes como muros, rellenos y bóvedas, se construían con el utilizo de piedras toscamente desbastadas que se avalaban de un uso copioso de morteros para conformar la superficie deseada y garantizar su estabilidad. Era común utilizar diferentes tipos de piedra: para los elementos estructurales se utilizaban piedras más duras y para elementos decorativos se recurría a piedras más blandas. Los edificios también se completaban con obras de albañilería que podían venir maquilladas en un segundo momento con sillares y juntas pintadas ${ }^{16}$.

Todo el territorio catalán es rico en variedad y calidad de piedras de construcción, que han sido utilizadas localmente y exportadas vía mar para realizar edificios religiosos y civiles de gran importancia.

En general se han utilizado todo tipo de piedras que cumplan con los requisitos para la construcción, es decir las características de homogeneidad, compacidad, resistencia a

\footnotetext{
15 A este propósito recordamos las claves de la Catedral de Barcelona, de aproximadamente dos metros de diámetro, que se tallaban en la cantera del Montjuix y se traían a la obra de la Catedral preparadas para su colocación inmediata.

16 En Cataluña se observan todas las condiciones que se acaban de exponer. Es un ejemplo la Universitat de Cervera, donde han sido utilizado dos piedras distintas, una para la construcción de los marcos de puertas y ventanas y otra para el levantamiento de los muros, y que, a distancia de dos siglos, ya tiene bien evidenciados los signos del efecto de la corrosión y del disgregamiento en la piedra más barata.
} 
compresión, impermeabilidad y facilidad de labra.

Sin embargo, la presencia de canteras cercanas a los principales núcleos urbanos ha también favorecido el utilizo de ellas ${ }^{17}$ y el desarrollo de arquitectura en piedra desde la época romana, como por ejemplo las canteras de Montjuïc al lado de ciudad de Barcelona, citadas con gran elogio por el jesuita Pere Gil, hacia 1600:

"la montanya de Mont Juich junt a Barcelona és de consideració per averse edificada

d'ella tota Barcelona. Diuen que la pedra creyx en ella: y que se a treta més pedra d'ella que no pujaria tota la dita montanya. Les moles d'ella van per tot lo món."

Se ha utilizado piedra del Montjuïc en la realización del Palau de la Generalitat de Perpiñán, donde los reyes de Mallorca construyeron su residencia con piedra de Santanyí, trasportada en las carenas de las naves; esta piedra fue también utilizada para la edificación del Castel Novo en Nápoles, mientras que Pere Blai trajo la caliza de Tarragona llamada Ilisós, una piedra calcárea más blanda y de tonalidad dorada, para construir el cuerpo nuevo del Palau de la Generalitat de Barcelona.

Más aun, las características mecánicas de un determinado tipo de piedra han permitido el desarrollo de formalismos arquitectónicos típicamente catalanes: es el caso de la caliza nummulítica de Girona, piedra extremadamente dura, que ha permitido la construcción de columnas de sorprendente esbeltez, características del gótico catalán.

\subsection{Manuscritos de estereotomía antiguos}

\subsubsection{La codifica de la estereotomía}

La codifica de la estereotomía moderna se debe a los primeros tratados y manuscritos sobre esta disciplina que fueron compilados durante el siglo XVI en Francia y España, consecuentemente a la llegada del nuevo espíritu y repertorio formal renacentista. En estos países se manifestó con otro soporte constructivo que in Italia, donde las arquitecturas se formalizaban con técnicas de construcción ligadas a la albañilería y al cubrimiento de las superficies con estucos, pinturas y losas de mármol: la construcción con ladrillo, por ser una pieza pequeña en comparación con el objeto que se pretende construir, permite conformar cualquier superficie con la simple repetición del mismo elemento colocado sobre un soporte que reproducía la superficie a determinar ${ }^{18}$.

El desarrollo de la disciplina que culminó en la estereotomía renacentista se puede originar a varios siglos antes: podemos datar las primeras arquitecturas que presentan cualidades estereotómicas a la Roma Imperial, donde aparecieron, aunque en manera puntual y definitivamente no metódica, obras en cantería caracterizadas por geometrías complejas que eran resueltas con dovelas en sillares claramente definidos. A este propósito se recuerdan los primeros ejemplos de arcos oblicuos (arco de Augusto en Perugia, el arco dei pantani en el foro de Augusto, en Roma) las bóvedas en media naranja y de arista (por ejemplo, el

17 Carbonell i Buades, 2008: 113-114

18 Palacios Gonzalo 2003 
Tetrápilo de Caparra en Cáceres) y las decendas de cava realizadas en piedra. En la praxis constructiva característica de la arquitectura Imperial romana, se utilizaba el recurso más conveniente y de fácil ejecución que no comprometiera la grandiosidad y la escala de la arquitectura. Por esta razón en la península italiana se utilizaba principalmente el ladrillo y el conglomerado de hormigón, mientras que se recurría a la piedra casi exclusivamente para revestimiento o para la construcción de obras de ingeniería que necesitaban una particular resistencia estructural. Se intentaba crear bóvedas de geometrías sencilla, evitando transiciones irregulares, superficies cónicas y arcos que se desarrollaban afuera del plano. Cuando era imposible evitar formas más complejas, el hecho de construir con ladrillos no comportaba particulares problemas a la hora de conformar los nudos y las superficies. En las provincias orientales del Imperio, en el sur de la Gallia y en algunas ciudades de la Hispania, la dificultad a encontrar madera apta para la construcción y ladrillos, era suplida por la abundancia de piedra fácilmente utilizable, que se utilizó extensivamente en las construcciones Imperiales.

El desarrollo de las tradiciones constructivas de origen de la Roma Imperial, pasando por conquistas, intercambios culturales y nuevas innovaciones tecnológicas, floreció en los siglos a seguir contribuyendo así a definir los aparejos de la cantería medieval. Esta prefiguración estética proto-estereotomica pasó desde ser un hecho casual de la arquitectura Imperial a un rasgo premeditado de la arquitectura Románica.

En el Languedoc aparecieron con más frecuencia estos prototipos Románicos. Era un territorio con una fuerte tradición constructiva en piedra de origen Romana, se piensa benefició especialmente del intercambio cultural con Tierra Santa inducido por las cruzadas y recibió la influencia de la arquitectura bizantina a través de las relaciones con el norte de Italia ${ }^{19}$. En esta área geográfica se creó un foco estereotómico que en los siglos a seguir se fue desplazando moviéndose a lo largo del arco mediterráneo, desde el sur de Francia alcanzó Andalucía, pasando por Cataluña, Baleares, el Levante y Murcia, quizás encontrándose con otros que se desarrollaban en paralelo.

Durante el tardo romano (siglos XII y XIII) se difunden en Cataluña los primeros aparejos estereotómicos, como las trompas cónicas, utilizadas para resolver la transición entre la planta cuadrada del encuentro de nave y transepto con la planta octagonal del cimborio, y los arcos abocinados, que salvan los grandes espesores de los muros de iglesias y castillos. En esta época se realizan esplendidos ábsides en media naranja perfectamente adovelados en sillares concéntricos donde se abren arcos en muros curvos, también aparecen con más constancia en el área Mediterránea los prototipos que irán a caracterizar la estereotomía "moderna", cuales las bóvedas en decenda de cava y en rincón de claustro, las bóvedas esquifadas y los arcos oblicuos. No podemos afirmar con precisión cuales habrían podido ser los métodos de talla y dibujo hasta el alto medioevo, hay algunos elementos que nos hacen pensar que en muchos casos los procedimientos eran empíricos y faltaban de una metodología continua y un saber codificado, como por ejemplo la calidad de ejecución y las irregularidades geométricas de las dovelas. Las estructuras abovedadas que nos

19 También gracias a la explotación de las bibliotecas bizantinas después la ocupación de Constantinopla por los cruzados en 1204 
han llegado, las organizaciones gremiales y las bases metodológicas del trabajo, sin duda alguna señalan la herencia cultural que tuvieron para el futuro desarrollo de la estereotomía clásica. Se piensa que la tradición constructiva románica del Languedoc y de Cataluña hayan tenido un peso en las técnicas de construcción en piedra del quinientos, como han formulado Pérouse de Montclos y Philiipe Potié20

En el reino de Mallorca también se había conservado durante los siglos XIII y XIV la práctica de la estereotomía, como demuestran las trompas aparejadas de las cabeceras de las capillas de los palacios reales de Perpiñán (1295-1309) y de la Almudena de Mallorca (antes de 1309), así como de la capilla de la Trinidad de la Catedral de esta misma ciudad (ca. 1330). Asimismo, es importante indicar el aporte y las invenciones de la cantería del Cuatrocientos valenciano al desarrollo de la estereotomía ${ }^{21}$, en particular la obra de Francesc Baldomar (activo entre 1425 y 1476) y Pere Compte (activo entre 1454 y 1506), respectivamente maestro y discípulo, que acabó con la muerte de este último y la dispersión de la estructura gremial al seguido de las guerra de las Germanías. Como ha puesto de resalto Arturo Zaragozá Catalán, la arquitectura valenciana desarrolla y resume, a lo largo del siglo XV, una amplia serie de novedosas aplicaciones geométricas para el trazado de arcos, de bóvedas, de escaleras y de soportes ${ }^{22}$. Sin embargo, todavía no conocemos cual fue la formación y la codifica de los conocimientos prácticos y geométricos de estos dos autores $^{23}$. No han llegado trazas y dibujos de construcciones geométricas de esta época. Fue el periodo a seguir, empezando por el Renacimiento, que elaboró cuadernos manuscritos y tratados de estereotomía con la intención de divulgación dejándonos, afortunadamente, una amplia literatura sobra la materia.

\subsubsection{Manuscritos Góticos y Tardogóticos centroeuropeos}

Dentro del corpus de fuentes documentales relacionadas con el corte de la piedra y la construcción de bóvedas de crucería, existen numerosos manuscritos de tradición Gótica y Tardogótica centroeuropeos. En ellos destaca la producción de trazas de bóvedas de crucería de los textos del siglo XVI, que superan en cuanto a cantidad de ejemplos a los tratados franceses y españoles, a parte de la obra de Ribes; encontramos algunos aparejos estereotómicos (trompas, escaleras de caracol y arcos oblicuos) y varios dibujos de plantas y alzados de catedrales góticas. El primer texto conservado es la libreta de apuntes de Villard de Honnecourt (c. 1225), que puede ser interpretado como un álbum de viaje que recopila modelos arquitectónicos encontrados en sus viajes por Francia y Alemania, llegando hasta Hungría. Todavía no son dibujos muy sofisticados del punto de vista geométrico, pero registran ideas proyectuales y soluciones constructivas en corte de piedra, revelándose una

\footnotetext{
20 Philippe Potié, Philibert de L'Orme : Figures de La Pensée Constructive (Marseille: Editions Parenthèses, 1996): 19.

21 José Calvo López, "Cerramientos y Trazas de Montea de Ginés Martínez de Aranda" (Tesis Doctoral, 2000): 245-246

22 Arturo Zaragozá Catalán, Arquitectura Gótica Valenciana, Siglos XIII-XV (Valencia: Generalitat Valenciana, Conselleria De Cultura, Educació I Ciència, Direcció General De Patrimoni Artístic, 2000).

23 Arturo Zaragozá Catalán, El Arte de Corte de Piedras En La Arquitectura Valenciana Del Cuatrocientos :

Un Estado de La Cuestión... (Valencia Real Academia De Bellas Artes De San Carlos De Valencia, 2008): 42
} 
herramienta necesaria para la transmisión de ideas. Después de Villard, tienen que pasar más de dos siglos antes de encontrar una obra parecida, sin embargo, nos han llegado dibujos y trazas de composiciones arquitectónicas de estilo gótico producidas durante estos siglos. Mas tarde, a finales de siglo XV Matthaüs Roriczer, maestro de obra de la Catedral de Ratisbona, produce Puchlein der fialen gerechtikait (1486) que explica cómo se construye el alzado de un pináculo desde la planta y sucesivamente Geometria Deutsch (1487), que trata de la geometría euclidiana. Los folletos de Roriczer todavía no aportan informaciones sobre el corte de piedra de la construcción gótica. Se encuentran trazas de bóvedas (Fig. 2.4) en el libro de patrones de Hans Hammer de la Biblioteca Augusta de Wolfenbüttel (ca. 1500); Codex Miniatus de la Biblioteca Nacional de Austria ${ }^{24}$, conocido como cuaderno de Dresde (1560-1570); la colección Wiener Sammlungen de la Academia de Bellas Artes de Viena25; el cuaderno del maestro WG de Frankfurt (c. 1560, Instituto Städel de Munich) ${ }^{26}$. El Codex Miniatus también ofrece un diagrama que define los alzados de los nervios empleando el Prinzipalbogen ${ }^{27}$, procedimiento geométrico para garantizar la correcta ejecución de las bóvedas del gótico germánico, que se exhibe también en el libro del maestro $W^{28}$.

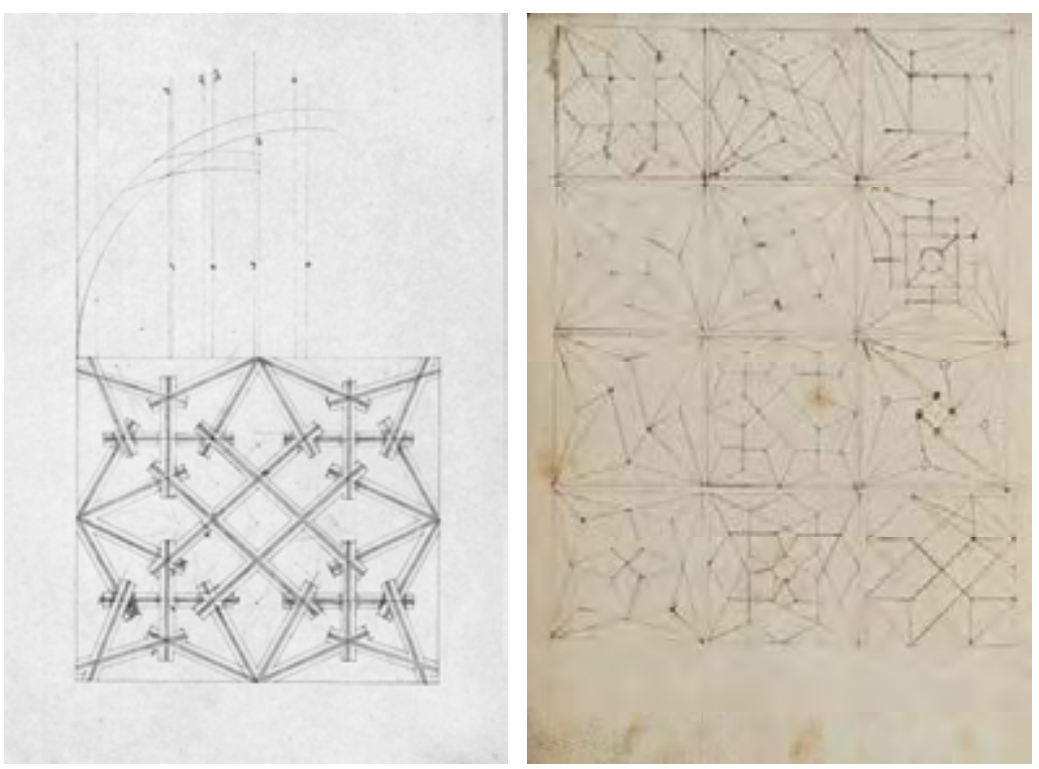

Fig. 2.4. Bóvedas de crucería en los manuscritos medievales del Codex Miniatus, folio 3r y de Hans Hammer, folio 48.

\footnotetext{
24 Werner Müller and Norbert Quien, Virtuelle Steinmetzkunst Der Österreichischen Und BöhmischSächsischen Spätgotik : Die Gewölbeentwürfe Des Codex Miniatus 3 Der Österreichischen Nationalbibliothek in Wien (Petersberg: Michael Imhof Verlag, 2005).

25 Johann Josef Böker, Architektur Der Gotik : Bestandskatalog Der Weltgrößten Sammlung an Gotischen Baurissen (Legat Franz Jäger) Im Kupferstichkabinett Der Akademie Der Bildenden Künste Wien : Mit Einem Anhang Über Die Mittelalterlichen Bauzeichnungen Im Wien Museum Karlsplatz (Salzburg ; München: A. Pustet, Cop, 2005).

26 WG, Meister, Steinmetzbuch (Städelsches Kunstinstitut und Städtische Gallerie 1560-1572): 8-494

${ }_{27}$ Enrique Rabasa Díaz, José Calvo López, and Rafael Martín Talaverano, "Bóvedas de Crucería Que Se Proyectan En Planta Según Una Matriz de Estrellas. Transmisión de Conocimiento Técnico En El Tardogótico Europeo", in Actas Del Décimo Congreso Nacional y Segundo Congreso Internacional de Historia de La Construcción: Donostia-San Sebastián, 3 a 7 de Octubre 2017, ed. Santiago Huerta, Paula Fuentes, and Ignacio J. Gil Crespo (Madrid: Instituto Juan De Herrera, 2017).

28 José Calvo López, "La Literatura de La Cantería: Una Visión Sintética," in El Arte de La Piedra Teoría y Práctica de La Cantería. Cuadernos de Investigación, vol. Número 01 (CEU Ediciones, 2009).
} 


\subsubsection{Los tratados de estereotomía en España}

El arte de la montea tuvo un gran desarrollo en el siglo XVI y fue acompañada por una prolija producción de manuscritos de cantería (Fig. 2.5). En España se compilaron principalmente para el uso personal de los maestros de obra y circularon principalmente entre los ambientes profesionales, mientras tanto en Francia los textos dedicados a la estereotomía fueron inmediatamente impresas y lograron una amplia difusión como es el tratado Philibert De L' Orme (1567). No está totalmente clara la influencia que tuvieron los textos de un país con el otro, la idea más reconocida en la actualidad es que la estereotomía de ambos países nació de un foco común, como explicado anteriormente en esta tesis, sin embargo, la movilidad de los canteros y la divulgación de los manuscritos había facilitado la transmisión de los conocimientos técnicos y el desarrollo de la estereotomía en lugares alejados geográficamente.
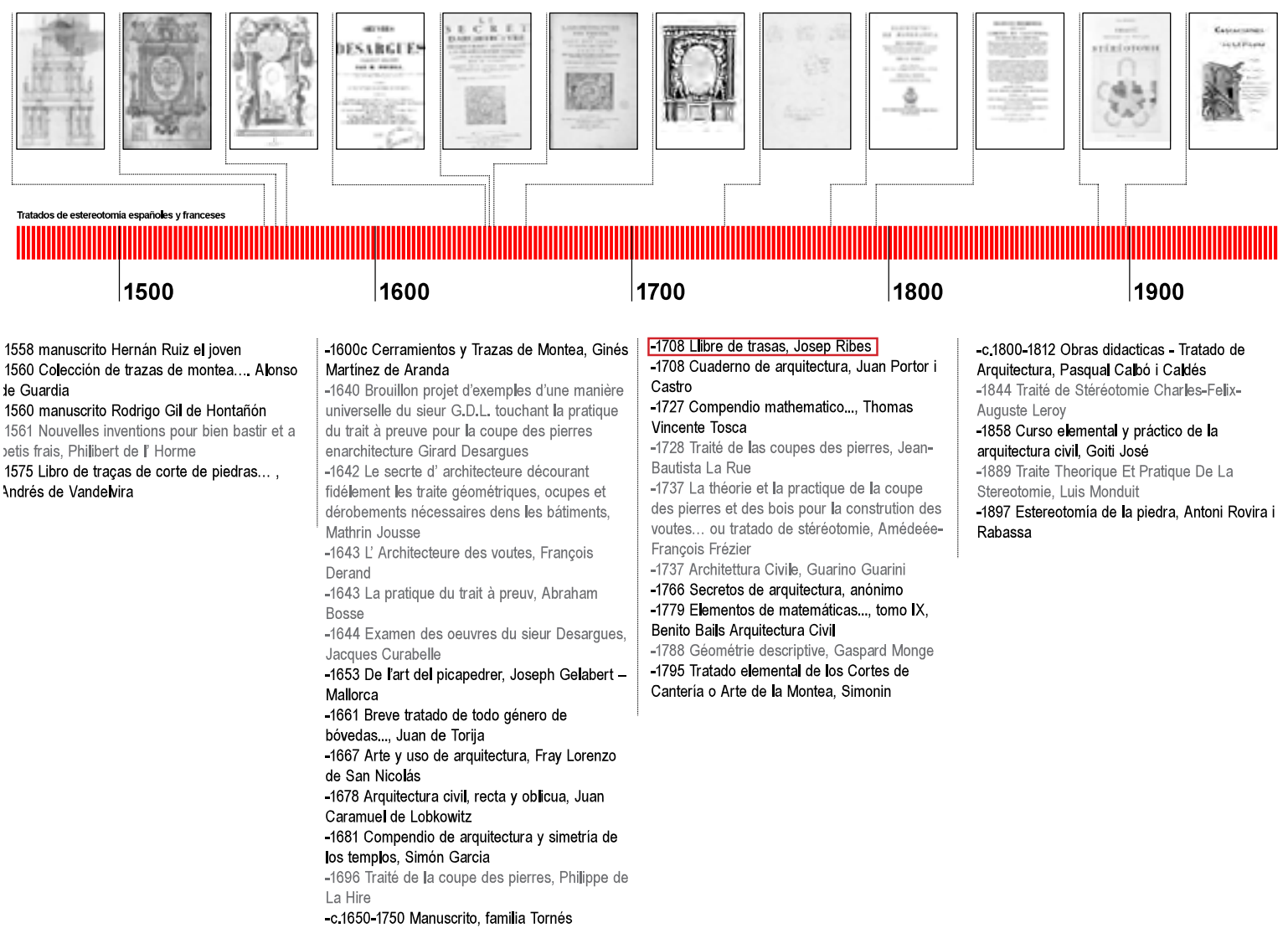

-c.1800-1812 Obras didacticas - Tratado de Arquitectura, Pasqual Calbó i Caldés -1844 Traité de Stéréotomie Charles-FelixAuguste Leroy

-1858 Curso elemental y práctico de la arquitectura civil, Goiti José -1889 Traite Theorique Et Pratique De La Stereotomie, Luis Monduit -1897 Estereotomia de la piedra, Antoni Rovira Rabassa -1643 L' Architecteure des voutes, François Derand

-1653 De l'art del picapedrer, Joseph Gelabert Mallorca

e San Nicolás

-c.1650-1750 Manuscrito, familia Tornés

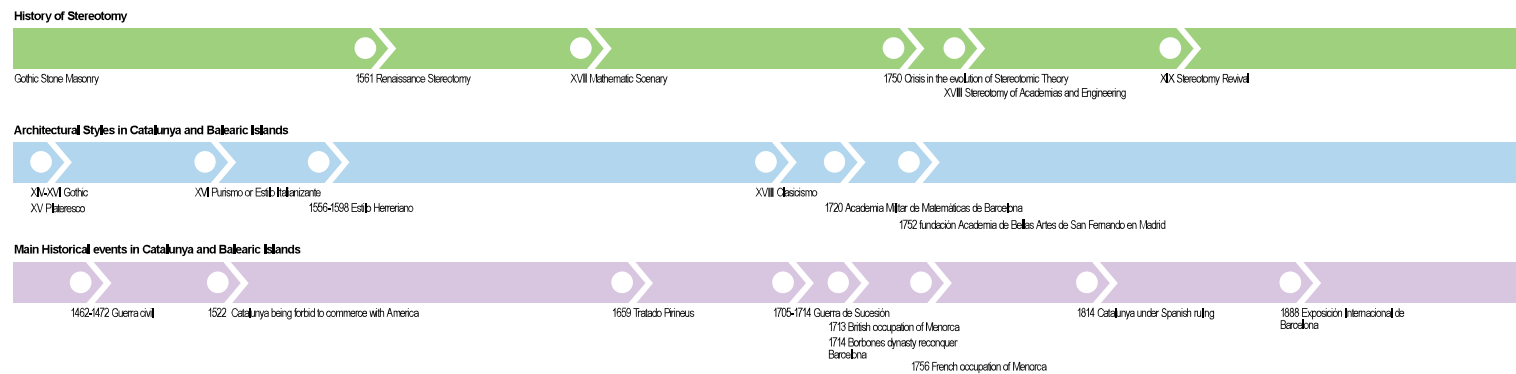

Fig. 2.5. Cronología de los tratados de estereotomia 
En España el primer texto sobre el arte de montea fue el manuscrito de Hernán Ruiz el Joven, pero los más importantes tratados de este periodo son los de Alonso de Vandelvira y Ginés Martínez de Aranda.

El cuaderno de Hernán Ruiz el Joven, escrito entre 1562 y $1569^{29}$, contiene textos que tratan de los multíplices conocimientos del arquitecto renacentista: geometría, relojes, estudio de órdenes clásicas, perspectiva, proporciones, planos de edificios religiosos y civiles, anatomía, joyería. Con respecto a la montea y la cantería en general, existen analogías con el léxico del tratado de Vandelvira. Después de su descubrimiento y la breve información dada por Manuel Gómez Moreno ${ }^{30}$ en 1949, los primeros estudios sobre el manuscrito de Hernán Ruiz fueron publicados por Pedro Navascués Palacio en $1974^{31}$ impulsando el estudio de la estereotomía en España.

Vandelvira compiló un tratado de cantería en la década de 1580 que nos ha llegado a través de copias del '600 y que conocemos como Libro de trazas de cortes de piedras. Las soluciones derivan en gran medida de la experiencia paterna y de lo aprendido junto a Hernán Ruiz ${ }^{32}$. Contiene 104 trazas distintas y presenta prácticamente todos los aparejos relevantes de la cantería de su época, ordenados con intento didáctico de los más sencillos a los de mayor dificultad. Es una obra muy singular por su completez y amplitud.

Ginés Martínez de Aranda escribió un manuscrito de Arquitectura o Cortes de Cantería que conocemos gracias a los autores del siglo XVIII, el abad Ponz, Eugenio Llaguno y el canon Martínez de Mazas ${ }^{33}$. El volumen que hemos recibido se encontró en 1984 en la biblioteca de los Ingenieros del Ejército de Madrid. Está dividido en tres partes, aunque la nota introductoria del autor informa que el libro consta de $5 \mathrm{y}$, de hecho, contiene numerosas páginas en blanco para la finalización del tratado. El manuscrito, aunque incompleto, es muy extenso y contiene 131 tipos diferentes de trazas (70 tipos de arcos, 50 habitaciones y capialzados, 11 escaleras de caracol). El tratado de Martínez de Aranda aborda numerosos casos particulares y sostiene que todos los modelos presentados en el tratado los realizó previamente.

El manuscrito de Rodrigo Gil de Hontañón (c. 1550) nos ha prevenido a través del manuscrito de Simón García, el Compendio de simetría y arquitectura de los templos (1681), que reconoce abiertamente haber empleado gran cantidad de material procedente del texto de Rodrigo Gil. Este texto describe la diferencia entre las bóvedas de rampante llano y las de rampante redondo que caracteriza la solución hispánica para las bóvedas nervadas. En el siglo XVII la evolución de la tratadística francesa y española divergen. En Francia se publicaron tratados de gran envergadura (Desargues, Jousse Derand) que tuvieron una gran difusión. En España Fray Lornezo San Nicolás dedica algunos capítulos del Arte y uso de la Arquitectura (Madrid 1639 y 1664) al problema del corte de la piedra sin aportar

\footnotetext{
29 Antonio Luis, El Proyecto Renacentista En El Tratado de Arquitectura de Hernán Ruiz (Sevilla: Secretariado De Publicaciones, Universidad De Sevilla, 2002).

30 Manuel Gómez-Moreno, El Libro Español de Arquitectura : Discurso (Madrid, 1949).

31 Pedro Navascués Palacio, "El Libro de Arquitectura de Hernán Ruiz. Introducción Histórica - Archivo Digital UPM," Oa.Upm.Es, 2011, https://doi.org/http://oa.upm.es/7636/

32 Calvo López, 2009: 120

33 Antonio Ponz y Aguilar, Viaje a España (Madrid: por la viuda de D. Joaquin Ibarra, 1794), http://www. bibliotecavirtualdeandalucia.es/catalogo/es/catalogo_imagenes/grupo.cmd?path=158256
} 
contribuciones particulares a la disciplina.

L'art de picapedrer del mallorquín Joseph Gelabert (1653) presenta trazas semejantes a las de escuela renacentistas de la península y tiene otras de tradición gótica mallorquina. Entre ellas, las bóvedas de crucería están resueltas con soluciones geométricas retardatarias en el siglo XVII. En su tratado se aprecia como los nervios conforman una superficie de intradós discontinua, en contraste con las bóvedas de crucería de rampante redondo difundidas en España en aquella época.

En esta línea se coloca también el Llibre de trasas de Ribes (1708) que recoge trazas de origen gótica, aparejos difundidos en los tratados de la época y, único caso en la tratadística española y francesa, muestra una amplia colección de bóvedas de crucería. Diferentemente de Gelabert, en este caso son más modernas al presentar casquete esférico y claves orientadas al centro de la bóveda. Estos dibujos de bóvedas de crucería gótica documentan el aún vivo interés para soluciones constructivas nervadas en España a los albores del siglo XVIII.

De la misma fecha de publicación de Ribes es el Cuaderno de arquitectura (1708) de Juan de Portor y Castro. El autor fue cantero en Santiago de Compostela en 1710 donde parece haberse formado. Sin embargo, se cree que su cuaderno tenga elementos que lo hagan derivar a Martínez de Aranda $^{34}$. El texto se centra en las bóvedas que es la parte correspondiente del manuscrito de Aranda no ha llegado.

Los tratados de Ribes y Portor y Castro son quizás los últimos en España a recoger los conocimientos gremiales y los regionalismos constructivos. Durante el siglo XVIII, el estado de las ciencias, el contexto político, cultural y científico cambiaron el sistema de enseñanza y de transmisión del saber. La permeabilidad de la información y la fuerte influencia del estado en las artes y en la arquitectura impulsó en España la producción de textos académicos de estampo francés. La práctica y enseñanza de la estereotomía fue englobada en los programas académicos.

Tomás Vicente Tosca (1651-1723), originario en Valencia, era un matemático del Oratorio de San Filippo Neri con formación Iluminista. Escribió el Compendio mathemático (17071715) que incluye el Tratado XV Montea y Cortes de Cantería, a su vez subdividido en cinco libros que describen 82 trazas de modelos estereotómicos obtenidos en su mayoría del texto de Millet-Dechales. El tratado de Tosca contiene una sección específica dedicado a una bóveda de crucería estrellada (hoja 16): es una "boveda por igual, o vaida con los arcos traviso, o cruceros sobredichosos", y por lo tanto todos los arcos son de punto medio. Los cruceros y los formeros son semicírculos completos, y los terceletes y ligaduras son porciones semicirculares. El tratado de Tosca venia utilizado en la recién fundada Real Academia Militar de Matemáticas en Barcelona (1720) que se estableció en la Ciudadela de Barcelona, el conjunto fortificado construido entre 1715 y 1719 tras la conquista de Barcelona en septiembre de 1714. En ella se formaron muchos maestros de obras y arquitectos.

Compilado entre 1650 y 1750 , el manuscrito de la familia Tornés de Jaca recoge trazas de estereotomía de las cuales han sido identificado semejanzas con los modelos de Martínez

34 Calvo López, 2009: 131 
de Aranda, Vandevlra y Philibert de L'Orme. Esta era una libreta de apuntes para uso privado con elementos del arte de la montea con soluciones a posibles problemas constructivos.

El cuaderno Secretos de arquitectura fue escrito por un anónimo en el Monasterio de San Miguel de los Reyes en la región valenciana en 1766, es una copia de la obra de Mathurin Jousse, Secrets de l'Architecture (1642), de más de un siglo antes.

En esta época Benito Bails compiló la Arquitectura Civil (Madrid 1776) copiando la obra de Frézier sin aportaciones propias. Sus tratados eran dirigidos a las academias y escuelas de dibujo durante la llustración.

Dentro de la reforma cultural promovida por la Academia de San Fernando, Fausto Martínez de la Torre y José Asensio Torres, editaron el Tratado en español elemental de los Cortes de Cantería o Art de la Montea escrito en francés por el Sr. Simonin profesor de Matemáticas (Madrid 1795), publicado tres años antes en París con el título Coupe des Pierres ou Art du Trait.

Del mismo estampo enciclopédico es la obra de Pascual Calbó Caldés (Obras didácticas, 1800-1812), originario de Mahón, que recompila numerosas trazas de aparejos estereotómicos, tal unas de complicada geometría.

En Barcelona se ha redactado Estereotomía de la piedra (1897) de Antoni Rovira y Rabasa. Escrito con finalidad principalmente didáctica y contiene dibujos y trazas copias de otros tratados tardíos franceses. Trata de la construcción en piedra desde sus albores e incluye la aplicación de la estereotomía a la madera y al hierro. De valor documental es la parte narrativa que describe algunos aparejos estereotómicos que existían en Barcelona antes del derribo de las murallas y de las numerosas operaciones de reconstrucción del tejido urbano de la ciudad.

Otros textos todavía más tardíos, son conservados en la Biblioteca de la Escuela de Arquitectura y de Arquitectos Técnicos de Barcelona, y son más bien aplicaciones de geometría descriptiva para los alumnos arquitectos.

La biblioteca de la Confraria de Mestres de cases i Molers de Barcelona contenía textos de Vitruvio, Vignola, Guarini, Alberti, Serlio, Palladio, Scamozzi, Tosca, "llibres francesos per tallar pedra i fusta" ${ }^{35}$, después de la segunda mitad del siglo XVIII guardaba muchos libros franceses, sobre todo de estereotomía.

\subsection{Otros manuscritos catalanes}

El Llibre de Trasas de Ribes, a día de hoy, es el único manuscrito de cantería de procedencia catalana que ha sobrevivido ${ }^{36}$, sin embargo, a la luz de investigaciones recientes, con toda probabilidad, no fue el único. Tenemos constancia que Joan Fiter (1720), un maestro de obra catalán que operó entre finales de XVII y comienzo de XVIII, poseía un manuscrito de biaix y montea; el albañil Francesc Martí (1686) era propietario de un libro de montea

\footnotetext{
35 Montaner, 1990: 47.

36 Excluyendo el de Antoni Rovira por su contenido no original.
} 
manuscrito ${ }^{37}$; Josep Desrius (1641) tenía tres libros de trazas y Pere Rossell (1607) dos ${ }^{38}$; Juan Bell-lloc (1530), que dirigió las obras de la Catedral de Girona, poseía un libro de geometría ${ }^{39}$; Joan Sarnoto (1517), maestro de obra en la Catedral de Tortosa, también poseía un libro de geometría ${ }^{40}$; Rotllí Gautier (1442), escultor y maestro de obra de la Seu Vella de Lérida, tenía un cuaderno con ejemplos e imágenes de elementos arquitectónicos ${ }^{41}$. No sabemos con seguridad cuántos de ellos contenían trazas de estereotomía y cuántos eran instrucciones generales de obra; sin embargo, sí podemos afirmar que los manuscritos de cantería fueron siempre libros preciosos que daban prestigio al maestro que los poseía. No hay constancia documental que el tratado de Ribes fuera conocido por los otros tratadistas, y el tratado de Antoni Rovira i Rabasa, autor del extensivo tratado presente de referencias a la estereotomía catalana, no contiene alguna información ni textual ni grafica que haga suponer que conociera el Llibre de trasas.

\subsection{Autores Contemporáneos}

Hoy en día, la estereotomía es una materia cuyo estudio no está codificado unívocamente en el mundo Académico: en algunos centros universitarios es una asignatura consolidada en los programas de estudio y en los proyectos de investigación, en otros es una disciplina arcaica cuyo contenido es totalmente ignorado o malinterpretado.

Los estudios y las investigaciones sobre la estereotomía han crecido notablemente en las últimas decenas de años ${ }^{42}$ y se ha producido un creciente interés para la experimentación proyectual y constructiva. En el ámbito académico el interés para esta disciplina no se limita al aspecto histórico y documental, como viene testimoniado por los números artículos y proyectos dedicados, viene también considerada como medio fundamental para entender en su totalidad la construcción de las fabricas arquitectónicas y, en algunos casos, como disciplina a vocación proyectual. La metodología de estudio de los distintos centros académicos es variada ya que puede organizarse alrededor de un aproche más teórico o puede avalarse de talleres prácticos que permiten estudiar y aprender las técnicas estereotómicas tradicionales, como por ejemplo los talleres de Cantería y de Construcción Gótica de la ETSAM. En algunos centros pioneros se utilizan también sistemas de construcción robotizada que permiten reproducir arquitecturas históricas, así como investigar nuevas formas y, en alguna manera, actualizar el corpus teórico de la estereotomía.

\footnotetext{
37 Carbonell, 2008: 117 «apud» Manuel Arranz, La menestralia de Barcelona al segle XVIII. Els gremis de la construcción. (Barcelona, 2001): 89.

38 Antonia Maria Perelló Ferrer, L'arquitectura Civil Del Segle XVII a Barcelona (Barcelona L'abadia De Montserrat, 1996: 49.

39 Carbonell, 2008: 142.

40 J. Vidal Franquet, "Els Dos Testaments Coneguts de Petit Joan Sarnoto. Edició i Notes.," RACBASJ. Butlletí XXIII-XXIV (2009): 23. Cita la tesis doctoral de Miguel Falomir publicada en 1996 con el título Arte en Valencia, $1472-1522$.

41 Fiteé i Llevot, "L'alberg i l'inventari Patrimonial de Rotllí Gautier, Escultor i Mestre d'obra de La Seu de Lleida (1442)," Seu Vella: Anuari d'història i Cultura, no. 3 (2001): 123-150.

42 Giuseppe Fallacara, Stereotomia Ri-Composta. L'evoluzione Di Una Disciplina Che Insegna a Costruire Lo Spazio (Roma: Aracne, 2012).
} 
A través la construcción de modelos estereotómicos es posible entender más profundamente el comportamiento estático de las fábricas y la morfología constructiva.

El aproche tradicional a la materia que ha caracterizado los talleres de construcción histórica de algunas universidades ha sido acompañado por métodos de trabajo contemporáneo, poniendo las bases para una posible metodología de construcción basada en formas estructurales auto portantes.

Giuseppe Fallacara ${ }^{43}$ ha encuadrado las publicaciones más importantes y los centros de investigación que han permitido definir la disciplina en su segundo renacimiento, o sea desde los primeros estudios aislados que se han originado después las dos Guerras Mundiales hasta las escuelas consolidadas del día de hoy, reconstruyendo así un mapa geográfico/cultural que conforma el actual estado del arte.

Se puede observar cómo esta tesis va a rellenar un vacío documental de la estereotomía, posicionándose en ese punto del mapa, hasta ahora no marcado, correspondiente a Cataluña, territorio cuyo interés en el ámbito estereotómico ha sido mencionado por algunos historiadores, pero sin nunca ser objeto de estudios específicos.

Se recordarán a seguir algunos de los centros y de los historiadores que, en alguna manera, hayan sido parte del contexto y que puedan relacionarse con el objeto de estudio de esta tesis.

Quizás la publicación de Pérouse de Montclos de 1982, el libro L'Architecture à la française, du milieu du XVe à la fin du XVIIle siècle, fue una de las piedras millares en el concepto de identificación de unas estereotomías nacionales, o sea de caracteres constructivos estereotómicos ligados a un determinado territorio. En esta obra, centrada exclusivamente sobre los monumentos franceses, se mencionan también aparejos de origen y carácter español y catalán.

En este mismo año Sergio Luis Sanabria, de la Princeton University, publica el articulo The mechanization of design in the 16th century: the structural formulae of Rodrigo Gil de Hontañón, explicando el intento de sistematizar los conceptos estructurales góticos descritos en el manuscrito de Rodrigo Gil.

En España el estudio de la estereotomía ha sido impulsado inicialmente por el texto de Pedro Navascues Palacio fechado 1974 sobre el manuscrito de Hernán Ruiz, y sucesivamente por Antonio Bonet Correa que en 1986 describe el tratado de Ginés Martínez de Aranda y en 1989 introduce los estudios nacionales con Los tratados de cortes de piedra españoles en los siglos XVI, XVII y XVIII.

El primer texto que "decodifica" las trazas de los tratados, descifrando y representando gráficamente en su volumetría las trazas, es la tesis doctoral de José Carlos Palacios, leída en 1986 en la ETSAM, que arranca así esta rama de la historia de la construcción y pone las bases a los exitosos estudios posteriores producidos en la escuela de Madrid. Su tesis, que se publicó en el libro Trazas y cortes de cantería en el Renacimiento español

${ }^{43}$ Giuseppe Fallacara et al., Stereotomy : Stone Architecture and New Research (Paris: Presses Des Ponts, DI, 2012). 
de 1990, reveló por primera vez las trazas del tratado renacentista de Vandelvira y de la estereotomía Andaluza.

A este trabajo le siguieron los estudios de Enrique Rabasa con los primeros artículos sobre la estereotomía de los arcos oblicuos (1994) que, juntos a otros estudios sobre el tema, se publicaron en 2000 en el libro Forma y construcción en piedra. De la cantería medieval a la estereotomía del siglo XIX. El profesor Rabasa también analizó el contenido del manuscrito de Gelabert y su relación con la estereotomía mallorquina (2011).

En 1999, siempre en la ETSAM, José Calvo-López discutió su tesis doctoral sobre Martínez de Aranda, produciendo sucesivamente numerosos estudios de estereotomía en la Universidad de Cartagena.

En el área valenciana Arturo Zaragozá puso en resalte los alardes estereotómicos de la arquitectura del Levante, identificando las origines y singularidades de muchos aparejos característicos de esta área geográfica y promoviendo el concepto de Gótico Mediterráneo. En Italia, el estudio de la estereotomía empezó tímidamente con algunos estudios esporádicos como las primeras investigaciones sobre la materia de Camillo Trevisan en 1997, hasta la lectura de la tesis doctoral de Giuseppe Fallacara dirigida por Claudio D'Amato presentada en Bari en 2004, que puso las bases para los numerosos estudios históricos y proyectuales producidos cada año en el Politecnico di Bari. El gran éxito de esta línea de investigación fue celebrado con la construcción de prototipos de bóvedas en piedra en escala real en la X Bienal de Venecia en 2006.

En Sicilia, Marco Rosario Nobile, profesor en la Università degli Studi di Palermo está promoviendo el estudio de la estereotomía en el ámbito Mediterráneo conjuntamente al grupo de estudios de docentes españoles guiados por Arturo Zaragozá. En particular se está llamando la atención sobre la estereotomía del Mediterráneo Central, en las islas de Sicilia y Malta.

Siempre en Italia, en el IUAV de Venecia, Agostino de Rosa guía otro grupo de investigación de estereotomía.

En el ámbito europeo, Werner Müller en 1968 postuló como el conocimiento de los medios geométricos de la estereotomía no necesariamente conducían a una buena arquitectura, resultado que solo Philibert de L'Orme y Guarino Guarini pudieron alcanzar. Se dedicó también al estudio de la construcción de bóvedas góticas del ámbito alemán y publicó en 1990 el libro Grundlagen gotischer Bautechnik: ars sine scientia nihil.

David Wendland en la TDU de Dresde continuó el estudio y la experimentación constructiva de las bóvedas centroeuropeas. Su trabajo incluyó la reconstrucción de las bóvedas del castillo de Dresde.

En Francia, la tradición que empezó gracias a Pérouse de Montclos, recibió importantísimas contribuciones por el trabajo de Joël Sakarovitch, hace pocos años fallecido, y a la tradición muy viva de las escuelas de Compagnonnage. Uno de sus miembros, Luc Tamborero, ha podido unir con grande éxito conocimientos tradicionales con tecnologías más contemporáneas de corte de la piedra.

A testimoniar la fascinación que el estudio de la estereotomía produce en el mundo académico, observamos como estudios dedicados se están desarrollando con continuidad 
en algunas universidades norte-americanas.

Desde 2002 John A. Ochsendorf, docente del Masonry Research Group del M.I.T., estudia el comportamiento mecánico de estructuras abovedadas.

Benjamin Ibarra-Sevilla, influenciado por los estudios históricos de los investigadores europeos, sigue en la University of Texas at Austin su investigación sobre las bóvedas mixtecas.

De gran interés y variedad son los estudios sobre la estereotomía francesa conducidos por Richard Etlin en la Maryland University.

En 2017 Giuseppe Fallacara tuvo un curso anual en el New York Institute of Technology impartiendo clases de proyectos estereotómicos.

En el ámbito norte-americano se quiere recordar el estudio desarrollado por el autor de esta tesis sobre la estereotomía en la ciudad de New York, parte de cual investigación ha sido publicada en un artículo dedicado al estudio de las bóvedas de la Public Library de dicha ciudad ${ }^{44}$.

La importancia del estudio de la estereotomía, fuera de un fin puramente historiográfico, se reconoce en las cualidades necesarias para entender plenamente la arquitectura. Es una disciplina que desarrolla, obviamente, la capacidad de dibujo en proyección, pero también la intuición estructural, la visión espacial, la creatividad constructiva, la racionalización constructiva y ejecutiva ${ }^{45}$. Con estos propósitos también el arquitecto contemporáneo puede sacar gran provecho en su práctica profesional cultivando esta materia.

En un contexto cultural marcado por un mayor interés por la estereotomía y las realizaciones en los diferentes ámbitos territoriales, destaca el hecho que, hasta esta tesis, Cataluña se haya omiso de las mayores líneas de investigación, no obstante, como señaló Carbonell ${ }^{46}$ sea un área llena de ejemplos significativos.

Con esta tesis se quiere llenar este vació, empezando por un importante documento "redescubierto" en la Biblioteca Nacional de Catalunya.

\footnotetext{
44 Jose Antonio Garcia Ares and Fabio Tellia, "Some Instances of Arch and Vaulting Construction at the New York Public Library," in Proceedings of the First Construction History Society Conference, Queen's College, University of Cambridge 11th-12th April 2014, ed. James W P Campbell (Ascot: Construction History Society, 2014).

45 A este propósito se quiere mencionar que Gaudí estudió estereotomía en su carrera y un ojo atento puede reconocer en sus obras una práctica estereotómica y un rigor geométrico muy afinado.

46 Carbonell, 2008: 116: "Por tanto, el uso de la piedra estaba prácticamente generalizado en todo el país. Y, aunque los estudios sobre el arte del corte de piedra o estereotomía en Cataluña van con retraso en relación a otras regiones, como Valencia y Mallorca, debemos suponer que los conocimientos de nuestros mestres de cases no eran inferiores a los de las zonas limitrofes, por el norte y por el sur. Quizá no poseyeran el virtuosismo de algunos contemporáneos franceses, mallorquines o valencianos, pero los picapedreros catalanes también fabricaban arcos en esviaje (se descubren fácilmente en la catedral de Barcelona, la catedral de Girona, el hospital de la Santa Creu, etc.), caracoles a la manera de Mallorca y de nabo, arcos rampantes, pilares helicoidales o entorxats, capiteles pinjantes, etc., es decir, comparten un similar repertorio de soluciones formales y constructivas de gran originalidad, participan de la koiné empírica y matemática de sus colegas tardomedievales".
} 


\subsection{Contexto histórico}

El conocimiento acertado de la fecha de compilación del manuscrito permite delinear el cuadro político-cultural de un periodo histórico particularmente relevante para España y para Cataluña en particular y evaluar las relaciones entre los factores político-culturales y los caracteres de la arquitectura.

El tratado se coloca en un periodo caracterizado por cambios profundos a nivel político que se reflejan en manera significativa en el mundo de la construcción y en el sistema de formación de las profesiones a esa relacionadas.

Haber comprobado la exactitud de la fecha del manuscrito a través de la marca de agua del papel nos permite construir con precisión el contexto histórico.

La historia de la construcción es una disciplina fuertemente relacionada con la historia económica y política de un territorio, del mismo grado de importancia que la historia de la arquitectura, entendida como desarrollo y evolución de los estilos y de las formas, tiene con los citados factores sociales. A través de ella podemos conocer los avances tecnológicos y científicos, las relaciones entre los territorios, las migraciones, las estructuras sociales, la prosperidad económica y las crisis.

Es posible reconocer identidades nacionales y locales dentro del utilizo de una tecnología constructiva, como que fuese un matiz incorporado en una más amplia corriente arquitectónica; con la análisis de cómo la misma geometría o el mismo elemento viene construido en un determinado lugar, se pueden registrar analogías constructivas que se hallan en territorios que eran relacionados económicamente con ese lugar; o se pueden subrayar la unicidad de una manera constructiva debido a la sensibilidad, al gusto y a la situación económica de dicho lugar.

Por varias razones Cataluña ha tenido una respuesta diferente a la penetración de las corrientes arquitectónicas europeas respecto al resto de España, y ha tenido una diferente relación con otros países del área del mediterráneo, al punto que se han desarrollado cualidades constructivas propias de estas tierras. Basta pensar a la caracterización del románico catalán en el siglo $\mathrm{XI}$, con sus naves totalmente recubiertas con bóvedas en piedra, que abandonaban los techos de madera característicos del norte de Italia, como si fuera una adaptación a la persistencia de la cultura constructiva romana que se conservaba a través de la época carolingia ${ }^{47}$.

\section{Los Siglos XI y XII}

Las adquisiciones territoriales de Ramón Berenguer I (1035-1076) permitieron incorporar a Cataluña los dominios de Carcasona y Bézier, a las cuales sucesivamente Ramón Berenguer III (1096-1131) añadió la Provenza y el Verán, consolidando las relaciones culturales y políticas con la Provenza y el Languedoc.

El matrimonio de su hijo, Ramón Berenguer IV (1131-1162), con Petronila de Aragón permitió la creación de la Corona de Aragón, resultado de una unión dinástica pactada que, desde su nacimiento, se caracterizó por ser más una superestructura política que un territorio con

47 Fernando Chueca Goitia, Historia de La Arquitectura Española : Edad Antigua y Edad Media (Madrid: Editorial Dossat, 1965): 150. 
intereses comunes en la cual los monarcas permitieron mantener por separado sus propias leyes e instituciones.

Los siglos XIII y XIV

La expansión mediterránea de la Corona de Aragón empezó con la conquista de Mallorca por parte de Jaume I en 1229 y de Valencia en 1238, y fue consolidada durante el reinado de Jaime II (1291-1327) que consiguió extender al máximo los territorios dominados por la Corona de Aragón, hasta incluir bajo la misma corona Aragón, Cataluña, Mallorca, Perpiñán, Sicilia, Cerdeña, Nápoles, y, tras la expedición a Asia Menor de Roger de Flor (1303), un ducado catalán en Atenas.

La conquista de Mallorca, previamente ocupada por poblaciones musulmanes, comportó la construcción de arquitecturas religiosas y civiles de la nueva hegemonía política y permitió la colonización de la isla con poblaciones procedentes de la Catalunya Vella y de la Catalunya Nova. Por tanto, los primeros habitantes de origen cristiana eran procedentes del Rosselló. Desde el primer momento se estableció una conexión entre Mallorca y la región de Perpiñán, que, durante un tiempo, estuvieron bajo la misma jurisdicción y las mismas directrices políticas y orientaciones artísticas.

El intercambio cultural de la Cataluña de los siglos XIII y XIV interesó las inmigraciones hacia el norte de Cataluña causadas por el fenómeno albigense en el sur de la Francia. La sensibilidad artística del levante ibérico llevó a la definición del Gótico Meridional que se desarrolló a lo largo de todo el siglo XIV con la construcción de las grandes catedrales en tierra catalana.

Pere el Ceremonioso (1336-1387) tuvo que enfrentarse al definitivo triunfo de la monarquía y a la propagación de la peste negra que en 1348 afligió todo el Occidente cristiano. El gran despoblamiento que le siguió provocó una fuerte inflación favoreciendo la prosperidad del comercio exterior de Cataluña.

\section{El siglo XV}

El siglo XV se caracterizó por una importante actividad comercial y la sucesiva crisis económica que culminó en $1480 \mathrm{ca}$. y que, juntamente a la progresiva pérdida de hegemonía a favor de Aragón y los enfrentamientos sociales que culminaron en guerra civil (14621472), favoreció al ascenso económico de Valencia.

En esta época, en el territorio valenciano también se desarrollaron esplendidas construcciones estereotómicas, testimoniadas por las obras de Francesc Baldomar y Pere Comte; en Mallorca y en el Reino de Nápoles se difundieron las invenciones estereotómicas góticas de Guillerm Sagrera. La arquitectura gótica de esta área geográfica se caracterizó por el desarrollo de soluciones en corte de piedra que alcanzó niveles de afinamiento espectaculares. Basta pensar a las innovaciones de los primeros maestros valencianos ${ }^{48} \mathrm{O}$ mallorquines del siglo XV. Las experimentaciones y los conocimientos técnicos madurados a pie de las catedrales circulaban con los maestros de obras y se difundían dentro del

48 Arturo Zaragozá ilustra los avances de la arquitectura valencianas del '400 en varios textos, en particular: Eduardo Mira and Arturo Zaragozá Catalán, eds., Una Arquitectura Del Gótico Mediterráneo. Catálogo de La Exposición (Valencia: Generalitat Valenciana. Conselleria de Cultura i Educació, 2003). 
territorio catalán, donde también llegaban trabajadores de piedra procedentes de Francia ${ }^{49}$. La arquitectura gótica meridional conoció el momento de máximo esplendor durante este siglo, durante el cual se construyeron importantes edificios civiles y religiosos, entre los cuales lonjas y ayuntamientos. Fueron introducidos temas decorativos de procedencia italianizantes y germánica limitados a la decoración mientras que la composición y la estructura del edificio siguieron siendo góticas. Probablemente, el nuevo gusto del Renacimiento italiano no se afirmó como estilo principalmente por la firme cultura y espiritualidad catalana que se encontraba plenamente identificada en las formas góticas. Otras posibles razones de su limitada difusión fueron principalmente económicas, ya que no se pueden descartar las ventajas constructivas de la arquitectura gótica.

En 1469 se efectuó el enlace matrimonial entre Isabela de Castilla y de Fernando de Aragón, dando inicio a la unión dinástica entre los dos reinos, que siguieron funcionando independientemente, con sus propias instituciones y parlamentos.

\section{Los siglos XVI y XVII}

En el siglo XVI la Corona de Aragón fue cada vez más castellanizada y más desestructurada, y su marginalización a la política imperialista de la monarquía la dejaron alejada del comercio con América y de la riqueza que conocieron las ciudades andaluzas. Valencia era el centro de la comunidad catalana.

En este periodo hay la síntesis de las formas catalanas con las nuevas procedentes de Italia, sin embargo, obras propiamente renacentistas sin rastros góticos se presentan aisladas.

Durante los siglos XV y XVI, Mallorca adquirió poder económico y se estableció como centro de comercio importante del Mediterráneo, especialmente para los mercantes genoveses, que montaron su bolsa propia en Palma. Mallorca desarrolló un comercio significativo con las potencias del Mediterráneo Oriental y con los estados italianos, particularmente con Pisa, Génova y Florencia ${ }^{50}$. En estos siglos, las islas Baleares, por su ubicación geográfica y por su situación económica y política, se relacionaron desde el punto de vista arquitectónico principalmente con el levante ibérico y con la península italiana ${ }^{51}$. Hasta el principio del siglo XVII fue muy evidente la diferenciación estilística entre la arquitectura privada, que utilizaba el Renacimiento, y el universo de la iglesia fiel al estilo gótico. Como en Cataluña, la influencia italiana afectaba especialmente los repertorios decorativos ${ }^{52}$.

\section{El siglo XVIII}

En 1714 Cataluña sufrió la represión de su orden político y social por haber suportado el archiduque Carlos de Austria en la Guerra de Sucesión. Las instituciones oficiales fueron abolidas y se instituyó un poder militar de ocupación en la ciudad. La subida al trono de los Borbones y la consecuente reorganización económica y cultural comenzada no empobrecieron Barcelona, sino le dieron otra dirección, impulsada por la fuerte influencia

\footnotetext{
49 Carbonell 2008 Pag. 148

50 Marella Caracciolo and Francesco Venturi, Casas Señoriales de Mallorca (Londres: Cartago, 2004): 48.

51 George Kubler, Arquitectura de Los Siglos XVII y XVIII En España (Madrid, 1957), 25.

52 Maria Perello Ferreŕ, Esglésies Dels Segles XVII i XVIII a Ciutat de Mallorca: Influències Tendències $i$ Tipologies Artístiques (Palma De Mallorca: Moll, 1985).
} 
del estado central que imponía su autoridad sobre la cultura a través de la institución de las academias.

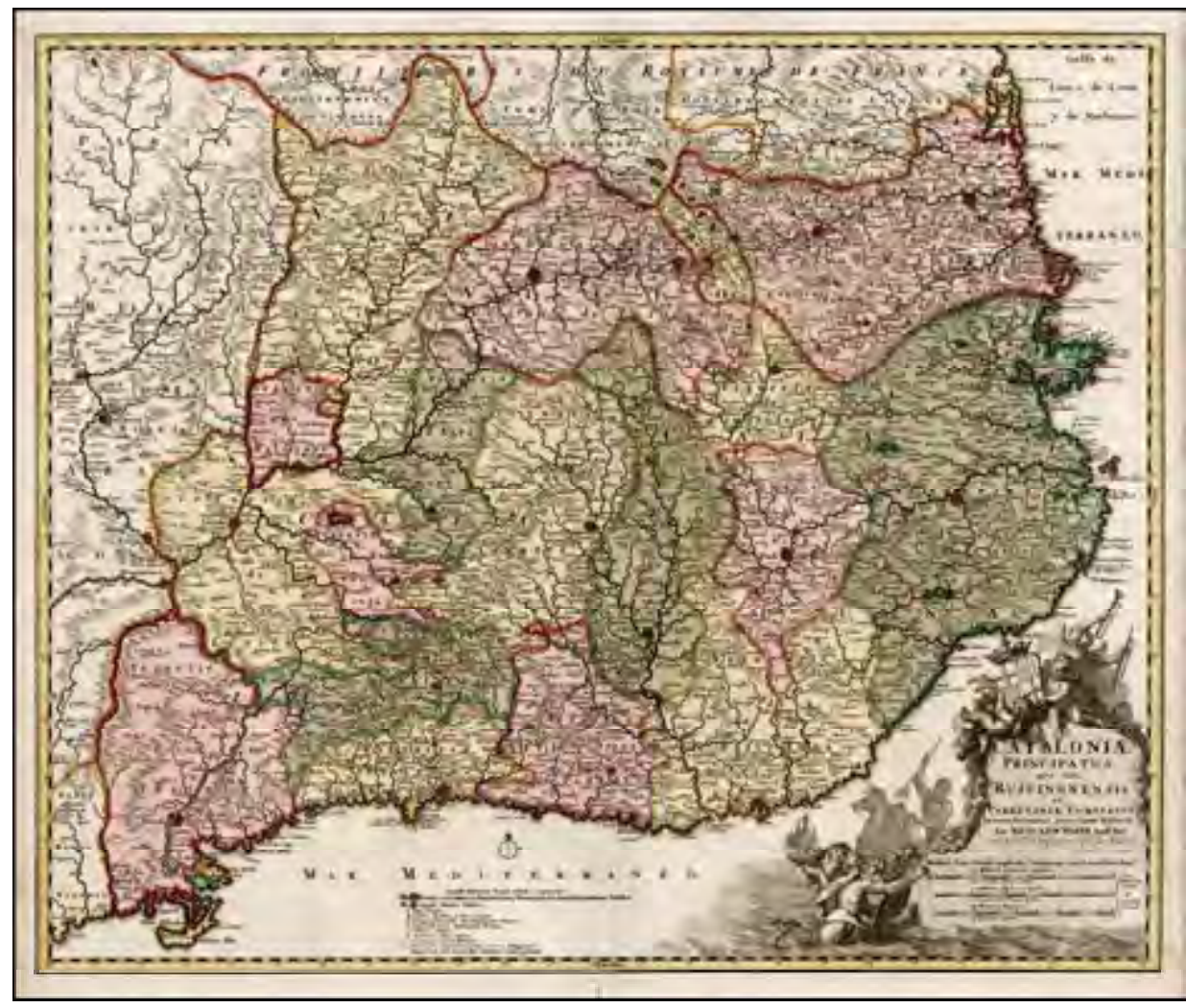

Fig. 2.6. Cataloniae Principatus et Ruscinonensi et Cerretaniae in eorum Vicariatus peraccurate Distincti. Nicholas Visscher, 1690ca

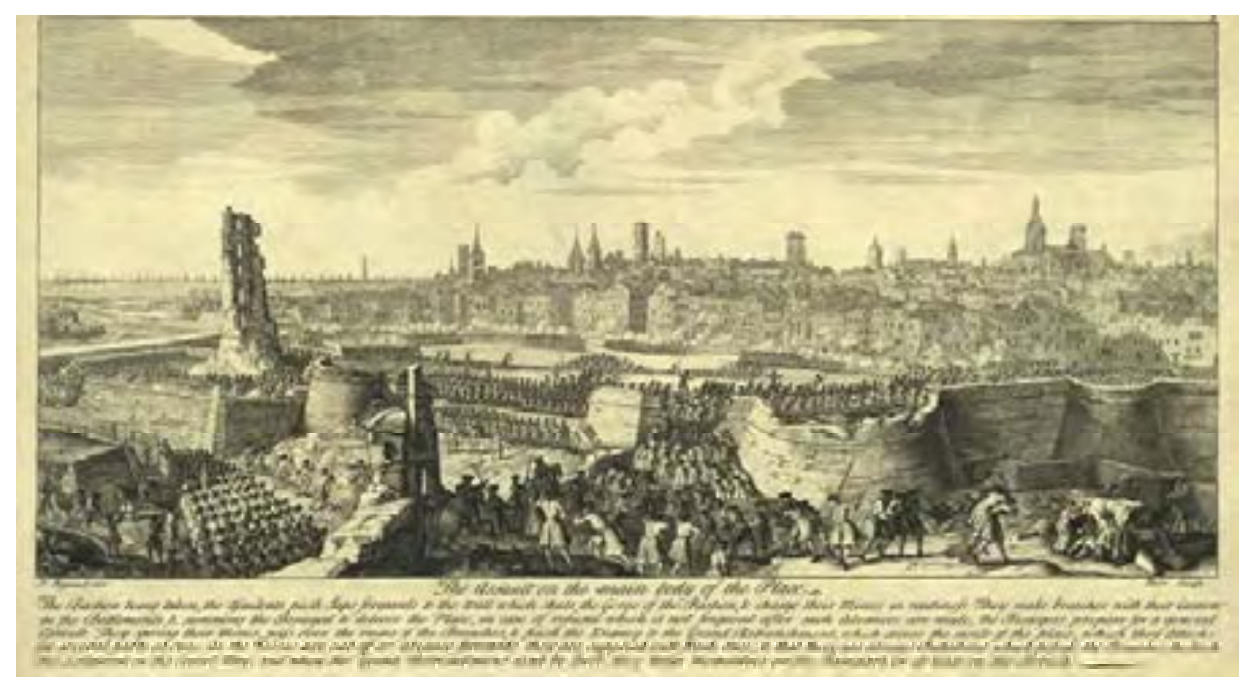

Fig. 2.7. Asalto final de las tropas borbónicas sobre Barcelona el 11 de septiembre de 1714 . Jacques Rigaud (1680-1754) / Parr / Bowles - Institut Cartogràfic de Catalunya 


\subsection{Trasmisión del saber}

\subsubsection{Antes de la llustración}

Las estructuras corporativas, es decir los gremios, mantuvieron su carácter exclusivo y cerrado hacia sus secretos profesionales hasta la mitad del siglo XVIII controlando la la transmisión del saber en un ámbito muy limitado y selecto.

En Barcelona, todas las cuestiones relativas a la actividad profesional de los maestros de obra eran regulada por la Confraria de Mestres de cases i Molers, que se formó de la unión del Gremi de Mestres de Casas, Picadors i Trencadors de pedra, con el Gremi de molers, en 1432. Los pedreros se habían agremiado en 1211, y los Mestres arquitectos, paletos y pedreros en $1327^{53}$. Los gremios reglamentaban la formación profesional a través del aprendizaje y de los exámenes de maestría. El aprendizaje ${ }^{54}$, de la duración total de 8-10 años, culminaba con el examen, que consistía en dibujar ordenes, trazas y elementos de arquitectura, y poner en obra una traza. Era de numero cerrado y favorecía a los hijos de los maestros de obra, contribuyendo de esta manera a guardar los secretos corporativos ${ }^{55}$. La transmisión del saber entre lugares geográficos distintos se realizaba a través de tres modalidades: la movilidad de los mestres de obras, de los picapedreros, y la circulación de los pocos tratados disponibles.

Con referencia a Cataluña y los territorios relacionados, recordamos el movimiento de algunos maestros importantes.

Ponc Descoll, que trazó las trompas del Palacio de los Reyes de Mallorca en Perpiñán (1295-1309) se transfirió a Mallorca donde construyó las trompas del Palau de la Almudaina (1309) y las trompas de la Capilla de la Trinidad en la Catedral de Palma (c. 1330). Gullierm Sagrera, un nativo de Felanitx en Mallorca, ganó una posición como arquitecto en St. Jean en Perpiñán. En 1416 fue llamado para determinar la continuación de la catedral de Girona. Sucesivamente regresó a Mallorca para el encargo de arquitecto de la Catedral (1422) y para proyectar la Lonja de Palma. Pere Compte, originario de Girona, desde el 1481 trabajó en el Palau de la Generalitat de Valencia y en 1490 empezó a trabajar en la Seu de Tortosa. Se formó probablemente con Frances Baldomar (activo en Valencia entre 1425 y 1463), el autor de emblemáticas construcciones estereotómicas. Hubo también importantes migraciones de mestres de cases de Francia a Cataluña, como documenta el contrato de construcción de la Iglesia de Sant Vincenç de Montalt:

Aquests anys del segle XVI foren d'un important redreçament econòmic que provocà un foit augment demogràfic, ajudat pels immigrants procedents de terres franceses. Aquesta immigració no fou únicament de braços per a l'agricultura o de peonatge, ja que trobem mestres de cases francesos, entre ells l'esmentat Joan de Tours a Calella, Pierre Ddquer que construeix el campanar de Llavaneres i Perris Rohat, establert a Mataró.

\footnotetext{
53 Montaner, 1990: 47.

54 Antonia Maria Perelló Ferrer, L'arquitectura Civil Del Segle XVII a Barcelona (Barcelona L'abadia De Montserrat, 1996): 37.

55 Montaner, 1990: 39-42.
} 


\subsubsection{Llegada de la Ilustración}

La práctica de la arquitectura en el siglo XVIII en España fue profundamente definida por la institucionalización del saber, a través de la creación de la Academia Militar de Matemáticas de Barcelona en 1720 y de la Real Academia de Bellas Artes de San Fernando de Madrid en 1752, instituida siguiendo el modelo francés de la Acadèmie de Colbert de 1671. La Academia Militar formó en Barcelona numerosos maestros de obras y arquitectos civiles ${ }^{56}$, que pudieron tener acceso a los nuevos conocimientos científicos y a las nuevas técnicas. Como ha notado el historiador Marià Carbonell ${ }^{57}$ en Barcelona al final del ' 600 existían dos tipos de profesionales de la construcción: ingenieros militares, de formación forastera, y los mestres de casas, cuya actividad estaba sujeta a las ordenaciones gremiales y a una formación tradicional y eminentemente práctica que ocurría a pie de obra bajo el tutelaje de los maestros canteros. En este contexto, los libros de arquitectura y de trazas eran a disposición solo de los maestros de obra más importantes.

Con las Academias se originó un cambio radical en las modalidades de aprendizaje que pasaron de la tradición oral típica de la época gremial a la formación institucionalizada.

Se difundió el conocimiento de la estereotomía desarrollada en las academias francesas gracias a la llegada a Barcelona durante el siglo XVIII de los textos franceses sobre la materia, entre los cuales se encuentran los tratados de Derand, Desargues, Frezier y de la Rue $^{58}$, pero también gracias a las obras españolas de Bails y Tosca ${ }^{59}$.

La estereotomía caracterizó numerosas obras civiles y religiosas de esta época, siendo disciplina que representaba la solemnidad del estado y el conocimiento técnico de los autores, así como caracterizó las fortificaciones en piedra proyectadas por los nuevos profesionales de la construcción.

En este contexto ideológico de predominio del pensamiento llustrado, con la creación de las Academias se favoreció la transmisión de los conocimientos, pero también se instauró una estructura de vigilancia en el campo artístico y arquitectónico, en contra a los principios del saber iluminado de búsqueda de la verdad, libertad individual y abertura mental.

56 Manuel Arranz Herrero, "Los Profesionales de La Construcción En La Barcelona Del Siglo XVII" (Tesis Doctoral, 1981).

57 Marià Carbonell i Buades, "L'arquitectura a l'època Del Barroc," in L'època Del Barroc i Els Bonifàs : Actes de Les Jornades d'Història de l'Art a Catalunya, Valls, 1, 2 i 3 de Juny de 2006, ed. Bonaventura Bassegoda, Joaquim Garriga, and Jordi Paris (Barcelona: Universitat De Barcelona, 2007): 24-25.

58 Montaner, 1990: 127.

59 Ibid. 373. 


\section{Metodología}

El trabajo previo al análisis del tratado de Ribes ha sido la búsqueda y la catalogación de las arquitecturas estereotómicas principalmente en Cataluña y en menor medida en las Islas Baleares y en el arco mediterráneo occidental. La metodología empleada para la catalogación sigue la clasificación utilizada por los tratadistas españoles, que solían dividir los aparejos en familias de piezas de cantería. Se ha querido analizar las arquitecturas de estas regiones por las relaciones políticas y culturales que estos territorios han tenido a lo largo de la historia.

A continuación, se ha desarrollado la base de conocimientos necesarios para entender el marco cultural de esta tesis. De hecho, esta investigación presupone la familiaridad con los métodos estereotómicos y el avance de la disciplina, la comprensión de los problemas constructivos de los diferentes trazados geométricos, el conocimiento de los principales acontecimientos en la política y en la arquitectura del ámbito geográfico y temporal de esta tesis.

El corpus central de la investigación es el análisis del tratado de Ribes en su marco histórico y en su contenido, enfocándose en el estudio de la concreción geométrica de las trazas y los métodos de proyección sobre el plano. Se pueden entonces encontrar las correspondencias con otros tratados y con los aparejos construidos en Cataluña que han sido anteriormente catalogados.

Sucesivamente cada elemento viene modelado en tres dimensiones con el empleo del ordenador para visualizar su técnica constructiva. La representación infográfica permite apreciar con más facilidad el aparejo pensado por Ribes. La totalidad de los modelos constituyen entonces un catálogo de imágenes representativas de las trazas del Llibre de trasas clasificadas y agrupadas en familias.

Durante el desarrollo de esta tesis se ha podido también experimentar directamente las teorías y los modelos sobre los cuales se enfocaba mi investigación. La oportunidad me ha sido ofrecida en el curso del Taller de Cantería Gótica del Prof. Palacios, donde se pudo construir en tamaño real una de las bóvedas de crucería del tratado de Ribes.

Para esta experimentación, durante el estudio de la volumetría de la bóveda se han utilizado programas paramétricos, normalmente utilizados para el diseño de arquitecturas contemporáneas.

La bóveda construida ha sido publicada en la página web del grupo de investigación al cual pertenezco, en algunas comunicaciones a congresos de historia y de historia de la construcción, en una revista indexada y ha aparecido en un artículo de El País. 


\subsection{El Manuscrito}

Este manuscrito se guardaba en la biblioteca privada de un profesor de la Universidad de Barcelona, experto de ópera y melodrama, que lo adquirió a un vendedor de antigüedades. Sucesivamente en 2003 fue adquirido por la Biblioteca Nacional de Cataluña por el Dr. Francesc Fontbona, que compró el documento cuando era director de la Unitat Gràfica de la Biblioteca de Catalunya, por la cifra de 6.000 euros y desde entonces se conserva en la sección de archivos históricos.

El Llibre de Trasas ha pasado casi completamente desaparecido hasta ahora, sin embargo, el documento lo dio a conocer por primera vez el catedrático de historia del Arte de la UB, Joan Ramon Triadó en 1984 en su volumen dedicado al Barroco de la Historia de l'Art Català , donde menciona el manuscrito y reproduce alguna de sus páginas.

El trabajo de investigación de la D.ra. Perelló Ferrer ${ }^{1}$ anotó (1993) la existencia del Llibre de Trasas y proporcionó una breve descripción del contenido, que al tiempo era todavía propiedad de una colección particular:

"Una mostra eloqüent del que eren aquests libre de traces la constitueix l'obra realitzada pel mestre Josep Ribas, l'any 1708, recollint per tant els coneixements de finals del segle XVII, amb el títol de Llibre de trassas de viax y muntea.

«Muntea» és l'art de la talla de la pedra o estereotomia, i, tal com anuncia el títol del llibre, en ell es donen les plantilles de tallar les pedres per a realitzar cada un dels mes de cent exemples d'elements arquitectònics continguts. Després d'una primera pàgina en què l'autor demostra el seu virtuosisme traçant diverses

figures geomètriques dins circumferències del mateix diàmetre, Ribas inicia un recorregut, que sempre va de la solució mes senzilla a la més complexa, per diferents elements arquitectònics. En tractar dels arcs i de les voltes, que arriben a ser d'onze claus, dóna la plantilla i els diferents talls que ha de tenir cada pedra per a aconseguir la perfecció d'encaix. Es també exhaustiu el tractament que fa dels portals i dels diferents tipus de "revolts», o formes que pot donar a l'intradós de l'arc («ravol ab talus y canto», "ravol baix», «ravol ab anell»...).

Posa també un exemple d'escala de cargol i d'escala de dos replans. El llibre de traces de Josep Ribas, a més de les més de 200 imatges que conté, dóma consells o "receptes» pràctiques per a unir pedres, per a daurar les claus de volta o per a llustrar la pedra."

\footnotetext{
1 A. M. Perelló Ferrer en L'arquitectura civil del segle XVII a Barcelona, (L'Abadia de Montserrat, 1996): 4950, procedente de su tesi doctoral de 1993, anotó la existencia del Llibre de Trasas y proporcionó una breve descripción del contenido.
} 
Sucesivamente (2008), un artículo de Marià Carbonell i Buades² volvió a llamar la atención sobre el manuscrito:

"Que esta tradición del trabajo de la piedra se perpetuó lo demuestra también un texto muy poco conocido - sin duda porque, siendo hasta hace poco de propiedad particular, se ha mantenido inédito-, comparable al tratado de estereotomía del mallorquín Josep Gelabert, aunque cincuenta años más tardío. Se trata del Llibre de trassas de viaix y muntea (es decir, de trazas de esviaje y montea) de Josep Ribes, fechado en $1708^{\prime \prime 3}$

El contenido del manuscrito fue primera vez descrito en una comunicación del autor de esta tesis ${ }^{4}$ en el Séptimo Congreso Nacional de Historia de la Construcción en Santiago de Compostela (2011). Otros artículos a seguir del autor han desvelado algunas de las características geométricas y constructivas de las trazas del Llibre de trasas.

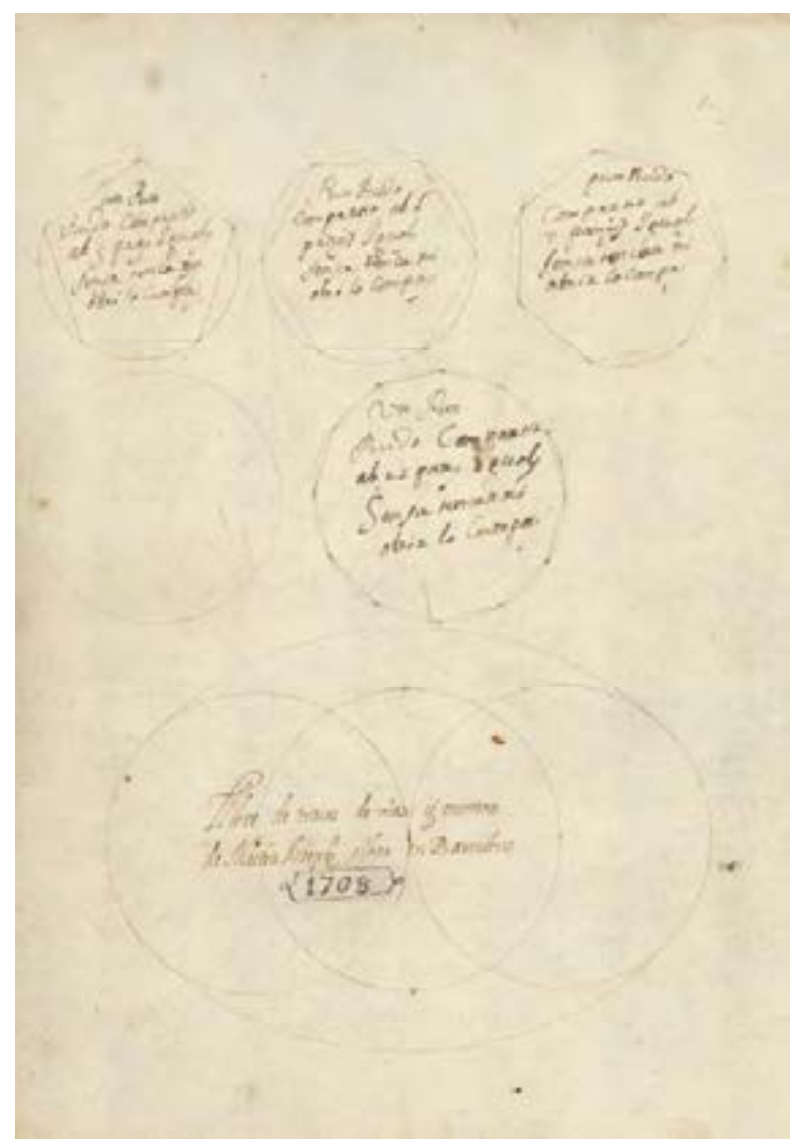

Fig. 3.1. Portada del Llibre de Trasas

2 Carbonell i Buades, 2008: 97-148.

3 Ibid. 117.

${ }^{4}$ Fabio Tellia, "El Tratado de Estereotomía de Joseph Ribes, 1708," in Actas Del Séptimo Congreso Nacional de Historia de La Construcción, Santiago de Compostela, 26-29 Octubre de 2011, ed. Santiago Huerta Fernández, vol. 2 (Madrid: Instituto Juan de Herrera, 2011), 1413-20. 


\subsection{Contenido y estructura del manuscrito}

El Llibre de trasas de viax y muntea ${ }^{5}$ es un extraordinario manuscrito sobre cantería y estereotomía redactado a principios de siglo XVIII en Barcelona por el Mestre Joseph Ribas. Contiene 135 modelos de trazas de cantería, algunas de ellas de origen clásico y otras de inspiración gótica. Algunas de estas trazas son ya bien conocidas por estar presentes en anteriores tratados; sin embargo, otras son originales y totalmente inéditas ${ }^{6}$. Su contenido abarca trazas de montea destinadas a construir en piedra de cantería arcos, trompas, capialzados, escaleras, así como un amplio capítulo que contiene un extraordinario repertorio de bóvedas de crucería y adoveladas.

Podemos contar 26 tipos de puertas, 5 arcos, 27 bóvedas compuestas, 40 bóvedas de crucería, 8 pechinas, 2 escaleras y 27 capialzados.

El manuscrito consta de 240 páginas encuadernadas con hilo, con dibujos en tinta color sepia realizados con compás y regla. Se ordena por temáticas similares que van conformando capítulos claramente diferenciados. En cada sección del manuscrito la estructura es la misma: Ribes comienza por desarrollar la solución más sencilla y, con los sucesivos ejemplos, va añadiendo variaciones geométricas que conducen hacia trazas más complicadas. Es muy metódico en esta catalogación, aunque a veces repite el mismo aparejo con variaciones mínimas de geometría, casi para acentuar la meticulosidad del orden establecido. Hacia el final del tratado, quizás si por error o por haber decidido ampliar posteriormente alguna familia de trazados, mezcla unos ejemplos de traza de diferentes grupos.

La mayoría de los aparejos vienen explicados en dos hojas. En la página a la izquierda el autor proporciona la planta y sección - o alzado, si se considera más oportuno para aclarar la traza- y a la derecha, en la página opuesta, añade las informaciones adicionales necesarias para determinar las plantillas, los ángulos de corte y las verdaderas magnitudes de las caras.

Diferentemente de otros autores contemporáneos, no utiliza dibujos en axonometría para visualizar los aparejos de manera más clara o explicar métodos de corte.

El tratado de Ribes carece de un texto que describa el procedimiento empleado para llevar a cabo la construcción geométrica expuesta, afortunadamente, las trazas son claras y están meticulosamente dibujadas lo cual hace innecesarias mayores explicaciones a un lector familiarizado en el arte de la cantería.

\footnotetext{
5 Joseph Ribes, Llibre de Trasas de Vias y Muntea (Barcelona: Ms. Biblioteca Nacional de Catalunya, 1708).

6 Por ejemplo, el Portal ap Campana caracterizado por una insólita clave que se empotra con las dovelas adyacentes; o las trompas cónicas con clave central a diente de sierra, un modelo existente en Cataluña desde el siglo XV. Otra traza, la Bolta per aresta que las filadas rrodan, es de muy escasa difusión ya que podemos recordar solo un pequeño grupo de ejemplos construidos en Francia y aparece solamente en los tratados de Philibert de L' Horme (Voûte en pendentifs, Ch. 12. Premier tome de l'Architecture, Livre III) y en los Rasguños de Alonso de Guardia.
} 
Las únicas referencias presentes en el tratado se refieren a números que señalan vértices y claves, con ellos es posible entender las correspondencias entre plantas, alzados y secciones.

Sólo al final el manuscrito consta de dos páginas con algunas instrucciones técnicas que, como un apartado independiente, instruyen sobre cómo proceder para enlucir paramentos de piedra y fabricar morteros (Fig. 3.2), informaciones que demostrarían que es un cuaderno destinado a la construcción.

Betum per afegir pedra: pendra dos lliures de pega grega. una lliura de sofre, dos unsas de trementina, dos unsas de mostach y mitxa unsa de cera nova y fondreu ab una cassola nova y quant sera fos pendrer picadis pasat per un sedas. Posarli apoch apoch y remenant ab un basto y fer que no sia massa magra y despres buidarlo sobre una post mullada y sen farant trosos rodons y de llarchs, de modo que bulgant...

La portada del tratado contiene el título, el nombre del autor y el dibujo de algunos polígonos regulares de $5,6,7$ y 12 y de un ovalo.

Comparte con Gelabert algunas trazas similares en nomenclatura y geometría: probablemente no había tomado visión conocía directamente su tratado, pero sus conocimientos eran parte del saber común de los canteros de esta área geográfica.

Recordamos las trazas que tenían en común, es decir la escalera escarzana, también elemento característico de esta área geográfica, el portal entre dos torres cilíndricas, el interés por las bóvedas de crucería, la bóveda de arista con pared disminuida, la trompa con perfil poligonal, las varias opciones de arcos que se presentan primeros rectos y luego en talud.
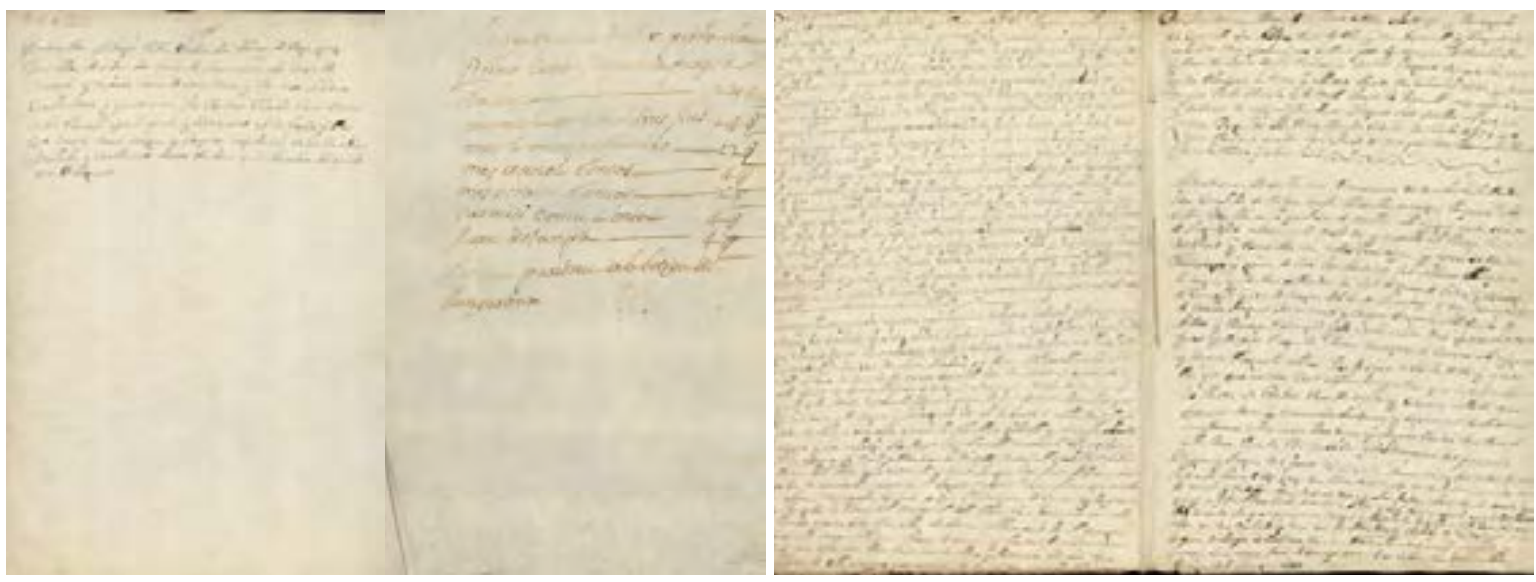

Fig. 3.2. Folios 245-246; y 249-250 


\subsection{Elenco trazas}

El elenco a seguir contiene el nombre de las trazas del Llibre de trasas y su traducción en castellano, en el orden tal como aparecen en las páginas del manuscrito.

1. Portal Rado

2. Portal escasa

3. Portal recto

4. Portal ab anclavias

5. Portal ab campana

6. Portal a un biax

7. Portal biax ab contra biax

8. Portal ab canto

9. Portal ab canto y talus

10. Portal ab canto y talud y paret derra

11. Portal a braco biax

12. Portal a braco y talus

13. Portal a braco y talus y paret derra

14. Portal ab tora radona

15. Portal ab tora radona y talus

16. Portal ab tora radona y talus y paret derra

17. Portal ab tora acabada

18. Portal ab tora acabada y talus

19. Portal ab tora acabada y talus y paret derra

20. Portal ab canto y tora acabada

21. Portal ab tora radona y raco

22. Portal ab tora radona y canto

23. * $\sin$ nombre

24. Bolta per aresta

25. Bolta per aresta per llongada

26. Triangul per aresta

27. Bolta per aresta

28. Bolta per aresta

29. Bolta per aresta que las filadas rrodan

30. Bolta per aresta, en planta rrodona

31. Bolta per aresta ab lunetos

32. Bolta per aresta biaxa

33. Bolta de postexa

34. Bolta pastexa y gradordi

35. Bolta bivitavada ab pasteza

36. Bolta ab pastexa y triangol

37. Bolta dela pastexa ab aun cap rrodona

38. Bolta ab pastexa ab tres pans

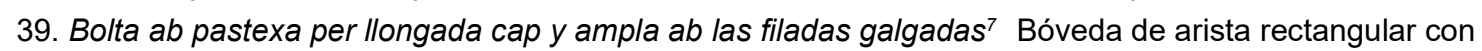
lados estrecho y ancho y las juntas ajustadas

40. Bolta ab pastexa per llongada

41. Bolta ab pastexa biaga

42. Bolta ab pastexa biaxa ala un cap rrodona
Portal de medio punto

Portal escarzado

Portal adintelado

Portal adintelado con junta discontinua

Portal a campana

Portal a un esviaje

Portal en viaje y contra viaje

Portal en esquina

Portal en esquina y talud

Portal en esquina y talud y pared recta

Portal en rincón en esviaje

Portal en rincón y talud

Portal en rincón y talud y pared recta

Portal en torre redonda

Portal en torre redonda en talud

Portal en torre redonda y talud y pared recta

Portal en torre cava

Portal en torre cava y talud

Portal en torre cava y talud y pared recta

Portal en esquina y torre cava

Portal en torre redonda en rincón

Portal en torre redonda en esquina

Portal en torre redonda y torre cava

Bóveda de arista

Bóveda de arista rectangular

Bóveda de arista triangular

Bóveda de arista triangular

Bóveda de arista rectangular

Bóveda de arista por hiladas redondas

Bóveda de arista en planta circular

Bóveda de arista con lunetos

Bóveda de arista en viaje

Bóveda en rincón de claustro

Bóveda de arista en planta romboidal

Bóveda en planta octagonal (Ochavo igual)

Bóveda en rincón de claustro en planta triangular

Bóveda de arista (rincón de claustro) con una testa redonda

Bóveda de arista con tres paños

\footnotetext{
7 Galgar: accion de ajustar o trabar las distintas partes de la piedra para que puedan encajar unas con otras y: 'mida fixada que han de tenir certes pedres de construcció',
} 
43. Bolta ab pastexa ab lunetas ala un cap rrodona Bóveda de arista con lunetos y una testa redonda 44. bolta ab pastera viaza ab un cap gra de (...), saltre cap escarza, saltre rodo Bóveda de arista en viaje con un capo grande, otro escarzano, otro redondo

45. bolta ab pastera rodona

46. Volta pastera ab un cap rodona

47. Boveda ab pastera ab un rodo

48. Boveda ab sub bino cuadrat

49. Boveda ab sub bino ab pastexa

50. Volta ab sub biño

51. Volta ab una clav

52. Volta ab una clav cuberta

53. Volta ab duas clavs

54. Volta ab duas clavs

55. Volta ab tres claves

56. Volta ab cuatra claves

57. Volta ab cinc claves

58. Volta ab cinc claves y per llongada

59. Volta ab cinc claves

60. Volta ab cinc claves coberta

61. Volta ab sis claves

62. Volta ab set claves

63. Volta ab voit claves

64. Volta ab nou claves

65. Volta ab nou claves

66. Volta ab nou claves

67. Volta ab nou claves

68. Volta ab deu claves

69. Volta ab bonsa claves

70. Volta ab dotsa claus

71. Volta ab treise claves

72. Volta ab catorse claves

73. * $\sin$ nombre

74. * $\sin$ nombre

75. Volta ab setse claves

76. Volta ab dicet claves

77. Volta ab bona clan ab rampan

78. Volta ab bona clau ab triangol

79. Triangol ab bona clau cuberta

80. Volta ab triangul y ab bona clau y rrampan

81. Triangol ab tres claves

82. Volta ab tres claves

83. Volta ab Quatre clan ab triangol

84. Volta ab triangola ab set clavs

85. Volta ab planta rrodona

86. Volta ab planta rrodona (cuberta)

87. Volta ab planta rrodona y rampan

88. Volte ab cinc clavs y ab planta rrodona

89. volta ab nou clavs y ab planta rrodona

90. Volta bvitavada ab una clau

91. Volta bvitavada ab rrampan ab una clau

92. Volta bvitavada ab nou clau

93. Rebolcura de Marcella
Bóveda de torre redonda

Bóveda con una testa redonda

Bóveda con un testero redondo

Patio cuadrado

Bóveda en patio cuadrado y redondo

Patio redondo

Bóveda de una clave

Bóveda de una clave cubierta (plantillas perpendiculares)

Bóveda de dos claves

Bóveda de dos claves (dos crucerías yuxtapuestas)

Bóveda de tres claves

Bóveda de cuatro claves

Bóveda de cinco claves

Bóveda de cinco claves rectangular

Bóveda de cinco claves a disposición cuadrada

Bóveda de cinco claves cubierta

Bóveda de seis claves

Bóveda de siete claves

Bóveda de ocho claves

Bóveda de nueve claves a disposición circular

Bóveda de nueve claves a disposición cuadrada

Bóveda de nueve claves a disposición cuadrada y circular

Bóveda de nueve claves estrellada

Bóveda de diez claves

Bóveda de once claves

Bóveda de doce claves

Bóveda de trece claves

Bóveda de catorce claves

Capialzado de Marsella en esviaje

Arco viaje contra viaje

Bóveda de dieciséis claves

Bóveda de diecisiete claves

Bóveda de una clave a rampante

Bóveda de una clave en planta triangular

Bóveda de una clave en planta triangular cubierta

Bóveda de una clave en planta triangular rampante

Bóveda de tres claves en planta triangular

Bóveda de tres claves en planta triangular

Bóveda de cuatro claves en planta triangular

Bóveda de siete claves en planta triangular

Bóveda de crucería en planta redonda

Bóveda en planta redonda (con plementería)

Bóveda en planta redonda con rampante

Bóveda en planta redonda de cinco claves

Bóveda en planta redonda de nueve claves

Capilla ochavada de una clave

Capilla ochavada de una clave y rampante

Capilla ochavada de nueve claves

Capialzado de Marsella 
94. Rebole de Marcella, anell y rrevol

95. Rravol rrodo

96. Rravol rrodo anell y rrevol

97. Rravol ascasa

98. Anell y rravol, ascasa

99. Rravol rracgole

100. Rravol rracgole, anell y rrevol

101. Rravol ab canto

102. anell y rravol tot de una pesa ab canto

103. Rravol ab talus y canto

104. Rravol ab rraco

105. anell y rravol ab raco

106. Rravol ab talus y raco

107. Rravol ab torra rrodona

108. Rravol ab talus y torra rrodona

109. anell y rravol ab torra rrodona

110. Rravol ab talus y torra rrodona

111. Rrabol ab torre acabada

112. Rravol ab talus y torra acabada

113. Rrabol ab torre acabada y torra rrodona

114. Rravol ab talus torre acabada torra rrodona per dins

115. Rrabol ab canto y torra acabada

116. * $\sin$ nombre

117. Rrabol ab talus y canto y torra acabada

118. Rravol biax

119. Arch biax per tests ablas bocas iguals

120. Arch biax per testa

121. Rravol cap y al

122. Rravol cap y al

123. Portal ab rraco, y canto, cap y al

124. Patxina dela primera planta

125. Petxina ab canto

126. Patxina apañada

127. Patxina ab torra rradona

128. Patxina ab canto

129. Rravol ab rraco y ab torra cabada

130. Caragol

131. Escala ab rramplans

132. Portal ab torra Rodona

133. Portal ab torra cabada

134. Patxina dela primera planta

135. Patxina ab canto
Capialzado de Marsella, anillo y revuelto

Capialzado redondo

Capialzado redondo anillo y revuelto

Capialzado de Marsella *no escarzano

Capialzado de Marsella anillo y revuelto *no escarzano

Capialzado en puerta cuadrada

Capialzado en puerta cuadrada anillo y revuelto

Capialzado de Marsella en esquina

Capialzado de Marsella en esquina todo de una pieza

Capialzado de Marsella en esquina y talud

Capialzado de Marsella en rincón

Capialzado de Marsella en rincón anillo y revuelto

Capialzado de Marsella en rincón y talud

Capialzado de Marsella en torre redonda

Capialzado de Marsella en torre redonda y talud

Capialzado de Marsella en torre *cava anillo y revuelto

Capialzado de Marsella en torre *cava

Capialzado de Marsella en torre cava

Capialzado de Marsella en torre cava y talud

Capialzado de Marsella torre cava y redonda

Capialzado de Marsella en torre cava y talud, en torre redonda hacia adentro

Capialzado de Marsella en esquina y torre cava

Trompa en esquina con trompillón en diente de sierra

Capialzado de Marsella en talud en esquina y torre cava

Capialzado de Marsella en esviaje

Arco en viaje por testa con las bocas iguales

Arco en viaje por testa

Arco capialzado

Arco en descenda de cava

Arco en esquina y rincón (*no hay capialzado)

Trompa de medio punto

Trompa en esquina

Trompa de medio punto de tres paños ( ${ }^{*}$ poligonal)

Pechina en torre redonda

Pechina en esquina y recta

Capialzado de Marsella en esquina y en torre cava

Escalera a caracol de husillo

Escalera de dos rampantes

Portal en torre redonda y pared recta

Portal en torre cava y pared recta

Trompa de medio punto

Trompa en esquina de arco escarzado 


\subsection{El papel y la marca de agua}

El manuscrito muestra el año de 1708 en su portada, fecha importante porque al ser esa verdad, pondría en discusión algunos conocimientos comúnmente adquiridos, primero de toda la dilatación del periodo Tardo gótico. Por esa razón ha sido importante analizar verificar la exactitud, para lo cual se ha efectuado una investigación sobre el papel que ha sido confirmada por la Biblioteca Nacional de Cataluña.

Sus folios, de $35 \times 26 \mathrm{~cm}$ de tamaño, en los cuales se pueden detectar marcas de puntas de compás y trazas "blancas" o sea razados delineados con una punta seca, contienen una marca de agua situada en la parte central del papel.

Las marcas de aguas o filigrana eran las contraseñas de los papeleros y a través de ellas es posible reconocer la calidad o procedencia de un papel. La filigrana apareció por primera vez en el siglo XIII cuando unos fabricantes empezaron a posicionar un alambre metálico sobre el molde utilizado para hacer la hoja del papel cuando la masa estaba todavía húmeda. Al secarse de esta, por la menor cantidad de papel depositada en correspondencia de los alambres, se distinguía al trasluz la huella dejada por el alambre mismo. El derecho de utilizar una determinada filigrana era protegido e implicaba el pago de un impuesto.

La filigrana del Llibre de trasas es el escudo de la ciudad de Tarragona (Fig. 3.3), con las características líneas onduladas, como era después de 1645 cuando fueron añadidas la corona y la palma ${ }^{8}$, emblema de Santa Tecla patrona de la ciudad. Hay evidencia de la instalación de un molino papelero en Tarragona en 1686 que utilizaba como marca el escudo de la ciudad ${ }^{9}$. Según Oriol Valls en su Paper and watermarks in Catalonia la filigrana es de $1704^{10}$. En el manuscrito de Ribes la fecha anotada bajo el título es 1708.

En la hoja suelta presente en el Libre de trasas hay un fragmento de marca de agua diferente de la precedentemente descrita y que no ha sido posible identificar.
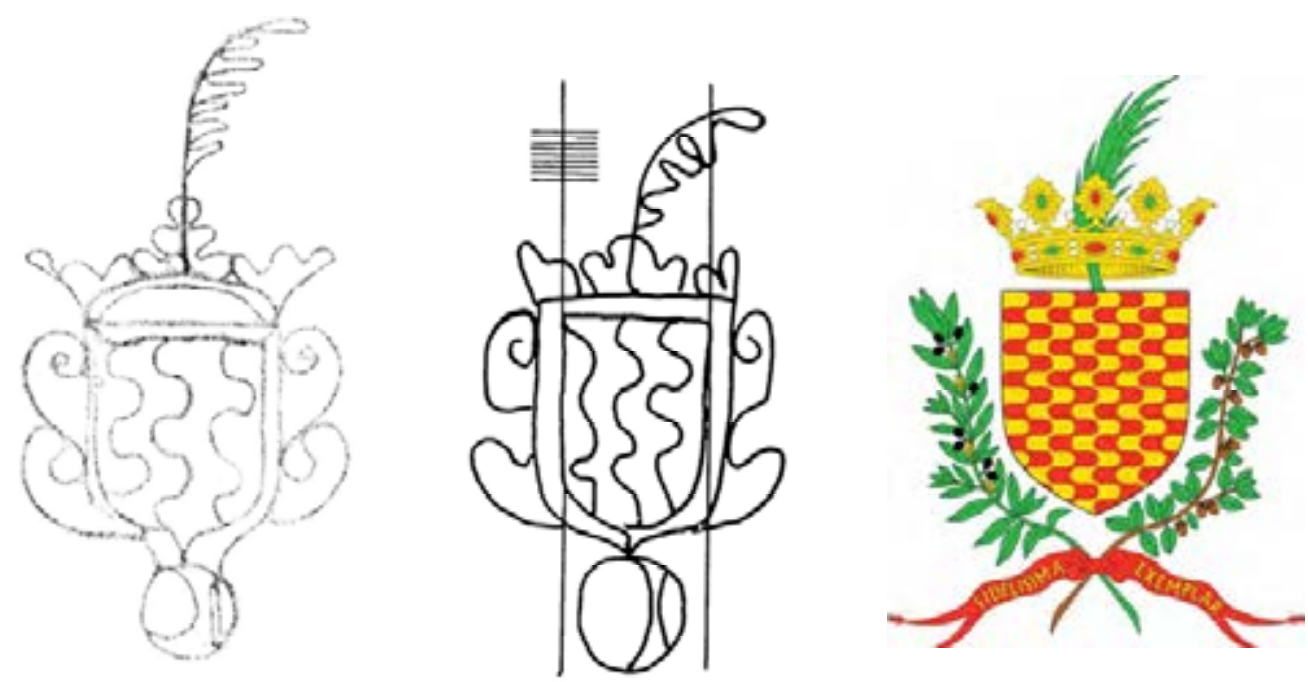

Fig. 3.3. La marca de agua del Llibre de trasas, la marca de agua del molino papelero identificado por Oriol Valls y el escudo de la ciudad de Tarragona.

8 Juan Salvat, El Escudo de Armas de La Ciudad de Tarragona (Tarragona: Ayuntamiento, 1975), 45.

9 Gonzalo Gayoso Carreira, "Apuntes Para La Historia Papelera de Las Provincias de Tarragona, Baleares y Canarias," in Investigaciones y Tecnica Del Papel (Madrid, 1974), 675.

10 Oriol Valls i Subirà, Paper and Watermarks in Catalonia (Amsterdam: Paper Publications Society, 1970). Agradezco a la Biblioteca de Catalunya y en particular la Sra. Iris Torregrossa por el asesoramiento bibliográfico. 


\subsection{Léxico}

La similitud en las ideas y en la nomenclatura de las trazas de este manuscrito, en comparación con otros tratados de estereotomía, confirma la influencia, quizás recíproca, de la estereotomía francesa y andaluza en Cataluña, y al mismo tiempo es posible reconocer un desarrollo paralelo de algunas características.

Las diferentes escuelas de cantería españolas de los siglos XV-XVII se pueden identificar en los focos estereotómicos que se desarrollan a lo largo del arco mediterráneo que, empezando desde el Languedoc, baja por Cataluña, Baleares, el Levante, Murcia y Andalucía; a estos se añaden los centros del interior como Burgos y Toledo y los del norte, cuales Cantabria y Galicia.

El conocimiento de modelos franceses en España y modelos españoles en Francia se da por cierto, como ha sido argumentado originariamente por Pérouse de Montclos ${ }^{11}$ y tenemos constancia de los numerosos intercambios culturales y de la transmisión del saber de los masones entre el Languedoc, las Islas Baleares, el Levante y Cataluña ${ }^{12}$. También existen estudios que sugieren el desarrollo de aparejos y de unas ciertas modalidades estereotómicas especificas del Levante ${ }^{13}$.

El léxico de la tratadística española de mayor envergadura, es decir los tratados renacentistas de Vandelvira y de Aranda, utilizaba numerosos prestamos procedentes del francés como reflejo de una tradición didáctica, primero oral y solo en un segundo momento escrita.

A menudo, los vocablos o verbos que denotan el nombre de una traza, las herramientas específicas y las operaciones de cantería, tienen su procedencia en el área geográfica de origen de un grupo de canteros que los utilizaban con anterioridad y que los introdujeron a un territorio. Esta proposición, obviamente, puede ser muy debatida porque las dinámicas de desarrollo y difusión de un idioma son extremadamente complejas y hay que considerar que todas las lenguas de este territorio proceden de una raíz común, el latín.

En este contexto es entonces interesante identificar la etimología del léxico utilizado por Ribes que pertenece a un vocabulario especificadamente canteril.

La novedad y originalidad del Llibre de trasas hace una contribución significativa a la estereotomía catalana no solo por el contenido gráfico, sino también por documentar los términos estereotómicos típicos de la lengua catalana, algunos de los cuales tuvieron un influjo en el vocabulario de los canteros castellanos y franceses, entre los cuales Martínez de Aranda y Vandelvira, y por ser una pequeña muestra de la jerga de los canteros barceloneses de la época.

El articulo elaborado por Guillermo Herràez Cubino ${ }^{14}$ identifica y registra los catalanismos en el arte del corte de la piedra. Llama la atención el origen catalán de los términos

\footnotetext{
11 Jean-Marie Pérouse De Montclos, L'architecture À La Française : XVI-XVII-XVIII Siècles. (Paris: Librarie La Porte Etroite, 1982).

12 Verse al resguardo los estudios de Joan Domenge i Mesquida y Mercedes Gomez-Ferrer.

13 En particular, Eduardo Mira y Arturo Zaragozá, 2003.

14 Guillermo Herráez Cubino, Catalanismos En El Léxico de Los Canteros Del Renacimiento Español, Biblioteca Virtual Miguel de Cervantes (Alicante: Biblioteca Virtual Miguel de Cervantes, 2008), 700-705, https://doi.org/ https://dialnet.unirioja.es/servlet/dcart?info=link\&codigo=5511118\&orden=1.
} 
capialçar, biaxe y petxina, y de los sustantivos específicos para la construcción de la bóveda de crucería (xarxa, terceret, trasdossa), todos aparejos tratados extensivamente en el manuscrito de Ribes.

En el Llibre de trasas se utiliza cap y al para indicar el verbo 'capialzar' y no su forma compuesta catalana capialçar. Este término viene aplicado para describir la testa de un arco y no viene utilizado para describir la traza comúnmente conocida en castellano como 'capialzado', por la cual Ribes usa el termino Rravol, similar a la palabra Rravolt utilizada por Gelabert.

La palabra biax, del mismo origen incierto que el francés y occitano biais, viene utilizada por Ribes con el mismo significado de la versión castellanizada 'viaje' en los tratados de Vandelvira y Martínez de Aranda. Gelabert también utiliza el termino biax, pero también su variante de genero biaxa.

Ribes utilizaba el termino Boveda o Bolta para nombrar bóvedas de intradós continuo (esféricas, arista, cañón, esquifadas, etc.) y Volta para las bóvedas de crucería. Diferentemente, Gelabert utilizaba Volta para las bóvedas de intradós continuo y Capilla para las trazas de las bóvedas de crucería.

En general, se puede reconocer en la terminología de Ribes una fuerte relación con el léxico del mallorquín Gelabert (Ribes: Patxina; Gelabert: Pitxina; Escala/Scala; Caragol/ Caragol).

En el tratado de Ribes, algunos aparejos se vuelven redundantes al repetir una variación muy similar a la traza original. La única variación es la mocheta añadida al arco que aloja la carpintería y que se materializa con un contorno ligeramente perfilado en la piedra, que en el dibujo recuerda un anillo. Para definir esta variación, al nombre de la traza viene añadida el término anell.

La expresión que define estas trazas, anell y rravol, recuerda el juego de palabras volt y revolt de Gelabert para indicar aparejos caracterizados por ser de una sola pieza y tener dos tipos de arcos distintos a cada lado de la pared. Símilmente, Ribes utiliza un juego de palabras para las trazas que presentan un tipo de arco o de capialzado por un lado del muro, y por el otro la mocheta que recibe la carpintería encavada en la piedra. 


\subsection{El Autor}

De la vida de Joseph Ribes sabemos muy poco. Las únicas informaciones que poseemos proceden de la investigación de Manuel Arranz ${ }^{15}$, el historiador que ha estudiado la vida de los maestros de obra del siglo XVIII comparando los documentos de los archivos históricos de la ciudad, los libros de Confraria y los protocolos notariales.

Todavía, en 1708 vivían dos maestros de obra con el mismo nombre: Joseph Ribes, el padre, y Joseph Ribes i Ferrer, el hijo. Se pueden avanzar algunas hipótesis sobre la posible identidad del autor del Llibre de Trasas.

\section{Opción 1 - Ribes padre}

Joseph Ribes, nacido en 1655, era el hijo de un payés de Santa Creu d'Olorda, una pequeña localidad al oeste de Barcelona, empezó los rudimentos del oficio en 1670 con los maestros barceloneses Francesc Salazar i Jeroni Poses, fue investido mestre de la Confraria en 1688 y murió en 1713 o 1714. Su descendencia prosiguió en el oficio de la construcción hasta culminar con Joseph Ribes i Margarit, arquitecto de indudable éxito profesional, activo en Barcelona en la segunda mitad del siglo XVIII.

Podríamos suponer que Ribes escribió el tratado para transmitir su saber a su hijos, Jaume y Joseph, como ha sido el caso de otros manuscritos de cantería cuya historia ha sido mejor documentada ${ }^{16}$ o, quizás, debido a la falta de un texto de referencia, el Llibre de trasas deba considerarse como un libro de obra, con los apuntes de estereotomía de un cantero.

Era praxis difundida que el padre cantero recogiera informaciones para el hijo. Se materializaba así la transmisión intergeneracional del conocimiento. Recordamos por ejemplo el caso de Lorenz Lechler, que escribió su obra en 1516 con el intento de transmitir el saber a sus hijos, documentando dibujos de geometría y otros temas de construcción.

Rodrigo Gil también escribí el Compendio para pasarlo al hijo. En Barcelona, Francesc Renard escribió en el siglo XVIII los Ligalls, o sea una serie de escritos de arquitectura, para la educación de sus hijos.

\section{Opción 2 - Ribes hijo}

Como la cuestión no ha sido del todo cerrada, y con el fin de agotar las opciones, se podría opinar que el autor del manuscrito fuera el hijo de Joseph Ribes: llamado Joseph también y de apellidos Ribes i Ferrer que, nacido entre 1682 y 1685, recibió el título de mestre de cases en 1707 a la edad de 22-25 años.

También para esta opción no faltan elementos que la justifiquen. El Llibre de trasas puede

\footnotetext{
15 Manuel Arranz, Mestres d'obres i Fusters : La Construcció a Barcelona En El Segle XVIII (Barcelona: Col•legi D'aparelladros I Arquitectes Técnics, 1991).

16 Rodrigo Gil escribe el Compendio para pasarlo a su hijo, en: Javier Gómez Martínez, El Gótico Español de La Edad Moderna: Bóvedas de Crucería (Universidad Valladolid: Secretariado De Publicaciones e Intercambio Científico, 1998). El Unterweisung, fue escrito por Lorenz Lechler en 1516 para su hijo Moritz y contenía dibujos geométricos y otros temas de construcción: Lonnie R Shelby, Gothic Design Techniques : The Fifteenth-Century Design Booklets of Mathes Roriczer and Hanns Schmuttermayer (Carbondale: Southern Illinois University Press, 1977).
} 
ser una libreta de apuntes de trazas compilada al término de la etapa de aprendizaje de maestría. El examen final consistía en dibujar ordenes, traces y elementos de arquitectura, y la puesta en obra de una traza.

Igualmente, Ribes habría podido recolectar las trazas en una libreta después de haber conseguido el título de mestre de cases, ya que no era insólito que maestros de obra escribieran por un deseo de demostrar las propias capacidades no solo prácticas, pero también teóricas, o por un deseo de ayudar otros aprendices que se acercaban a la profesión, como sería el caso de la colección de dibujos de Dresde o del "cuaderno de Viena", que contienen trazas y ejercicios de examen.

Si el autor fuera el hijo, tendríamos una historia muy similar a la de Gelabert ${ }^{17}$, el cantero mallorquín autor de las Verdaderas trazas del piacapedrer el cual a los 18-22 años se preparó para el examen de cantero y, 7 años después, decidió producir su tratado ${ }^{18}$, como testimonian las palabras del mismo Gelabert:

Pero lo qui fa mon preposit es que com las opinions de los tracistas son tan difarents parex que per los principiants qui platican aquest Art ve a ser una confusio molt gran. Alomenos jo per curiositat assent de edat de 18 anys poc mes o manco vulgui escudriñar el parer de alguns asirca de algunas traces dificultosas y veent tanta diversitat de opinions em trobave sens poder determinar anaqual avia de donar credit; $y$ axi que despres de aver pesat set anys de mon Axamen mogut de bon zel em som posat a estudiar per veura si trobaria una regla certa que seguint aquella noi agues perill de enar engañat y per aquest afecta e trebellat dos anys y a forsa de mon treball e trobat lo que sercave ${ }^{19}$.

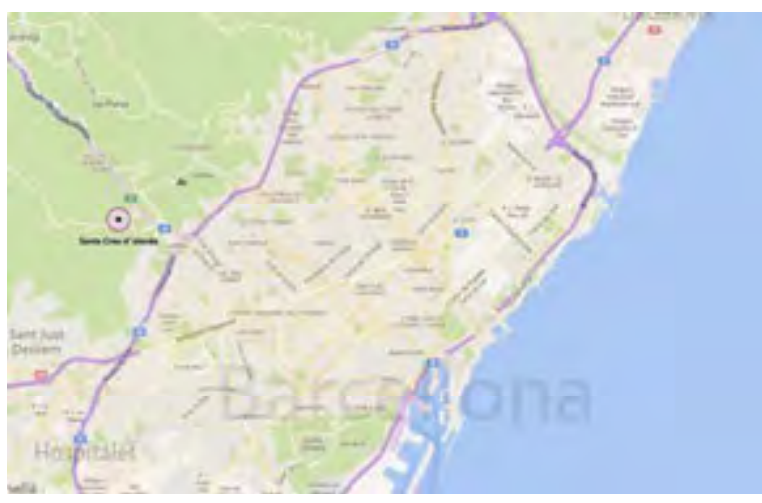

Fig. 3.4. Santa Creu d'Olorda, Barcelona

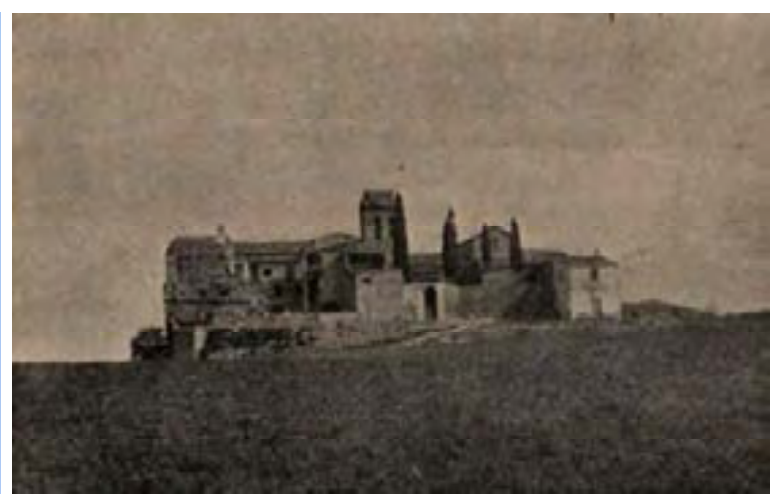

Fig. 3.5. Santa Creu d'Olorda al principio del sigo XX https://ca.wikipedia.org/wiki/Santa_Creu_d'Olorda_(antic_municipi)

\footnotetext{
17 Joseph Gelabert escribió su tratado como si fuera un manual para los profesionales de la construcción (Enrique Rabasa, El Manuscrito de Cantería de Joseph Gelabert: Titulado Vertaderas Tra-Ces Del Art de Picapedrer: Transcripción, Traducción Anotación e llustración Del Texto y Los Trazados, [Ms. 1653] (Madrid: Fundacion Juanelo Turriano, 2011).

18 Ibid. 25.

19 Traducción de Rabasa en el Texto en los fols. 4r, 4v "Pero el caso es que, como las opiniones de los tracistas son tan diferentes, parece que se transmite una gran confusión a los empiezan a practicar este oficio. Por lo menos a mí que, por curiosidad, a los dieciocho años de edad, poco más o menos, quise indagar el parecer de algunos acerca de ciertas trazas dificultosas, y viendo tanta diversidad de opiniones, no podía determinar a quién había de dar crédito. Así que, siete años después de haber pasado mi examen, movido de buen celo, me puse a estudiar para ver si encontraría una regla segura, tal que, siguiéndola, no hubiese peligro de engañarse, y en eso he trabajado dos años, y con mi esfuerzo he encontrado lo que buscaba."
} 
El Llibre de traces de biaix y montea de Joseph Ribes 


\section{Arcos}

El Llibre de trasas de viax y muntea comienza con una larga serie de arcos que van a conformar lo que podríamos considerar el primer capítulo. Ribes aborda las trazas de modelos más sencillos y continua con la descripción de arcos oblicuos y peraltados de mayor complejidad. Entre ellos destacan un ejemplar de arco con un despiece de dovelas inédito y otro original arco en decenda de cava. Este primer capítulo se constituye de 31 ejemplos ${ }^{1}$ que a su vez se pueden agrupar en tres grandes familias de arcos divididos en función de sus características geométricas (Fig. 4.1).

- El primer bloque incluye todos los arcos generados a partir de una superficie cilíndrica yacente sobre un plano horizontal. En función del tipo de plano de corte que secciona este cilindro es posible obtener una variedad de tipos de arcos: a) un plano de cortes ortogonal al eje del cilindro produce un arco recto; $b$ ) si el corte es oblicuo respecto al eje se obtiene un arco con perfil de testa elíptico; c) seccionando el cilindro con un diedro se obtiene un arco en esquina o rincón; d) cuando el plano es una superficie cilíndrica se generan arcos cóncavos o convexos y e) si el plano de corte no es vertical se generan arcos en talud o arcos avanzados.

- El segundo bloque está compuesto por arcos generados al depositar el eje de la bóveda sobre un plano inclinado respecto al horizonte, como los arcos peraltados y las decendas de cava.

- El tercer bloque lo constituyen aquellos arcos cuyas líneas de impostas no son paralelas entre ellas y aquellos arcos oblicuos cuya superficie de intradós no viene conformada por una extrusión recta.

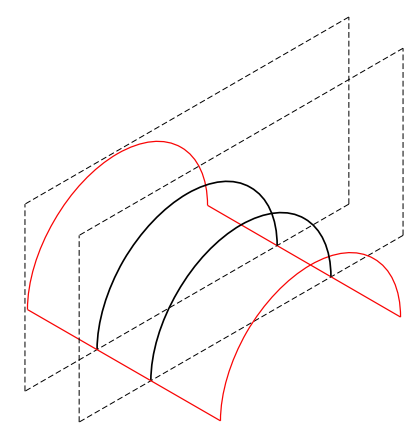

I. Cilindro sobre el plano horizontal

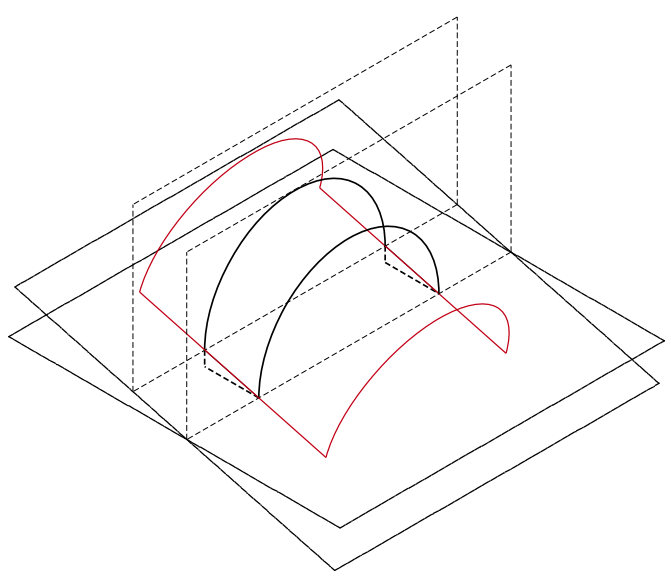

II. Cilindro sobre el plano inclinado

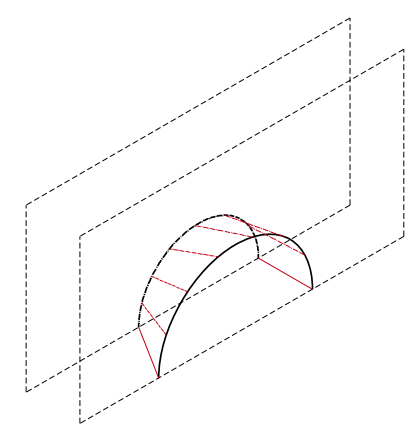

III. Impostas no paralelas

Fig. 4.1. Tipologías de arcos. Dlbujo del autor.

\footnotetext{
1 Ribes los nombra portales, arcos o capialzados (26 portales y 5 arcos)
} 
En el Llibre de trasas se tratará de la estereotomía del arco también en las trazas relativas al desarrollo de bóvedas compuestas, trompas y bóvedas de crucería, en específico con el estudio requerido para definir las curvas espaciales que se producen al encuentro de dos bóvedas o para determinar los arcos resultantes de la intersección de una bóveda con las superficies (inclinadas o cilíndricas) que delimitan su perímetro.

La estereotomía del arco ha sido descrita en los cuadernos de apuntes medievales y en los varios tratados de los siglos sucesivos. En particular, la estereotomía renacentista se ha ocupado de todas las posibles contingencias volumétricas del arco de medio punto ${ }^{2}$ que han sido resumidas en los tratados de Vandelvira y Martinez de Aranda ${ }^{3}$. La ejecución y determinación geométrica de algunas de las definiciones formales de los arcos oblicuos, por su notable complejidad, han sido plenamente resueltas solo en el siglo XIX ${ }^{4}$ después del desarrollo de la geometría descriptiva como disciplina.
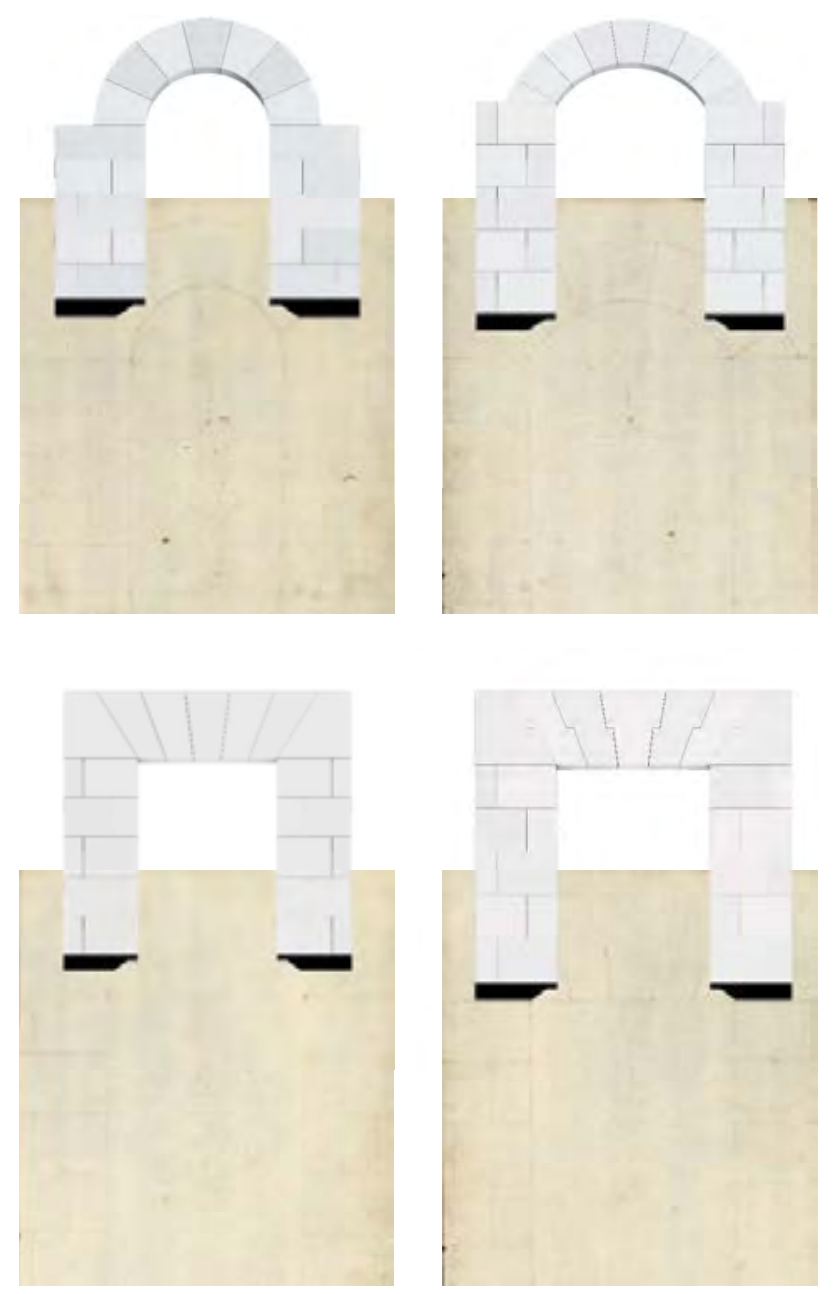

Fig. 4.2. Portal rado, escasa, recto y ab anclavias

\footnotetext{
2 Jose Carlos Palacios Gonzalo, "Invención y Convención En Las Técnicas Constructivas Del Renacimiento Español" (Tesis Doctoral, 1987): 95.

3 El tratado de Martinez de Aranda contiene un gran numero de trazas de arcos. Se recomienda consultar la tesis doctoral de Jose Calvo Lopez Cerramientos y trazas de montea...

4 Enrique Rabasa Díaz, "Los Arcos Oblicuos En La Traza de Cantería," Revista de E.G.A., no. 2 (1994): 150.
} 
4.1 Primer bloque: arcos rectos, arcos elípticos, arcos en esquina o rincón, arcos cóncavos y convexos, arcos en talud y arcos avanzados.

La primera traza que Ribes presenta es el arco de medio punto de la cual propone la variación de arco escarzano (Portal escasa) y de arco plano, este último a su vez en las versiones con dovelas sencillas (Portal recto) y con juntas discontinuas (Portal ab anclavias). El arco es un elemento constructivo vehículo de transmisión de cargas que salva el espacio abierto entre dos pilares o muros. En su forma pura, es decir el arco recto, es un elemento compuesto por dovelas que trabajan siempre a compresión y que dirigen sus empujes hacia sus laterales. La definición geométrica y su estereotomía son operaciones sencillas que pueden complicarse en su ejecución solo en el caso de dovelas con juntas discontinuas, donde la precisión del corte es importante para garantizar una distribución uniforme de las fuerzas y evitar fracturas en el material.

Los arcos en talud no vienen descritos en el tratado de Ribes pero son muy frecuentes en particular en las fortificaciones de la arquitectura militar, como los ejemplos que se encuentran en el Castillo del Montjuix o en las Murallas de Barcelona de la cual queda intacta solo la puerta de Santa Madrona.

En este primer bloque podemos encontrar ejemplos descritos a seguir.

\section{Portal Rado - Portal de medio punto}

Folio 8 (Traza 1)

El arco recto es determinado geométricamente por una superficie de intradós cilíndrico, generada por una recta horizontal, que es delimitada en longitud por dos planos de testa, ortogonales a la generatriz del intradós.

\section{Portal escasa - Portal escarzano}

Folio 9 (Traza 2)

El arco escarzano es de idéntico principio mecánico del arco de medio punto y su geometría podría ser definida por un arco de radio de longitud mayor al medio punto o de radio infinito.

\section{Portal recto - Portal adintelado}

Folio 10 (Traza 3)

El portal adintelado corresponde a un arco plano, o sea un arco de radio infinito. Los empujes se dirigen hacia los salmeres.

\section{Portal ab anclavias - Portal adintelado con junta discontinua}

Folio 11 (Traza 4)

Esta traza corresponde a un portal adintelado con las juntas discontinuas para garantizar una mayor resistencia al deslice de las dovelas. 


\section{Portal ab campana - Portal a campana}

Folio 12 (Traza 5)

El portal ab campana (Fig. 4.3), caracterizado por una insólita clave que se empotra con las dovelas adyacentes, es una solución inédita de Ribes que no aparece en los otros tratados de estereotomía. Este modelo es un arco cuya clave tiene forma de cruz y el conjunto va a conformar una puerta con dovelas de intradós plano y extradós de arco de medio punto. Esta traza se podría construir sin cimbra. La clave viene instalada después de haber puesto en sitio los salmeres y solo posicionado un soporte puntual bajo ella, podría sujetar las dovelas adyacentes gracias a su geometría.

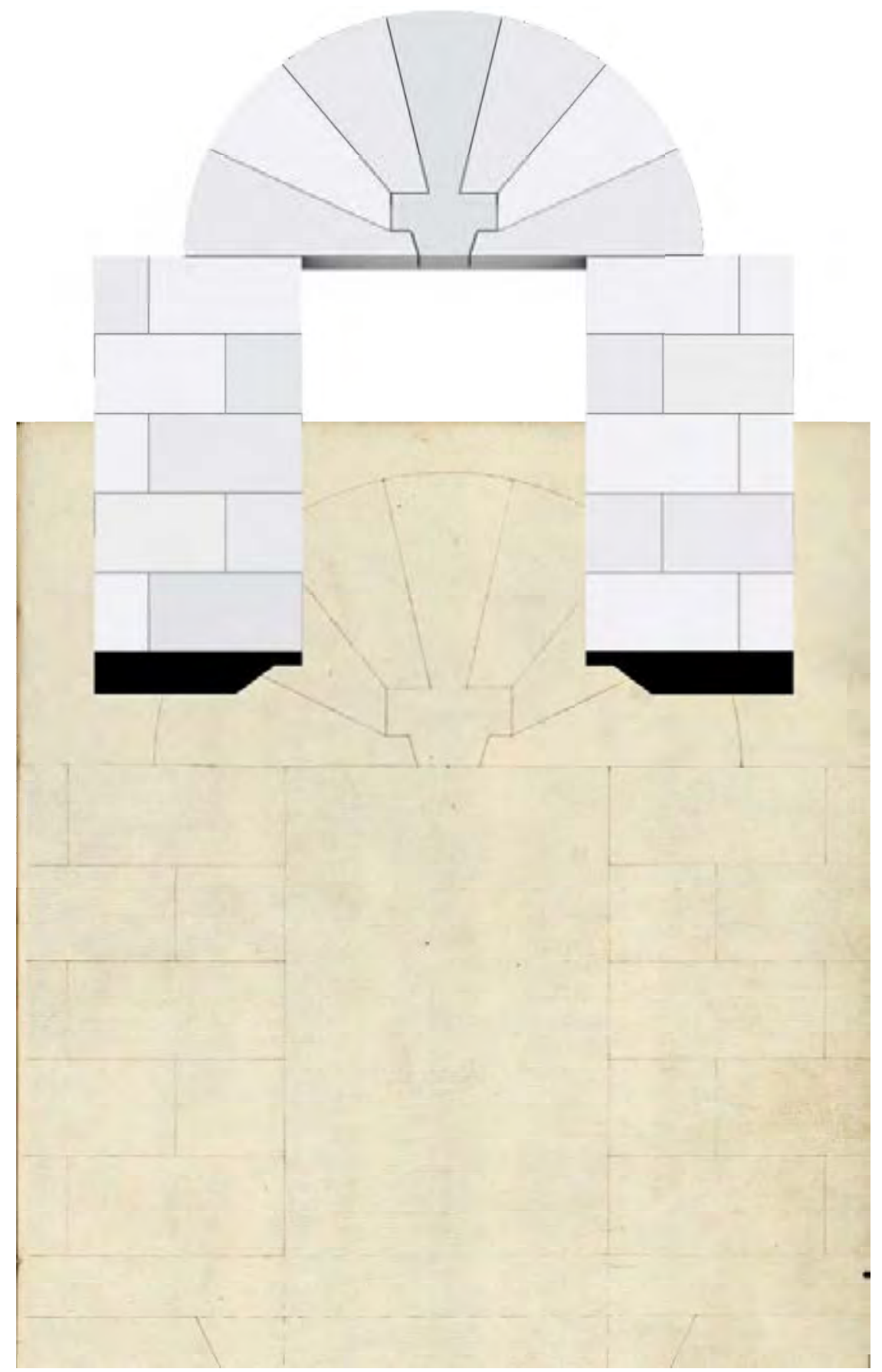

Fig. 4.3. Portal ab campana 

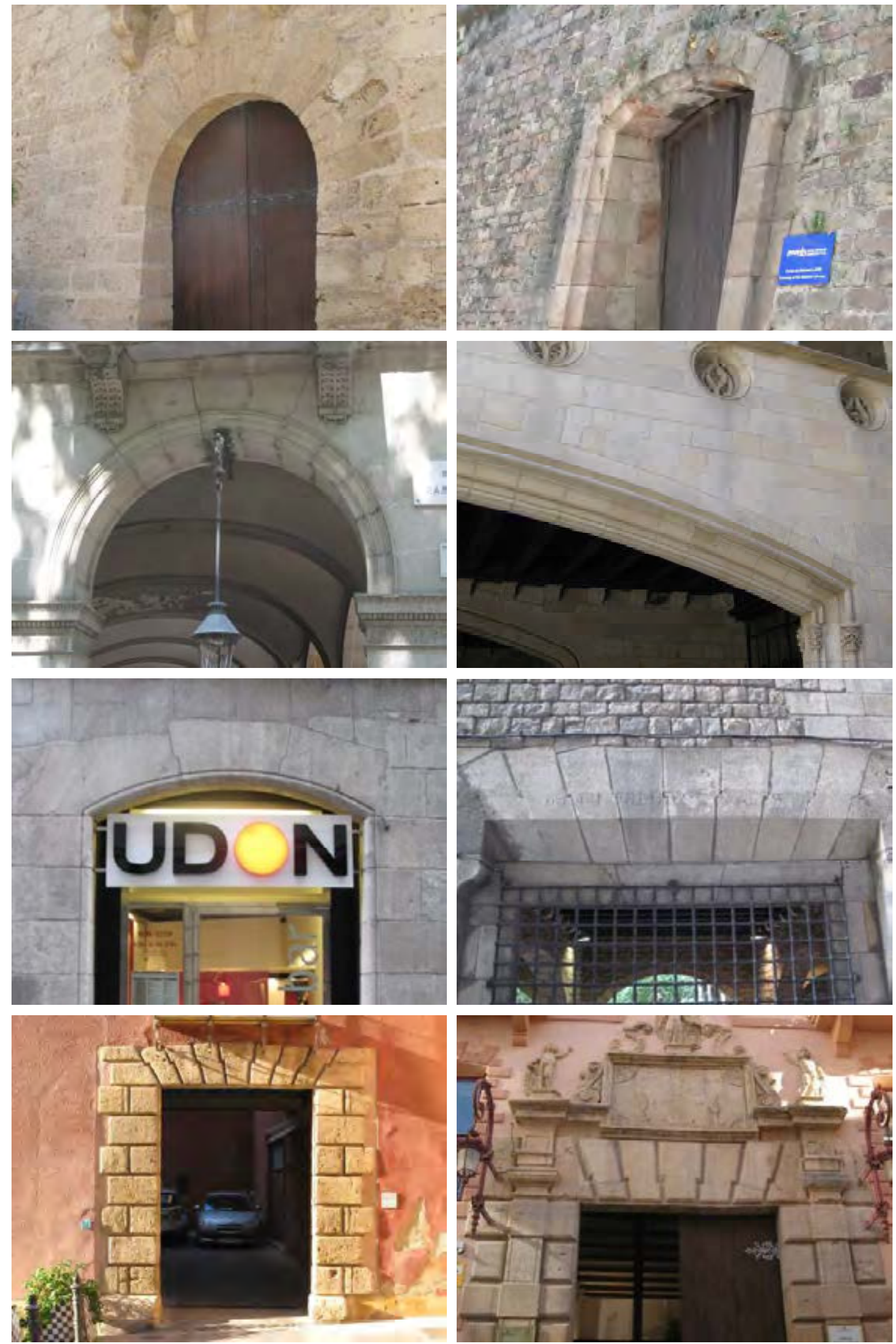

Fig. 4.4. Arcos en talud en las murallas de Mallorca y Barcelona, arcos adintelados en la Plaza Reyal de Barcelona, en el Palau de la Generalitat de Barcelona, en el Barri Gotic de Barcelona, en Tarragona y en el Antic Hospital de la Santa Cruz, Tortosa. Fotos del autor. 


\section{Arch biax per testa - Arco en viaje por testa}

Folio 224 (Traza 120)

Este arco (Fig. 4.5) se produce al abrir un hueco en un muro con un arco de medio punto en dirección oblicua al plano de la pared. Se caracteriza por tener el intradós cilíndrico, las jambas paralelas y los arcos de embocadura elípticos. De hecho, al seccionar una superficie cilíndrica con un plano oblicuo se genera una elipse. Ribes también estudia un arco con embocadura de medio punto, el Arch biax per tests ablas bocas iguals (Arco en viaje contra viaje, Traza 119), como se verá más adelante.

Esta traza se encuentra hacia el final del manuscrito, sin embargo, se ha modificado el orden expositivo para describir este modelo juntamente a los arcos del primer bloque, los de intradós cilíndrico, para una mayor claridad expositiva.

Ribes resuelve esta traza con el método del baivel. Es necesario entonces conocer las plantillas de las caras de lecho de las dovelas, realizando un abatimiento sobre el plano horizontal del ancho de la dovela escogida; para obtener las saltarreglas se procede de manera similar abatiendo el plano de junta. Con este procedimiento podemos dibujar las plantillas de los lechos que nos servirán para hallar las saltarreglas. Ribes dibuja las plantillas de las caras de lecho de cada dovela sobrepuestas a la planta, mientras que reproduce las plantillas de intradós en las esquinas del dibujo.

Para la talla es necesario el baivel, confeccionado específicamente para el arco que se quiere tallar, que permite obtener la curvatura de la cara interior de la dovela. Desde el bloque de piedra inicial, se dibuja la planta de intradós sobre una de las caras. Con el baivel trabajamos en vertical quitando volumen de piedra, obteniendo a la misma vez la curvatura del intradós y el derrame de una cara lateral. Con el mismo baivel volteado, se consigue el derrame del otro lado. Del prisma obtenido se procede tallando la testa de la dovela, que se produce al quitar la parte sobrante del bloque con la asistencia de las saltarreglas previamente determinadas.

Ribes resuelve la mayoría de los arcos con el método de baivel, que, aunque requiere producir más dibujos y más maestría en el cortar la piedra, permite un considerable ahorro de material. En el Llibre e trasas se puede observar la minuciosidad con la cual Ribes se preocupa de dibujar las plantas de intradós, de lecho y de cara que servirán para confeccionar las plantillas utilizadas para tallar las dovelas por baivel. Aunque tenga preferencia para este método, es posible cortar las dovelas por robos, o sea con el método que requiere quitar del bloque de piedra las proyecciones horizontales y verticales de cada dovela, como claramente nos deja entender en algunos ejemplos. En el método por robos se inscribe la dovela en un rectángulo, el sólido capaz, y una vez obtenida la proyección horizontal (no la cara de intradós) y marcada la posición de los vértices, se procede quitando material al volumen de piedra hasta obtener la dovela. Se empieza dibujando la dovela de testa sobre el bloque inicial y se trabaja en posición vertical.

Gelabert también describe esta traza que llama Arco de medio punto esviado por testa. 


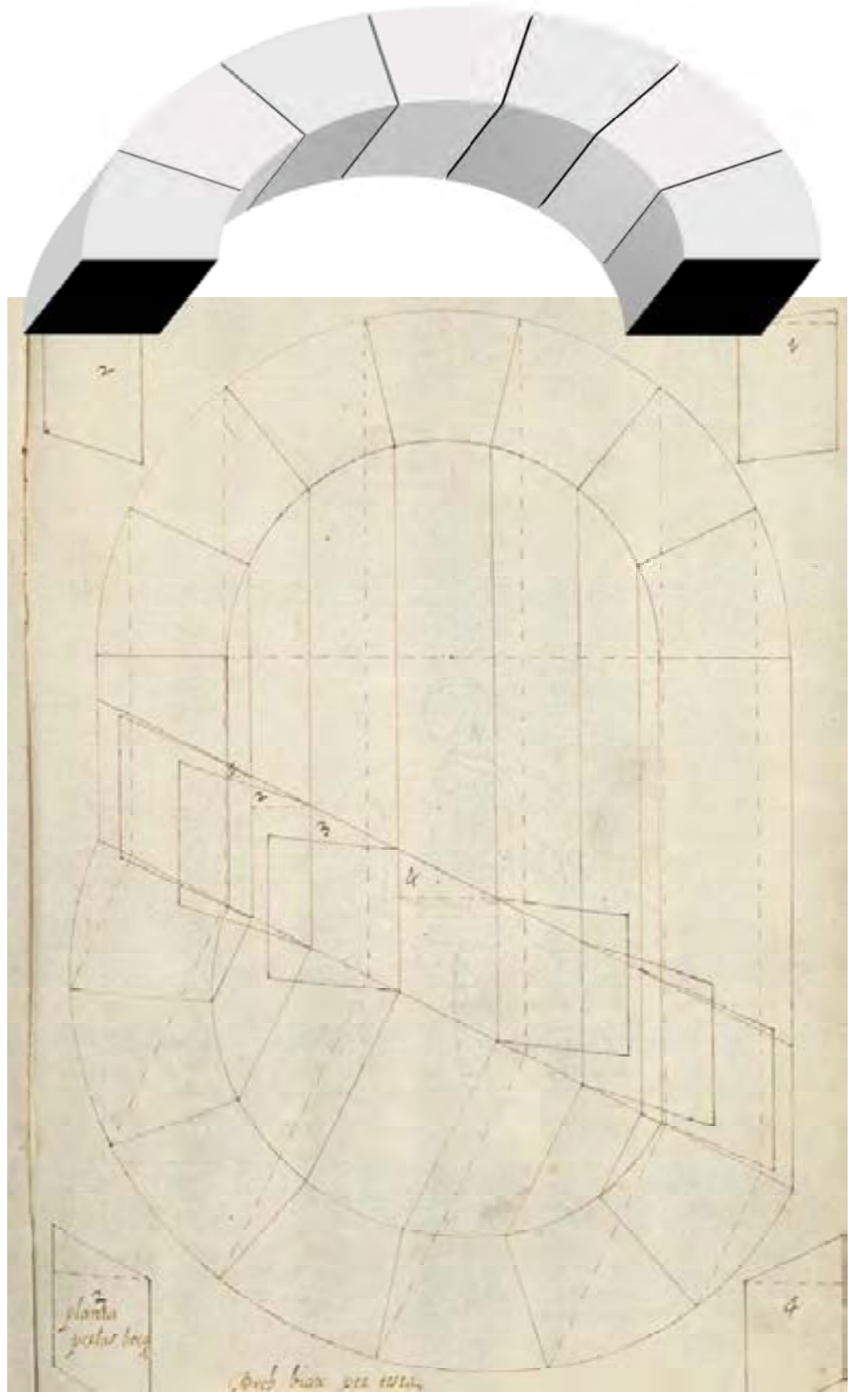

Fig. 4.5. Arch biax por testa. Dlbujo del autor.
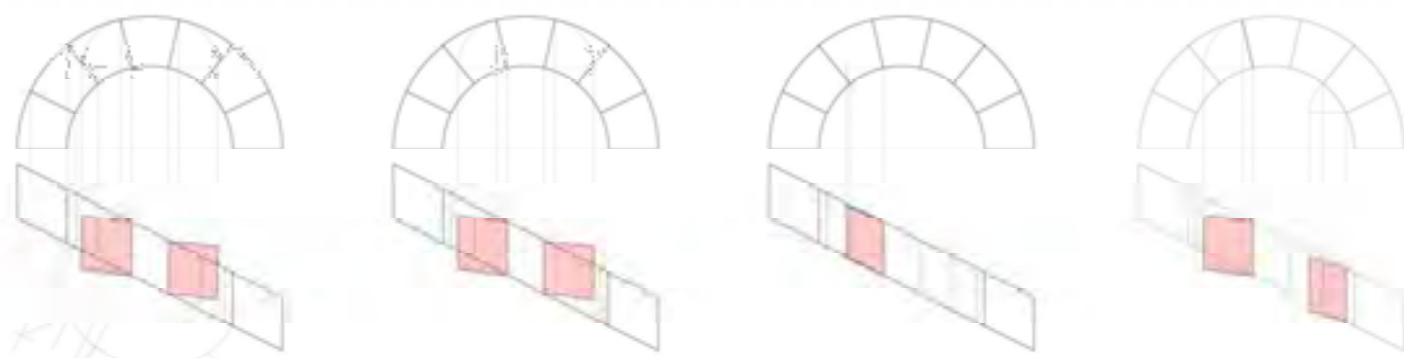

Fig. 4.6. Dibujo de las plantillas. Dlbujo del autor. 

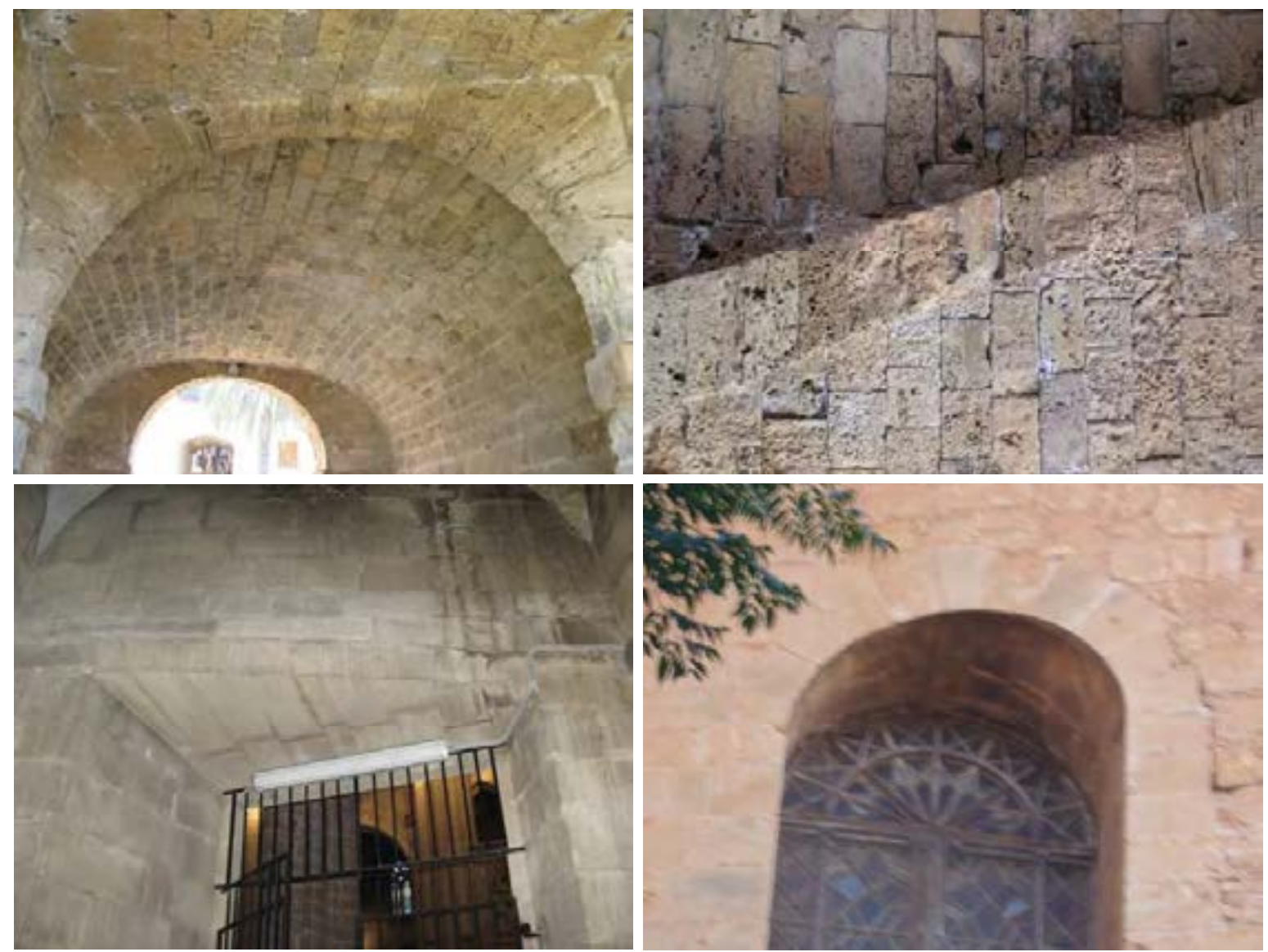

Fig. 4.7. Arco en viaje en las murallas de Mallorca y un arco adintelado en viaje en el patio de la Catedral de Tortosa y un arco en viaje en la Iglesia de Campos (Mallorca). Fotos del autor. 


\section{Portal ab canto - Portal en esquina}

Folio 15-16 (Traza 8)

El Portal ab canto (Fig. 4.8) es el primero de una serie de arcos de los cuales Ribes desarrolla primero su traza base y sucesivamente presenta dos variaciones de la misma traza, una con las dos paredes en talud y otra con una pared en talud y la otra vertical. Aplicará esta secuencia a otros arcos y capialzados que se desarrollan sobre una pared curva o diédrica. Este arco viene trazado mediante la proyección recta de un arco de medio punto sobre los planos de una pared en esquina, alineando en este caso el eje del arco con la recta bisectriz de la esquina, que es entonces pasante por la arista de la pared. La silueta del arco se deforma tanto más cuanto se aleja de la clave de testa, recorriendo el arco hacia las impostas. Se utiliza para dar paso a un hueco de ventana en un muro en esquina y es típico de las ventanas de los balcones del renacimiento español, sin embargo, no son frecuentes en Cataluña.

Para esta traza Ribes dibuja las plantillas del intradós (mollos de las bocas) y, solo para la dovela de clave, la plantilla de extradós. Se utiliza una plantilla rígida, de cartón o de madera que representa la silueta de la dovela apoyada sobre un plano que pasa por sus vértices de intradós. No viene representado el desarrollo de la superficie de intradós, para lo cual se requeriría una plantilla flexible que se pueda acomodar a la superficie curva. Para obtener los patrones Ribes saca la cimbria, o silueta del arco proyectada sobre la pared, y dibuja el lecho de las dovelas en verdadera magnitud.

Un ejemplo muy sugestivo de esta traza es incorporado en una puerta de la Lonja de Mar de Barcelona (Fig. 4.13), obra de Juan Soler i Faneca de 1772, como parte de una composición arquitectónica más compleja. En el porticado que circunda el patio, una de las puertas que se abren hacia el exterior en el lado norte del edificio es posicionada sobre un eje estructural. Para suplir a esta situación, quizás por necesidad, quizás como ostentación, el arquitecto ha ideado un arco que del pilar del patio se liga con la dovela de testa del arco de la puerta, permitiendo abrir la puerta en correspondencia del eje estructural. El arco, perfectamente labrado en piedra de cantería, se interpone entre dos bóvedas que conforman el pórtico construidas en ladrillos y sucesivamente estucadas. Esta solución estructural no es nueva en Barcelona ya que aparece en el patio de la Catedral. La puerta de acceso a la sacristía está posicionada en correspondencia del eje estructural de un arco del patio. Aquí la imposta del arco se descarga sobre la dovela de clave del arco que salva el hueco de la puerta.

\section{Portal ab canto y talus - Portal en esquina y talud}

Folios 17-18 (Traza 9)

A seguir Ribes describe dos versiones más de esta traza, una con una pared en talud y la otra con una pared en talud y otra vertical. La traza con las dos paredes en talud permite reutilizar las dovelas de una mitad del arco, ya que por simetría serán iguales a la otra mitad.

El diagrama del talud se encuentra en el lado izquierdo del alzado/sección, de manera muy parecida a los dibujos de Gelabert. 

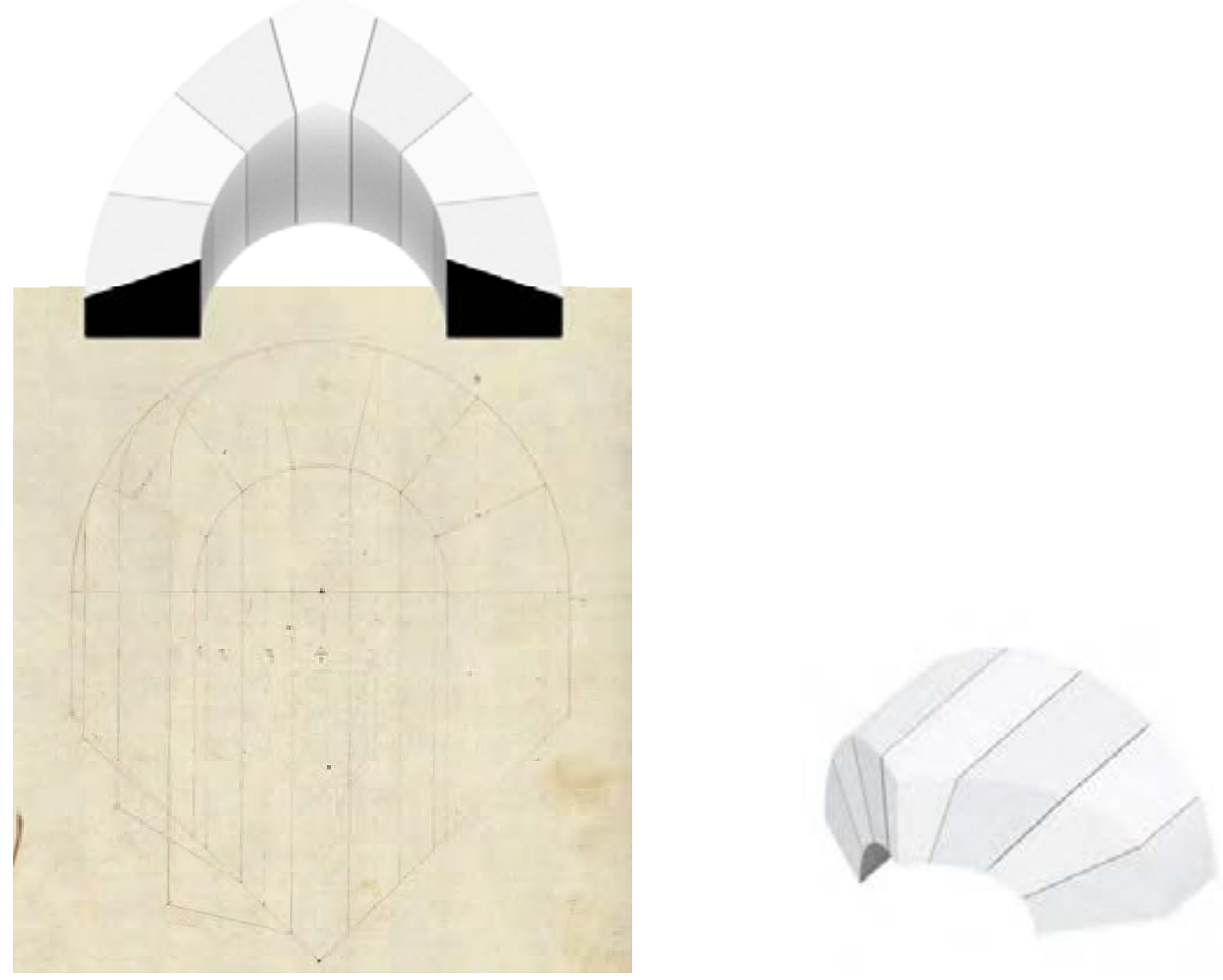

Fig. 4.8. Portal ab canto. Dlbujo del autor.

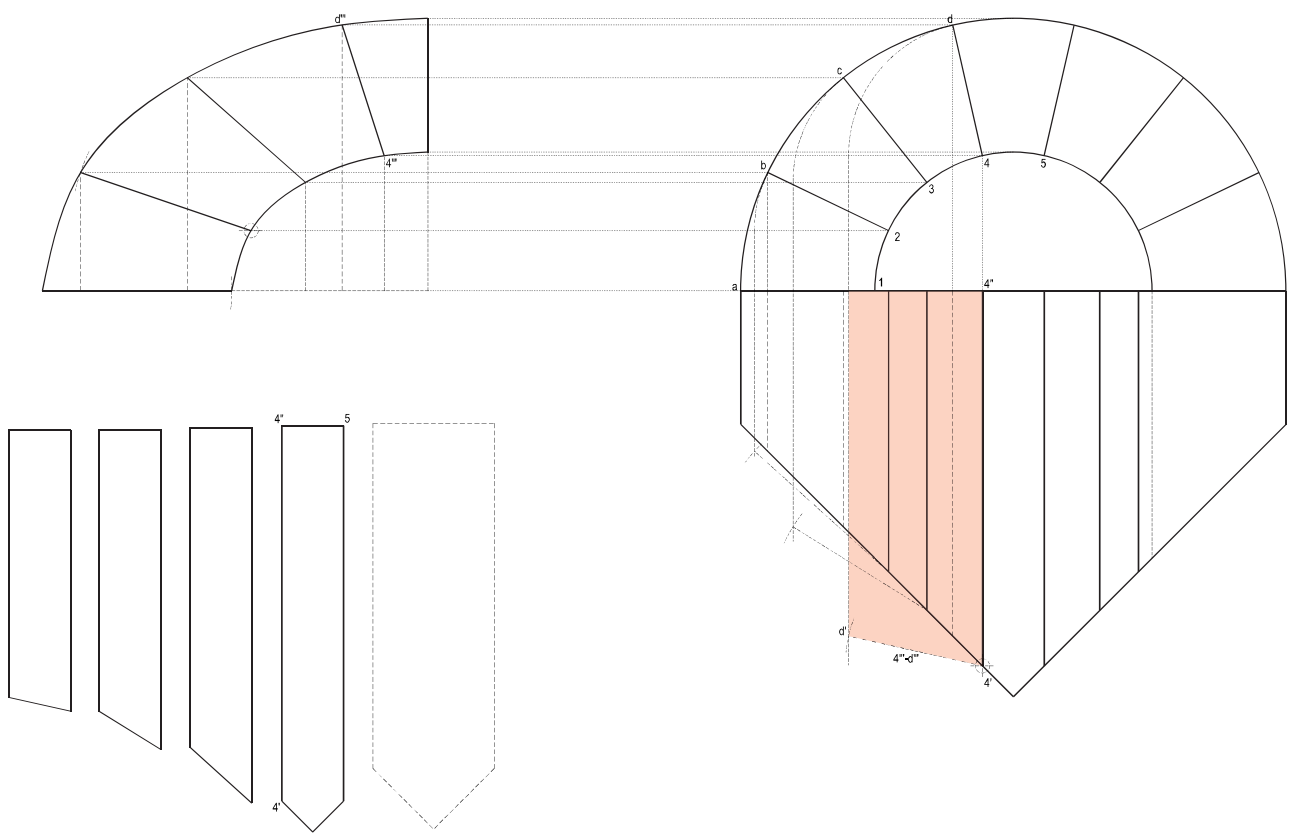

Fig. 4.9. Dibujo de las plantillas. Dlbujo del autor. 


\section{Portal ab canto y talus y paret derra - Portal en esquina y talud y pared recta}

Folios 19-20 (Traza 10)

Este arco tiene con la dificultad añadida de tener una de las paredes del rincón recta y la otra en talud. En este caso, las dovelas de una mitad del arco serán diferentes de la otra mitad y no será posible reutilizar las plantillas de una mitad como en el caso precedente.

\section{Portal ab raco biax - Portal en rincón en esviaje}

Folios 21-22 (Traza 11)

Esta traza sigue el mismo método del modelo anterior abatiendo las caras de intradós y de juntas, pero considerando que, por ser asimétrico, requiere la traza de las plantillas y saltarreglas de cada dovela.

Hay un arco en rincón en esviaje en la Catedral de Barcelona (Fig. 4.16, c y d): este arco sirve de paso entre la anti-sacristía y la sacristía y está cortado dentro de los contrafuertes de la cabecera.

Gelabert describe esta traza Portal de raco retirat a una part y Vandelvira lo nombra Arco en Rincon desigual. Cuando el arco sufre una fuerte deformación en sus testas, Vendelvira recomienda obtener la cimbra o silueta proyectada del $\operatorname{arco}^{5}$. En el caso de molduras como en el arco en rincón de la Catedral de Lleida, el dibujo de la cimbra facilita el trabajo del cantero para controlar las deformaciones. La decoración, dibujada sobre una malla regular, al ser proyectada sigue relacionándose a la geometría, permitiendo de controlar las deformaciones.

\section{Portal ab raco y talus - Portal en rincón y talud}

Folios 23-24 (Traza 12)

Esta traza es igual a la precedente con la complicación de tener las dos paredes en talud. Es posible reutilizar las dovelas una mitad del arco, ya que por simetría serán iguales a la otra mitad.

\section{Portal ab raco y talus y paret derra - Portal en rincón y talud y pared recta}

Folios 25-26 (Traza 13)

Este arco tiene con la dificultad añadida de tener una de las paredes del rincón recta y la otra en talud. En este caso, las dovelas de una mitad del arco serán diferentes de la otra mitad y no será posible reutilizar las plantillas de una mitad como en el caso precedente.

\footnotetext{
5 Palacios, 1990: 116.
} 

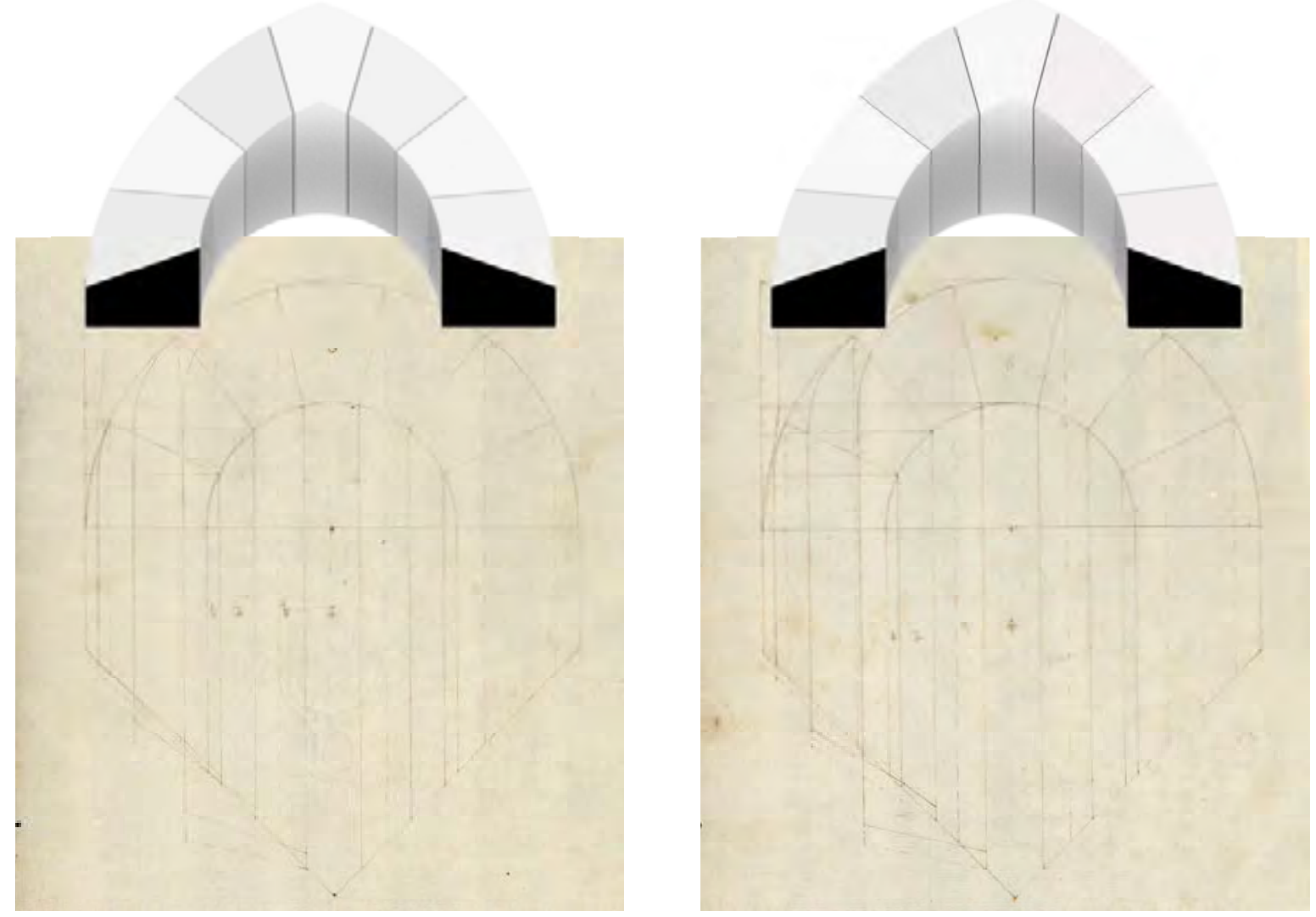

Fig. 4.10. Portal en esquina y talud; Portal en esquina y talud y pared recta

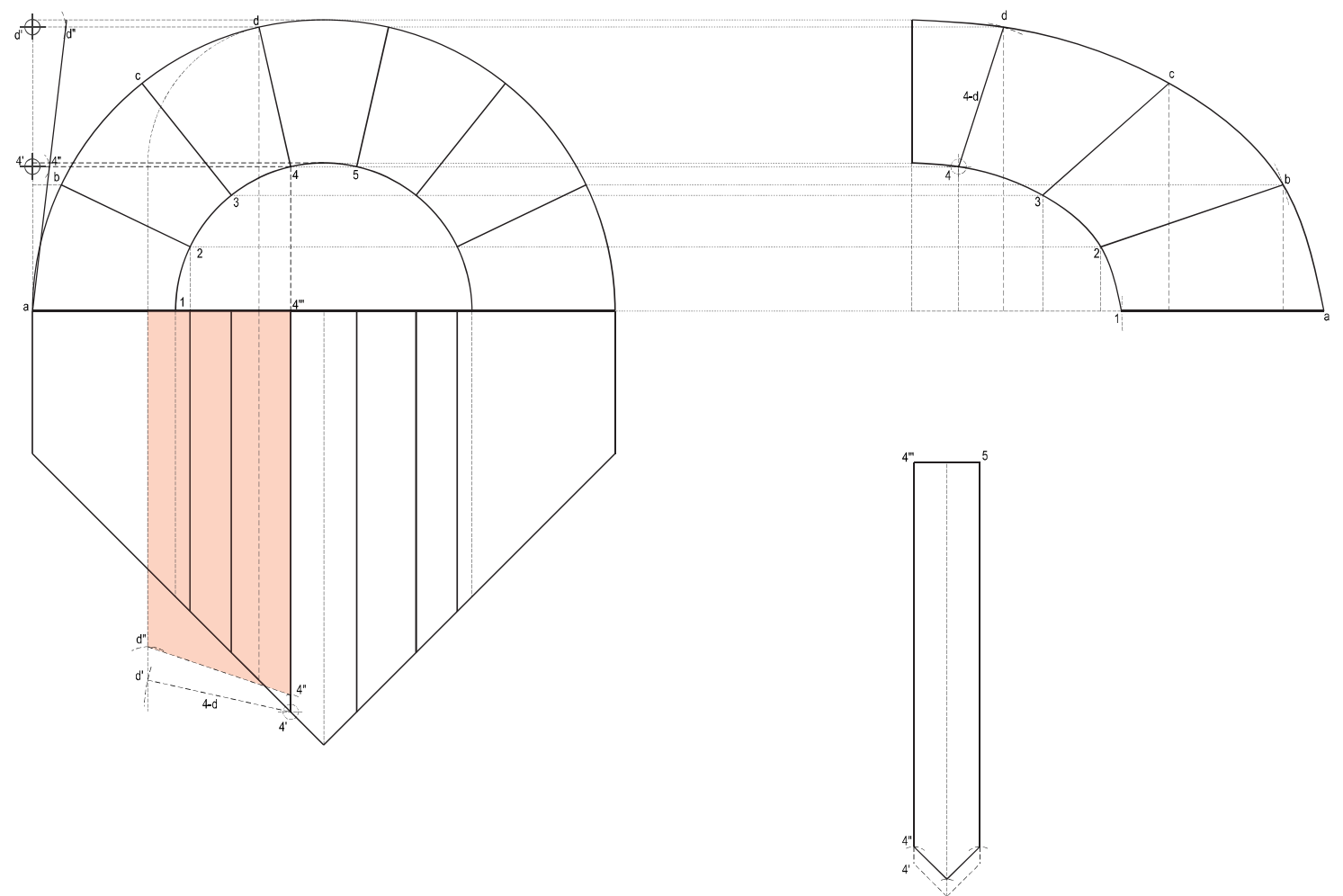

Fig. 4.11. Dibujo de las plantillas. Dlbujo del autor. 

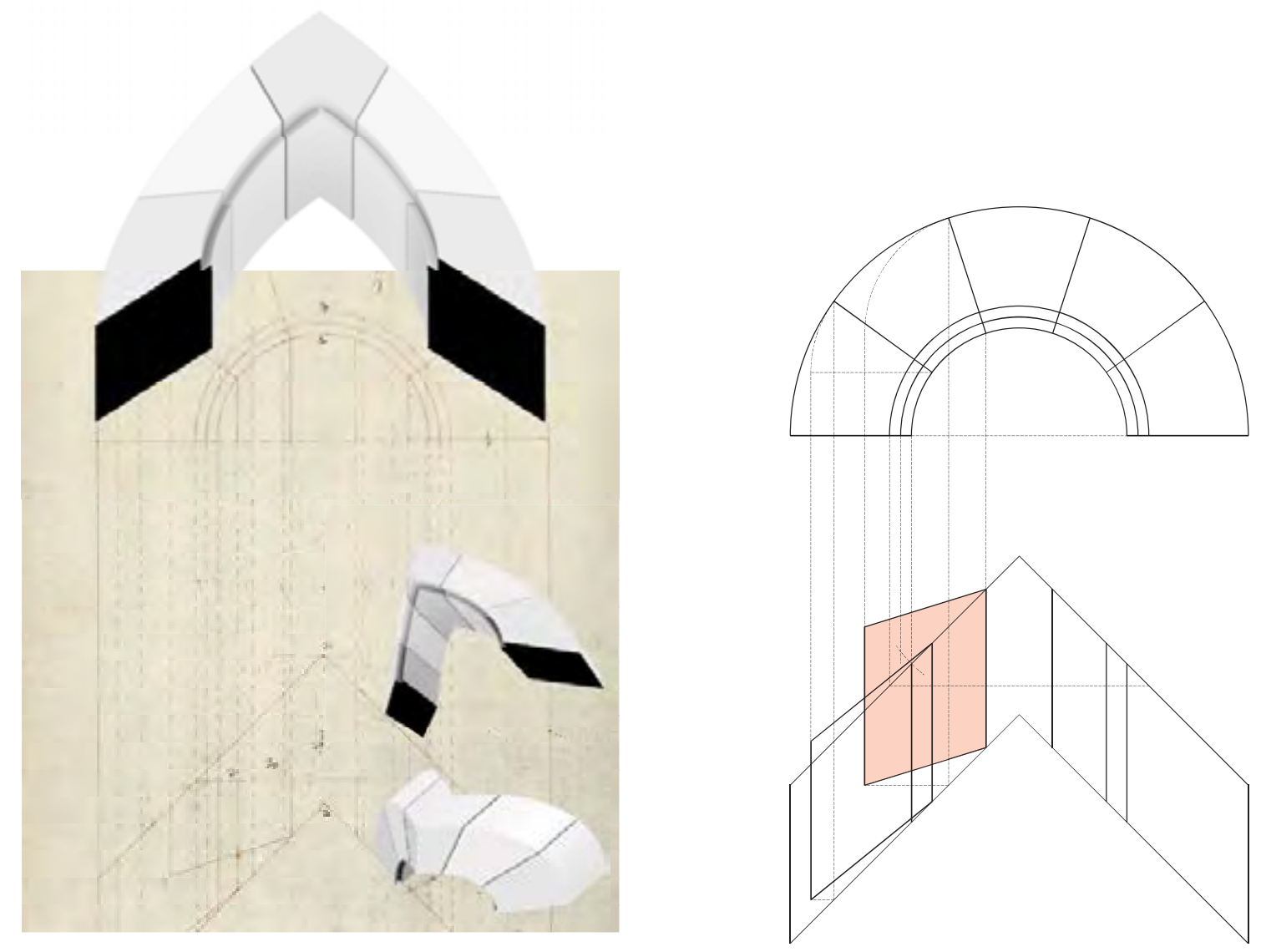

Fig. 4.12. Portal en esquina y rincón. Dlbujo del autor.
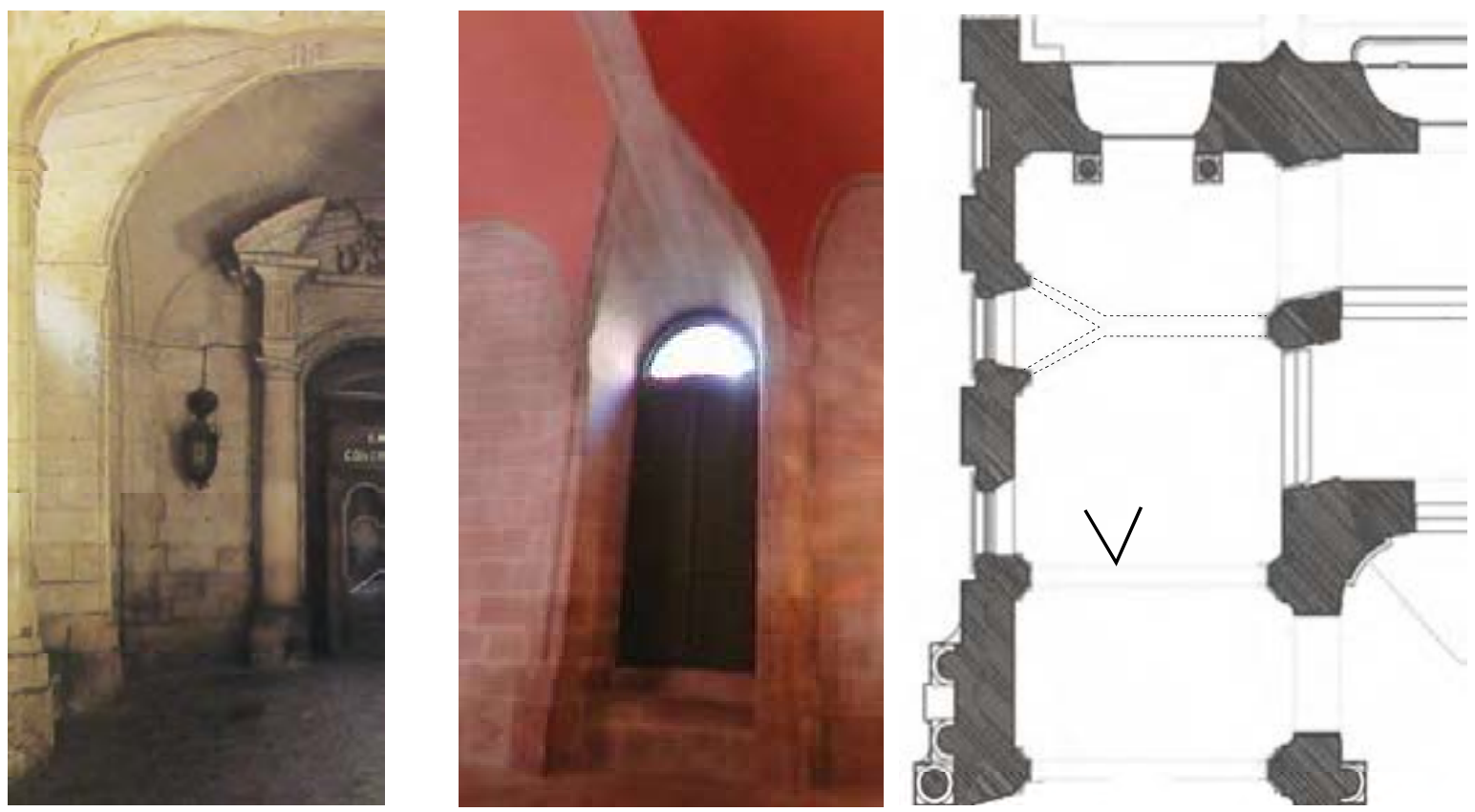

Fig. 4.13. Arco en esquina incorporado en las bóvedas del patio de la Llonja de Mar de Barcelona. (Foto A y C publicadas en Llotja Oberta). 

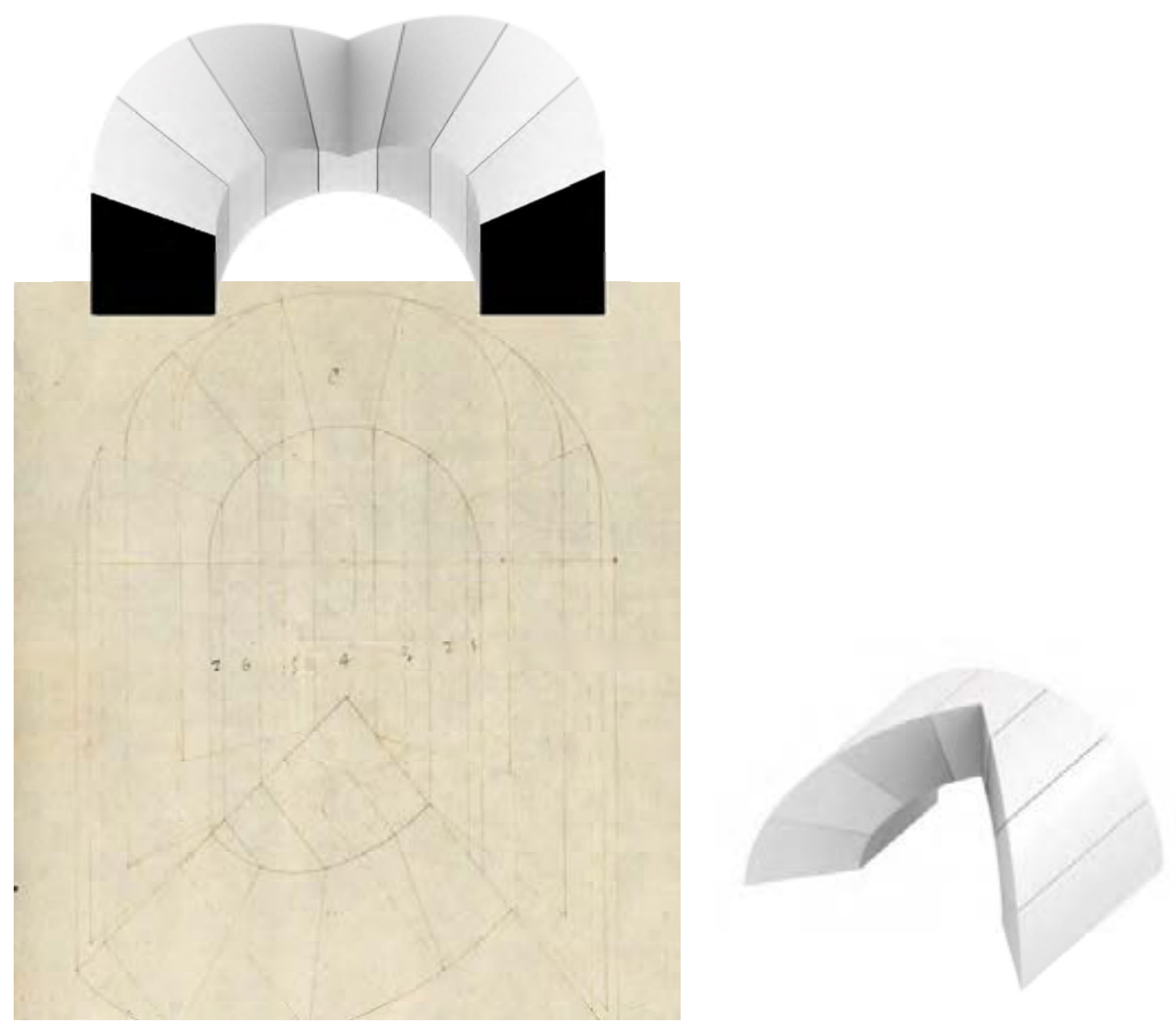

Fig. 4.14. Portal en rincón
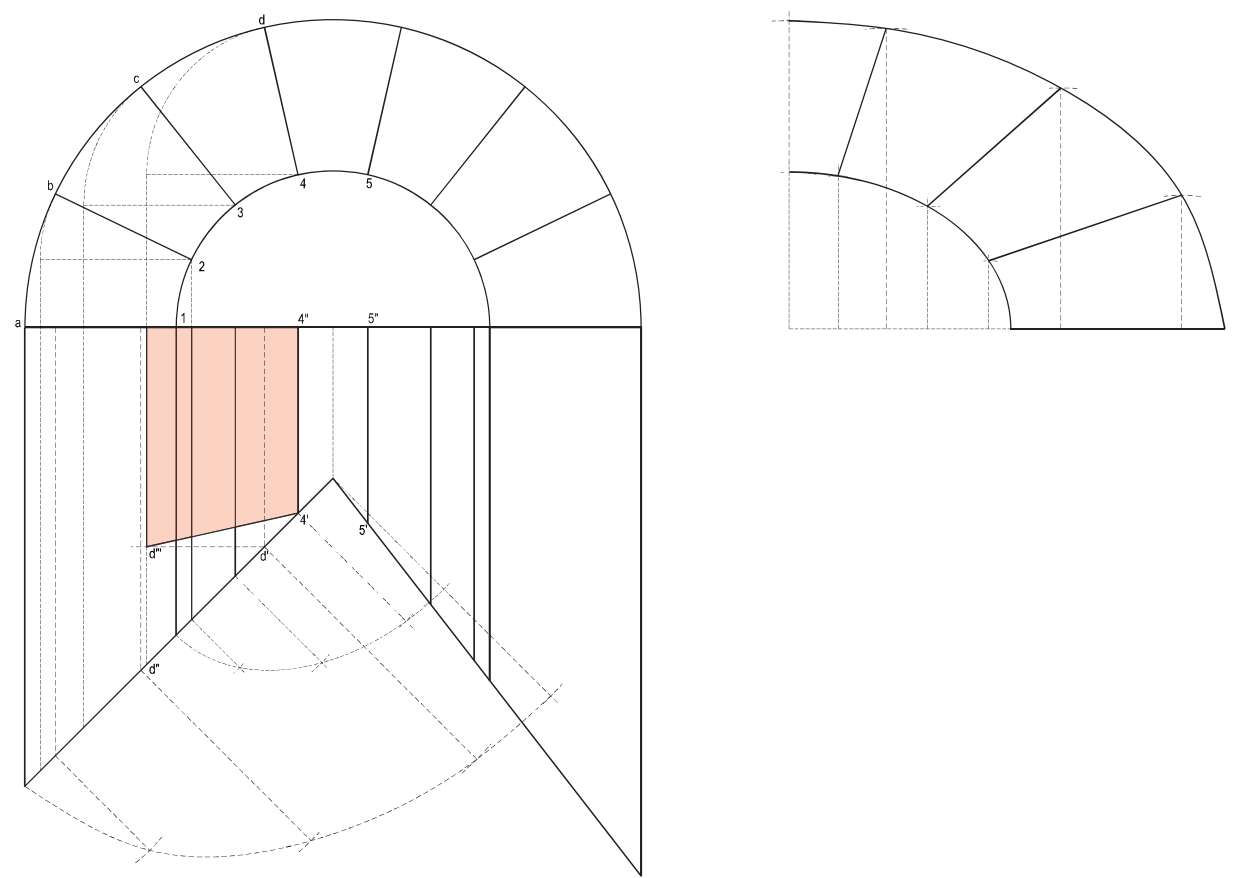

Fig. 4.15. Arco en rincón: dibujo de las plantillas. Dlbujo del autor. 

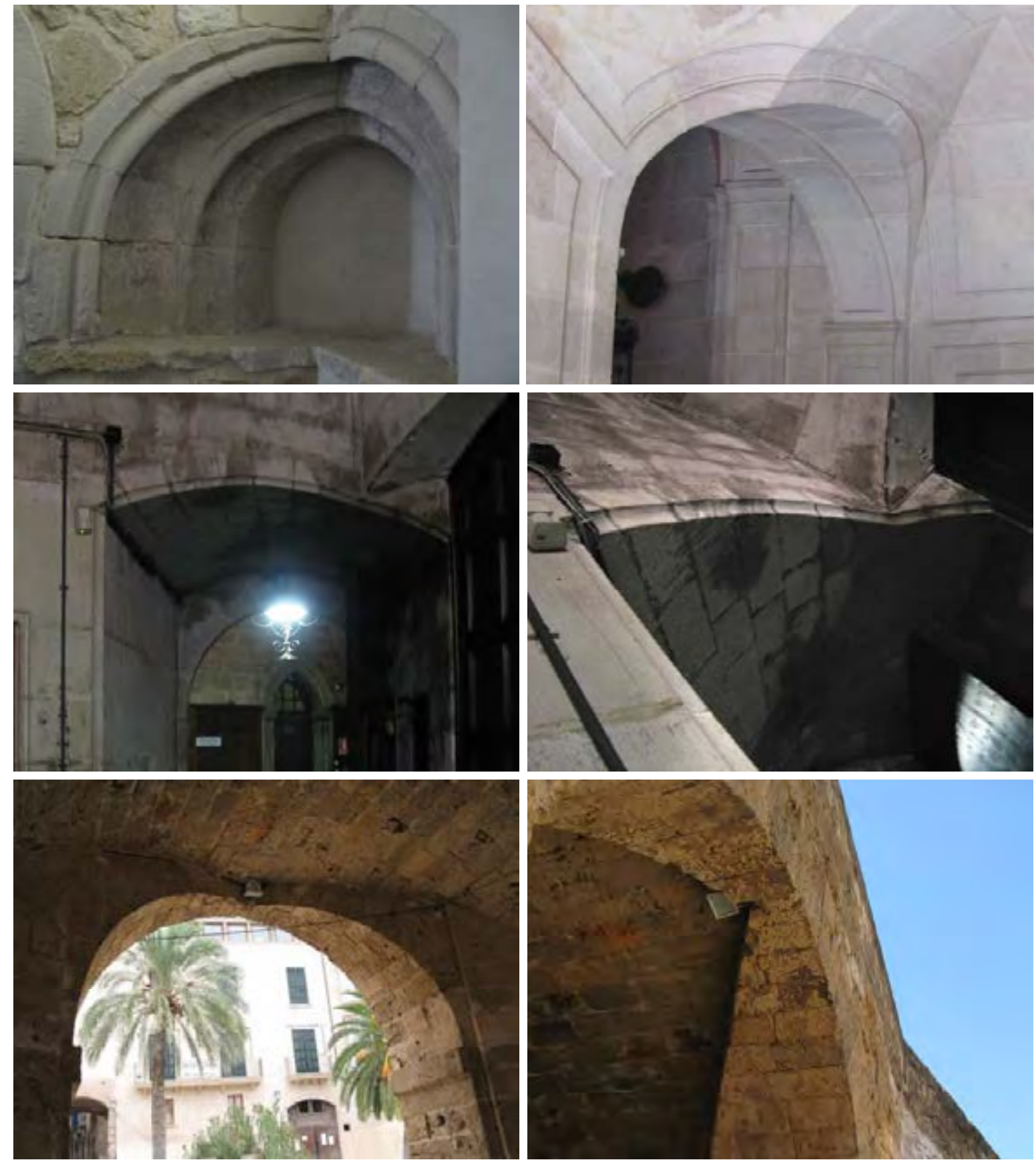

Fig. 4.16. Arcos en rincón en la Catedral Vieja de Lleida; Llonja de Mar de Barcelona; Sacristia de la Catedral de Barcelona; murallas de Palma de Mallorca. Fotos del autor. 


\section{Portal ab tora radona - Portal en torre redonda}

Folios 27-28 (Traza 14)

Este ejemplo describe la estereotomía de un arco de medio punto tendido sobre una pared convexa (Fig. 4.17). A este seguirán dos trazas que describen sus variacciones, una con muro a talud y otra con muro parte en talud, parte vertical.

La proyección de un arco sobre una pared de superficie curva va a originar en la silueta proyectada fuertes deformaciones. De hecho, cortando una superficie cilíndrica con un plano de corte curvo, el arco resultante de la intersección se desarrollará en el espacio. Las dovelas deben mantener siempre el mismo espesor y de consecuencia la silueta del arco se deformará en toda su extensión, aumentando al recorrer el arco desde la clave hasta las impostas. Las juntas verticales de las dovelas del arco son curvas, lo cuale requiere obtener para cada junta el angulo que esta forma con el intrados y su propia curvatura.

Para obtener las plantillas de las dovelas se abate el plano que define la junta de la dovela utilizando el alzado del arco de medio punto y de la planta del arco. Esta línea es curva en el plano abatido, por lo cual se hace necesario abatir también el punto intermedio, que Ribes precisa para cada dovela marcándolo con una línea de trazos.

En la parte inferior del dibujo Ribes reproduce los patrones de las caras de intradós (mollos de las bocas) y de extradós (mollos dela rardosa), las plantillas de los lechos de las dovelas están abatidos en la planta.

\section{Portal ab tora radona y talus - Portal en torre redonda en talud}

Folios 29-30 (Traza 15)

Esta traza describe el arco que se acaba de exponer con la dificultad añadida de tener las paredes en talud. Por simetría las plantillas de una mitad del arco se pueden reutilizar al revés.

\section{Portal ab tora radona y talus y paret derra - Portale en torre redonda y talud y pared recta}

Folios 31-32 (Traza 16)

Ribes contempla un tercer arco de esta serie al que acabamos de referirnos, pero con una pared parcialmente en talud y parcialmente recta, como se puede ver desde el diagrama del talud en la parte izquierda de la sección. Al respeto de esta geometría, todas las dovelas de una mitad del arco serán diferentes.

\section{Portal ab tora acabada - Portal en torre cava}

Folios 33-34 (Traza 17)

Se genera al perforar un muro cóncavo talla de la pieza similar al arco en torre redonda. El dibujo de las plantillas se resuelve por abatimientos alrededor de la junta de intradós 


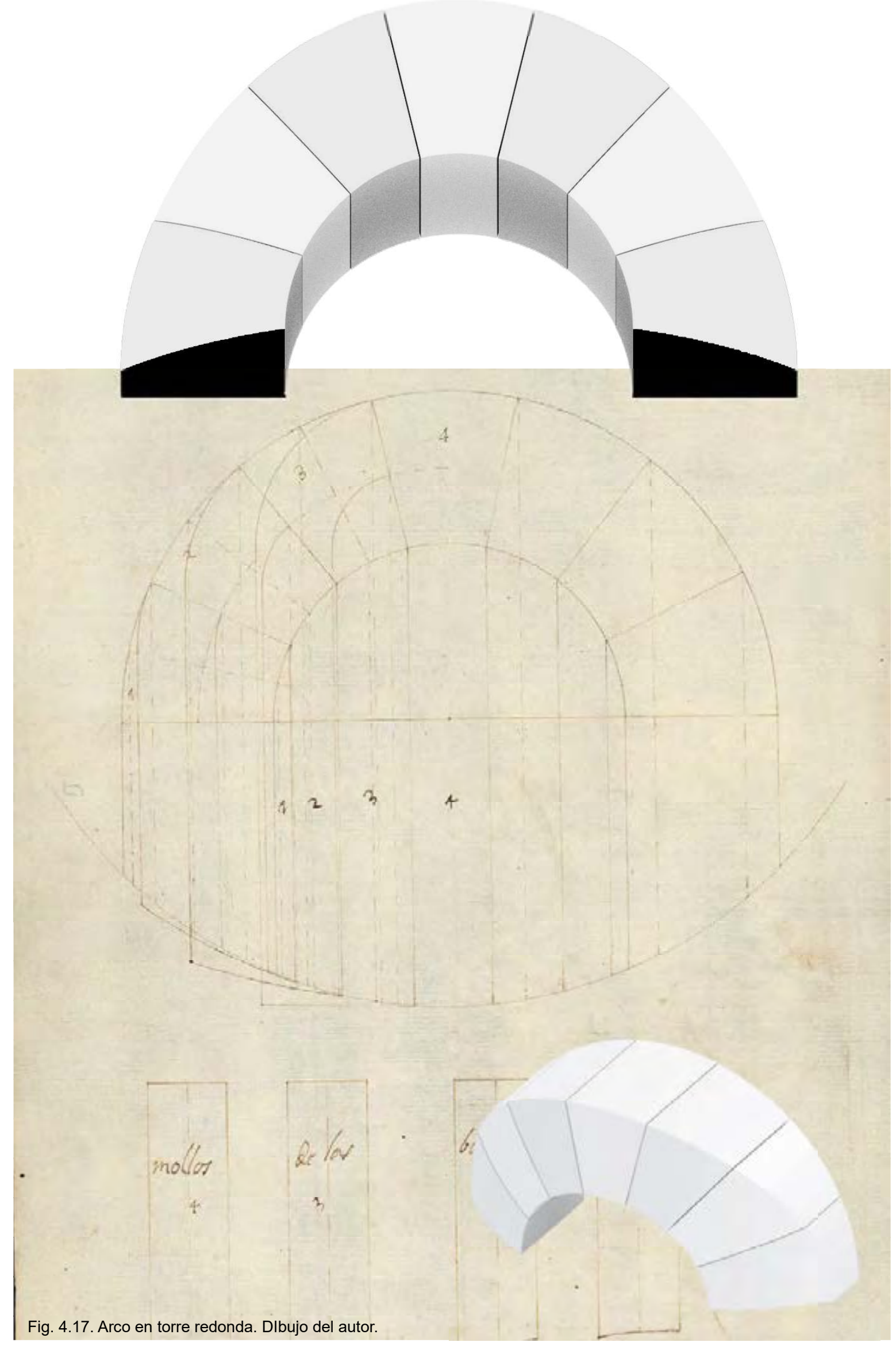


Los títulos a seguir son otras variaciones de aberturas sobre muros curvos que presentan notables similitudes con las trazas descritas anteriormente:

Portal ab tora acabada y talus - Portal en torre cava y talud

Folios 35-36 (Traza 18)

Portal ab tora acabada y talus y paret derra - Portal en torre cava y talud y pared recta Folios 37-38 (Traza 19)

Portal ab canto y tora acabada - Portal en esquina y torre cava

Folios 39-40 (Traza 20)

Portal ab tora radona y raco - Portal en rincón y torre redonda

Folios 41-42 (Traza 21)

Portal ab tora radona y canto - Portal en esquina y torre redonda

Folios 43-44 (Traza 22)

*sin nombre - Portal en torre redonda y torre cava

Folios 45-46 (Traza 23)

Portal ab rraco, y canto, cap y al - Arco en esquina y rincón ("no hay el capialzado)

Folios 227 - 228 (Traza 123)

Portal ab torra Rodona - Portal en torre redonda y pared recta

Folio 239 (Traza 132)

Portal ab torra cabada - Portal en torre cava y pared recta

Folio 240 (Traza 133)

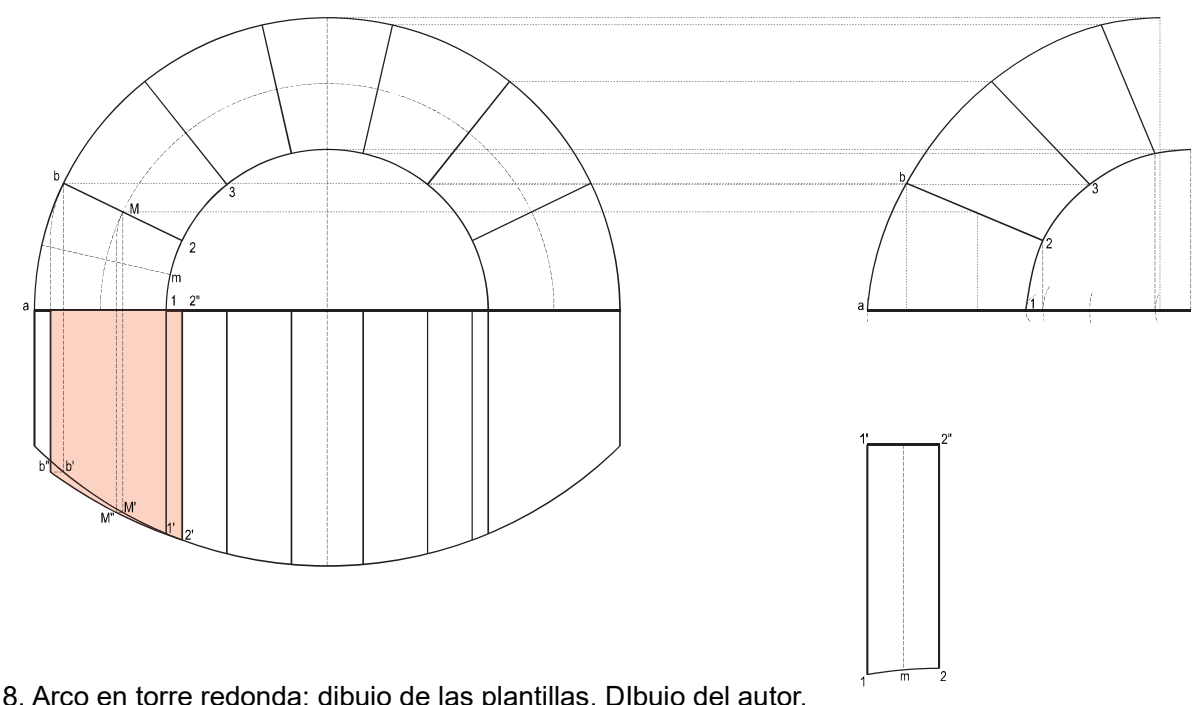

Fig. 4.18. Arco en torre redonda: dibujo de las plantillas. Dlbujo del autor. 


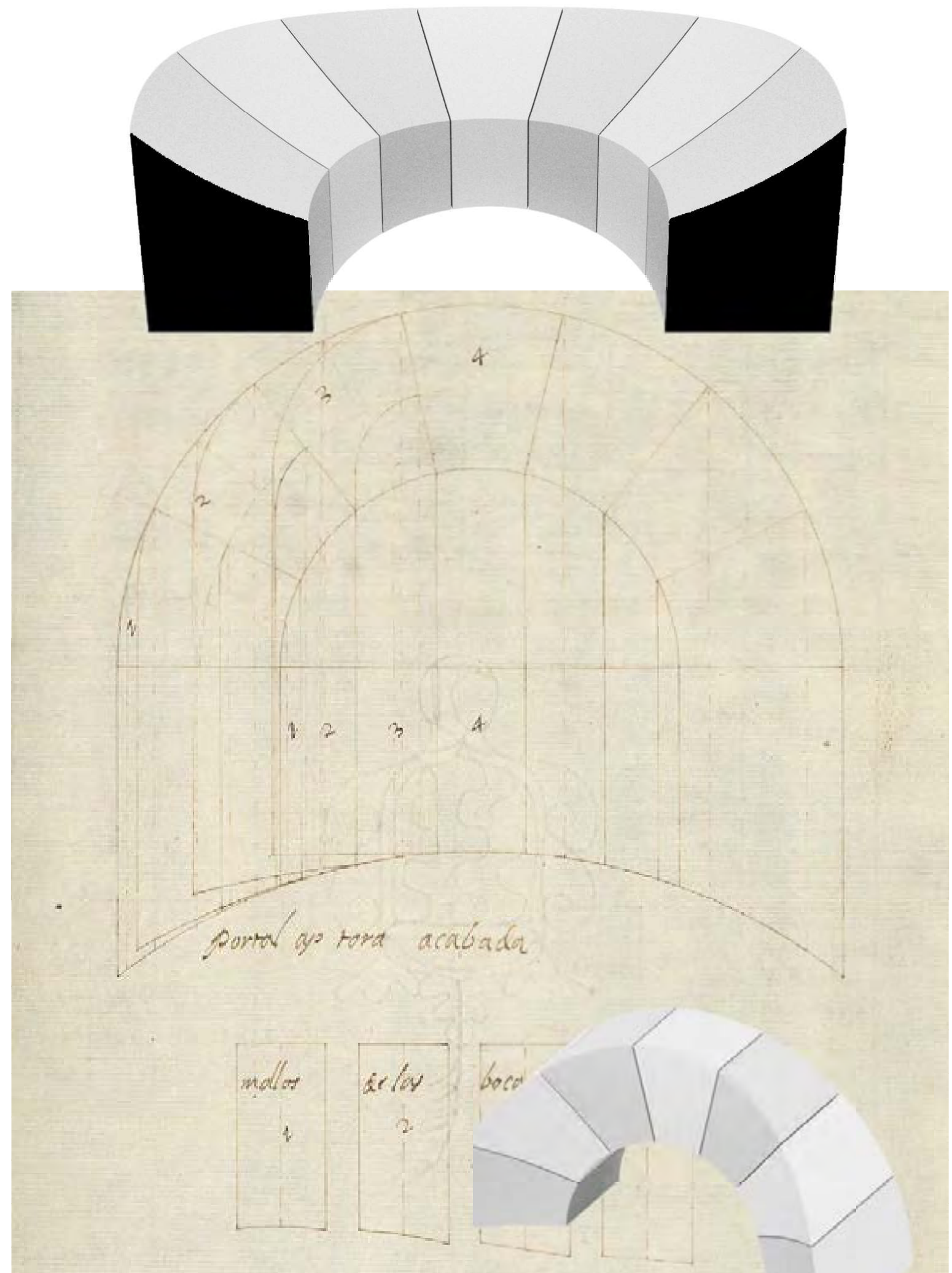

Fig. 4.19. Arco en torre cava. Dlbujo del autor. 

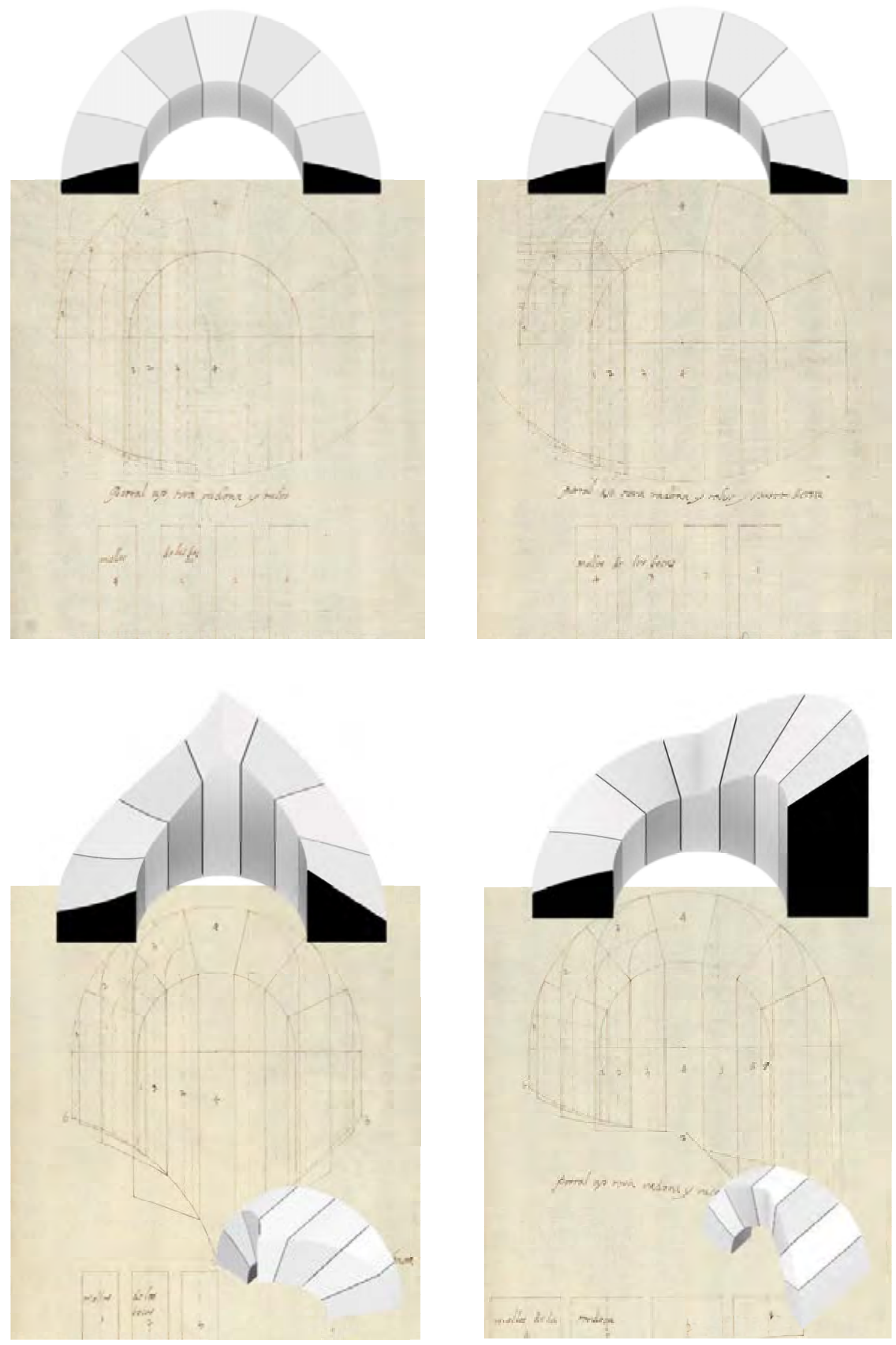

Fig. 4.20. Variaciones de arcos redondos y en esquina. Dlbujo del autor. 

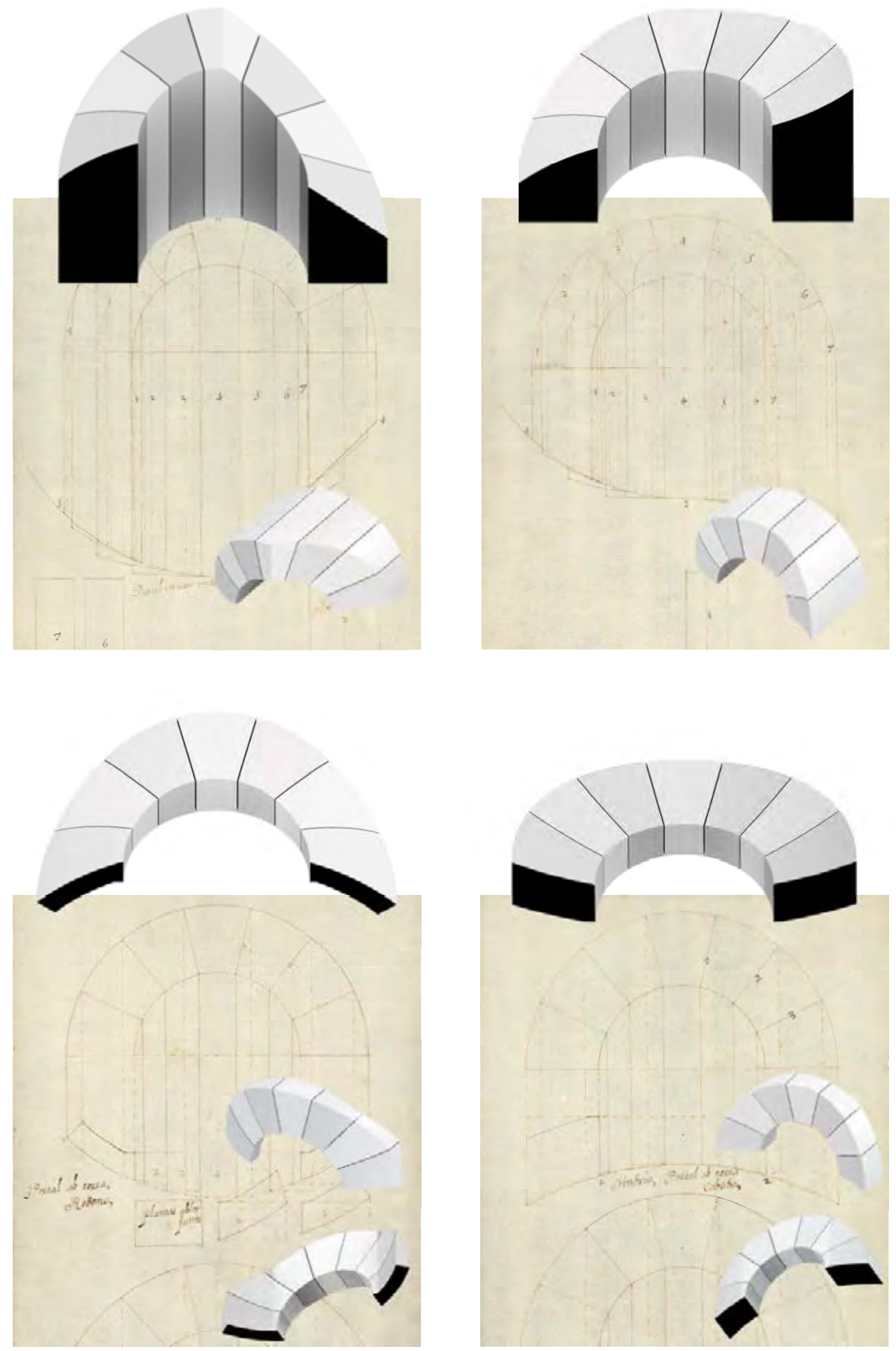

Fig. 4.21. Variaciones de arcos redondos y en esquina. Dlbujo del autor. 

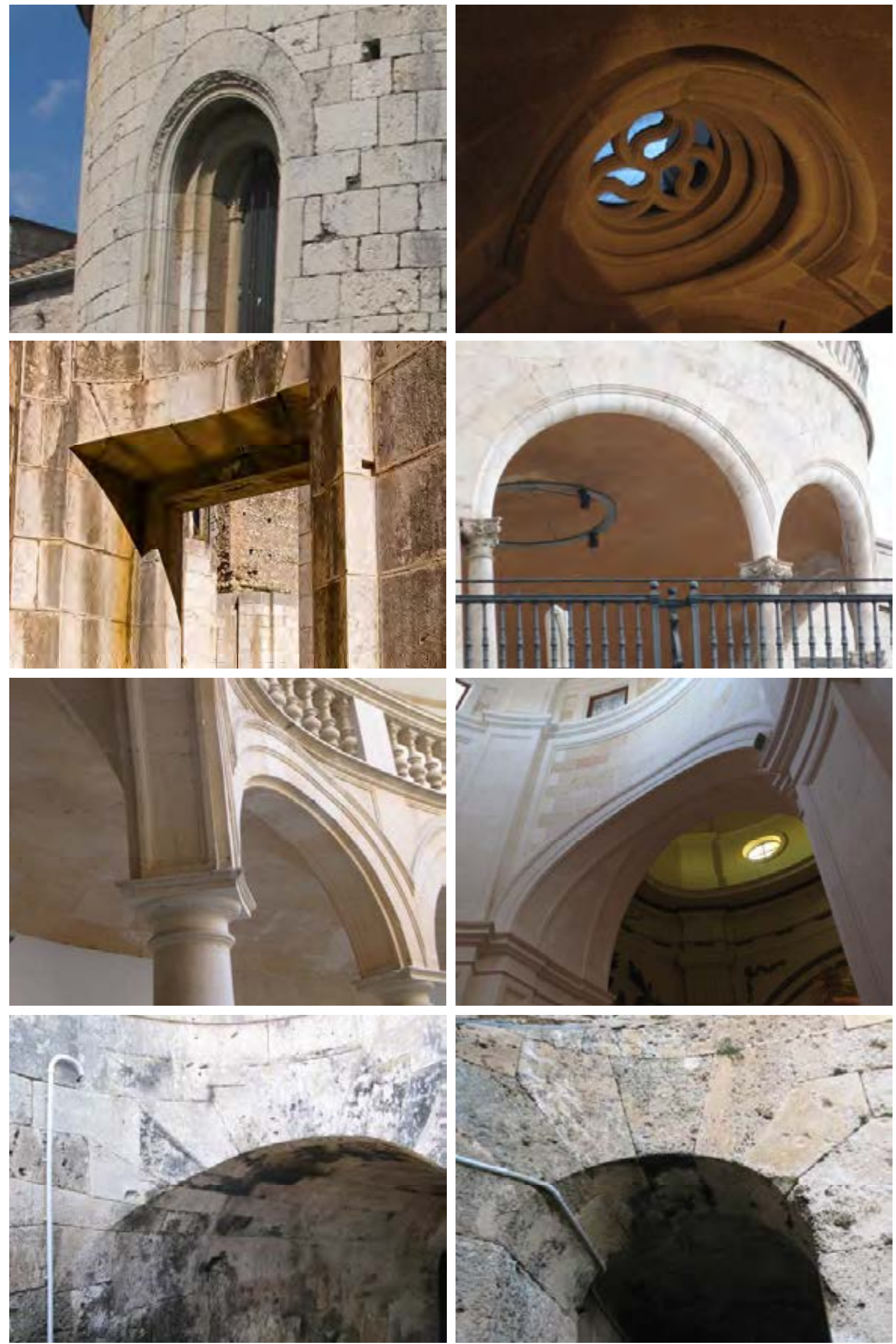

Fig. 4.22.Catedral de Girona; Monasteri del Bellpuig; Fortaleza de San Fernando de Figueres; Palma de Mallorca; patio de San Antoni Abad, Palma de Mallorca; Palau March, Palma de Mallorca; Catedral de Menorca; Fortaleza de la Mola de Menorca. Fotos del autor. 


\subsection{Segundo bloques: arcos capialzados y decendas de cava}

Al segundo bloque pertenecen los arcos generados depositando el eje de la bóveda sobre un plano inclinado respecto al horizonte, con las embocaduras situadas a alturas diferentes.

Ribes describe dos ejemplos de arcos caracterizados por una superficie de intradós que no es cilíndrica.

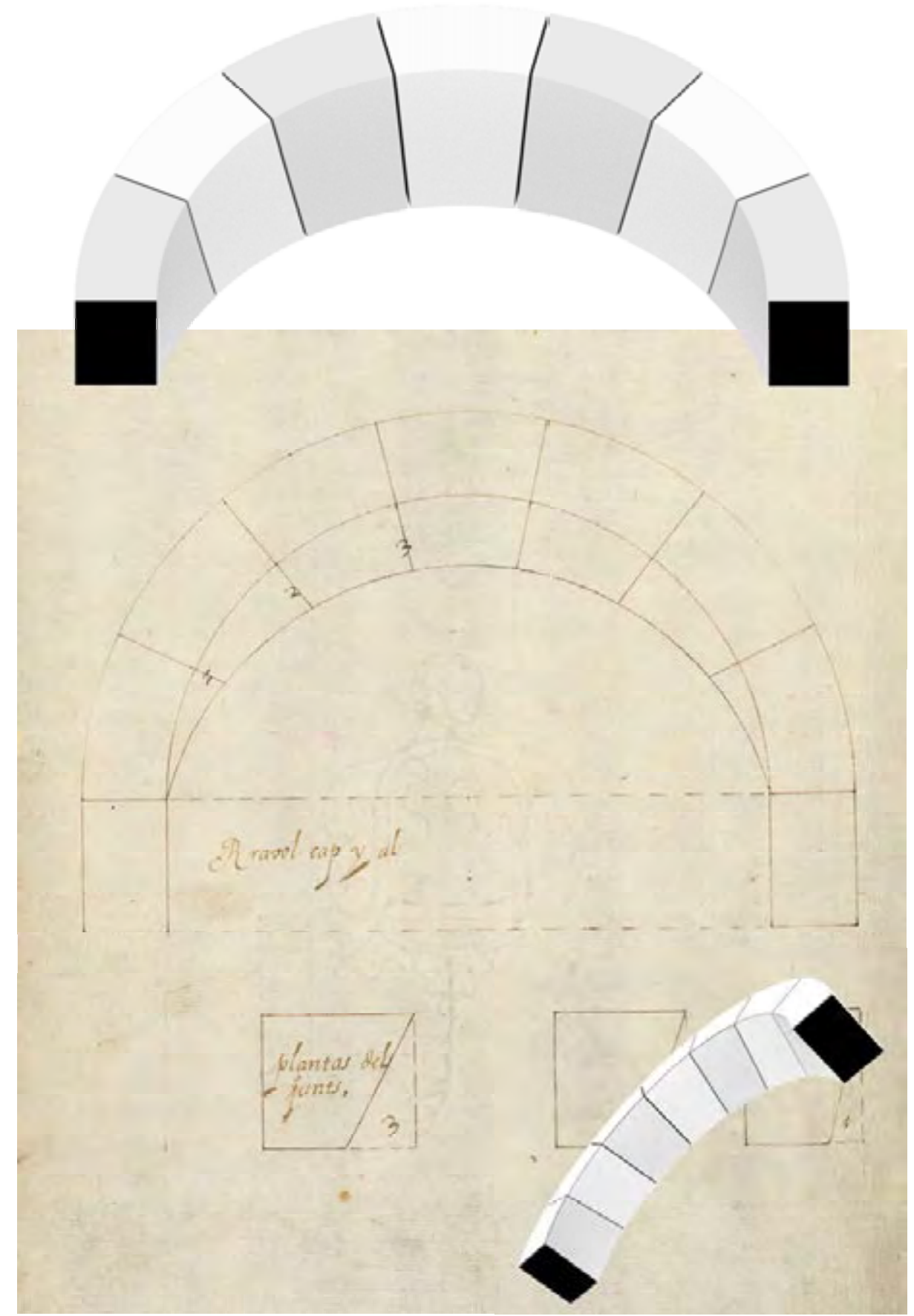

Fig. 4.23. Arco capilazado 


\section{Rravol cap y al - Arco capialzado}

Folio 225 (Traza 121)

El Rravol cap y al es un arco capialzado generado por un arco de testa de medio punto y otro escarzano situado a una cota diferente (Fig. 4.23), de manera muy parecida a un capialzado a regla, pero en este caso la línea de cota más baja no es una recta sino una curva. Esta traza es un aparejo muy difundido en la práctica de la cantería catalana, especialmente en su variante con ambos arcos escarzanos: es característica de los arcos que encabezan el arranque y la terminación de las bóvedas de las escaleras claustrales de las casas nobles catalanas. El capialzo acompaña la pendiente de la escalera para evitar cabezazos y para motivos estilísticos, de hecho, también los capiteles y las bases de columnas que soportan los arcos se deforman en directriz oblicua orientadas con la misma pendiente.

La talla de las dovelas se puede obtener por robos. Se talla primero una dovela recta y se aplican sobre ella las plantillas de las siluetas de los arcos de testa de ambos lados. Sucesivamente se hace recorrer una regla tendida entre las siluetas de los arcos recién marcados descantillando la piedra en exceso hasta obtener la superficie del intradós, definido geométricamente por una reglada. Aunque no sean necesarias, Ribes dibuja las caras de lecho: quizás se representan para que sea más fácil entender la volumetría de la traza.

Gelabert incluye una traza similar en el folio 27 (Arch y arquet pujant descala) para definir un arquillo de subida de escalera.

Muy sugestivos, son los arcos rampantes capialzados de geometría muy dilatada que flanquean la escalera del Palau de la Virreina en Barcelona (Fig. 4.25), obra de Josep Ausich.
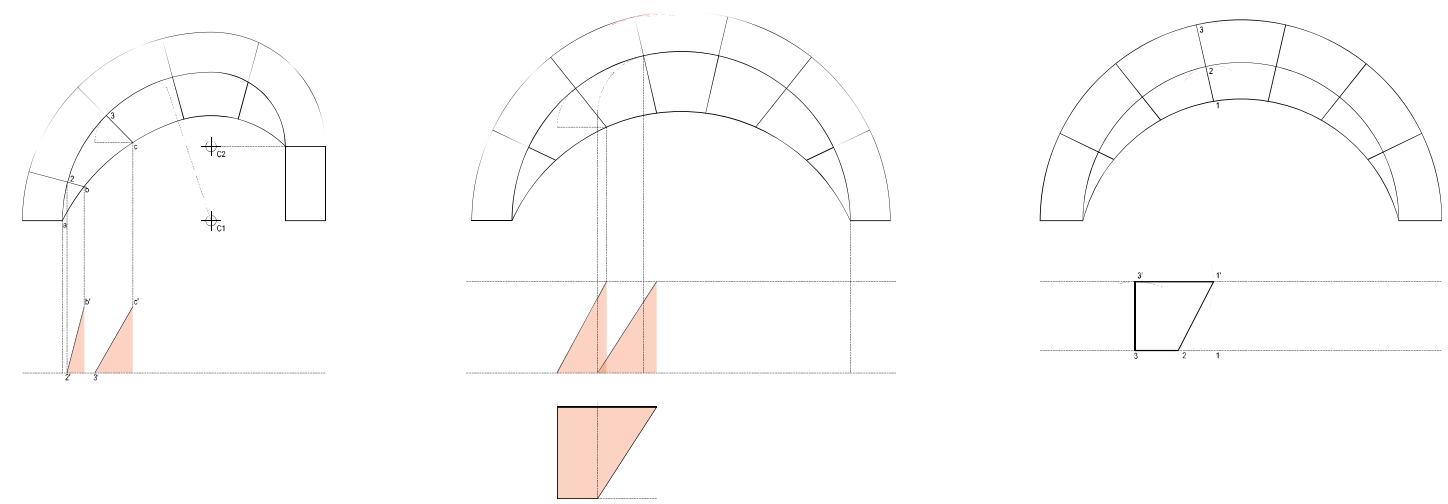

Fig. 4.24. Dibujo de las plantillas de arcos rampantes capialzados y arcos capilazados. Dlbujo del autor. 

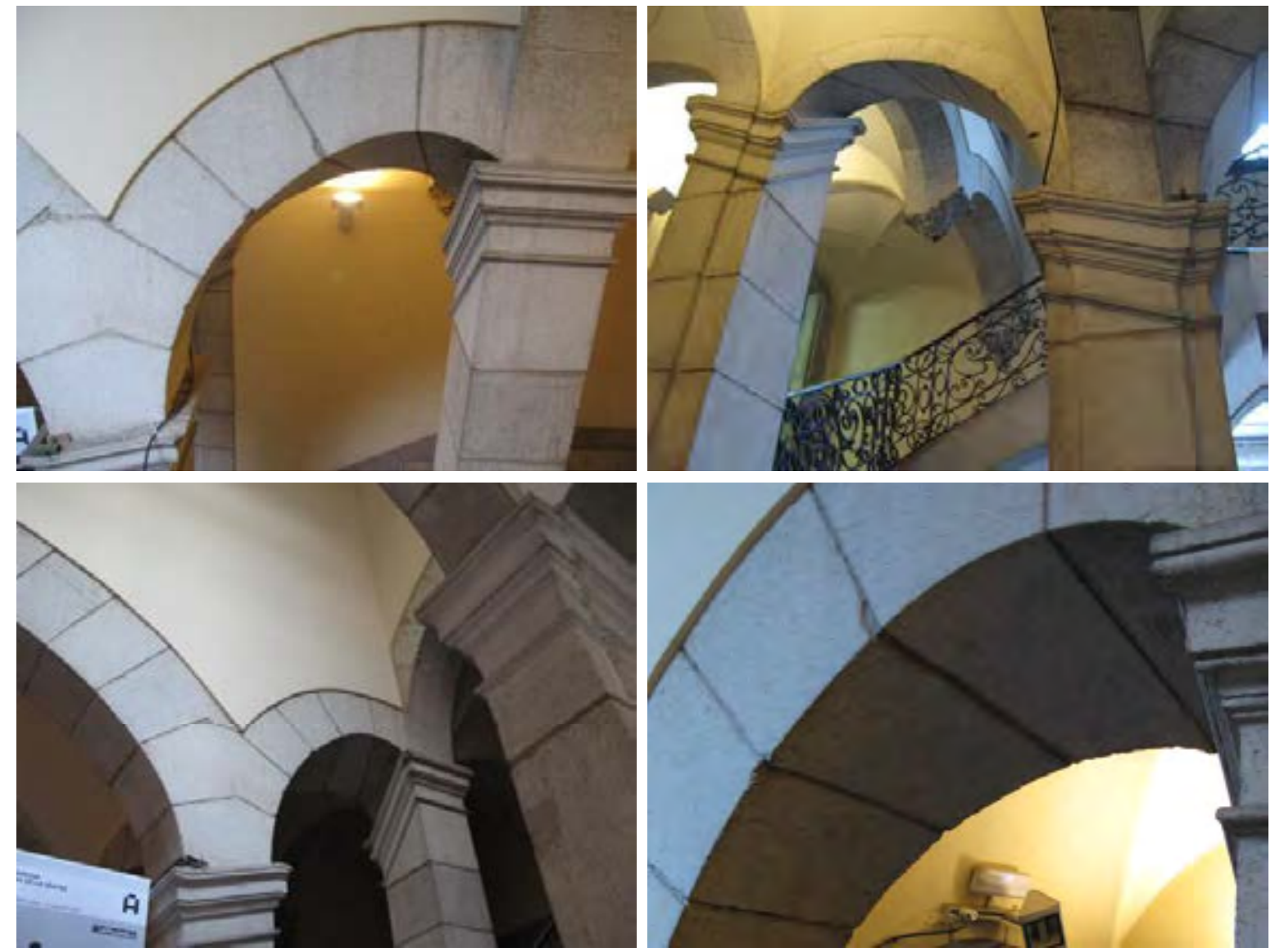

Fig. 4.25. Arcos rampantes capialzados en el Palau de la Virreina, Barcelona. Fotos del autor. 


\section{Rravol cap y al - Arco en decenda de cava}

Folio 226 (Traza 122)

Esta traza (Fig. 4.27) describe un arco inclinado que es parecido a la decenda de cava recta de Vandevira. Las embocaduras son arcos de medio punto enfrentados entre sí, pero con centro colocado a distinta cota. El plano de imposta es inclinado y las juntas de intradós no son paralelas entre sí ni perpendiculares al plano de proyección frontal. Esto impide abatir los planos de las caras de intradós y de junta alrededor de las rectas de puntas pasantes por los vértices de las dovelas.

La solución que se propone, basada en triangulaciones, recurre a calcular las diagonales de las caras de intradós y de junta. Para cada dovela, se sacan las diagonales de la plantilla de intradós empezando por la cara del frente y luego por la cara de detrás. Las diagonales se obtienen formando un triángulo rectángulo que tiene por catetos su proyección horizontal y la diferencia de cotas entre sus extremos que una vez abatido nos da conocer su verdadera magnitud. Transportando en el plano las diagonales y las distancias entre vértices de las dovelas en es posible definir patrones de las caras de intradós. Del mismo modo se emplean las diagonales de las caras de lecho para definir los patrones relativos.

Ribes traza una representación esquemática de las diagonales sobrepuestas a la planta del arco. Este es el indicio que nos hace pensar que Ribes haya visto la traza de la decenda de cava en otro tratado. Sin embargo, este dibujo no es correcto y las plantillas que produce son de tamaño y forma equivocada. Hay un error en el procedimiento que denota como Ribes no haya entendido enteramente el procedimiento geométrico. También se puede suponer que Ribes simplemente no se haya preocupado de desarrollar por completo esta traza, que quizás era comúnmente conocida por los canteros catalanes por el facto que en Barcelona existan varios ejemplos construidos de este tipo de arquillo.

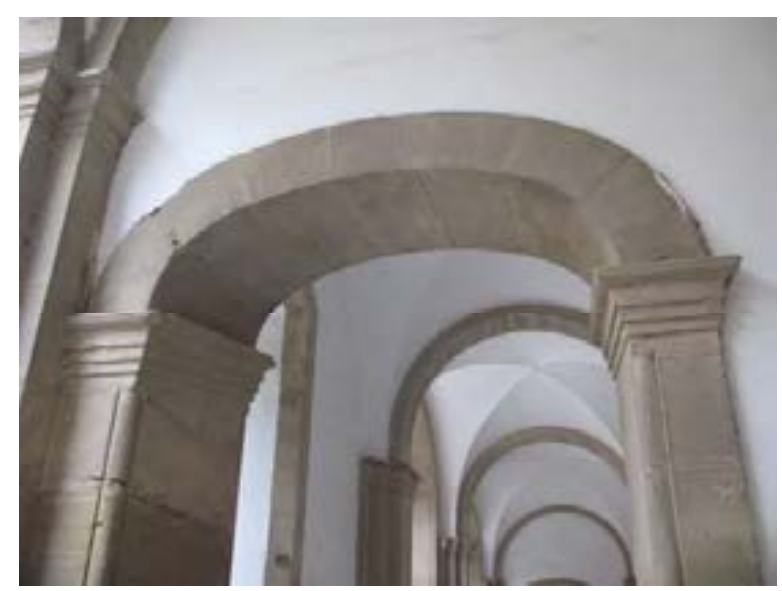

Fig. 4.26. Universitat de Cervera. Fotos del autor.

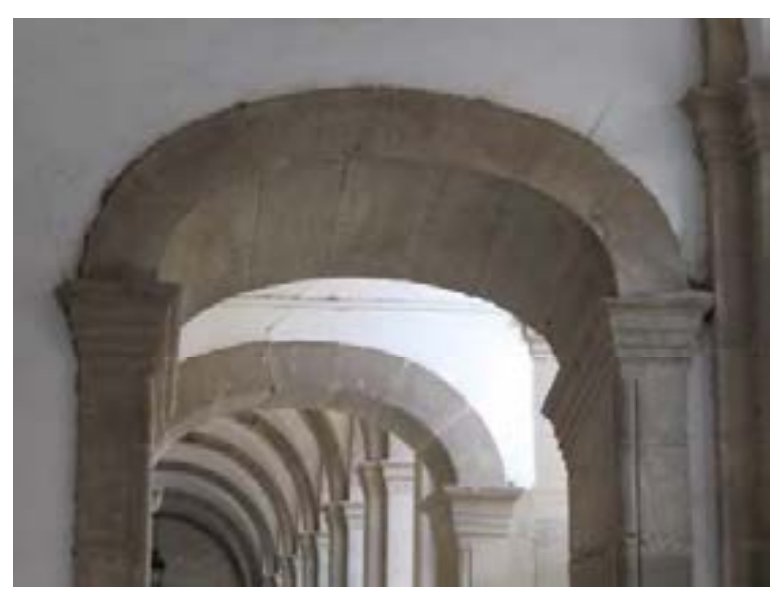




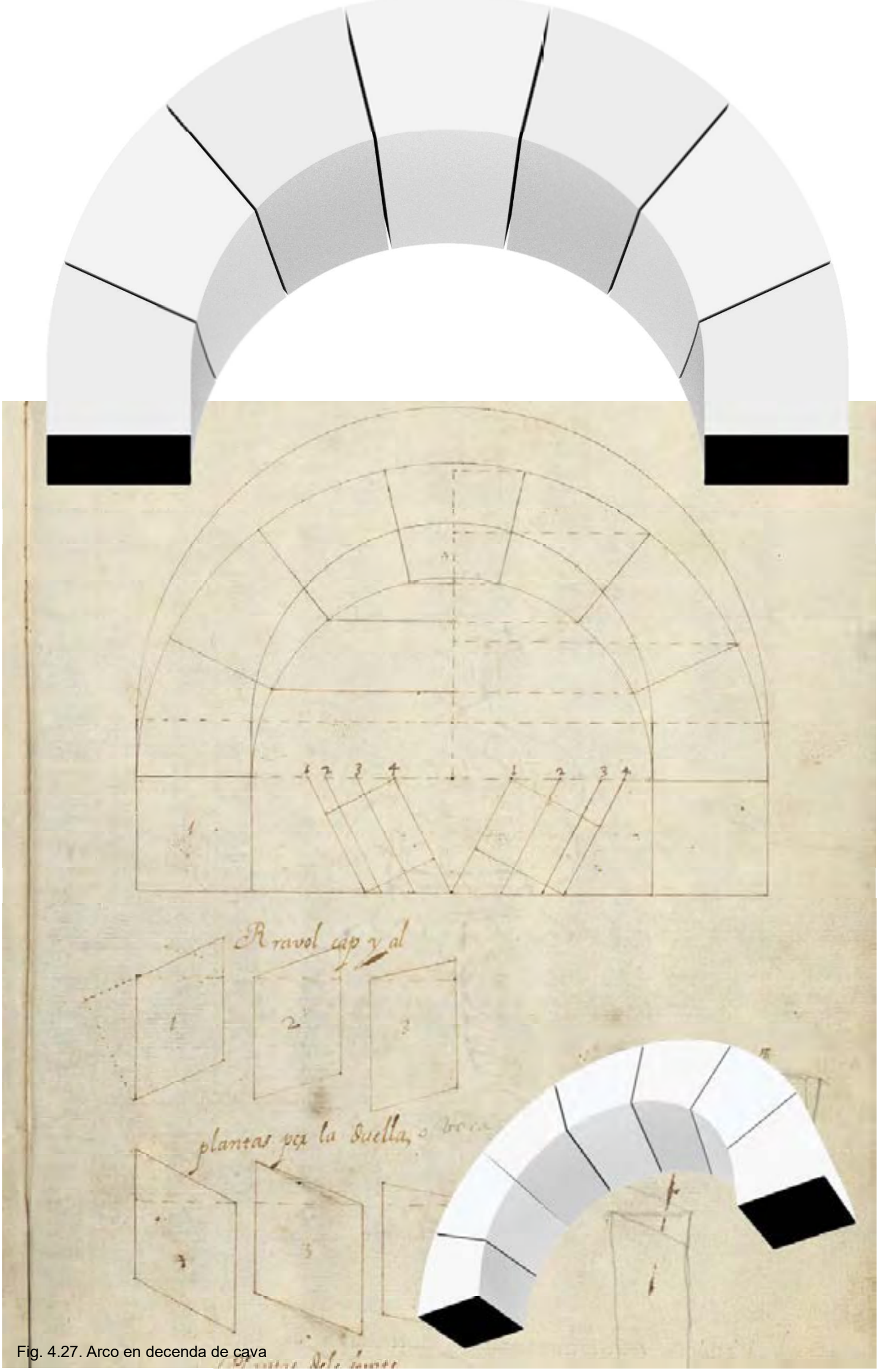



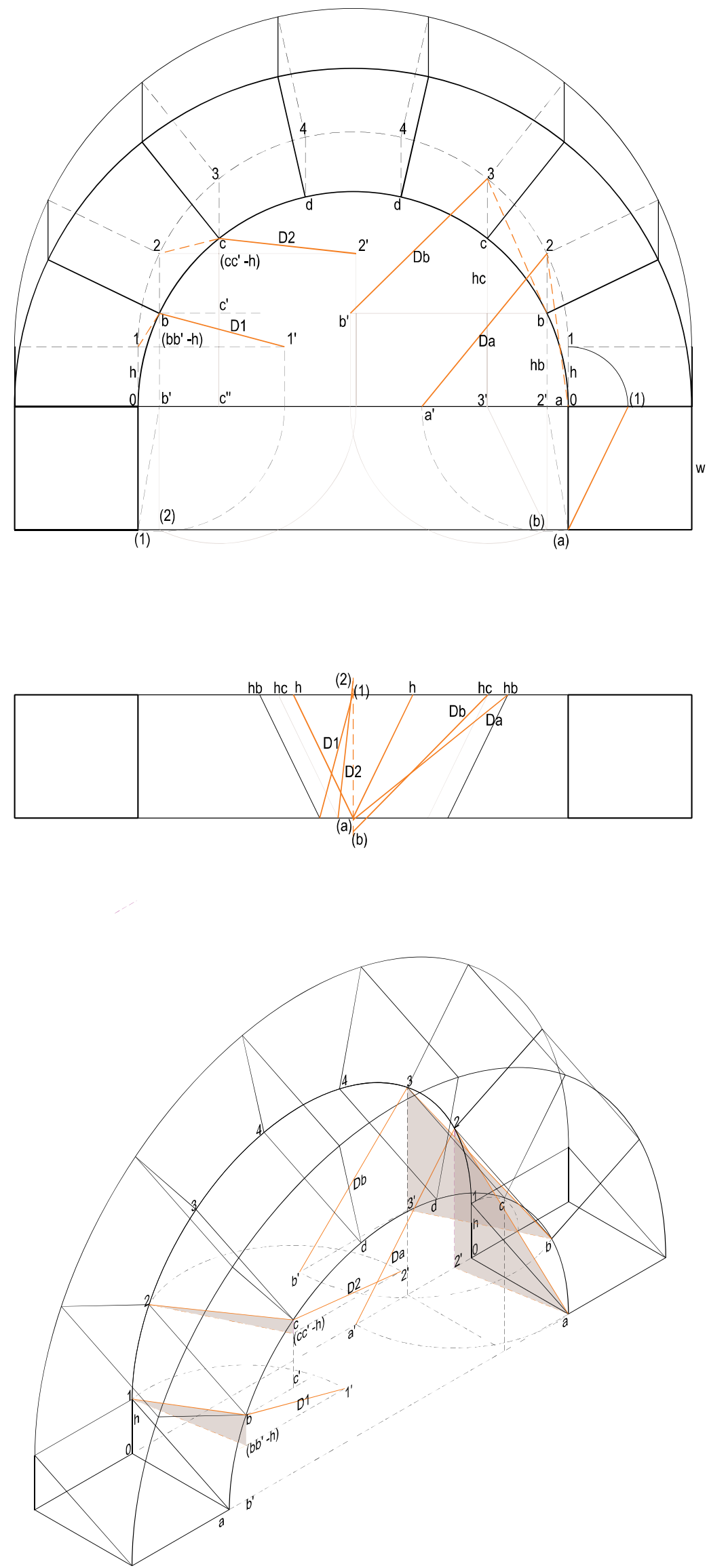

Fig. 4.28. Arco en decenda de cava: dibujo plantillas. Dlbujo del autor. 

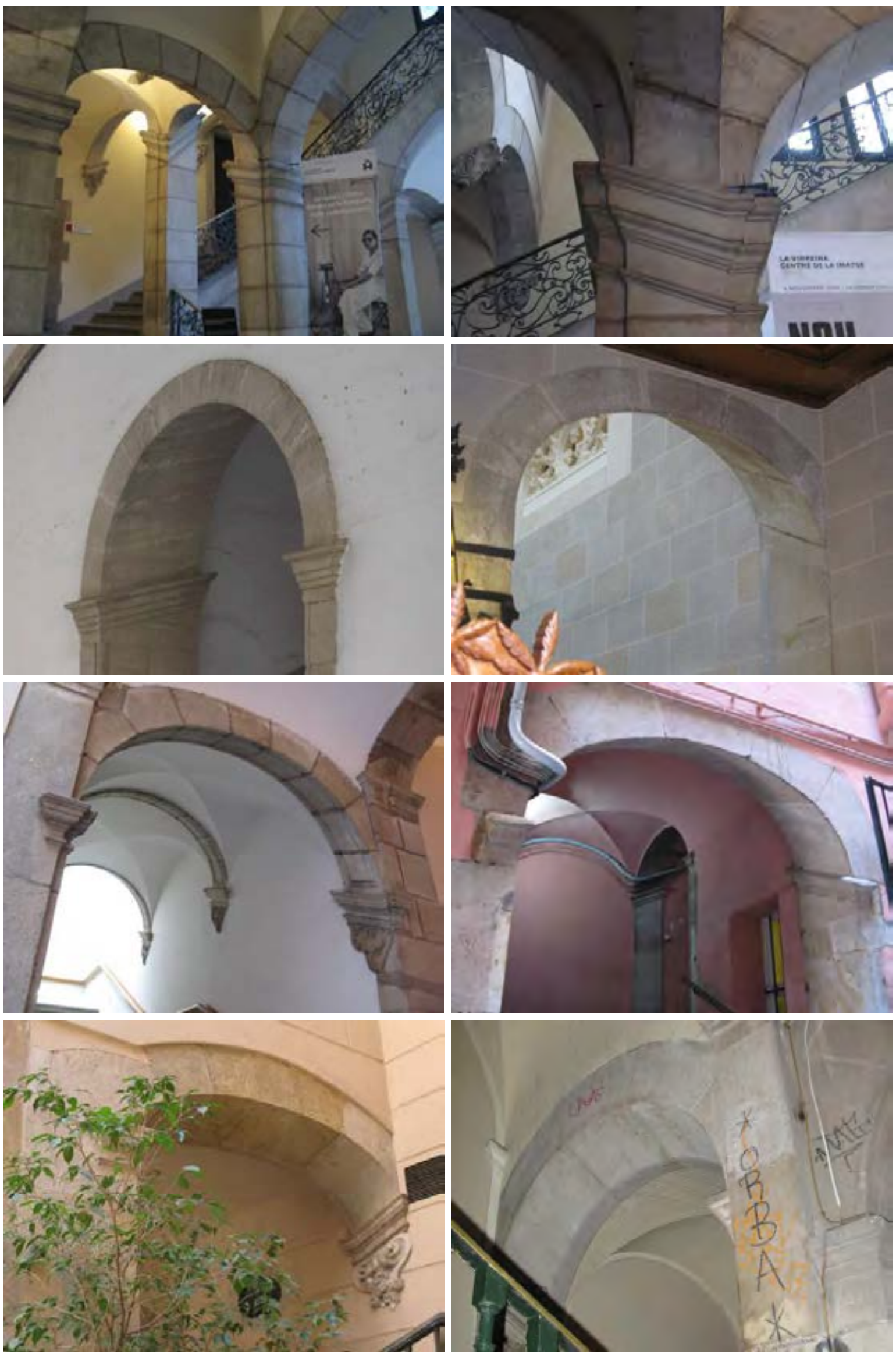

Fig. 4.29. decendas de cava en: Palau de la Virreina (A, B), Barcelona; Universitat de Cervera; Barcelona; Palau Bru, Barcelona; Carrer Moncada 2, Barcelona; Palau Fivaller, Barcelona; Casa Arti i Fabregues, Portaferrissa 17, Barcelona. Fotos del autor. 

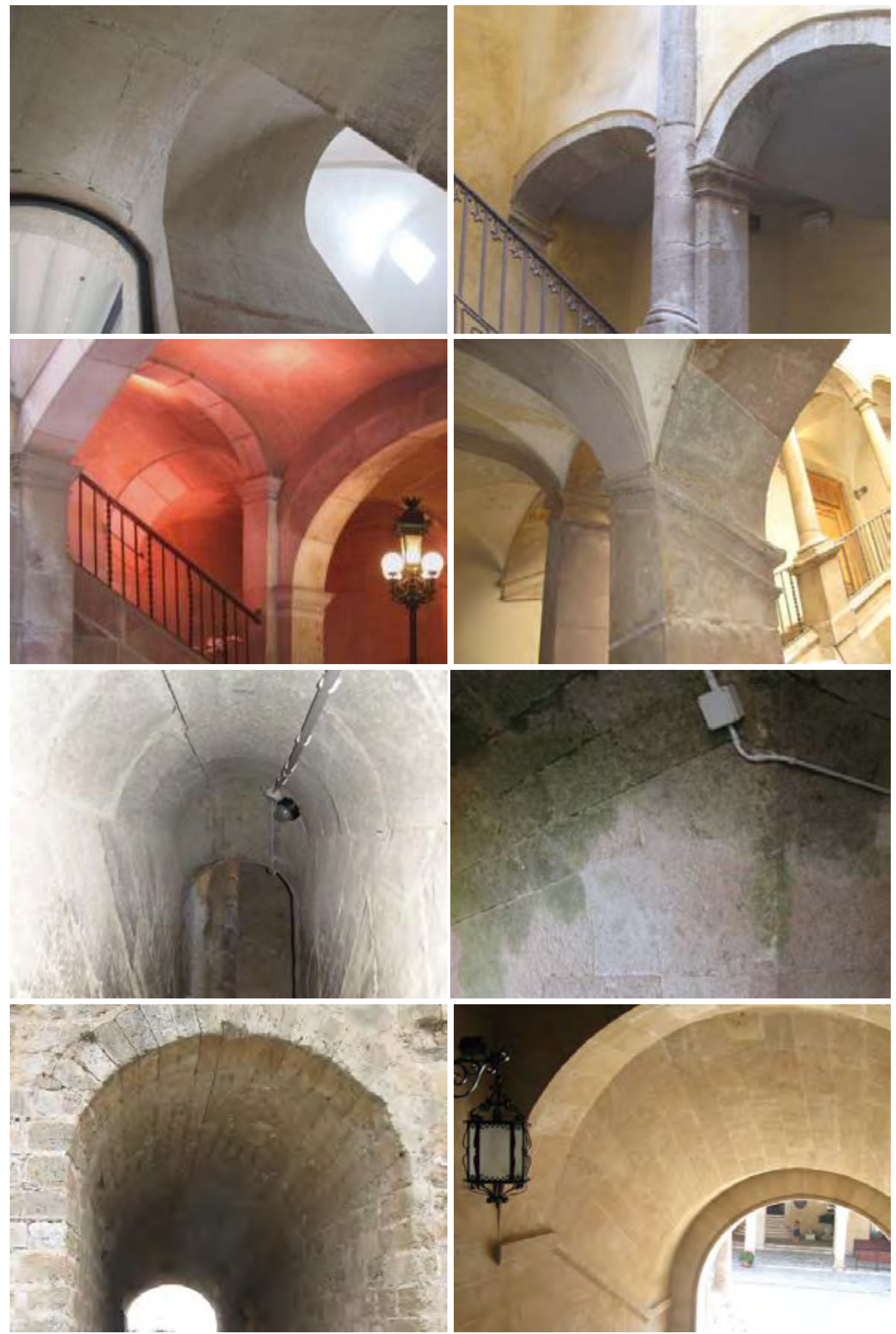

Fig. 4.30.Antic Hospital de la Santa Creu, Tortosa; Pati Llimona, Barcelona; Palau March, Barcelona; Carrer d'Avinyo, Barcelona; Seu de Manresa; Mola de Menorca; Es Baluard, Palma de Mallorca; Palu del Almudaina, Palma de Mallorca. Fotos del autor. 


\subsection{Tercer bloque: arcos con superficie de intradós no cilíndrica}

\section{Los arcos en esviaje}

En la práctica del tracista, el arco oblicuo se origina al perforar oblicuamente un muro con una superficie cilíndrica para crear un portal o un pasaje. Cortando una superficie cilíndrica con dos planos no ortogonales a la generatriz de este, se obtendrán arcos elípticos en los planos de testa. Si al revés definimos antes los arcos sobre la pared como arcos de medio punto, la superficie de intradós que los une no será más un cilindro de revolución. Enlazando las dos circunferencias con una extrusión recta, se originará una superficie de intradós elíptica, una superficie de laboriosa ejecución porque presupone definir una plantilla para cada dovela de una mitad del arco en lugar de un único baivel y, por su mayor singularidad de las piezas, requiere una mayor atención por la catalogación y almacenamiento de las piezas antes de la puesta en obra.

Al aumentar la profundidad del arco, o con esviajes notables, se amplifica también el problema estático: ahora los empujes, siempre perpendiculares a los lechos de las dovelas, se dirigen hacia fuera de la sección del arco, originando lo que ha sido definido el "empuje al vacío”. Es posible resolver el problema estático y facilitar la ejecución de un esviaje con arcos de testa de medio punto enlazando las dos siluetas de cada lado de la pared con una superficie reglada ${ }^{6}$. La superficie reglada formará una "panza", poco visible y desdeñable en arcos de espesor limitado, que es posible eliminar cavando en la superficie del intradós formando entonces una línea de lecho curva. La talla se producirá quitando a un arco recto la cantidad de material necesario para obtener la oblicuidad. La superficie de intradós es una reglada que se genera dividiendo los dos arcos de testa en dovelas de igual dimensión y sucesivamente enlazando los vértices de las líneas de junta de los arcos de testa a cada lado de la pared.

Los lechos de las dovelas del arco son determinados por un haz de planos perpendiculares a la superficie del paramento en el que se abre el arco. De tal manera, aunque el arco tenga una oblicuidad considerable, el comportamiento estructural es igual que un arco recto. Las dovelas se podrían entonces entender como dovelas de un arco recto cavadas en la cara de intradós hasta conformar la volumetría requerida. Los esfuerzos se transmiten perpendicularmente entre las dovelas en su sección resistente, y los extremos, cortados con un considerable ángulo, pero todavía parte de la dovela, no tienen necesidad de ofrecer soporte estructural. Este tipo de arco aparece en los tratados de Philibert de l'Orme ${ }^{7}$ (que llama biais pase) y de Martinez de Aranda, mientras que Vandelvira solo propone el arco oblicuo con las hiladas dispuestas en dirección del eje de la bóveda, sin preocuparse de los problemas estructurales que pueda tener. Casi todos los tratados posteriores contienen ambas soluciones.

\footnotetext{
6 Enrique Rabasa Díaz, Forma y Construcción En Piedra : De La Cantería Medieval a La Estereotomía Del Siglo XIX (Madrid: Akal Ediciones, 2000): 304.

7 Enrique Rabasa especifica como su dibujo es algo incoherente: el texto como la dovela representada en perspectiva caballero explican la talla de las dovelas sustraendo a una pieza de arco recto hasta que se consiga la oblicuidad. En este caso los lechos tienen que ser perpendiculares a los paramentos. Forma y construcción en piedra pag 304
} 


\section{Portal a un biax - Portal a un esviaje}

\section{Folio 13 (Traza 6)}

Esta traza se encuentra casi al principio del manuscrito de Ribes, aunque en esta tesis se ha agrupado al tercer bloque de arcos.

El portal a un biax, que corresponde al Arco en cuadrado y viaje del tratado de Vandelvira y al Viaje contra cuadrado de Cristóbal de Rojas, se conforma con un arco de embocadura circular de diferente diámetro a ambos lados de la pared. Las jambas son una recta y la otra con un esviaje, las líneas de juntas de las dovelas son convergentes al centro del arco de medio punto de la embocadura más estrecha y el intradós es aparentemente una superficie cónica.

La talla de las dovelas se puede obtener por robos. Similarmente al procedimiento del arco peraltado descrito anteriormente, también en este caso es suficiente encontrar solo las aristas de los dos arcos de embocadura, que tienen luces diferentes. Por tanto, se confeccionan primero las plantillas de las caras de testa y de detrás que se aplicarán sobre una dovela recta, luego se marcan las siluetas de los arcos de intradós y se empieza a descantillar y alisar la piedra hasta que sea posible hacer recorrer fácilmente una regla tendida entre las aristas de los arcos de testa recién creados.

Ribes dibuja también las caras de lecho quizás para un mayor control geométrico durante la talla o solo para conocer la verdadera forma de las caras de intradós.

En Cataluña hay un arco carpanel a un esviaje en el Palau Dalmases en Barcelona (Fig. 4.33); otros ejemplos se han encontrado en Mallorca y en Girona; en otro ejemplo en la Catedral vieja de Lleida se puede apreciar la deformación de la moldura.

Bastante singular es el arco a un esviaje de las Ramblas de Barcelona, situado en proximidad del Teatro Principal, que se caracteriza por un intradós constituido por dos superficies cilíndricas distintas parecido al cuerno de vaca doble de Cristóbal de Rojas, solución que evita el alabeo de la superficie de intradós.
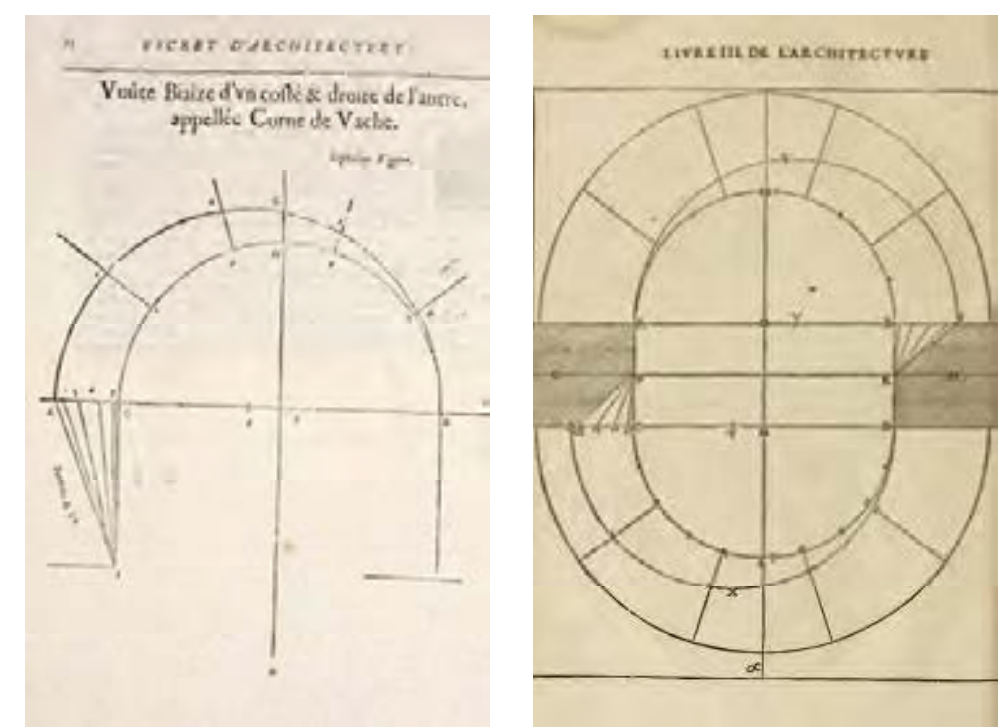

Fig. 4.31. Arco a un esviaje por Jousse; Cuerno de vaca doble por Philibert de L'Horme 


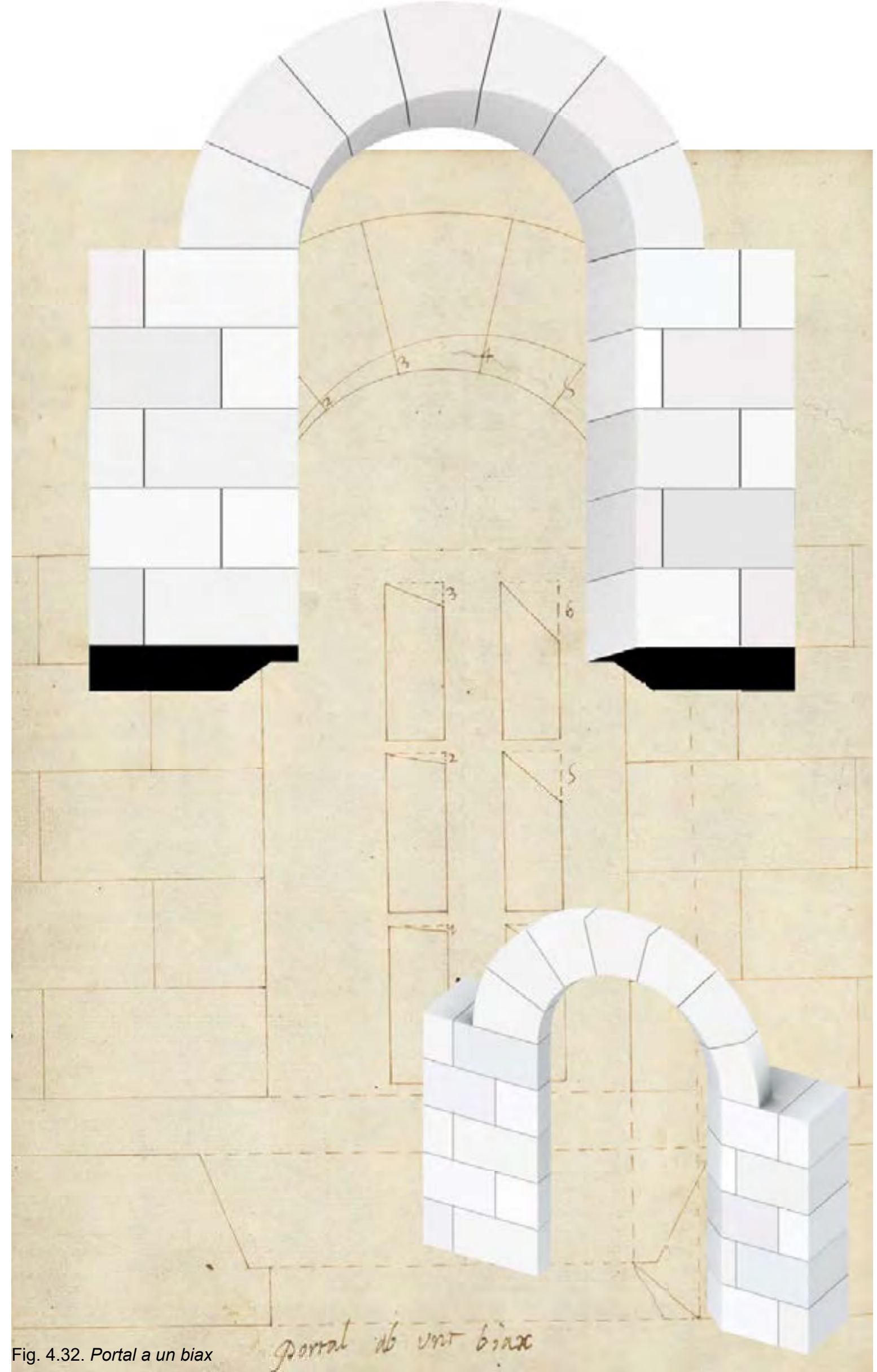



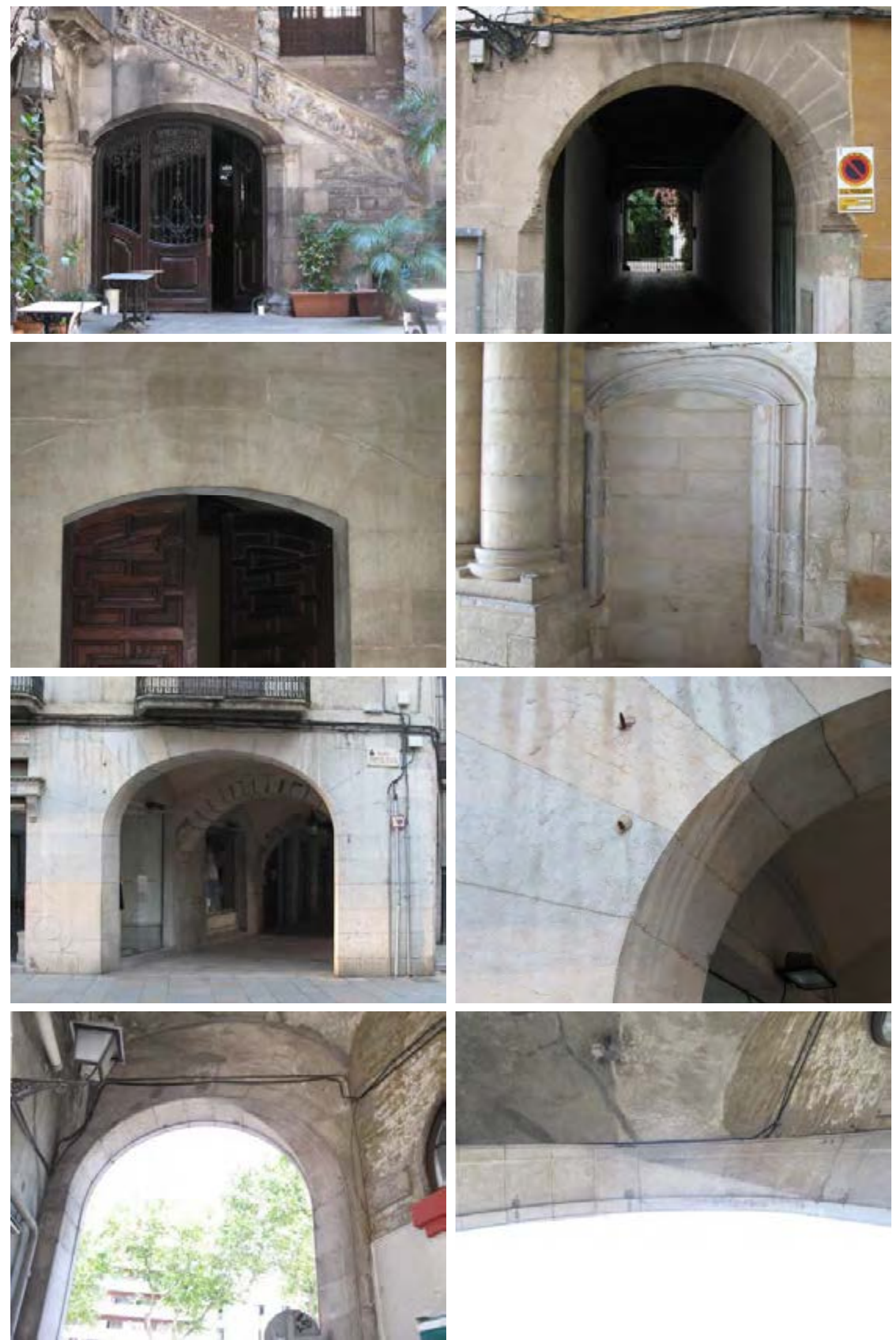

Fig. 4.33. Arco a un esviaje en Palau Dalmases, Barcelona; Mallorca, Catedral Nueva de Lleida; la Catedral Vieja de Lleida; Plaza Mayor (E, F), Girona; Teatro Principal, Ramblas de Barcelona. Fotos del autor. 


\section{Portal biax ab contra biax - Portal en viaje y contra viaje}

Folio 14 (Traza 7)

Este arco tiene las dos embocaduras circulares y el intradós reglado. Aunque formalmente parecidas, desde el punto de vista geométrico es una traza muy diferente del Arch biax per tests ablas bocas iguals (Arco en viaje contra viaje del Folio 223) que tiene también las dos embocaduras circulares, pero con el intradós conformado por una bóveda elíptica, y diferente del Arco biax por testa (Folio 224) que tiene arcos de embocadura elípticos y intradós de la bóveda de cañón recta.

En el Portal biax ab contra biax los planos de lechos de las dovelas se forman a partir de un haz de planos perpendicular a la pared con centro en punto medio de la anchura del hueco. Las dovelas resultarán ser distintas por cada mitad del arco. Similarmente al portal a un biax, la talla de las dovelas se puede obtener por robos. Ribes dibuja las plantillas de los lechos de las dovelas, pero en este caso aprovecha de la simetría del arco para dibujar los patrones de una sola mitad. Para el otro tramo es suficiente rotar de $180^{\circ}$ la plantilla y reutilizarla. El proceso de talla se producirá quitando a un arco recto la cantidad de material necesario para obtener la oblicuidad. Se requiere encontrar primero el sólido capaz de la dovela, delimitado por los planos de los paramentos verticales, los planos de junta y la superficie de intradós, es decir la superficie que conecta la silueta del arco de la cara anterior y posterior, y el extradós del arco. Se definen entonces las aristas de los arcos de las caras de testa y de detrás y se van enlazando las dos siluetas de cada lado de la pared con una superficie reglada.

\section{*sin nombre - Arco en viaje contra viaje}

Folio 142 (Traza 74)

Esta traza representa un arco oblicuo con las embocaduras de arco de medio punto y las juntas definidas por un haz de planos paralelos al eje de la bóveda. Conectando las dos circunferencias con una extrusión recta, se originará una superficie de intradós elíptica, de laboriosa ejecución porque presupone definir un baivel para cada dovela de una mitad del arco.

\section{Arch biax per tests ablas bocas iguals - Arco en viaje contra viaje}

Folio 223 (Traza 119)

Esta versión de arco oblicuo también tiene las embocaduras de arco de medio punto y el intradós conformado por una bóveda elíptica. Ribes dibuja las plantillas de las caras de lecho y las plantillas de caras de intradós. 


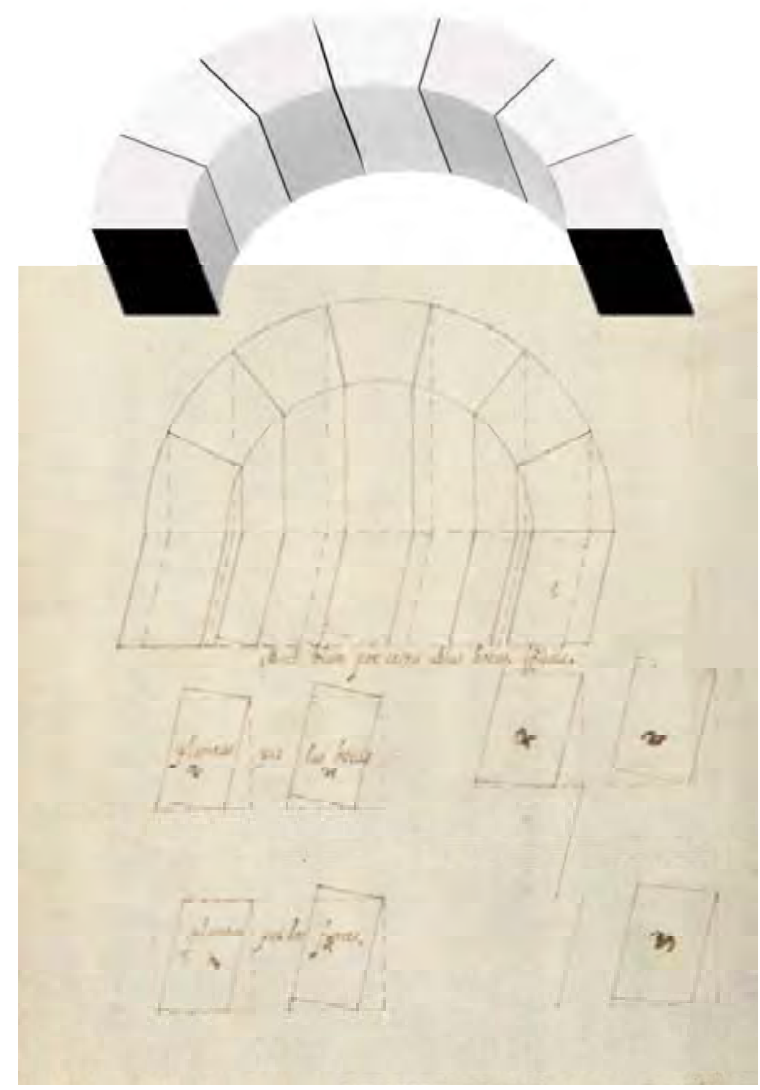

Fig. 4.34. Arco en viaje y contra viaje

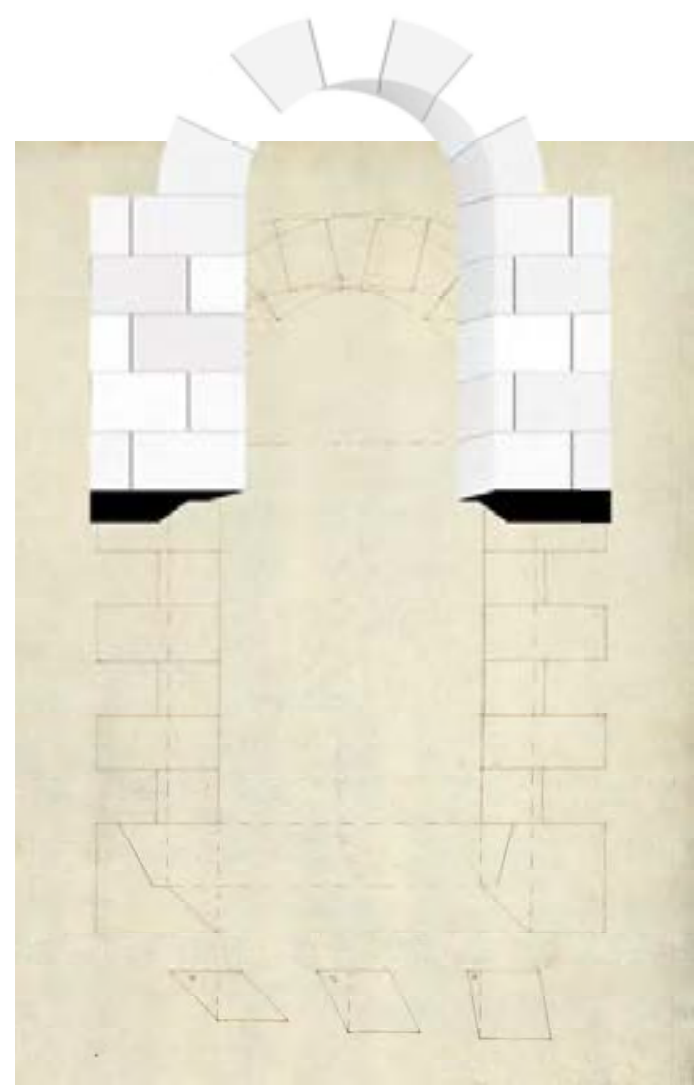

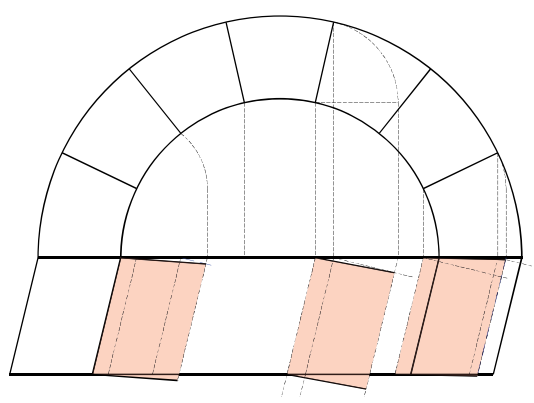

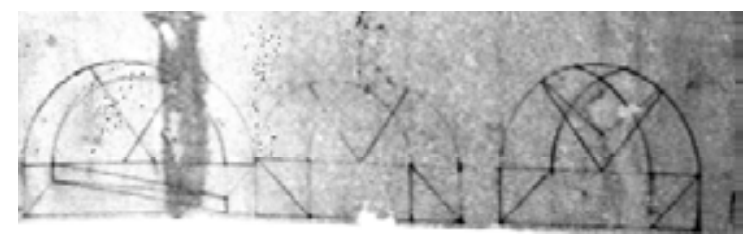

Fig. 4.35. Arcos en viaje en los dibujos del Akademie der bildenden Künste

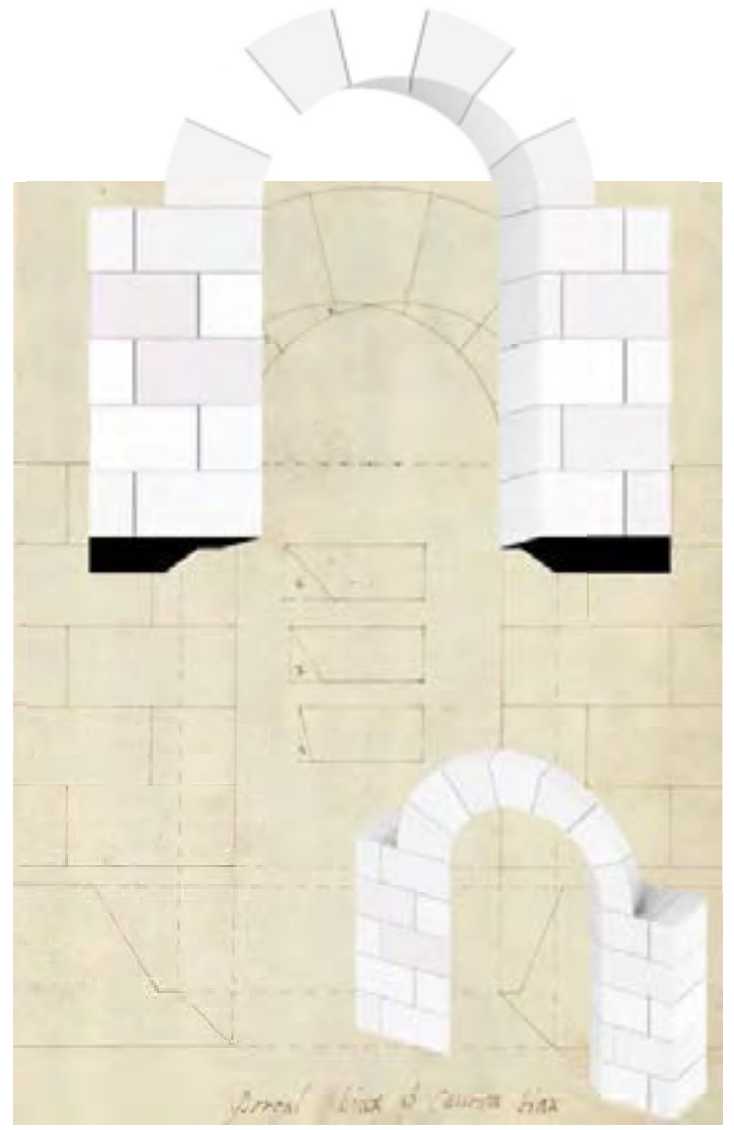




\subsubsection{Notas históricas sobre los arcos oblicuos}

Los arcos oblicuos sencillos se representan por primera vez $z^{8}$ en los apuntes de Villard de Honnecourt (1225-1235) reafirmando su uso y construcción en la arquitectura medieval, aunque sus problemáticas geométricas no eran posiblemente comprendidas. Los tratados de estereotomía renacentistas españoles y franceses desarrollaron con completez las trazas de estos aparejos, aunque los problemas intrínsecos de su geometría se resolvieron solo en el siglo $X I X^{9}$. Trazas de arcos en viaje fueron producidos también en el área germánica, como el arco oblicuo que se encuentra en el corpus de dibujos medievales de la Akademie der bildenden Künste in Wien, Inv.-Nr. 16929, de particular interés por la moldura oblicua de su intradós, o la original serie de arcos en viaje (Fig. 4.35), uno de los cuales describe un arco en viaje generado por arco apuntado, siempre procedentes de la colección de dibujos de Viena ${ }^{10}$.

La construcción de arcos oblicuos caracterizó la arquitectura valenciana de la segunda mitad de siglo XV con las novedosas aplicaciones geométricas de Pere Comte ${ }^{11}$ y Francesc Baldomar y conoció una extraordinaria fortuna en todo el Gótico Mediterráneo ${ }^{12}$.

En Cataluña, en estos siglos, también se fabricaron arcos en esviaje ${ }^{13}$; aunque fue más tarde, ya en los siglos XVII y XVIII, cuando se reveló un particular interés por la experimentación en la estereotomía de este aparejo con soluciones no necesariamente dependientes de la arquitectura más erudita, como la gramática compositiva teorizada por Juan Caramuel de Lobkowitz en su Arquitectura Oblicua, o de la renovación en la estereotomía francesa, pero quizás alimentados por la tradición local ${ }^{14}$. Se manifestaron entonces con toda su fuerza arcos oblicuos, peraltados, rampantes y capiteles suspendidos que fueron caracterizando los patios de las casas burgueses de Barcelona, definiendo un interesante episodio en la cantería catalana. Los arcos oblicuos que Ribes describe representan el vivo interés de aquella época para este elemento arquitectónico y deberían poner en evidencia las raíces medievales que sustentan la estereotomía catalana del siglo XVIII.
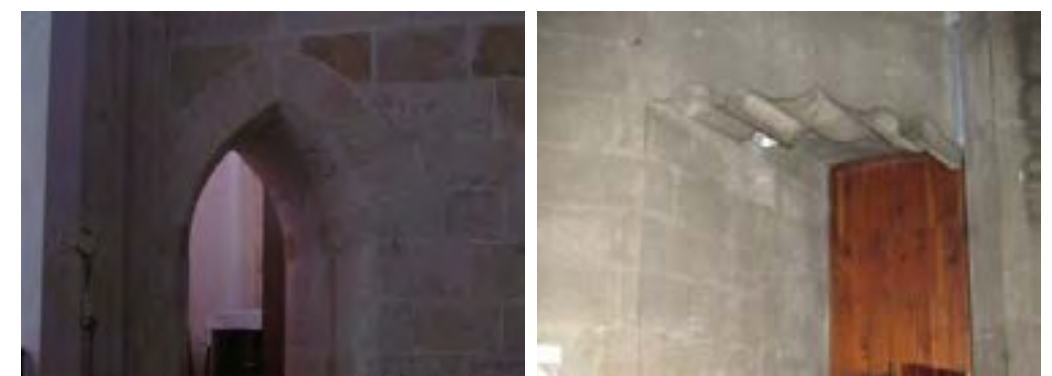

Fig. 4.36. Arcos de directriz oblicua en la Catedral de Ibiza y de Girona. Fotos del autor.

\footnotetext{
8 Los arcos oblicuos aparecieron por primera vez en la arquitectura Imperial Romana en formas "protoestereotómicas" y se pueden recordar los raros ejemplos del arco triunfal de Perugia, el "arco dei pantani" en el foro de Augusto en Roma, la Porta Tiburtina del muro de Aureliano en Roma y un ejemplo en las Arenas de Arles en Provenza.

9 Rabasa Diaz, 1994: 145-154.

10 Publicados en: Johann Josef Böker, Architektur der Gotik/Gothic Architecture. Bestandskatalog der weltgrößten Sammlung an gotischen Baurissen

11 De Pere Comte recordamos los arcos oblicuos del portal de Cuarte (desde 1444); la entrada a la sacristía de la capilla real (h. 1451); las ventanas de la ampliación cuatrocentista de la catedral de Valencia (a partir de 1458) y el acceso al archivo desde la sacristía de la misma catedral.

12 Mira y Zaragozá, 2003: 150-151.

13 Carbonell i Buades, 2008: 114.

14 Pérouse de Montclos, 1982.
} 
El Llibre de traces de biaix y montea de Joseph Ribes 


\section{Bóvedas y bóvedas compuestas}

En este capítulo se van a estudiar las bóvedas de intradós continúo conformadas por superficies de extrusión y revolución. Se incluyen las bóvedas de cañón y de arista, las bóvedas en rincón de claustro y las cabeceras ochavadas, las bóvedas de media naranja y las bóvedas anulares. Ribes aborda diferentes casos de bóvedas de arista y en rincón de claustro y como estas se instalan sobre una planta cuadrada y rectangular, pero también en plantas más inusuales como la trapezoidal, triangular, hexagonal y octagonal.

También hacen parte del capítulo las bóvedas compuestas por la intersección y unión de partes de diferentes bóvedas. Esta serie de trazas tratan determinar las dovelas que se encuentran en la intersección entre dos superficies continuas distintas, afrontan el desarrollo de la esfera y la construcción de superficies tóricas. Aunque haya un generoso número de trazas de bóvedas del Llibre, hay una cierta repetición de aparejos que no aportan nuevas notas de interés. De toda forma, hay una traza bastante única de bóveda en abanico que se estudiará en más detalle.

El desarrollo de superficies cónicas, presentadas en el capítulo de las trompas, es el punto de partida para el desarrollo de las medias naranjas y en este manuscrito las geometrías esféricas se resuelven sólo con el uso de desarrollos cónicos, omitiendo el método de desarrollo por meridianos que se encuentra en otros tratados.

La tradición románica languedociana y catalana basadas en el aparejo de toda la bóveda han dejado un legado importante en la cantería renacentistas ${ }^{1}$ y numerosos ejemplos catalanes perspiran de esta práctica.

\subsection{Bóvedas de arista}

La bóveda de arista se origina con la intersección de dos bóvedas de cañón y se pueden instalar sobre plantas de diferente número de lados configurando y resolviendo correspondientes soluciones espaciales.

La bóveda de arista en planta cuadrada (Bolta per aresta, Traza 24) se conforma por la intersección de dos bóvedas de cañón cilíndricas de luces iguales y de directriz perpendicular la una a la otra. La talla de la porción en cañón no presenta dificultades al ser un arco de medio punto, más atención hay que ponerla en la arista procedente del encuentro de los dos cañones. Con el método de talla por robos, se aplica la plantilla a una de las caras de un prisma en piedra y se procede quitando material. Para la arista se toma un bloque ya tallado en una dirección y se le aplica la misma plantilla en la cara ortogonal. Para el canon se puede utilizar una plantilla para todas las dovelas, para la arista cada hilada requiere una plantilla correspondiente.

1 Philippe Potié, Philibert de L'Orme : Figures de La Pensée Constructive (Marseille: Editions Parenthèses, 1996): 19. 
A seguir en el tratado se encuentran bóvedas de arista en plana triangular, que se desarrolla con el mismo procedimiento, y bóvedas en planta rectangular. Para la capilla perlongada, una bóveda que conforma la arista es de canon circular, la otra por tener al clave a la misma altura con un ancho diferente será elíptica. En este caso para conformar el cañón los patrones de la bóveda elíptica serán diferentes para cada hilada.

Entre los ejemplos hay una bóveda en planta circular que mas no es que una bóveda en planta cuadrada con los extremos de la bóveda perfilados sobre una planta circular, que va a producir arcos en torre redonda que ya han sido desarrollados en el capítulo dedicado a los arcos. Esta serie termina con una bóveda de arista con lunetos de arcos apuntados y una bóveda de arista que es rematada en un lado con arco disminuido.

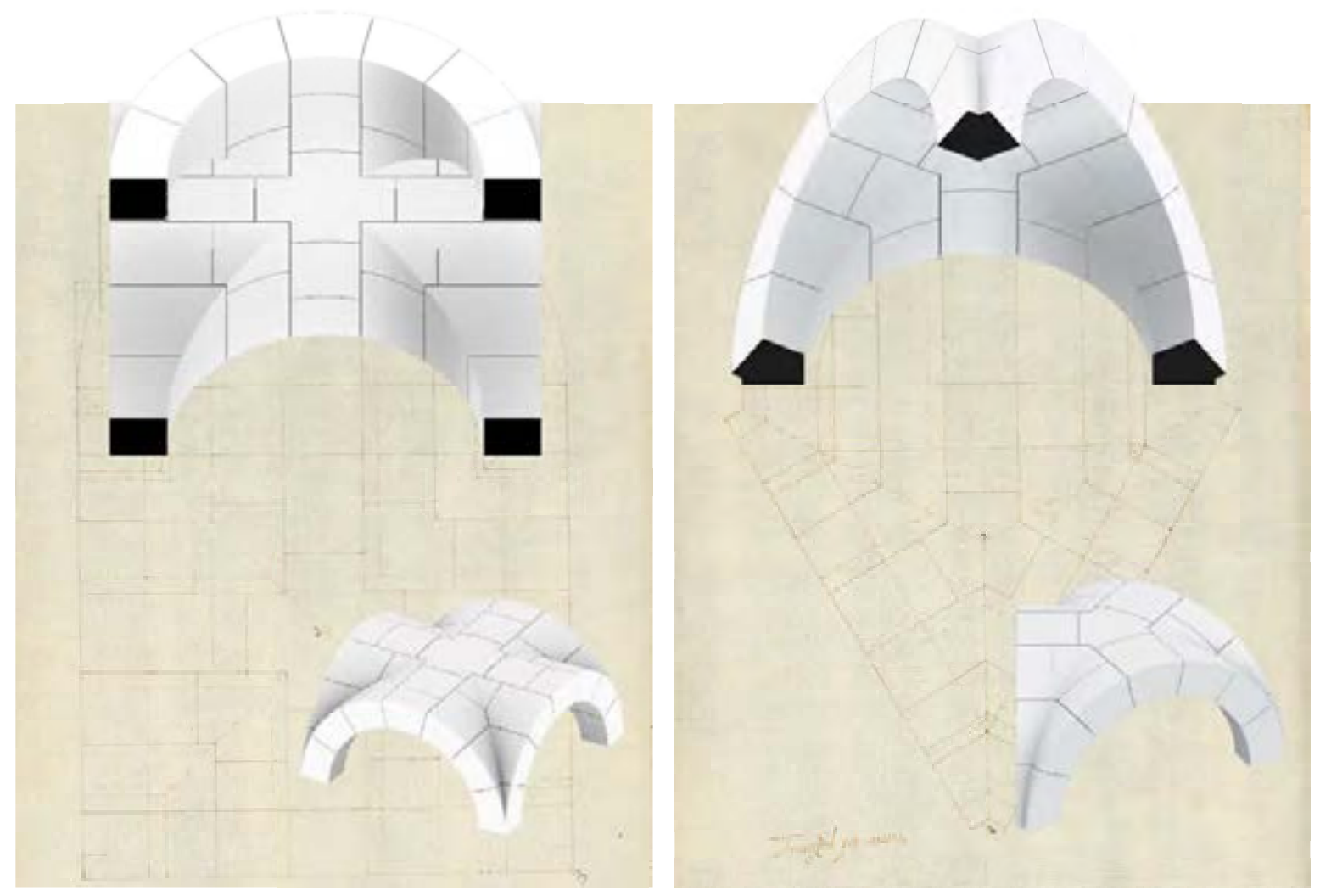

Fig. 5.1. Bovedas de arista en planta cuadrada y triangular en el Llibre de trasas. Dibujo del autor.
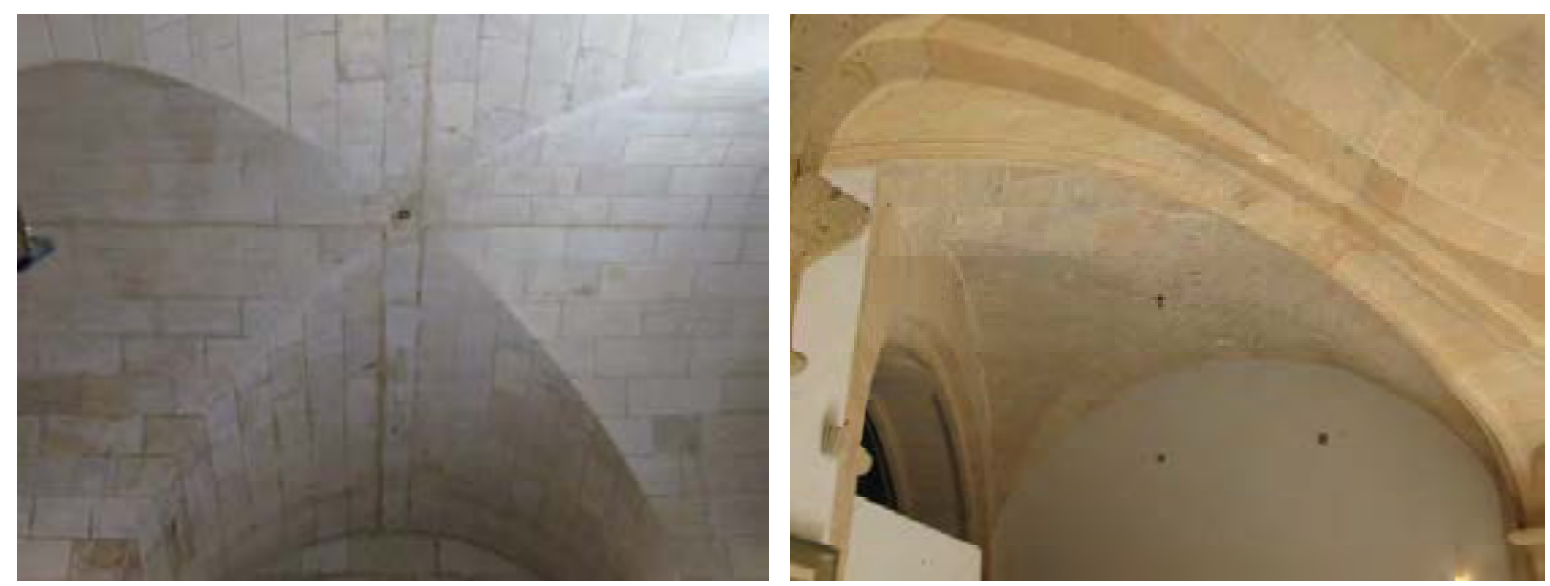

Fig. 5.2. Bovedas de arista en el Palau Robert, Barcelona y en el Pati de Sant Antoni, Palam de Mallorca. Fots del autor. 

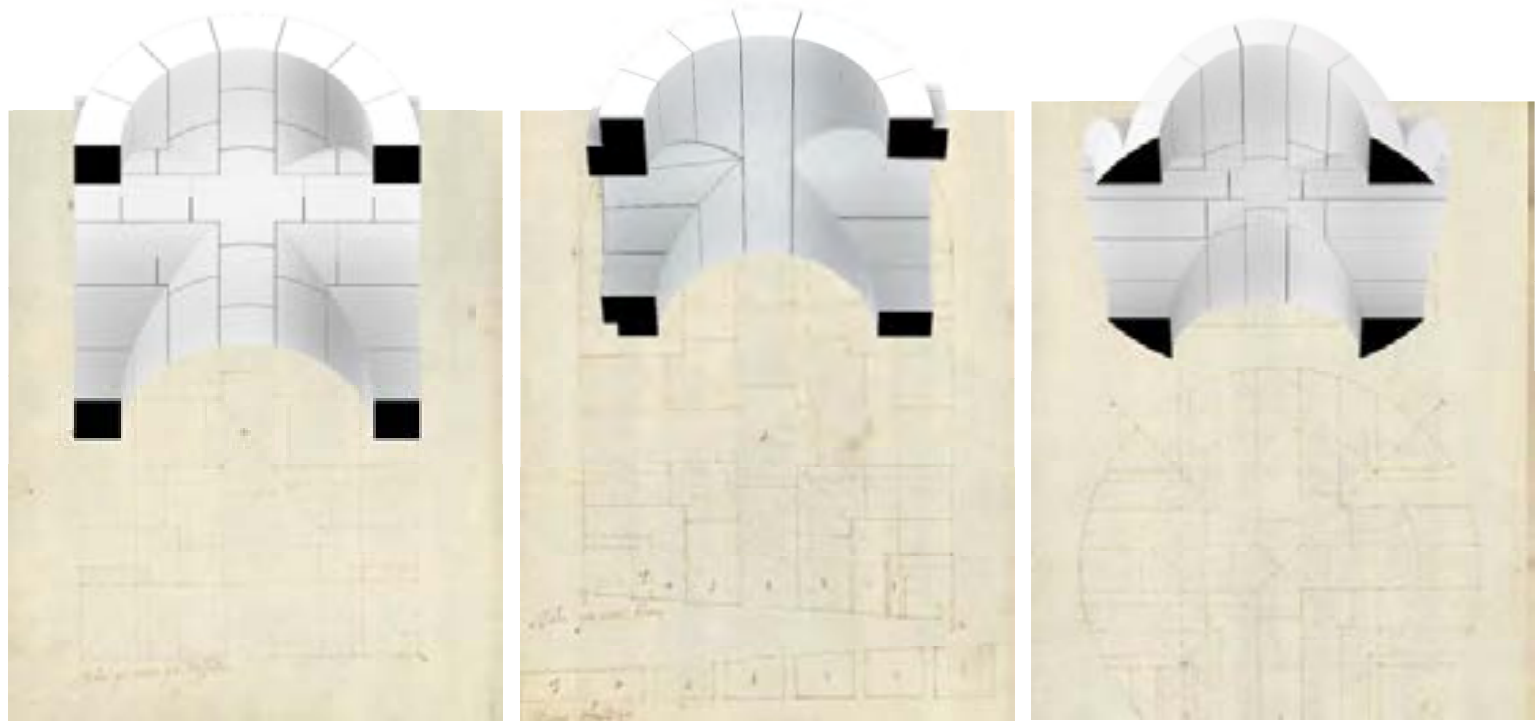

Fig. 5.3. Bovedas bde arista en planta rectangular y diferente configuracin de los lunetos. Dibujo del autor.
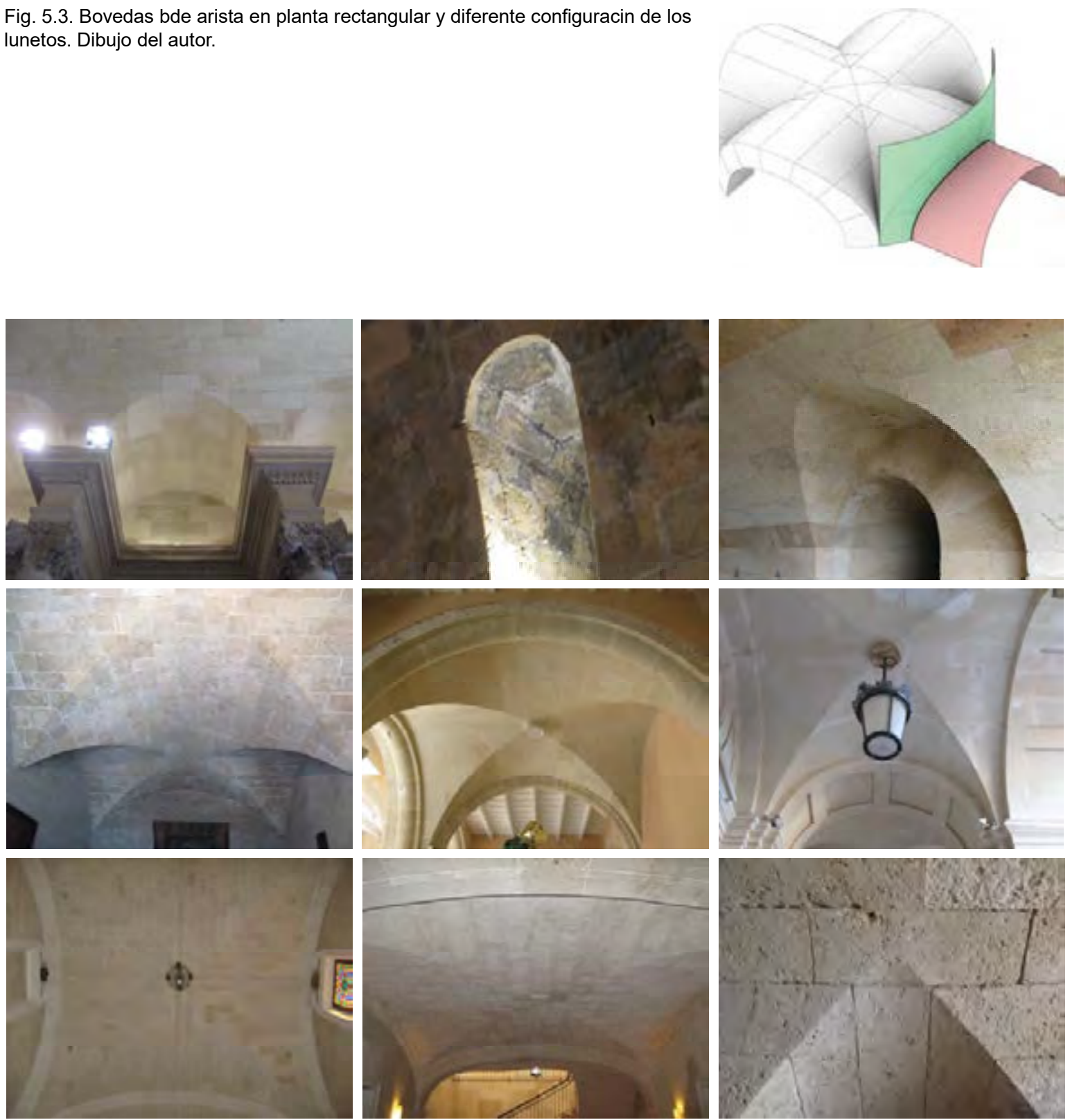

Fig. 5.4. Bovedas de cruceria y lunetos en: Palau Robert; Catedral de Tarragona; Mola de Monrca; Palau de l' Almudaina y casco historico de Palma de Mallorca; Menorca (F, G, H, I). Phoos del autor. 


\subsection{Bóvedas en rincón de claustro}

La bóveda en rincón de claustro sobre planta cuadrada, llamada bolta de postexa (Traza 33) en el Llibre de trasas, viene definida por la intersección de dos cilindros considerando el espacio común interior a ambos ${ }^{2}$, el encuentro entre los cilindros es en este caso entrante y la línea resultará alabeada. Ribes aborda diferentes configuraciones de la bóveda en rincón de claustro cambiando el tipo de planta que cubren, incluyendo triángulos, rombos y trapecios (Fig. 5.6 y 5.8). Para la talla de las dovelas, se definen primero sobre un prisma de piedra los límites del intradós marcando las aristas inferiores y el rincón en vertical, luego con baivel con la curvatura de la bóveda de cañón se talla hasta encontrarse en la diagonal, teniendo cuidado a no cometer errores en el encuentro. Ribes dibuja plantillas para comprobar la curva del rincón.

La bolta bivitavada ab pasteza (Traza 35) es la traza de un ochavo, que son bóvedas que cubren una planta octagonal y tuvieron un cierto éxito en el renacimiento para conformar ábsides. Se encuentran también cubriendo capillas y salas de torres y campanarios. Para la talla es necesario encontrar los patrones de las caras interiores y seguir las pautas de las bóvedas en rincón de claustro. Por simetría es suficiente desarrollar una de sus caras.
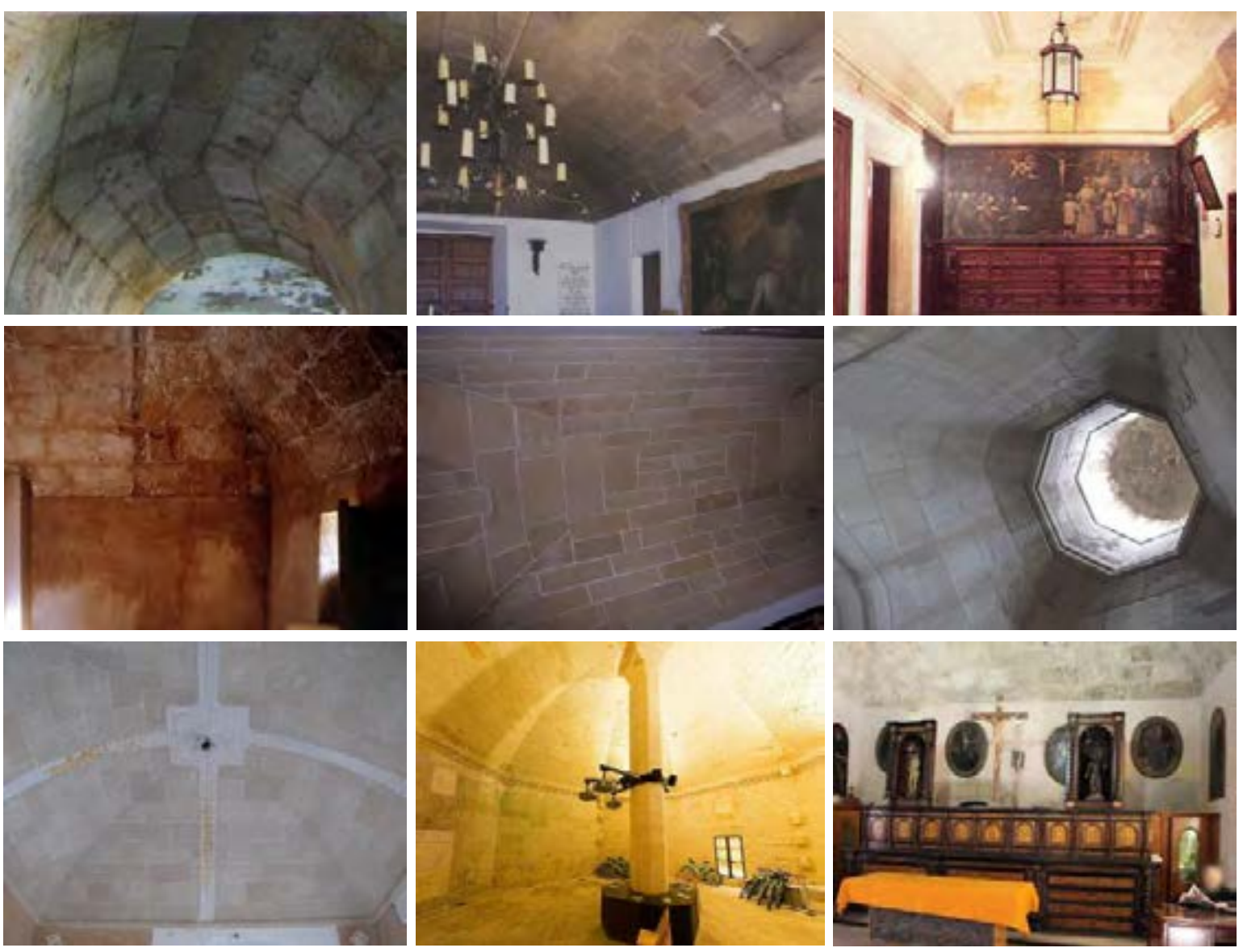

Fig. 5.5. Castell de San Nicolau, Menorca; S'Estaca, Valldemosa (foto publicada en Casas señoriales de Mallorca); Sant Bonaventura, Llucmajor; Museu dels molins, Palma de Mallorca (foto de Duccio Malagamba); Iglesia parroquial de Campos; monumento funerario en el Cementerio de Barcelona; Claustro del Mercat del Carme, Maó; Castell San Nicolau, Ciutadella de Menorca; Sagrestia San Francesco, Alghero (foto de JoJan - CC BY 3.0 Wikimedia Commons). Fotos del autor.

2 Rabasa, 2011: 156. 

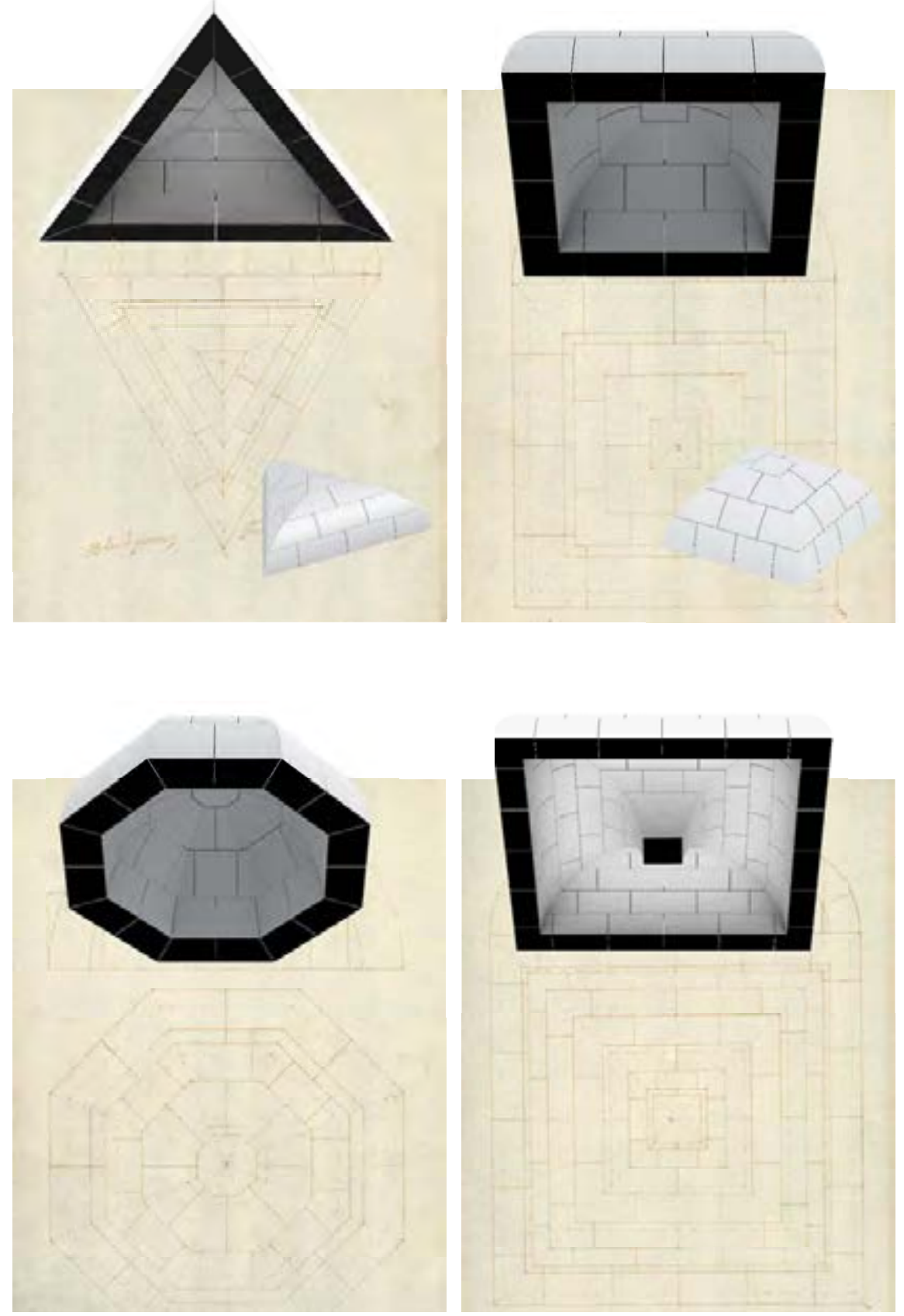

Fig. 5.6. Bóvedas en rincón de claustro en planta triangular, cuadrada, octagonal y en directriz cuadrada. Dibujo del autor.
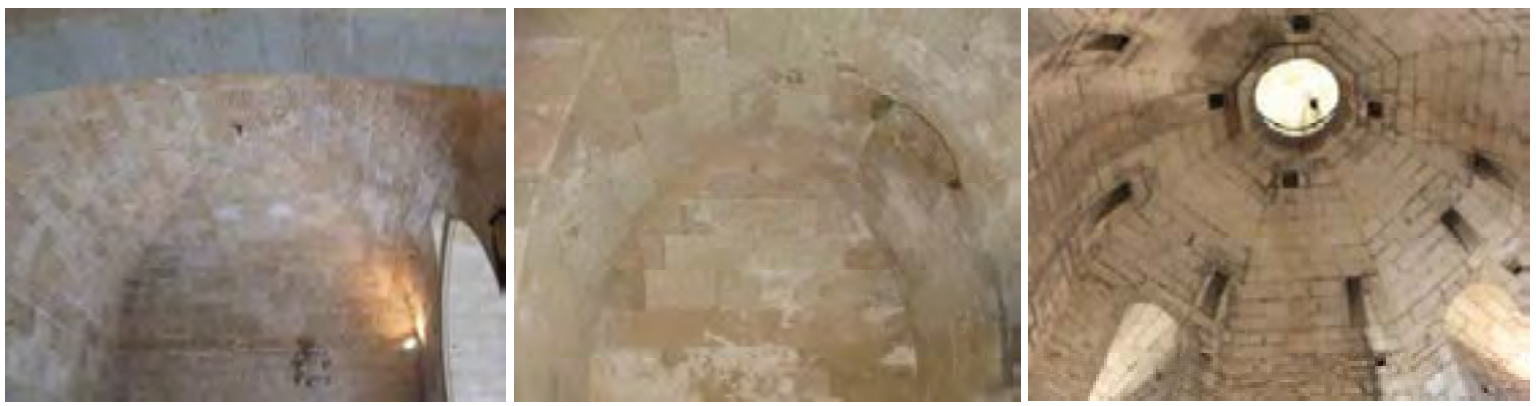

Fig. 5.7. Palau del Amudaina, Palma de Mallorca; Mola de Menorca (foto del autor). Campanario Iglesia del Pi, Barcelona (foto de https://www.ceetiz.fr/barcelone/billet-pour-basilique-santa-maria-del-pi). 

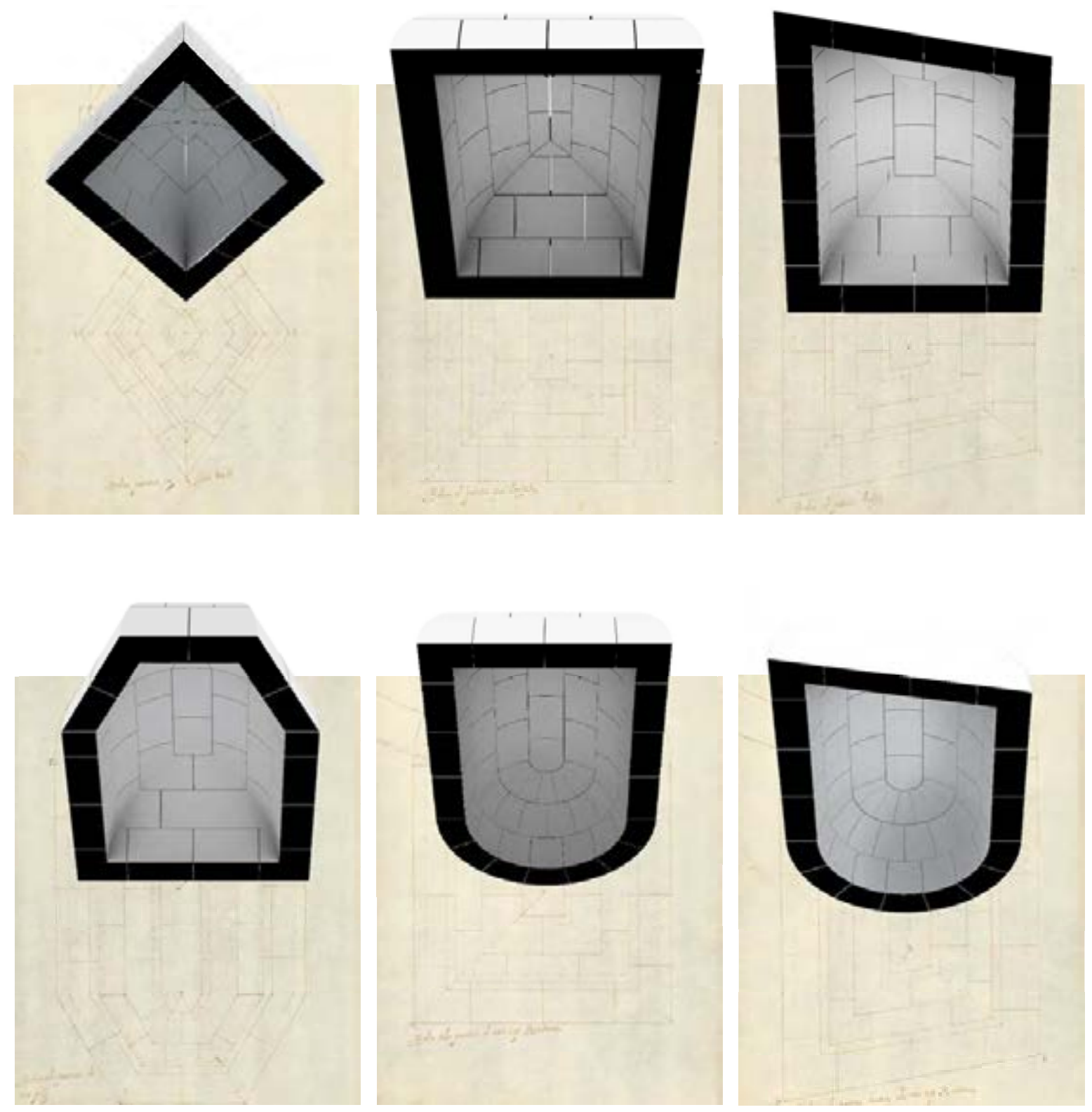

Fig. 5.8. Bóvedas en rincón de claustro compuestas. Dibujo del autor. 


\subsection{Bóvedas en vuelta de horno (esféricas y de directriz curva)}

En este grupo se incluyen las bóvedas originadas por superficies de rotación de un arco de circunferencia alrededor de un eje o de directriz curva. Las dovelas están dispuestas en hiladas paralelas

\subsubsection{Bóvedas esféricas}

Sobre el desarrollo de la bóveda de media naranja se basa prácticamente toda la estereotomía renacentista. Ribes describe la bolta ab pastera rodona (Bóveda de torre redonda, Traza 45) y desarrolla con las superficies cónicas (Fig. 5.10). Se encuentra primero la superficie aproximada a la esfera dibujando las superficies cónicas que se adaptan para cada hilada que desarrollándose van a conformar la proyección de cada hilada sobre la respectiva superficie cónica. Para la talla de las dovelas, hace falta el patrón de intradós ser flexibles para adaptarse a la superficie esférica y el baivel con una cara recta orientada hacia el centro de la esfera y la otra cortada con la curvatura del intradós. Al ser determinadas por superficies cónicas, las dovelas van a tener el plano de lecho inferior convexo y el superior cóncavo. De un bloque de piedra que contiene la dovela se obtiene la aproximación a la cara interior cuya curvatura que viene comprobada con el baivel perfilado.

Al seccionar una media naranja con los planos verticales que corresponden en planta al cuadrado inscrito, se obtiene una bóveda baída que se distingue de la media naranja por la particularidad de asegurar el pasaje de la planta cuadrada a la forma circular.

El dibujo de las plantillas de las dovelas de la bóveda baída no es diferente de la bóveda hemisférica. Las hiladas del casquete superior, eso que está por arriba de los muros no tiene particularidades, para determinar las cuatro pechinas se empieza desarrollando las hiladas de cada dovela y luego llevando la longitud de las juntas horizontales se conforman las siluetas laterales.

Muy parecidas a las bóvedas baídas, las bóvedas escarzanas tienen la sección de superficie conformada por un arco escarzano y permiten rebajar la altura de la clave mediante la traza de una superficie esférica que tiene su centro por debajo del plano de imposta. Recordamos los ejemplos de gran interés en la ampliación de Pere Blai en el Palau de la Generalitat de Cataluña en Barcelona, los pórticos de la Lonja de Barcelona y de la Catedral Nova de Lleida. Las bóvedas escarzanas del Palau de la Generalitat (Fig. 5.12) se encuentran en el vestíbulo que se abre hacia la plaza de Sant Jaume. El espacio está cubierto en su tramo central por tres bóvedas baídas elípticas y en las dos galerías que lo flanquean respectivamente por lado con dos bóvedas baídas circulares y una elíptica. El diseño está relacionado con las bóvedas del sotocoro de la iglesia del Monasterio de El Escorial por la visita que Pere Blay hizo en Madrid en 1597. El enlace entre la imposta de las bóvedas y el remate de los pilares se hace a través de pechinas, como en la traza pechina para capilla oval de Vandelvira.

Las bóvedas baídas de la Lonja de Barcelona (Fig. 5.13) fueron construidas con la reforma de Juan Soler i Faneca (1771), cubriendo el porticado que fue concebido como entrada principal. Los casquetes, de intradós aparentemente esférico y muy rebajado por encima 

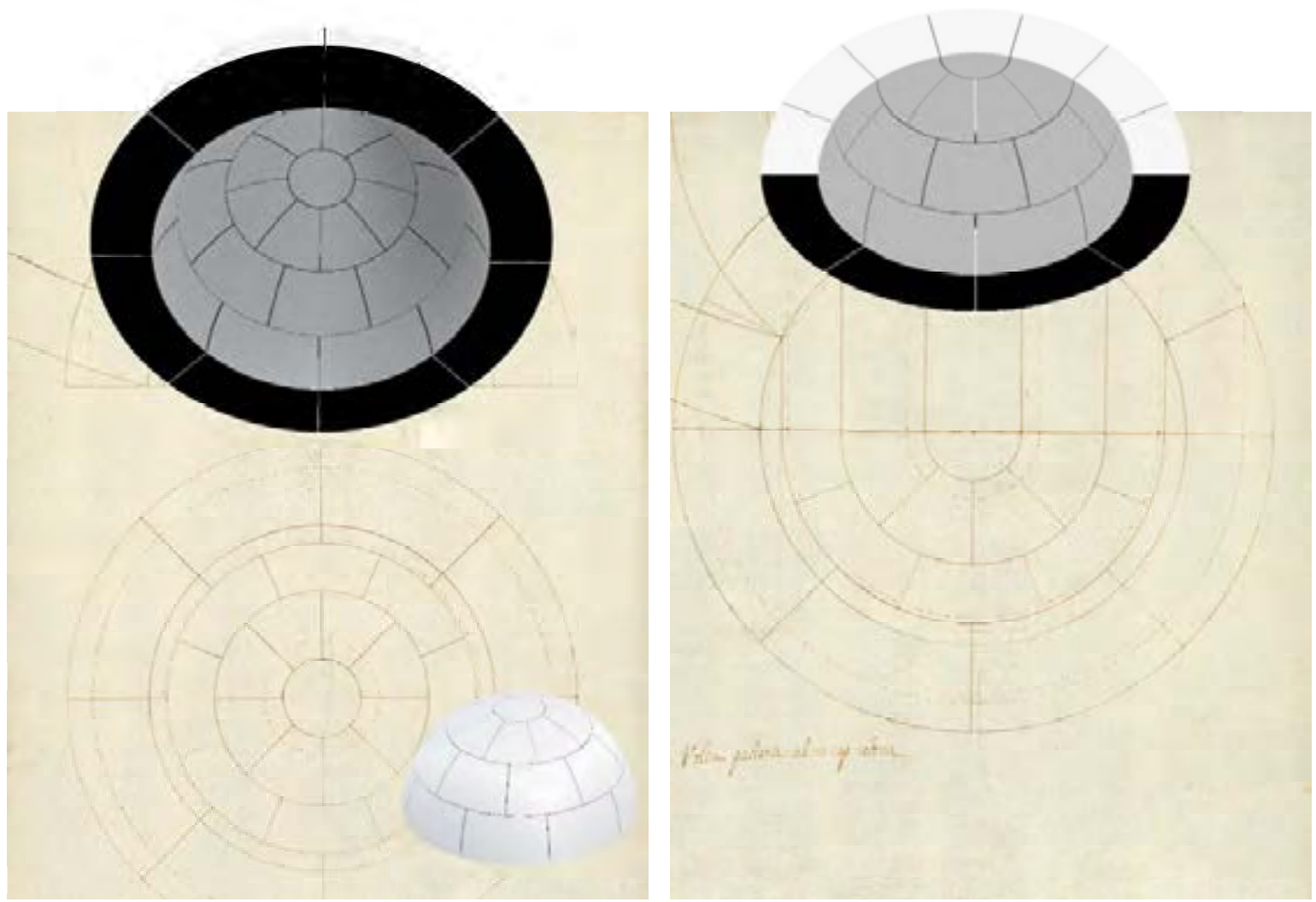

Fig. 5.9. Bóvedas esfericas. Dibujo del autor.

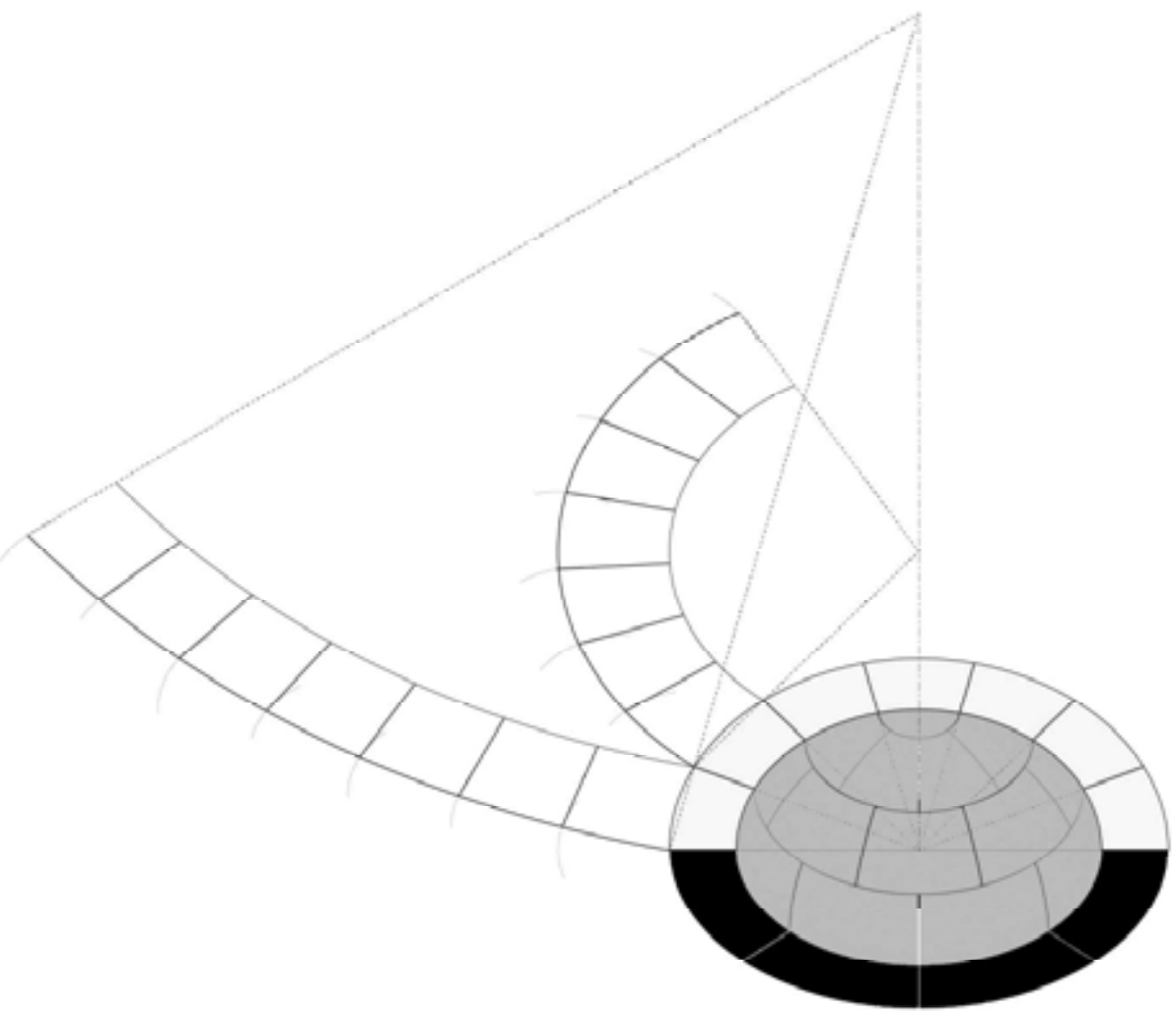

Fig. 5.10. Desarrollo bóveda esferica. Dibujo del autor. 
de la clave de los arcos fajones, se instalan en los extremos del pórtico sobre una planta rectangular y en los tramos centrales en una planta de proporción más cuadrada. Las pechinas resuelven la transición sin solución de continuidad entre el casquete y los soportes verticales. Una situación similar se puede observar en el pórtico de la Catedral Nueva de Lleida cubierto por bóvedas escarzanas. Los casquetes esféricos se insertan en una planta rectangular muy elongada que determina una visible diferencia de cota en los arranques de los arcos desde los muros perimetrales.

Podemos constatar que las bóvedas baídas en Cataluña están asociadas al lenguaje de la estereotomía clasicista y castellana. Las bóvedas de Pere Blai fueron construidas durante el Renacimiento según el modelo del Escorial y los ejemplos de la Lonja de Barcelona y de la Catedral Nova de Lleida son de estilo clasicista.

\subsubsection{Bóvedas ovales}

Cuando la bóveda tiene que adaptarse a una planta rectangular se puede seguir utilizando una bóveda de superficie esférica (Fig. 5.14) que tendrá arcos de imposta de altura diferente por los lados cortos y largos de la planta. Los óvalos y en mayor medida las elipsis se pueden insertar con precisión dentro un rectángulo muy elongado y mantener las impostas a la misma altura, permitiendo de esta manera una transición más proporcionada con los soportes verticales. La traza de la bóveda planta oval no está contenida en el Llibre de trasas.y es de escasa difusión en España, sin embargo tienen una presencia de resguardo en Cataluña por la obra de Pere Blay que se ha citado antes.

A la hora del planteamiento de una bóveda oval, el tracista debe tener en cuenta algunas consideraciones geométricas para determinar el tipo de curva de la planta (ovalo o elipsis) y su volumetría. No hay elipses paralelas, facto que se puede observar en las bóvedas de la Generalitat de Cataluña donde hacia la terminación del eje mayor las juntas se alejan y dilatan notablemente. Las juntas radiales, que tienen que mantener la perpendicularidad con las juntas horizontales, no están orientadas a la misma dirección si observamos mismos sectores de hiladas distintas. Sobre una planta elíptica se instalan entonces elipsoides de traza muy dificultosa, por otro lado, si la bóveda es un ovalo, la cascara es una composición de trozos de superficies semiesféricas. En una cúpula oval, las juntas horizontales son de ancho constante.

Otras bóvedas ovales en Mallorca (Catedral de Palma y castillo del Bellver) y Menorca (Catedral de Mahón y algunas salas de la fortaleza de la Mola) se instalan sobre espacios de planta oval y no requieren pechinas. 


\subsubsection{Trompas esféricas}

Bajo la gran familia de bóvedas originadas por la media naranja se pueden también agrupar las trompas esféricas y las hornacinas, construidas en Barcelona generalmente del siglo XVIII en adelante, que aparecen con diferentes tipos de dovelaje (Fig. 5.16,17,18). Podemos clasificar diferentes diseños: hay ejemplos con dovelas convergentes al punto medio situado en la imposta del cuarto de esfera que resemblan el despiece de las trompas clásicas, otras dispuestas en vuelta de horno como las bóvedas de media naranja; disposiciones de dovelas las hiladas por meridianos, o sea que giran alrededor del eje vertical; bóvedas con hiladas verticales girando alrededor del eje horizontal; y de despiece por hiladas paralelas al eje vertical de la esfera. En la Lonja de Barcelona (Fig. 5.11) se pueden ver cuatro despieces diferentes en los aparejos de las hornacinas que corresponden a cada rincón del patio. Son muy notables también los colosales ábsides aparejados con despiece convergente de las iglesias de Menorca.
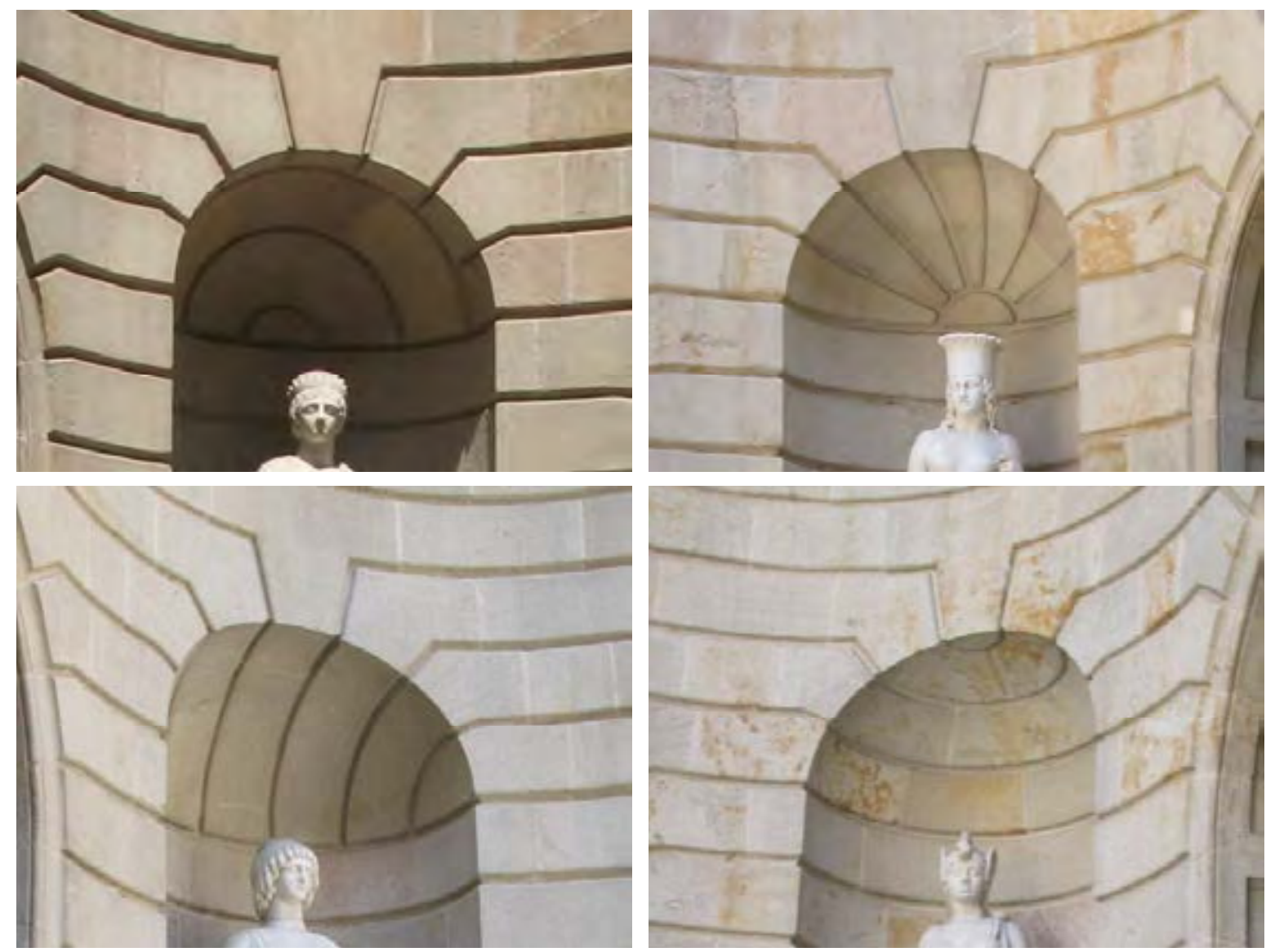

Fig. 5.11. Bóvedas esfericas de distinto despiece en el patio de la Lonja de Barcelona. Fotos del autor. 

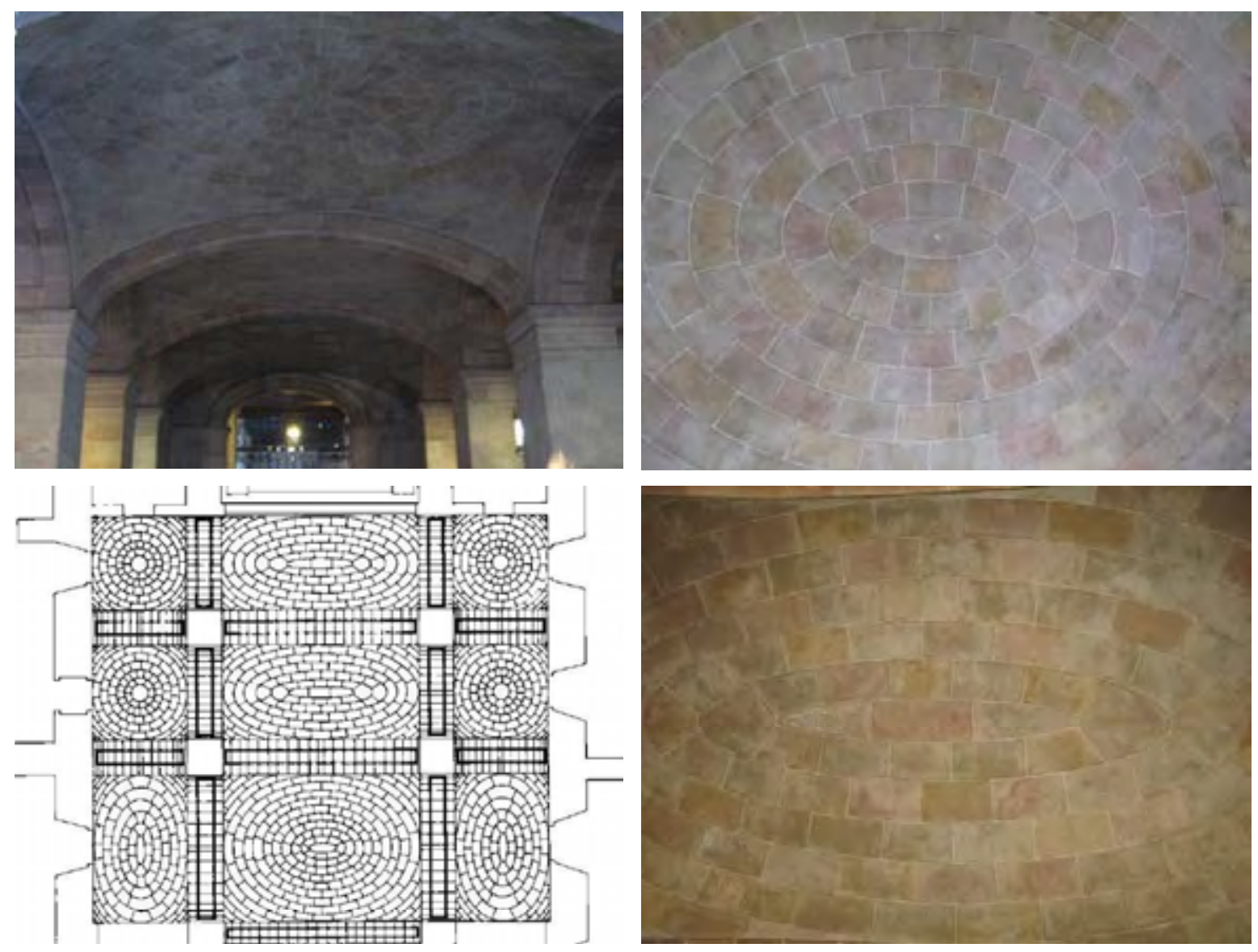

Fig. 5.12. Bovedas baidas de Pere Blay en el Palau de la Generalitat de Catalunya (fotos del autor). Planta del techo de las caballerizas.

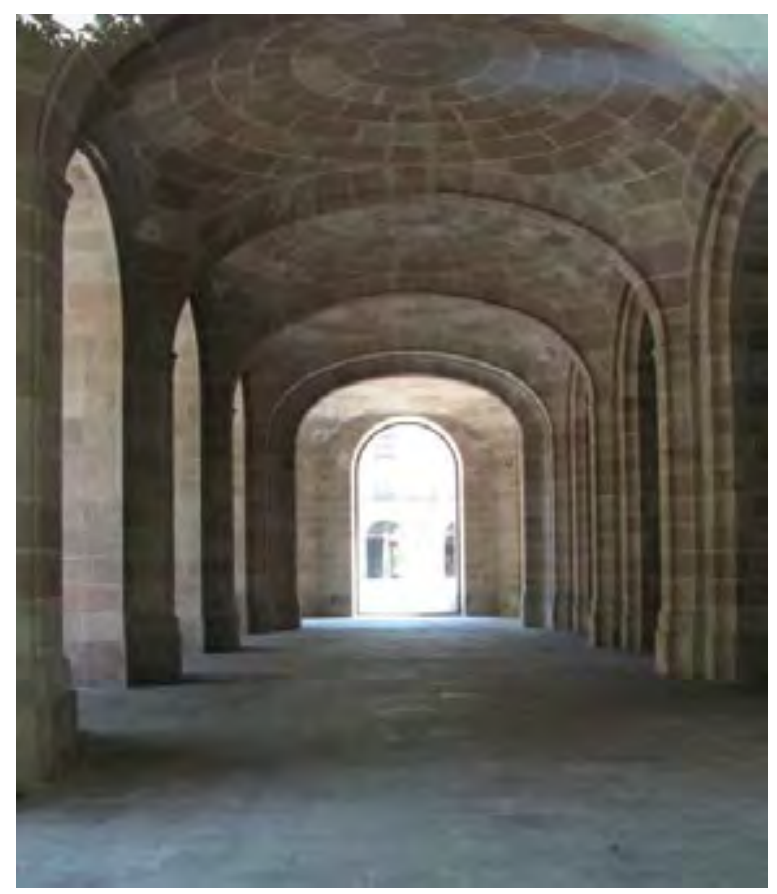

Fig. 5.13. Portico de la Lonja de Barcelona. Foto del autor; Detales de las bovedas. Fotos publicadas en Llotja oberta y en La casa Llotja de Mar de Barcelona
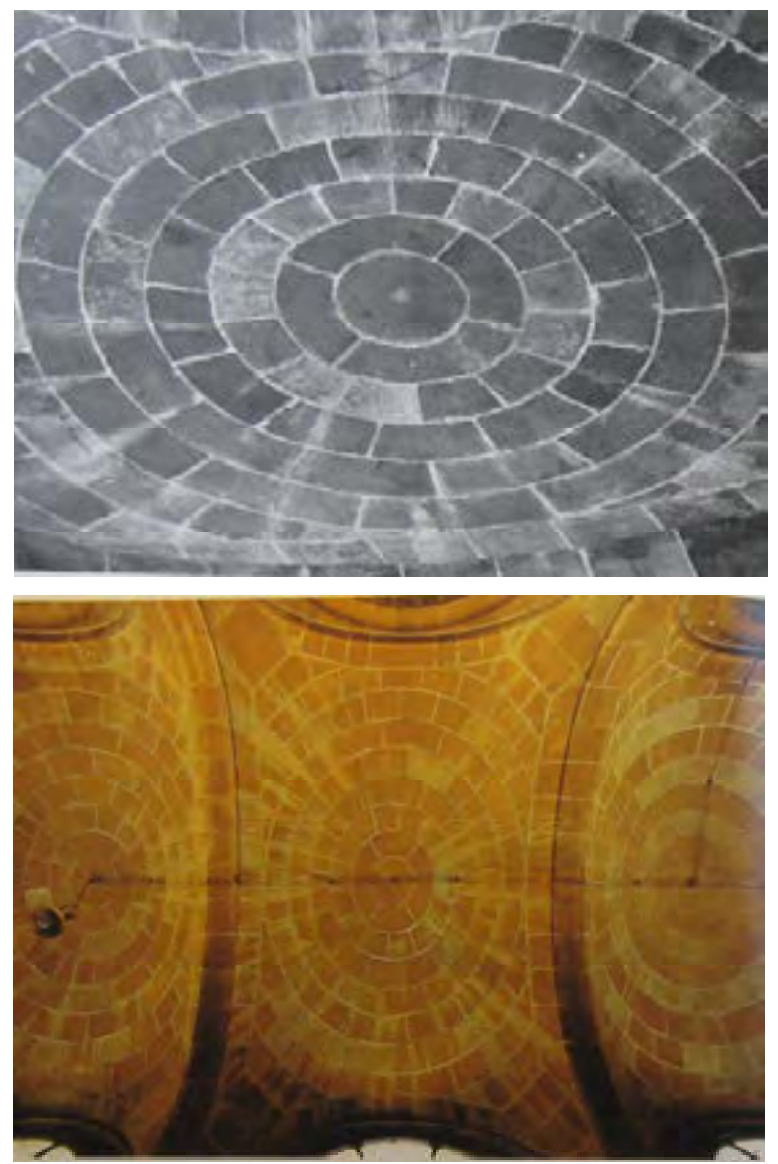

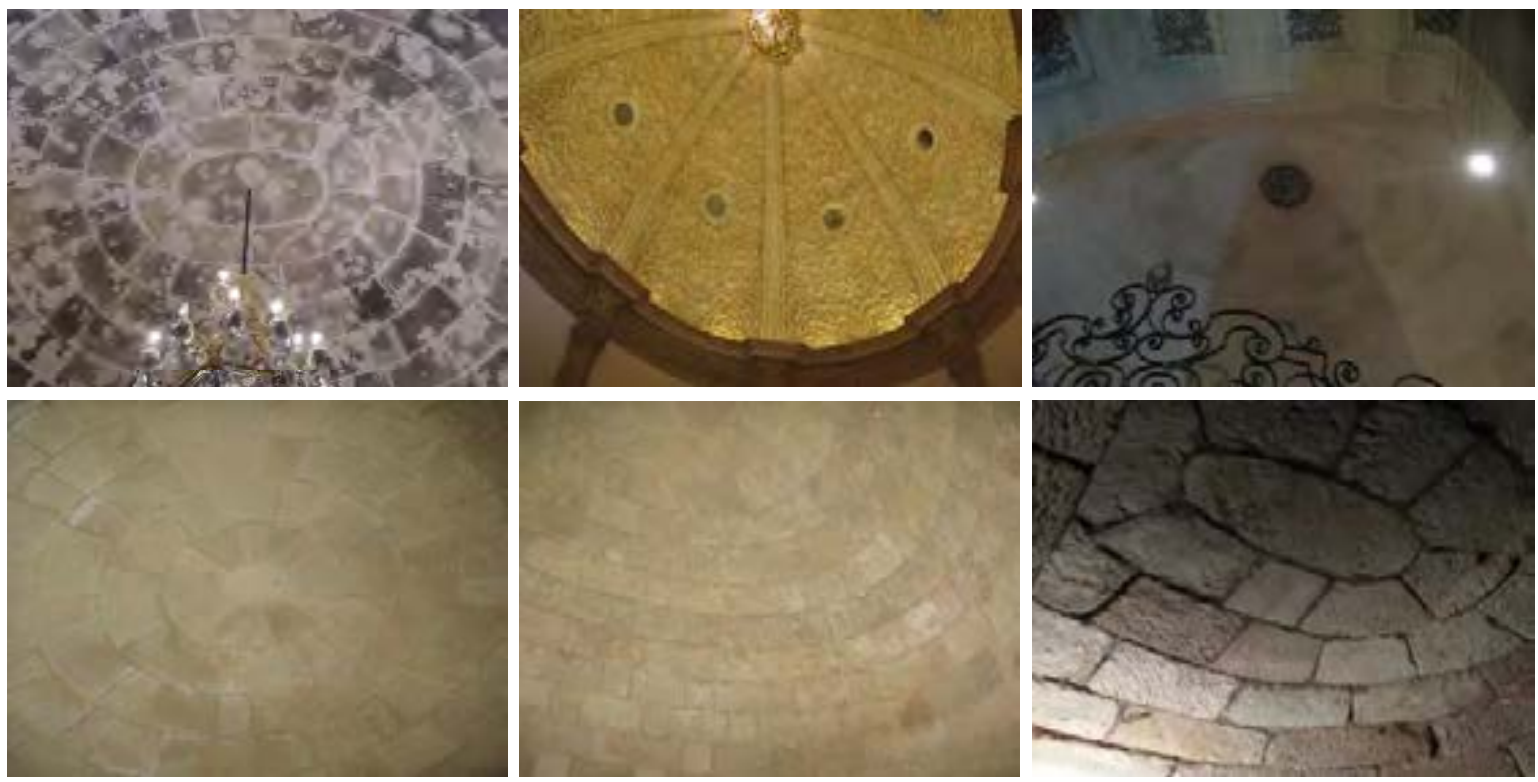

Fig. 5.14. Bovedas baidas en planta elíptica. Castillo de Bellver; Catedral de Palma de Mallorca; Santa Maria de Mahon; Mola de Menorca (D y E); San Lorenç, Lleida. Foto del autor.
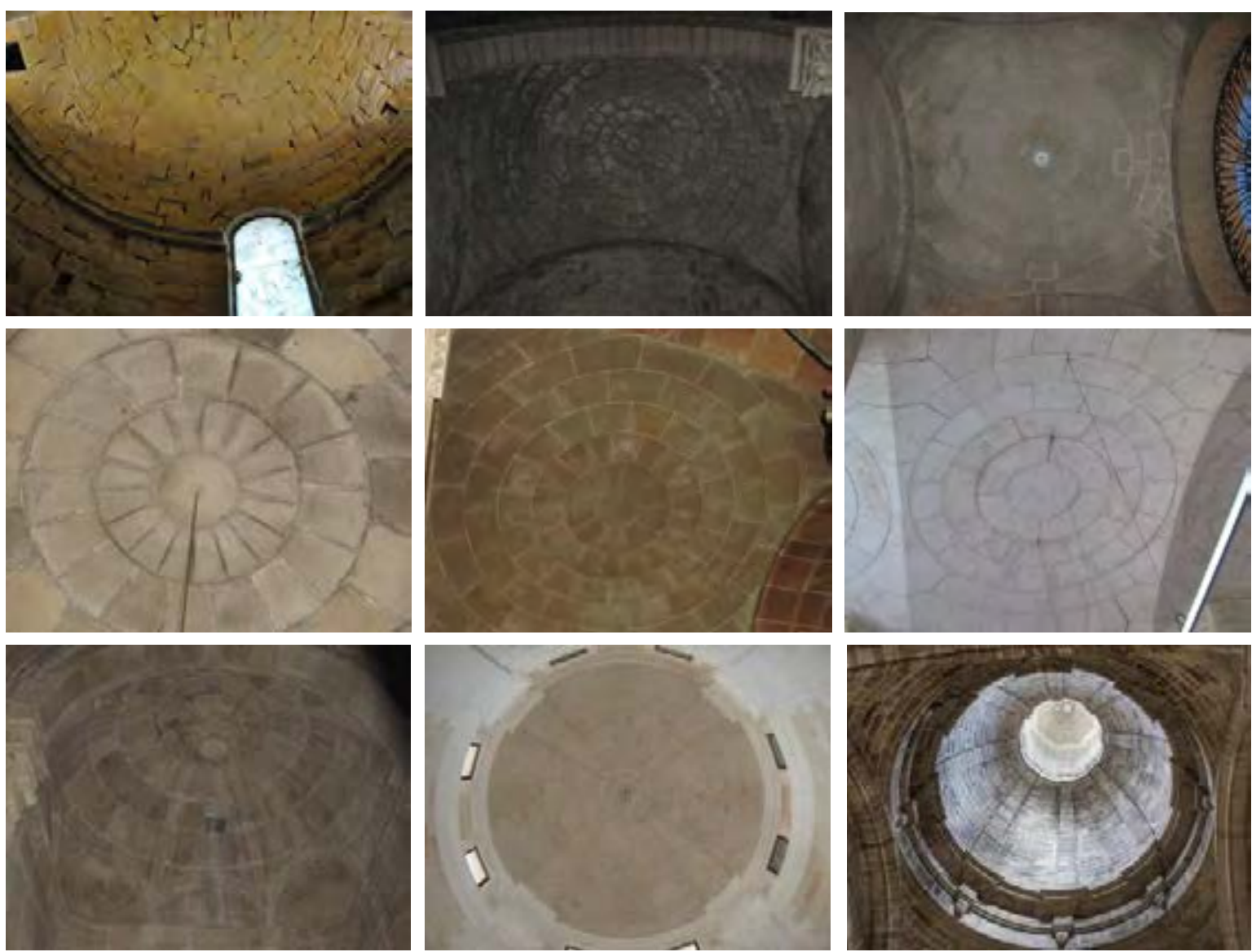

Fig. 5.15. Bovedas con despiece en planta circular. Castillo de Miravet; Catedral Nueva de Lleida (B y C); Murallas de la Catedral Vieja de Lleida; Palau de la Generalitat de Catalunya; Sagrada Familia; Catedral de Tortosa; Catedral de la Ciudadella de Menorca; Iglesia de Sant Jaume, Alcudia (foto de Fernando Sancho - wikicommon). Fotos del autor. 

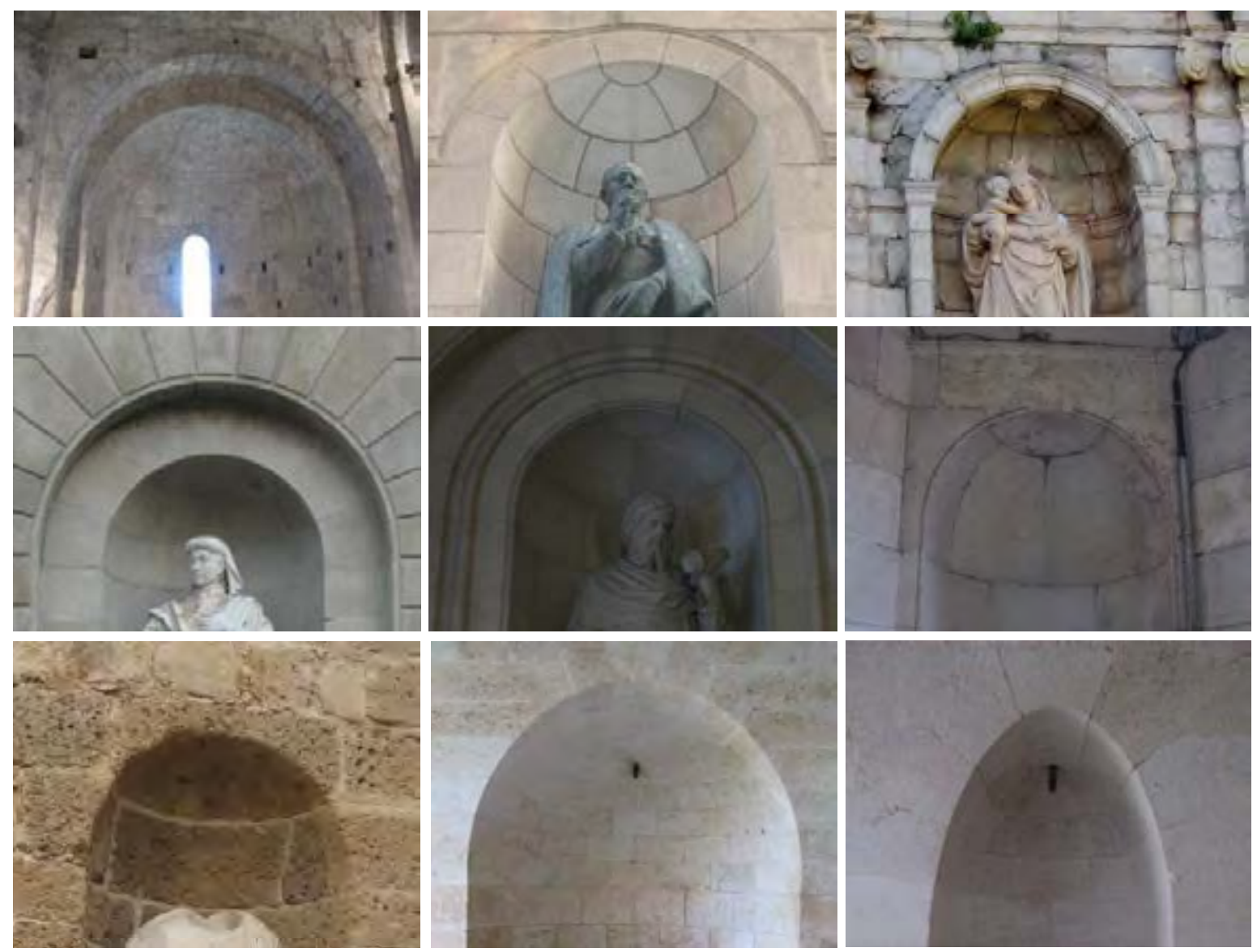

Fig. 5.16. Nichos esféricos con dovelaje horizontal. Sant Pere Glligans, Girona; Bisbat de Barcelona; Cartoixa d' Escaladei; Casa de la Ciutat, Barcelona; Universitat de Barcelona; Plaza Reyal, Barcelona; Murallas de Ibiza; Mola de Menorca (H y I). Fots del autor.
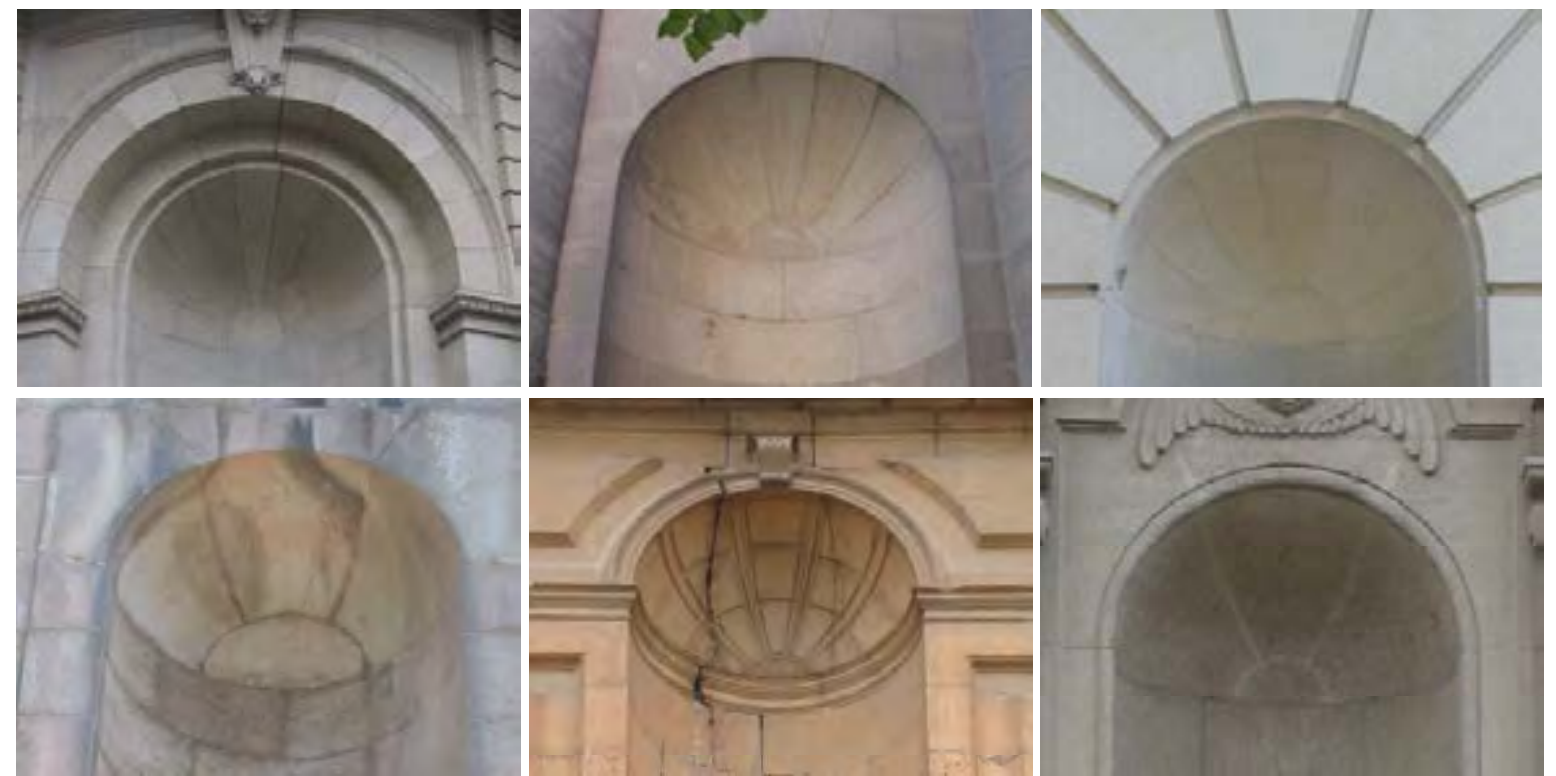

Fig. 5.17. Nichos esféricos con dovelaje convergente al centro. Monument al pintor Fortuny, Barcelona; Catedral Nueva de Lleida; Plaza de la Catedral, Barcelona; Academia de Medicina, Barcelona; Alcover; Catedral de Vic. Fots del autor. 

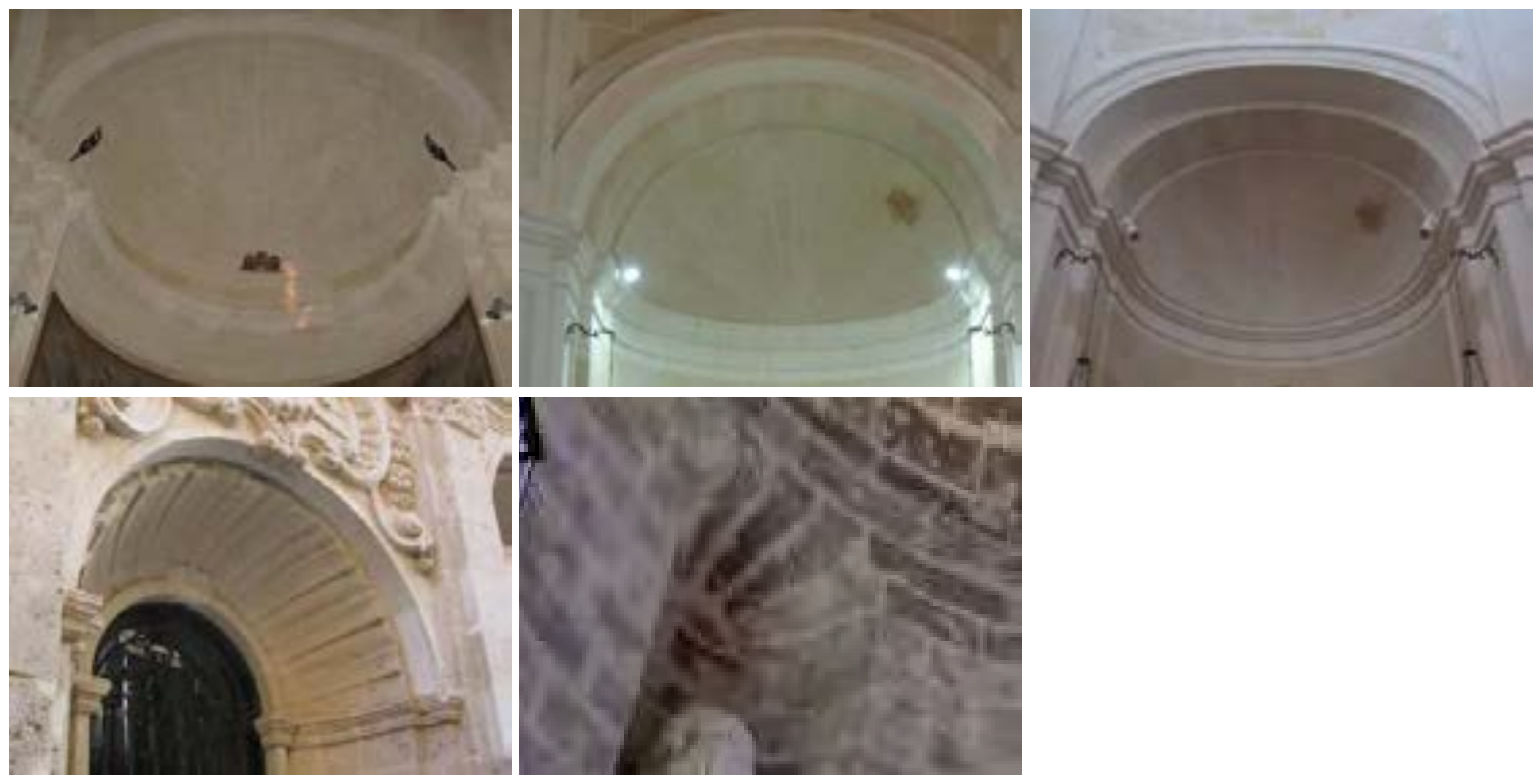

Fig. 5.18. Nichos esféricos con dovelaje convergente al centro (Baleares). Mehon; Ciudadella; Catedral de la Ciudadella de Menorca; Iglesia del Socors, Ciudadella de Menorca; Castillo del Bellver, Mallorca. Fotos de autor.
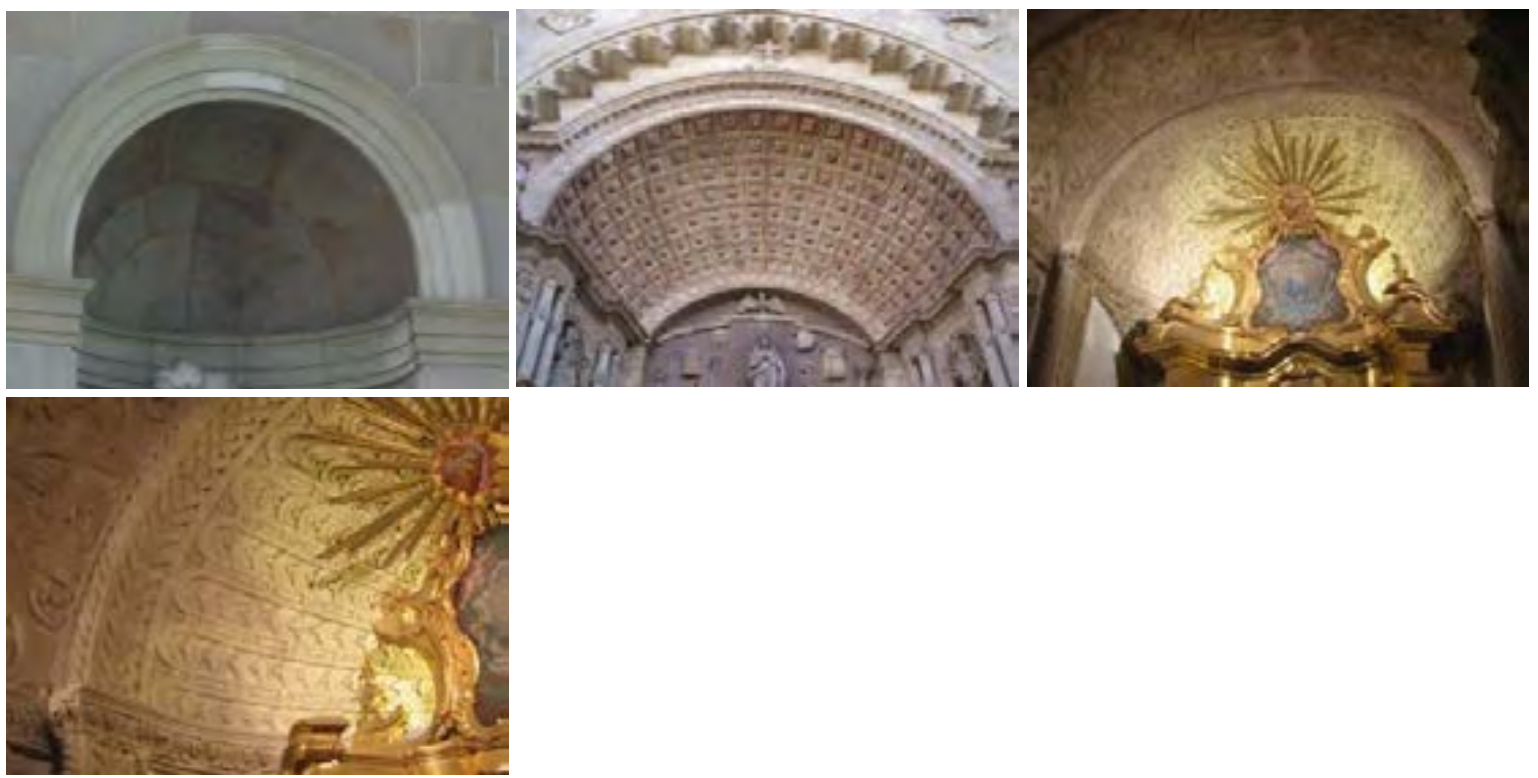

Fig. 5.19. Nichos esféricos con dovelaje vertical. Plaza de España, Barcelona; Catedral de Palma de Mallorca: portal, nicho y detalle del despiece del nicho. (B, C, D). Fotos del autor. 


\subsubsection{Volta ab sub biño - Bóveda en patio redondo (anular)}

\section{Folio 93 (Traza 50)}

Bajo este apelativo se incluyen las bóvedas originadas por superficies de rotación de un arco de circunferencia alrededor de una directriz curva, o sea que conforman una superficie tórica.

Las dovelas están dispuestas en hiladas horizontales que permiten el desarrollo de los conos inscritos con juntas paralelas orientados hacia la directriz del cañón. Las juntas radiales se orientan hacia el centro de la bóveda y son constituidas por planos de cortes verticales. Es necesario sacar un patrón por cada hilada de la sección de la bóveda. Desde la sección, se sacan los patrones de testa.

Existen algunas muestras de bóvedas anulares en sillería de origen románica en las comarcas de Girona (Fig. 5.21). En Mallorca se encuentra un ejemplo de excelente calidad constructiva y planteamiento geométrico es la bóveda en patio con columnas que se instala sobre una planta elíptica en el patio del ex hospital y Iglesia de Sant Antoni en Palma de Mallorca, construido por Lucas Mesquida y Rosselló en 1768. La bóveda es de sección carpanel con lunetos abiertos hacia el lado del patio y el intercolumnio viene salvado con arcos en torre cava y redonda. Este tipo de bóveda aparece también muy a menudo en la arquitectura defensiva del siglo XVIII, como testimonian las galerías de la Mola de Menorca. A esta traza se pueden relacionar las bóvedas helicoidales o vis de San Giles, que vendrán explicadas en el capítulo dedicado a las escaleras.

Otra traza clásica de la estereotomía de una bóveda con superficie tórica es el Ochavo de la guardia, que no está incluida en el tratado de Ribes, pero del cual encontramos algunas muestras en las Islas Baleares.

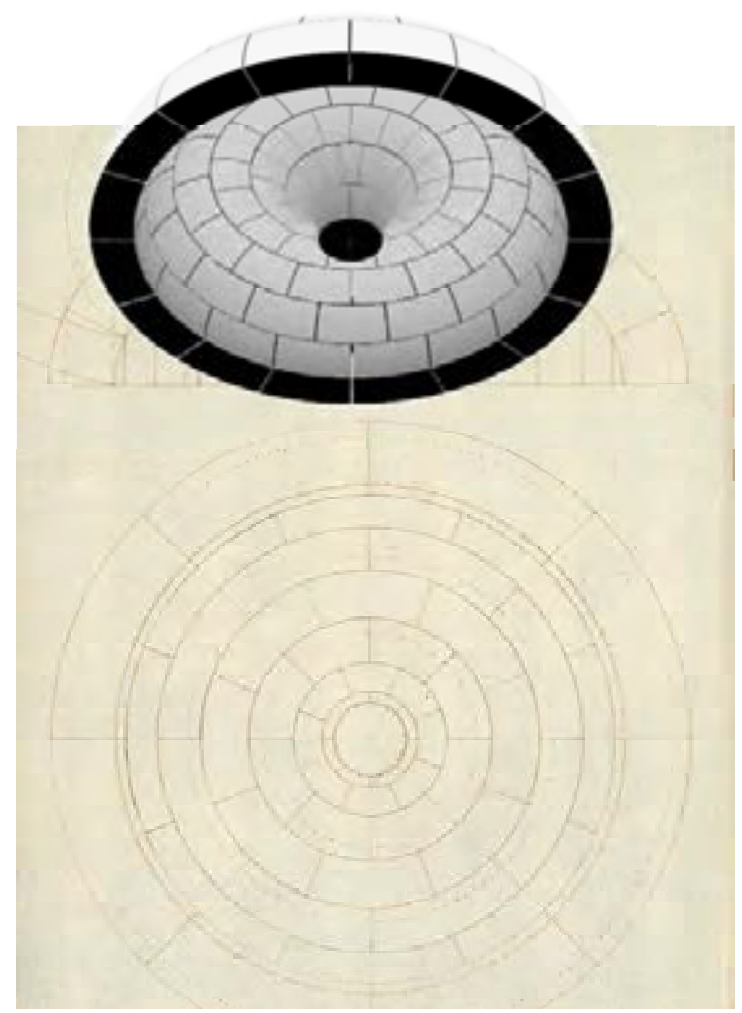

Fig. 5.20. Volta ab sub biño. Dibujo del autor 

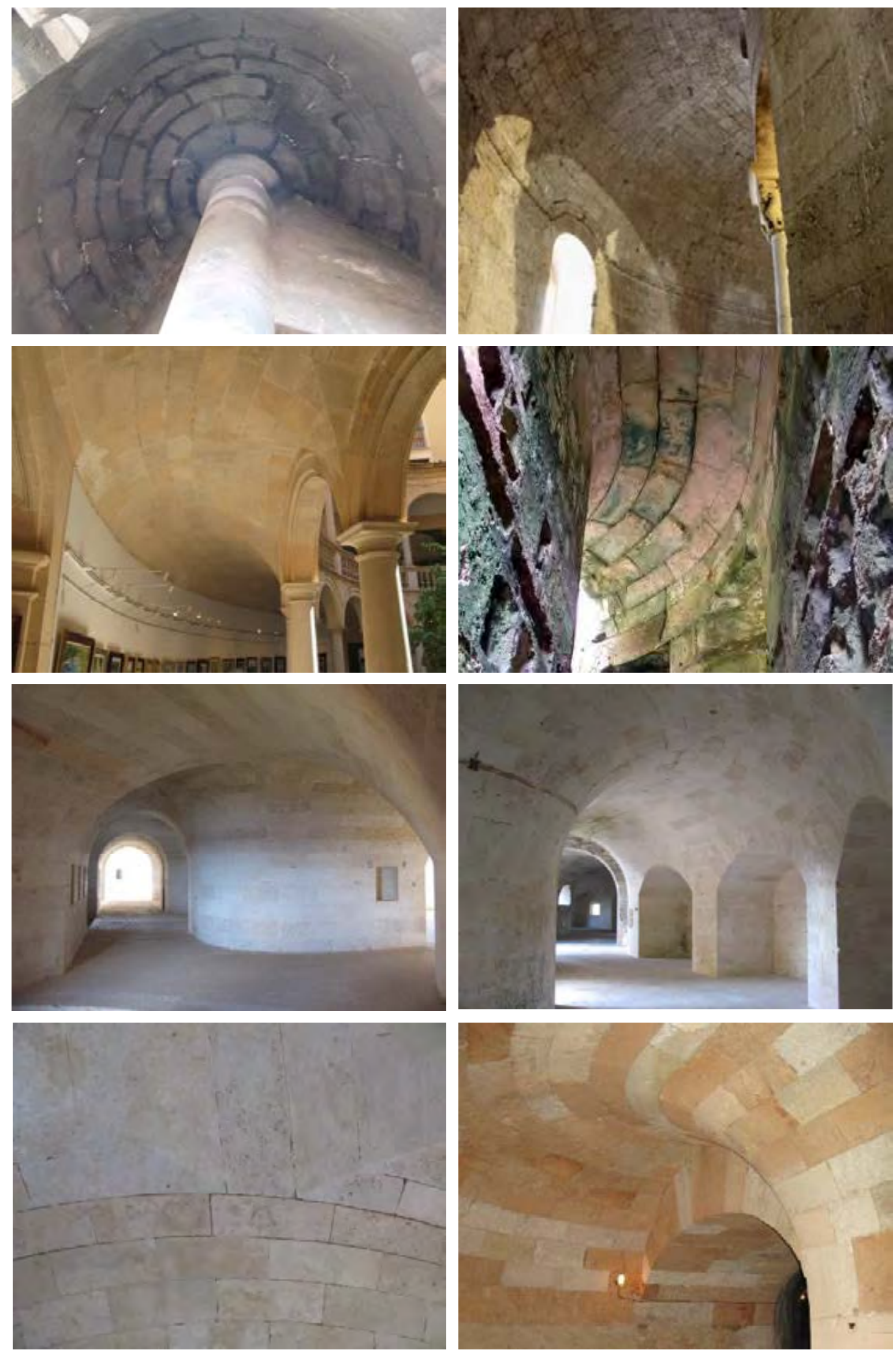

Fig. 5.21. Escalera del portal de Sant lu, Catedral de Barcelona; Sant Pere de Besalù; Pati de Sant Antoni, Palma de MaIlorca; Castillo de San Felipe, Menorca; galerias de la Mola de Menorca. Fotos del autor. 


\subsubsection{Bolta per aresta que las filadas rrodan - Bóveda de arista por hiladas redondas} Folio 57-58 (Traza 29)

Esta singular traza (Fig. 5.23), a parte el manuscrito de Ribes, aparece solo en el tratado de Philibert de L'Horme ${ }^{3}$ y en Alonso de Guardia ${ }^{4}$, aunque para ambos autores es una bóveda baída con despiece en abanico y intradós esférico como se puede observar por el rampante de la bóveda. Diferentemente, Ribes dibuja el arco diagonal como ovalo, quizás inspirándose a uno de los dos manuscritos (con más probabilidad de L'Horme), pero termina por representar una bóveda con una volumetría distinta. En Ribes, no es un casquete esférico con despiece en abanico. El intradós de la bóveda se genera haciendo rotar un arco sobre los ejes verticales de los rincones de la bóveda formando un conoide. Los perfiles superiores de los cuatro conoides se pueden enlazar con una superficie plana o con una ligera concavidad como en el caso de Ribes. Como se puede observar del dibujo del rampante, Ribes aquí cava ligeramente el intradós para obtener una transición sin solución de continuidad con la superficie los conoides de lados opuestos y evitar la parte plana del centro de la bóveda.

En la práctica canteríl, es una bóveda de escasa difusión, podemos recordar solo un pequeño grupo de ejemplos construidos en Francia datado entre 1700 y $1740^{5}$ : el vestíbulo de la abadía de Dames de Caen (1704), el claustro de la abadía de Notre-Dame de la Couture, en Le Mans (1720-1739), abadía de Saint-Florentin en Bonneval (1735), abadía de Beaulieu-lès-Loche y abadía de Saint-André en Villeneuve-lès-Avignon (Fig. 5.28). A excepción de la abadía de Caen, son todas bóvedas relacionadas a San Mauro que parecen tener origen normando.

Todos los antecedentes medievales se encuentran en Inglaterra, habiendo aparecido por primera vez con las fan vaults del claustro de la catedral de Gloucester entre 1351 y 1377. La superficie de intradós viene creada por la rotación del nervio alrededor del eje vertical situado en correspondencia de los arranques y va formando pequeñas celdas que fragmentan la bóveda. La estructura es una cascara continua de bloques de piedra adovelada y, en la parte central, los huecos que quedan entre los cuatro conoides se rellenan con paneles de piedra horizontal. Hay un ejemplo castellano parecido a una fan vault inglesa en la Antesacristía de la Catedral de Santiago de Compostela (Fig. 5.22). En este caso los arcos de igual curvatura están orientados en abanico, aunque el despiece de las dovelas de la cascara no sigue el perfil del conoide. Hace falta notar que todos los ejemplos franceses, así como el modelo e Ribes, no tienen nervios y presentan una superficie de intradós continua.

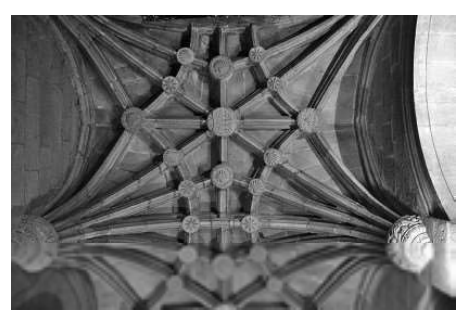

Fig. 5.22. Antesacristia de la Catedral de Santiago de Compostela (foto de Freire Tellado)

\footnotetext{
3 De L'Horme. Voute en pendentifs appareillée sur le plan de la voute en éventails, fol. 114

4 Alonso de Guardia. Rasguños, fol. 67

Perouse de Montclos, 1982: 161.
} 


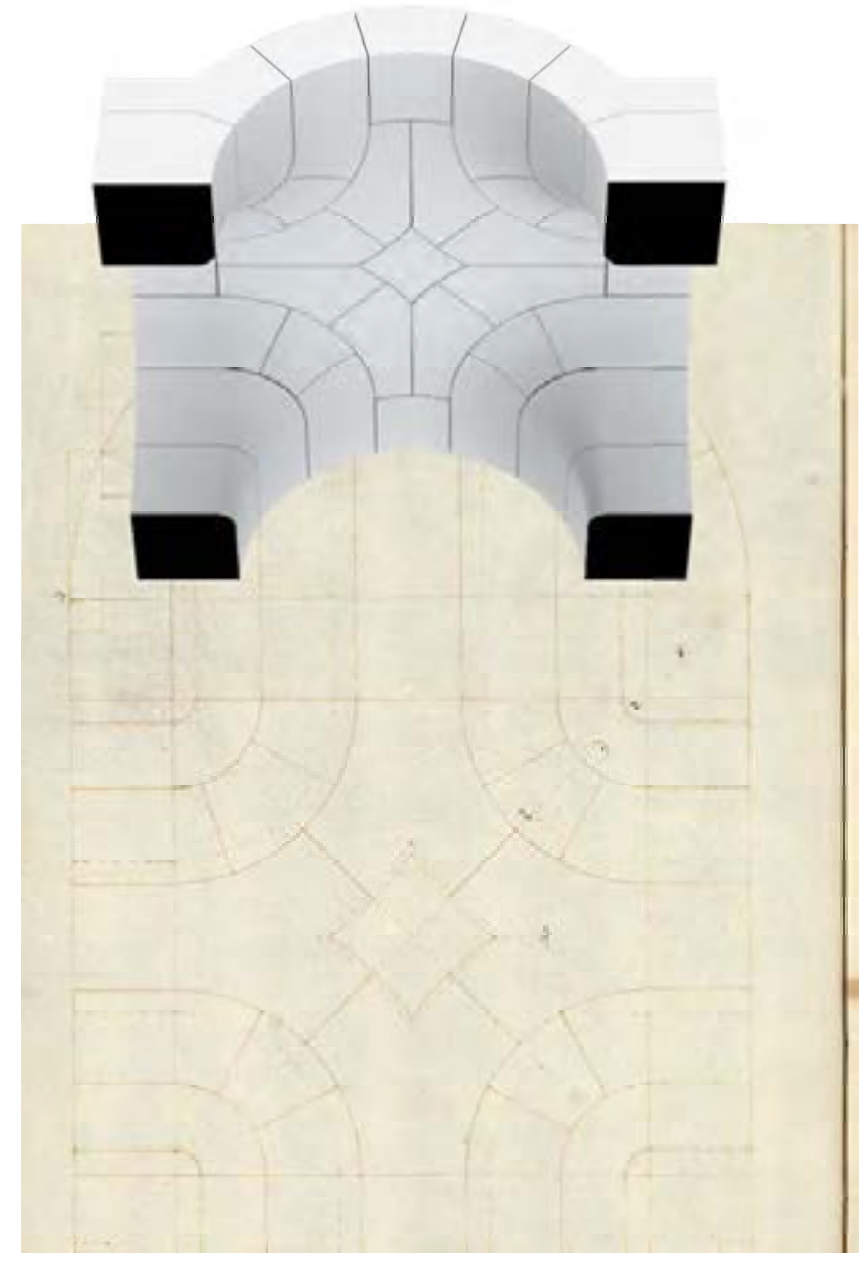

Fig. 5.23. Bolta per aresta que las filadas rrodan .Ribes, folio 57-58
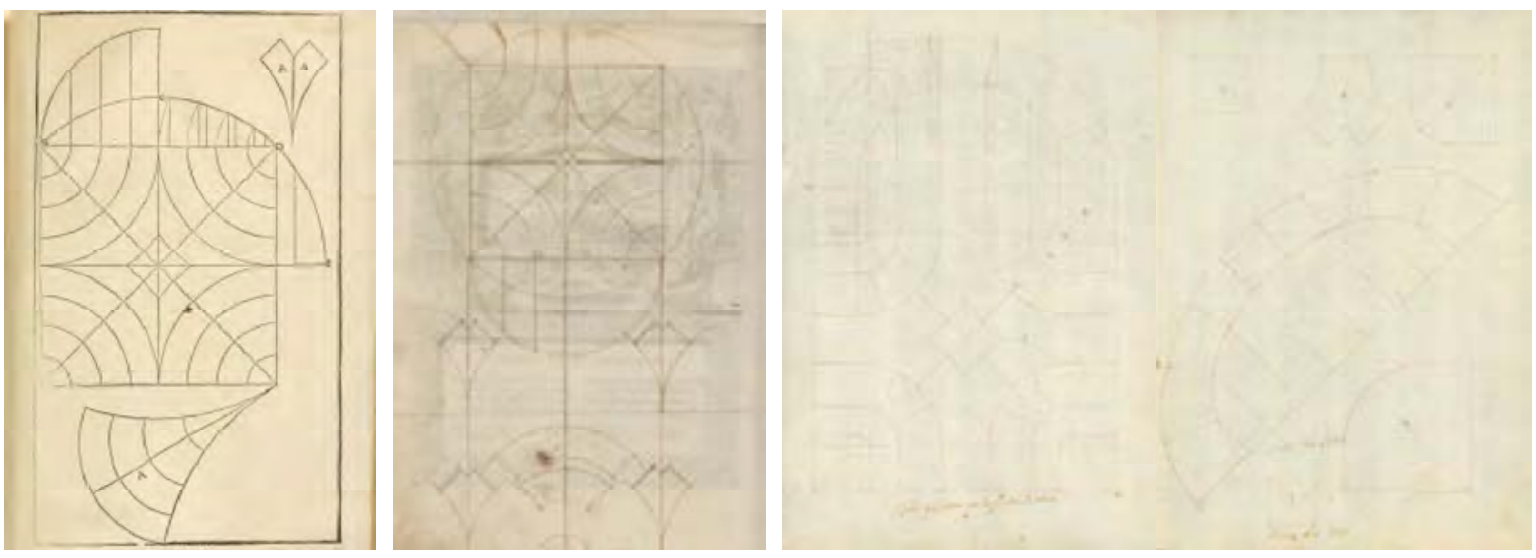

Fig. 5.24. Philibert de l'Orme, Voute en eventails; Alonso de Guardia, Rasguños fol 67, Boveda baida con despiece en abanico; Ribes, Bolta per aresta que las filadas rrodan, folio 57-58 

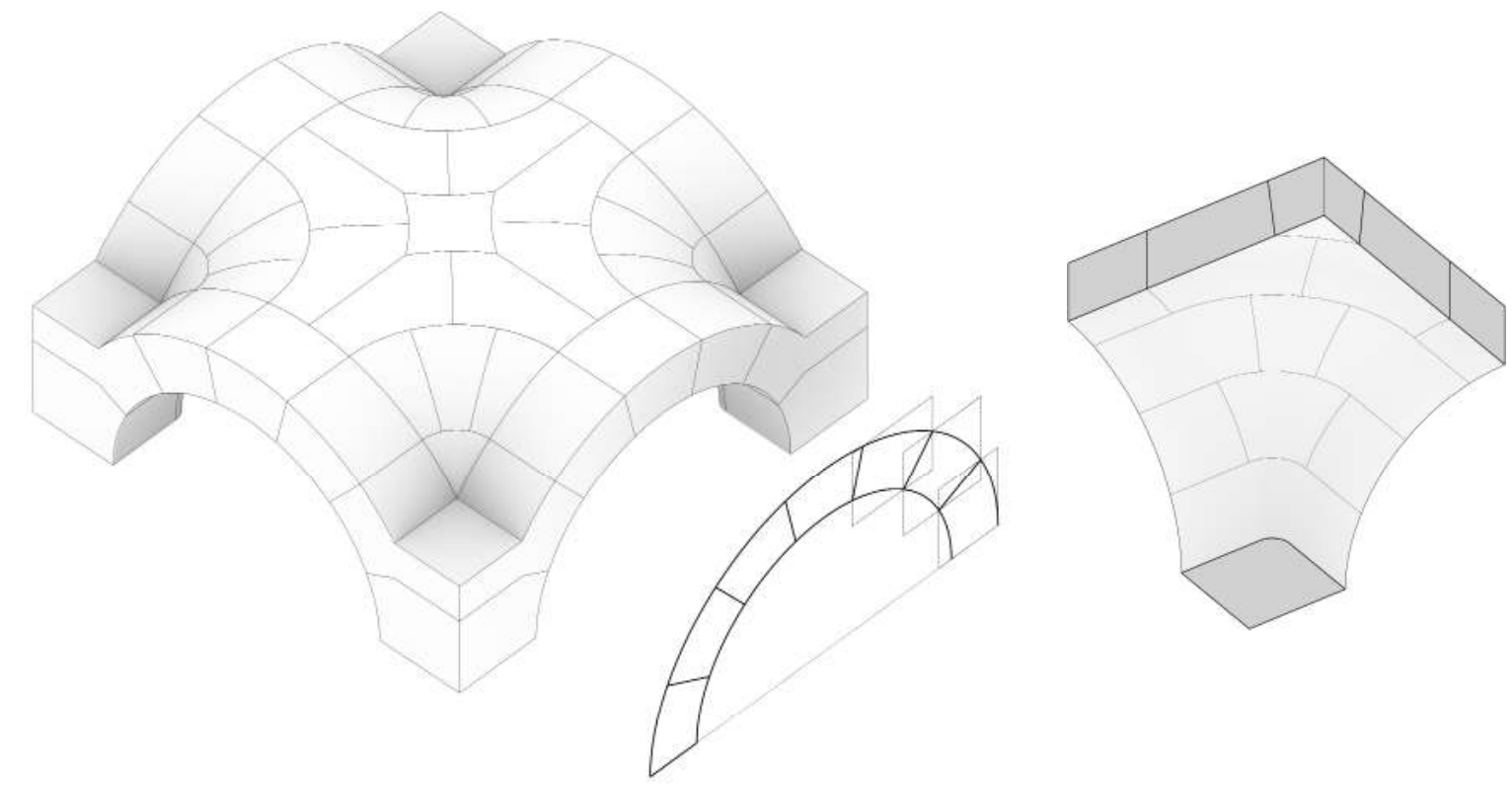

Fig. 5.25. Bóveda de arista por hiladas redondas. Dibujo del autor.
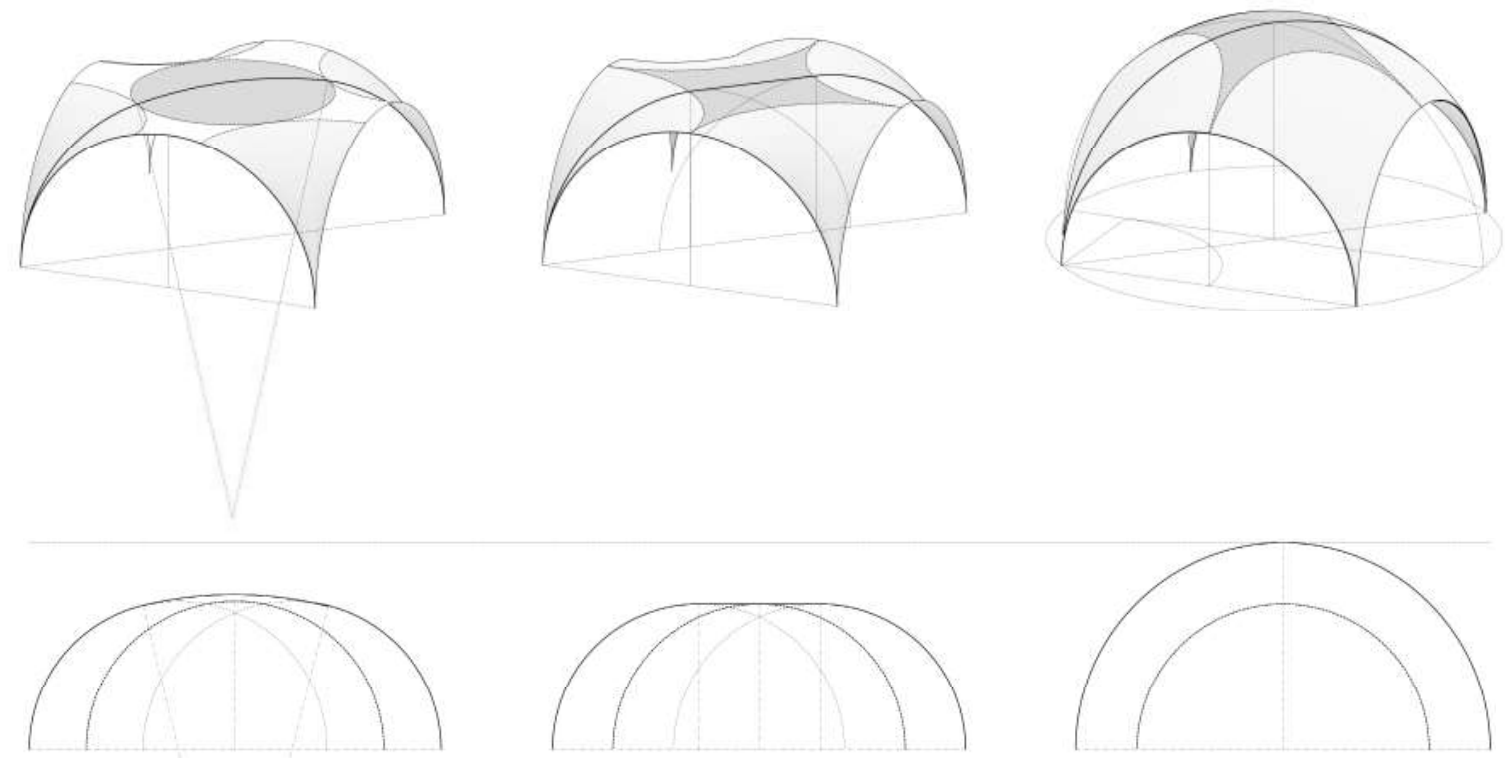

Fig. 5.26. Estudio geometría de la bóveda. Dibujo del autor. 


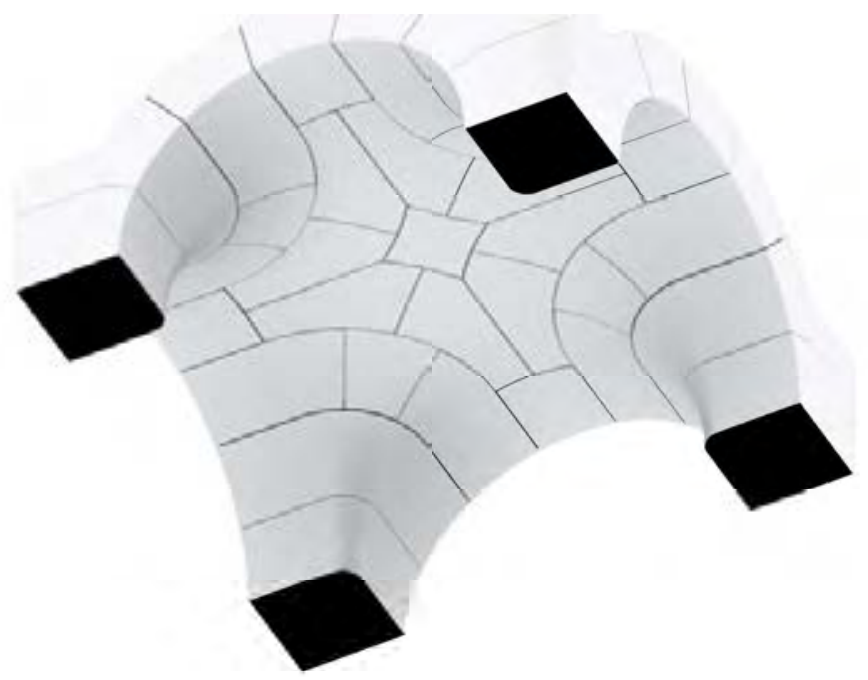

Fig. 5.27. Bóveda de arista por hiladas redondas. Dlbujo del autor.
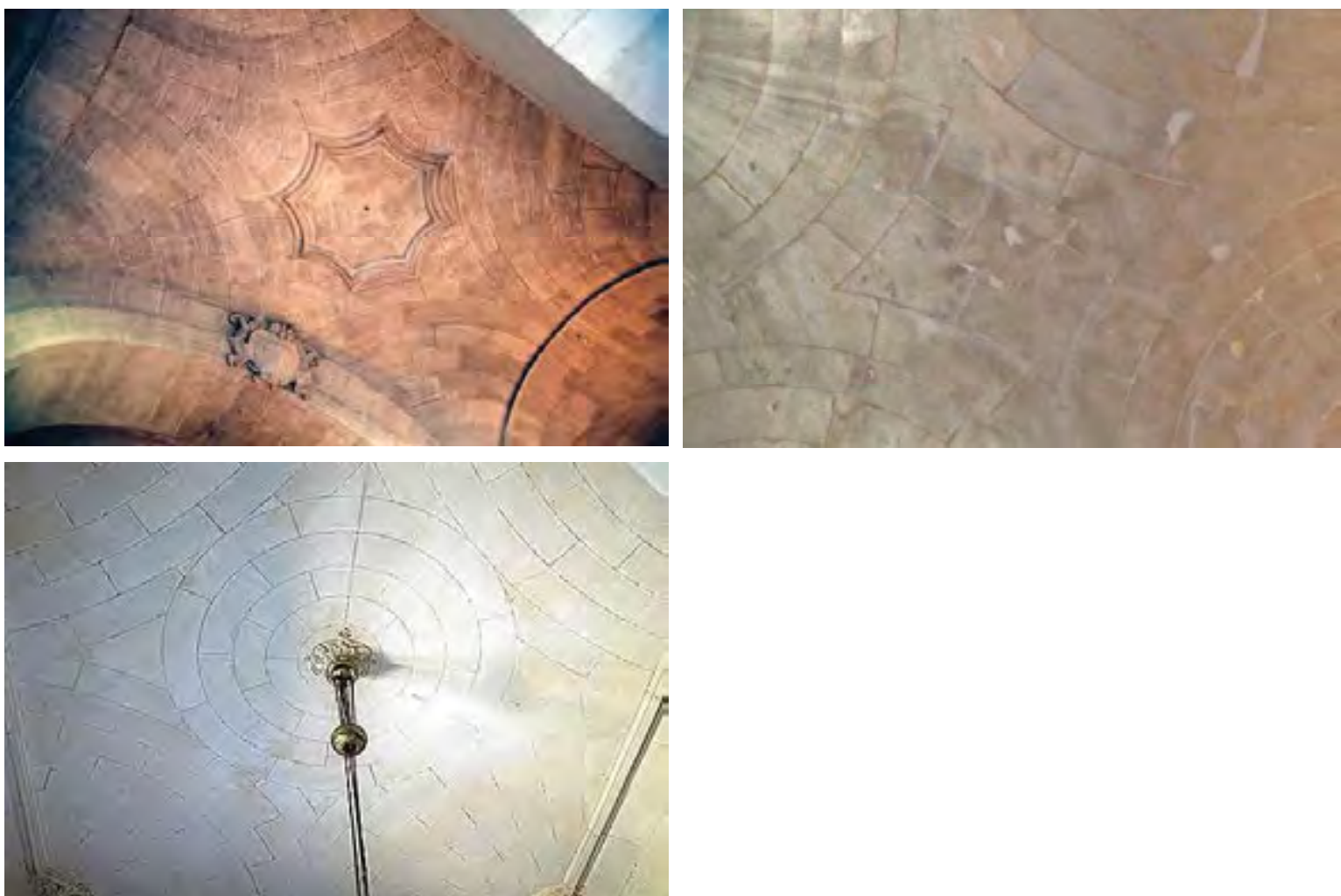

Fig. 5.28. Abbaye Sant-Aundre, Llanguedoc; Abbaye-aux-Dames, Eglise Trinite (foto de SDHA); Berbantane 


\subsection{Bóvedas compuestas}

La Bolta dela pastexa ab aun cap rrodona (Bóveda en rincón de claustro y torre redonda, Traza 37$)^{6}$ es la primera de la serie de bóvedas compuestas ilustradas en el Llibre de trasas. Estos modelos se conforman por la adición y fusión de diferentes aparejos, produciendo situaciones reales o representando casos abstractos como posibles ejercitaciones geométricas para estudiar el encuentro entre bóvedas de diferente tipología. En este caso Ribes termina una bóveda en de cañón con una bóveda en rincón de claustro por un lado y con una bóveda de media naranja por el otro, que aquí compare por primera vez en el manuscrito. En las páginas a seguir del tratado se dedicará otra traza para describir exclusivamente la geometría de una bóveda de casquete esférico (Traza 45), y otra para describir un cuarto de una esfera, que corresponde a media bóveda de media naranja (Traza 46). El procedimiento geométrico utilizado para obtener las plantillas de la media naranja emplea el desarrollo en el plano de los paralelos de la esfera que se ha analizado antes.

En las trazas a seguir vendrán representadas otras combinaciones. Ribes traza una bóveda compuesta por un rincón de claustro que termina con media planta hexagonal como podría ser un ábside, un rincón de claustro trapezoidal combinado con media naranja y una bóveda de arista con lunetos de arcos apuntados que termina con una media naranja. Los ejemplos se finalizan con un modelo de cubierta abovedada que se instala sobre una planta en cruz con arista central y que termina cada brazo con una bóveda distinta, precisamente una en medina naranja, un rincón de claustro rectangular, un rincón romboidal y un rincón en en planta trapezoidal.

Asociada a la bóveda en patio redondo, hay la versión en patio cuadrado (Bóveda ab sub bino cuadrat), o sea una bóveda creada por la extrusión de un arco de circunferencia a lo largo de una directriz en forma de cuadrado, que va conformando cuatro tramos de bóveda de canon que en las esquinas producen encuentros en rincón de claustro y arista.

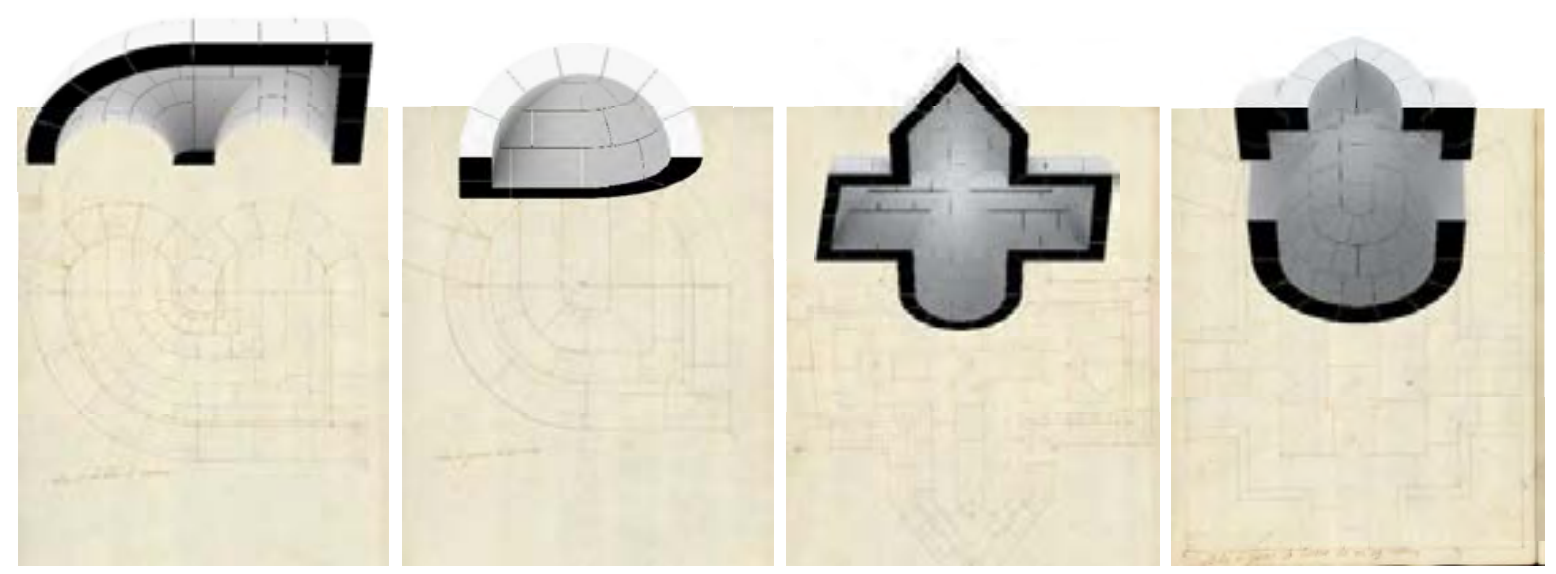

Fig. 5.29. Bóvedas compuestas. Dibujo del autor.

\footnotetext{
6 Hay una traza similar en el manuscrito de Gelabert, la volta radona ab un cap o capser rado
} 

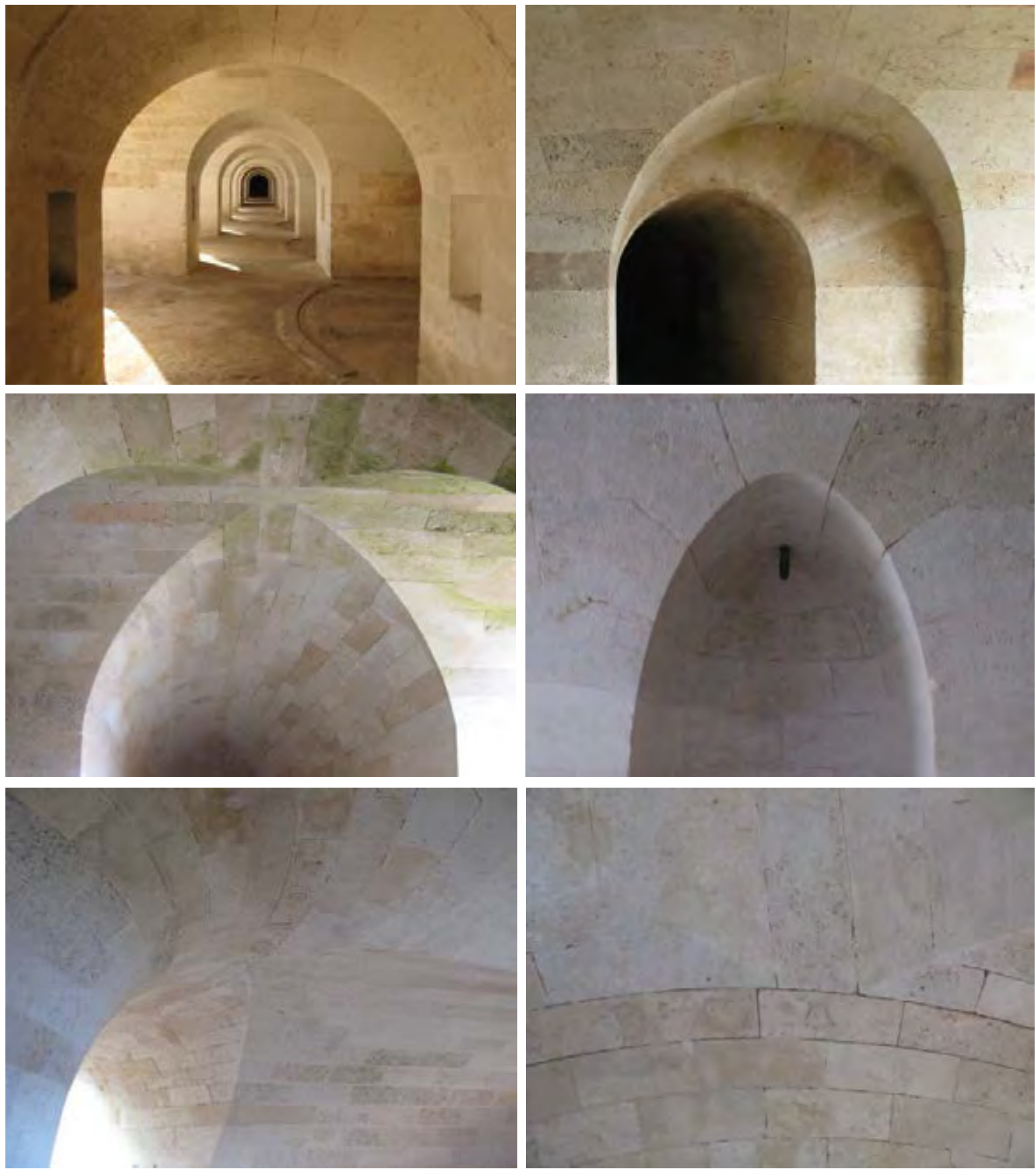

Fig. 5.30. Bóvedas compuestas en la Mola de Menorca. Fotos del autor. 


\section{Bóvedas de crucería}

Como se mencionó precedentemente, una característica verdaderamente notable de esta obra es el extenso capítulo dedicado a las bóvedas de crucería góticas. El peculiar interés que Ribes manifiesta por ellas no es en realidad anacrónico, se inscribe en una innegable y contundente prolongación del gótico a lo largo de los siglos XVII y XVIII. Este gótico, escasamente conocido, está reclamando un estudio profundo que haga aflorar una arquitectura cuya existencia contradice la cronología de la historiografía más ortodoxa. Su desarrollo, paralelo al Barroco y Neoclásico, nos habla de perennidad de un estilo que, lejos de desaparecer, termina por conectarse con el gótico romántico del siglo XIX.

El Llibre de Trasas se inscribe en el contexto anteriormente descrito que hizo posible las numerosas obras de concepción gótica que en la ciudad de Barcelona se fueron construyendo hasta los siglos XIX y XX. Algunos de sus ejemplos más notables fueron, por ejemplo, la fachada y el cimborio de la Catedral de San Eulalia o el Puente del Bisbe, sin lugar a dudas una de las obras de arquitectura mas fotografiados por los visitantes de la Ciudad Condal.

Joseph Ribes estudia cuarenta bóvedas de crucería clasificándolas en tres grandes bloques: bóvedas de planta cuadrada y rectangular, bóvedas triangulares y bóvedas redondas y octagonales $^{1}$ (Fig. 6.1). Posteriormente las ordena por el número de sus claves, empezando por la bóveda de una clave, hasta terminar con una bóveda estrellada de 17 claves. La mayor parte de ellas son de simetría central, otras son de simetría axial y, en ocasiones, con diseños de nervaduras inéditas en el gótico español. Al mismo tiempo experimenta con otros recursos compositivos, por ejemplo, yuxtaponiendo bóvedas cuatripartitas (Fig. 6.2) para crear trazas similares a las bóvedas de la Sala de Contratación de Valencia $(1481)^{2}$, en otras ocasiones crea diseños de bóvedas de eje de simetría diagonal, que visualmente dan la impresión de ser trazas asimétricas (Fig. 6.3).

En este capítulo observamos de inmediato un orden de creciente complejidad según el número de claves de que consta la bóveda.

La parte dedicada a las bóvedas de crucería ocupa una parte de relieve fundaméntale en el tratado y en consecuencia en el presente trabajo la atención prestada al tema prevalece en comparación con el espacio reservado para los otros elementos arquitectónicos

\footnotetext{
124 bóvedas de crucería en planta cuadrada, 1 rectangular, 7 triangular, 5 redonda, 3 capillas ochavadas

2 Los primeros ejemplos de bóvedas cuadripartidas unidas a formar una sola se pueden encontrar desde principio del siglo XIII en la Catedral de Lincoln, en Inglaterra, y en Nuestra Señora de Tréveris, en Alemania: en Javier Gómez Martínez, El Gótico Español de La Edad Moderna: Bóvedas de Crucería (Universidad Valladolid: Secretariado De Publicaciones e Intercambio Científico, 1998): 86.
} 

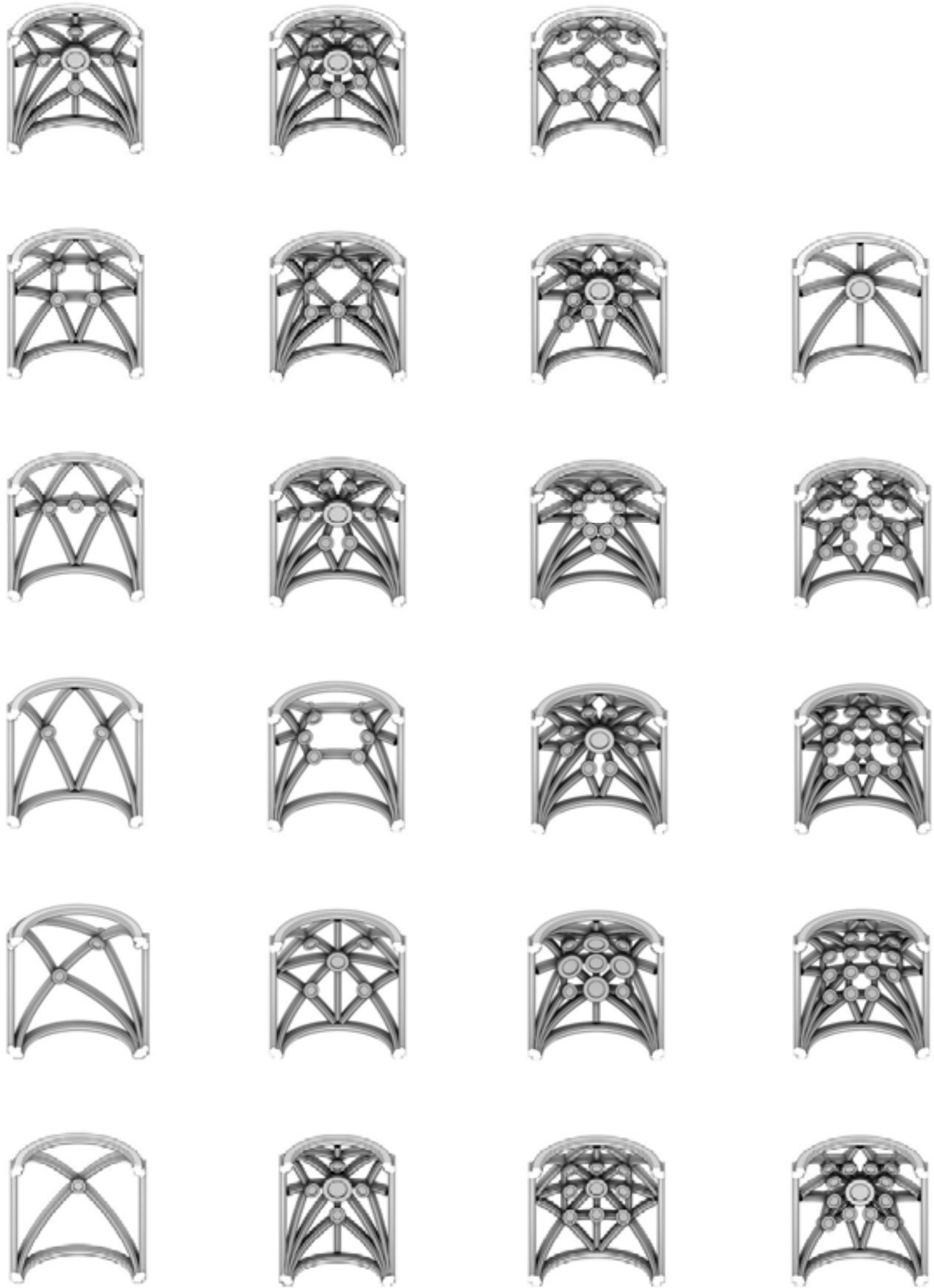

Fig. 6.1. Las bovedas de cruceria del Llibre de Trasas. Dibujo del autor 

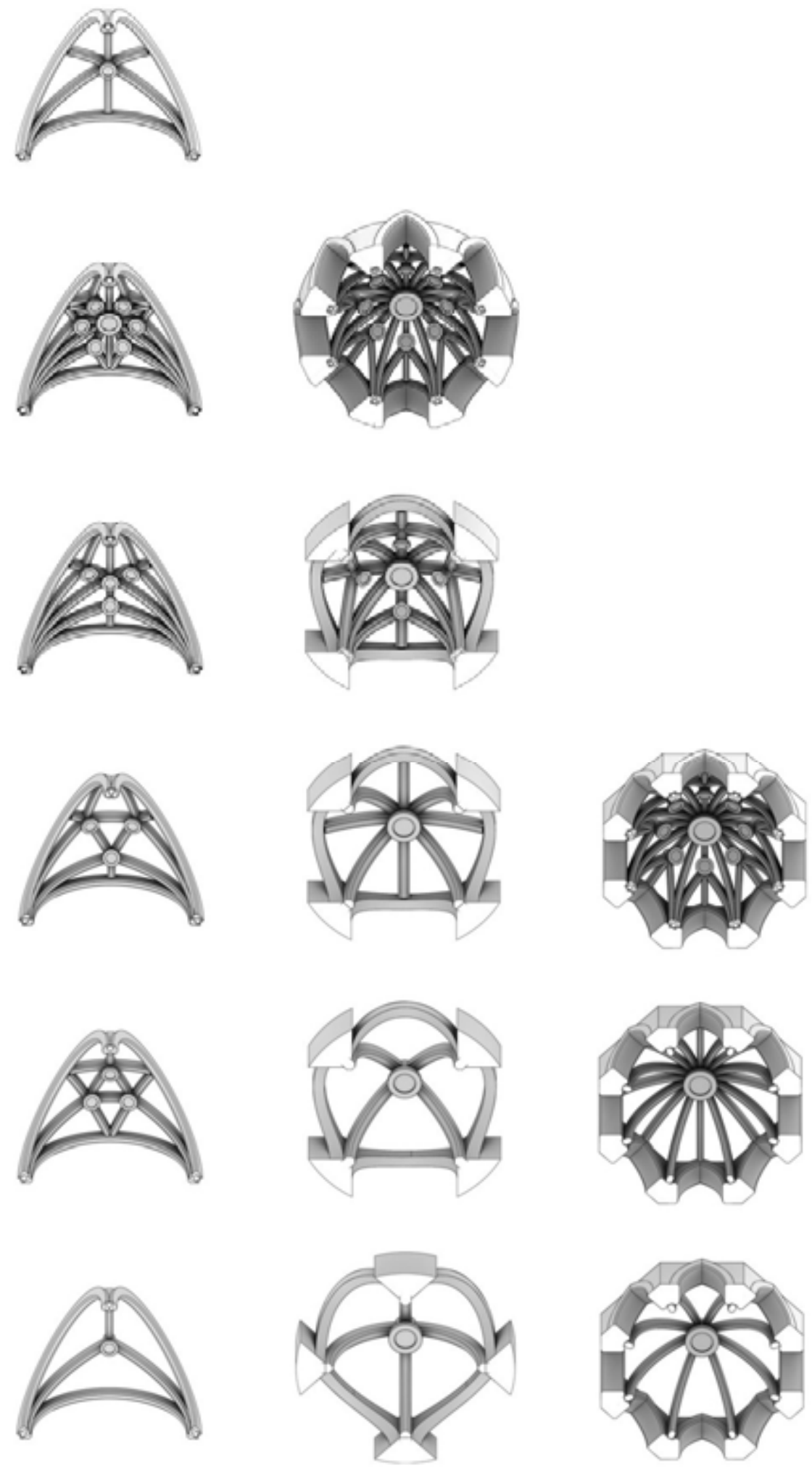

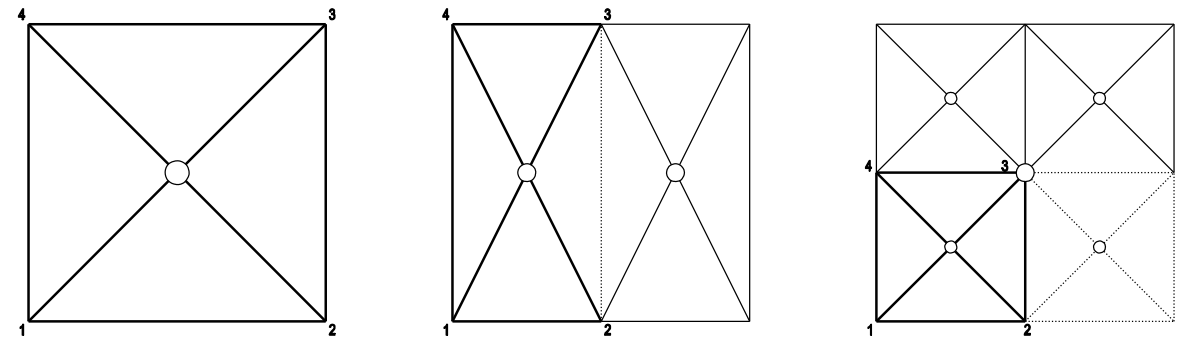

Fig. 6.2. Bóvedas cuatripartitas yuxtapuestas. Dibujo del autor.
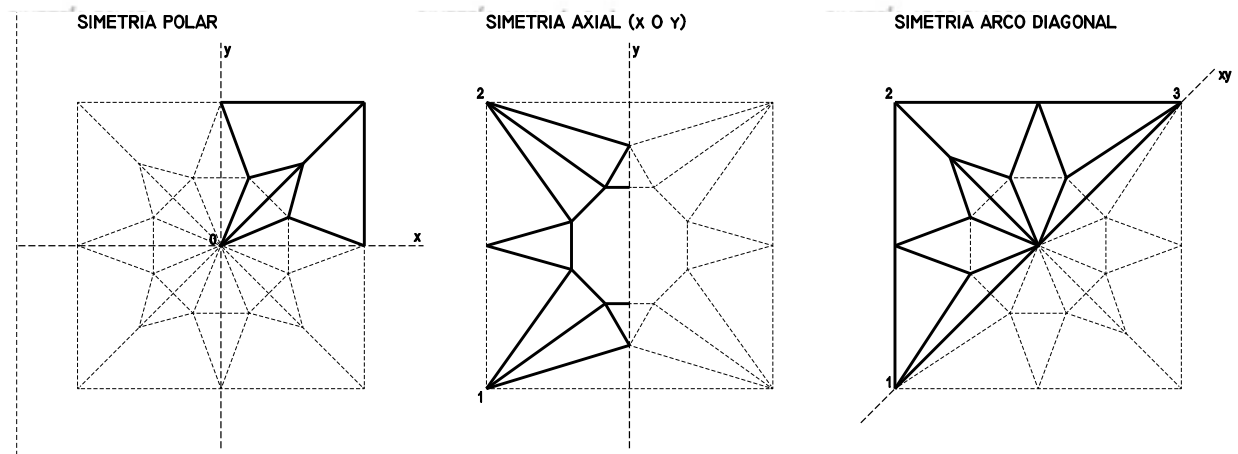

Fig. 6.3. Simetría de las bóvedas (desde la izquierda): simetría central, axial y diagonal. Dibujo del autor

\subsection{Descripción tipológica elemento y características geométricas}

Todas las bóvedas de crucería de Ribes presentan una característica común: son bóvedas de intradós esférico. Independientemente de la geometría de la planta, ya sea poligonal o circular, todas ellas se resuelven con arcos de crucería de medio punto y rampante redondo. Probablemente, Ribes dibuja sus bóvedas con geometría esférica con el objetivo de simplificar el dibujo y, al mismo tiempo, destacar y comparar con más facilidad los nervios de las diferentes monteas del tratado. Sin embargo, la geometría esférica de la cáscara de una bóveda implica que todos los nervios tengan curvaturas diferentes y, en consecuencia, sus dovelas deben labrarse con la curvatura de cada arco. Esta particularidad complica notablemente la construcción de la bóveda y la aleja de los principios de estandarización del gótico. Otra característica singular de las bóvedas de Ribes es que todas ellas tienen sus claves inclinadas: son claves en el que el eje del cilindro central se orienta hacia el centro de la bóveda ${ }^{3}$. Es ésta una particularidad constructiva, escasamente señalada, que hace su aparición en las bóvedas de crucería construidas a partir del siglo XVI en España y Portugal ${ }^{4}$. Por lo demás, identifica la forma de las claves como típicamente mediterráneas,

\footnotetext{
3 En Cataluña muchas claves son verticales pero el disco del intradós es tangente a la cáscara, dando apariencia que toda la clave sea inclinada, como por ejemplo en San Nicolau de Bellpuig (segunda mitad s. $\mathrm{XVI}$ ). La razón principal en elegir una clave inclinada respecto a una vertical, razones estilísticas aparte, se encuentra en el considerable ahorro de material. El volumen del sólido capaz de una clave inclinada es mucho menor de una clave vertical. Esto se puede apreciar especialmente en las claves periféricas, las que están mas alejadas del centro de la aboveda. La relativa sencillez de la trama de las bóvedas góticas catalanas no ha requerido el utilizo sistemático de este avance técnico del gótico peninsular.
}

4 Al respecto se puede consultar: Jose Carlos Palacios Gonzalo and Fabio Tellia, "Inclined Keystones in 
con su característico perfil acampanado tan alejada de las claves del área castellana.

Los dibujos del Llibre de Trasas recuerdan la obra de Joseph Gelabert, De l'art de picapedrer ${ }^{5}$, próxima al tratado de Ribes por área geográfica y por fecha. No obstante, las trazas de las capillas góticas de Gelebaert son completamente distintas ya que, aunque sus claves sean también inclinadas, los nervios son siempre apuntados y, en consecuencia, las plementerías forman superficies alabeadas entre ellos. El resultado final son bóvedas de volúmenes completamente alejados de las formas esféricas de Ribes ${ }^{6}$.

Otra característica interesante de las bóvedas de Ribes es el considerable tamaño de las claves en relación a la superficie de la bóveda, lo cual es característico del gótico catalán ${ }^{7}$, si bien, en las trazas de Ribes, al alternarse claves de diferentes dimensiones, se crea una jerarquía y un interesante motivo compositivo que se añade al diseño de las nervaduras.
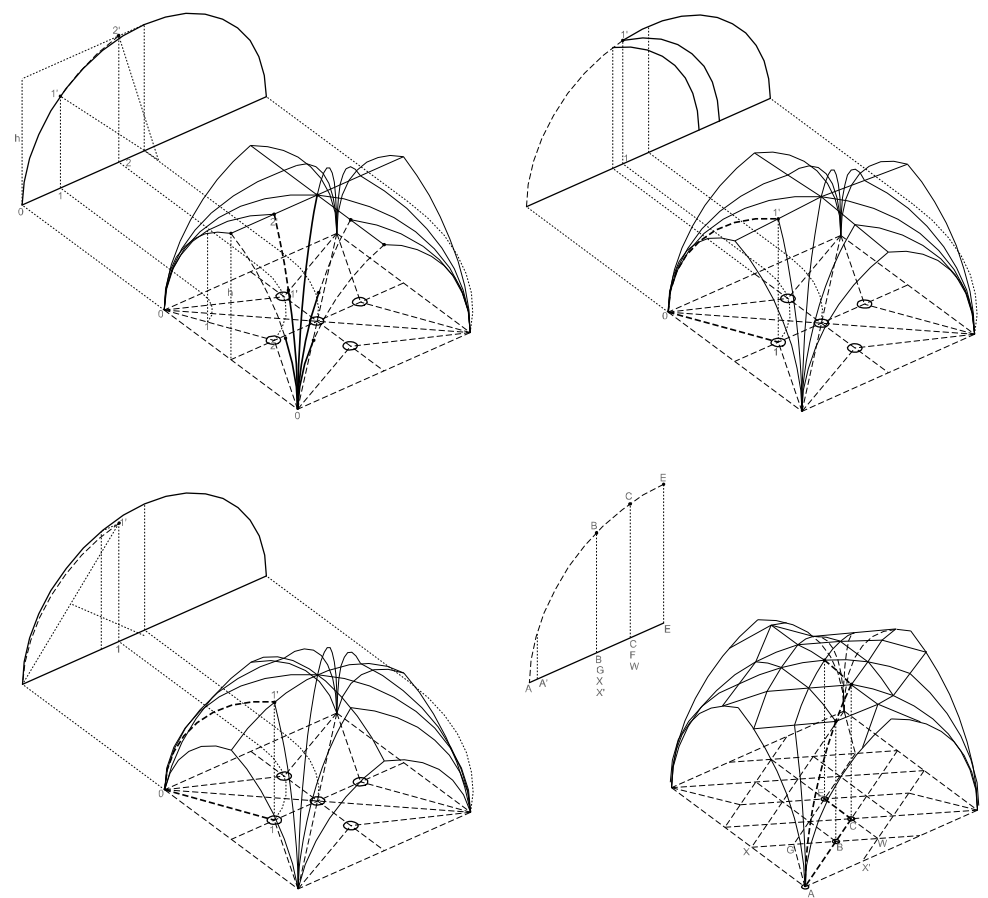

Fig. 6.4. Métodos de estandarización de los nervios. Dibujo del autor.

Spanish Late Gothic," in Proceedings of the Fifth International Congress on Construction History in Chicago, June 3rd-7th, (Chicago 2015) (Chicago, 2015).

5 Joseph Gelabert, De l'art de Picapedrer, Manuscrito Facsímile, [1653] (1653; repr., Palma de Mallorca: Diputación, 1977).

6 En la tratadistica española, el estudio de la bóveda de crucería es un tema desarrollado por diferentes autores: Rodrigo Gil describe la construcción y montaje de una bóveda gótica semiesférica, Hernan Ruiz (c.1560) de una bóveda de rampante redondo tendente a la esfericidad. Vandelvira (c.1591) substituye los procedimientos de la cantería medieval con el método de talla de dovelas esféricas.

7 Arturo Zaragozá Catalán ("A Propósito de Las Bóvedas de Crucería y Otras Bóvedas Medievales," Anales de Historia Del Arte, 2008: 99-126) también nos recuerda que Bassegoda ha propuesto que primero se situaba la clave en su lugar en el espacio por medio de un castillete y luego se construía el resto de la bóveda. Este procedimiento será descrito en la segunda parte de este artículo dedicada a la construcción de una bóveda del tratado de Ribes. 


\subsection{La persistencia del gótico en el siglo XVIII, el gótico de después}

Como en un principio se hizo mención, las bóvedas de Ribes nos hablan de un gótico que, definitivamente, se resiste a desaparecer y nos empuja a abrir una nueva puerta en la historiografía de este estilo: el gótico de después. A partir del siglo XVI, un gran número de construcciones góticas, algunas de ellas colosales, se siguen llevando a cabo en nuestro país; la mayor parte de estas obras no merece la menor atención. Casi todos los tratados españoles del XVII, incluido el de Benito Bails ya en plena llustración, incluyen estudios más o menos extensos de bóvedas de crucería. En nuestro país hay claros indicios que nos impulsan a abrir un área de conocimiento del gótico todavía no explorado. De la misma manera que un día no muy lejano el tardogótico alcanzó el nivel de consideración que merecía, ahora el gótico de después está exigiendo su lugar en la historia. Los alemanes hace ya un tiempo que la abrieron, nos referimos al Nach Gotic.

\subsection{Clasificación geométrica de las bóvedas de Ribes}

Como se ha indicado antes, las bóvedas de Ribes se pueden agrupar en tres grandes bloques en función de la planta en la cual se van a insertar, es decir bóvedas de planta cuadrada y rectangular, bóvedas triangulares y bóvedas redondas y octagonales.

El trazado de los nervios define otras dos tipologías: hay bóvedas de diseño geométrico rectilíneo vinculado al foco toledano de Juan Guas y Enrique Egas y otras en que se usan nervios de proyección horizontal curvilínea, vinculadas al foco burgalés y a Simón de Colonia ${ }^{8}$. Ribes, como también el gótico catalán ${ }^{9}$, es apegado a los diseños rectilíneos. Igualmente, las bóvedas de crucería se pueden clasificar en dos grandes grupos ${ }^{10}$ : las bóvedas estrelladas de diseño centralizado alrededor de la clave central y las bóvedas en red, en las cuales los nervios secundarios se entrelazan con las bóvedas adyacentes.

\subsubsection{Bóvedas en planta cuadrada y rectangular}

Donde Joseph Ribes pone de manifiesto su originalidad compositiva es en las bóvedas en planta cuadrada; en ellas, para definir la posición de ojivos y terceletes, Ribes propone diferentes estructuras geométricas completamente inéditas. El único ejemplo de bóveda en planta rectangular que aparece en el tratado de Ribes es una bóveda estrellada de 5 claves con proporción sesquiquarta (5:4), la Volta ab cinc claves y per llongada (Traza 58).

\footnotetext{
8 José Carlos Palacios Gonzalo, La Cantería Medieval : La Construcción de La Bóveda Gótica Española (Madrid: Munilla-Lería, 2009): 77.

9 En realidad, se ha encontrado un ejemplo de bóveda de crucería rebajada con combados en Tortosa, de la cual no se conoce la datación y se supone que los nervios no sean estructurales, sino una decoración en yeso.

10 Ibid. 77.
} 
BISECTRIZ

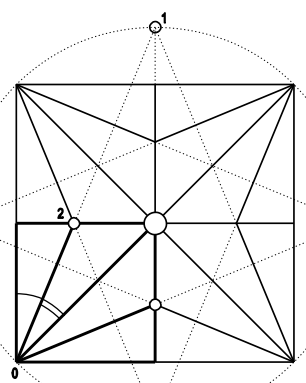

TRAMA

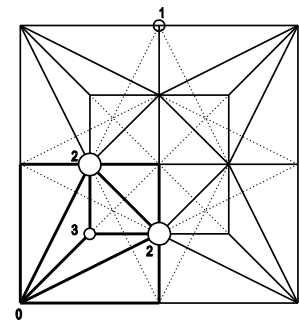

FIGURA CENTRAL

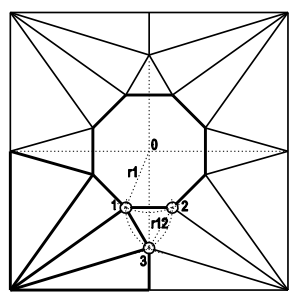

RED

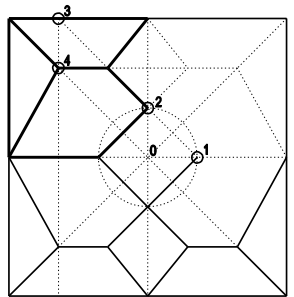

Fig. 6.5. Dibujo de crucería partiendo de terceletes situados en la bisectriz. Dibujo del autor.

\subsubsection{Bóvedas estrelladas}

En el diseño más tradicional de crucería estrellada, los terceletes pueden estar colocados en la bisectriz del ángulo que se crea entre el nervio diagonal y el perpiaño. La construcción geométrica consiste en trazar una circunferencia circunscrita a la planta de la bóveda, se continúan los ejes de simetría, y en el punto en que estos ejes corten a la circunferencia se une una recta que conecta este punto con el vértice opuesto de la bóveda; esta recta coincide con la bisectriz y su traza determina la posición del tercelete. En otros casos, Ribes sitúa el tercelete sobre la recta que conecta una esquina de la planta de la bóveda con el punto medio del lado opuesto.

Algunas trazas se forman con la ayuda de una figura geométrica central ya sea un rombo o un octógono; en este caso, el tercelete es un elemento de conexión entre los vértices de esta figura central y las esquinas de la bóveda. Sobre estas geometrías, añadiendo y sustrayendo claves, Ribes va creando variaciones que pueden enriquecerse mediante el uso de tramas ortogonales (Fig. 6.6).

SISTEMA MIXTO: ESTRELLA+TRAMA
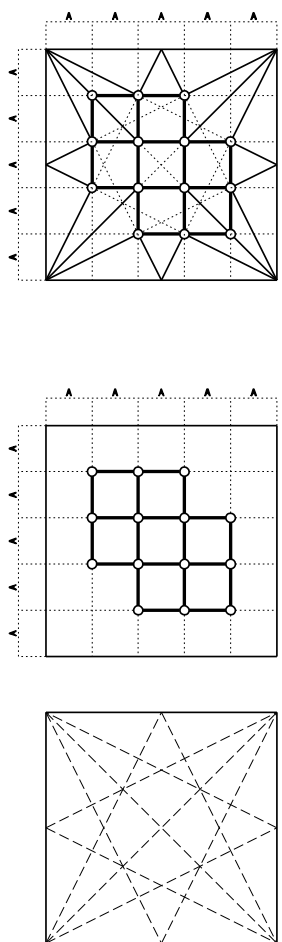

SISTEMA MIXTO: CRUCERIA+TRAMA
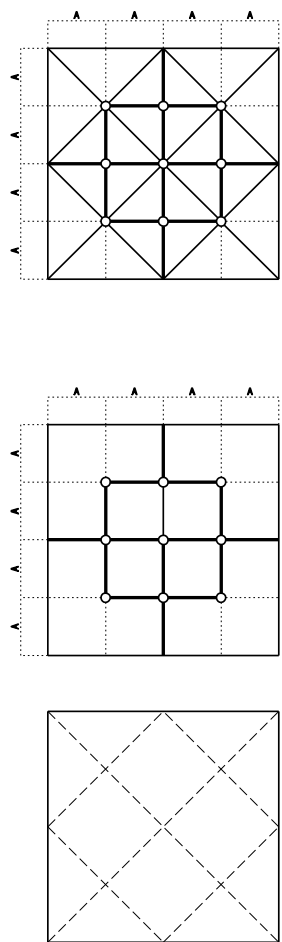
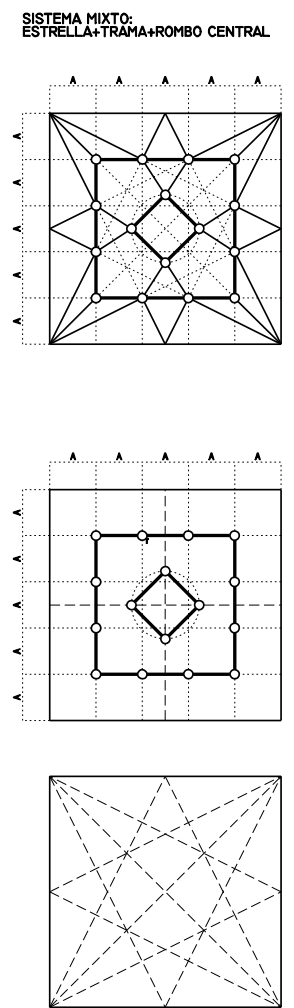

Fig. 6.6. Superposición de tramas. Dibujo del autor. 
Los diseños estrellados, cuyo origen quizás haya que buscarlo en las Sterngewölbe alemanas, alcanzaron un enorme grado de sofisticación y complejidad en Castilla ${ }^{11}$, en Cataluña, aunque no llegaron al mismo grado de desarrollo, existen, sin embargo, algunos ejemplos notables. Podría decirse que en el gótico catalán mantuvo siempre un carácter más esencial y estructural en el que la amplitud y altura de las bóvedas ${ }^{12}$, así como la gran esbeltez de los pilares, fueron sus características más notables. Algunos de los elegantes ejemplos recogidos en el Llibre de Trasas son diseños que tuvieron una cierta difusión en las regiones levantinas, como por ejemplo la volta ab nou claus, una bóveda estrellada a ocho puntas y clave central, que encontramos en la capilla de los Santos Felipe y Jaime el Menor, anteriormente Capilla de la Confraria dels Mestres de Cases i Molers, en el claustro de la Catedral de Barcelona, que fue acabada por Bartolmeu Gual en 143113 (Fig. 6.7).
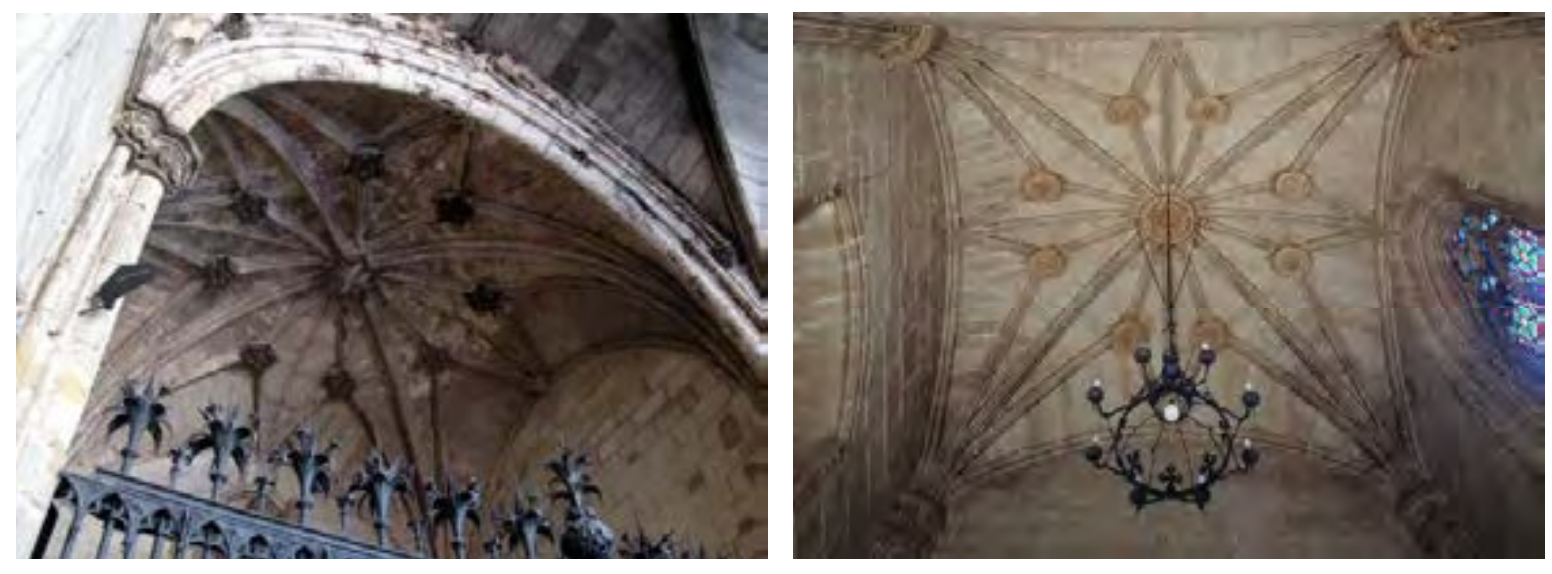

Fig. 6.7. Boveda de la Capilla de la Confraria dels Mestres de Cases i Molers (1431) en la Catedral de Barcelona y Capilla de la Virgen de la Misericordia (1484) en al Lonja de Valencia. Foto del autor.

Es éste un precoz ejemplo de bóveda estrellada con rampante redondo y superficie de intradós levemente cupulada, muy parecido a la bóveda de 9 claves de la capilla dedicada a la Virgen de la Misericordia construida entre 1484 y 1486 en la Lonja de Valencia donde pudo haber colaborado Juan Guas, maestro mayor de obras de los Reyes Católicos ${ }^{14}$. Tampoco se puede olvidar la semejanza con las bóvedas que el mismo Guas construyó en el Real Monasterio de Santo Tomás de Ávila, terminado en 1493. Ribes propone algunas variantes a este modelo: una bóveda a siete claves (como en Saint-Gervais en Paris), y otra más compleja de 17 claves cuyo dibujo puede inspirarse en algunas bóvedas germánicas.

\footnotetext{
11 Ibid.

12 La nave de la Catedral de Girona alcanzó los 22,8 metros de anchura, la Catedral de Mallorca 19,4m de anchura y $44 \mathrm{~m}$ de altura, Santa Maria de Manresa 18,5m, San Juan de Perpiñan 18,29m, Castelló d'Ampuries $15 \mathrm{~m}$. Se puede hacer una comparación con las fabricas castellanas: en la Catedral de Segovia, mas tardía, la luz de las bóvedas del tramo central es de 13,74m, en la Catedral de Córdoba de 13,7m. En Francia, las bóvedas de la nave central de Notre-Dame d'Amiens, con $14.6 \mathrm{~m}$ de ancho, alcanzan los $42.3 \mathrm{~m}$ de altura. La nave mas alta, inacabada, alcanza los 48m en Saint-Pierre de Beauvais. Wikipdia: <https://en.wikipedia.org/ wiki/Main_Page>. Fecha de acceso: 23 jun. 2015.

13 Mariá Carbonell i Buades, "Marc Safont ( ca. 1385-1458 ) En l' Arquitectura Barcelonina Del Segle XV. Documents per a Un Esbós Biogràfic," Estudis Històrics i Documents Dels Arxius de Protocols 21 (2003): $181-226$.

14 Arturo Zaragozá Catalan and Maria Gomez-Ferrer Lozano, Pere Comte, Arquitecto (Generalitat Valenciana, 2007): 84-86.
} 
Ribes, en ocasiones, muestra otras bóvedas menos "ortodoxas", caracterizadas por su diseño aparentemente asimétrico originado por el posicionamiento de algunas claves aparentemente extrañas a la composición.

Mencionemos también otro alarde compositivo de Ribes, que se produce al transformar el conocido dibujo de la bóveda cuadrada con un octógono formado por ligaduras alrededor del polo ${ }^{15}$, en un inesperado diseño carente de clave central (Fig. 6.9).
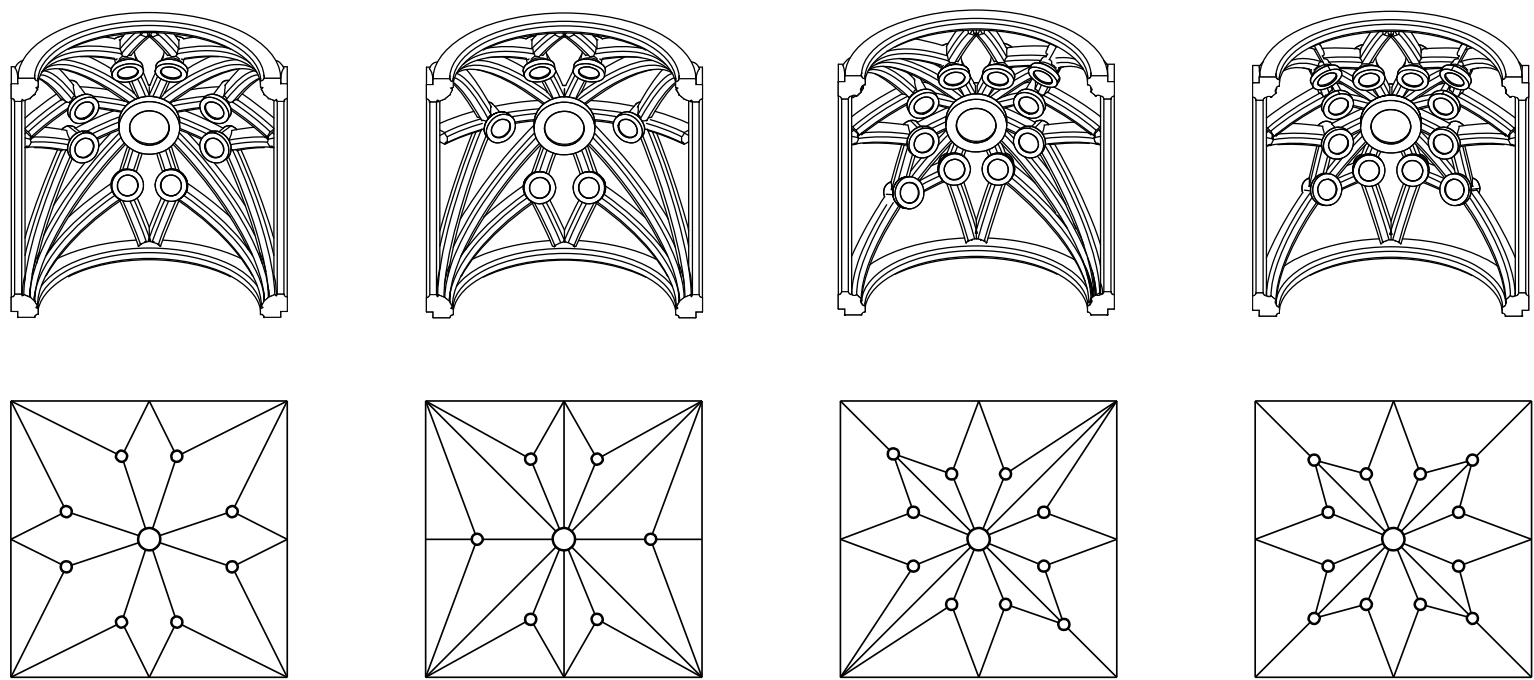

Fig. 6.8. Bóvedas estrelladas: elaboraciones sobre el mismo prototipo. Dibujo del autor.
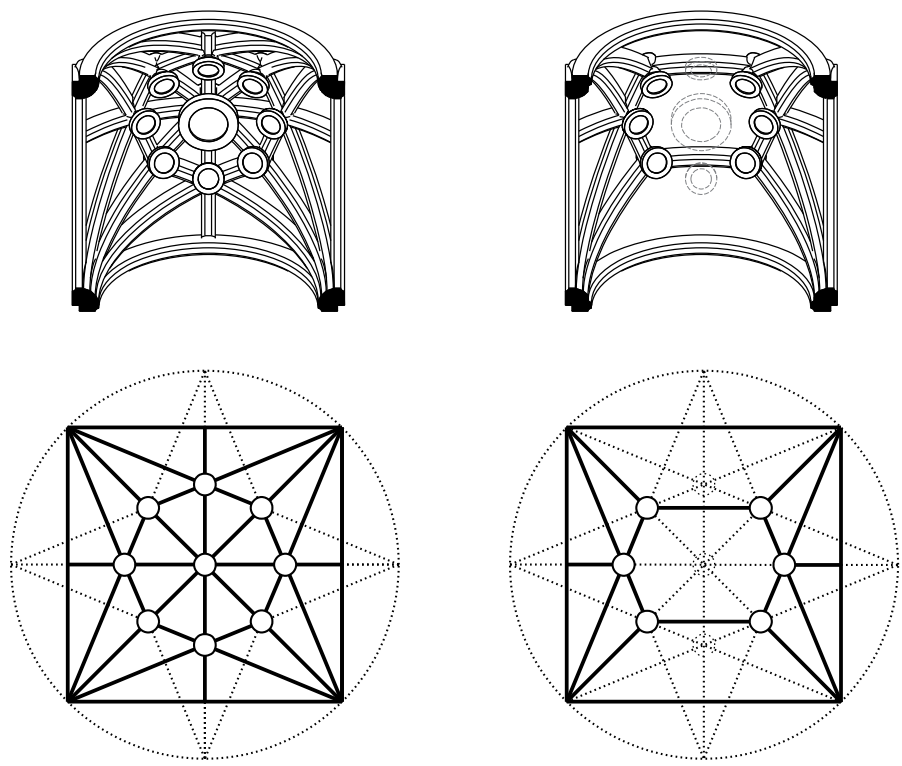

Fig. 6.9. Sustracción de claves y nervios. Dibujo del autor.

15 Navarro Fajardo describe la incidencia de esta bóveda en el Levante y nos recuerda que Arturo Zaragozá ha visto como precedente la bóveda de la capilla de la Visitación de la Catedral de Burgos (1440-1442), obra de Juan de Colonia. Juan Carlos Navarro Fajardo, "Bóvedas Valencianas de Crucería de Los Siglos XIV AI XVI: Traza y Montea" (Tesis Doctoral, 2004): 114. 


\subsubsection{Bóvedas en red}

Una de las bóvedas del Llibre de Trasas, la volta ab dotsa claus (Traza 70), tiene una regla compositiva singular, es una bóveda en red de tipo alemán, una netzgewölbe, es decir, una bóveda en red de geometría insólita tanto en Castilla como en Cataluña, de la cual nos ocuparemos con más detalle en el capítulo de esta tesis relativo a la construcción de una bóveda de crucería de Ribes. La volta ab dotsa Claus (Fig. 6.10), que se caracteriza por su simetría axial, carece de nervios diagonales y tampoco clave central, la cúspide de la bóveda se cierra con cuatro claves, a partir de la cual, se originan la retícula de los nervios. La traza en planta de la bóveda se inicia con el cuadrado que forman las cuatro claves centrales, equidistantes del centro, y de las diagonales y las ligaduras que las conectan las claves entre sí. Las bóvedas en red, al contrario que las bóvedas estrelladas, carecen de clave central. Se construyen con una red de nervios que forman una retícula de geometría más o menos compleja. Este tipo de bóvedas alcanzan el máximo de su expresividad en las iglesias en planta de salón, es decir, con las naves a la misma altura. En este tipo de iglesias, el diseño de la red va conectando todos los tramos entre sí hasta extenderse a la totalidad del templo. En Alemania, este tipo de bóvedas se construían con un solo arco. Por compleja que fuera la red, un sólo arco y por tanto una única dovela, permitía construir toda la bóveda.

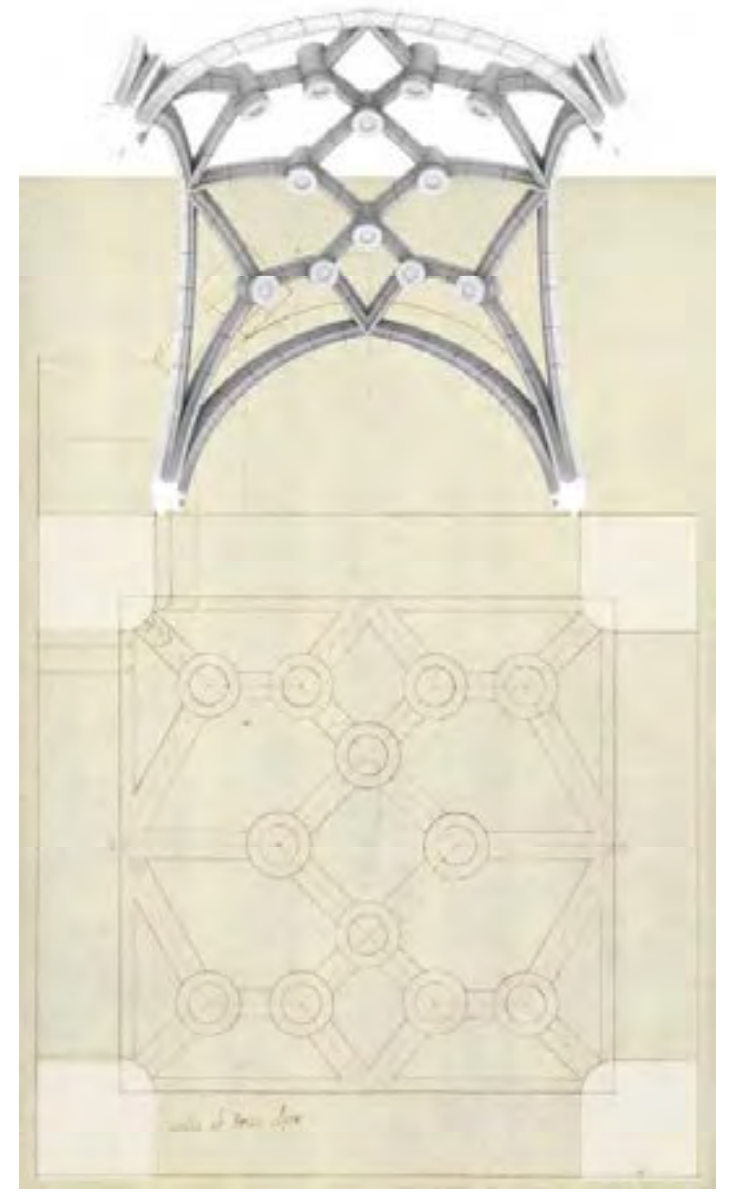

Fig. 6.10. Volta ab dotsa claus. Dibujo del autor. 

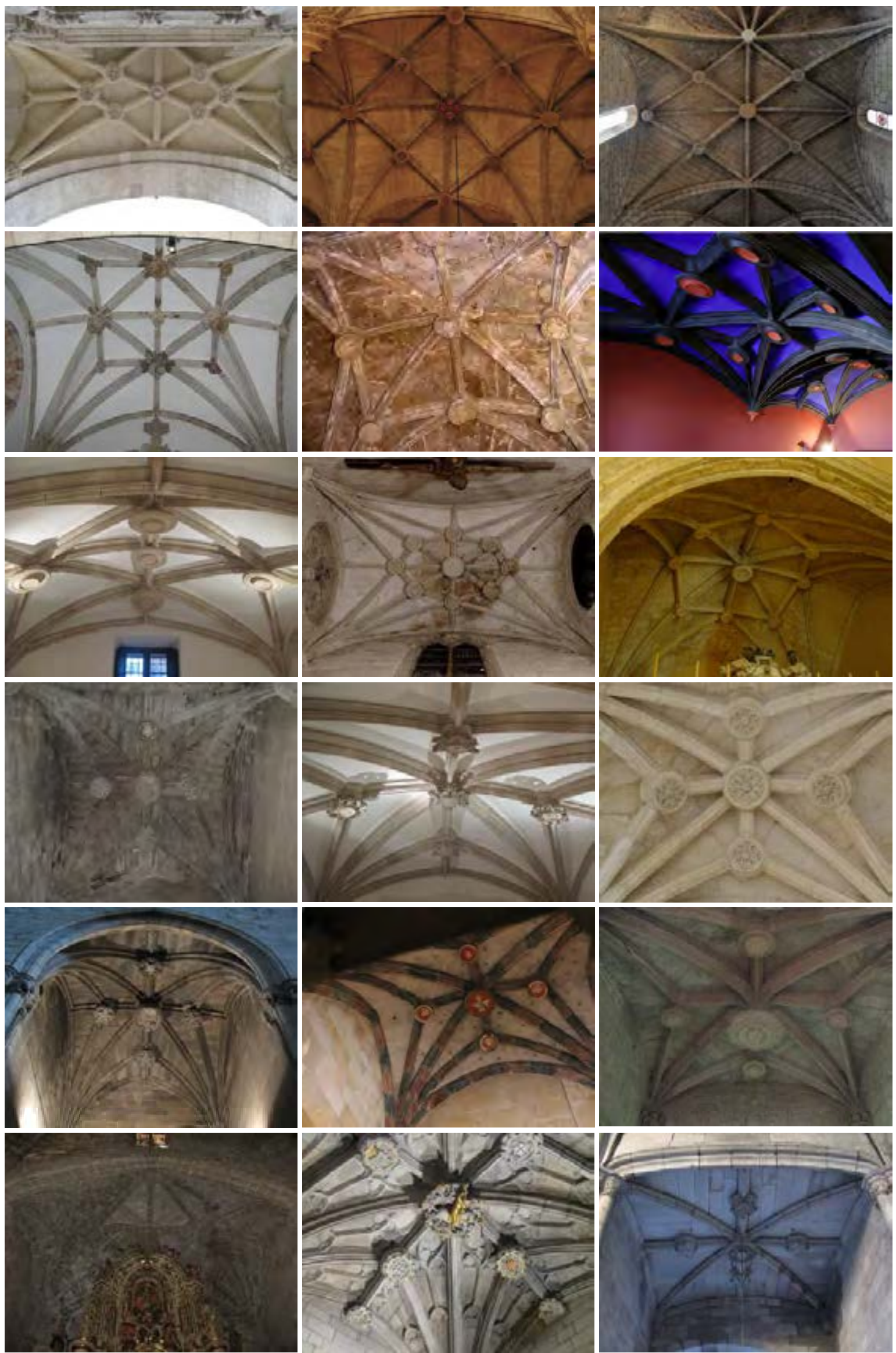

Fig. 6.11. Catedral de Sassari; Lonja de Valencia; Santa Maria de Flix; Capilla Hospital de la Santa Creu, Barcelona; Collegiata de Sant Pere d'Auger; Sacristia del Monasterio de Bellpuig (F y G); Sala Capitular de la Catedral de Valencia; San Giacomo, Cagliari; Catedral de Girona, Monasterio de Bellpuig; Catedral de Cagliari; Catedral de Barcelona; Catedral de Tarragona; Catedral de Lleida; Catedral de Tortosa; Capilla de Sant Jordi, Palau de la Generalitat de Barcelona; Catedral de Barcelona. Fotos del autor. 

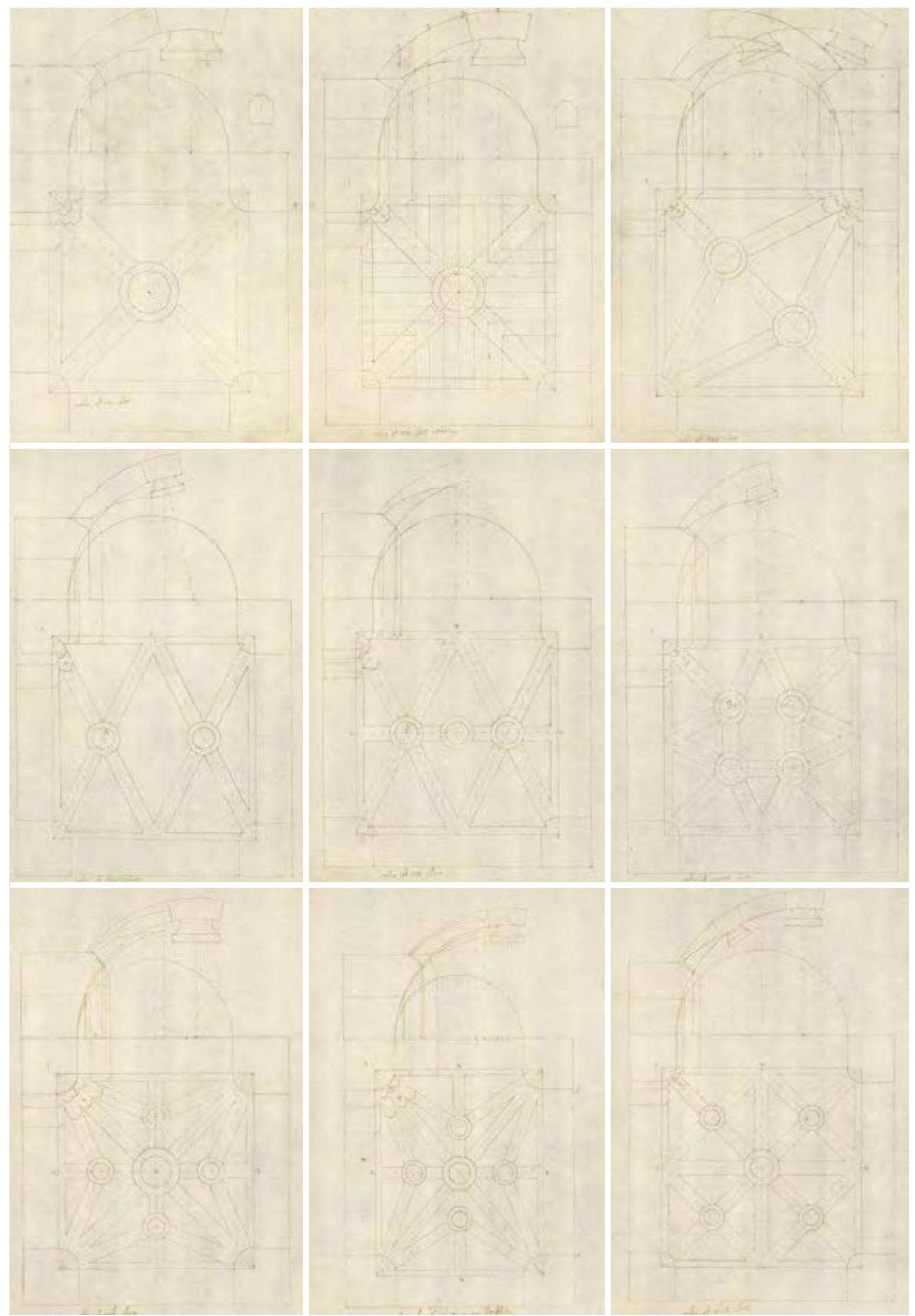

Fig. 6.12. Bovedas de cruceria en el Llibre de Trasas 

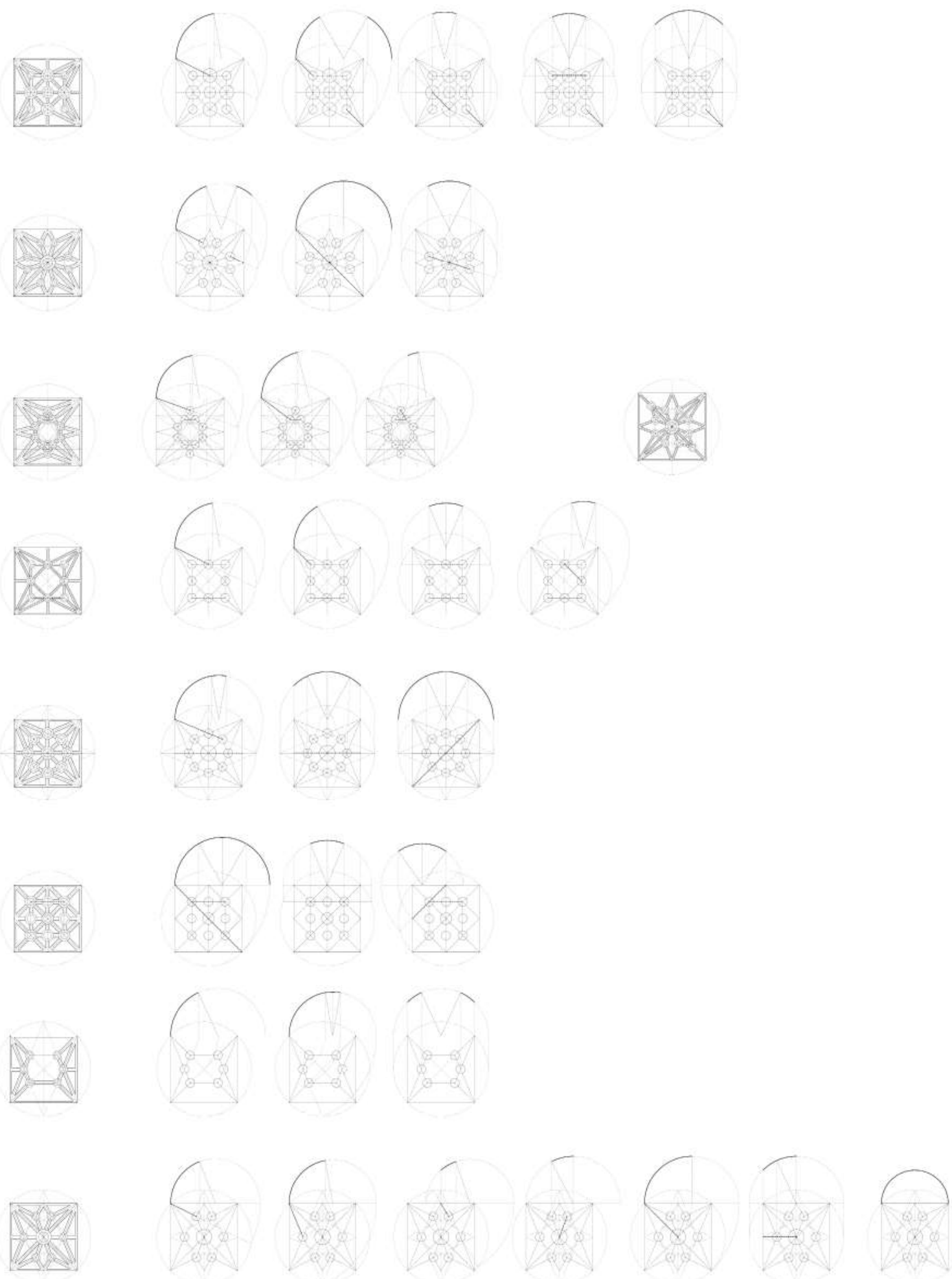

Fig. 6.13. Montea de las bovedas. Dibujo del autor. 

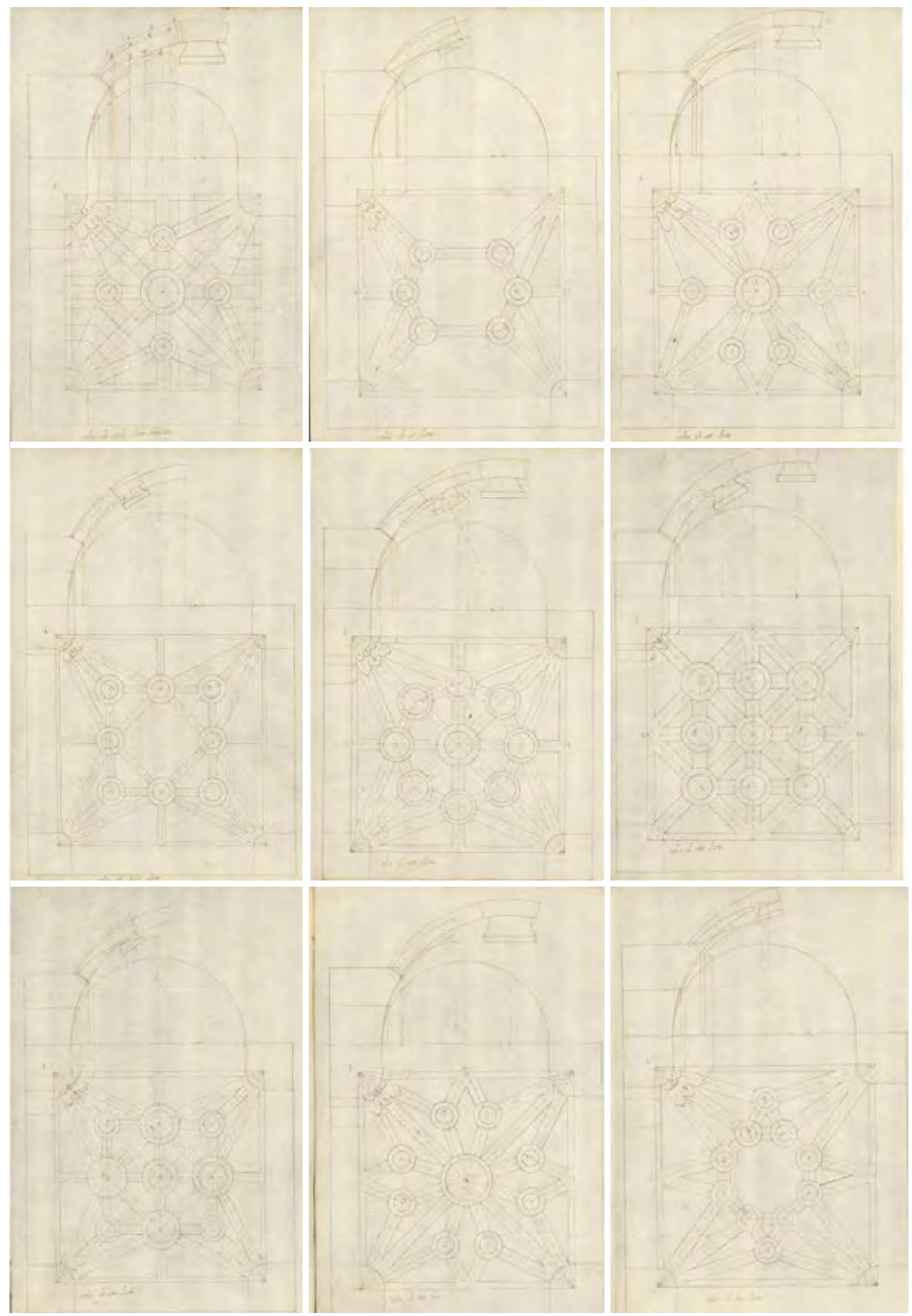

Fig. 6.14. Bovedas de cruceria en el Llibre de Trasas 

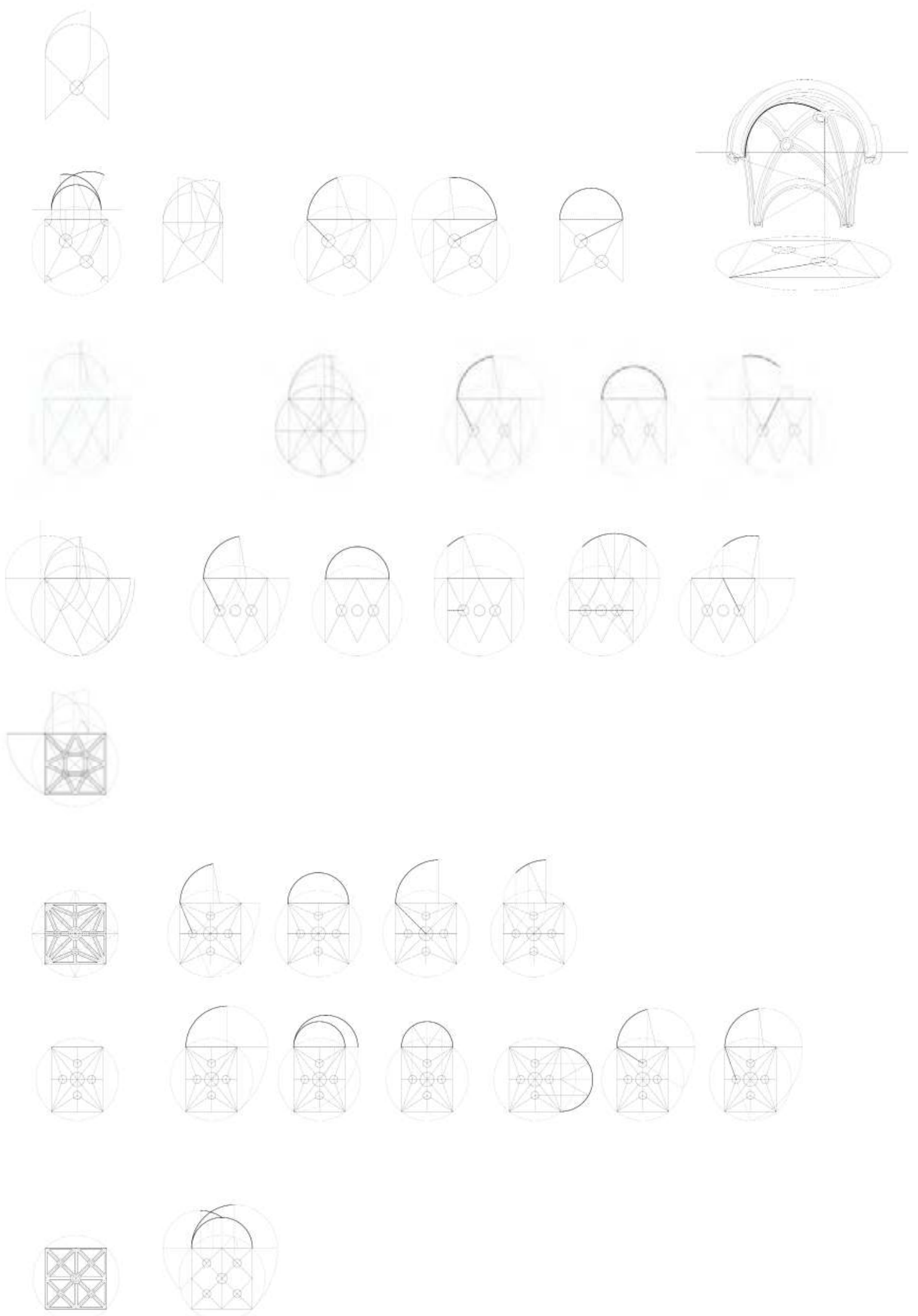

Fig. 6.15. Montea de las bovedas. Dibujo del autor. 

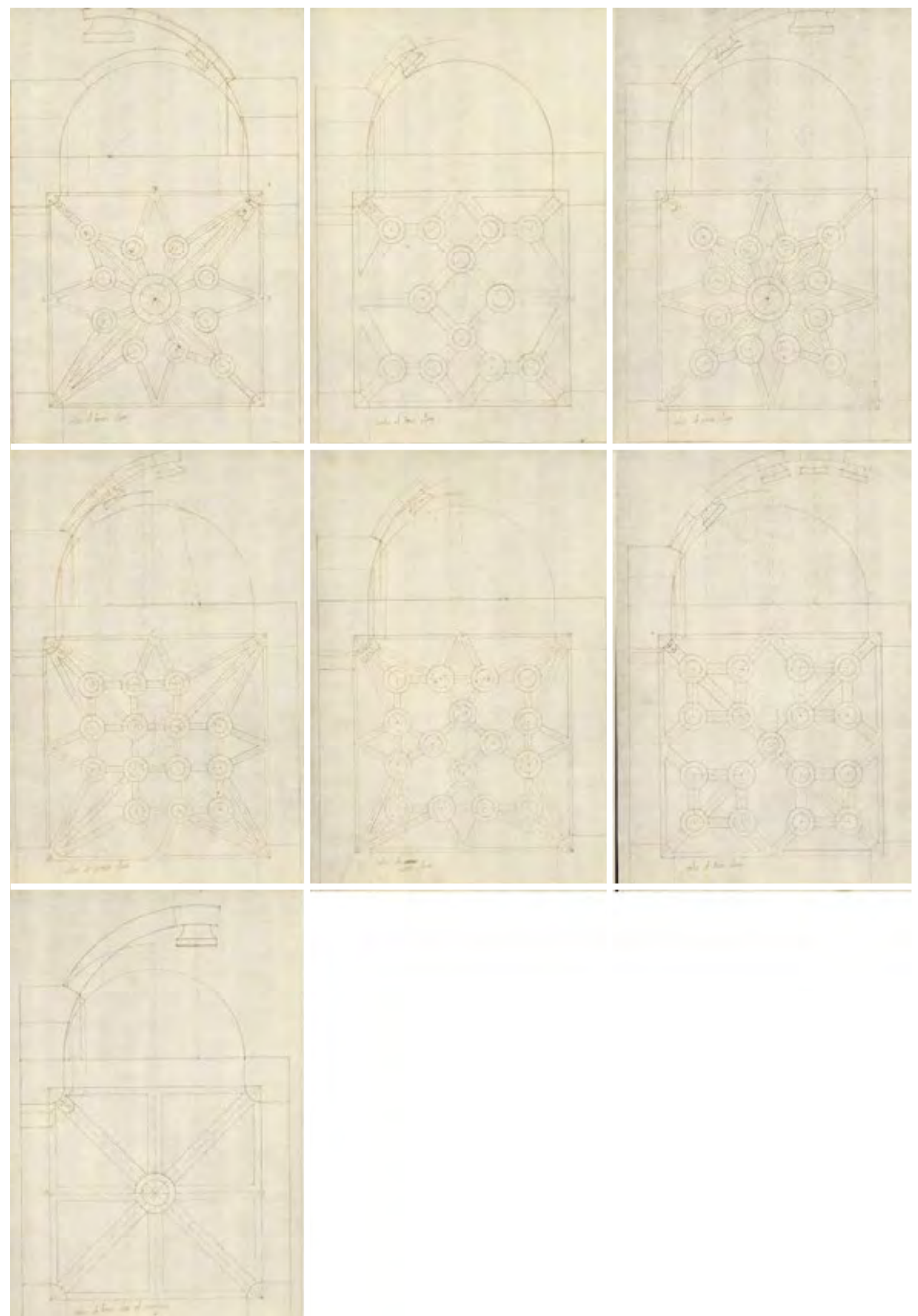

Fig. 6.16. Bovedas de cruceria en el Llibre de Trasas 

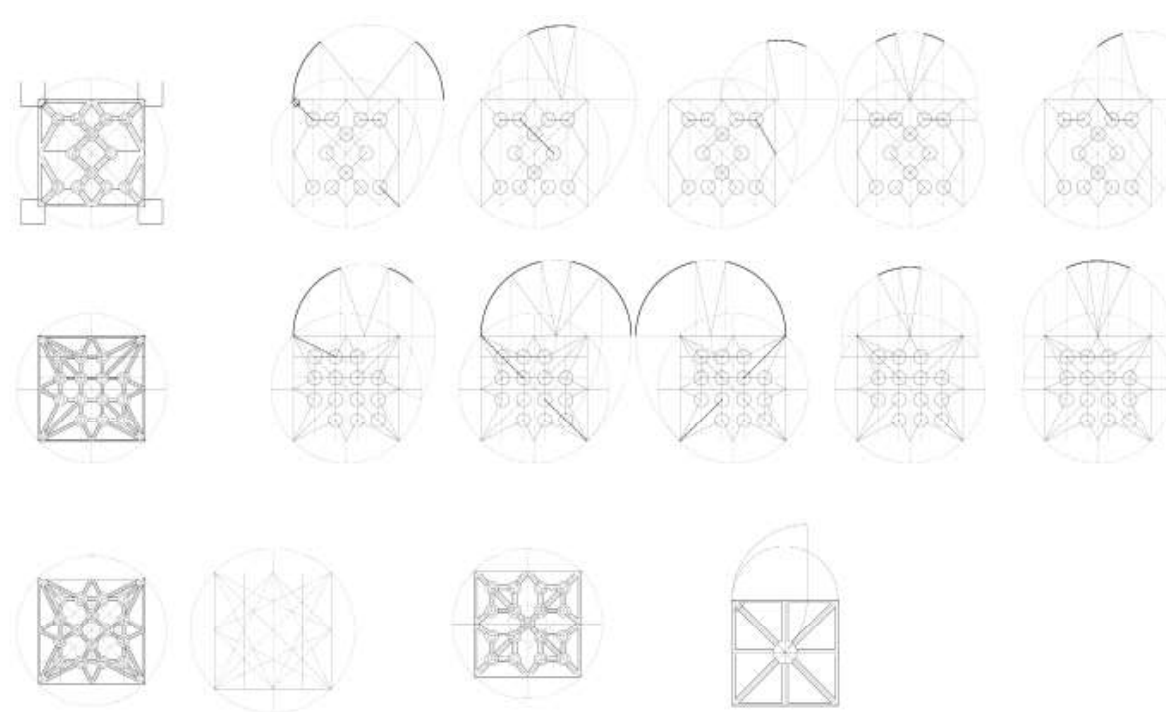

Fig. 6.17. Montea de las bovedas. Dibujo del autor.
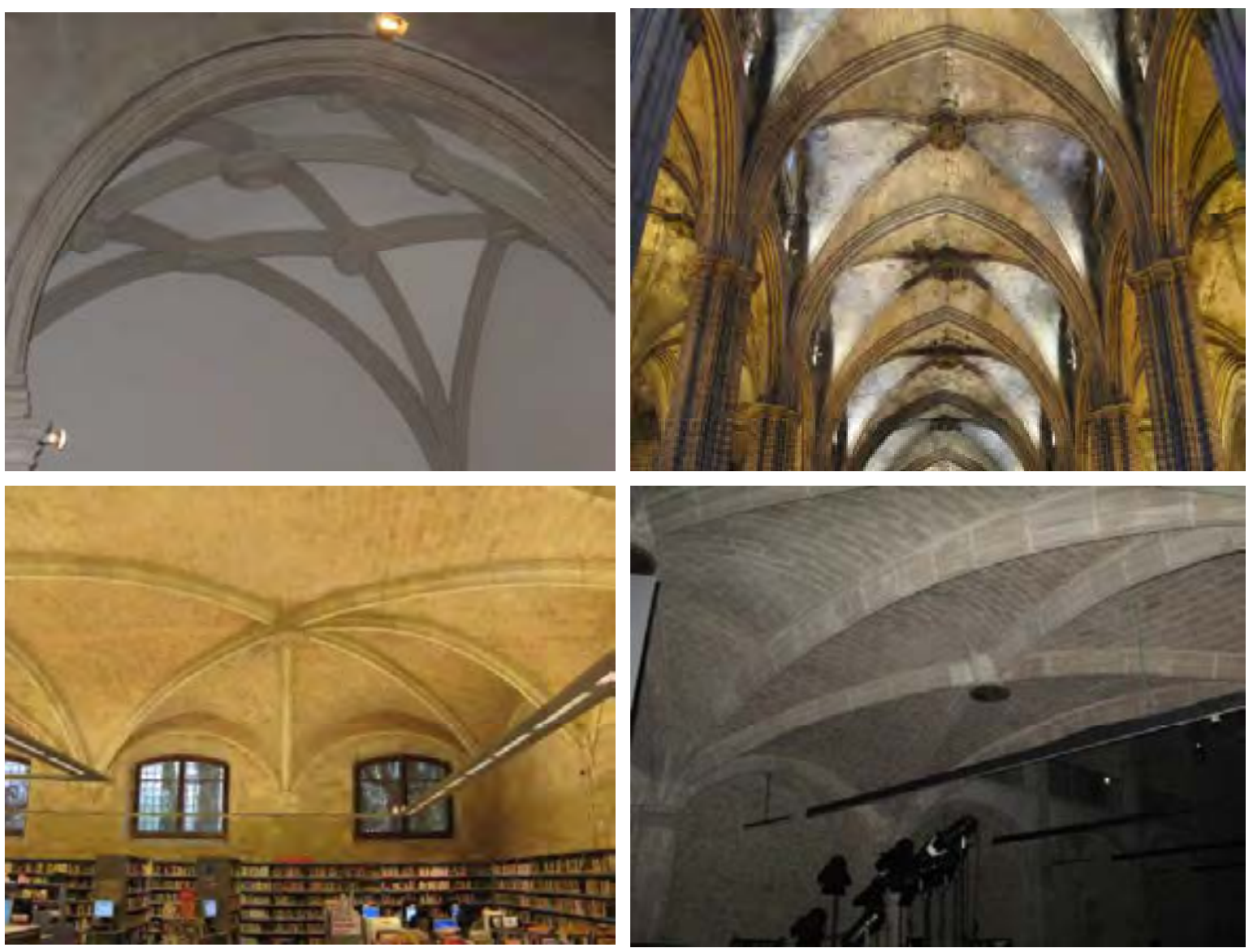

Fig. 6.18. Iglesia Parroquial de Bellpuig; Catedral de Barcelona. Fotos del autor.

Bovedas de arcos muy rebajados en el Hospital de la Santa Creu y en el Convent dels Angels, Barcelona.

Fotos del autor. 


\subsubsection{Bóvedas en planta triangular, redonda y octagonal}

La arquitectura gótica, con frecuencia, utilizaba trompas de terceletes para resolver la transición entre formas cuadradas y poligonales. En lugar de las trompas cónicas del Románico, las trompas góticas eran bóvedas de crucerías de planta triangular. Así son los tercerols del cimborio de la Catedral de Barcelona o de la cabecera de la Capilla del Palau Episcopal de Tortosa. Es muy singular la volumetría de los tercerols de la ex Sala Capitular de la Catedral de Barcelona ${ }^{16}$, ahora conocida también como Capilla del Cristo de Lepanto, por sus asimetrías. Se encuentran a un nivel más bajo en respecto a altura de la bóveda estrellada de la sala, de manera parecida a los ejemplos de la gran sala de Castelnuovo en Nápoles o del caso de la Capilla del Palau Episcopal de Tortosa, diferentemente del caso de la bóveda del aula capitular de Valencia.

En otras ocasiones, la bóveda en planta triangular, lejos de ser un elemento accesorio, era un elemento protagonista de la composición del edificio, tal es el caso de Nôtre-Dame de Moulins y St-Jean-au-Marché en Troyes (s. XVI) donde aparece la boveda ab quatre claus ab triangol (Figura 11). En su tratado, Ribes dibuja este tipo de bóvedas con planta de triangulo equilátero de intradós esférico.

Por lo que respecta a las bóvedas de planta circular, Ribes describe cinco casos resueltos con bóvedas estrelladas de 5 y 9 claves. Estos modelos, con frecuencia estaban destinados para ser utilizados en las torres campanarios; recordemos al respecto la capilla del campanario de la Catedral de Alghero, completado en 1547 en estilo gótico-catalán, cuya traza corresponde a la volta ab planta rrodona, o sea una bóveda de crucería sencilla sobre planta redonda. Curiosamente, en el ejemplo citado aparece el despiece de la plementería que, sorprendentemente, en lugar de aparejarse en vuelta de horno como hubiera sido lo natural, lo hace a la francesa, es decir, según el eje $\mathrm{X}$ e $\mathrm{Y}$. Las bóvedas de crucerías en planta ochavada y redonda estaban destinadas a conformar las cabeceras de los templos, los cimborios y las capillas. También en este caso Ribes proporciona ejemplos que van, desde los casos más sencillos hasta los más elaborados. En Cataluña estas estructuras tuvieron notable éxito y difusión, desde las soluciones más elementales con los nervios tímidamente marcados en la cabecera del Monestir de Sant Cugat, hasta el notabilísimo ejemplo de la ex Sala Capitular de la Catedral de Barcelona.

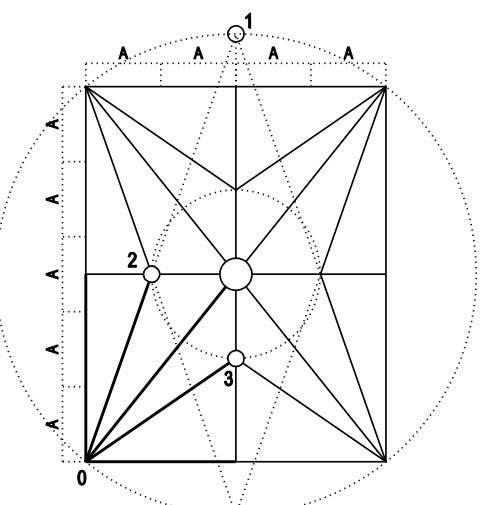

Fig. 6.19. Boveda Sexquicuarta (5:4). Dibujo del autor.

16 Obra de Arnau Bargués, fallecido en 1413 

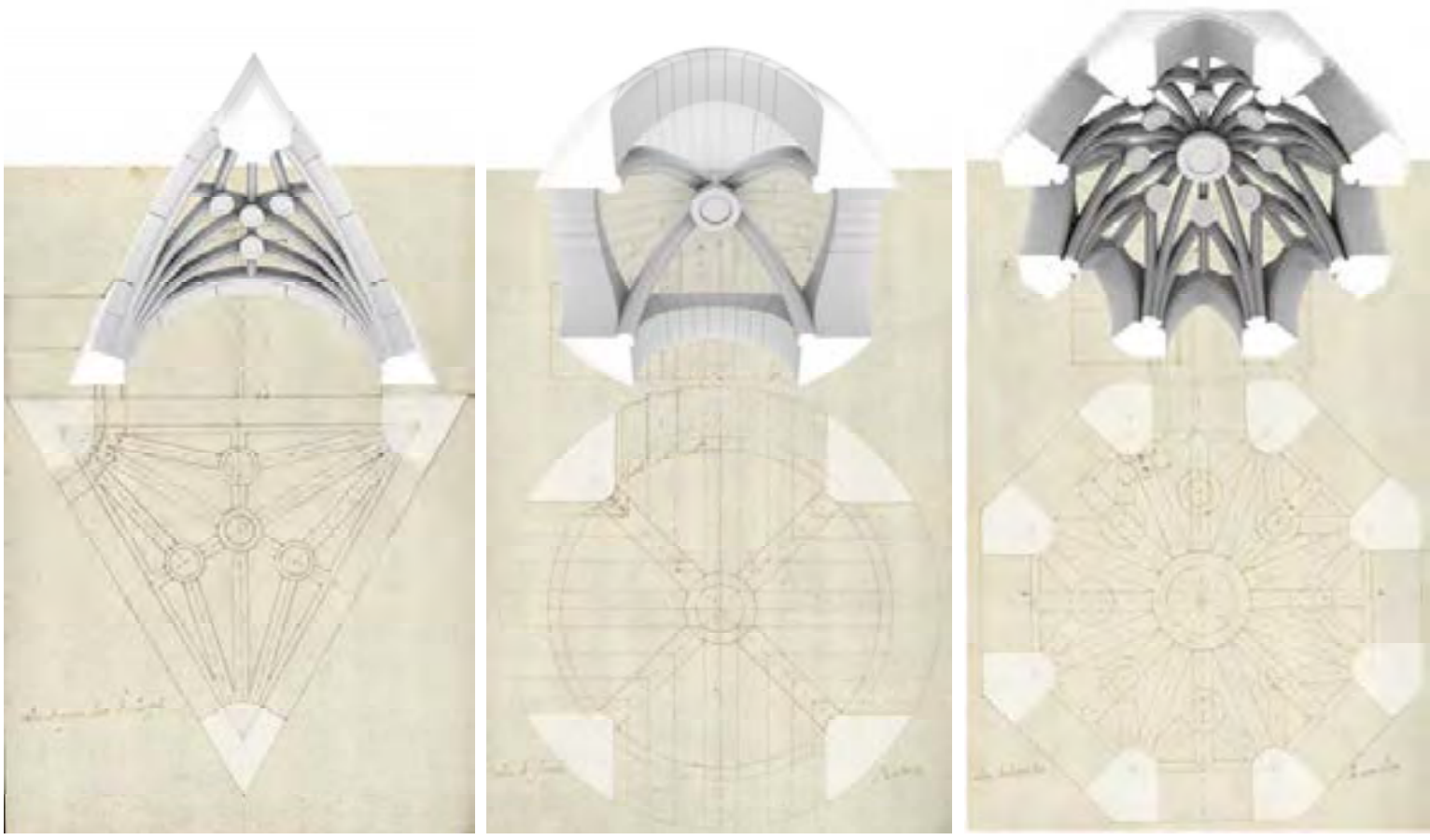

Fig. 6.20. Boveda ab quatre claus ab triangol; Volta ab planta rrodona; Volta buitavada ab nou claus. Dibujo del autor.
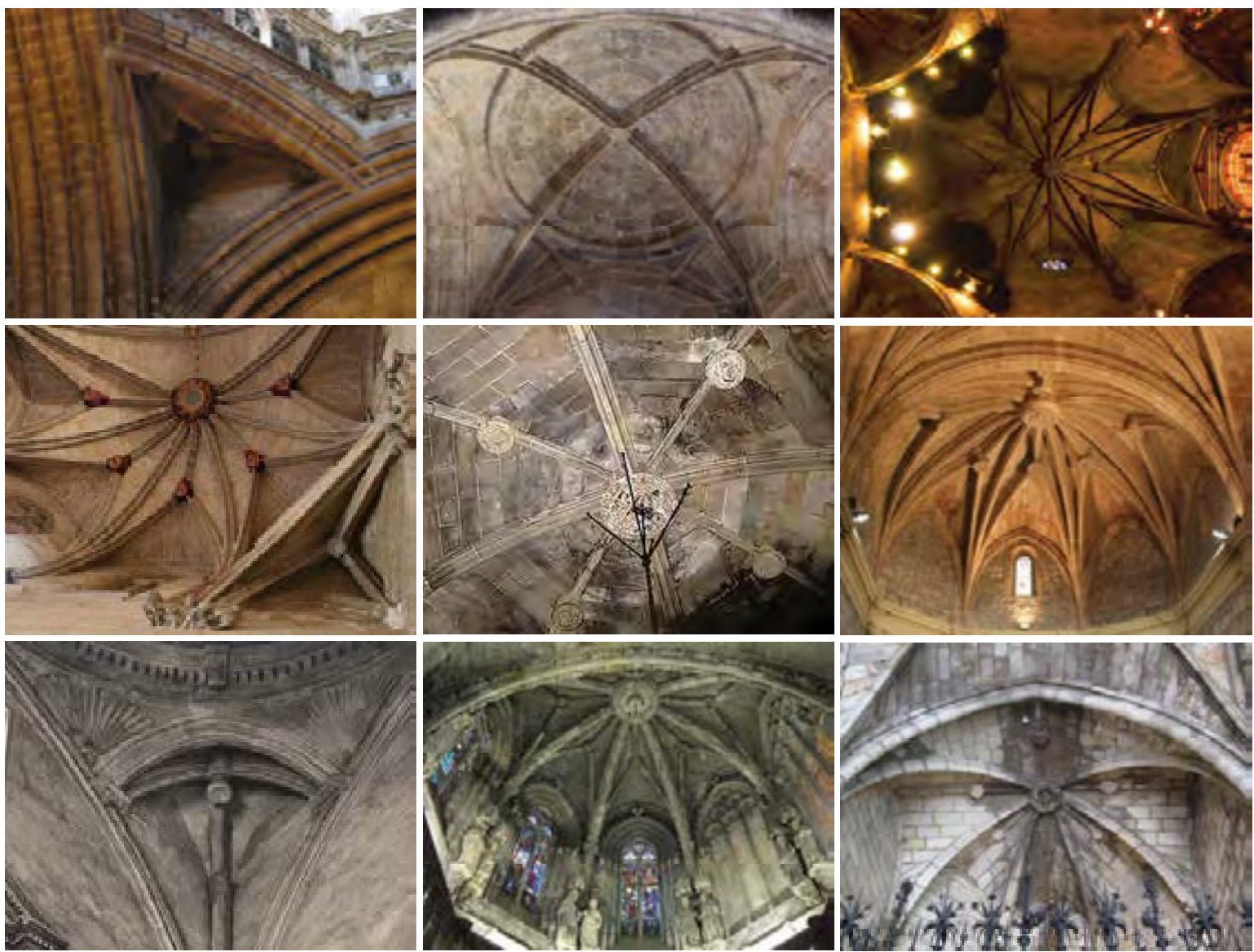

Fig. 6.21. Cimborrio Catedral de Barcelona; Catedral de Alghero; Catedral de Barcelona; Bisbat de Tortosa; Iglesia Santa Ana, Barcelona; Pobla de Massaluca; Catedral de Oristano, antiguo coro; Catedral Vieja de Lleida; Catedral de Barcelona. Fotos del autor. 

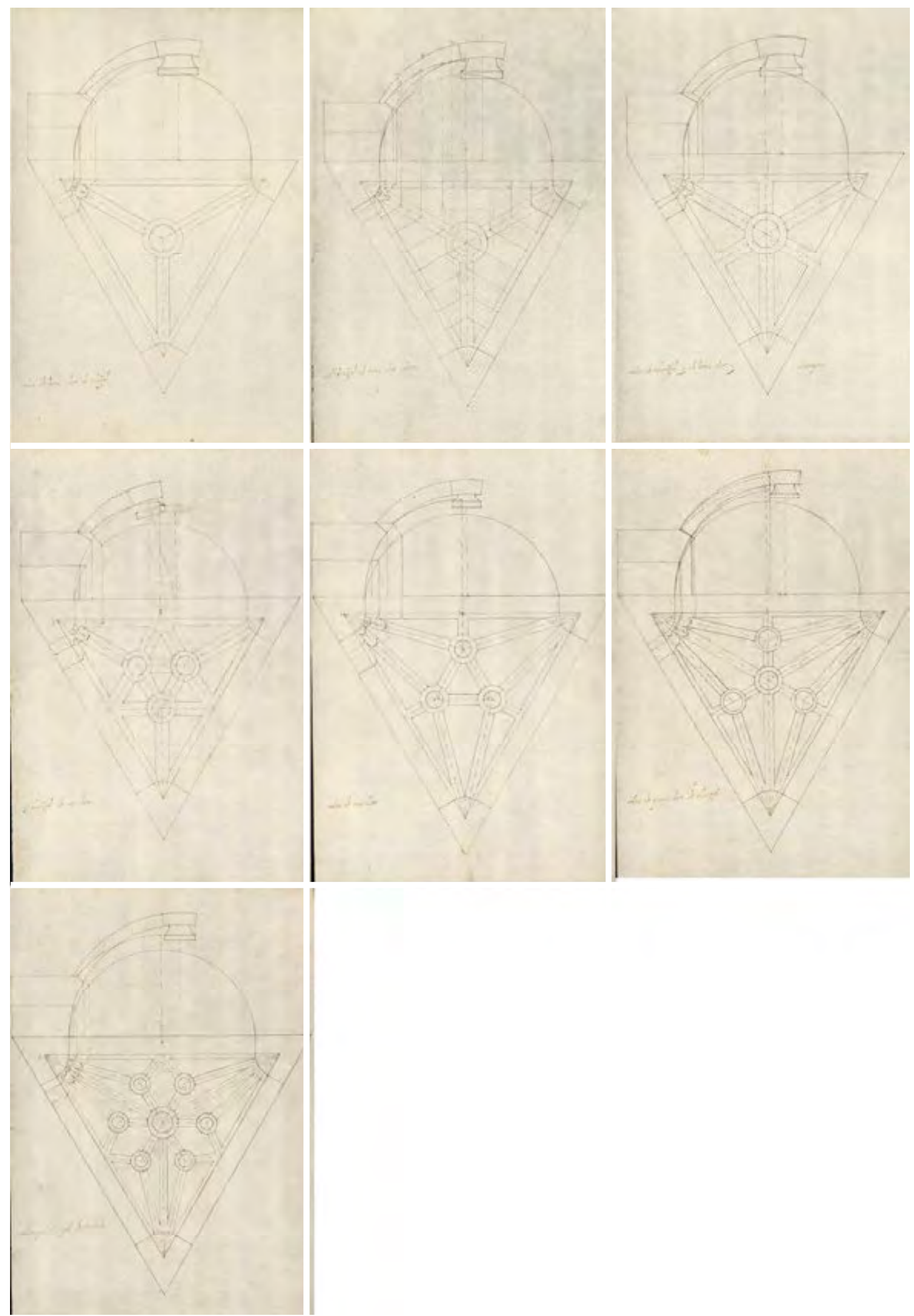

Fig. 6.22. Bovedas de cruceria en el Llib e de Trasas 

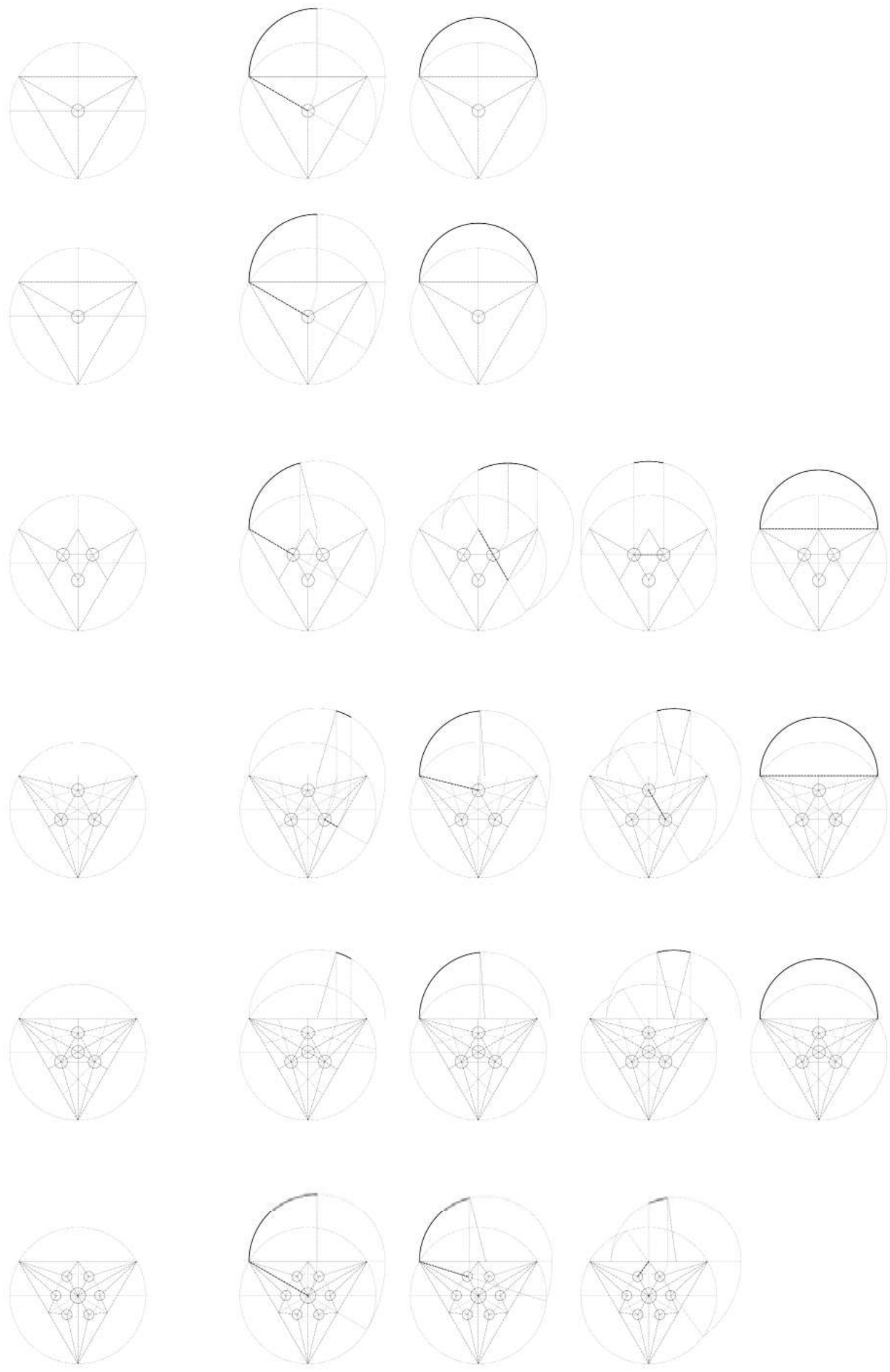

Fig. 6.23. Montea de la bovedas. Dibujo del autor. 

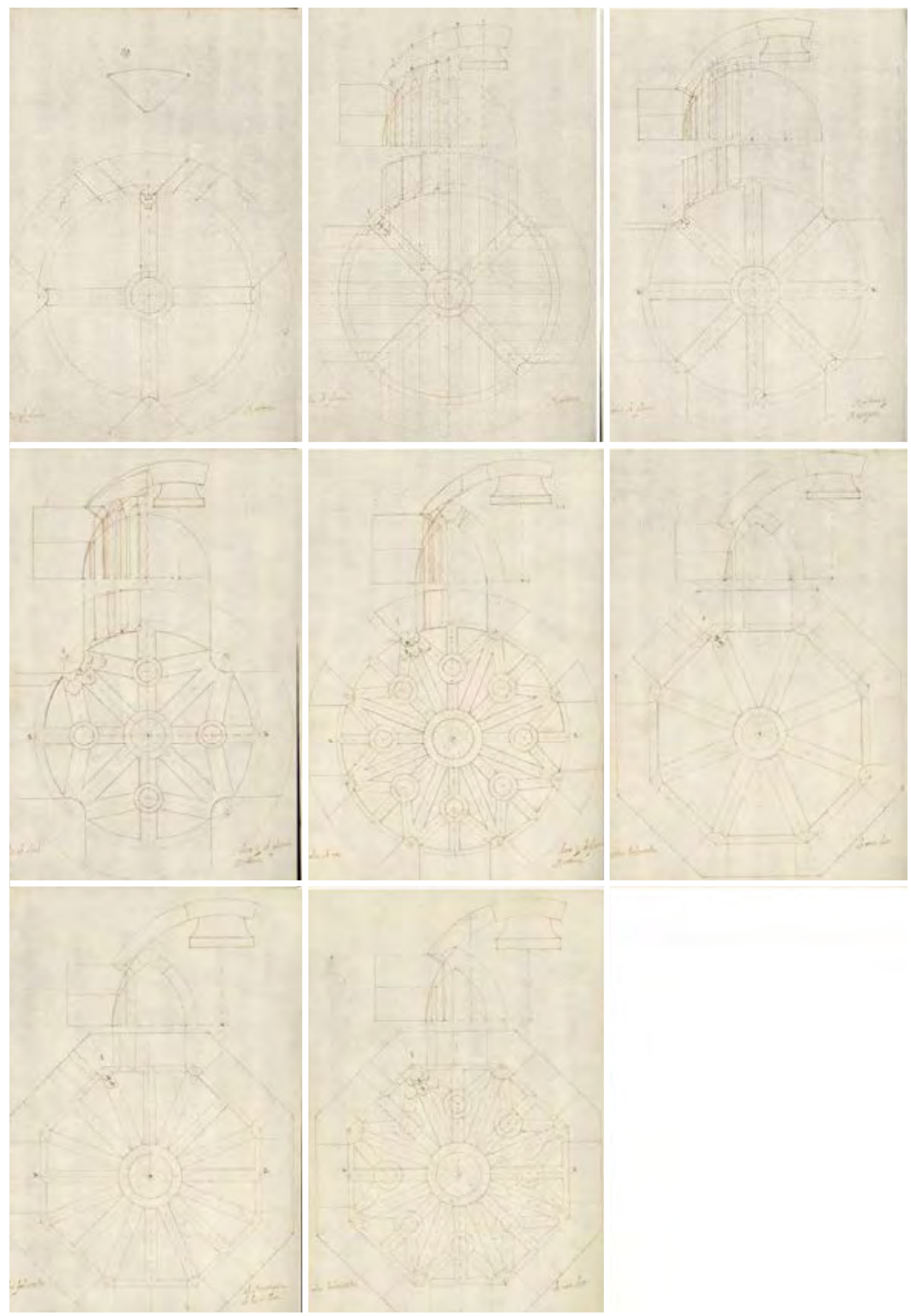

Fig. 6.24. Bovedas de cruceria en el Llibre de Trasas 

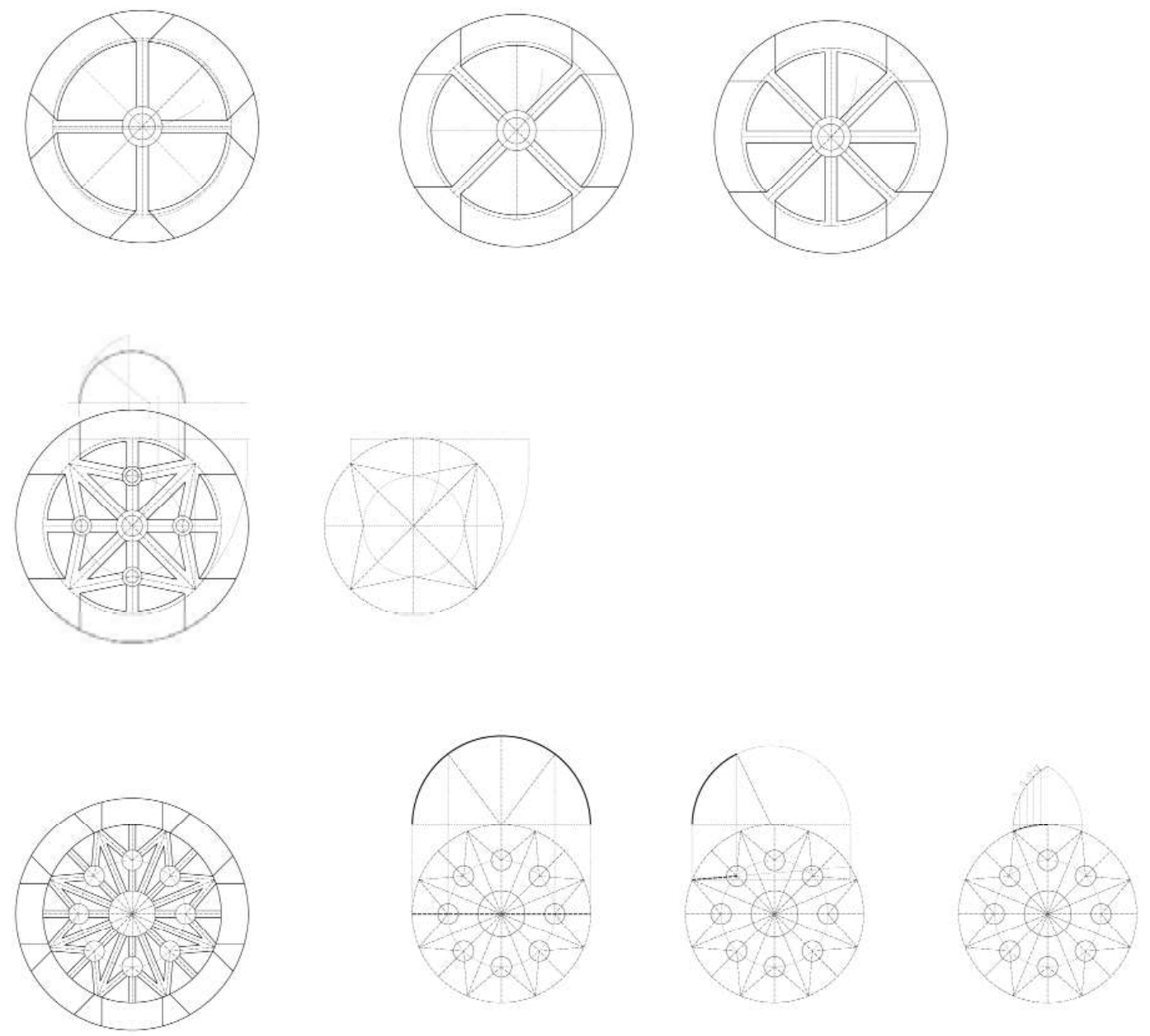

Fig. 6.25. Montea de las bovedas en planta circular. Dibujo del autor.
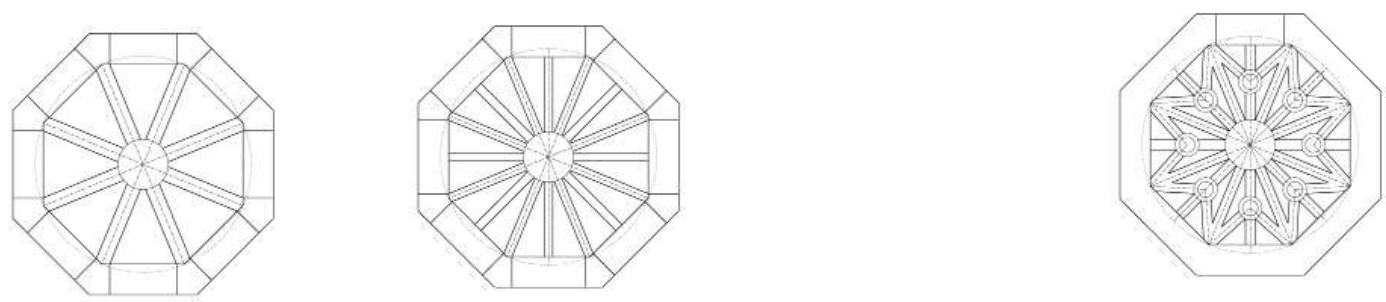

Fig. 6.26. Montea de las bovedas en planta octagonal. Dibujo del autor. 


\subsection{Otros elementos compositivos de la bóveda: plementería, enjarjes, claves}

\subsubsection{Plementería y jarjas}

Algunas trazas del Llibre presentan el dibujo de la plementería con geometría romboidal. En el citado artículo de Carbonell, se hace mención a la observación de Javier Gómez que la bóveda estrellada de 5 claves ${ }^{17}$ que cubre el templete de la fuente del claustro de la Catedral de Barcelona (Fig. 5.27) tiene un despiece romboidal ${ }^{18}$. Según la clasificación de Viollet le Duc, esta disposición de la plementería es de escuela normanda, diferente de la plementería a la francesa de las otras bóvedas del claustro.

Para el apoyo de los nervios y el contrarresto de los empujes, la bóveda requiere de la construcción las jarjas. Ribes representa las dovelas de arranque de la bóveda empezando con sillares horizontales sobresalientes de los soportes laterales, en línea con la tradición constructiva gótica.
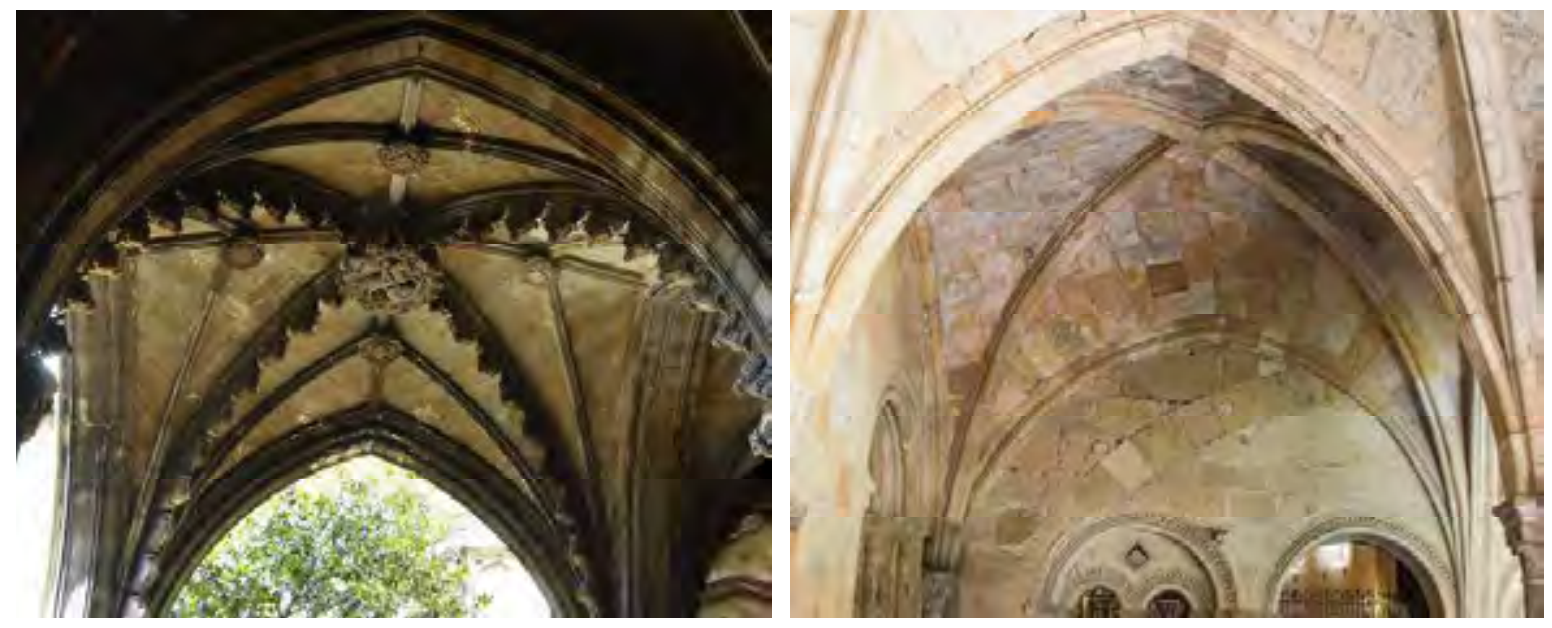

Fig. 6.27. Templete en el calustro de la Catedral de Barcelona; Claustro de la Catedral de Tarragona. Fotos del autor.

\subsubsection{Claves}

Uno de los recursos más interesantes de la construcción de las bóvedas de crucería tardogóticas es, probablemente, el que se refiere a la talla de sus claves. En España, gran parte de las bóvedas construidas en el siglo XVI tienen sus claves inclinadas; es decir, son claves en el que el eje del cilindro central se orienta hacia el centro de la bóveda. Es ésta una particularidad constructiva que caracteriza notablemente las bóvedas del último gótico. Este apartado se dirige precisamente hacia este tema, con el convencimiento de que, tras él, se oculta una de las páginas más interesante de la cantería y de la geometría de origen medieval.

Tradicionalmente, tanto las nervaduras como las claves góticas son siempre verticales; es decir, que el cilindro central de la clave permanece siempre vertical respecto al plano horizontal de tierra ${ }^{19}$, como muestra la figura 6.28 en su parte izquierda. Esta particularidad

\footnotetext{
17 Esta bóveda es coronada con la clave de Antoni Claperós fechada a 1448

18 Carbonell i Buades, 2008

19 Palacios Gonzalo, 2009. Sobre este tema puede también consultarse: Jose Carlos Palacios Gonzalo and Rafael Martín Talaverano, "La Construcción de Una Bóveda de Crucería En La Escuela Técnica Superior de Arquitectura de Madrid," Informes de La Construcción 61, no. 515 (September 14, 2009): 49-58.
} 
es una consecuencia de su construcción. La labra de una clave gótica requiere conocer exactamente sus proyecciones horizontal y vertical, es decir, el dibujo en planta y alzado de la misma. Los maestros de cantería góticos llegaron a dominar con total precisión el dibujo en planta y en alzado de la bóveda, incluyendo todas las piezas que la forman: dovelas, jarjas y claves. Trazar la montea de la bóveda consistía precisamente en esto, en la traza, a escala natural, del dibujo en planta y alzado de la bóveda.

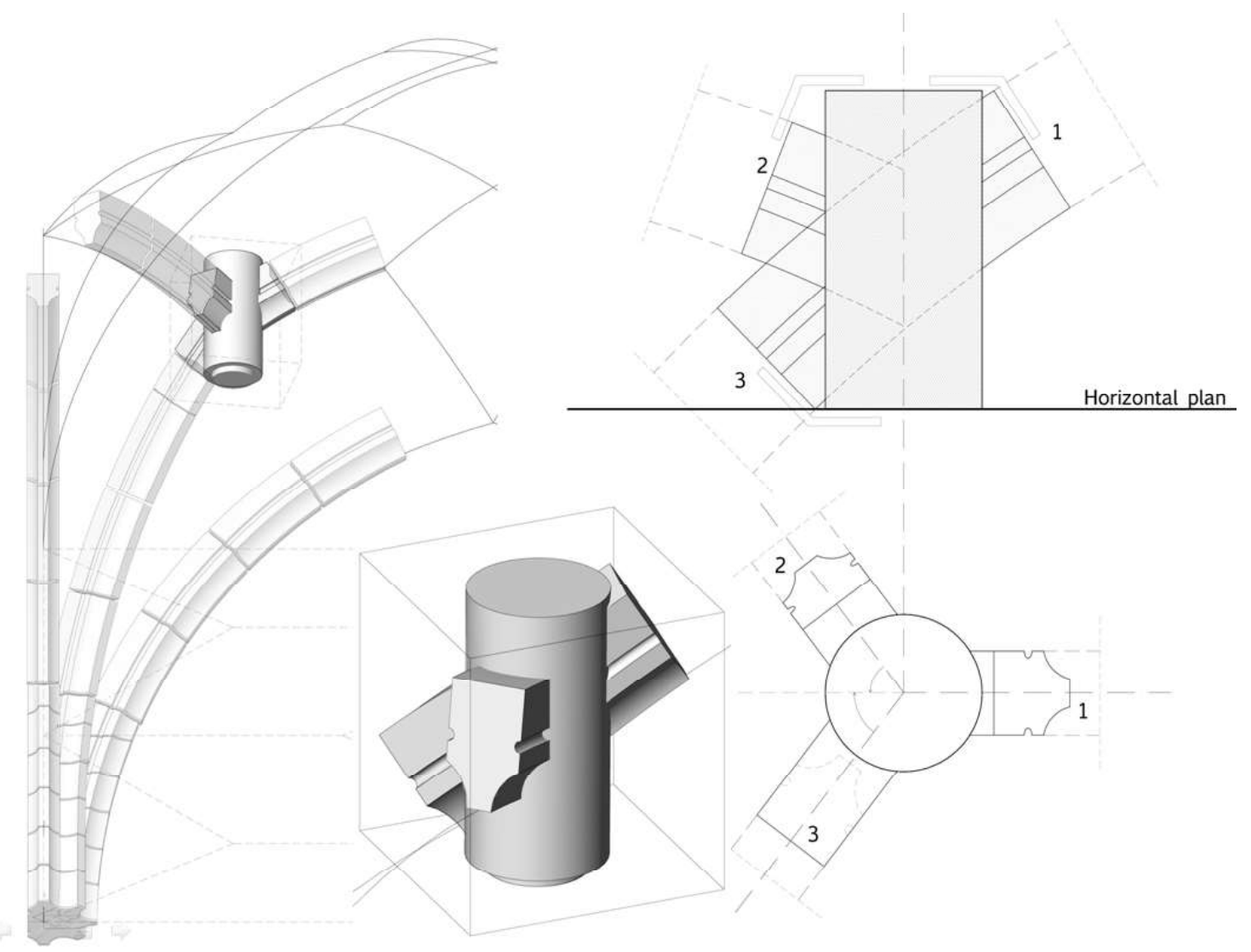

Fig. 6.28. Vista de una clave vertical, proyección vertical y horizontal de la misma. Dibujo del autor.

Aunque la facilidad de talla entre la talla inclinada o vertical es innegable, existe otra razón mucho más poderos que justifica el cambio en el diseño de las claves: el ahorro del material. El volumen de piedra que requiere una clave inclinada puede llegar a ser la mitad que la que necesita una clave vertical. La verdad, es que esta afirmación puede variar bastante; ya que, si la clave se encuentra cerca del cenit de la bóveda, la diferencia entre una y otra es inapreciable, pero, si como suele ocurrir en las bóvedas tardogóticas, existen multitud de clave alejadas del centro de la bóveda, las diferencias de volumen de piedra pueden llegar a ser muy notables.

Podría hacerse un fácil análisis comparativo dibujando la misma clave de la bóveda de Joseph Ribes en su versión vertical o radial. La figura 6.29 muestra la diferencia de su sólido capaz y, se puede comprobar que en este caso el volumen de piedra requerida es algo más del doble. Una pequeña maqueta de resina en 3D de las dos claves pone en evidencia, aún con mayor claridad, las diferencias entre ambas. 
En la construcción histórica, los costes relativos a la extracción de la piedra en cantera han sido siempre mucho más importantes que el coste de mano de obra; además, a estos gastos hay que añadir los gastos de acarreo y transporte de toneladas de piedra de cantería a través de caminos infernales, los cuales podría llegar a ser astronómicos. Sin lugar a dudas, el ahorro de algunas toneladas podría ser fundamental para obtener un contrato. Más allá de las consideraciones económicas, se puede extraer otra observación interesante. La clave inclinada, como acabamos de ver, requiere la proyección sobre el plano tangente, o, dicho de otro modo, sobre el plano de trasdós de la bóveda. Recordemos que toda la estereotomía clásica y el corte de dovelas para la construcción de cúpulas esféricas se basan precisamente en la proyección de la dovela sobre la cara de intradós (Fig. 15). Es extraordinariamente interesante observar cómo, tanto la cantería de origen medieval como la estereotomía clásica, convergen en el mismo punto: la proyección sobre el plano tangente.
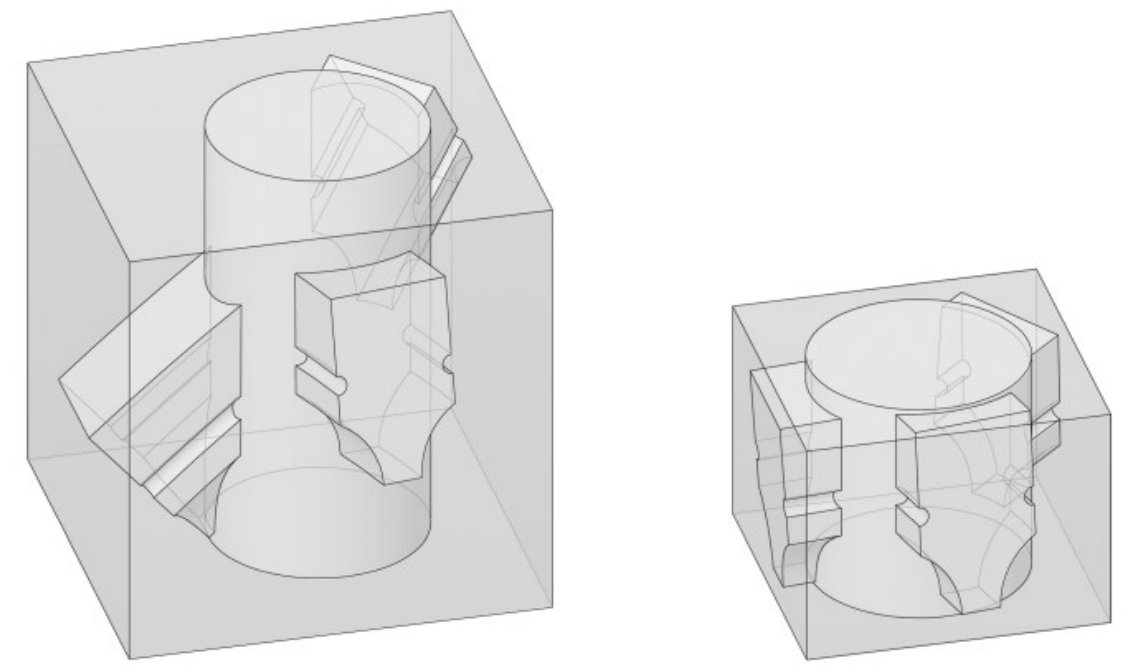

Fig. 6.29. Dos prototipos volumétricos que muestran la misma clave resuelta en vertical o inclinada Las diferencias de volumen son extraordinarias. Dibujo del autor.

\subsubsection{Las claves verticales}

Antes de proceder a la labra de una clave era necesario realizar el dibujo de la bóveda a tamaño natural, en planta y en alzado ${ }^{20}$. Cada una de las claves se dibujaban con total precisión en las intersecciones de los nervios, como muestra la figura 6.29, a la derecha. Posteriormente, el dibujo de la proyección horizontal se dibuja sobre la cara superior de un bloque de piedra prismático y, siguiendo su contorno, se procedía a su talla vertical; un cantero especialista en talla de claves comenzaba la labra trabajando en vertical, quitando la piedra sobrante hasta obtener el volumen de la clave. Al finalizar esta primera etapa, podría reconocerse la forma de la clave con sus brazos y su cilindro central, como muestra la figura 6.30A en el centro.

20 Enrique Rabasa Díaz, "Construcción de Una Bóveda de Crucería En El Centro de Oficios de León," in Actas Del Cuarto Congreso Nacional de Historia de La Construcción. Cádiz, 27 - 29 de Enero de 2005 (Madrid: Instituto Juan de Herrera, 2005). 
Viene ahora la operación más delicada: el corte inclinado de los brazos. Para conocer estos ángulos de corte, el cantero debe observar la montea vertical de la clave, en la que se puede contemplar cómo cada arco acomete a la clave con un ángulo preciso. Con respecto al plano superior puede medirse fácilmente el ángulo con que debe cortarse cada brazo para que la clave encaje en su posición. Fue Robert Willis ${ }^{21}$ el primero que llamó la atención sobre la importancia de este plano superior al cual llamó plano de referencia.

El cantero, armado de un falso compás, colocaba uno de los brazos sobre el plano horizontal, y el otro, lo hacía coincidir con el plano de acometida del arco sobre la clave. A continuación, trasladaba este ángulo sobre el brazo correspondiente de la clave lo que permitía cortarlo con la inclinación precisa (Fig. 6.30). Una vez que todos los brazos estuvieran cortados podría procederse a la labra decorativa de la clave con la seguridad de que ésta terminaría encajando con total precisión en su posición. Por tanto, las claves tradicionales, se tallaban a partir de sus dos proyecciones, horizontal y vertical, lo que explica que este tipo de claves sean siempre verticales.

Sin embargo, este tipo de claves, tienen un inconveniente nada desdeñable, requieren volúmenes de piedra muy considerables; efectivamente, al necesitar conservar el plano superior de referencia para su talla, hace que el sólido capaz de piedra necesario para labrar la clave sea bastante más grande que la clave resultante. Cuando la clave ocupa una posición central en la bóveda este hecho no tiene mayor importancia, pero, a medida que la clave se encuentra más alejada del centro de la bóveda, el volumen de piedra es cada vez mayor. Seguramente es esta la razón que explica que a finales del gótico los canteros cambien de técnica, paulatinamente, van a sustituir la clave cilíndrica vertical por una clave inclinada, es decir un cilindro radial situado en el punto de cruce de los arcos.
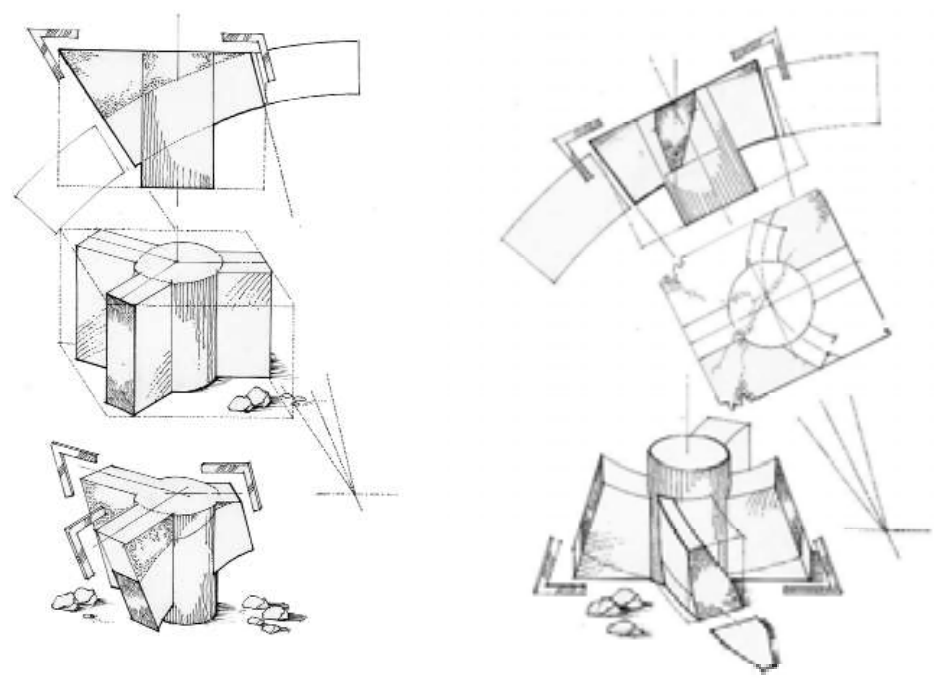

Fig. 6.30. A: Proceso de labra de la clave vertical en tres fases: en primer lugar el dibujo de la montea vertical y la determinación de los ángulos de corte de los brazos, en segundo lugar, corte por extrusión vertical a partir del dibujo de la planta y, en tercer lugar, corte de los brazos.

B: Proceso de labra de la clave inclinada: en primer lugar dibujo de la clave y determinación de los ángulos de corte, dibujo de la plantilla de la clave proyectada sobre el plano tangente y, por último, talla de la clave desde el plano tangente. Dibujo de J.C. Palacios.

${ }^{21}{ }^{21}$ Robert Willis, Transactions of the Royal Institute of British Architects of London (London: Longmans, 1842). 


\subsubsection{Las claves inclinadas}

La clave inclinada viene a resolver el problema del cruce de nervios de forma extraordinariamente práctica ya que, en muchas ocasiones, la clave es sólo un cilindro más o menos decorado en el que acometen los nervios. Esto sucede con frecuencia en las bóvedas de Joao del Castillo ${ }^{22}$ en el que las claves son simplemente cilindros intercalados radialmente en los cruces de nervios.

Sin embargo, como se dijo anteriormente, las claves verticales tenían siempre unos pequeños brazos sobre los que acometían los nervios y, en consecuencia, una cuidadosa labra de las claves inclinadas requeriría que también éstas estén dotadas de sus pequeños brazos prominentes. Estos brazos aseguran el perfecto ensamblaje de la clave con los nervios (Fig. 6.32); sin embargo, al intentar dibujar la clave inclinada con sus correspondientes brazos surge un problema geométrico de notable complejidad.

Recordemos que las claves verticales se labran a partir de la proyección de ésta sobre el plano horizontal, con lo que dibujar la posición de los brazos es inmediato e intuitivo; sin embargo, el dibujo exacto de la clave inclinada requiere proyectarla sobre el plano tangente a la bóveda y lo cual requiere una destreza geométrica nueva. La proyección sobre el plano tangente es un nuevo recurso muy notable y de extraordinario ingenio que jamás había sido empleado en la cantería gótica, su aparición en el siglo XVI, nos permite apreciar el alto nivel que llegó a alcanzar la geometría proyectiva de origen medieval.

La labra de la talla inclinada debe tomar como plano de referencia, no el plano horizontal de la cara superior de la clave, al que se refería Robert Willis, sino el plano tangente a la bóveda allí donde se encuentre la clave. Como muestra la figura 6.30B en la parte inferior, la labra se hace perpendicularmente al trasdós de la clave y, como puede ya apreciarse fácilmente, el volumen de piedra necesario para su labra se reduce considerablemente.

\subsubsection{El dibujo de las claves inclinadas}

A la izquierda en la figura 6.33 a la derecha, vemos una de sus claves radiales de la bóveda de Joseph Ribes con su eje perpendicular a su plano tangente; a la izquierda, esta dibujada la clave perpendicular a su plano tangente y, en la parte superior, su proyección sobre dicho plano. Sin embargo, la confección de este dibujo que constituye la plantilla de labra más importante para poder tallar la dovela, requiere unas destrezas geométricas que vamos a exponer a continuación.

Observemos ahora el dibujo que muestra la figura 6.32, en su parte izquierda, vemos dibujada, en alzado, una clave inclinada; en la parte superior, se ha trazado su proyección sobre el plano tangente, sin embargo, este dibujo no es nada fácil de realizar; a priori, no está nada clara la posición que ocupa cada brazo. Veamos a continuación cómo se ha logrado saber la posición exacta que ocupa cada brazo. Partimos del dibujo del alzado de la clave de la figura 6.32. En una línea perpendicular al plano de tangencia, se dibujó la circunferencia de la clave con centro en $\mathrm{O}$ y, a continuación, se trazó uno cualquiera de

22 Soraya Genin, "Les Voûtes Manuelines de João Del Castilho. Histoire et Conservation" (Tesis Doctoral, 2014). 


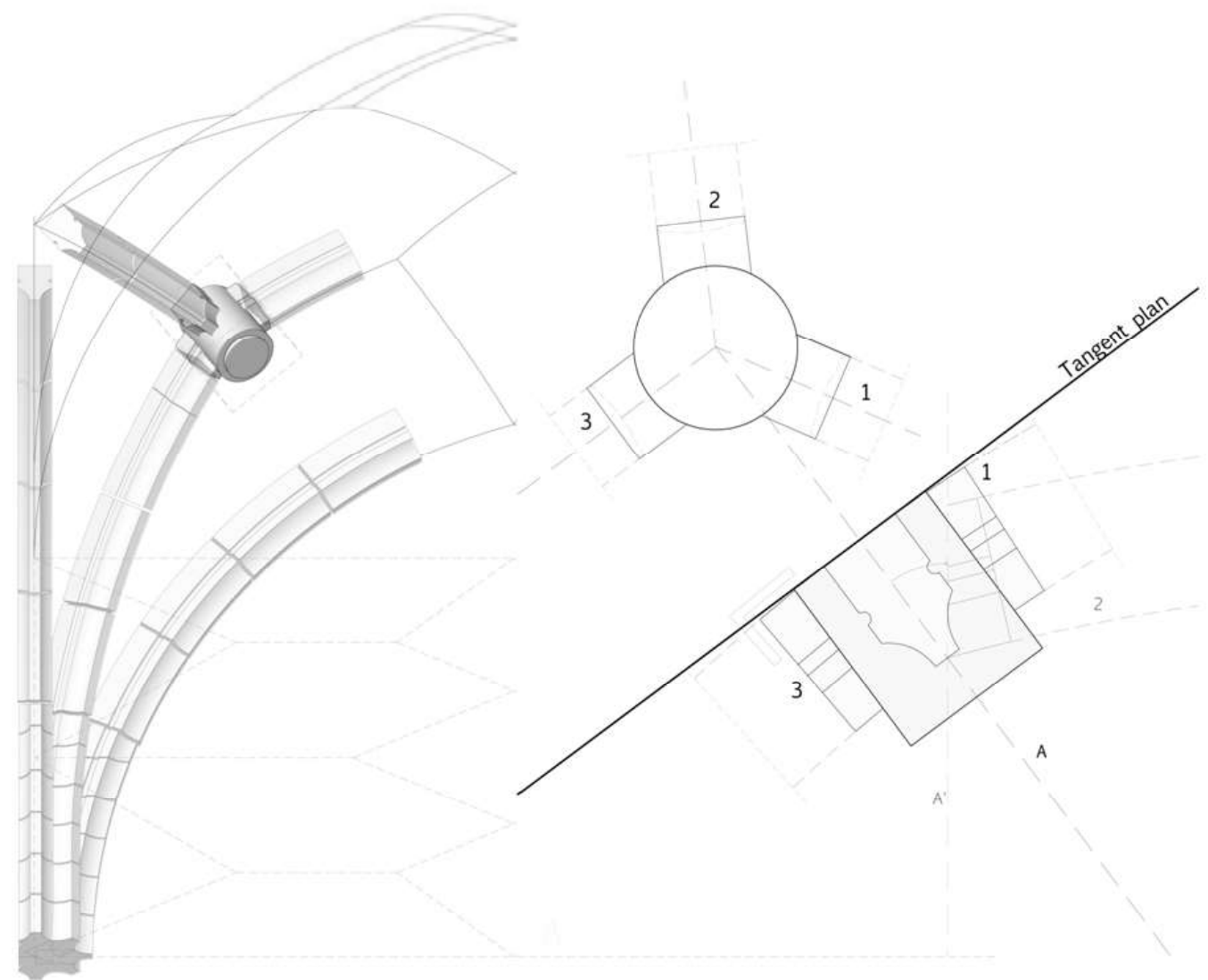

Fig. 6.31. La clave inclinada y su dibujo: alzado y proyección sobre el plano tangente. Dibujo del autor.
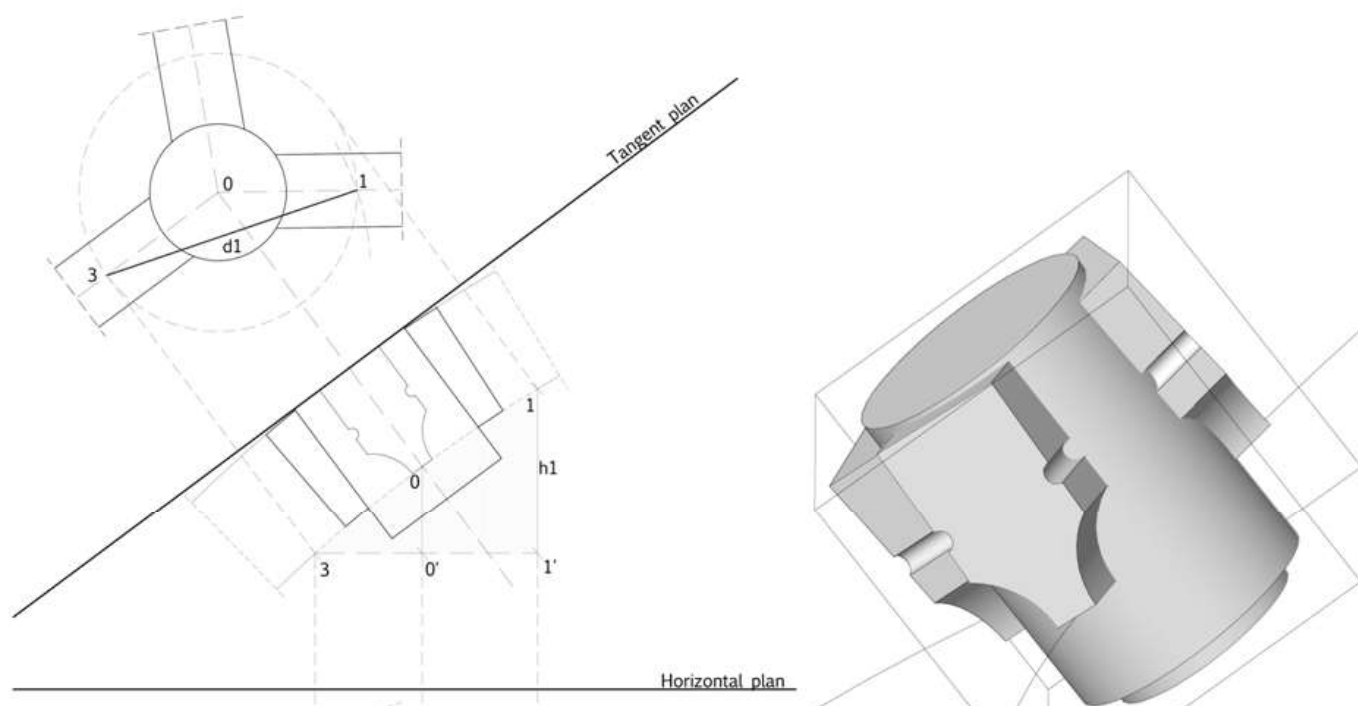

Fig. 6.32. La proyección sobre el plano tangente. Dibujo del autor. 
los brazos de la clave, por ejemplo, el brazo 3, sin importarnos la longitud del mismo. Se plantea ahora el problema, ¿cómo situar la posición de los otros dos brazos?

Tracemos, con centro en 0 , otra circunferencia concéntrica al cilindro de la clave con cualquier radio (circunferencia de línea a puntos). A continuación, proyectemos la circunferencia concéntrica sobre el alzado de la clave (dibujo del centro), en la cual sí es posible dibujar el nervio 3 y el 1, como si estuvieran en el mismo plano. Quedan con ello determinados los puntos 3 y 1 y, además, podemos apreciar la diferente altura a la que se encuentran ambos puntos, ya que sobre una línea horizontal que pase por $3\left(3,0^{\prime}, 1^{\prime}\right)$, el punto 1 se encuentra a una altura h1, del punto 3 ,

Vayamos ahora sobre la proyección horizontal de la clave, siempre en la figura 6.32. En la parte inferior del dibujo, vemos aquí la clave y los tres brazos. Sobre el brazo 3 , marquemos las distancias 3,0' y, sobre el brazo 1, la distancia 0',1' obtenidas del dibujo del alzado. La distancia que separa el brazo 3 del brazo 1 es dl, desgraciadamente, esta distancia no la vemos aquí en su verdadera magnitud, para obtener su verdadera dimensión, bastará con situar, sobre una perpendicular en el punto 1', la altura h1, obtenemos así un triángulo cuya hipotenusa es dl, ahora sí, en su verdadera magnitud.

Volvamos de nuevo al dibujo superior, si desde el punto 3, con la distancia dl, ahora ya con su dimensión exacta, se traza un arco de círculo que corte a la circunferencia concéntrica, este corte define el punto 1 . Ahora, si desde 0 se traza una línea que pase por 1 , tenemos ya la posición exacta del nervio 1 en la proyección tangente. El otro nervio se haría de la misma forma con lo que se habría obtenido el dibujo de la proyección completa de la clave sobre el plano tangente.

Esta ingeniosa construcción geométrica se encuentra perfectamente documentada. Aparece en el tratado de Alonso de Vandelvira, con ocasión de las "bóvedas por cruceros"23. Estas bóvedas, según el autor, son bóvedas baídas esféricas que se construyen mediante cruces de nervios tallados en piedra. Esos cruceros han de tallarse según Vandelvira a partir de su cara de intradós, lo cual requiere conocer la proyección de cada crucero sobre el plano tangente. Es entonces cuando Vandelvira pone en uso este singular método y nos permite asegurar que este tipo de proyecciones era ya conocido en la cantería del siglo XVI.

A partir de este dibujo, el proceso de labra es similar al ya descrito anteriormente para las claves verticales, la diferencia estriba ahora en que el plano de referencia es el plano que tangente a la clave por el trasdós. Una vez que maestro cantero ha dibujado la proyección de la clave sobre este plano, puede redibujarla sobre un prisma de piedra y, a continuación, proceder a la talla en vertical contra este plano (Fig. 6.30B). Por lo que respecta a los ángulos de corte de los brazos, el problema ahora se simplifica extraordinariamente ya que, en este caso, los brazos deben cortarse con las mismas inclinaciones que cualquier otra dovela. Imaginemos una compleja bóveda tardogótica, muy probablemente toda ella

\footnotetext{
23 Sobre las bóvedas por cruceros: Palacios Gonzalo, 2003. Trazas y Cortes de Cantería en el Renacimiento Español. También puede consultarse: José Carlos Palacios Gonzalo and Sandra C Bravo Guerrero, "Diseño y Construcción de Las Bóvedas Por Cruceros En España Durante El Siglo XVI," Informes de La Construcción 65, no. Extra-2 (October 14, 2013): 81-94.
} 
estandarizada, es decir, con todos sus arcos de igual curvatura; en tal caso, en toda la bóveda, sólo se produce un solo ángulo entre la curvatura de intradós y los lechos entre las dovelas que son siempre radiales, el mismo ángulo con que deben cortarse los brazos de la clave.

Como podemos apreciar, el cambio del plano de referencia, logra una simplificación extraordinaria en la talla de estas complejas piezas. Siguiendo las pautas anteriormente indicadas, en la Escuela de Arquitectura de Madrid, con ocasión de la construcción de la bóveda de J. Ribes a la que anteriormente hicimos mención, se confeccionaron los dibujos a tamaño natural que permitieron obtener la proyección tangente de la clave (Fig. 6.33 izquierda). Gracias a ellos, posteriormente, se pudo llevar a cabo la talla de la clave.

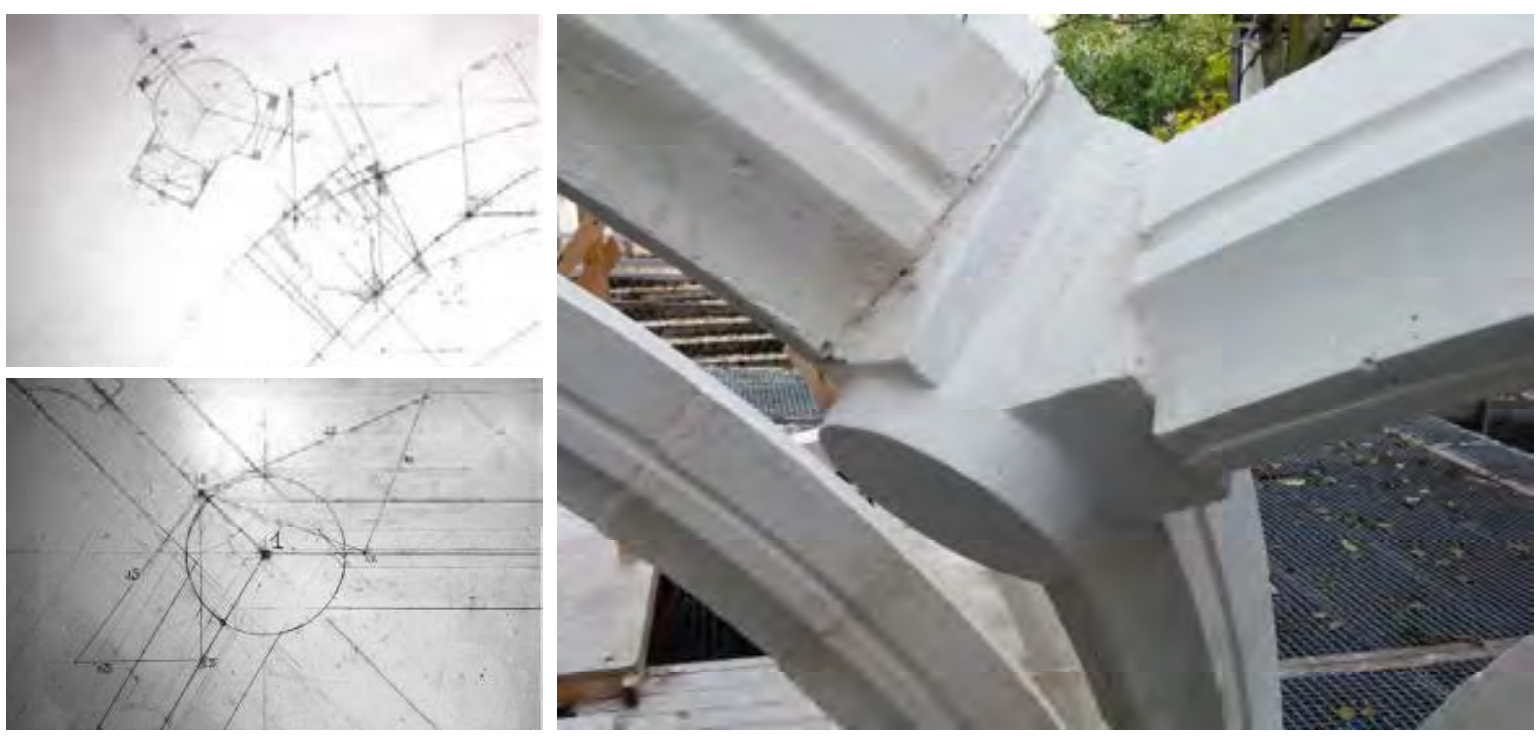

Fig. 6.33. Las Monteas, es decir, los dibujos a tamaño natural mostrando los recursos geométricos que requiere la confección de la proyección horizontal de la clave; una de las claves inclinadas de la bóveda de J. Ribes ejecutada en la Escuela Superior de Arquitectura de Madrid. Fotos del autor.

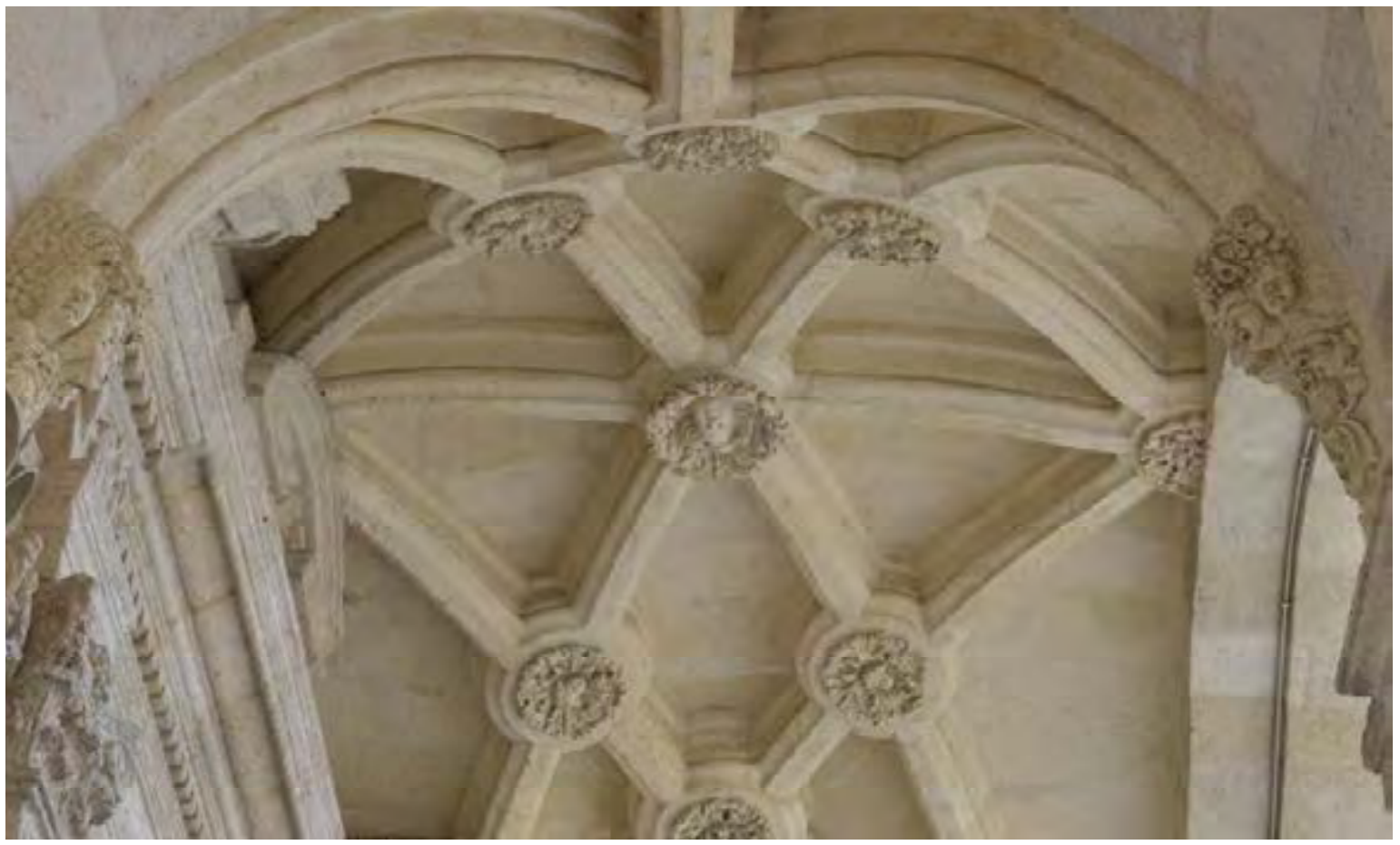

Fig. 6.34. Claves inclinadas en la Catedral de Sassari, Sardinia. Foto del autor. 


\section{Capialzados}

Después haber tratado arcos, bóvedas de arista y de crucería, Ribes presenta a continuación una serie de capialzados. Estas son piezas formadas por una superficie de intradós que se apoya sobre dos testas, que pueden ser curvas o rectilíneas puestas a niveles distintos. Los capialzados sirven para comunicar dos huecos de diferente tamaño o para crear en el muro el espacio necesario para abrir las puertas sin que tropiecen con la pared. Existen numerosísimas variaciones de capialzados, así como vienen descritas en los varios tratados, sin embargo, en relación al tipo de geometría que define del intradós, se podrían clasificar cuatro tipos: los capialzados en puerta cuadrada, de San Antonio, de Montpellier y de Marsella.

Este capítulo del Llibre de trasas llama la atención por su extensa colección de capialzados de Marsella, que se produce al desplazar una generatriz sobre un arco de medio punto y otro escarzano ${ }^{1}$ y por la presencia, aunque menor, de capialzados a regla, que son resueltos con una testa en arco y la otra en dintel, y de capialzados abocinados, que son arcos con una testa que es mas ancha que la otra.

El capialzado de Marsella, característico de la tratadística francesa, viene descrito por primera vez en España en el manuscrito de Alonso de Guardia², aunque es en el Llibre de trasas de Ribes que este aparejo viene desarrollado con sistematicidad, elaborando numerosos casos y aplicaciones. En esta instancia entonces el Llibre de trasas se separa de la tratadística española, la cual sí describe los capialzados, y en el caso de Martinez de Aranda con numerosísimas variaciones, pero exclusivamente en el modelo en puerta cuadrada. De este ultima tipología de capialzados, Ribes describe solo un modelo en puerta cuadrada. A la familia de los capialzados Ribes añade un arco abocinado con intradós adulcido.

Posteriormente a Ribes, cuando ya se habían instituido las academias y ya habían llegado a España los textos impresos franceses, otros tratadistas copiaron la traza del capialzado de Marsella directamente de las fuentes documentales recién llegadas.

Con el objeto de completar la catalogación de los aparejos estereotómicos de ámbito territorial de esta tesis, se querría también recordar a otra tipología de capialzado presente en Cataluña que no sigue los modelos presentes en el Llibre de trasas. El capialzado de San Antonio está conformado por un intradós curvado que conecta un arco adintelado en el exterior y un arco de medio punto en el interior. Se quiere recordar el ejemplo presente en la sala de contrataciones de la Lonja de Barcelona, descrito en el tratado de estereotomía de Antoni Rovira i Rabasa.

Palacios Gonzalo, 1990: 137.

2 E Rabasa menciona la semejanza con una traza todavía anterior, la traza a la vuelta del fol. 71 del manuscrito de Alonso de Guardia, que pudo tomarlo de de l'Horme. Enrique Rabasa Díaz, Forma y Construcción En Piedra : De La Cantería Medieval a La Estereotomía Del Siglo XIX (Madrid: Akal Ediciones, 2000): 285. 
En toda esta sección del manuscrito, algunos aparejos se hacen redundantes por repetir una variación muy similar a la traza original. La única variación es la mocheta añadida al arco que aloja la carpintería y que se materializa con un contorno ligeramente perfilado en la piedra, que en el dibujo recuerda un anillo. Por eso el nombre viene añadida el término anell.

La expresión que define estas trazas, anell y rravol, recuerda el juego de palabras volt y revolt de Gelabert para indicar aparejos caracterizados por ser de una sola pieza y tener dos tipos de arcos distintos a cada lado de la pared. En Ribes se puede entender la similitud del caso, presentando un tipo de arco o de capialzado por un lado y por el otro dibujando la mocheta que recibe la carpintería.

\subsection{Rrebolcura de marcella - Capialzado de Marsella}

\section{Folio 179 (traza 93)}

Esta traza se llama así por el modelo que existía en las murallas de Marsella ${ }^{3}$; como dicho anteriormente este aparejo cubre un hueco de una puerta y lo hace enlazando un arco de medio punto a un arco escarzano que se encuentra a una cota más alta, creando así una superficie reglada que se apoya en ambos. El intradós puede ser "adulcido", o sea ligeramente cavado hacia el interior para que sus formas aparezcan mas armoniosas, como informan las secciones de las plantillas de lecho que Ribes dibuja.

A parte de su primera función arquitectónica-compositiva de salvar un hueco en un muro, este capialzado absuelve una función practica: su superficie de intradós, delimitada por la característica curva en los paramentos verticales, acomoda perfectamente el semicírculo superior de la puerta del hueco cuando está en posición abierta hacia el plano de derrame, impidiendo que tropiece con la arista del muro.

Este es un aparejo que ha suscitado mucho interés en los tratadistas hasta el siglo XIX por las problemáticas relativas a la definición geométricas de la superficie de intradós, en particular en la porción triangular que arranca de los extremos del arco de medio punto. En esta investigación, esta cuestión vendrá dejada fuera por ser efectivamente poco relevantes, ya que es una problemática enunciada en el siglo XIX y porque no hay constancia en los dibujos del Llibre de trasas que hagan pensar que Ribes haya tenido en cuenta de eso. Se supone que la habilidad del cantero haya podido ser suficiente para materializar la transición en la manera correcta. Es una traza típica en los tratados franceses, apareciendo, quizás en manera no totalmente clara, en l' Architecture de Philibert de l'Orme (1567); viniendo explicada y nombrada así por primera vez por Jean Chéreau en su Livre d'architecture (1567-1574); y consecuentemente estudiada en los tratados de Derand (1643), Jousse (1642), de la Rue (1728) y Frezier (1737-1739). ${ }^{4}$ Curiosamente, hasta que se diera a conocer el contenido del tratado de Ribes que adelanta los otros autores peninsulares ${ }^{5}$, el

\footnotetext{
3 Pérouse de Montclos, 1982 : 120.

4 François Derand, L'Architecture Des Voûtes... (Sebastien Cramoisy: Paris, 1643): 134-136; Jean-Baptiste De La Rue, Traité de La Coupe Des Pierres... (Paris: L'imprimerie Royale, 1728): 28; Amédée François Frézier, La Théorie de La Pratique de La Coupe Des Pierres... (Strasbourg ; Paris, 1737): 281, 440-442.

5 Tellia, 2011: 1413-1420.
} 

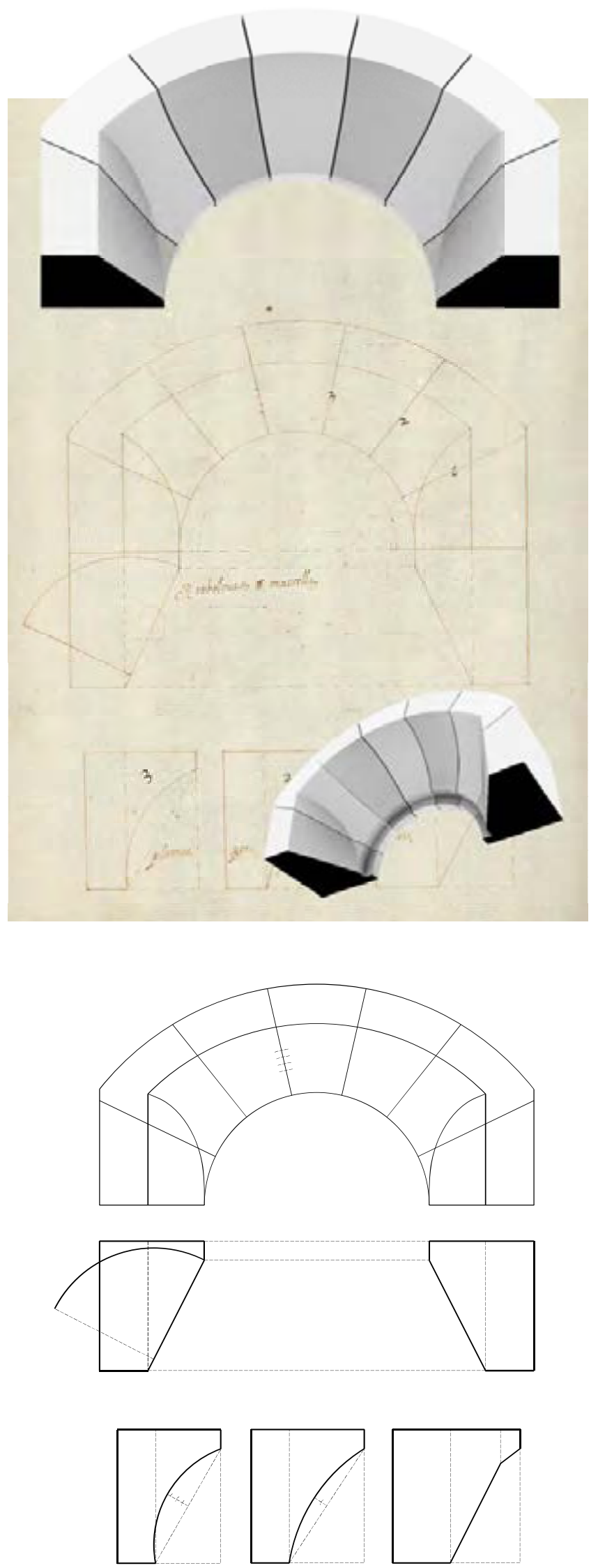

Fig. 7.1. Capialzado de Marsella. Dibujo del autor. 
primer tratadista español en representar el capialzado de Marsella fue padre Tosca $(1727)^{6}$, que lo copió de un francés. Se conocen también los modelos contenidos en el manuscrito del Real Monasterio de San Miguel de los Reyes en Valencia, los Secretos de Arquitectura $(1766)^{7}$, que es fundamentalmente una copia de algunas trazas de Le sècret d'architecture de Jousse, donde aparecen dos capialzados de Marsella, uno de medio punto y el otro carpanel. Le van a seguir los tratados de Benito Bails ${ }^{8}$, Rovira i Rabasa ${ }^{9}$, hasta convertirse uno de los típicos problemas de los textos de geometría descriptiva de las escuelas de arquitectura del principio del siglo XX.

El capialzado de Marsella no es un aparejo que haya tenido difusión en España, sin embargo, es interesante señalar que en los edificios de Barcelona aparece con una cierta frecuencia. Quizás, el más visible de ellos es el arco puesto en el acceso norte del patio del Hospital de la Santa Creu (Fig. 7.3). Desafortunadamente no sabemos el año de construcción del capialzado, si era parte de la construcción original de Guillem Abiell ${ }^{10}$ (terminada en 1414) o si haya sido realizado durante las modificaciones del siglo XVI. Notable por su calidad de ejecución, y digno de mención en esta sede, es el modelo que se encuentra en una de las galerías subterráneas de la Mola de Menorca, un conjunto arquitectónico que sorprende por la variedad, complejidad y la calidad constructiva de los modelos de arcos y bóvedas aparejadas que lo caracterizan.

Como en las hojas que le preceden, el dibujo del Llibre de trasas es claro y exhaustivo y proporciona las informaciones necesarias a su construcción. El arco es repartido en partes iguales con las juntas de testa convergentes al centro del arco de medio punto del hueco. La curva de derrame, producida en el encuentro entre el intradós y la jamba, viene dibujada en el alzado con su escorzo en proyección y viene representada en verdadera magnitud abatida sobre una de las jambas inclinadas en la planta. Las plantillas de lecho de cada dovela son representadas en la parte inferior de la hoja, y precisan en líneas de trazos la junta del intradós sin concavidad, y con línea continua la curva del intradós cóncavo.

Los baiveles, saltarreglas y cerchas necesarias se sacan del alzado del arco y de las plantillas de las caras de lecho. El método de talla que se puede deducir de los dibujos de Ribes prevé utilizar las plantillas del alzado y la profundidad del arco en planta para definir el sólido capaz de una dovela como si fueran de un arco recto, o sea sin el capialzado. Se posiciona primero la dovela orientada en vertical con la cara de testa paralela al plano de trabajo; sobre esta cara se calca la plantilla de testa y, apoyando una escuadría, se labra la piedra en vertical con un baivel, quitando el derrame de las caras de lecho. A continuación, se puede apoyar la plantilla de la cara de lecho a ambos lados, marcar con una cercha las líneas que delimitan el intradós del capialzado en las caras superior y lateral de la dovela

\footnotetext{
6 Tomás Vicente Tosca, Tratado de La Montea y Cortes de Cantería (Madrid: Imprenta de Antonio Mar, 1797): Lamina 103, figura 46.

7 Secretos de arquitectura (1766). Este manuscrito que ha sido encontrado en el Real Monasterio de San Miguel de los Reyes, al momento de publicación de esta tesis es inédito, sin embargo, es objeto de investigación.

8 Benito Bails, Elementos de Matemática, vol. IX (Madrid: en la impreta de la viuda de D. Joaquin Ibarra,

1796) 510-519. http://www.cervantesvirtual.com/obra/elementos-de-matematica---tomo-ix

9 Antoni Rovira y Rabassa, Estereotomía de La Piedra (Barcelona: Provincial de la Caridad, 1897).

10 Nacido en Barcelona y fallecido en 1420 en Palermo, Sicilia.
} 
y, tallando a regla, labrar la superficie del intradós. Seria también posible aproximarse al volumen de la dovela sin la necesidad de partir del arco recto, aprovechando así un prisma de piedra de menor volumen, operación que requeriría una mayor pericia y habilidad por parte del cantero.

Una vez obtenida la dovela con el capialzado a regla es posible proceder a labrar la concavidad del intradós que va a ser la de más difícil ejecución: por ser una superficie de radio variable es imposible utilizar una cercha o un baivel de manera ortodoxa. Estos instrumentos ayudaran a aproximarse a la geometría ideal pero su correcta ejecución depende mucho de la habilidad del cantero que puede controlar la concavidad con precisión solo apoyándose a las líneas curvas de las juntas que son de concavidad creciente y alcanzan su máximo en la dovela de clave. Ribes, para determinar más rigurosamente la profundidad del intradós cavado, se inventa una regla proporcional que se puede descubrir con las líneas y puntos que marca en el dibujo. Se nota que en el alzado toma el tramo que pertenece al intradós de la junta de la dovela de clave y lo divide en tres partes iguales; el segmento central recién obtenido viene dividido otra vez en tres partes iguales. A seguir toma esta longitud y la utiliza para definir la concavidad de la primera dovela, luego toma dos veces esta la misma longitud y la utiliza para determinar la concavidad de la segunda dovela y por finir utiliza tres unidades para la concavidad de la tercera dovela.

\subsection{Rropolt de mercella, anell y rrevol - Capialzado de Marsella, anillo y revuelto} Folio 180 (Traza 94)

A seguir viene presentado otro capialzado de Marsella, la única diferencia con el precedente reside en la mocheta del arco de medio punto, conformado para recibir la carpintería. Como se puede notar en la planta, la carpintería se inserta por el lado del intradós capialzado, dirección en la cual se tendría que abrir la puerta. Segun los dibujos de Ribes dicho dintel tiene que ser parte de las mismas piezas que componen el arco.

El proceso geométrico de traza y la manera de labrar las piedras es exactamente igual que el capialzado anterior.
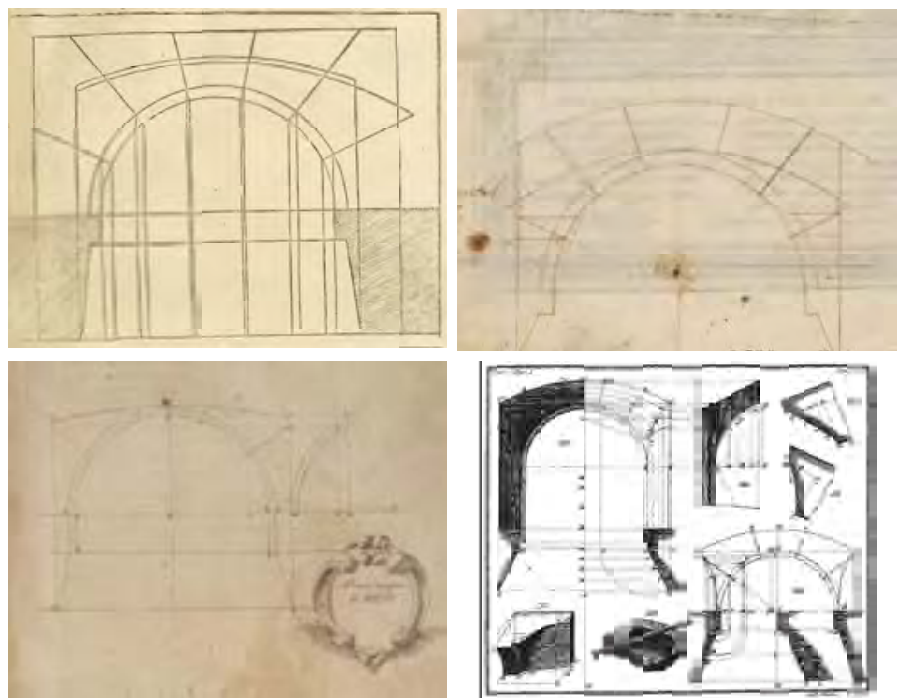

Fig. 7.2. Capialzado de Marsella en Philibert de l'Horme; Alonso de Guardia; Derand; Benito Bails, Elementos de Matemática, Tomo IX, parte 1 

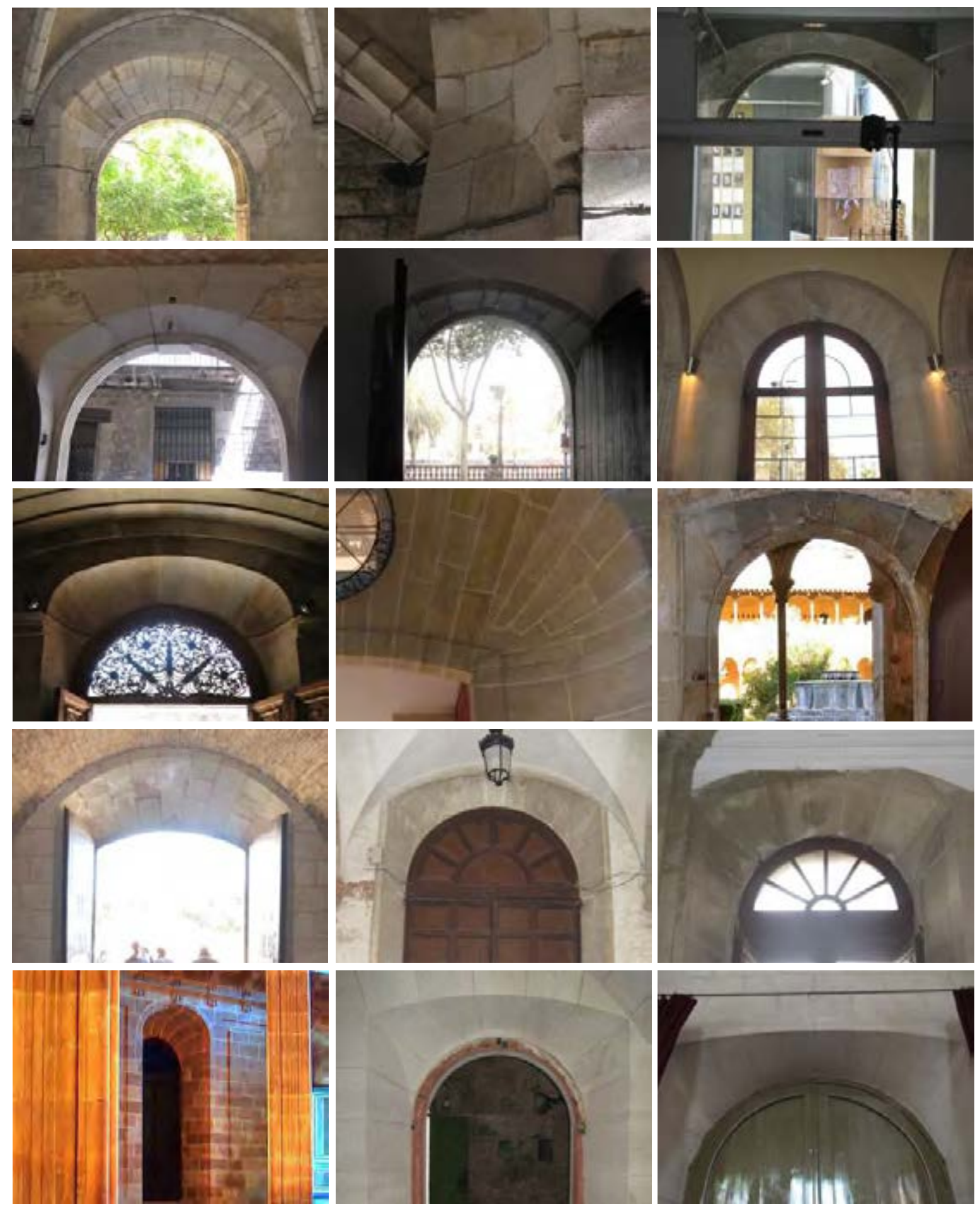

Fig. 7.3. Capialzados de Marsella: Hospital de la Snata Creu, Barcelona (A y B); Barri Gotic; Palau Nadal; Palau Bru; Universitat de Barcelona; Palau de la Generalitat; Hotel Scipion en Paris, con salmeres en diente de sierra; Sant Jeroni de la Murtra, Badalona (foto de Enfo - CC BY-SA 3.0, httpscommons. wikimedia.orgwindex.phpcurid=35373681); Castillo de Montjuix; Universitat de Cervera (K y L); Lonja de Barcelona (foto de David Chacobo - CC SA 2.0 Generic License); Mola de Menorca; Iglesia de Sant Telm, Ibiza. Fotos del autor. 


\subsection{Rravol ascasa - Capialzado de Marsella escarzano}

Folio 183 (Traza 97)

A pesar del nombre, que sugiere de hacer el arco situado a la cota inferior escarzano, este título no tiene diferencias con la traza genérica con arco de medio punto del Capialzado de Marsella. Si el error no es voluntario, podemos suponer que Ribes haya conocido el nombre de esta traza, quizás copiado de algún cuaderno de apuntes o oído en la práctica cantera, sin haber entendido exactamente la geometría que lo caracterizaba.

Aparece un capialzado de Marsella escarzano en Le sècret d'architecture de Jousse y otro en el manuscrito anónimo del Real Monasterio de San Miguel de los Reyes Secretos de Arquitectura (Fig. 7.4).

Respecto a los otros capialzados que aparecen en el Llibre de trasas, aquí Ribes dibuja las jambas de la puerta en toda su altura.

\subsection{Anell y rravol ascasa - Capialzado de Marsella escarzano anillo y revuelto} Folio 184 (Traza 98)

Este título, como en el caso que se acaba de exponer, no tiene diferencias con la traza genérica con arco de medio punto del Capialzado de Marsella. En esta traza Ribes ha añadido añadida la mocheta que sostiene los marcos de la carpintería (Anell y rravol).

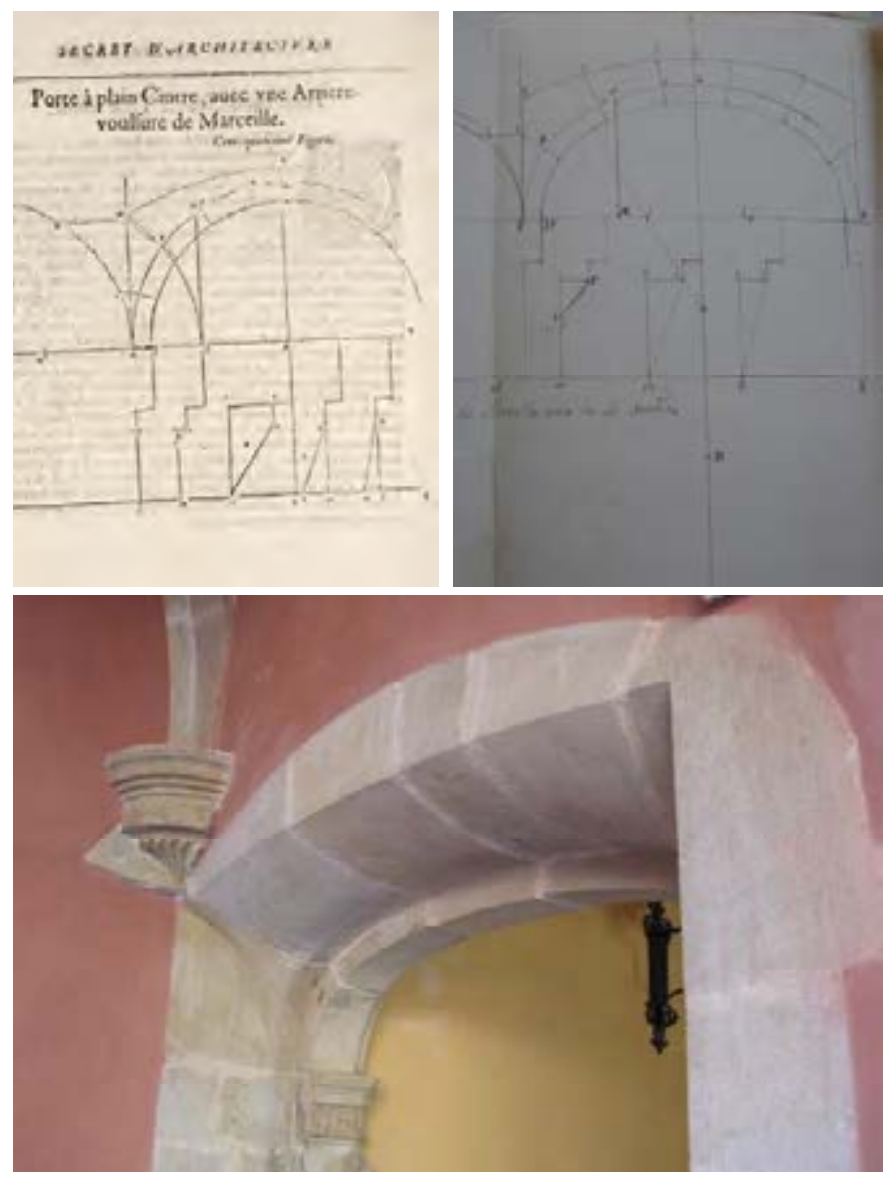

Fig. 7.4. Capialzado de Marsella escarzano en Jousse y en los Secretos y un modelo construido en los Colegios Reales de Tortosa. Foto del autor. 


\subsection{Rravol ab canto - Capialzado de Marsella en esquina}

Folio 187-188 (Traza 101)

Con este título se presenta una variante del Capialzado de Marsella que se abre sobre un muro en esquina. Viene trazado mediante la proyección de los arcos generatrices del capialzado sobre los planos que forman la esquina que vendrán enlazados con una superficie a regla y, en el caso aquí explicado por Ribes, "adulcidos" cavando ligeramente la superficie de intradós.

Efectuando los mismos tipos de abatimientos utilizados para definir el arco en esquina, una traza relacionada a este titulo, Ribes va a determinar las plantillas de testa, de lecho y el extradós de la dovela de clave.

Como en la mayoría de los casos que se han visto precedentemente, parece que Ribes aconseje empezar imaginando las dovelas de un arco como si fueran completas, o sea como si no hubiera el capialzado, y sobre ellas calcar las plantillas de lecho que van a definir los límites del intradós capialzado. Esta información se puede deducir al observar las plantillas de lecho que marcan con una línea de trazos la dovela del arco recto, delimitan la sección máxima y la mínima antes de "adulcir" el intradós. Ribes utiliza una regla proporcional para determinar mas rigurosamente la profundidad del intradós cavado que como previamente explicado resulta al analizar las marcas del dibujo. Desde el alzado toma el tramo que pertenece al intradós de la junta de la dovela de clave y lo divide en tres partes iguales; el segmento central recién obtenido viene dividido otra vez en tres partes iguales. A seguir toma esta longitud y la utiliza para definir la concavidad de la primera dovela, luego toma dos veces esta la misma longitud y la utiliza para determinar la concavidad de la segunda dovela y por finir utiliza tres unidades para la concavidad de la tercera dovela.

El arco es repartido en partes iguales con las juntas de testa convergentes al centro del arco de medio punto colocado a la cota inferior.

La curva de derrame, producida en el encuentro entre el intradós y la jamba, viene dibujada en el alzado con su escorzo en proyección, y viene representada en verdadera magnitud abatida sobre una de las jambas inclinadas en la planta.

Las plantillas de lecho de cada dovela son representadas en la pagina opuesta a la traza del arco, y precisan en líneas de trazos la junta del intradós sin concavidad, y con línea continua la curva del intradós cóncavo.

Los baiveles, saltarreglas y cerchas necesarias se sacan del alzado del arco y de las plantillas de las caras de lecho.

El método de talla que se puede deducir de los dibujos de Ribes prevé utilizar las plantillas del alzado y la profundidad del arco en planta para definir el sólido capaz de una dovela como si fueran de un arco recto, o sea sin el capialzado. Se posiciona primero la dovela orientada en vertical con la cara de testa paralela al plano de trabajo; sobre esta cara se calca la plantilla de testa y, apoyando una escuadría, se labra la piedra en vertical con un baivel, quitando el derrame de las caras de lecho. A continuación, se puede apoyar la plantilla de la cara de lecho a ambos lados, marcar con una cercha las líneas que delimitan el intradós del capialzado en las caras superior y lateral de la dovela y, tallando a regla, labrar la superficie del intradós. 


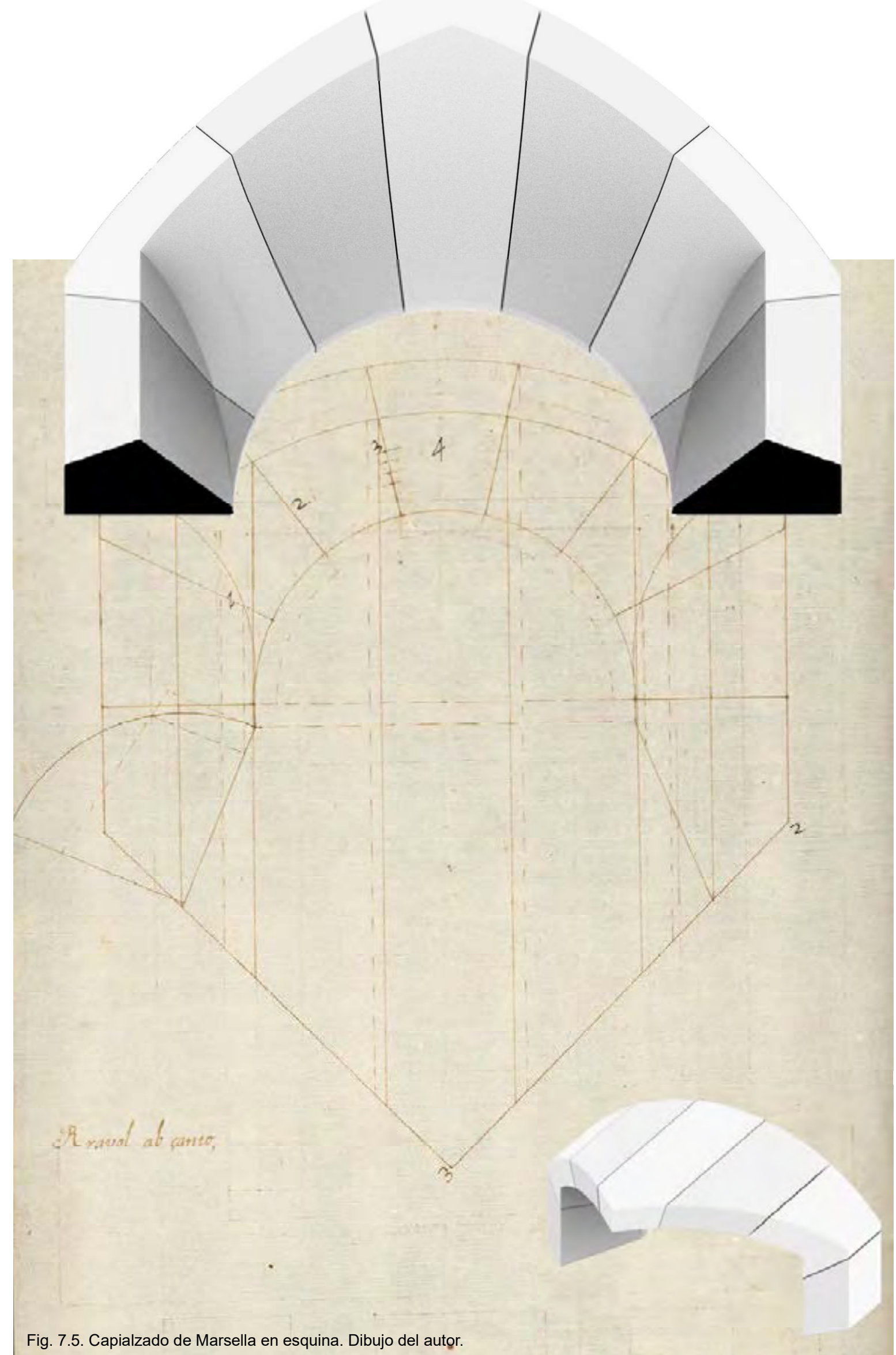


Seria también posible aproximarse al volumen de la dovela sin la necesidad de partir del arco recto, aprovechando así un prisma de piedra de menor volumen, operación que requeriría una mayor pericia y habilidad por parte del cantero. Una vez obtenida la dovela con el capialzado a regla es posible proceder a labrar la concavidad del intradós.

\subsection{Anell y rravol tot en una pesa ab canto - Capialzado de Marsella en esquina todo de una pieza}

Folio 189-190 (Traza 102)

Este título corresponde a la versión del capialzado de Marsella en esquina que se acaba de exponer con añadida la mocheta que sostiene los marcos de la carpintería.

Llama la atención el nombre de esta traza: si hacemos referencia a los arcos "en una sola pieza" de Gelabert, nos referimos a arcos constituidos por dovelas tallada de manera tal que configuren contemporáneamente dos distintos aparejos por cada lado, por ejemplo, un arco en esquina hacia el lado interior y un arco capialzado en el exterior. En este caso se puede suponer que Ribes define "en una pesa", en una pieza, porque por un lado la dovela materializa el capialzado y por el otro tiene la cavidad perfilado para alojar la carpinteria.

\subsection{Rravol ab talus y canto - Capialzado de Marsella en esquina y talud}

Folio 191-192 (Traza 103)

A continuación, Ribes traza ahora una variante del Capiazlado de Marsella en esquina con los paramentos exteriores del muro en talud, que se ha creado retrasando la parte superior del arco a partir de la línea de imposta.

El procedimiento para obtener las plantillas prevé determinar a priori los patrones del capialzado en esquina recto, según el método explicado en la traza anterior, y solo sucesivamente determinar el desplazamiento de cada vértice causado por la pendiente del muro en talud. La recta inclinada que aparece a la izquierda del alzado es la pendiente del muro y sirve para calcular la reducción del espesor del capialzado. La distancia delimitada entre la línea vertical y la línea oblicua es el desplazamiento horizontal al que se somete cada vertice por efecto del talud. Hay entonces que sustraer esta distancia a los vértices de las plantillas previamente obtenidas para el capialzado en rincón recto: se procede transportando con el compás las mediciones desde este diagrama hasta los en el vértice correspondiente de los patrones de junta y de intradós determinadno así la posición de las aristas.

Con las plantillas recien obtenidas se puede proceder al tallaje de las dovelas con el metodo de corte de los modelos precedentes. 

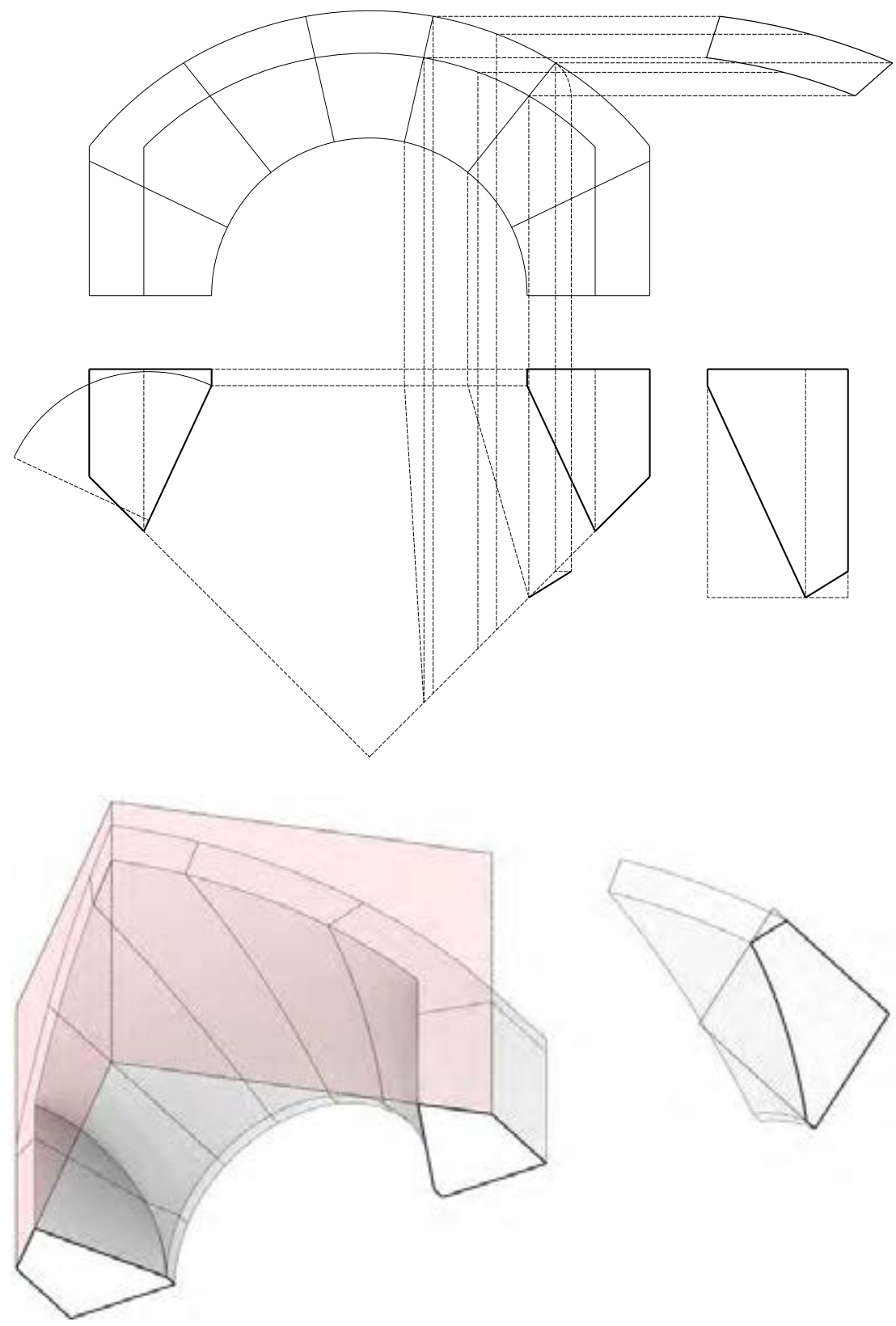

Fig. 7.6. Capialzado de Marsella en esquina. Dibujo del autor.
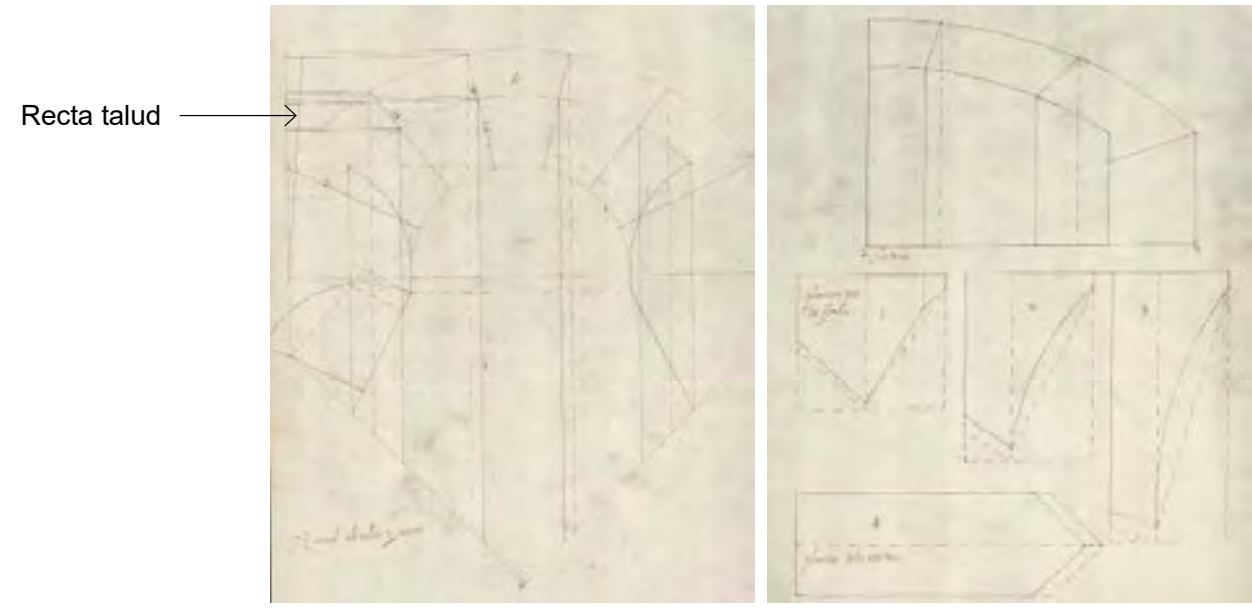

Fig. 7.7. Capialzado de Marsella en esquina y talud 


\subsection{Rravol ab raco - Capialzado de Marsella en rincón}

Folio 193-194 (Traza 104)

Con este título Ribes va a presentar un capialzado construido en un ángulo entrante que se produce al proyectar los arcos generatrices del capialzado sobre los planos que forman el rincón. El plano de origen de los arcos, escarzano y de medio punto, es perpendicular al plano bisector de los dos muros y forma entonces un ángulo de $45^{\circ}$ con los dos paramentos exteriores. Tambien en este caso la manera de trazar las plantillas está relacionada con la traza del arco en rincón, con la dificultad añadida por el capialzado.

El intradós que se va a materializar entre las dos siluetas va a tener una profunda deformación por la geometría que lo caracteriza, determinando dovelas muy largas en las impostas, y va a ser sucesivamente "adulcido", o sea ligeramente cavado.

Como en algunos casos que se han visto anteriormente, parece que en esta traza Ribes no aconseje partir de las dovelas de un arco como si fueran completas, o sea como si no hubiera el capialzado, porque por la mayor profundidad que se alcanza en la clave de testa se perdería mucha piedra. Esta informacion se puede deducir al observar las plantillas de lecho que en este caso ya no marcan con línea de trazos la dovela del arco recto, sino delimitan la sección mínima antes de "adulcir" el intradós.

Los patrones, que como costumbre de Ribes están reproducidos alejados del dibujo de la planta, describen las verdaderas magnitudes de las testas y de las juntas de las dovelas. El procedimiento a seguir para obtener las plantillas no difiere de los arcos en rincón o de los capialzados en esquina anteriormente presentados.

Para definir la planta de lecho de la segunda dovela, por ejemplo, se saca de la planta la longitud de la junta de intradós (A-A) y de estrados (B-B), que se redibujaran a distancia (C-C), también sacada del alzado. A continuación, a distancia (D-C), que es la profundidad total de la dovela, se dibuja el espesor del arco de medio punto con longitud $(F-F)$ también sacada de la planta. Los puntos así determinados representaran los vértices de la plantilla; para terminar, es posible ahora dibujar la curva del intradós adulcido.

A continuación, es posible dibujar la cimbra, o los patrones verticales de las caras de testa. Los arcos del capialzado, al ser proyectados sobre los planos oblicuos de esquina, se deformarán, produciendo un incremento aparente de las testas. Para obtener la cimbra de la segunda dovela, Ribes conoce la posición en altura de los vértices sacándola del alzado del arco a proyectar (A-A), mientras que la verdadera distancia en el plano horizontal es sacada directamente da la planta (T-T).

\subsection{Anell y rravol ab raco - Capialzado de Marsella en rincón anillo y revuelto} Folio 195-196 (Traza 105)

Este titulo corresponde a la versión del capialzado en rincón que se acaba de exponer con añadida la mocheta que sostiene los marcos de la carpintería. 


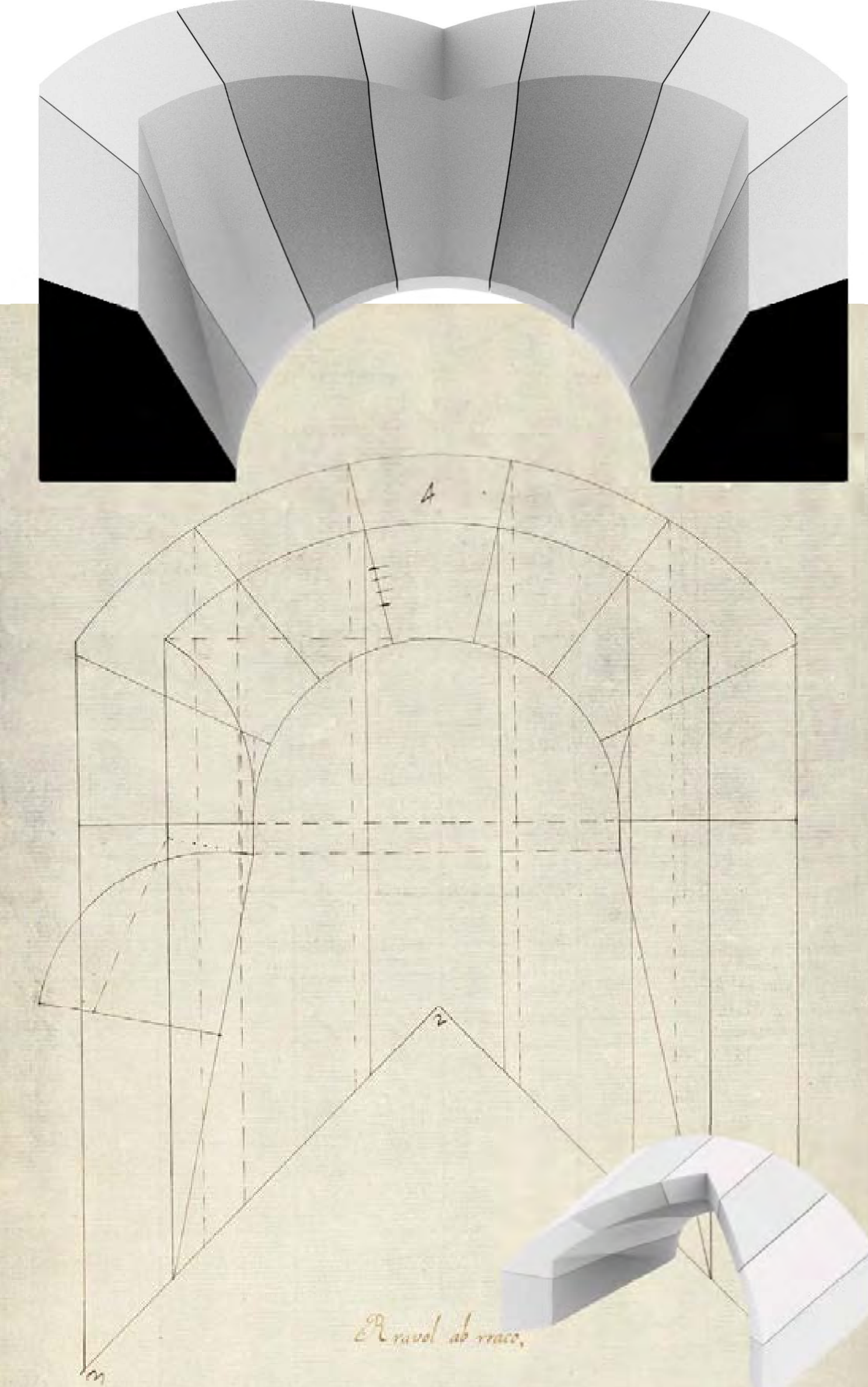

Fig. 7.8. Capialzado de Marsella en rincón. Dibujo del autor. 


\subsection{Rravol ab talus y rraco - Capialzado de Marsella en rincón y talud} Folio 197-198 (Traza 106)

Este título corresponde a una variación del capialzado en rincón que se acaba de exponer con los paramentos verticales del rincón en talud.
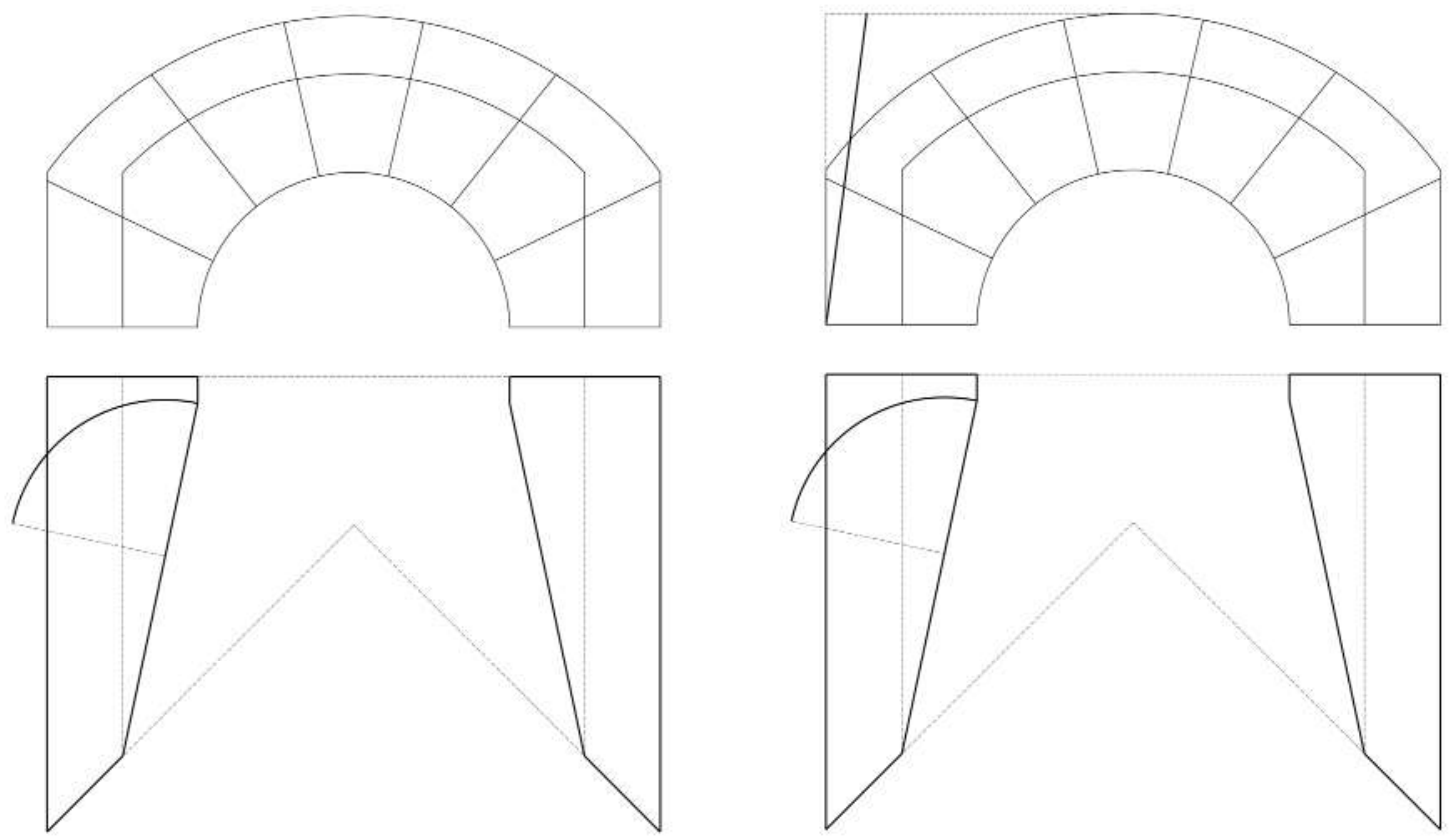

Fig. 7.9. Capialzado de Marsella en rincon y su correspondinete en talud. Dibujo del autor.

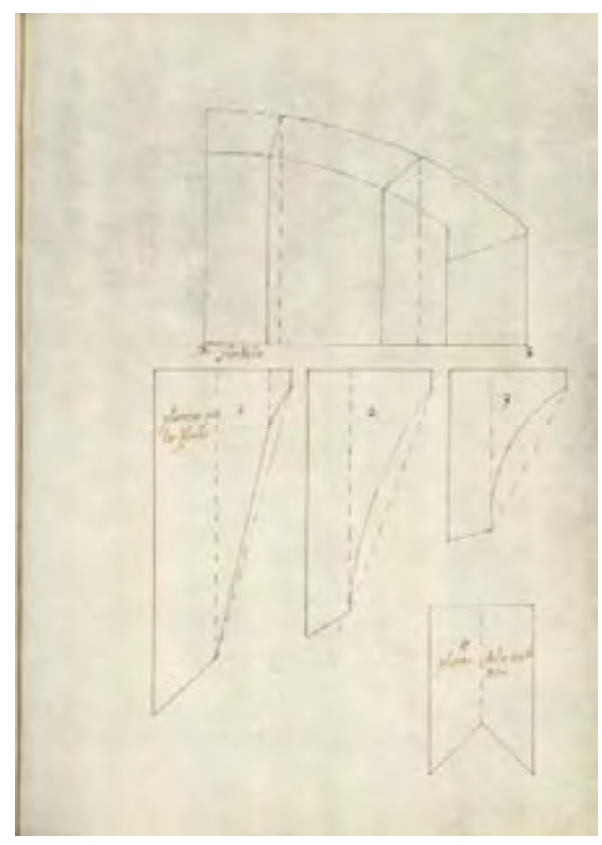

Fig. 7.10. Plantillas del capialzado en rincon 


\subsection{Rravol biax - Capialzado de Marsella en viaje}

Folio 221-222 (Traza 118)

Esta traza, que se encuentra en los folios 221 y 222 ha sido anticipada por claridad expositiva, antes que empiecen las familias de capialzados que insisten sobre paramentos curvos. El Capialzado de Marsella en viaje es una variación al capialzado original que se produce-al tener los arcos que configuran el intradós no enfrentados, sino uno en posición excéntrica respecto al otro. En este caso el hueco está desplazado hacia la izquierda, en contacto con la jamba, una de las cuales es recta y la otra es oblicua.

Como cabe considerar, todo el proceso de obtención de los patrones es similar al primer capialzado de Marsella de la serie que se ha precedentemente comentado, pero, al ser asimétrico, obliga a producir las plantillas de todas las dovelas.

En la Lonja de Barcelona hay un capialzado así en la puerta que comunica la sala de contratación con el patio central.

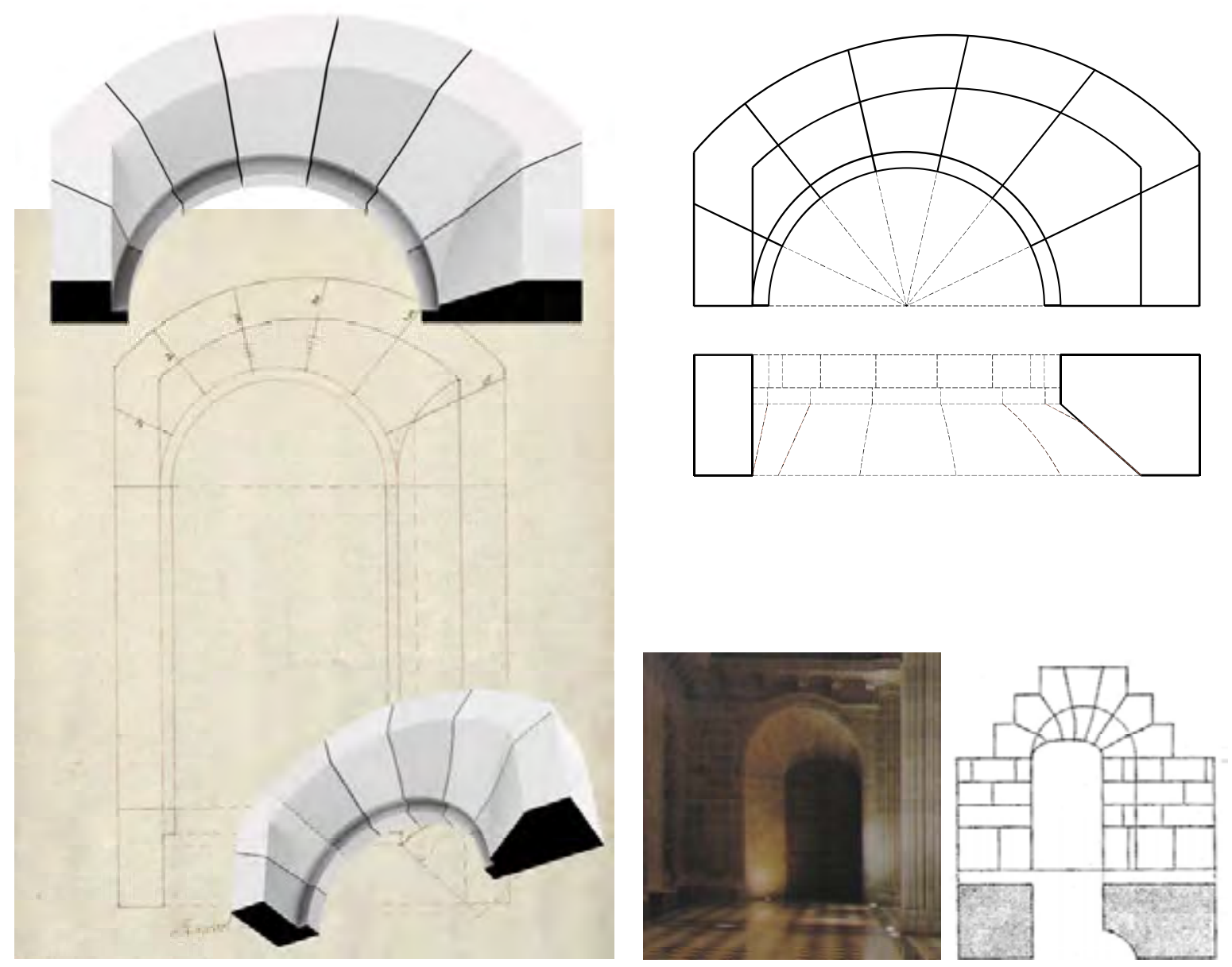

Fig. 7.11. Capialzado de Marsella en viaje (dibujo del autor) y los ejemplos de la Llonja de Barcelona y el dibujo de Rovira i Rabasa. 


\subsection{2 sin nombre - Capialzado de Marsella en viaje (en paso oblicuo)}

\section{Folio 141 (Traza 73)}

Esta traza se encuentra originariamente al folio 141, antes de toda la serie de capialzados. Su exposición se ha retrasado por claridad expositiva.

La planta sugiere que se utiliza este modelo en un paso oblicuo en el cual en un lado del arco las jambas son oblicuas y paralelas, una vez que se pasa el eje del muro, una jamba sigue con la misma pendiente mientras que la otra se abre hacia al lado opuesto, creando así una abertura abocinada. El arco de medio punto es excéntrico respecto al arco escarzano del capialzado y desplazado hacia la derecha. El intradós del capialzado esta cavado y la concavidad es más profunda en las juntas de la clave y se reduce progresivamente hasta desaparecer cuando alcanza las impostas. Aparentemente la transición entre superficie capialzada y jambas no es marcada con una línea curva clara como normalmente resuelta en los capialzados de Marsella.

Como en otros capialzados, Ribes dibuja en la planta y en el alzado un dintel donde apoyar el marco de la puerta.
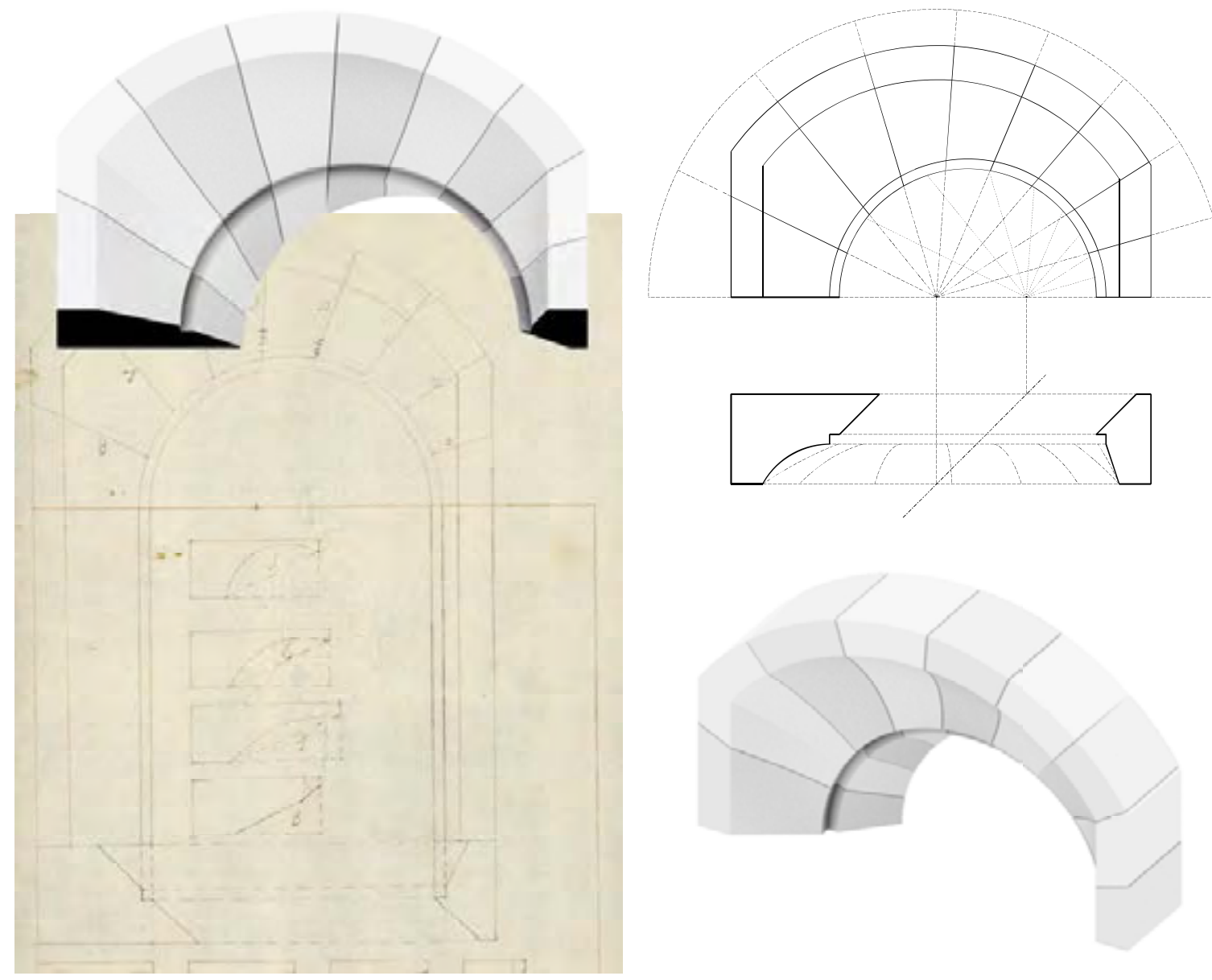

Fig. 7.12. Capialzado de Marsella en paso oblicuo. Dibujo del autor. 

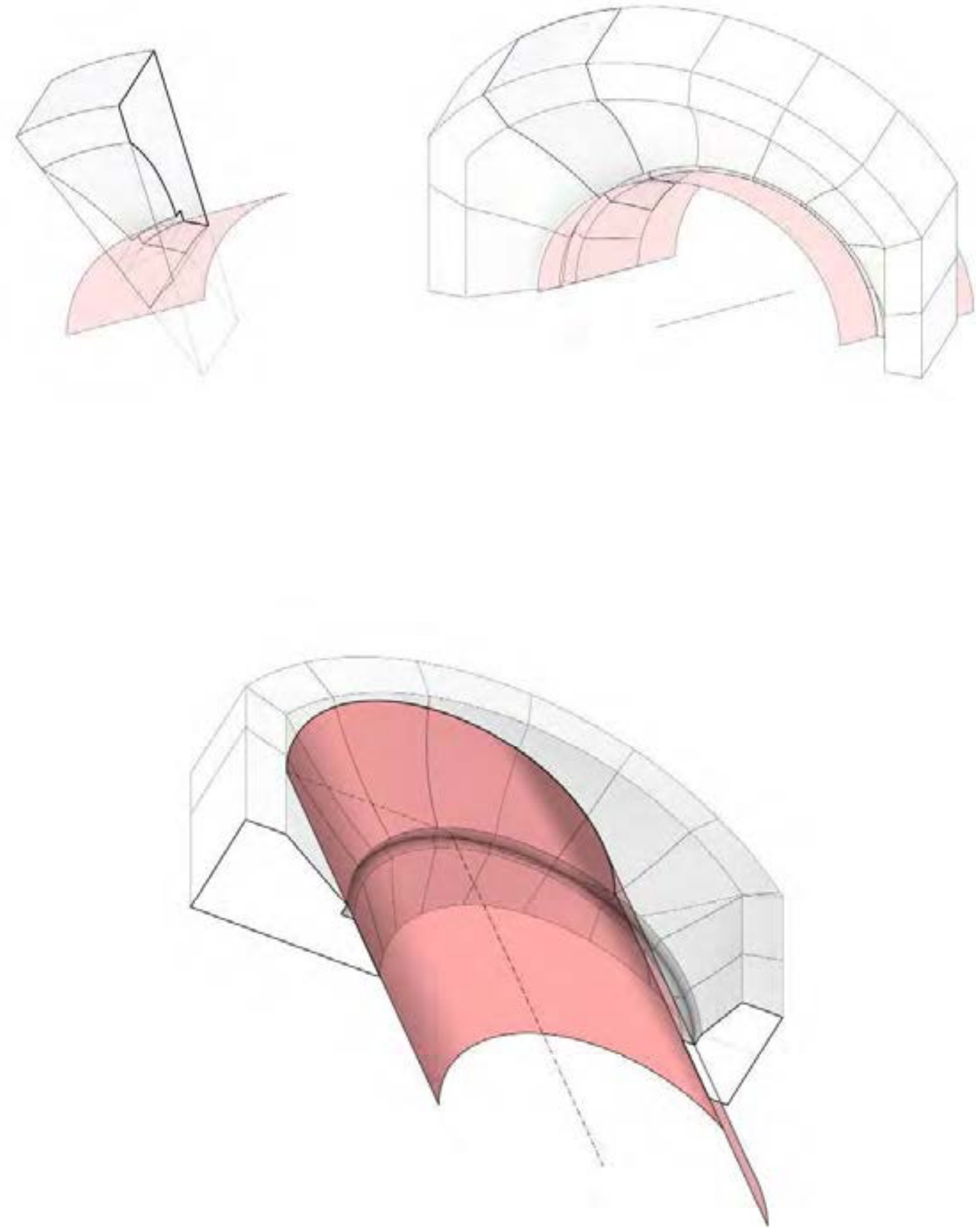

Fig. 7.13. Geometria del Capialzado de Marsella en paso oblicuo. Dibujo del autor. 


\subsection{Rravol ab torra rrodona - Capialzado de Marsella en torre redonda}

Folio 199-200 (Traza 107)

En esta traza el arco capialzado se abre en una pared convexa, es por lo tanto una figura relacionada con los arcos en torre redonda precedentemente presentados de los cuales comparte la metodología de construcción de los patrones. También este modelo va a tener el intradós ligeramente cavado.

Las generatrices del arco capialzado, el arco escarzano de la cota superior y el de medio punto de la cota inferior, vienen proyectadas ortogonalmente sobre una superficie cilíndrica convexa y el derrame de las jambas se abre del interior del cilindro hacia el exterior. Ribes va a construir el desarrollo del arco de testa, la sinbria, o cimbra, y obtiene las plantas por lechos y de intradós. Para dibujar las plantillas de testa y de intradós con mayor precisión, se efectúan los abatimientos también de los puntos medios de las juntas y de las aristas. De hecho, al ser una pared curva, también las plantillas tendrán un lado curvo, lo que necesita más precisión a la hora de trazar los patrones. Cabe recordar que las plantillas de intradós están construidas con la cuerda del arco y representan entonces la proyección sobre el plano pasante por los vértices. Los segmentos curvos de los patrones representan el tramo de la silueta del arco de testa y son su proyección, que solo se aproximan a la magnitud real. Sin embargo, en el caso de dovelas de dimensiones relativamente contenidas, es posible utilizarlas como guías, obviamente si se reproducen sobre un material flexible.

Diferentemente de las trazas precedentes, aquí parece que Ribes no aconseje partir de las dovelas de un arco como si fueran completas, o sea como si no hubiera el capialzado, porque por la mayor profundidad que se alcanza en la clave de testa el desgaste de material seria muy elevado. Esta información se puede deducir al observar las plantillas de lecho que en este caso ya no marcan con línea de trazos la dovela del arco recto, sino delimitan la sección mínima antes de "adulcir" el intradós. En línea con las trazas anteriores, Ribes utiliza una regla proporcional para determinar más rigurosamente la profundidad del intradós cavado. Desde el dibujo en alzado toma el tramo que pertenece al intradós de la junta de la dovela de clave y lo divide en tres partes iguales; el segmento central recién obtenido viene dividido otra vez en tres partes iguales. A seguir toma esta longitud y la utiliza para definir la concavidad de la primera dovela, luego toma dos veces esta la misma longitud y la utiliza para determinar la concavidad de la segunda dovela y por finir utiliza tres unidades para la concavidad de la tercera dovela.
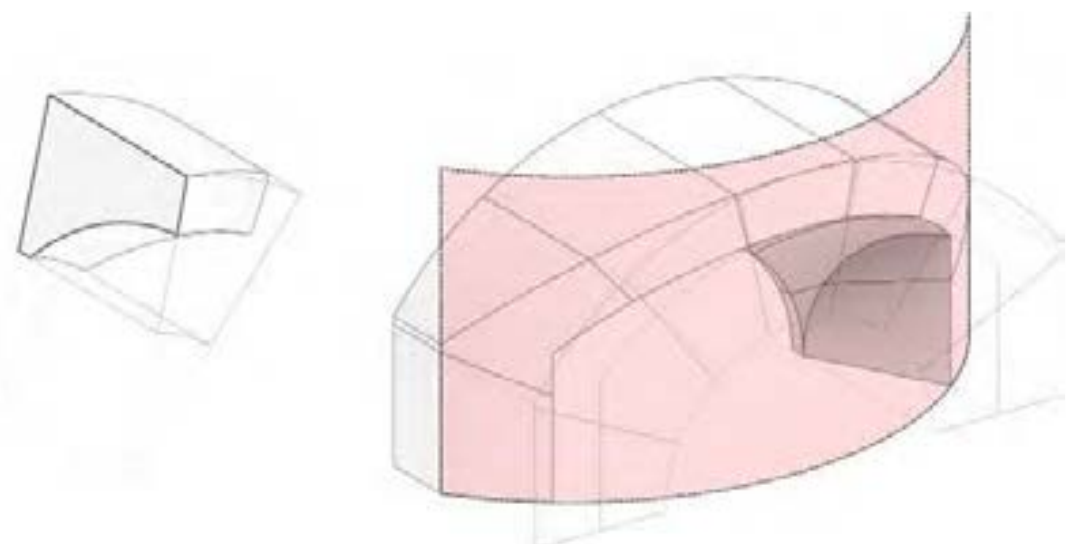

Fig. 7.15. Capialzado de Marsella en torre redonda. Dibujo del autor. 


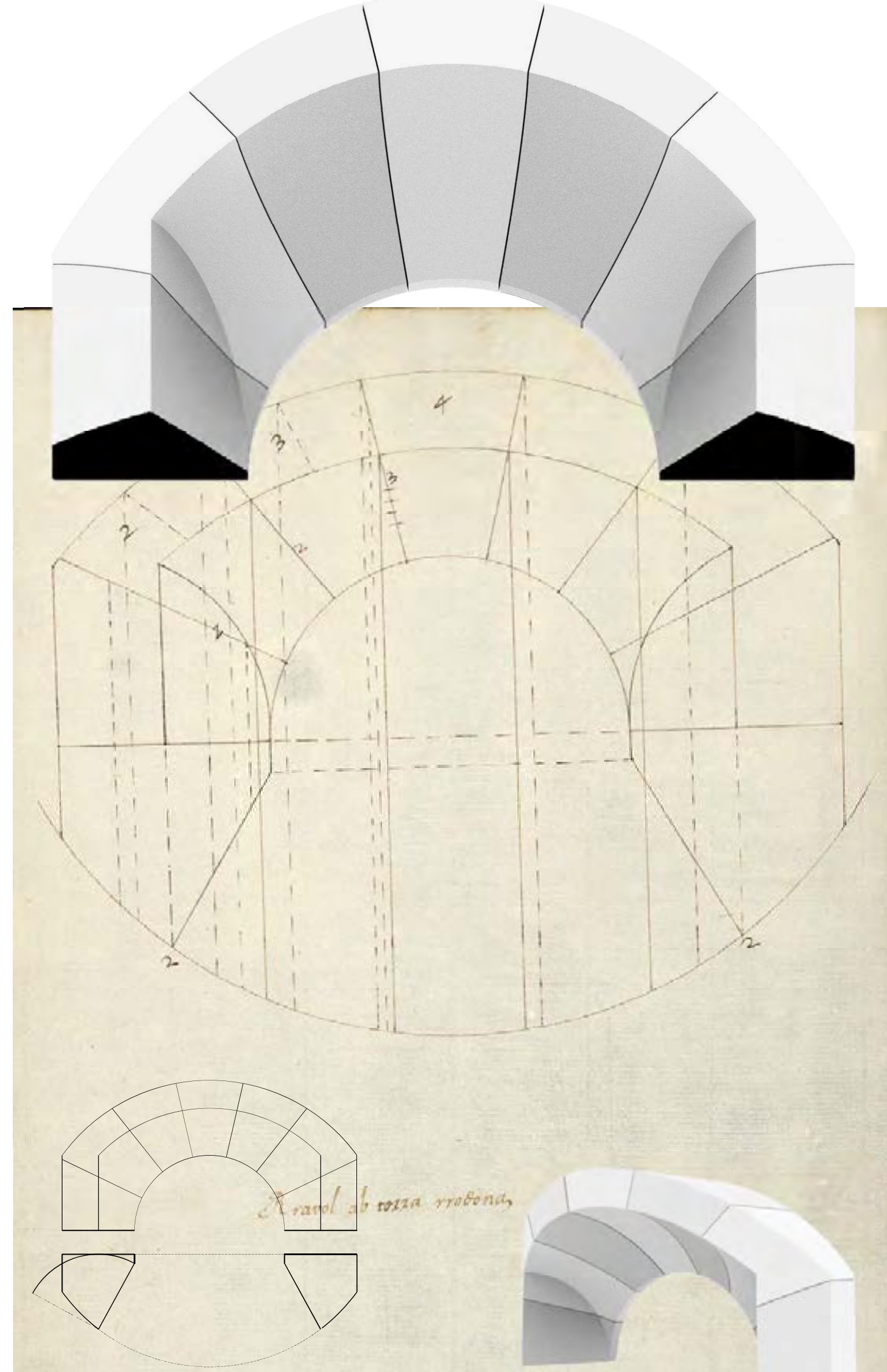

Fig. 7.14. Capialzado de Marsella en torre redonda. Dibujo del autor. 


\subsection{Rravol ab talus y torra rrodona - Capialzado de Marsella en torre redonda y talud} Folio 201-202 (Traza 108)

Este título corresponde a una variación del capialzado en torre redonda que se acaba de exponer con el paramento vertical en talud.

\subsection{Anell y rravol ab torra rrodona - Capialzado de Marsella en torre redonda (sic) anillo y revuelto}

Folio 203-204 (Traza 109)

En este caso el capialzado se abre hacia el interior del cilindro, conformando así un capialzado en torre cava y un arco en torre redonda, y no un capialzado en torre redonda como el título sugiere. Quizás se puede atribuir esta imprecisión a un error (la planta del capialzado dibujada arriba abajo) o a un cambio de idea, ya que se encontrará el capialzado en torre cava en una traza a seguir.

\subsection{Rravol ab talus y torra rrodona - Capialzado de Marsella torre redonda y talud} Folio 205-206 (Traza 110)

Aquí aparece otra contradicción del dibujo o cambio de idea: en el alzado parece que el diagrama del talud se refiera a la cara con el intradós del capialzado, pero en las plantillas se ve que el talud afecta el arco del hueco menor del capialzado, el arco en torre redonda.
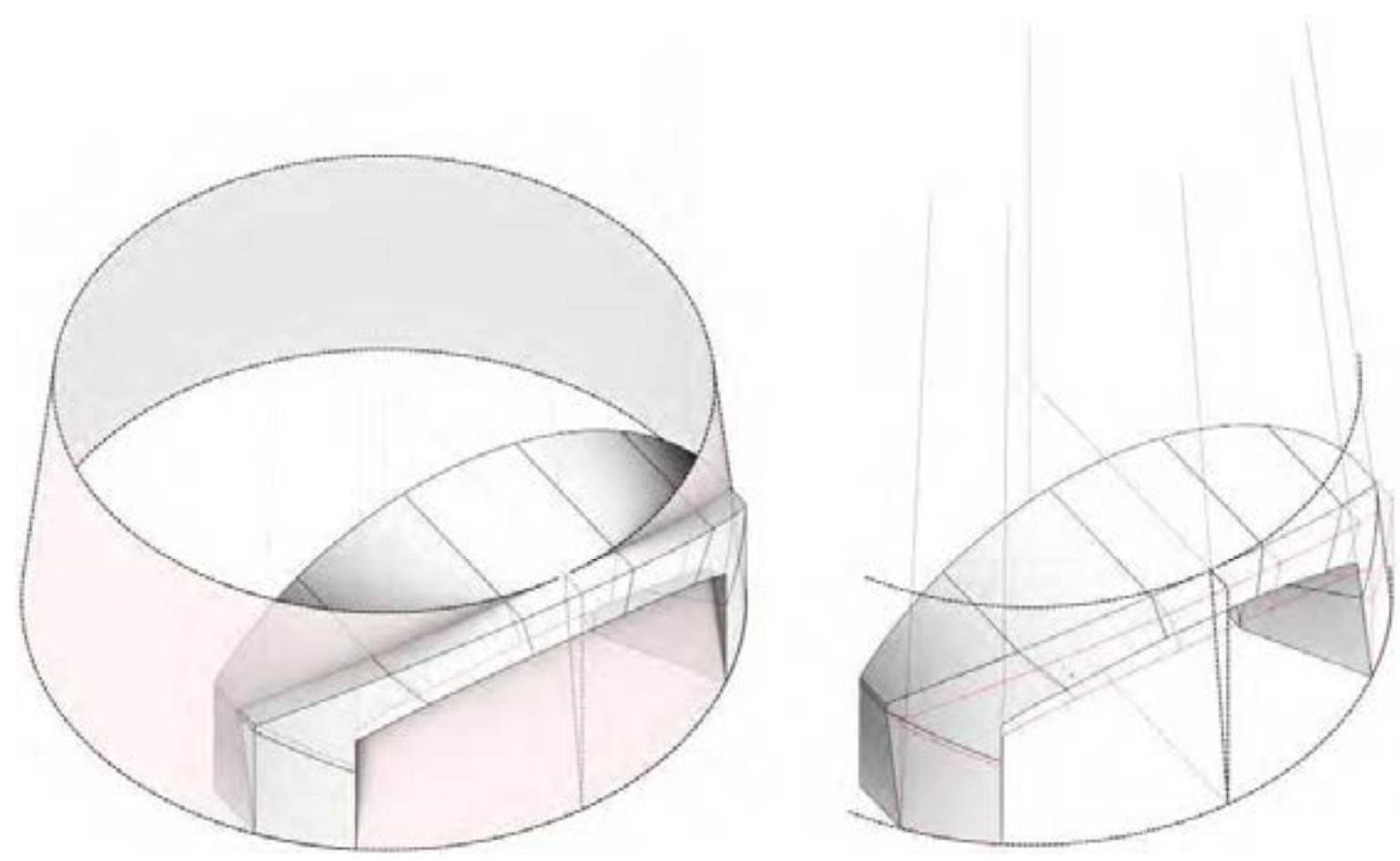

Fig. 7.16. Capialzado de Marsella en torre redonda con el corte conico del talud. Dibujo del autor. 


\subsection{Rrabol ab torra acabada - Capialzado de Marsella en torre cava}

Folio 207-208 (Traza 111)

La traza que se va a presentar ahora es un capialzado de Marsella sobre una pared cóncava. Las siluetas del arco escarzano y de medio punto del capialzado vienen proyectados sobre una pared cóncava, pero, a diferencia de la traza numero 203 , donde el aparejo se encontraba sobre una pared cilíndrica por ambos lados, en este modelo el muro situado al lado opuesto del capialzado es recto, simplificando así el proceso de obtención de los patrones. El problema estereotómico es el mismo de los otros capialzados sobre un paramento curvo; el proceso a seguir para obtener los patrones y saltarreglas es similar a los precedentes y no presentan algún cambio que es deberos anotar.

Las juntas verticales de las dovelas son curvas, razón por la cual Ribes, para alcanzar una mayor precisión, efectúa abatimeintos también de los puntos medios de las juntas y de la arista.

\subsection{Rravol ab talus y torra acabada - Capialzado de Marsella en torre cava y talud}

Folio 209-210 (Traza 112)

Según el aproche sistemático de Ribes que prevé complicar la traza base progresivamente, se encuentra ahora el capialzado de Marsella en torre cava con los paramentos exteriores en talud, que se ha creado retrasando la parte superior del arco a partir de la línea de imposta. El procedimiento para obtener las plantillas parte del capialzado en torre cava recto y solo sucesivamente se determina el desplazamiento de cada vertice causado por la pendiente del muro en talud. La recta inclinada que aparece a la izquierda del alzado es la pendiente del muro y sirve para calcular la reducción del espesor del capialzado.

La distancia delimitada entre la línea vertical y la línea oblicua es el desplazamiento horizontal al que se somete cada vertice por efecto del talud. Hay entonces que restar esta distancia a los vértices de las plantillas previamente obtenidas para el capialzado en rincón recto: se procede transportando con el compás las mediciones desde este diagrama hasta los en el vértice correspondiente de los patrones de junta y de intradós determinando asì la posición de las aristas.

Con las plantillas recién obtenidas se puede proceder al tallaje de las dovelas con el método de corte de los modelos precedentes.

\subsection{Rravol ab torra acabada y torra rrodona - Capialzado de Marsella torre cava y redonda}

Folio 211-212 (Traza 113)

Ribes combina las características de los aparejos clásicos de la cantería para inventar nuevos modelos. Se presenta a continuación un capialzado que insiste sobre una pared cilíndrica por ambos lados, como podría ser la caja de una escalera helicoidal, conformando un aparejo que tiene por un lado un capialzado en torre redonda y por el otro un arco en torre cava. 

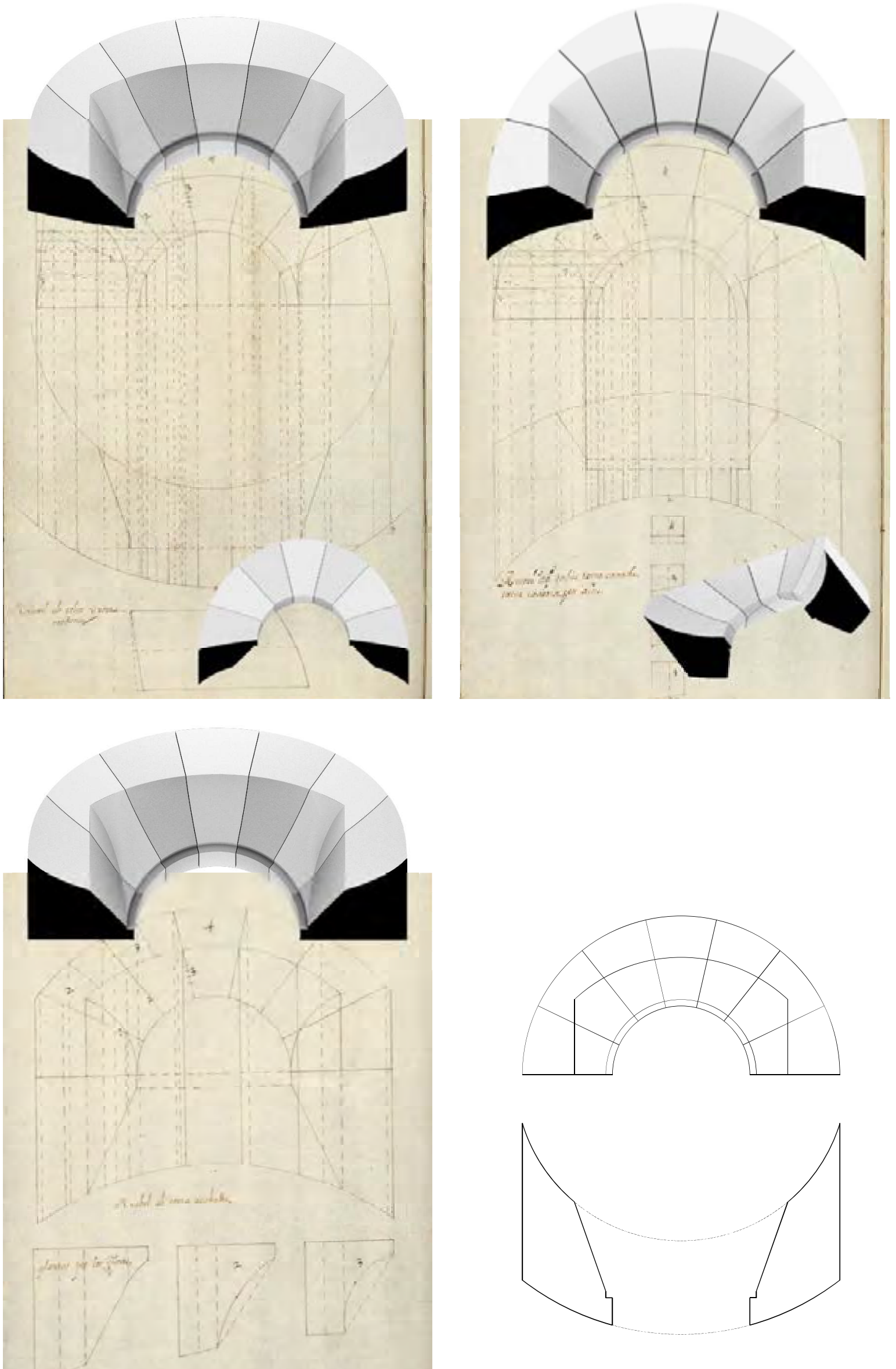

Fig. 7.17. Capialzado de Marsella en torre cava y redonda. Dibujo del autor. 
7.20 Rravol ab talus torra cavada. torra rodona, per dins - Capialzado de Marsella en torre cava y talud, en torre redonda hacia adentro

Folio 213-214 (Traza 114)

En esta traza el talud se encuentra en el lado interior del paramento: es una contradicción del dibujo o un cambio de idea: en el alzado parece que el diagrama del talud se refiera a la cara con el intradós del capialzado que es en el paramento convexo (torra redonda), pero en las plantillas se ve que el talud afecta el arco del hueco menor del capialzado, que es un arco en torre cava.

\subsection{Rravol ab canto y torra acabada - Capialzado de Marsella en esquina y torre cava} Folio 215-216 (Traza 115)

Ribes explora las posibles combinaciones, como había experimentado en la serie de arcos. Esta traza describe el insólito capialzado que se abre sobre una planta con cúspide entre dos paramentos curvos.

\subsection{Rravol ab talus y canto y torra acabada - Capialzado de Marsella en talud en esquina y torre cava}

Folio 219-220 (Traza 117)

Esta traza parte del modelo precedente de capialzado, pero con muro en talud en el lado del paramento curvo y del intradós del capialzado.

\subsection{Rravol ab rraco y ab torra cabada - Capialzado de Marsella en rincón y torre cava} Folio 235-236 (Traza 129)

Ultimo título de esta larga serie, esta traza se produce al poner en comunicación, mediante un capialzado, una pared en rincón y otra curva. Esto podría ser el caso de una torre circular que se conecta a una habitación con un pase posicionado justo en el eje bisector del ángulo.

Encontramos una referencia lejanamente parecida en el manuscrito de Gelabert, donde hay un arco capialzado y otro en rincón en el cruce de tres paredes discontinuas (Portal de raco a tres parets qui nos enquantren, traza 64 , folio $77 \mathrm{v}$ ). 

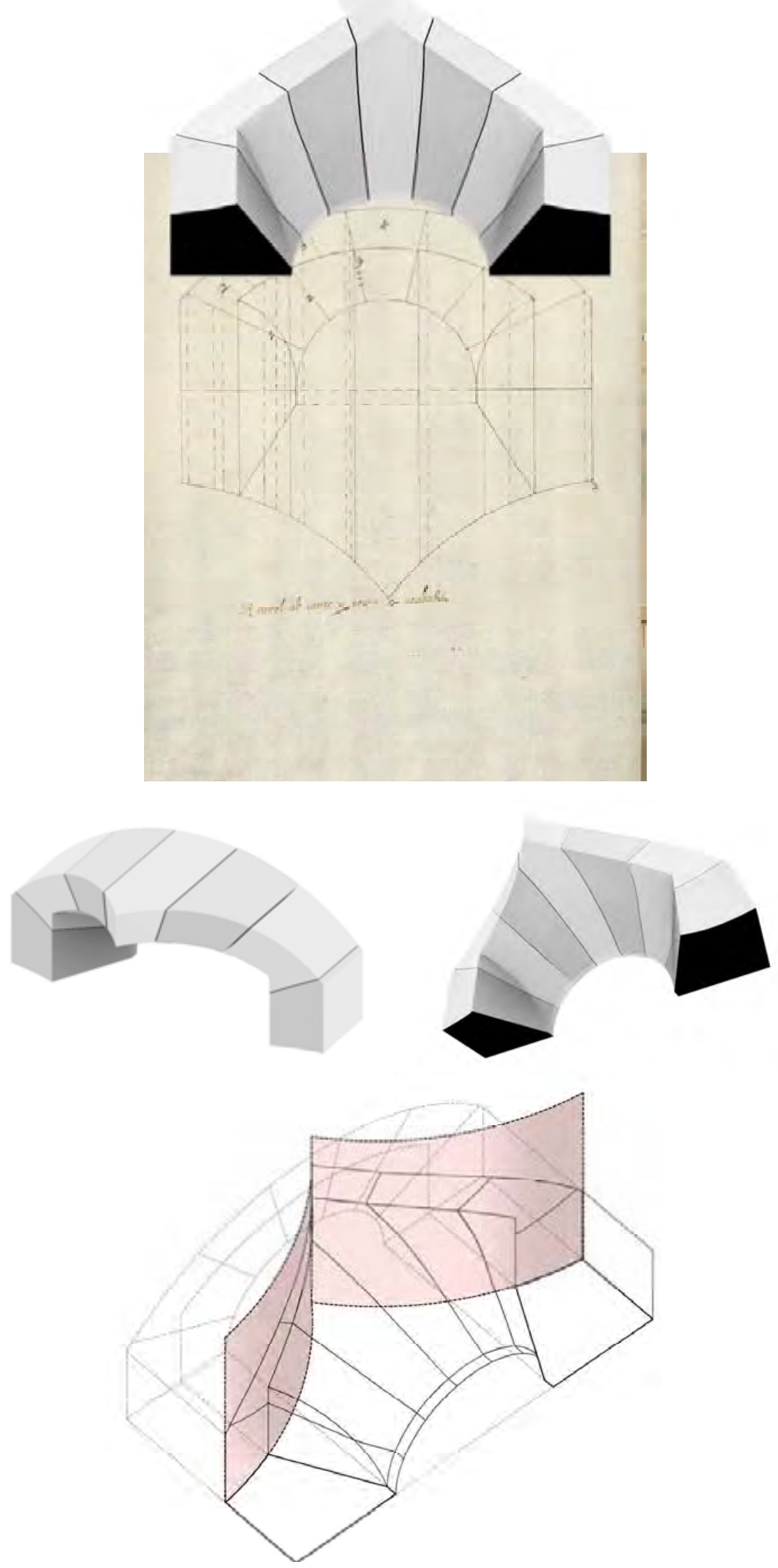

Fig. 7.18. Capialzado en esquina y torre redonda. Dibujo del autor. 

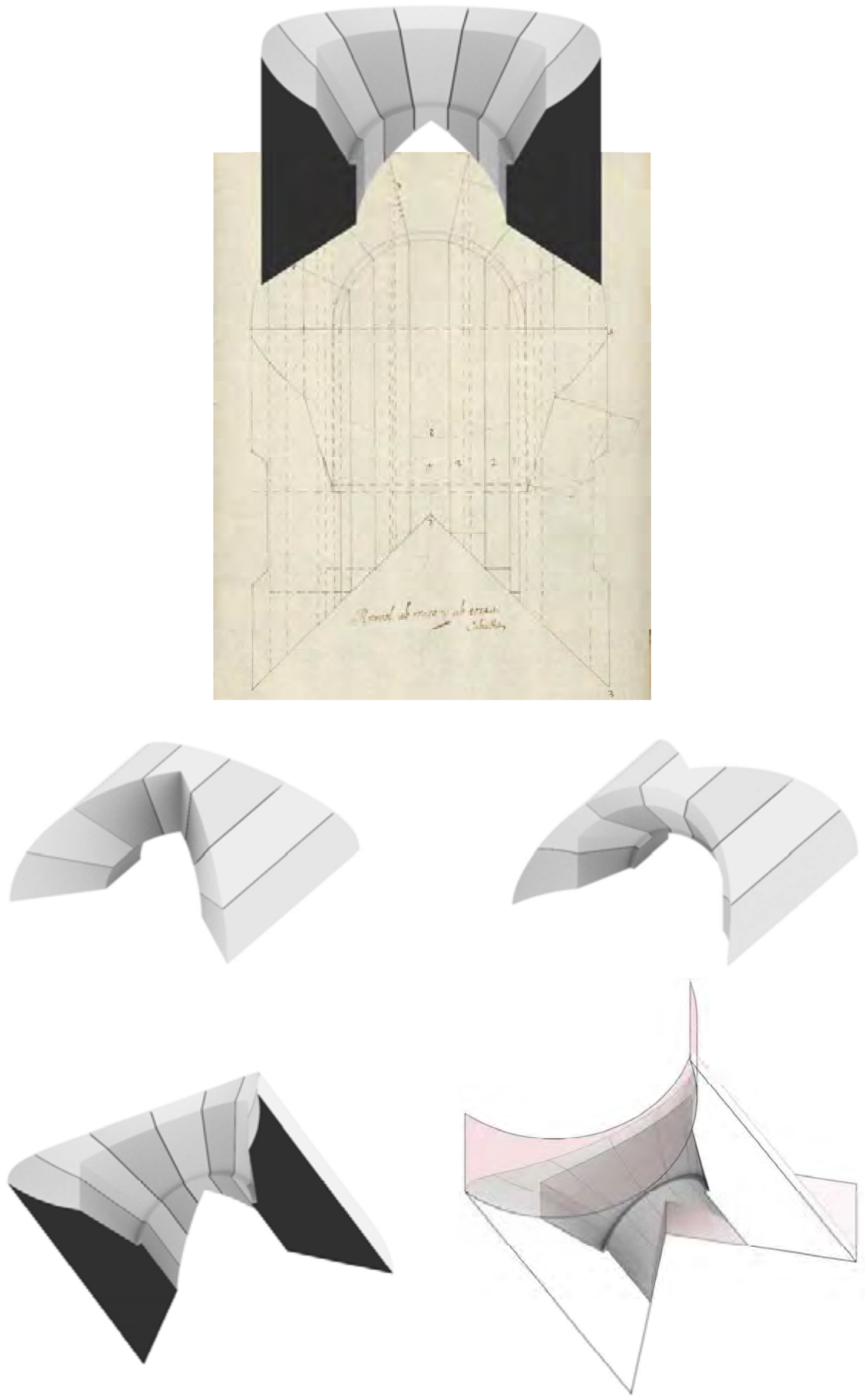

Fig. 7.19. Capialzado en esquina y torre cava. Dibujo del autor. 


\subsection{Rravol rodo - Capialzado redondo}

\section{Folio 181 (Traza 95)}

El capialzado que a continuación se expone, lo que Ribes llama rravol rrodo, capialzado redondo, con las jambas y el intradós que se abren en derrame hacia el interior, es en realidad un arco abocinado cuya superficie de intradós ha sido labrada para conseguir una concavidad. Los arcos abocinados son aquellos arcos conformados por dos testas de medio punto, de las cuales una es mas ancha y mas alta que la otra. Las impostas yacen en el mismo plano y la superficie de intradós así conformada pertenece a un cono que tiene por eje de revolución la misma recta que une los centros de los dos arcos.

Aunque no sean conformados como capialzados propiamente dichos, estos arcos absuelven la misma función de salvar dos cotas distintas en un hueco sobre una pared; la superficie de intradós que los caracteriza podría también considerarse como una hilada de dovelas componentes una trompa cónica. Es un elemento muy frecuente en la arquitectura catalana de todas las épocas, aparece en las iglesias románicas y góticas, así como en edificios públicos más tardíos como la Lonja y la Aduana de Barcelona o en las ventanas cañoneras de las fortificaciones. Se puede encontrar en su forma de arco de medio punto o de arco escarzano, como es el ejemplo del claustro del Hospital de la Santa Creu.

La traza y ejecución de este arco no presenta dificultades, también en este caso Ribes obtiene una sola plantilla de junta que servirá para determinar todas las dovelas del arco y de las jambas; en combinación con la plantilla de testa será posible definir el sólido capaz a labrar. Dependiendo de las habilidades del cantero, las dovelas se pueden definir como si fueran de un arco recto, o sea sin el capialzado, y solo después tallar el intradós abocinado, o para ahorrar material, utilizar un prisma de piedra que ya se aproxima al volumen final, sin necesidad de labrar primero la dovela del arco recto en su entereza. En ambos casos se labra la piedra en vertical con un baivel, quitando el derrame de las caras de lecho. A continuación, se puede apoyar la plantilla de las dos caras de lecho, se marca con una cercha las líneas que delimitan el intradós abocinado en las caras correspondientes y, tallando a regla, labrar la superficie cónica del intradós.

Se puede proceder ahora a "adulcir" el arco, es decir se puede proceder a cavar el intradós y las jambas hasta conseguir el aspecto deseado. Si la concavidad se extiende con la misma profundidad a lo largo de toda la longitud del arco y de las jambas, se puede utilizar el mismo baivel para comprobar la correcta concavidad, haciéndolo deslizar recorriendo la silueta del hueco. En este caso la superficie del arco a determinar será de concreción tórica y la superficie de las jambas cilíndrica.

\subsection{Rravol rodo anell y rravol - Capialzado redondo anillo y revuelto}

Folio 182 (Traza 96)

La traza del Folio 182 corresponde a la versión del capialzado redondo que se acaba de exponer con anadida la mocheta que sostiene los marcos de la carpintería. La traza y la talla son iguales al modelo anterior. 

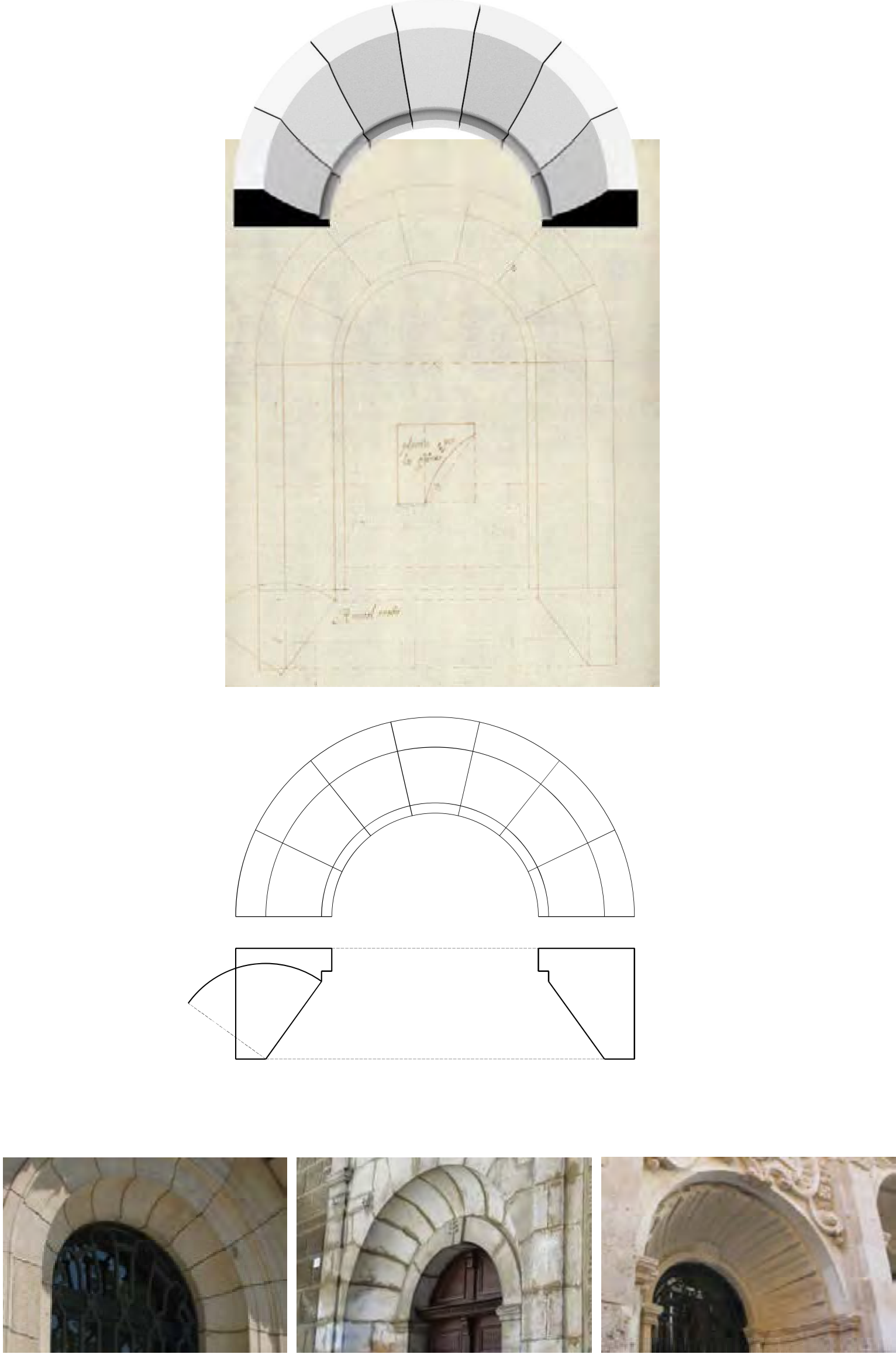

Fig. 7.20. Capialzado redondo en la Aduana de Barccelona; Sant Pere de Gessa; Esglesia Socors, Menorca. Dibujos y fotos del autor. 


\subsection{Rravol rracole - Capialzado en puerta cuadrada}

\section{Folio 185 (Traza 99)}

Con este título Ribes presenta el capialzado definido por una superficie reglada que se obtiene desplazando una recta sobre dos generatrices: un arco escarzano en la embocadura más amplia y un dintel recto en la otra. De acuerdo con la interpretación que Ribes propone en el Llibre de trasas, que resulta observando la sección de las plantillas, el intradós va a ser profundamente cavado.

La traza de este capialzado aparece con constancia en varios tratados españoles ${ }^{11}$ y es de uso muy común en la arquitectura española de todas las épocas.

Recordamos varios ejemplos de interés en Cataluña, como el capialzado de labra muy cuidada que cubre un pase de gran luz en la Catedral Vieja de Lleida, aparecen numerosos en los vanos de acceso de los edificios renacentistas de Tortosa, o en las construcciones borbónicas, posteriores a Ribes, de la Universidad de Cervera y de la Ciutadella de Barcelona, este último ejemplo presentando una concavidad muy pronunciada, exactamente como en la traza aquí descrita. Es también el modelo de capialzado más difundido en las Baleares, en los edificios públicos, privados y religiosos.

Una particularidad formal que acerca la traza del manuscrito de Ribes a la escuela francesa es el intradós "adulcido", aunque aquí de manera más acentuada, como recomendado por Philibert de l'Orme ${ }^{12}$ que también describe el uso:

... [en] grandes puertas, y especialmente las que se abren en muros de grandes espesores. Paragrandes luces, y los grandes pesos que sostienen encima [...] no se pueden hacer la parte de atrás de estas puertas rectas, sin peligro de que se rompan, por la gran carga que necesitan soportar: de manera que los morteros de las juntas se rompen y a veces las piedras [están] en peligro de caer.

Por esto es necesario que aunque la parte de delante de la puerta sea recta, que la cara de atrás sea un arco rebajado [...] Esta solución no sólo es buena y apropiada para las puertas y ventanas del primer piso sobre el terreno y sirven para las cocinas y otros lugares, sino que será muy apropiada para la parte posterior de las ventanas. ${ }^{13}$

\footnotetext{
11 A) Encontramos el Capialzado desquijado cuadrado en Gines Martínez de Aranda, Cerramientos y Trazas de Montea, Facsimilar (Madrid: CEHOPU, 1986): pl. 148. B) Alonso de Guardia, Manuscrito de Cantería (Ubicación: Biblioteca Nacional de España, Madrid. Signatura: ER/4196, 1598): ff. 72 v, 85 v. C) Pedro Navascués Palacio, “EI Libro de Arquitectura de Hernán Ruiz. Introducción Histórica - Archivo Digital UPM", 2011: f. 47. D) Capialzado en puerta cuadrada, en Alonso de Vandelvira, Libro de Cortes de cantería... [Manuscrito], [1588-1591]: f. 46 r. E) Juan de Portor y Castro, Cuaderno de Arquitectura de Juan de Portor y Castro [Manuscrito], 1708: f.37 v. F) En Gelabert hay el Portal roma volt y revolt tot duna pesa (traza n21, folio 33v), que es un arco adintelado por el lado exterior y un capialzado al interior, un capialzado arco escarzano y también su variación "en viaje" (traza 90, folios $103 v$ y 104r).

12 Philibert de L' Horme, Le Premier Tome de l'Architecture, vol. Livre III (Paris: Federic Morel, 1567), f. 64 r.

13 Calvo López, 2000 : 63, cita Philibert de L'Horme: «grandes ouuertures \& largueurs de portes\& grande pesanteur qu'elles soustiennent par le dessus [...] on ne peult faire les arriere - voulsures des dictesportes droictes \& quarrées, sans danger d'estre offensées, pour la grande charge qu'il fault qu'elles portent:de forme que les mortiers des commissures en sont rompus \& quelquefois les pierres en danger de detomber.Parquoy il est de besoing combien que le deuant de la porte soit quarrée et droict, que les arrierevoulsuresd'icelle soient d'vn arc surbaissé [...] Telle façon non seulement est bonne, \& propre pour lesportes \& grandes fenestres qui
} 


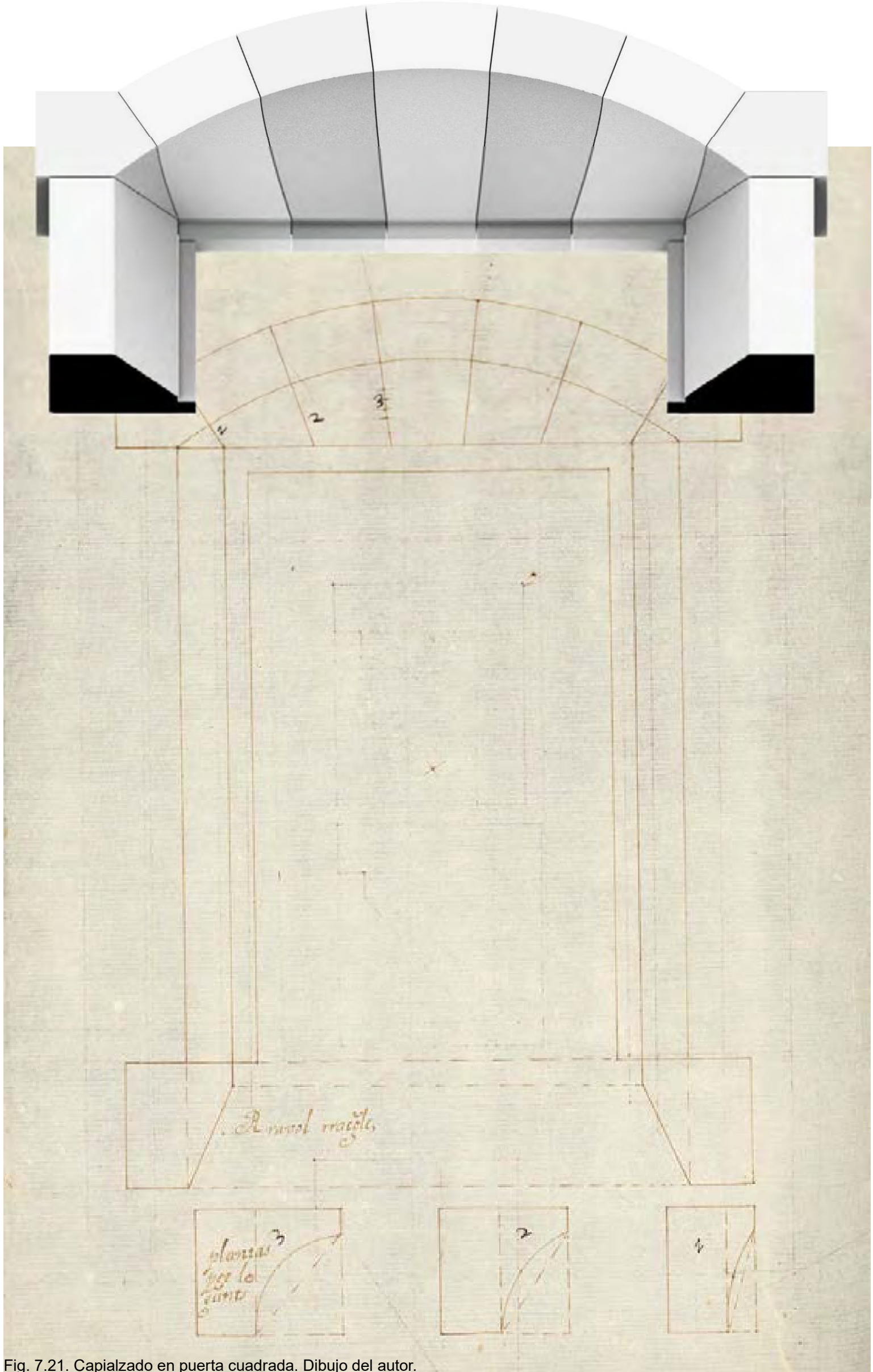

Fig. 7.21. Capialzado en puerta cuadrada. Dibujo del autor. 
Para la talla de esta pieza Ribes se sirve de los patrones de testa, que se sacan del alzado, y de las caras de junta, que reproduce en la parte inferior del dibujo.

Se procede entonces tallando las dovelas como si fueran completas, o sea como si no hubiera el capialzado, labrando en vertical la cara vertical del paramento de testa; a seguir, sobre las dovelas de este arco provisional recién obtenidas, se aplican las plantillas de lecho a las caras correspondientes y con la ayuda de una cercha se calcan las curvas que delimitan el intradós. Se procede desbastando la piedra y se labra la superficie del capialzado con la ayuda de una regla apoyada en el segmento del arco curvo y en el dintel recto.

Si es necesario, ahora es posible "adulcir" el intradós, o sea cavar la superficie, operación que en este caso depende mucho de las habilidades del cantero, que sí se puede orientar con las plantillas de junta, pero, al ser una superficie curva de radio variable, no tendrá un sistema de referencias de fácil control.

Podemos suponer que se aproxime a la superficie deseada dividiendo las dos líneas de junta curva en partes iguales y mientras esté descantillando la piedra, apoye una cercha en uno y otro extremo. Para el éxito de esta operación será determinante el buen ojo del cantero y su capacidad de mantener la tangencia del intradós entre todas las dovelas.

\subsection{Rravol rracole, anell y rrevoll - Capialzado en puerta cuadrada anillo y revuelto} Folio 186 (Traza 100)

Este título corresponde a la version del capialzado en puerta cuadrada que se acaba de exponer con anadida la mocheta que sostiene los marcos de la carpintería (anell y rrevoll).

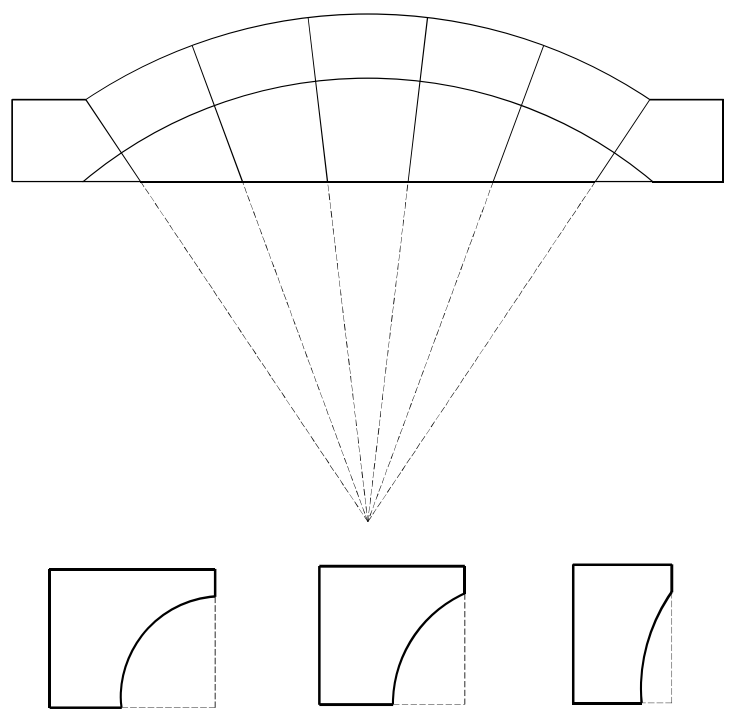

Fig. 7.22. Capialzado en puerta cuadrada con intrados adulcido. Dibujo del autor.

sont au premier estage dedans terre \& seruent pour les cuisines \& autreslieux, mais aussi elle viendra fort à propos pour les arriere - voulsures des croisseés [...]». 

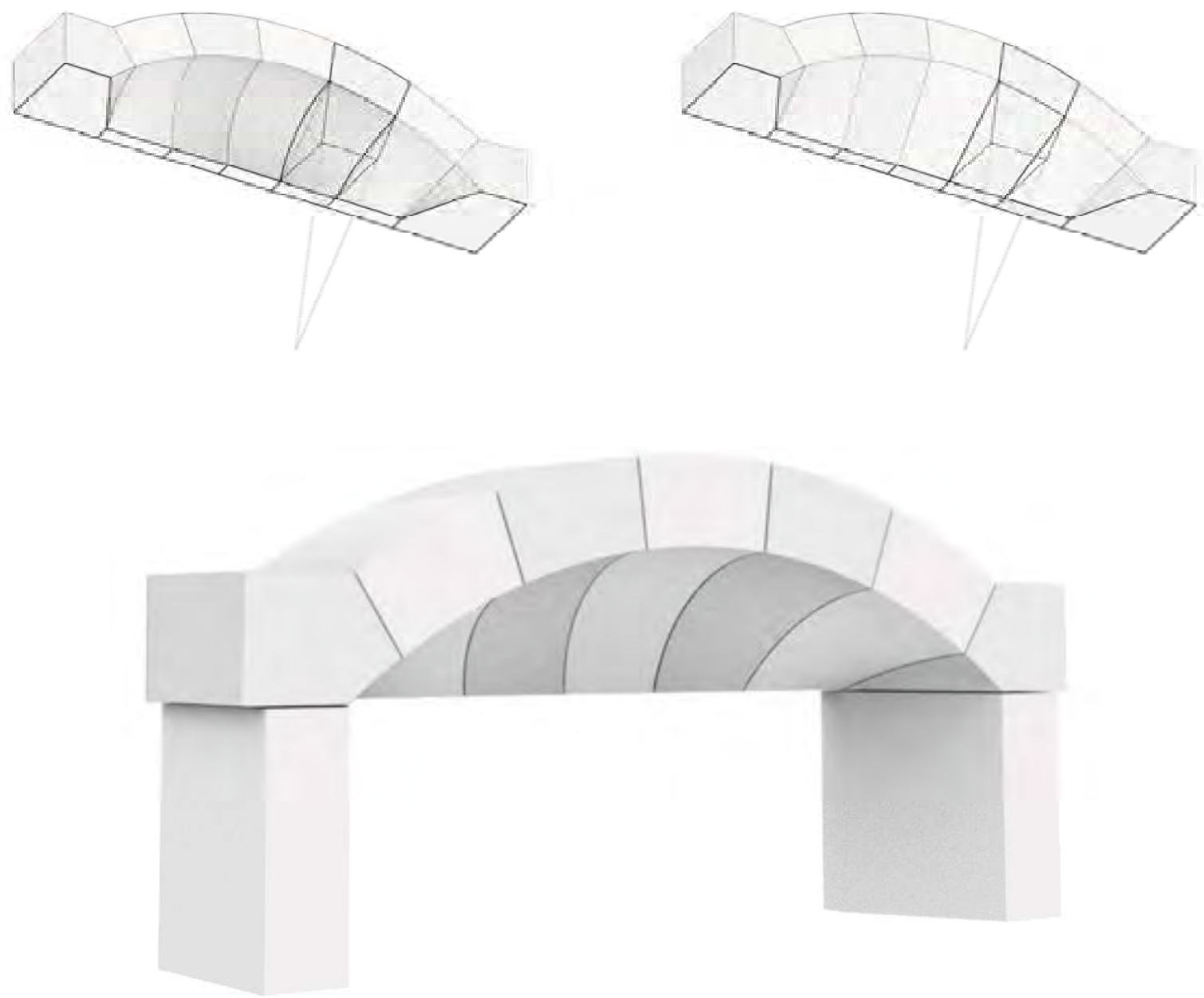

Fig. 7.23. Capialzado en puerta cuadrada con el intradós adulcido y a regla. Dibujo del autor.
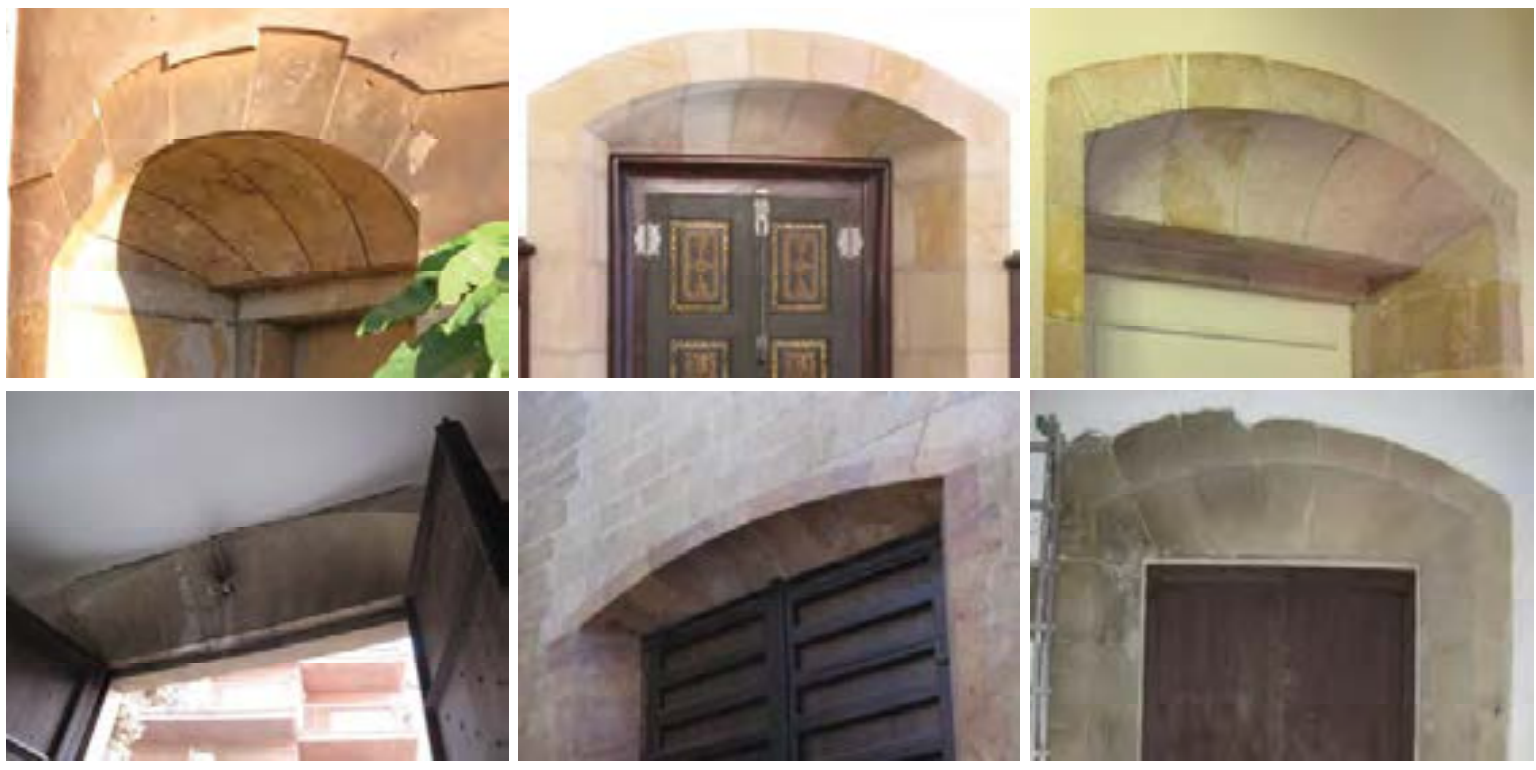

Fig. 7.24. Capialzados con intradós adulcido en: Iglesia Castrense de la Ciudadella; Parlament de Catalunya (B, C); Iglesia de Caldes; Catedral de Tortosa; Universitat de Cervera. Fotos del autor. 

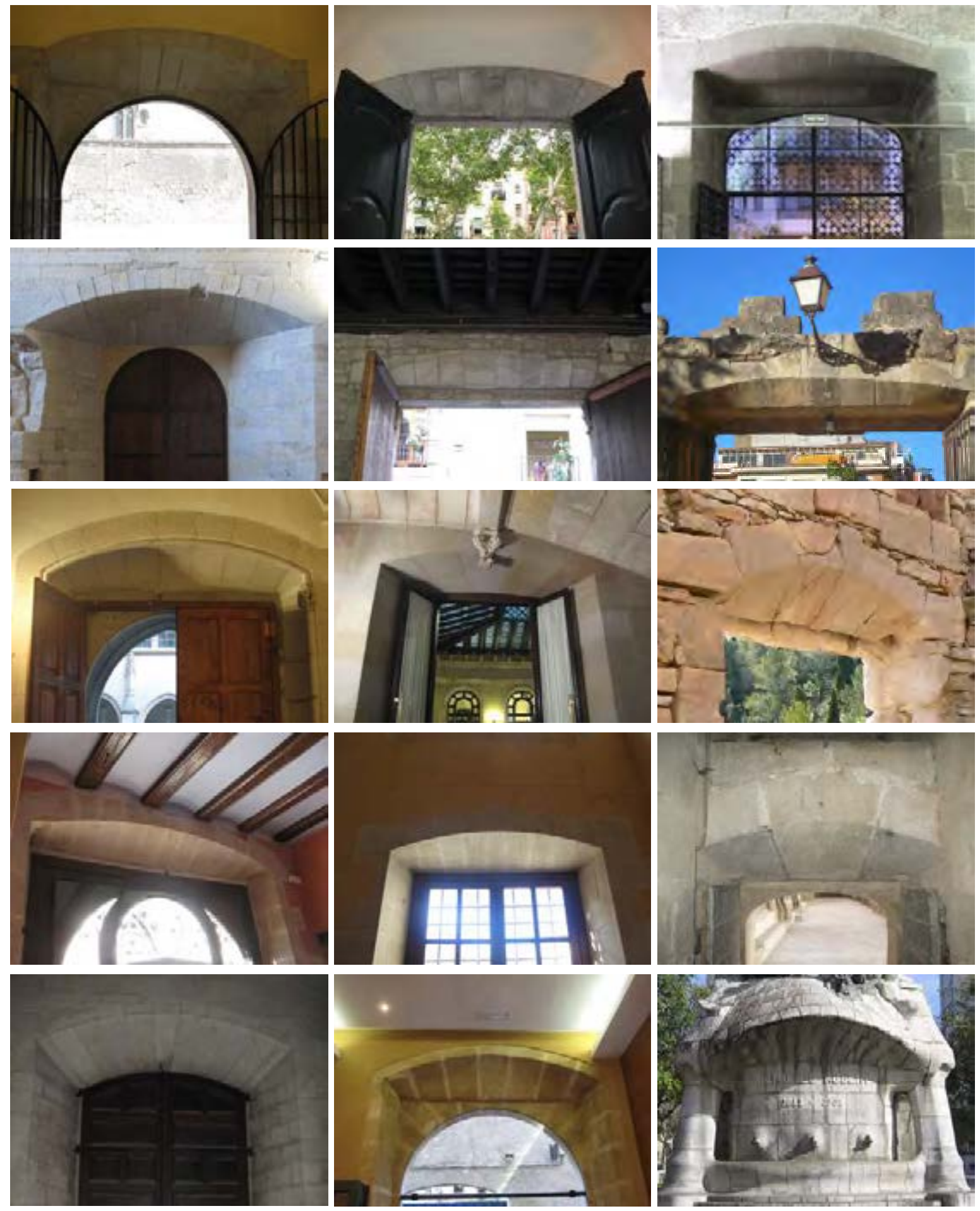

Fig. 7.25. Capialzados a regla: Palu del Lloctinent; Palau de la Virreina; Antic Hospital de Santa Maria, Lleida; Catedral Vella, Lleida; Antic Hospital de la Santa Creu, Barcelona; Monestir de Sant Cugat; Monasteri de Bellpuig; Ermita de Les Virtuts; Tortosa (J y K); Catedral Vieja de Lleida; Catedral Nueva de Lleida; Tarragona; Monument al Doctor Robert, Barcelona. Fotos del autor. 

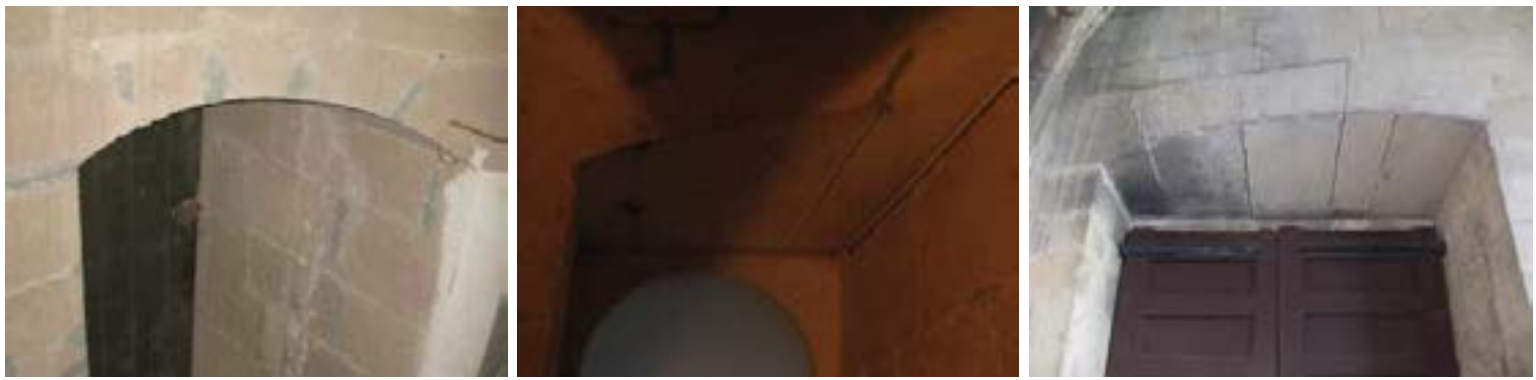

Fig. 7.26. Capialzados a regla sobre parede oblicua o curva: Monasteri de Bellpuig (A y B); Patio de la Catedral de Tortosa. Fotos del autor
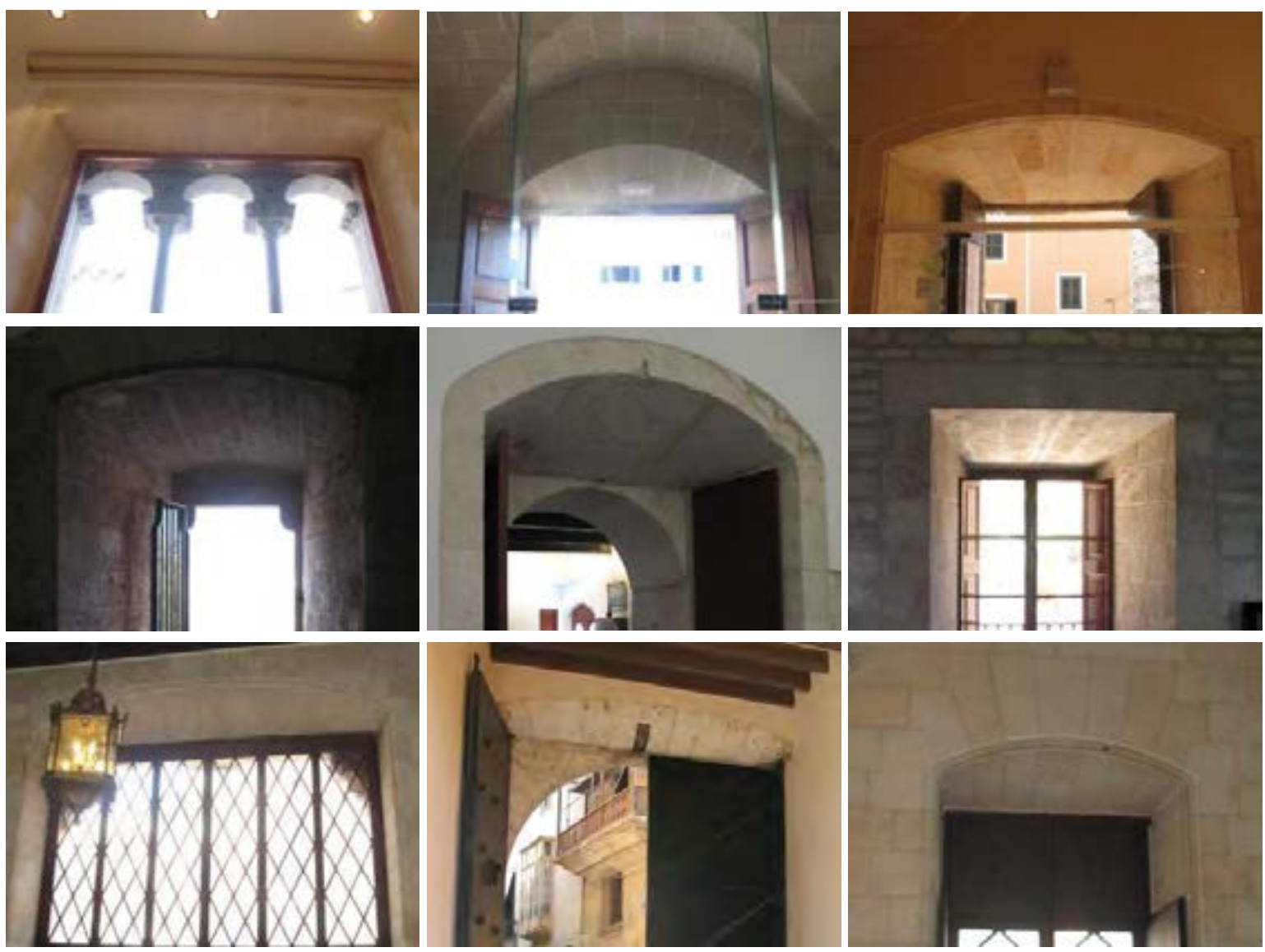

Fig. 7.27. Capialzados a regla en las Baleares: Can Comasema, Ibiza; Menorca (B y C); Palau de l' Almudaina (D, E, F, G); Palma de Mallorca ( $\mathrm{H}$ y I). Fotos del autor. 


\section{Trompas}

Ribes describe 8 ejemplos de trompas cuyas características generales están en línea con los otros tratados más importantes de la época. Un análisis cuidadoso de las trazas revela cómo en estas páginas introduce una característica constructiva única que no se ha repetido en otros tratados: algunas trompas se caracterizan por el original "trompillón" en forma de diente de sierra, probablemente originario del gótico catalán. Esta pieza, que corresponde a la parte inicial de un trompa, viene colocada en el vértice del cono para recibir los bloques y evita los ángulos muy agudos de la piedra, que causarían una rotura más fácil si las dovelas se encontraran en un solo punto.

Las trompas de Ribes son todas ejecutadas como bóvedas cónicas y en las páginas del tratado se reproducen exhaustivamente los datos necesarios para su construcción: las plantillas desarrolladas del intradós, las elevaciones desarrolladas, las secciones, los ángulos entre las juntas y los lechos de las dovelas. La metodología del tratado de Ribes se orienta hacia un objetivo: definir con precisión los paneles que se envuelven alrededor de cada dovela.

Este elemento arquitectónico, la bóveda cónica, permite la transición de una planta cuadrada a una geometría octogonal, haciendo posible, por ejemplo, el paso entre el cruce cuadrado de una iglesia y la base octogonal o circular de una cúpula que necesita ser instalada sobre eso ${ }^{1}$. El desarrollo de superficies cónicas no se finaliza con el estudio de los trompas, de hecho, sirve como punto de partida para el desarrollo de las plantillas para las bóvedas esféricas. La principal contribución geométrica del estudio de las trompas está en el desarrollo de superficies cónicas en el plano. La construcción geométrica de las trompas está también estrictamente relacionada con las bóvedas de cañón inclinadas, que requieren un procedimiento igual para determinar el ángulo que se crea entre las caras de intradós y las verticales y para la definición precisa de las curvas en el espacio. Este capítulo no estudiará los nichos y las trompas esféricas ya que se analizarán solamente los modelos con intradós cónicos. Ribes incluye nichos esféricos en el Llibre de trasas en los mismos folios donde describe las bóvedas. Ribes utiliza el termino pechina para denominar una trompa como era típico en la cantería de la época. Ahora para nosotros la pechina es el triángulo esférico ${ }^{2}$.

El origen de los trompas como medio de transmisión de cargas se encuentra en la Persia sasánida del siglo VII, cuando se construyeron bóvedas cónicas de piedra incoherente para sostener las cúpulas (Fig. 8.1). Los romanos desarrollaron el uso de algunas tipologías de trompas, tomándolas de sus provincias orientales, aunque no utilizaron sistemáticamente este nodo estructural, porque cubrían espacios cuadrados con bóvedas en rincón de claustro y espacios circulares con cúpulas hemisféricas. Las trompas de la

1 Palacios Gonzalo, 1990: 25.

2 Rabasa Diaz, 2011, 282 (nota 363). 
iglesia de T'alich en Armenia, datadas entre el 661 y el 682, son uno de los ejemplos más antiguos de trompa adovelada. Sucesivamente, este elemento constructivo caracterizó la arquitectura del Románico, llegado probablemente a través de los contactos ocurridos con las Cruzadas o desarrollado independientemente en Europa continental. De función similar pero diferente geometría, para resolver la transición entre un plano cuadrado y una cúpula circular, los bizantinos adoptaron y desarrollaron en su esplendor completo las pechinas (o pendentives), que son los triángulos esféricos que conectan la parte superior de los pilares a la base de la cúpula.

Podemos registrar la difusión de las trompas en Cataluña desde el siglo XI. Inicialmente estaban formadas por anillos concéntricos de piedra, cada uno superpuesto al anterior pero independiente entre sí. A partir del siglo XII se formaron con una sola superficie cónica formada por grandes y regulares piedras cortadas, que es cuando se puede comenzar a notar su carácter estereotómico.

La gramática gótica usó principalmente nervios y terceletes para resolver la transición entre formas cuadradas y poligonales, aunque esa no era una regla estricta. En la prolongada construcción de las catedrales románicas que se desarrolló a lo largo de este período y que presentaban muchos caracteres góticos, se construyeron trompas de gran tamaño para soportar las cargas estructurales y resolver la geometría, como es el caso de las trompas de la Catedral de la Seu Vella en Lleida o en la Catedral de Tarragona en Cataluña.

El Renacimiento y el Barroco, redescubriendo diferentes geometrías y composiciones espaciales, encontraron un nuevo propósito y significado para el uso de los trompes, como lo atestiguan los tratados y la arquitectura de la época, que se revelaron muy eficaces para crear voladizos en una esquina, un rincón o en un muro.

Otros tratados españoles contemporáneos a Vandelvira no incluyen trompes (Martínez de Aranda y Rodrigo Gil de Hontañón), mientras era un tema muy difundido en la tratadística francesa. 

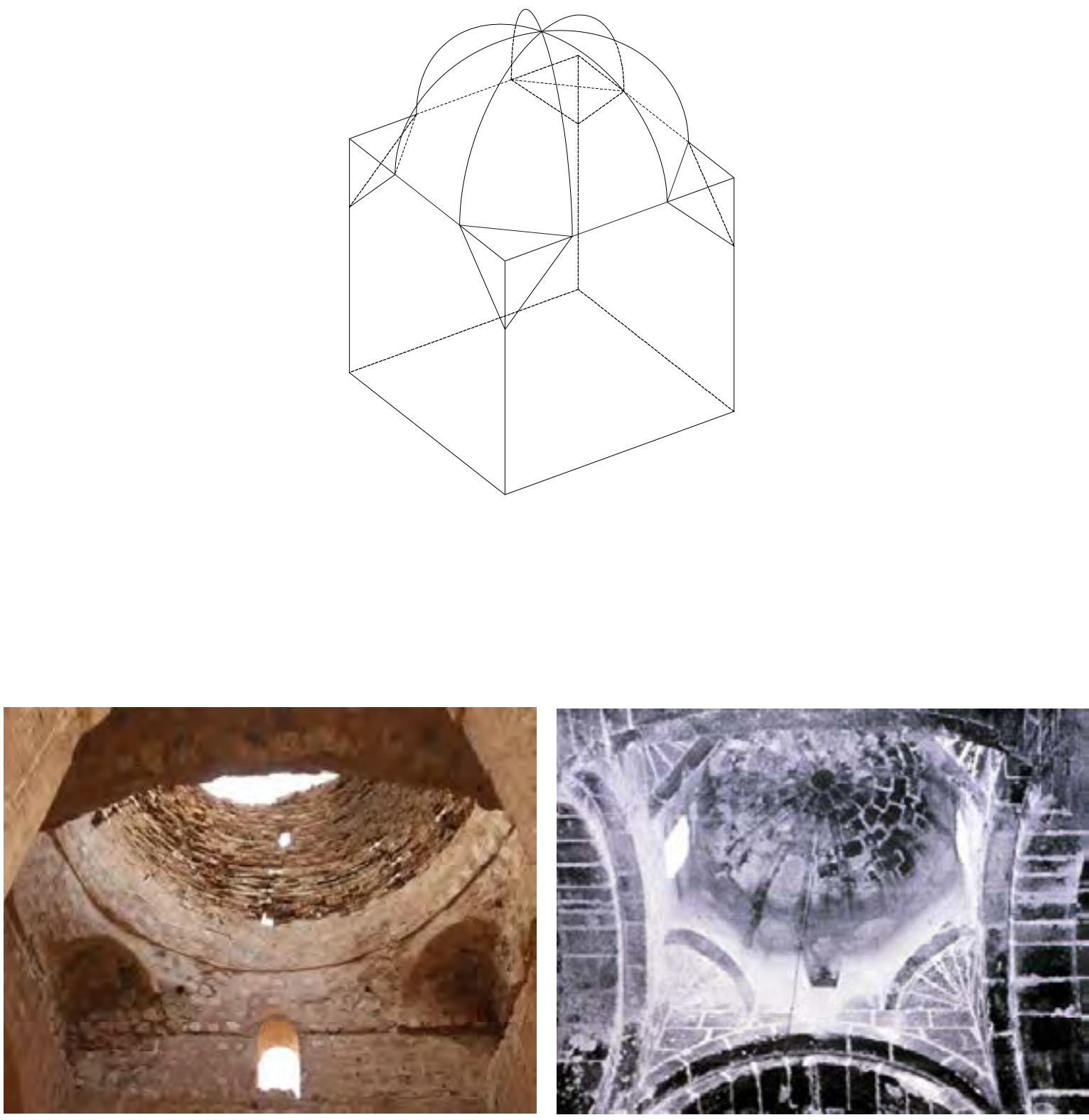

Fig. 8.1. Transición de planta cuadrada a octagonal; Sarvestan, Persia (Foto de J.C. Palacios); Odzun, Armenia, siglo VIII 


\subsection{Patxina ab canto - Trompa en esquina con trompillón en diente de sierra} Folio 217-218 (Traza 116)

Ribes describe 4 variaciones de trompas en esquina. El primer ejemplo que aparece en el manuscrito (Folio 217-218) ${ }^{3}$ no tiene título, pero es probablemente el diseño de trompa más distintivo y original del Llibre de trasas, no tanto por la tipología de la trompa (trompa en esquina), sino por su característico trompillón con geometría en diente de sierra (Fig. 8.2). Diferentes razones pueden haber determinado la forma inusual de este corte de piedra. Quizás se quiso conformar la pieza de tal manera para entrelazar los bloques, equilibrando así la dispersión horizontal de fuerzas resultante de empujes asimétricos. Su forma facilita la construcción en situ ya que aloja con precisión cada dovela en su posición, satisfaciendo una demanda estética con el diseño inusual de las líneas conjuntas resultantes y su volumen plástico.

El ejemplo construido más interesante de este trompillón se puede encontrar en Barcelona en el patio del antiguo Hospital de la Santa $\mathrm{Creu}^{4}$ del siglo XV que pudiera haber sido fuente de inspiración para Ribes (Fig. 8.3). En este caso el trompillón se funde con una de las dovelas de la base de la trompa y tiene que ser sacado con gran habilidad técnica de una pieza de piedra única. Otro ejemplo se localiza en la Iglesia Parroquial de Santa María en Caldes de Montbui, completada en 1714, para crear un voladizo en una esquina y alojar un pasaje. En ambos casos las trompas son de otra tipología y vendrán desarrolladas en el texto a seguir. Este rasgo característico del trompillón, se puede identificar en otro aparejo estereotómico localizado en Barcelona. Los salmeres del capialzado de la entrada principal del Palau de la Generalitat de Barcelona están conformados por dovelas en forma de volúmenes segmentados. Estos bloques, colocados simétricamente en los dos lados del arco, están recibiendo las dovelas y las fuerzas que actúan sobre la puerta.

Al fin de una catalogación geométrica, esta traza corresponde a una trompa en esquina.

Ribes dibuja la planta y la sección que se complementan con el desarrollo de las caras de testa en verdadera magnitud, la longitud de las líneas de junta del intradós, el desarrollo del intradós y la dimensión del ángulo que cada bloque forma con el plano horizontal. Ribes produce un notable error en su dibujo o quizás un ajuste voluntario para encajar en el papel el diagrama del desarrollo del intradós. La longitud de las dovelas no corresponde a la dimensión que debería tener si hubiera hecho la correcta construcción geométrica. Dibuja la longitud de las juntas tomando la medida de su proyección en alzado, mientras que debería haber utilizado la longitud real. Esta última medida se puede sacar del diagrama de construcción del mismo folio. Considerando por ejemplo la primera dovela, en lugar de utilizar la dimensión verdadera O-2c tomada en el diagrama de desarrollo, utiliza la longitud proyectada O-2b (Fig. 8.2, las líneas discontinuas representan las plantillas desarrolladas ideales de los intradoses construidos con las verdaderas dimensiones).

Otra inexactitud, aunque más parecida a una imprecisión gráfica, se puede encontrar en

\footnotetext{
3 El orden de las trompas como aparecen en el tratado de Ribes presenta algunas inconstancias y no están estrictamente agrupadas por tipología o dificultad de ejecución.

4 Martín el Humano colocó en 1402 la primera piedra para la construcción del hospital, con el fin paliar las consecuencias que la peste había dejado en Barcelona.
} 
Trompas
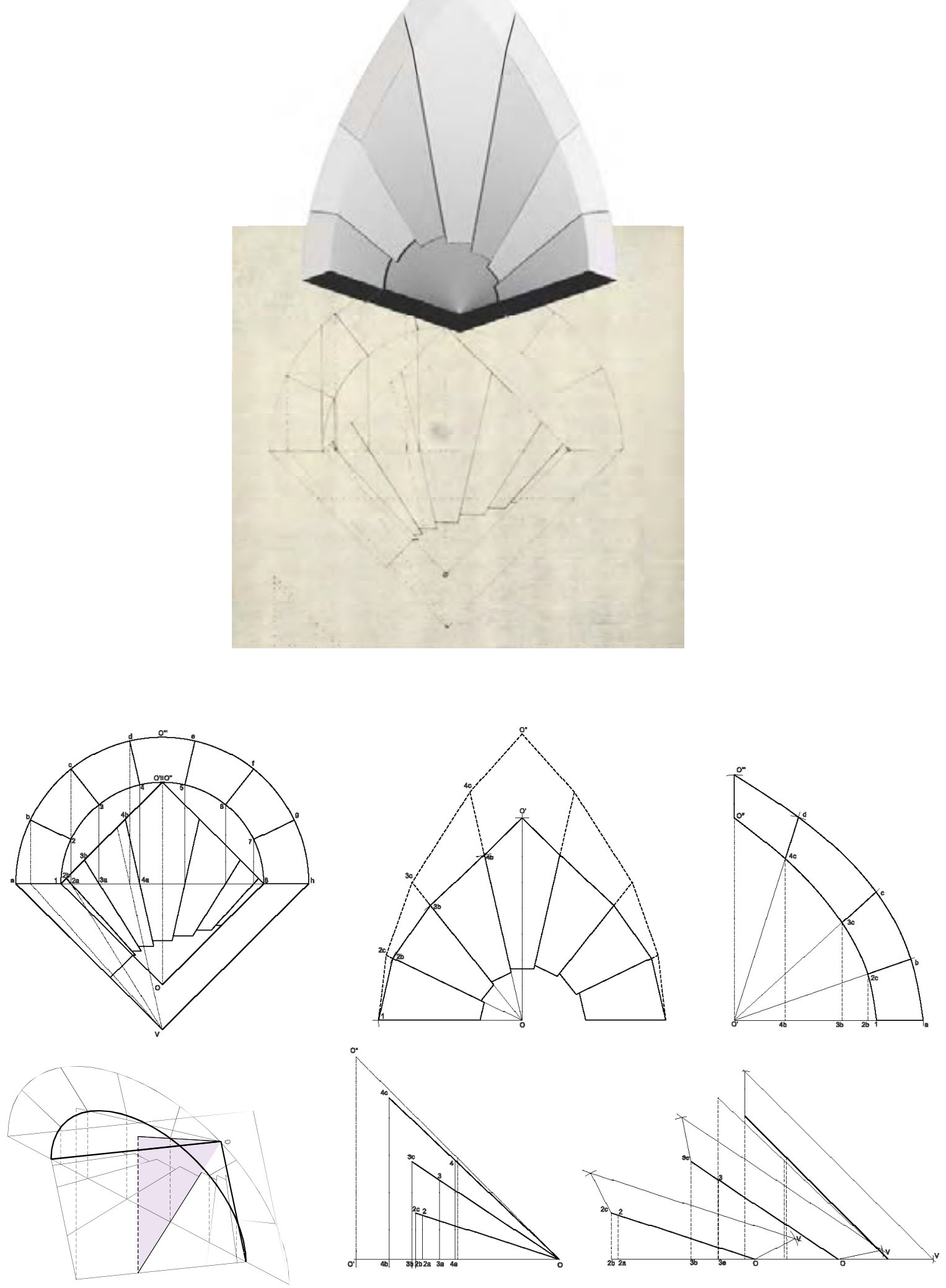

Fig. 8.2. Patxiina ab canto y desarrollo de las plantillas. Dibujo del autor.

197 
las plantillas del alzado de la trompa. El borde curvo ha sido dibujado como fueran arcos de circunferencia segmentados en lugar de una curva cónica, probablemente porque Ribes usó sólo compas y regla con insuficiente aproximación. El espesor constante de la cascara hace que las líneas de intradós y estrados de las caras verticales de las dovelas no sean paralelas.

Ribes dibuja la verdadera magnitud de las caras de junta y indica el grosor de la cascara ideal con una línea paralela a la junta de intradós, en contraste con Jousse y Derand cuyas trazas muestran las dovelas de extradós apuntando al vértice de la trompa que dará como resultado una concha con espesor que disminuye hacia el vértice del cono. De L'Orme, probablemente para evitar la confusión y la superposición de líneas, se limita a marcar la dimensión de la cara vertical y sólo el espesor a la testa de la trompa.

En el Llibre de trasas las plantillas de las caras de junta de las dovelas están representadas una traslada respecto la otra para evitar confusión. A través de una simple construcción geométrica, este diagrama también proporciona la dimensión del ángulo entre el borde del intradós y la cara vertical del bloque que se utilizará para construir el saltarregla ${ }^{5}$.

En la plantilla de las caras de junta están marcadas unas líneas que corresponden al punto de inserción de la dovela adyacente.

Vandelvira describe la traza de la trompa en esquina, pero con una diferencia importante; en su tratado la altura de la trompa no está determinada por la proyección ortogonal del arco guía en el plano normal al ángulo bisector de la trompa (el arco guía representa la elevación), mientras que en el dibujo de Ribes la altura de la trompa se establece por la proyección cónica del arco guía (el arco guía representa la sección), resultando en una trompa mucho más alta. Para este tipo de trompa, Jousse dibuja un arco escarzano para evitar la altura excesiva de la bóveda mientras que Derand utiliza la misma sección que Ribes. Exactamente como De L'Orme, cuyo tratado parece seguir estrictamente todas las pautas, Ribes trabaja con triángulos similares pertenecientes a la sección vertical que han sido rotados y volcados en el plano horizontal y posteriormente construye las plantillas a través de la trilateración. Si se conoce un triángulo que se encuentra sobre una sección constructiva definida por el arquitecto, es posible encontrar un triángulo similar situado en el mismo plano del triángulo anterior. Si conocemos una dimensión del segundo triángulo, esto implica que el triángulo similar se definirá en todas sus dimensiones. Las mismas operaciones se repiten para definir los puntos de extradós necesarios para construir las plantillas de las caras de junta. Vandelvira, con un proceso gráfico equivalente y un concepto casi idéntico, utiliza triángulos y abatimientos similares para construir los diagramas que usa para encontrar las verdaderas dimensiones de los bloques de piedra. Este modelo de trompa no está descrito en el tratado de Gelabert. Puede ser que este autor haya considerado suficiente para entender el procedimiento la traza de la Pechina de medio punto en tres paños.

\footnotetext{
5 La herramienta que el albañil utiliza para transferir los ángulos previamente calculados en el trazado a la piedra.
} 

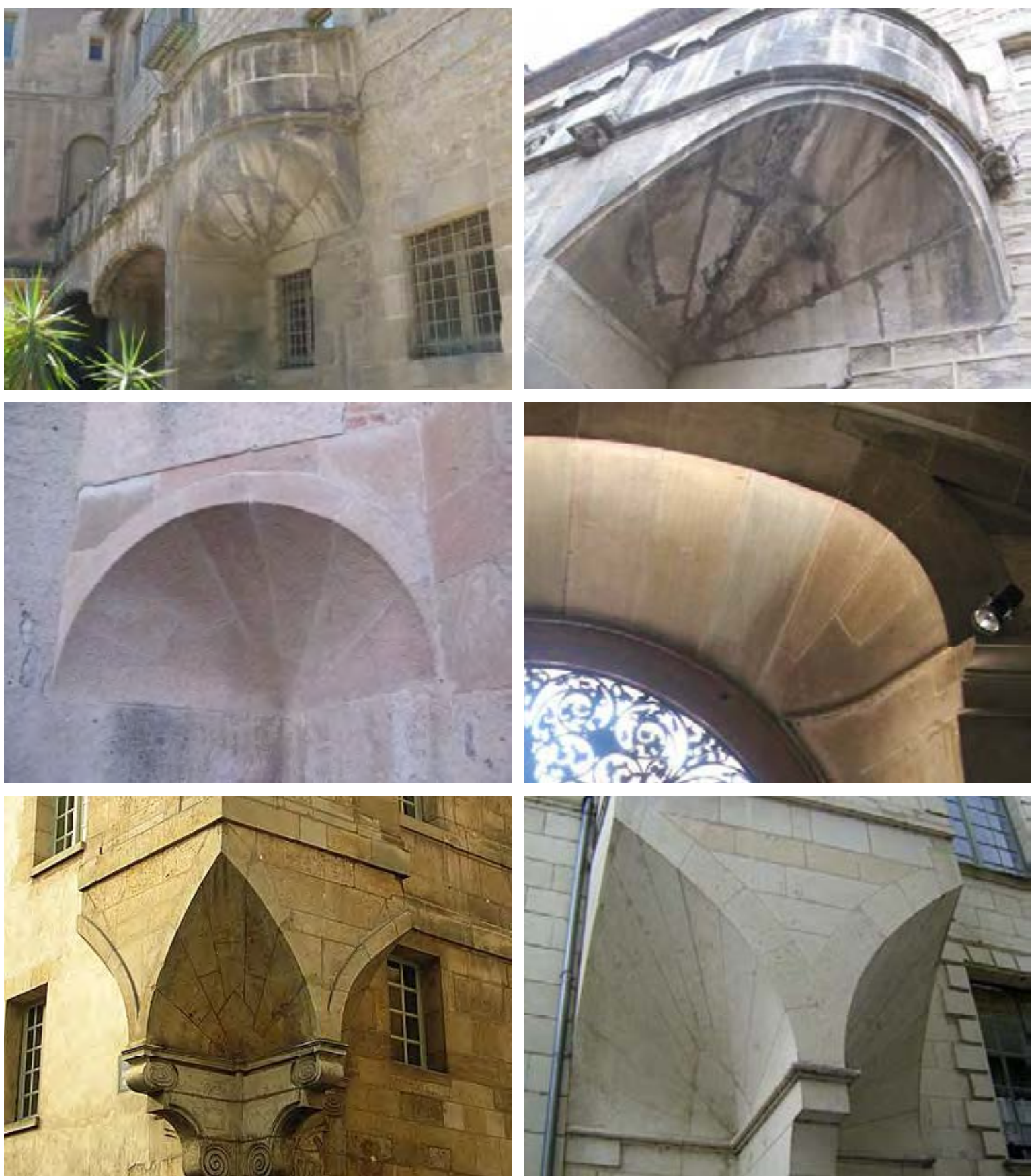

Fig. 8.3. Trompa Hospital de la Santa Creu, Barcelona; Iglesia de Caldes; particular del despiece en diente de sierra del capialzado del Palau de la Generalitat de Barcelona; trompas en Lamoignon, Paris y Hotel da Ville, Samur. Fotos del autor.
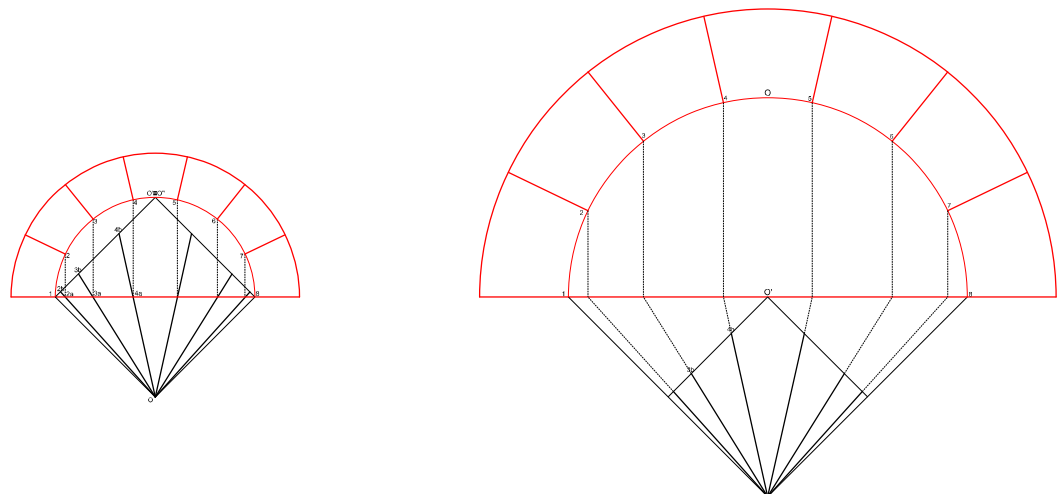

Fig. 8.4. Proyeccion del arco guia según A: Ribes, Derand y Jousse y B: Vandelvira. Dibujo del autor. 

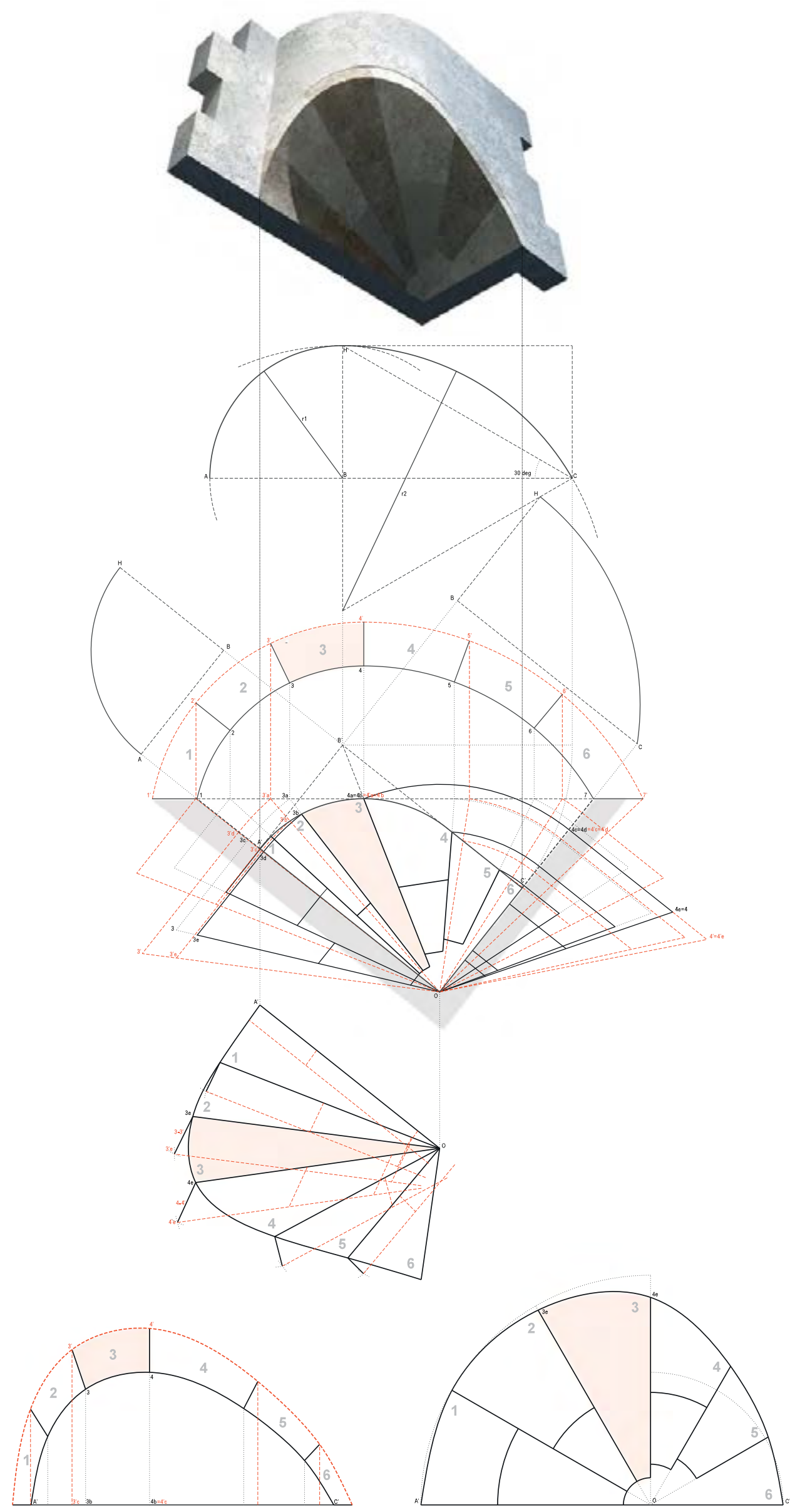

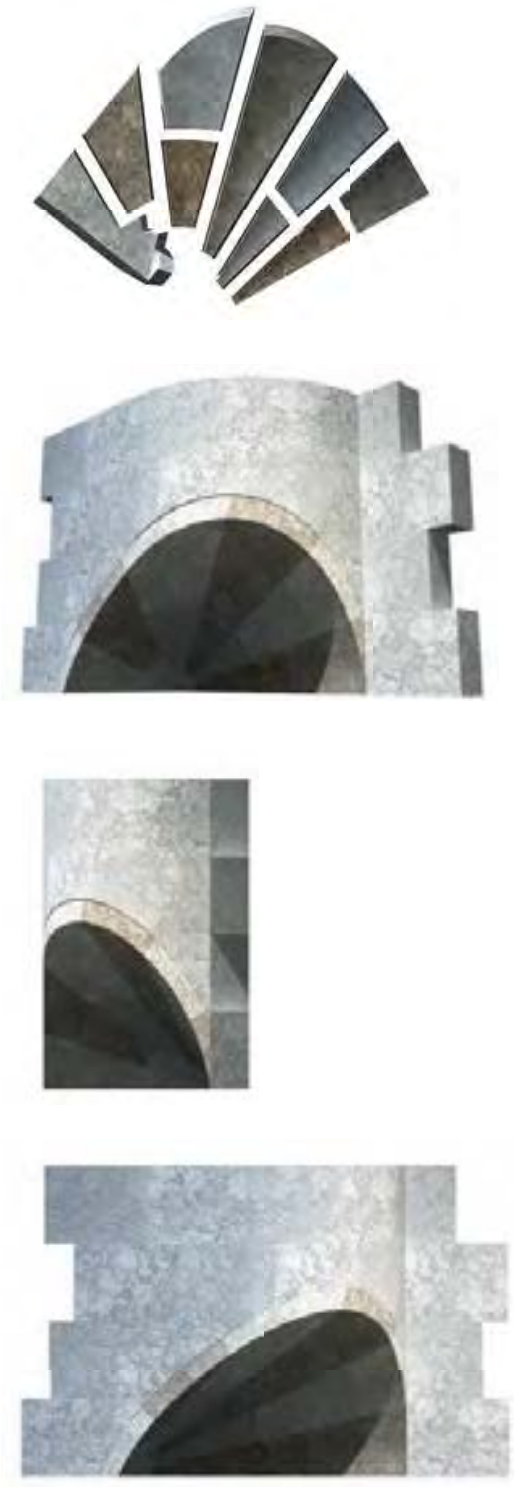
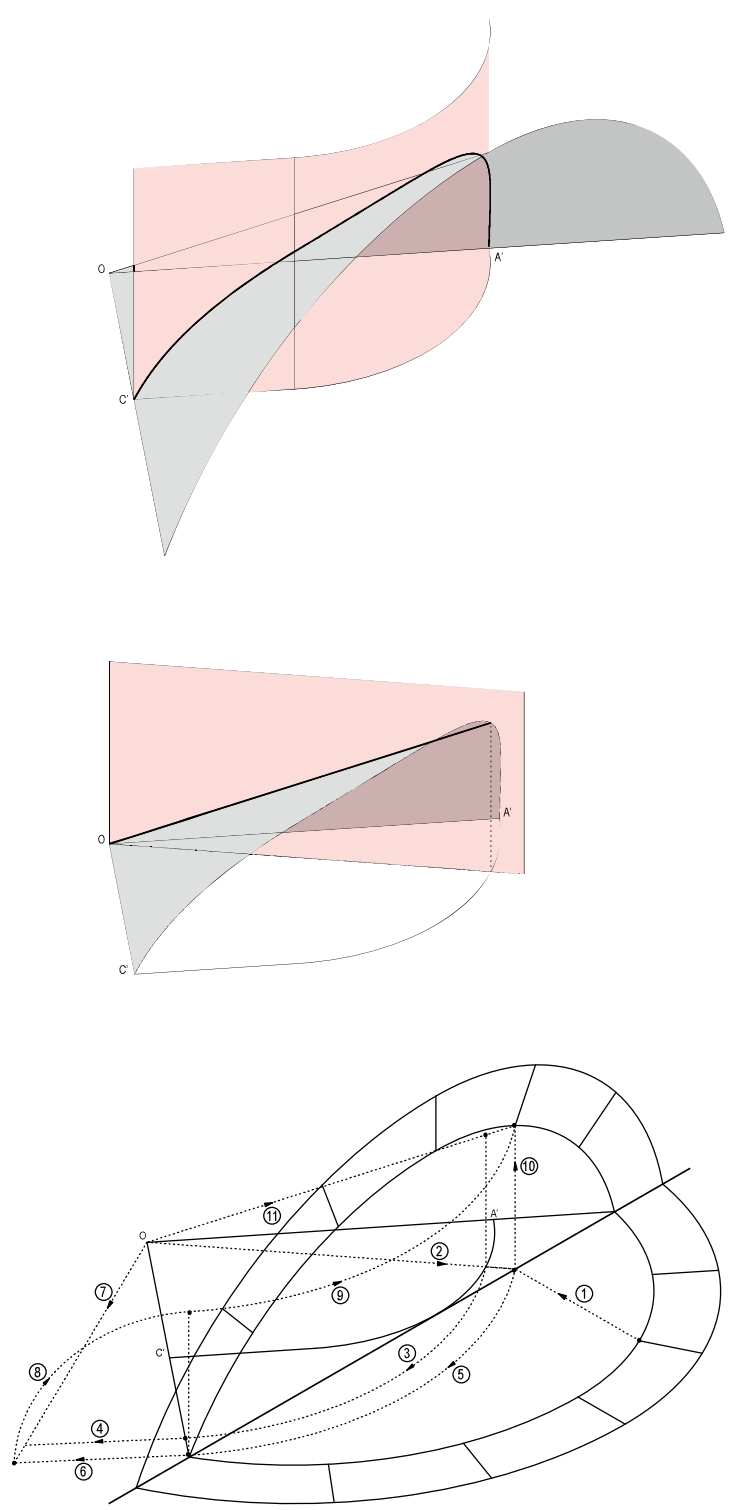

Fig. 8.5. Estudio de la traza de la trompa del Hospital de la Sanat Creu. Dibujo del autor.
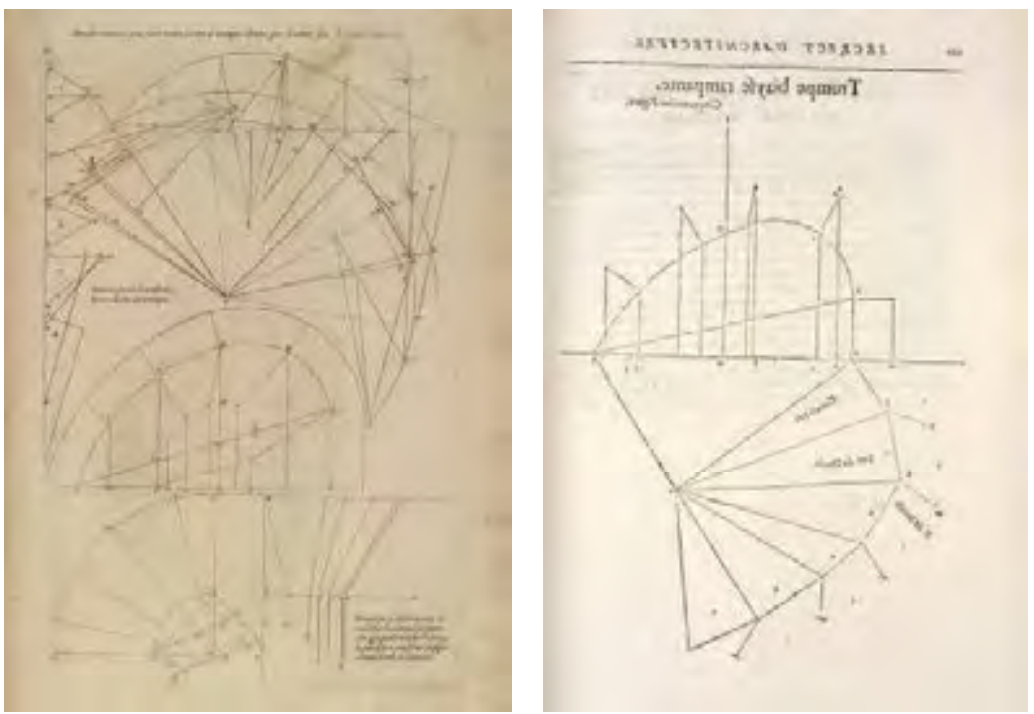

Fig. 8.6. Trompa rampante en Derand y Jousse 


\subsection{Patxina ab canto - Trompa en esquina}

Folio 230 (Traza 124) y Folios 233-234 (Traza 128)

Las trazas de Folio 230 y Folio 233-234 son trompas en esquina como el modelo que se acaba de exponer, pero presentan una solución de "trompillón" más común. En este case, la simetría del dibujo permite dibujar sólo la mitad de las plantillas para construir el conjunto. En la traza 124, los gráficos para calcular la pendiente y la verdadera dimensión de la sillería de la bóveda cónica son muy similares al método y representaciones empleadas por De L'Orme y Jousse. En la Traza 128 Ribes dibuja también la proyección del alzado sobre un plano perpendicular a la línea pasante por la bisectriz de la trompa.

El intradós puede ser liso o avenerado, como las trompas que se encuentran en la Catedral de Tortosa con las juntas coordenadas con el entallado de las conchas.

\subsection{Patxina ab canto (escasana) - Trompa en esquina de arco escarzado}

Folio 243-244 (Traza 135)

Ribes concluye su tratado con otra trompa que llama nuevamente Patxina ab canto. Se ha adelantado el orden por claridad expositiva. Este modelo difiere de la traza previamente descrita en el Folio 217-218 por su sección, formada por un arco escarzado y por la manera en la cual construye el trompillón, compuesto por varias pequeñas cuñas de piedra dispuestas en diente de sierra, simétricas respecto la bisectriz de la planta. Se han encontrado otros diseños vagamente similares de este original diseño del trompillón en el tratado de J. Chéreau (1575), en los trompes del Hôtel de Lamoignon en París (1584), en dos trompas del siglo XVII en Rue Basse St. Pierre en Saumur, y en un trompa en Toulouse no claramente datada. 
Trompas

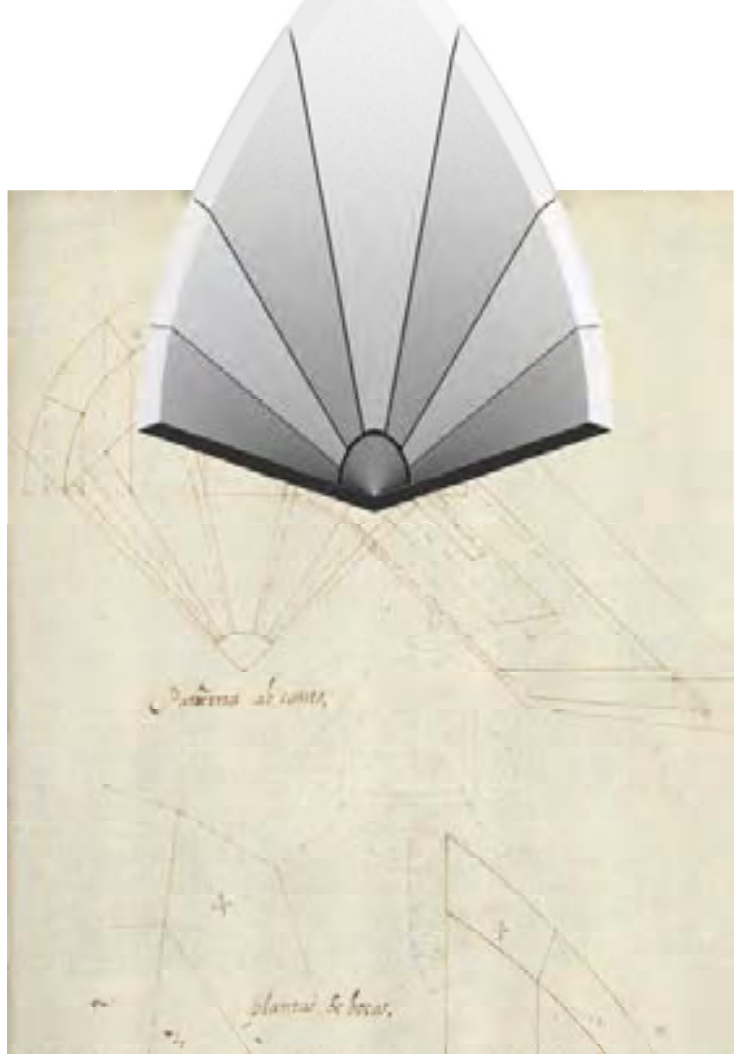

Fig. 8.7. Trompa en esquina
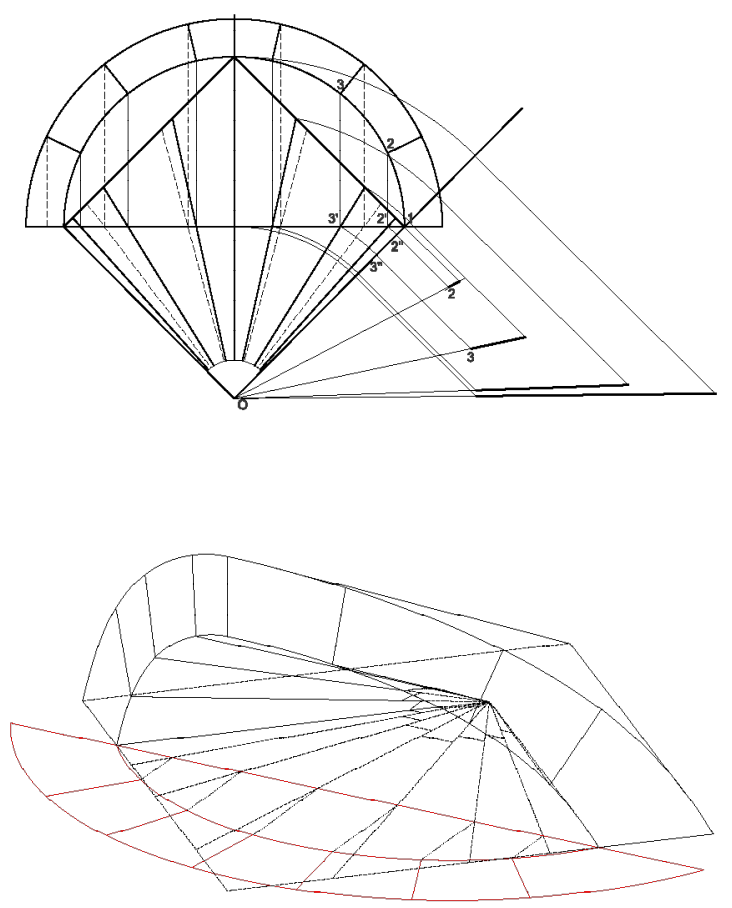

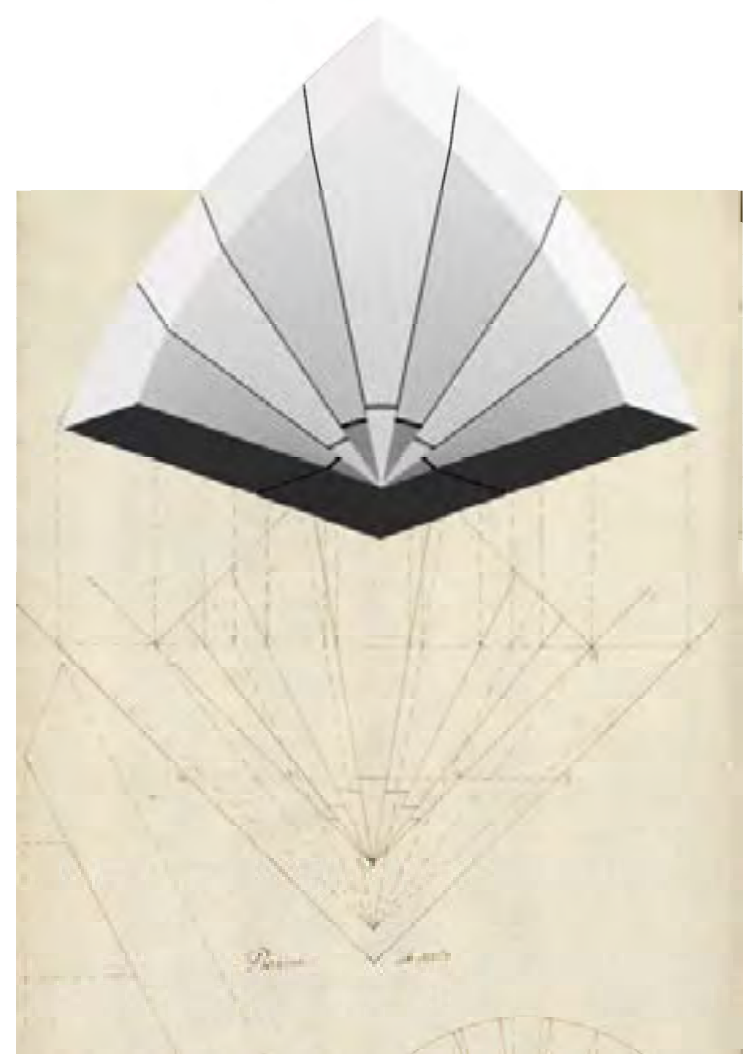

Fig. 8.8. Trompa en esquina de arco escarzado

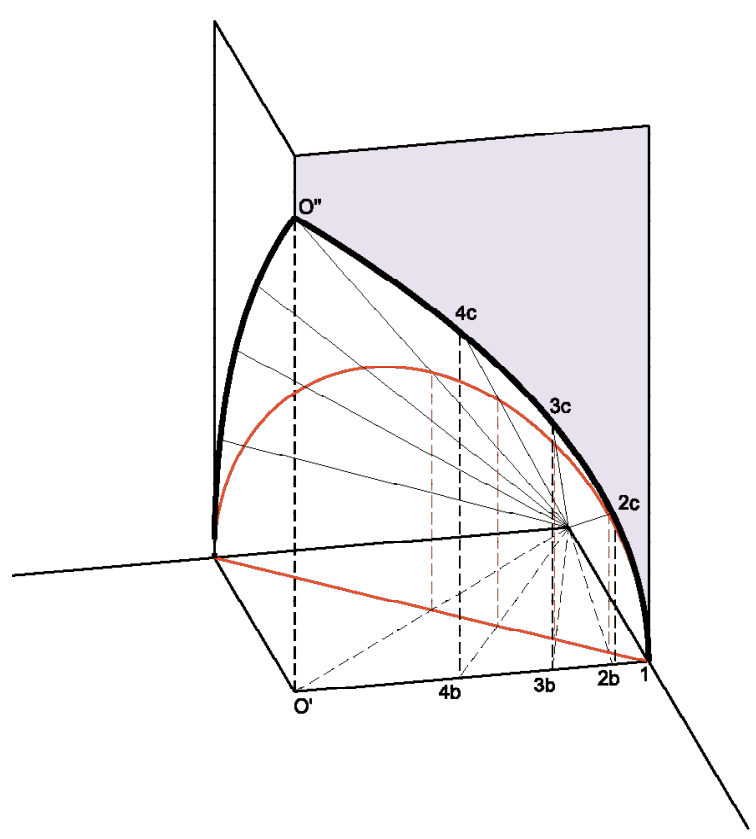

Fig. 8.9. Desarrollo geometrico de las trompas de Ribes. Dibujo del autor.

203 


\subsection{Patxina dela primera planta - Trompa de medio punto}

Folio 229 (Traza 124)

La trompa del folio 229 (traza 124) es el modelo de trompa más sencillo, numerosos ejemplos se encuentran en las iglesias románicas y góticas de Cataluña ${ }^{6}$, en Mallorca se cuentan muchos ejemplos en la arquitectura eclesiástica y en particular se quieren recordar las majestosas trompas de la Catedral ${ }^{7}$.

La construcción geométrica de Ribes sigue las pautas descritas en los otros tratados: después de dividir el intradós en dovelas iguales, los datos necesarios para conformar cada pieza consisten en determinar las plantillas de testa, de lecho y el ángulo que forma el intradós de la bóveda con el paramento vertical.

Antonio Rovira y Rabassa $^{8}$ describe y dibuja una trompa de esta tipología que existía en las fortificaciones de Barcelona, ahora destruidas:

La trompa cónica en esbiage establecida en el interior de un muro en talud (...) Un caso notable de trompa de esta naturaleza es la que estaba dispuesta en uno de los muros de las fortificaciones de la ex ciudadela de Barcelona.

Del dibujo sobresale el gran tamaño de la bóveda en comparación a la escala del hombre y del caballo representados (Fig. 8.14).
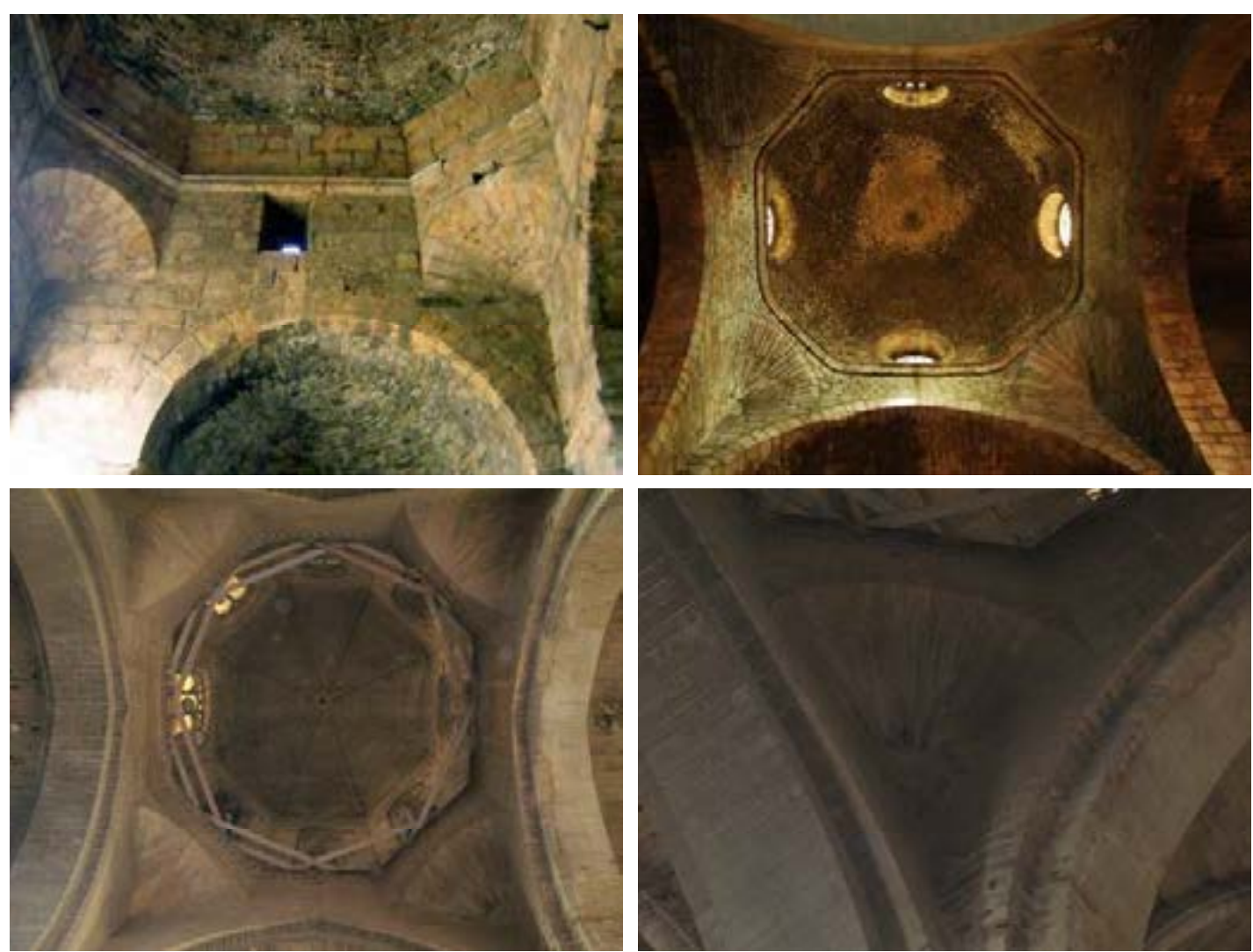

Fig. 8.10. Sant Pere i Sant Pau (1142); Sant Pau del Camp (siglo XIII), Barcelona; crucero de la Catedral Vieja de Leída (siglo XIII) y particular de una de las trompas. Fotos del autor.

\footnotetext{
6 Se quieren recordar los imponentes ejemplos construidos en la sala de relojes del campanario de la Catedral de Tarragona

7 Ponç Descoll trazó las trompas de la capilla del Palacio de los Reyes de Mallorca en Perpiñán (1295-1309) para luego trasladarse a Mallorca, donde construyó las trompas de la Capilla de Santa Ana en el Palau de la Almudaina (1309) y las trompas de la Capilla de la Trinidad en la Catedral (c. 1330).

8 Rovira y Rabassa, 1897: volumen II, 701.
} 


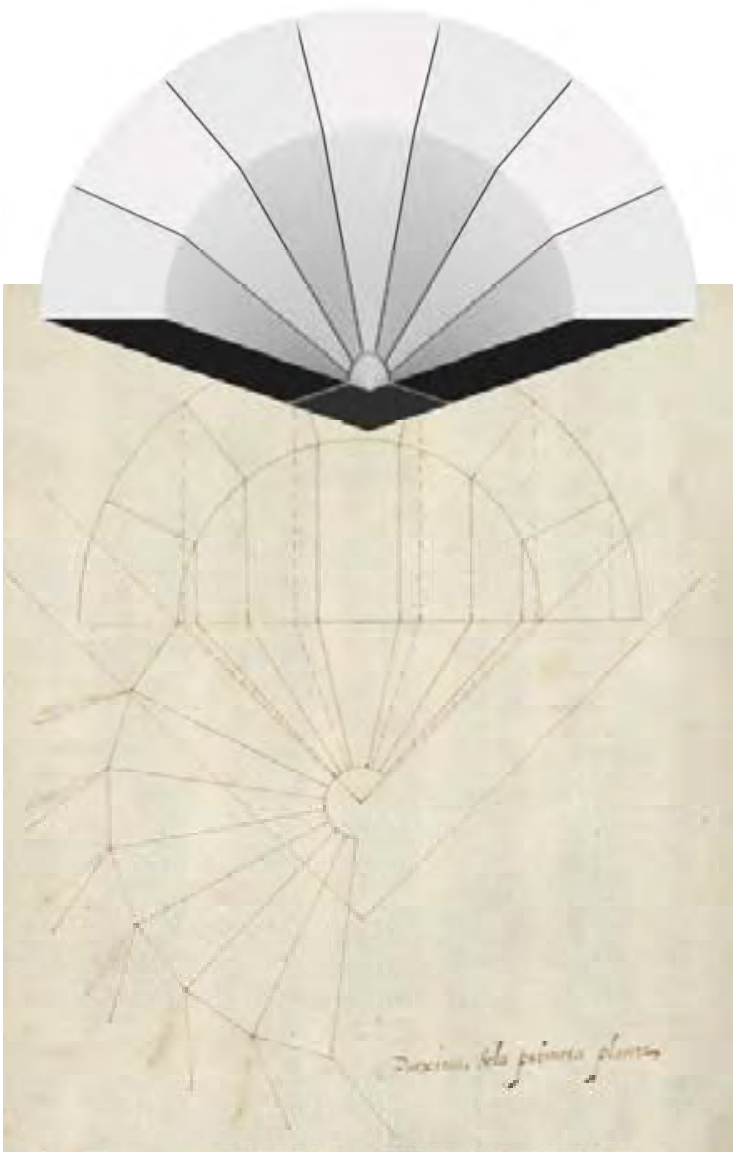

Fig. 8.11. Trompa de medio punto

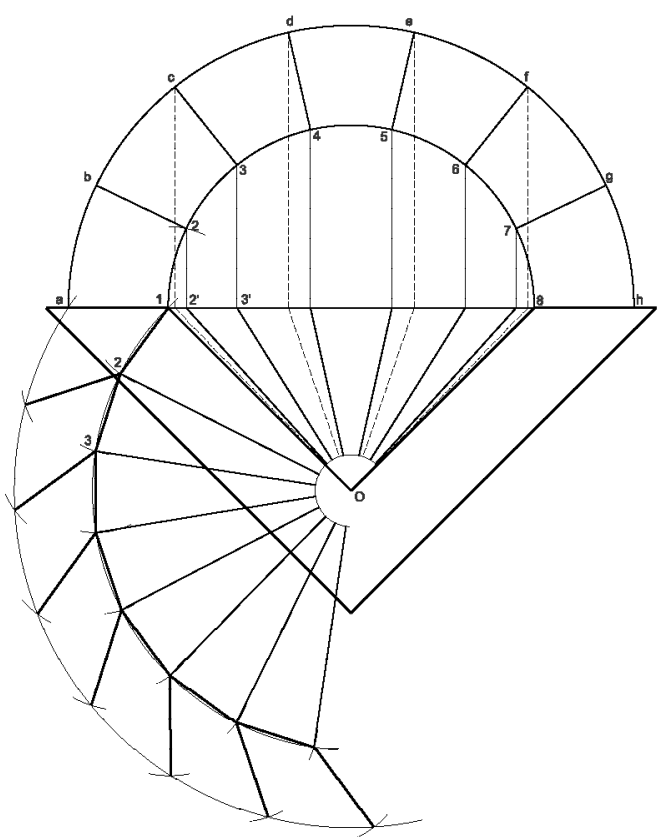

Fig. 8.13. Trompa de medio punto: desarrollo de las plantillas. Dibujo del autor.

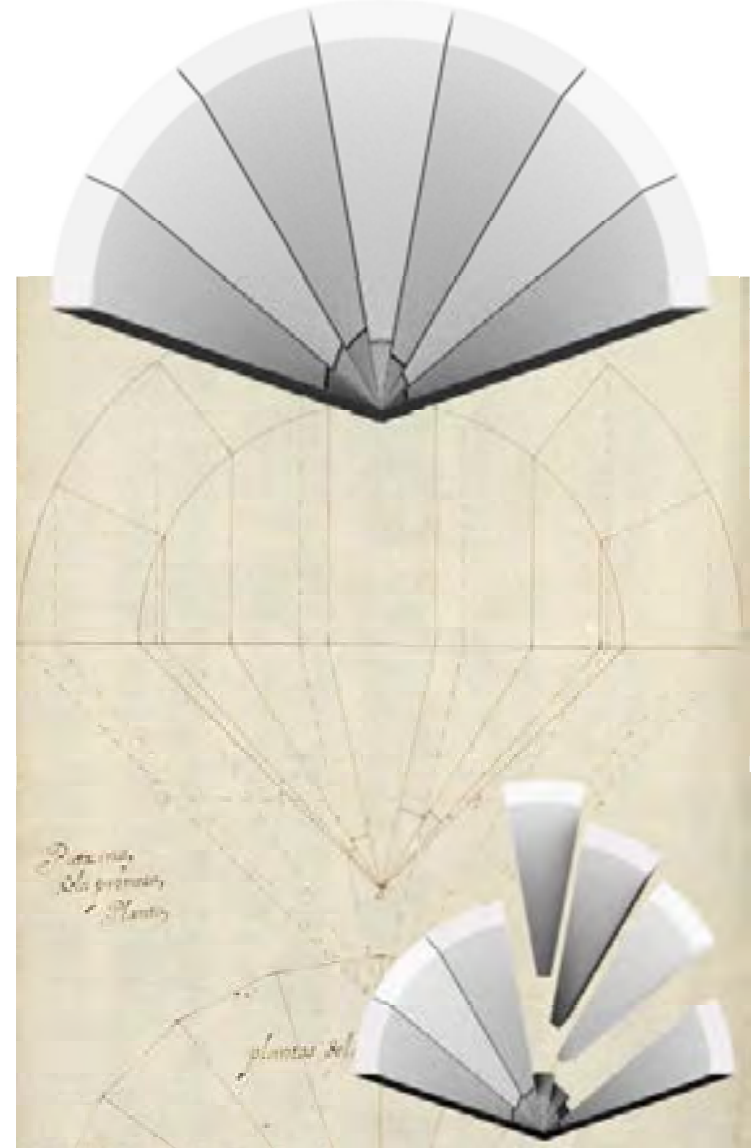

Fig. 8.12. Trompa de medio punto con trompillon segmentado

547. La trompa cónica en esbiage establecida en el interior de un muro en talud, se distingue de las demás en que no sostiene ninguna construcción voladiza, empleándose tan solo en el caso de que se quicra aprovechar un determinado espacio en el interior del muro en donde se construye, sir. viendo entonces para sostener la parte superior del muro en su continuación hasta la cresta.

Un caso notable de trompa de esta naturaleza es la que estaba dispuesta en uno de los muros (Fig. $\theta$ ) de las fortifica * ciones de la exciudadela de Barcelona.

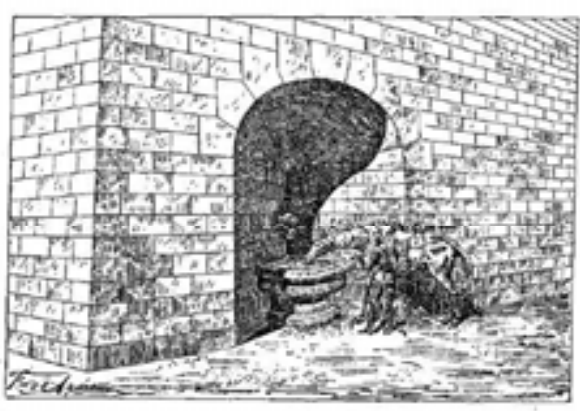

Viz: $\theta$

Fig. 8.14. Antonio Rovira y Rabassa 1897 , volumen I página 701 , nos recuerda otro ejemplo de trompe en las fortificaciones de Barcelona, ahora destruidas: " La trompa cónica en esbiage establecida en el interior de un muro en talud (...) Un caso notable de trompa de esta naturaleza es la que estaba dispuesta en uno de los muros de las fortificaciones de la ex ciudadela de Barcelona.". 


\subsection{Patxina dela primera planta - Trompa de medio punto}

Folios 241-242 (Traza 134)

Esta traza es de la misma tipología del ejemplo que se acaba de exponer, pero presenta otra variación del trompillón segmentado de diseño asimétrico. En este caso, en lugar de ser una piedra única, el trompillón se compone de varias cuñas de piedra más pequeñas, una en correspondencia de cada dovela que compone la bóveda cónica. Ribes dibuja las plantillas de intradós desarrolladas (plantas delas bocas) sacando la verdadera longitud de las juntas de unos diagramas que delinea en una hoja al lado que proporcionan también los patrones para las caras de los lechos (Plantas del junts) y los ángulos que estas forman con el paramento vertical. Las plantillas para las testas de las dovelas se pueden sacar directamente del alzado de la trompa ya que el paramento vertical coincide con el plano perpendicular al ángulo bisector de la trompa,

\subsection{Patxina apañada - Trompa de medio punto de tres paños (poligonal)}

\section{Folio 231 (Traza 126)}

La característica principal de esta trompa es su borde segmentado, consecuencia de una construcción con esquinas de forma poligonal.

El proceso utilizado en el manuscrito de Ribes para trazar las plantillas es el mismo que se utiliza para las otras trompas y no presenta ninguna dificultad técnica particular. Para facilitar el corte de los bloques de piedra es importante proyectar la trompa con cuidado, ya que las dovelas que tienen juntas que pasan través de los bordes discontinuos y a través de los diferentes planos verticales son más difíciles de conformar.

De L'Orme, Jousse y Derand proponen diferentes variaciones y casos particulares de este tipo de trompa; Gelabert muestra un diseño más simple y muy similar al descrito por Ribes. Vandelvira no describe esta tipología, de hecho, parece ser más común en la tradición gótica y francesa.

Una trompa en esviaje con perfil poligonal de notables dimensiones se puede encontrar en Felanitx, Mallorca, y otra en el Palau la Generalitat de Valencia ${ }^{9}$. Antonio Rovira y Rabassa ${ }^{10}$ recuerda otro ejemplo (Fig. 8.16), ahora destruido, de una trompa poligonal en Barcelona:

Ejemplo notable de este caso lo ofrece 'una trompa establecida en las ex-murallas de Barcelona (...) trompa de bastante vuelo y que aún recordamos, á pesar de los años transcurridos desde su demolición.

\footnotetext{
9 Rabasa Díaz, 2011: 299.

10 Rovira y Rabassa, 1897: volumen II, 692.
} 


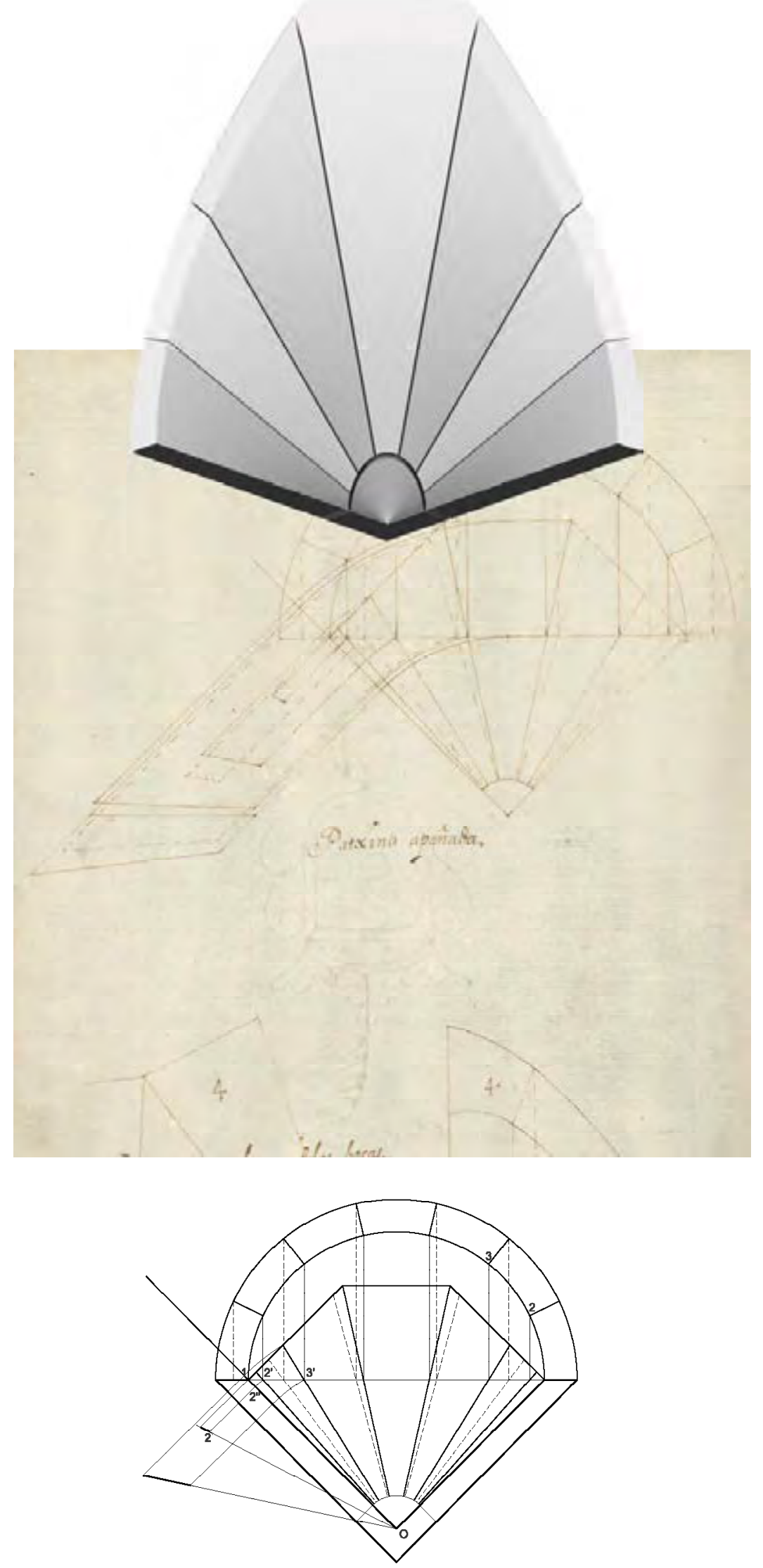

Fig. 8.15. Trompa de medio punto de perfil poligonal y desarrollo plantillas. Dibujo del autor. 

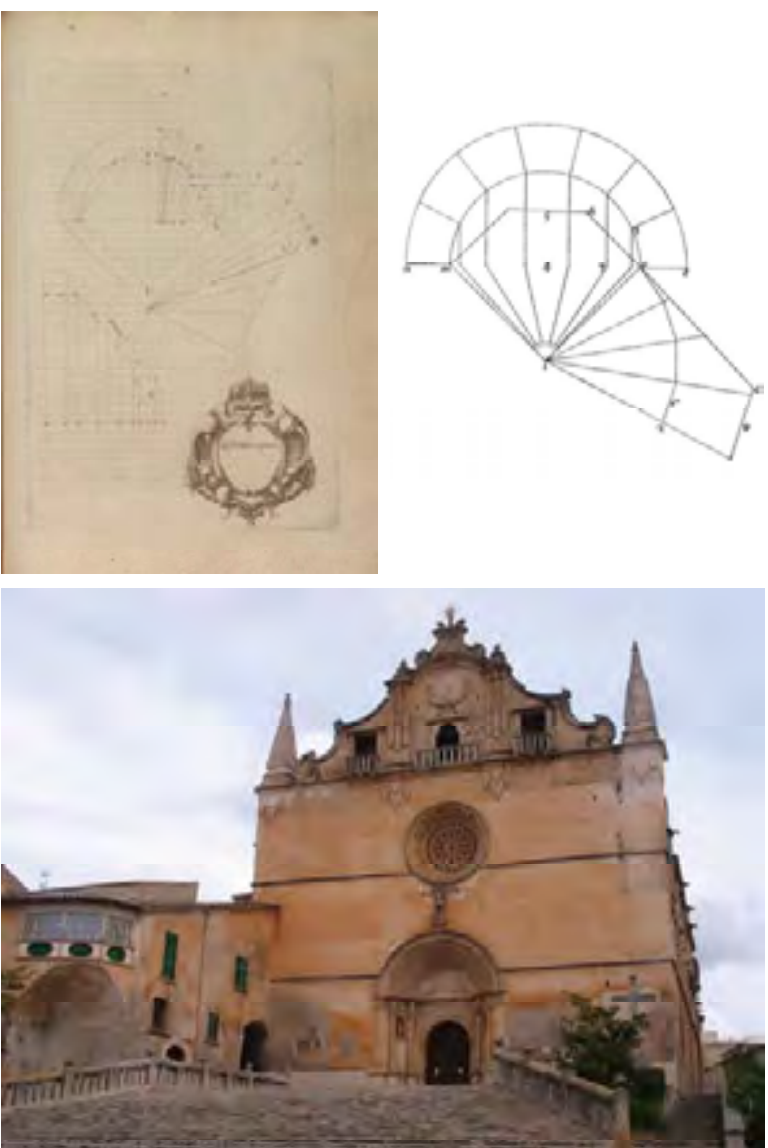

Fig. 8.16. Trompas poligonales en Derand y Gelabert (traza 95, folio 109); Antonio Rovira y Rabassa 1897, volume II pagina 692; Trompa en el palacio de la Generalitat de Valencia (foto de E. Rabasa); Iglesia de Felanix, Mallorca.

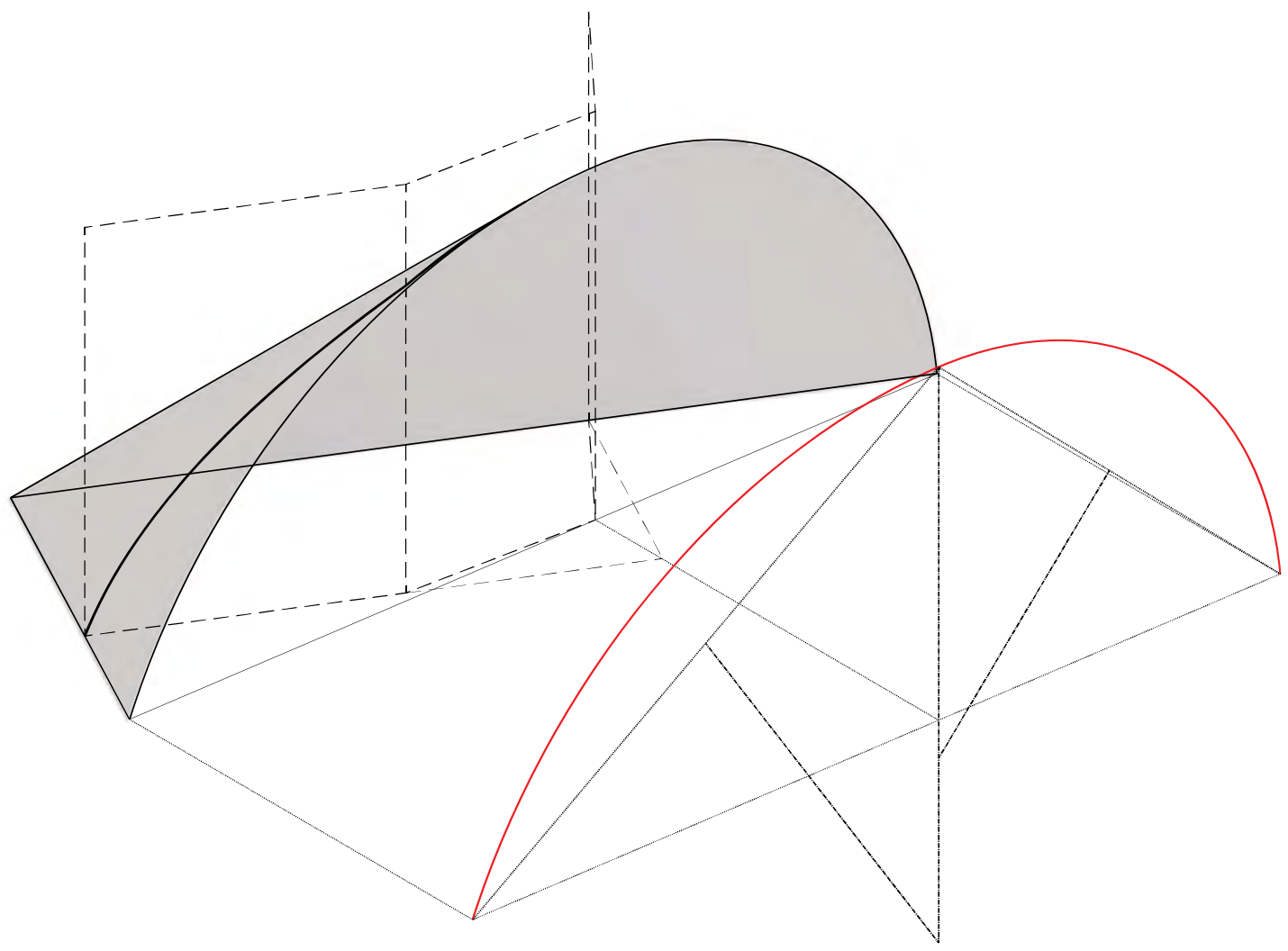

Fig. 8.17. Iglesia de Felanix, Mallorca; estudio geometrico de la traza. Dibujo del autor. 
Trompas
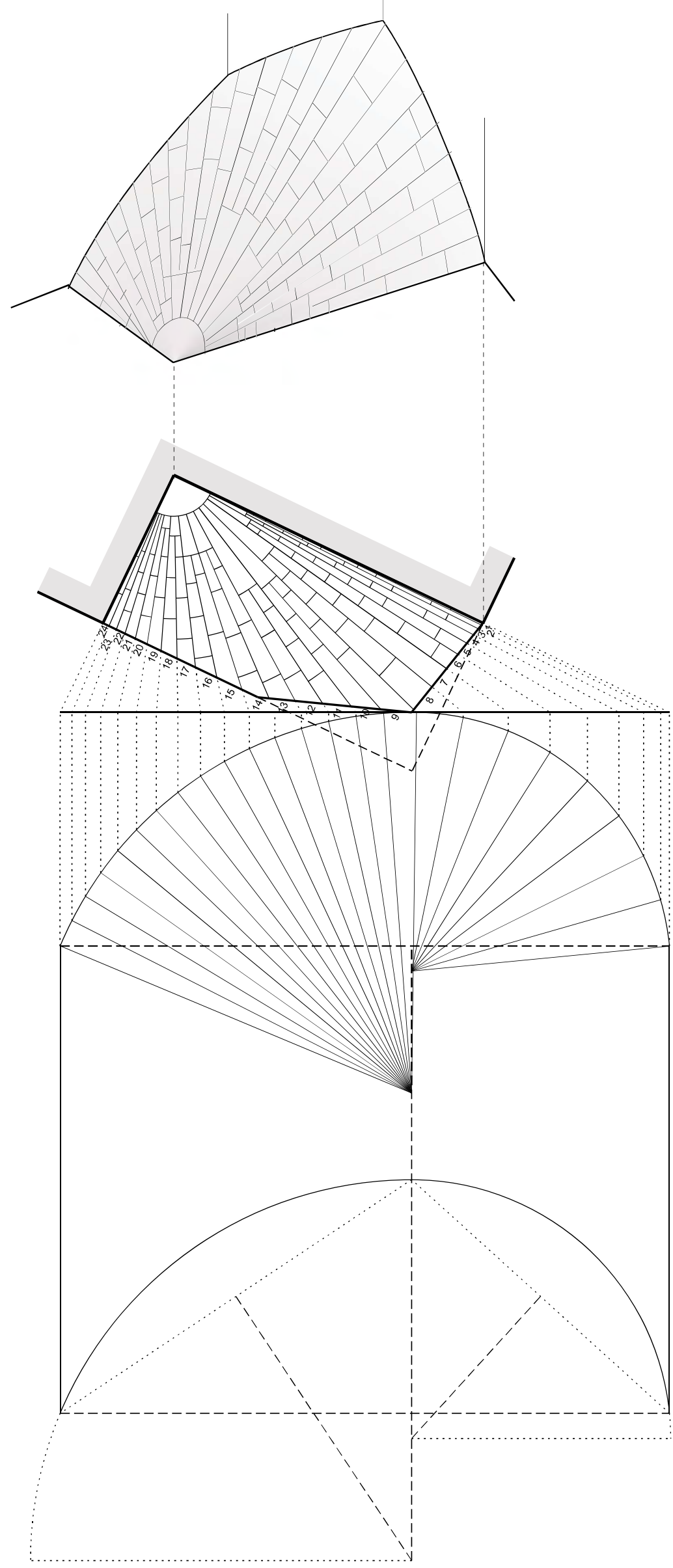

209 


\subsection{Patxina ab torra rrodona - Trompa en torre redonda}

\section{Folio 232 (Traza 127)}

Esta trompa viene adaptada para soportar una pared curvada y presenta un borde redondeado sin discontinuidad, que resulta de la intersección de la bóveda cónica con el cilindro de la envolvente vertical.

La geometría desarrollada por Ribes para su Patxina ab torra rrodona corresponde al modelo que Vandelvira llama "Trompa de Montpellier". En ambos autores la geometría del borde está determinada por la proyección cónica del arco guía, atributo que produce una bóveda más alta. El modelo que Vandelvira llama "Pechina torre redonda" tiene una característica geométrica distinta porque el arco guía se proyecta ortogonalmente a la fachada. Jousse y Derand utilizarán la misma diferenciación y nomenclatura (Fig. 8.18); Gelabert describe este modelo con cierta confusión ${ }^{11}$, pero la geometría del intradós desarrollado parece ponerlo en línea con los otros tracistas. De L'Orme no incluye este modelo en su tratado, pero en 1536 construye dos trompas de este tipo en Lyon.

Para la geometría de esta trompa, es especialmente importante desarrollar la curva tridimensional del borde curvado en un plano con más exactitud como sea posible para que su longitud se preserve. Esta es una etapa importante en la determinación de las plantillas de cara y Ribes introduce una línea de construcción en el punto medio para cada dovela para alcanzar una mayor precisión. Para esta traza Ribes dibuja las plantillas de intradós desarrolladas (plantas delas bocas), sacadas del diagrama de construcción de las líneas de junta del intradós, y las plantillas de las caras verticales de las dovelas.

Se puede relacionare a esta traza la ya citada trompa del Hospital de la Santa Creu del siglo XV. Este ejemplo es una trompa en torre redonda en viaje.
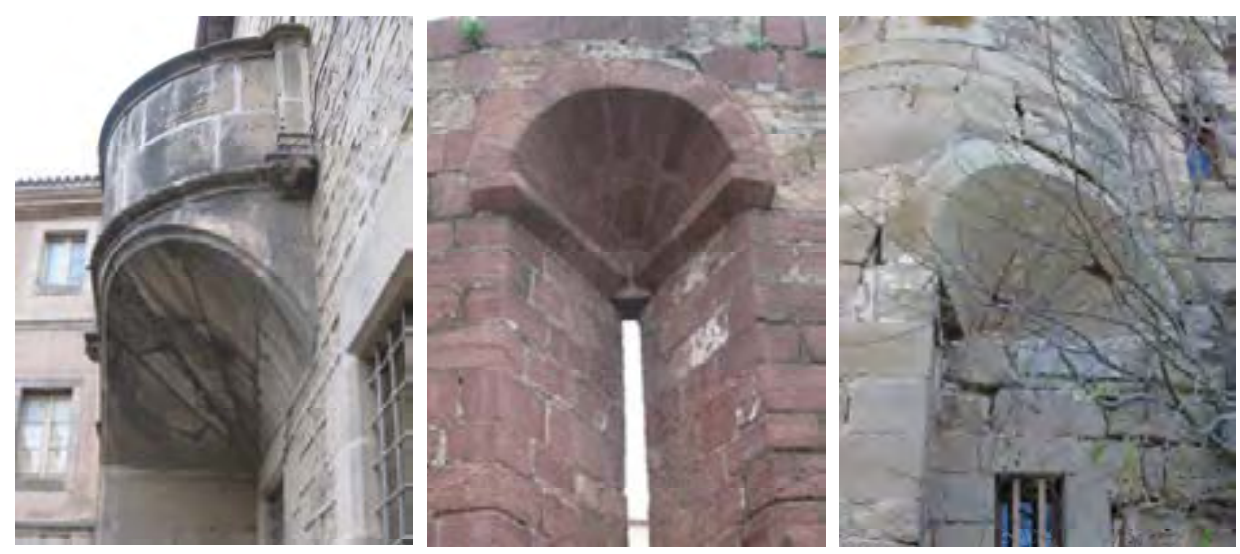

Fig. 8.18. Trompas en torre redonda en el Hospital de la Santa Creu, Barcelona; Alcover; Ratera. Fotos del autor.

11 Rabasa Díaz, 2011: 302.

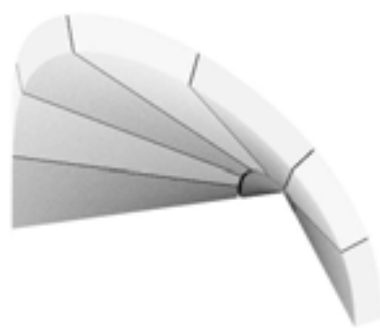




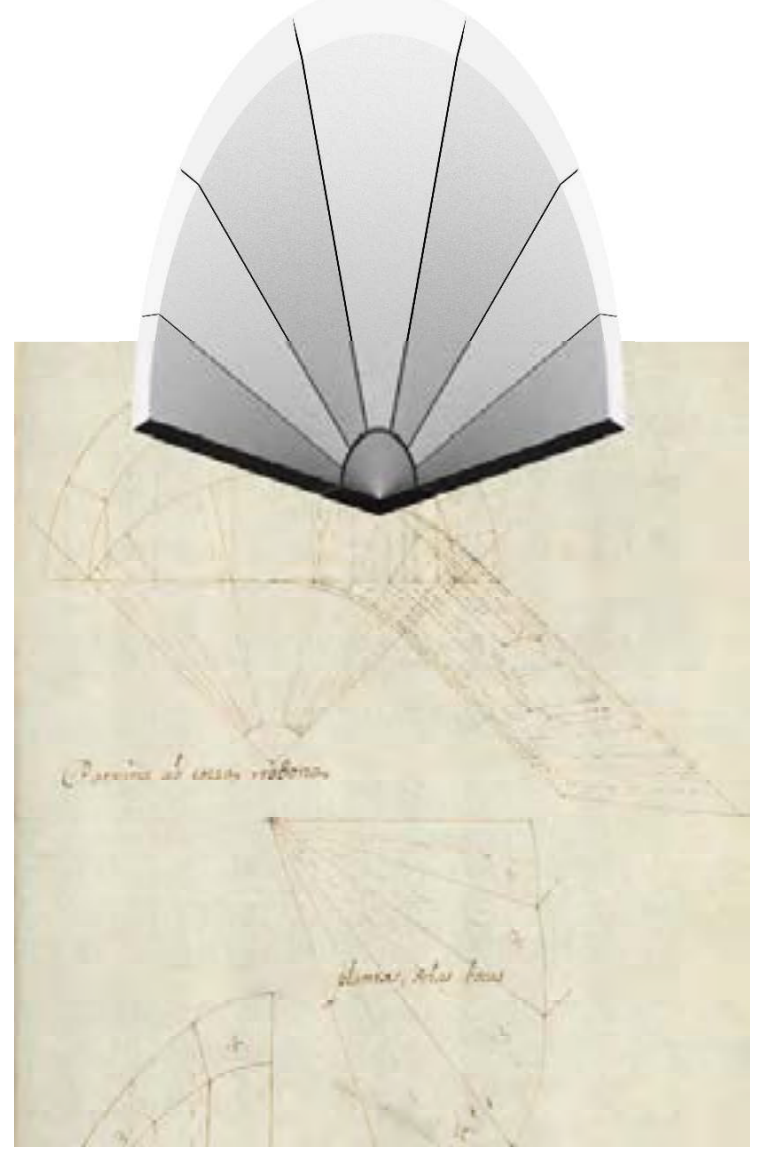

Fig. 8.19. Trompa en torre redonda
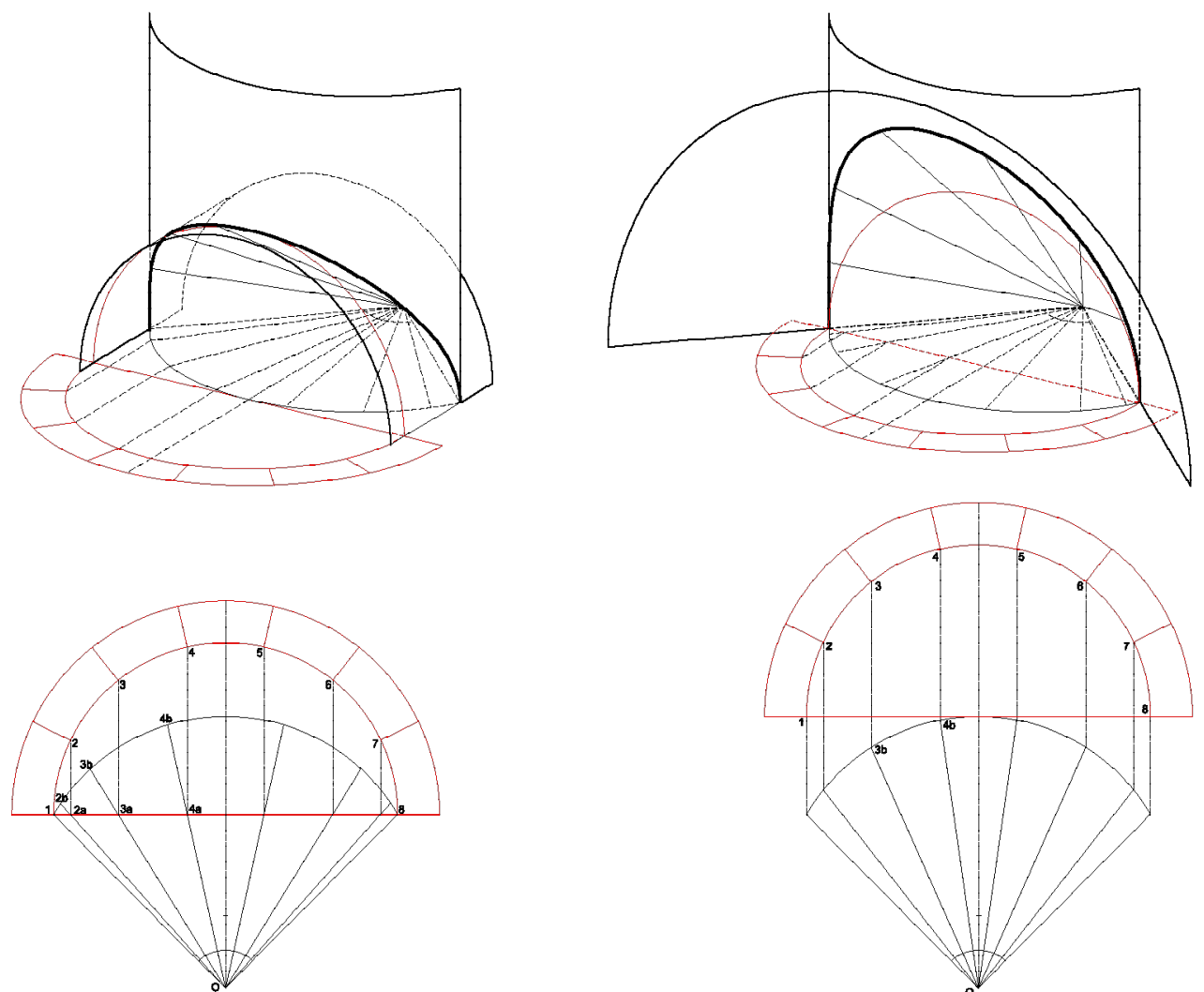

Fig. 8.20. Proyección ortogonal de Vandelvira (Pachina torre redonda) y proyección cónica según Jousse, Derand y Gelabert. Dibujo del autor. 

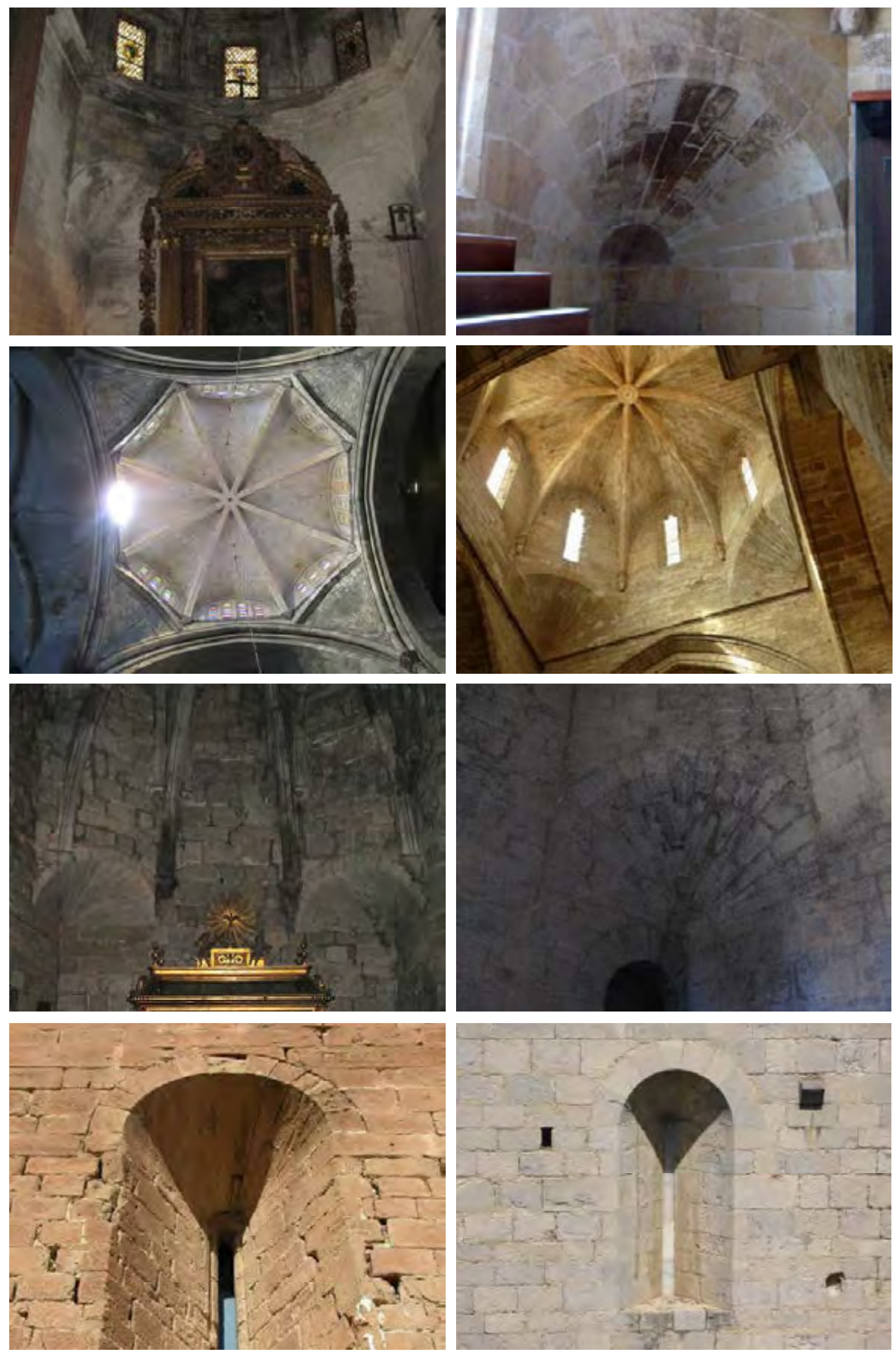

Fig. 8.21. Trompas de medio punto. Catedral de Tarragona: Capilla de San Francisco, Sala de las campanas, Crucero; Vallbona de las Monges; San Llorenc, Lerida; San Pere Galligans: Capilla de San Miguel, Girona; Santa Maria de Balaguer; Catedral de Girona. Fotos del autor. 

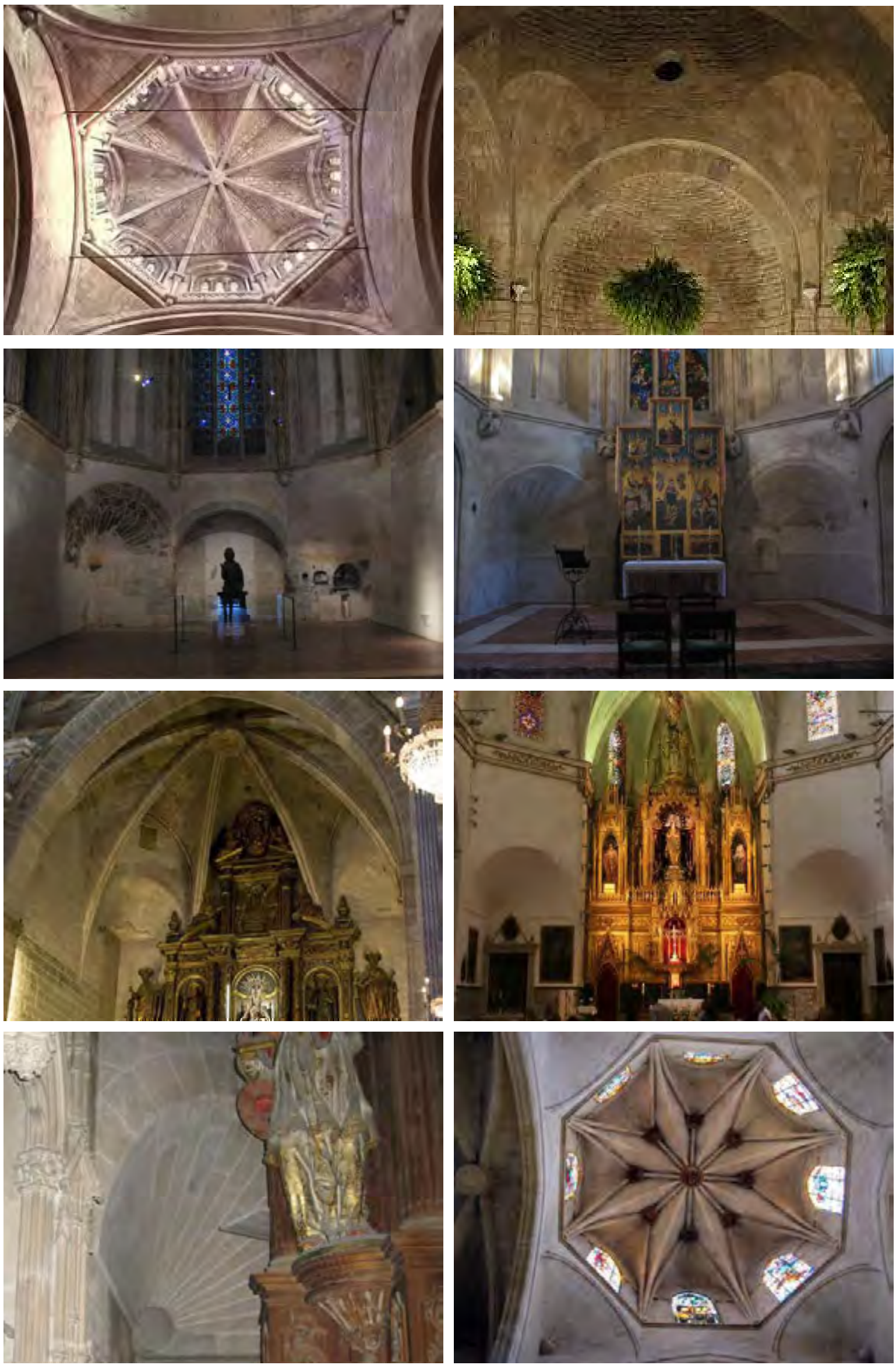

Fig. 8.22. Trompas de medio punto. Monasterio de Sant Cugat; Sant Nicolau, Girona; Palau de los Reyes de Mallorca, Perpiñan; Palau de l' Almudaina, Mallorca; Nuestra Senora de Montesion, Mallorca; Catedral de Plama de Mallorca; Santa Maria, Sineu. Fotos del autor. 

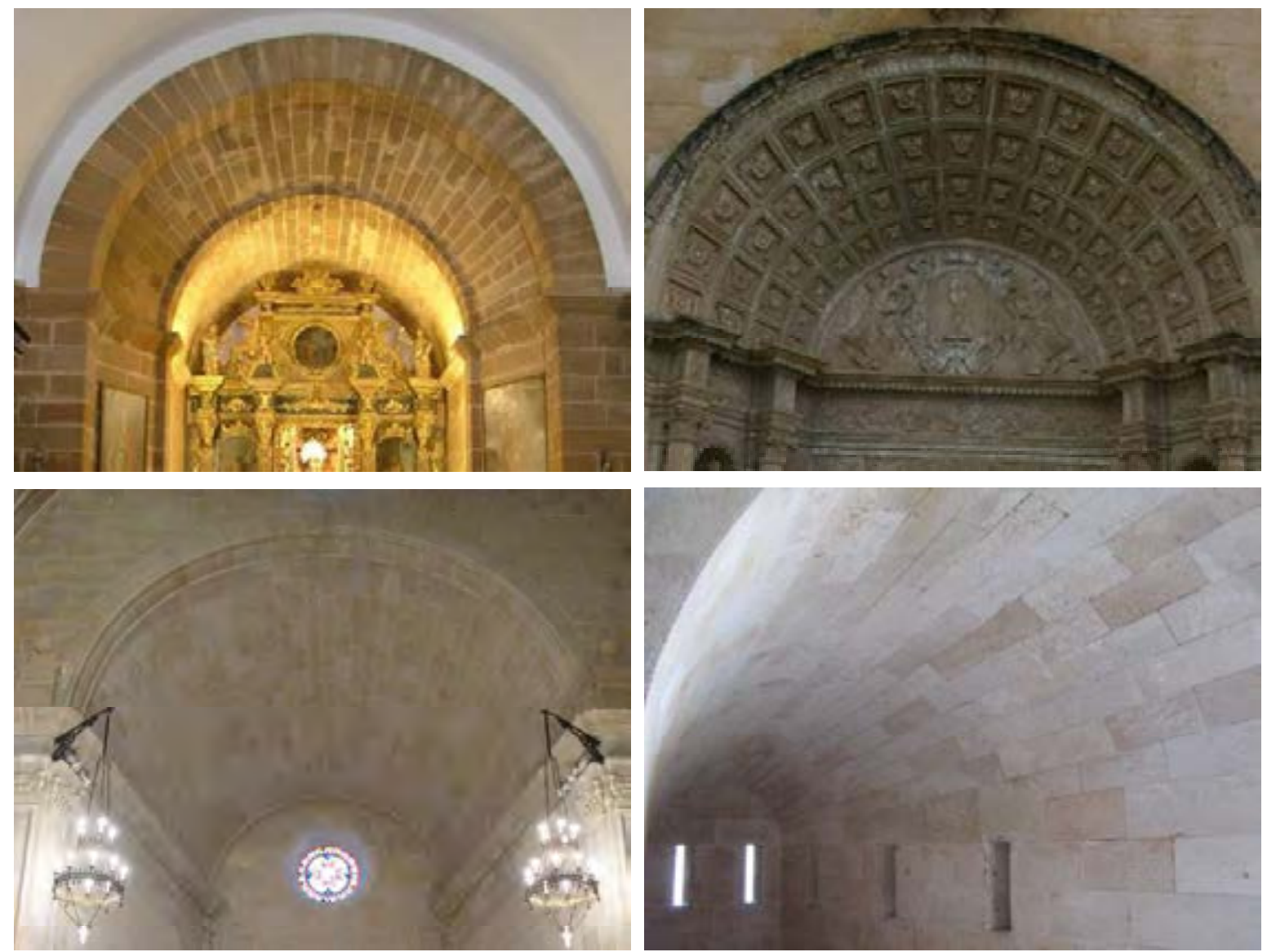

Fig. 8.23. Arcos abocinados en las Islas Baleares: Eremo de Santa Victoria, Alcudia; Iglesia de Felanix; Parròquia de Santa Eulàlia, Alaior; Mola de Menorca. Fotos del autor
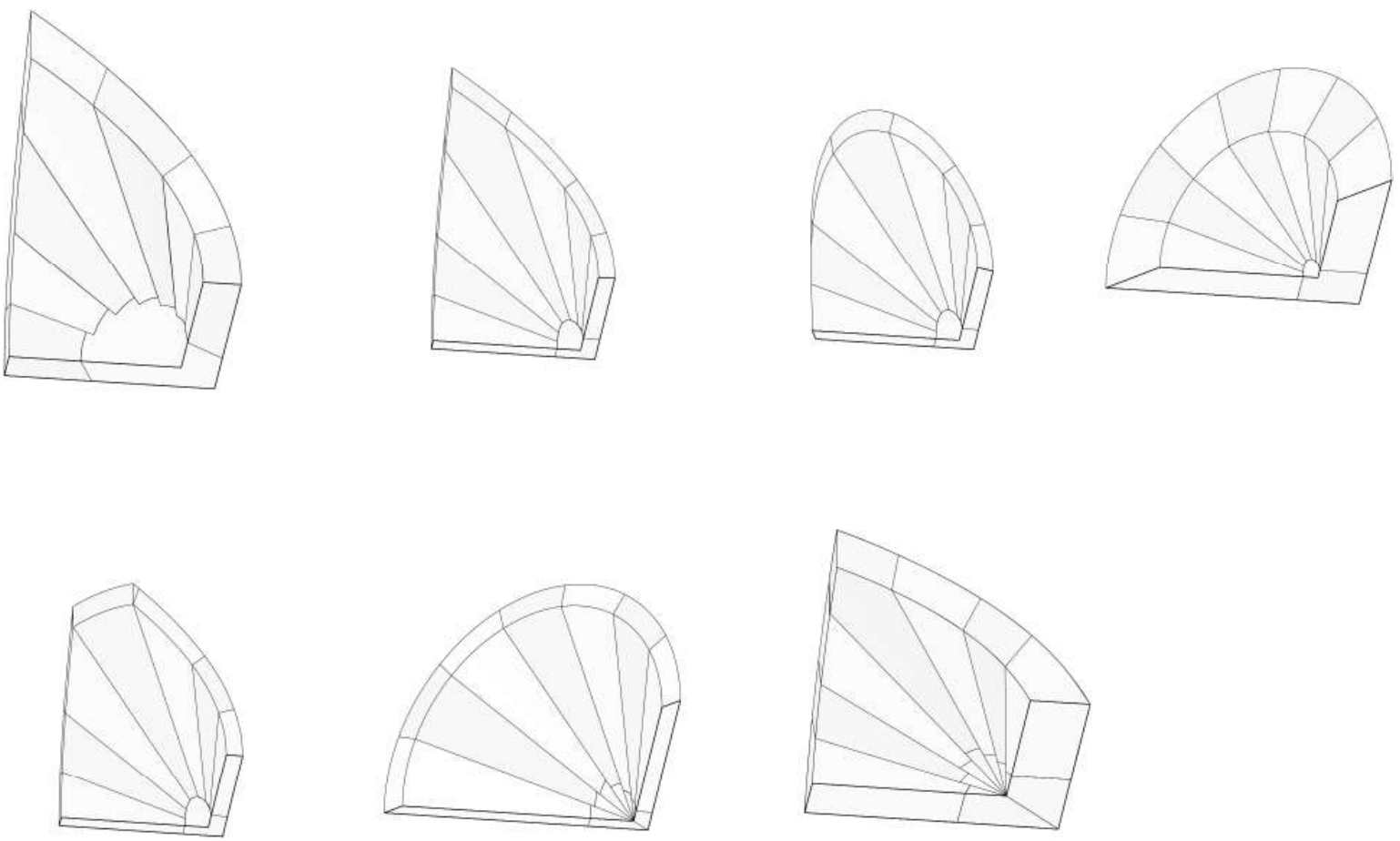

Fig. 8.24. Catalogo de trompas descritas por Ribes 


\section{Escaleras}

El ultimo tema tratado en el Llibre de trasas es el conciso capitulo de las escaleras que, compuesto de tan solo dos títulos, describe modelos de procedencia gótica que encontramos frecuentemente en Cataluña. El número circunscrito de modelos expuestos, en particular en comparación con los tratados de Alonso de Vandelvira, Martínez de Aranda, Thomas Vicente Tosca o de Joseph Gelabert, puede ser atribuido al facto que el tema de las escaleras es per se limitado en cuanto a tipologías, pero también a un menor interés de Ribes para este tema, limitándose a exponer los modelos mas característicos y comunes del área catalana, cuales el caracol de husillo ${ }^{1}$ y la escalera adulcida en cercha.

En cuanto a ordenación, el Llibre de Trasas se alinea al tratado de Gelabert que explica la razón por posicionar esta temática casi en la ultima parte de su texto2:

La causa perque e posat les escales casi alo ultim del llibra es perque conve moltque lo mestra qui a de posar en obra una escala sia molt destra de menetjar lo compas per dues rahons la primera es perque son enfadoses de tresar ab tanta menudensa de escursinats (que axo es el nom que te la obra que fa lo escalo anel cap) y la sagona es perque en moltas hocasions lo mestra no pot estar posat tant solament ab lo art sino que es nesesari que aja de posar ab dita obra tota la discresio que pot de tal menera que conega ala vista que tanga un bon parecer.

Las escaleras fueron objeto de atentos estudios durante el periodo Gótico en Cataluña, Levante y Mallorca, durante el cual aparecieron los caracoles de ojo abierto y la escalera empezó a tener mas importancia en la composición del edificio y en el utilizo ceremonial del edificio. En el gótico civil, la escalera, de simple elemento de servitud funcional, empezó a ser uno de los medios para representar la riqueza del comitente y el talento del maestro de obra.

1 El texto de referencia sobre las escaleras de caracol en todas sus variaciones tipológicas es Alberto Sanjurjo. 2016. La escalera de caracol en los tratados de estereotomía españoles

2 Gelabert, 1977 [1653]: folio 117v. 


\subsection{Caragol - Escalera de caracol de husillo}

Folio 237 (Traza 130)

La primera escalera que propone Ribes, la escalera en caracol de husillo (Fig. 9.1), es la tipología más sencilla en los edificios históricos e iban formando un complejo sistema de circulación. Como recuerda Fichten ${ }^{3}$, las escaleras de caracol, distribuidas en varios puntos de una catedral, facilitaban el acceso durante la construcción permitiendo alcanzar los andamios y subir material de construcción. El caracol de husillo manifiesta la optimización constructiva del gótico ${ }^{4}$ : responde al principio de economía de obra no necesitando cimbras para su edificación; enlaza el alma de la escalera a la caja haciendo el sistema más solidar; está constituido por piezas iguales, permitiendo construirse previamente y con la misma plantilla, facilitando así la construcción, el almacenamiento y la colocación en obra de cada pieza.

Viene compuesta por bloques de piedras sobrepuestos en hélice que se apoyan al machón central y al muro perimetral. Cada pieza viene conformada de manera que incorpore el peldaño, un tramo del machón central y un fragmento del muro perimetral. La superficie que conforma el intradós del paso de la escalera, comprendida entre machón y muro, frecuentemente venía labrada en forma de superficie helicoidal continua para evitar cabezazos.

La labra de los peldaños es fácil y queda reducida á la determinación de un prisma auxiliar con base el contorno de la totalidad del peldaño, con los tramos de machón y muro incluidos, y por altura la alzada del peldaño. Los bloques pueden ser prismáticos o si es requerido obtener un intradós continuo, se pasa a desbastar la parte inferior (Fig. 9.3B), operación que puede complicar la talla, para lo cual se hará pasar una recta por las generatrices que serán una el eje del cilindro y la otra una hélice arrollada en la caja de la escalera, paralela a la línea que conecta los vértices exteriores de la testa del peldaño y que corresponde entonces a la línea de empotramiento del peldaño en la caja.

Ribes representa dos plantillas de un peldaño y en una de ellas indica con una línea el solape de la pieza con la consecutiva. Por la falta de información en el alzado, no queda claro si en realidad estas dos plantillas son la representación de la planta del peldaño tomadas a la base y a la sumidad. SI fuera esto el caso, la superficie del intradós seria helicoidal. En la planta de la caja de la escalera se representa un hueco abocinado en torre cava.

\footnotetext{
3 John Fitchen, The Construction of Gothic Cathedrals : A Study of Medieval Vault Erection (1961; repr., Chicago: University Of Chicago Press, 1997): 21.

4 Perouse de Montclos, 1982: 146.
} 


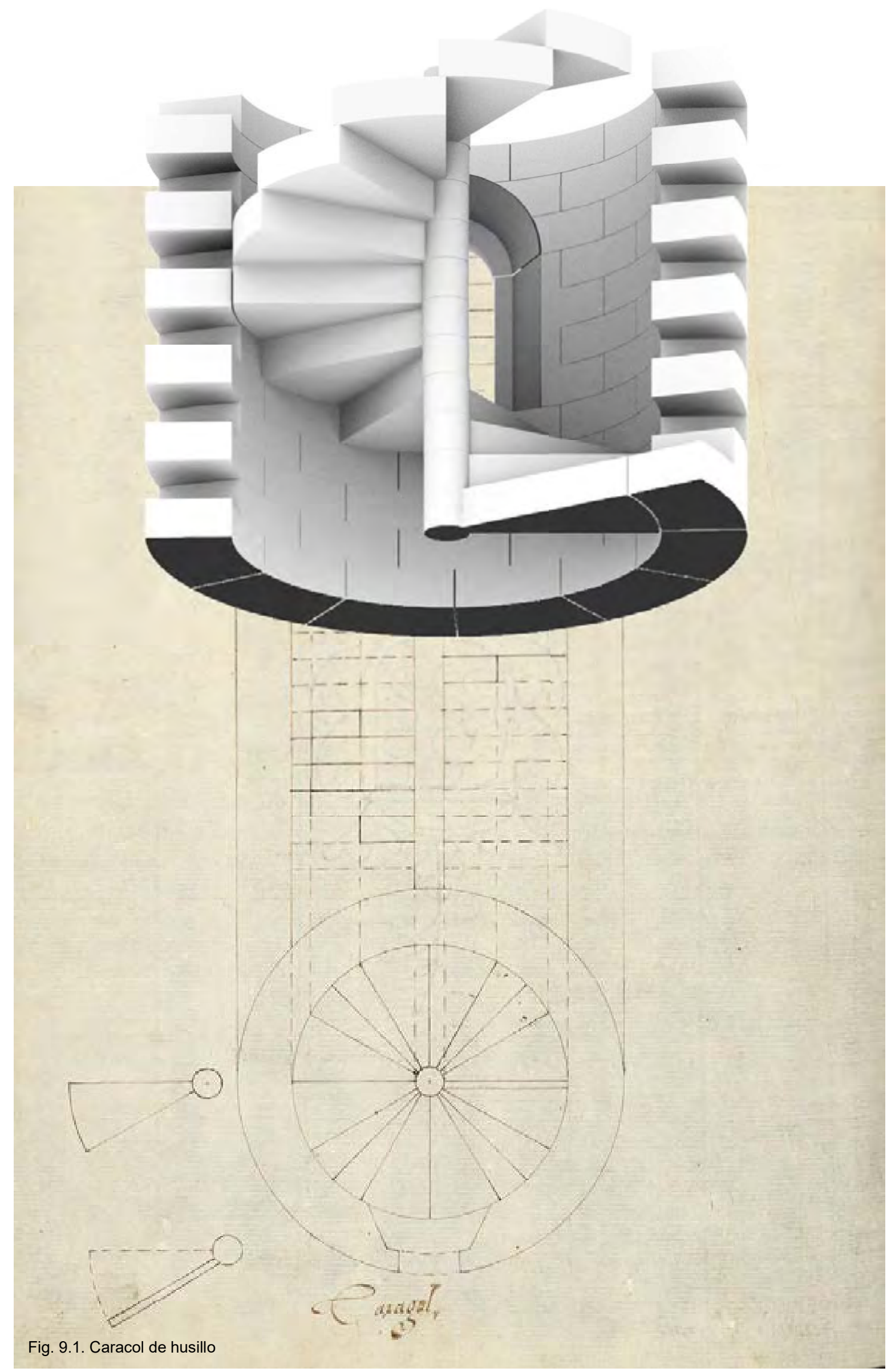


Una variación tipológica del caracol que no viene incluida en el manuscrito de Ribes es el caracol de husillo con escalones en forma de lúnula que fue construido en el portal de San Pedro en la Catedral de Tortosa ${ }^{5}$ en 1383. Se caracteriza por tener el intradós de los peldaños ligeramente cóncavos y la consecuente convexidad del intradós de la bóveda (Fig. 9.3C). Quizás se podría relacionar a los caracoles de generatriz circular horizontal ${ }^{6}$ pero, en este último caso, el intradós presenta una concavidad. Fray Lorenzo de San Nicolás, presenta la traza del caracol de husillo (Caracol Macizo) y dibuja dos plantas, una con peldaños rectos y otra con peldaños curvos.

Los caracoles de husillo pueden venir construidos con machón helicoidal, o sea cuando la directriz del machón no es una recta vertical sino una hélice. Formalmente, el caracol tiene el apoyo central como los de husillos convencionales y a la vez un hueco central. Es de aspecto parecido a un caracol de Mallorca y permite resolver una escalera de husillo en poco espacio, ya que permite colocar más peldaños por giro o que estos sean más cómodos $^{7}$. Como ha señalado Sanjurjo, el profesor Pinto propuso la hipótesis que esta sea una solución de transición entre el husillo gótico y el caracol de Mallorca ${ }^{8}$. Por otro lado, según la clasificación de Gelabert, en realidad este tipo de escalera es un caracol de ojo con un hueco pequeño y el pasamanos grueso ${ }^{9}$. En esta tesis, se seguirá la clasificación de Gelabert.
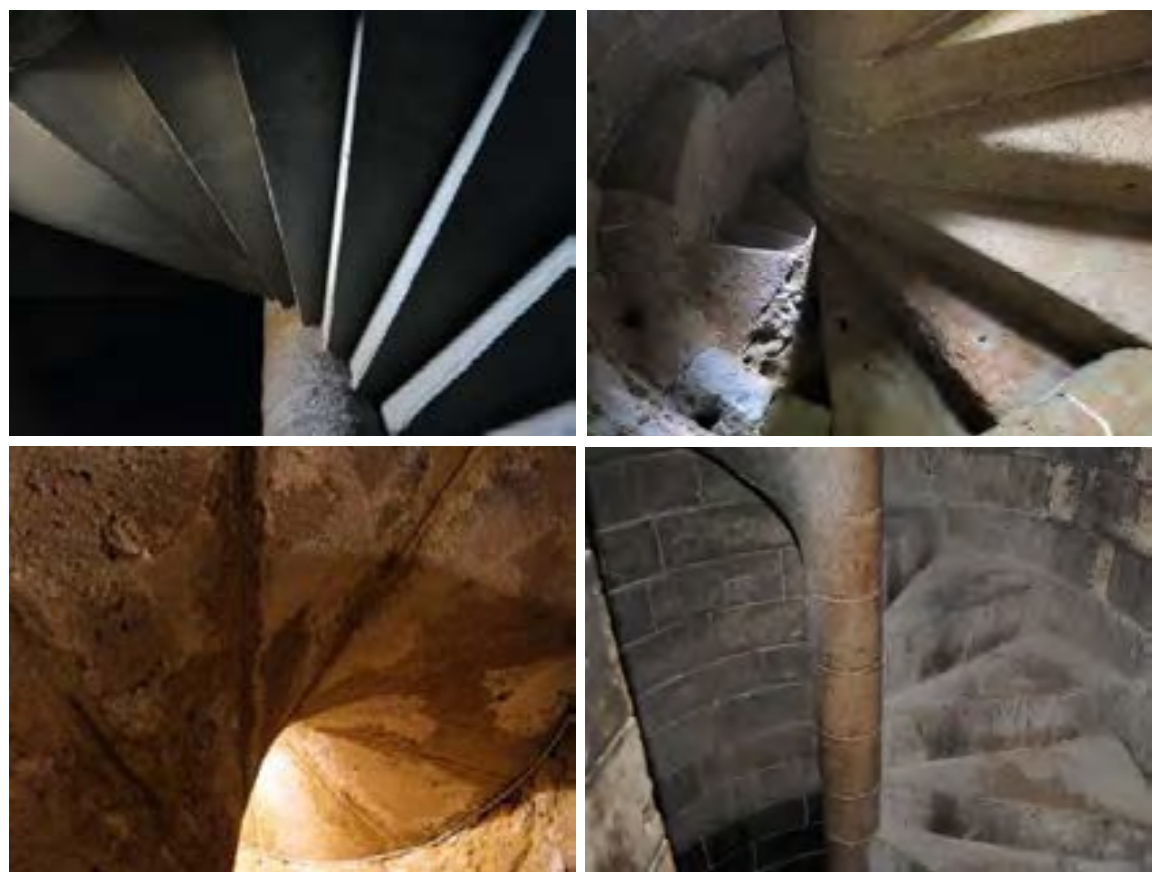

Fig. 9.2. Caracoles de husillo en la Catedral Vieja de Lleida. Fotos del autor.

\footnotetext{
5 Identificada por J. Lluis i Ginovart, "Geometría y Traza de Escaleras Góticas. Las Escuadras Como Ábacos En La Construcción de Los Caracoles de La Catedral de Tortosa," Informes de La Construcción 68, no. 541 (2012): 132, http://informesdelaconstruccion.revistas.csic.es/index.php/informesdelaconstruccion/article/ view/4672/5433.

6 Un ejemplar que se encuentra en la torre campanario de la Iglesia de Santa María la Mayor la Coronada de Medina Sidonia (Cadiz). Señalado por Alberto Sanjurjo en su tesis doctoral (Alberto Sanjurjo, "La Escalera de Caracol En Los Tratados de Estereotomía Españoles" (Tesis Doctoral, 2016): 181).

7 Ibid. 95.

8 Ibid. 95, citando Francisco Pinto Puerto "Forma y fabrica del templo gótico" en La catedral gótica de Sevilla. Fundación y fabrica de la obra nueva. Universidad de Sevilla. 2006. Pags. 210-295

9 Rabasa Díaz, 2911: 95 (Caragol boto rado y ull ubert).
} 

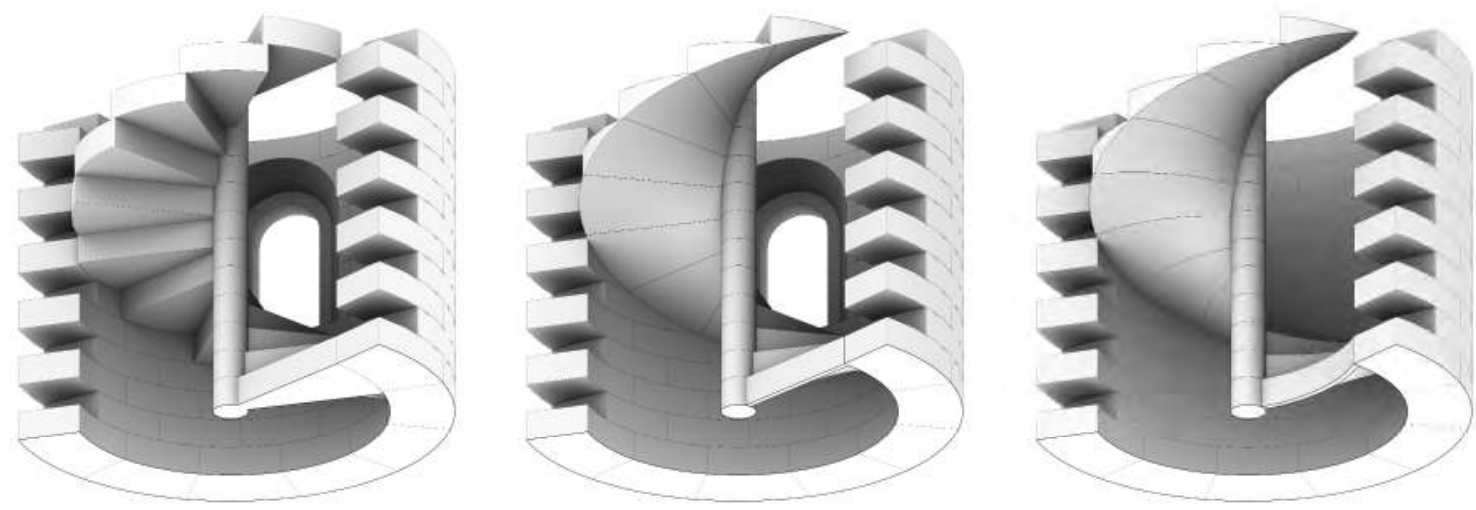

Fig. 9.3. Caracoles de husillo con intradós escalonado, labrado y con peldaños curvos. Dibujo del autor.

\subsection{Caracol de Mallorca}

El Caracol de Mallorca (Fig. 9.4) no aparece en el tratado de Ribes, sin embargo, se quiere mencionarlo en esta tesis por la extraordinaria elegancia de su diseño, sus vínculos históricos con las fabricas mediterráneas y su presencia en Cataluña.

Esta escalera es un caracol sin el machón central, es decir el cilindro central no alcanza el eje del caracol, sino que se ha reconfigurado con una directriz helicoidal, reduciéndose en tamaño hasta casi desaparecer y abriendo así un ojo central en la escalera, como se ve en la traza del Cargol ull ubert de Joseph Gelabert. Este es útil sobre todo para dejar entrar luz y hacer más accesible la escalera, facilitando el transporte de material sin que este venga restringido a la anchura del peldaño. Se piensa que tenga sus orígenes en el ejemplo construido en la Lonja de Palma de Mallorca por Guillerm Sagrera ${ }^{10}$ entre 1435 y $1446^{11}$ y era ya plenamente utilizado en España en el siglo XVI y contendido en la mayoría de los textos de cantería.

En todo el territorio catalán se encuentran algunos bellos ejemplos de caracoles de Mallorca. En la Catedral de Girona se señala la escalera que permita alcanzar el terrado y comunicar la que era la habitación del campanero ahora destruida. Este caracol destaca por la interesante superficie helicoidal que delimita el "negativo" del husillo y la moldura del pasamanos (Fig. 9.5). Esta forma se produce cuando en la plantilla del peldaño se introduce un hueco circular concéntrico en correspondencia del machón central, creando un hueco en el sitio donde se debería haber colocado el machón en una escalera de husillo.

En la Basílica de Santa María del Mar en Barcelona y en la Seu Vella de Lleida hay también caracoles de este tipo. Ambos se caracterizan por la moldura en relieve del pasamanos. Hay una escalera de nabo redondo y ojo abierto (el machón tiene directriz helicoidal) en la Iglesia Prioral de Sant Pere de Reus, inaugurada en 1569.

10 Eduardo Mira and Arturo Zaragozá Catalán, eds., Una Arquitectura Del Gótico Mediterráneo. Catálogo de La Exposición (Valencia: Generalitat Valenciana. Conselleria de Cultura i Educació, 2003): 153.

11 Tina Sabater Rebassa, "Guillem Sagrera, Arquitecto y Escultor," in Llonja de Palma (Palma de Mallorca:

Govern Balear, 2003): 223. 


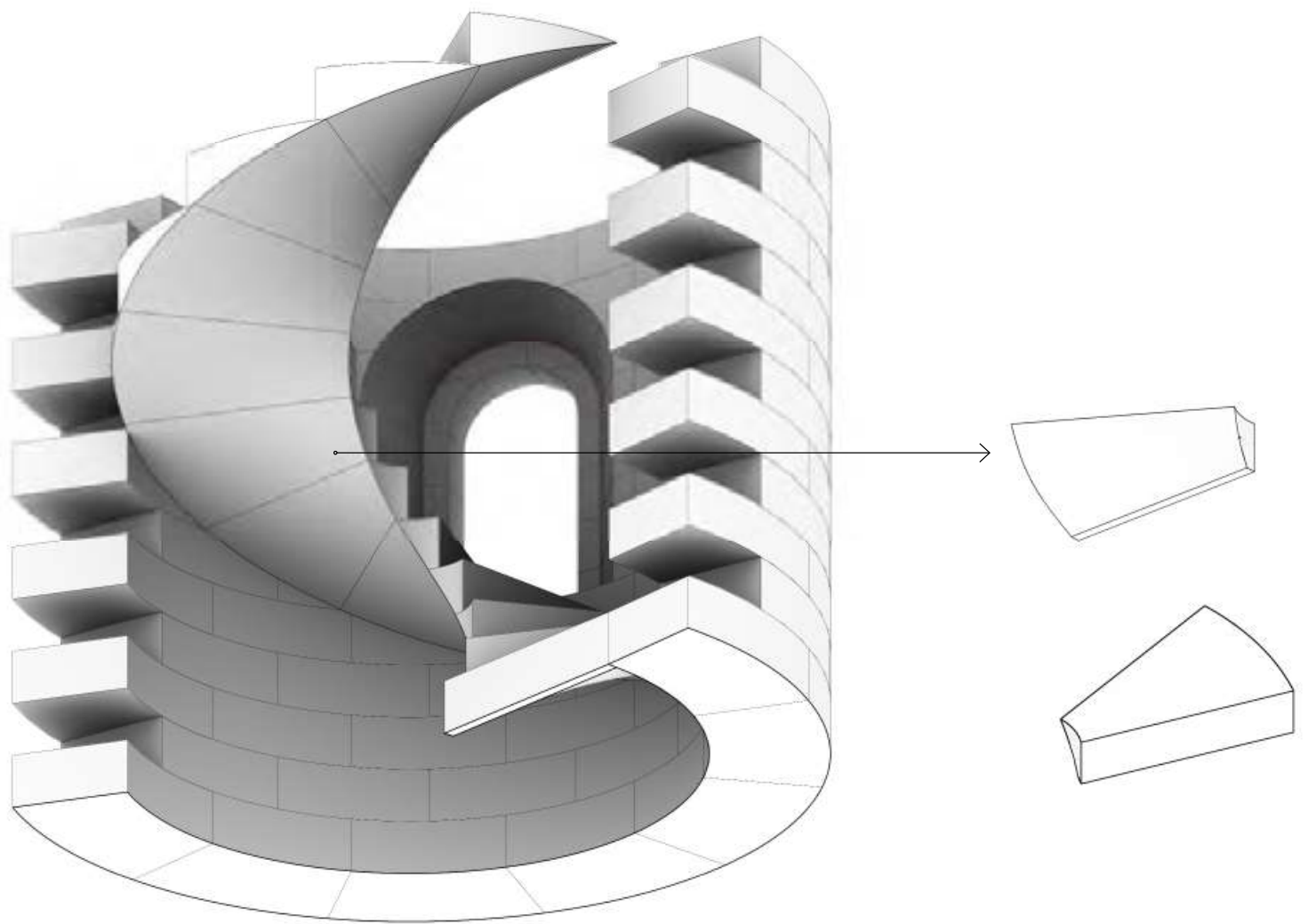

Fig. 9.4. Caracol de Mallorca y uno de sus peldaños. Dibujo del autor.
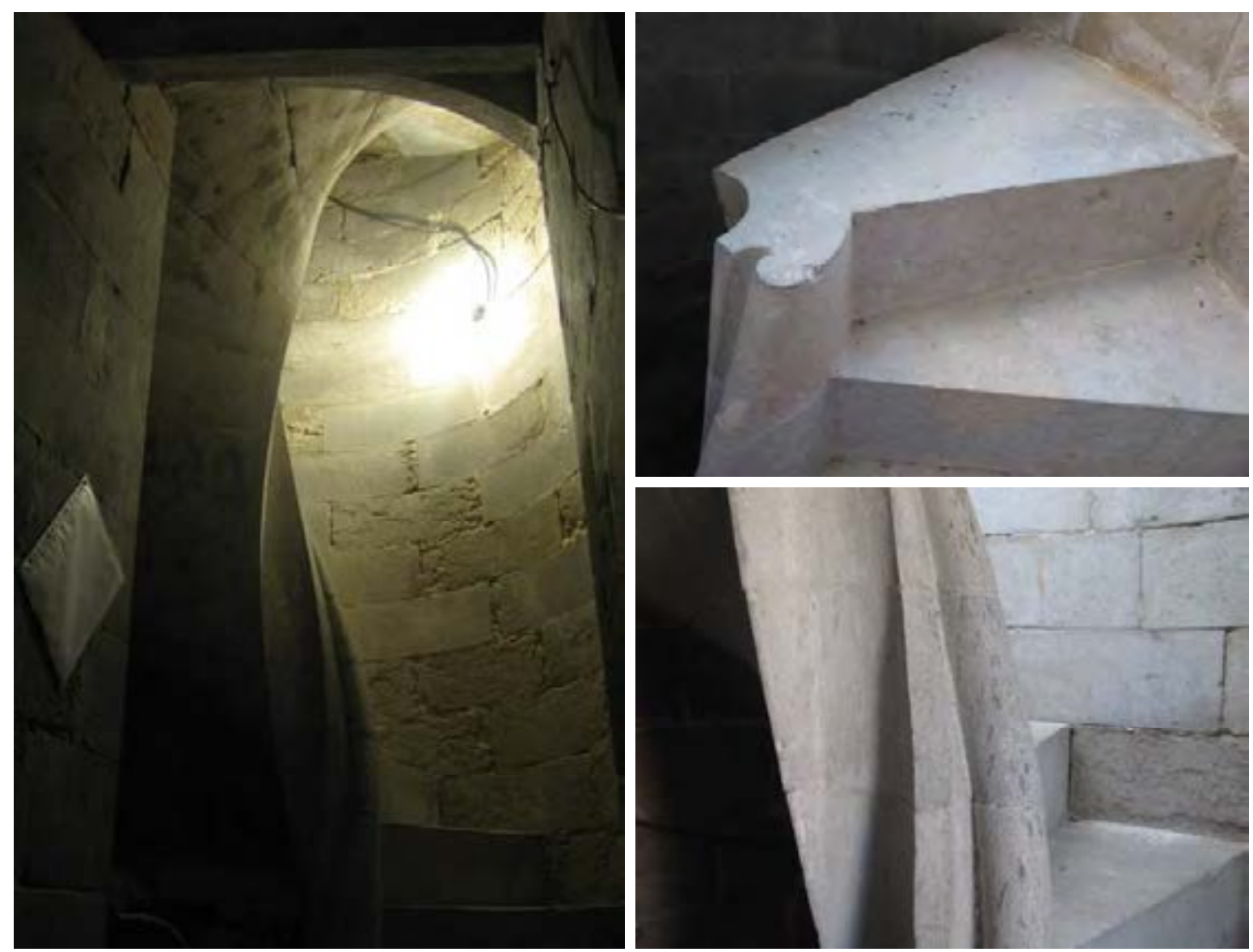

Fig. 9.5. Caracol de Mallorca en la Catedral de Girona. Fotos del autor. 

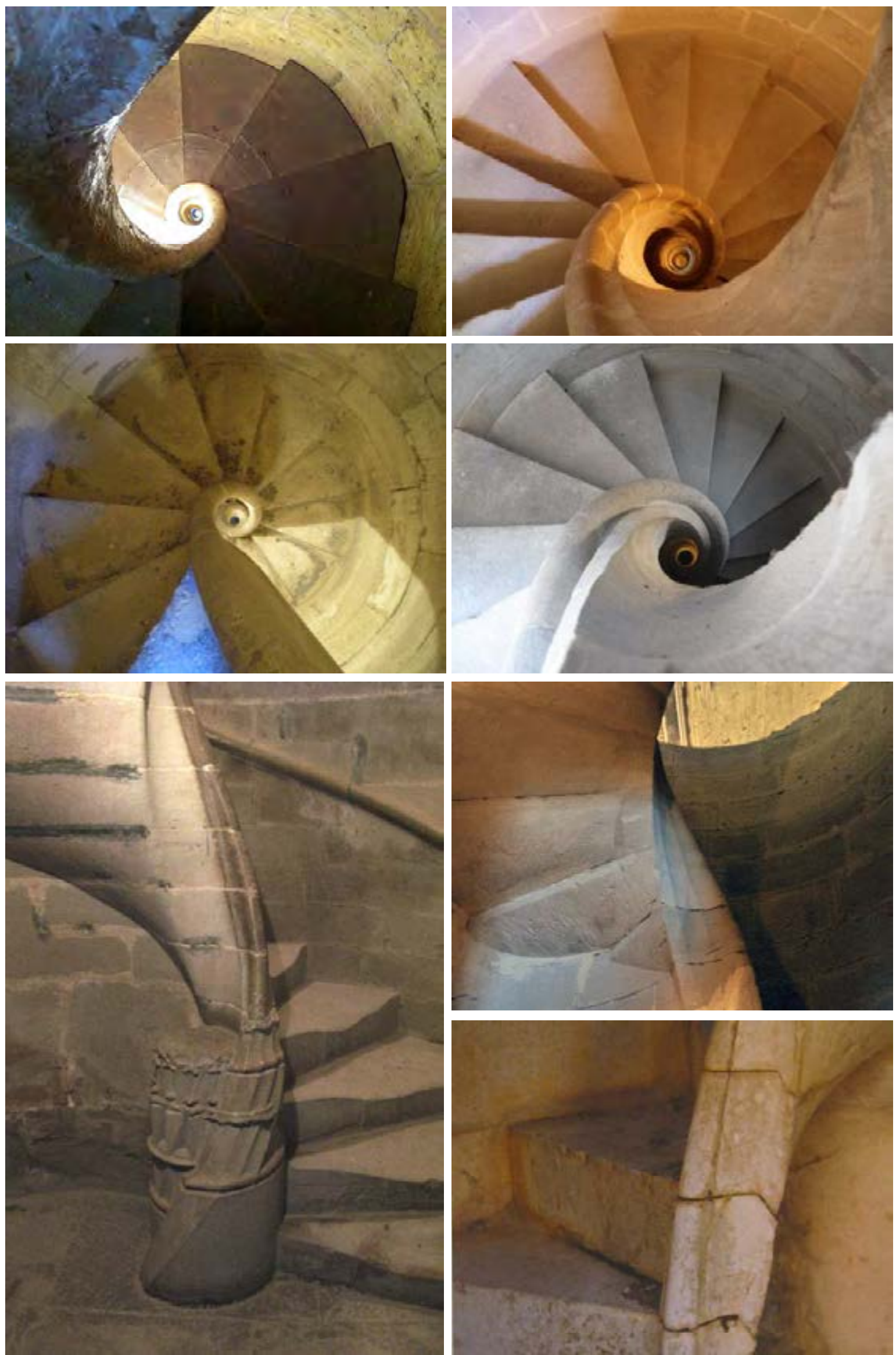

Fig. 9.6. Caracol de Mallorca en: Sant Pere de Reus; Convent de Bellpuig; Catedral de Palma de Mallorca; Catedral de Girona; detalle del arranque del caracol en el Monasterio de Bellpuig; Catedral Vieja de Lleida, arxiu notaril; Fortaleza de San Fernadno de Figueres. Fotos del autor. 


\subsection{Escala ab dos rraplans - Escalera de dos rampantes}

Folio 238 (Traza 131)

Las escaleras sobre arcos rampantes (Fig. 9.7) eran frecuentes en Cataluña y en todo el Levante desde el siglo XIV12, llevando un importante papel en la composición arquitectónica de los patios de los palacios urbanos. Estas escaleras se caracterizan por tener los peldaños colocados sobre una bóveda de piedra tendida entre el arco rampante escarzano que conforma la zanca de la escalera y el muro perimetral sobre el cual se adosa. Los tramos pueden ser rectos o encontrarse perpendicularmente, en este caso los rincones pueden instalarse sobre un soporte vertical o sobre una bóveda donde se acometen los arcos de las zancas. Esta última puede ser continua o tener una arista muy acentuada, resolviendo en ambos casos el acuerdo entre los tramos con un dovelaje premeditado. Los precursores de esta escalera se pueden reconducir a los ejemplos en tramos rectos suportados sobre arcos del Palacio Episcopal de Tortosa (1316), del monasterio cistercienses del Santa Creus (1349), de la Diputación de Barcelona (1429) y del Palacio de los Reyes de Mallorca en Perpiñán (1347) de dos tramos perpendiculares. El proceso de creación y desarrollo de escaleras con bóveda continua y con encuentro en arista parece haberse producido a fines del siglo XV en Valencia en el marco de las innovaciones de la estereotomía de la piedra que se produjo en esta ciudad ${ }^{13}$ que culminó a finales del siglo XVII con los ejemplos más importantes de esta tipología de escaleras en el monasterio de San Miguel de los Reyes y en el Colegio del Corpus Christi de Valencia.

Es remarcable recordar la escalera en bóveda continúa suspensa de la Lonja de Comercio de Barcelona, construida sobre modelos franceses por Juan Soler en 1772 tanto que se podría definir una escalera "a la Mansart", por el nombre del arquitecto que desarrolló las más sorprendentes escaleras en bóveda suspensa ${ }^{14}$. La bóveda de intradós conformante la escalera de la Lonja presenta numerosos aparejos estereotómicos, cuales diferentes tipos de arcos y bóvedas continuas, y las intersecciones de los tramos de las bóvedas es en rincón de claustro, o sea de carácter francés, a diferencia de la práctica castellana de utilizar las aristas salientes ${ }^{15}$.

En Barcelona, en numerosos casos la escalera monumental de los patios urbanos solía ser cubierta por arcos y bóvedas rampantes para protegerla de las intemperies y integrarla en la fachada interior. Aparecían entonces motivos decorativos que se adaptan a la pendiente de la rampa. Podemos encontrar no solo molduras y balaustras inclinadas, sino capiteles y bases de columnas oblicuas. El gusto estético madurado en este contexto era anterior a las teorías de la arquitectura oblicua propuestas por Caramuel y Lobkowiczen el siglo XVII que solo se sobreponían a modelos compositivos existentes en el territorio.

\footnotetext{
12 Catherine Wilkinson, "La Calahorra and the Spanish Renaissance Staircase," in L'Escalier à La Renaissance, ed. A. Chastel and J. Guillaume (Paris, 1985): 154.

13 Arturo Zaragozá Catalán, "Las Escaleras Con Bóveda Continua de Piedra: Técnicas y Significados. El Episodio Valenciano de La Edad Moderna," in Le Scale in Pietra a Vista Nel Mediterraneo, ed. Giuseppe Antista and María Mercedes Bares (Palermo: Caracol, 2013): 23.

14 Un ejemplo es la escalera del Hotel Guénégaud des Brosses, Paris (1653).

15 Perouse de Montclos, 1982: 207.
} 

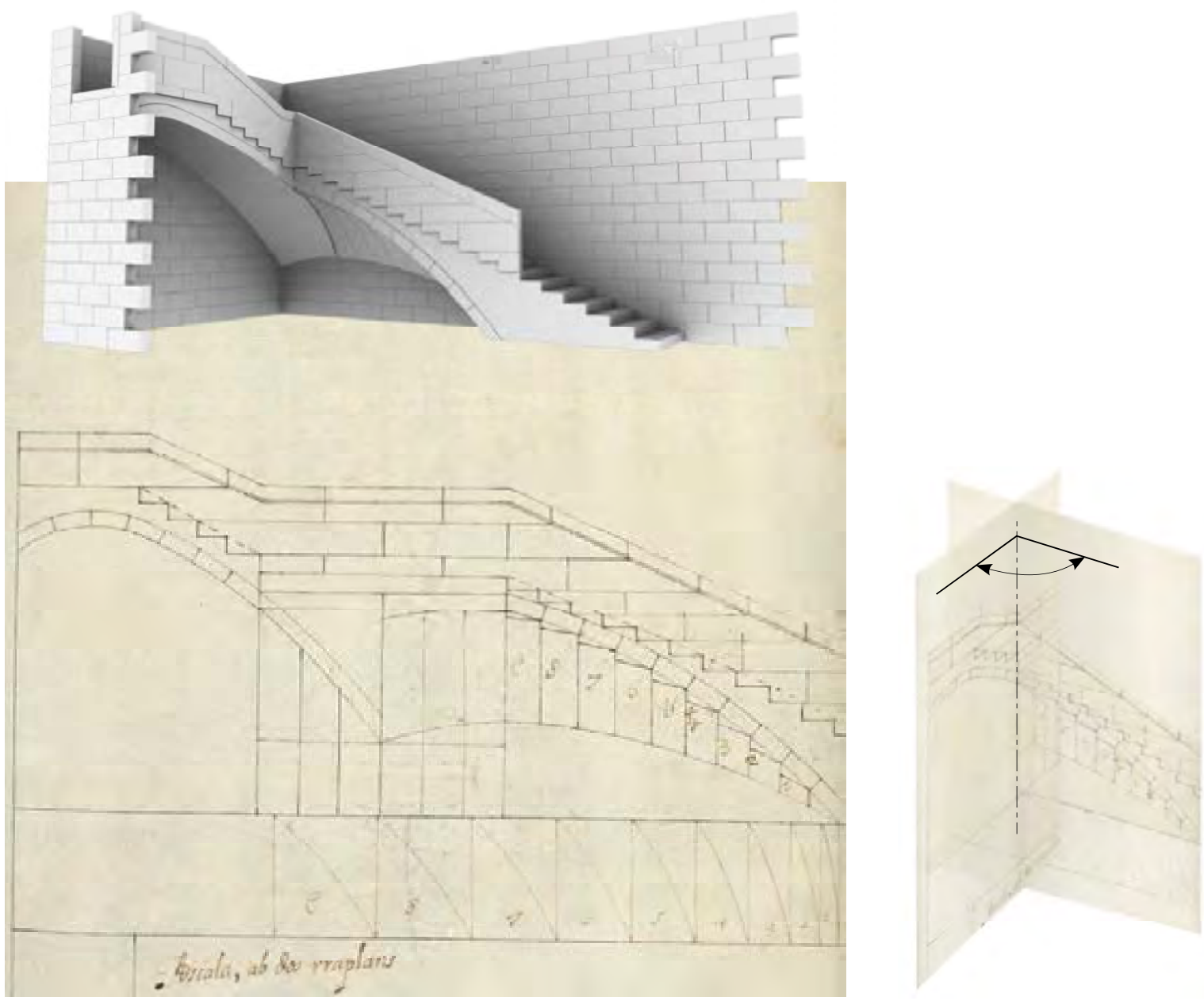

Fig. 9.7. Escala ab dos rraplans

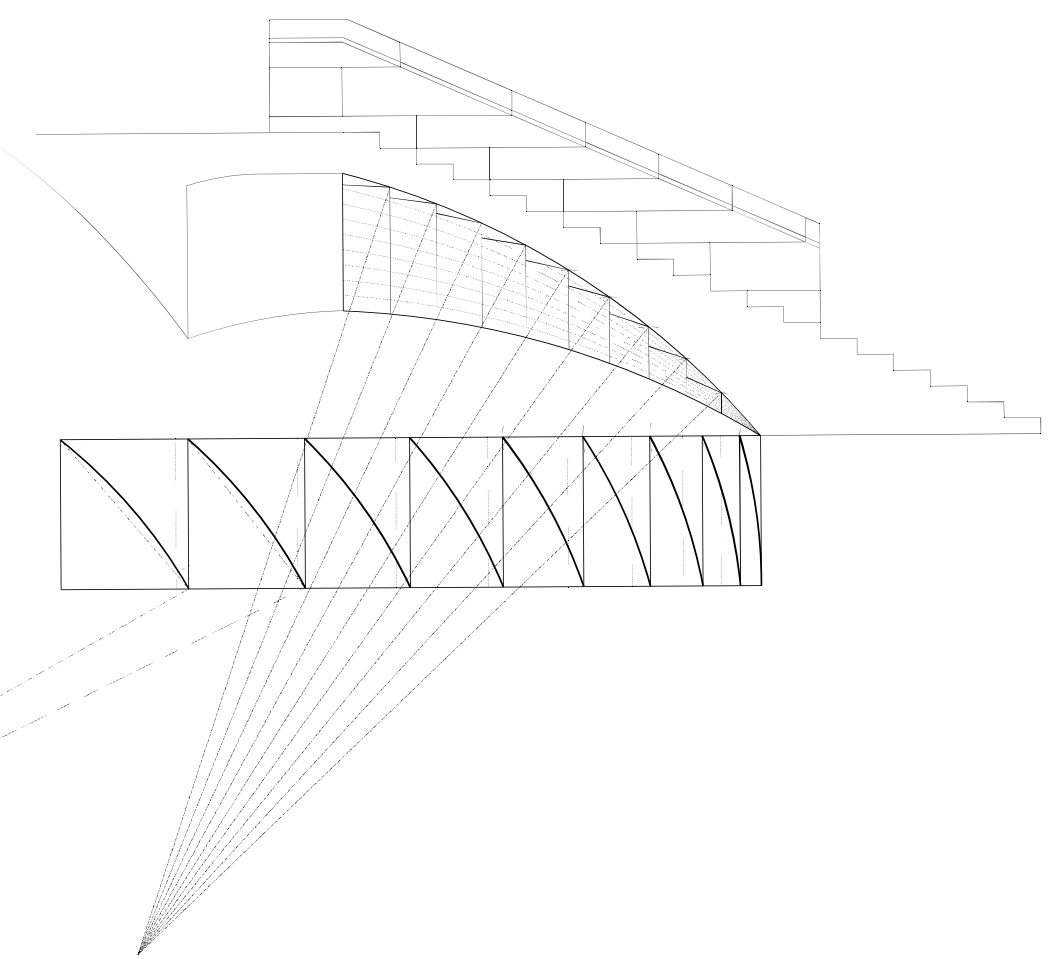

Fig. 9.8. Traza geométrica. Dibujo del autor. 


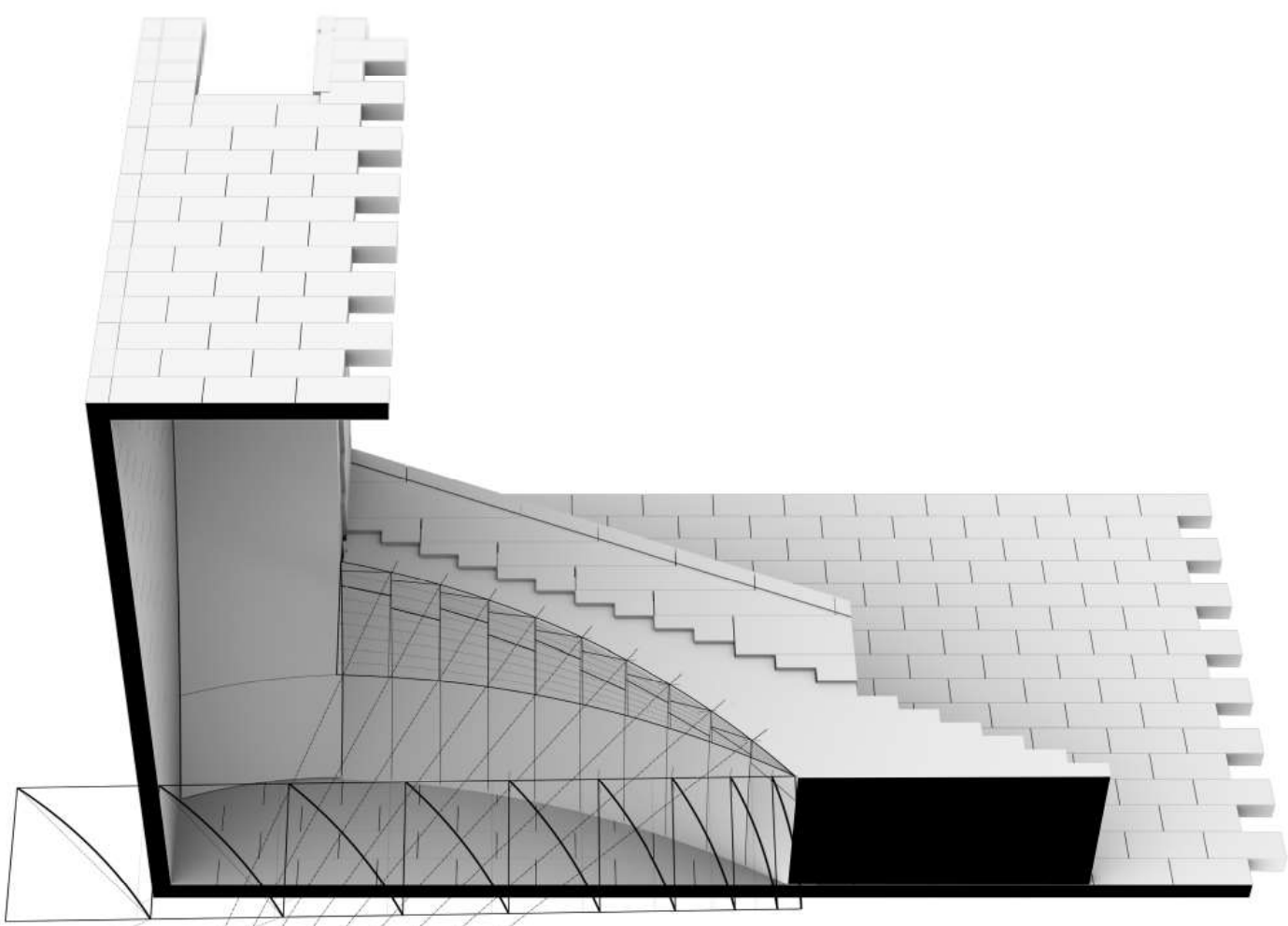

Fig. 9.9. Escala ab dos rraplans; axonometria. Dlbujo del autor.

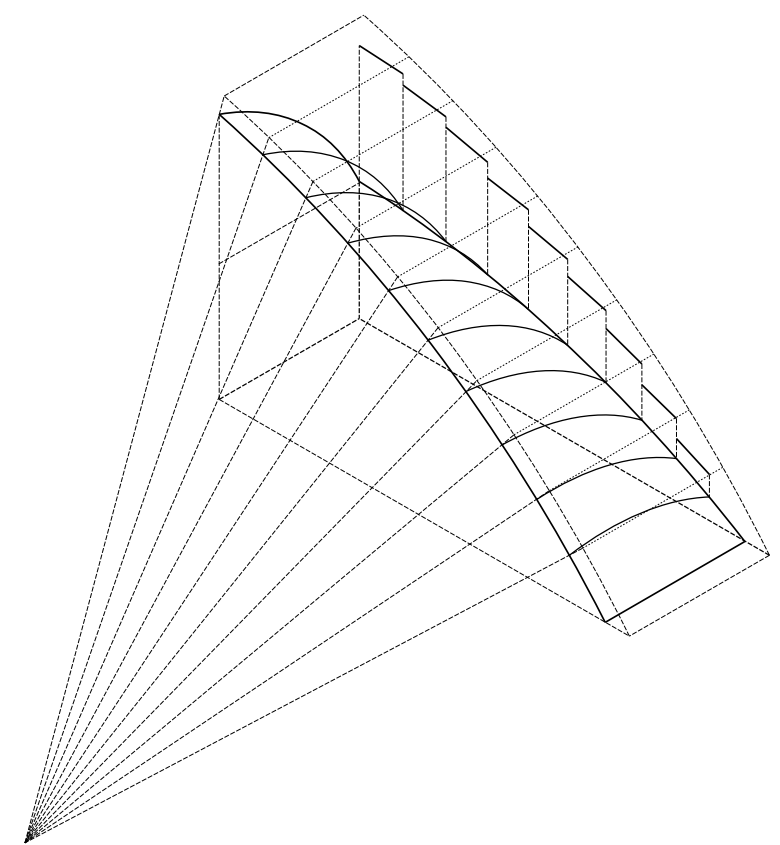

Fig. 9.10. Geometría de los peldaños . Dlbujo del autor. 
El manuscrito de Ribes muestra un modelo de escalera adulcida en dos tramos perpendiculares en la cual se produce un fundido entre las superficies de intradós en correspondencia del rincón. El dibujo aparenta a primera vista una escalera con dos tramos continuos que yacen en el mismo plano en cuanto los tramos vienen representados en el papel con la misma orientación, también puede llevar en engaño el facto que la barandilla en piedra viene dibujada como si tuviera una porción horizontal continua entre las dos porciones de barandilla inclinadas. En realidad, los tramos son ortogonales (Fig. 9.7B) y el dibujo solo sigue un método de representación que era habitual en los tratados de cantería de la época. Para determinar la geometría de la bóveda de intradós, Ribes recurre a un sistema proporcional que relacionar la curva del arco que conforma la zanca con la curva de la intersección de la bóveda con el muro y el ancho de la escalera. El diagrama puesto abajo del alzado muestra cómo se debe hacer ese paso (Fig. 9.9). Primero se define el arco escarzano de la zanca de la escalera, por arriba se traza la curva paralela que define el espesor de este arco y se hace la división en dovelas de igual longitud. Los peldaños son independientes de la pendiente del arco y se aproximan a ello solo in correspondencia de la parte terminal de cada tramo. Se traza entonces el ancho de la escalera y se define bajo a junta de la primera dovela a partir de la base del arco el primer punto que define la cota de la curva de intersección de la bóveda de la escalera con la pared. Con un compás se traza un circulo con el mismo radio del arco escarzano de la zanca que pase esta vez por la proyección de la cota de la primera dovela y se define así la cota del segundo punto de la curva de intersección que vendrá transportada bajo la junta de la segunda dovela. Se repite el procedimiento para cada dovela de la zanca y se puede entonces proceder a la traza del arco que conforma la intersección de la bóveda con la pared uniendo los puntos encontrados. El diagrama también define los patrones y los baiveles de las dovelas del intradós, de hecho, las hiladas que conforman la bóveda son perpendiculares al muro como ocurre en el área catalana, a diferencia de las escaleras adulcidas de tipo andaluzas y castellana donde corren paralelas a los muros. Las dovelas comienzan horizontales y se van inclinando más mano a mano que el arco rampante se eleva del terreno, pero las juntas pueden definirse con el mismo baivel que tiene como radio la misma dimensión del radio del arco de la zanca. Una vez construida la bóveda, será necesario alisar el intradós para dar continuidad a la superficie.

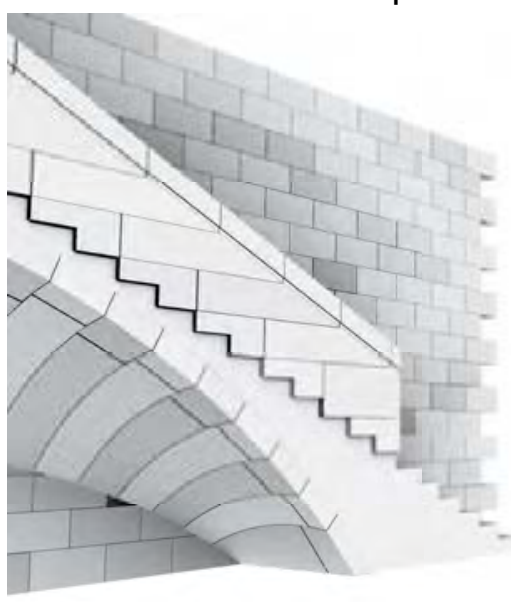

Fig. 9.11. Geometría de los peldaños

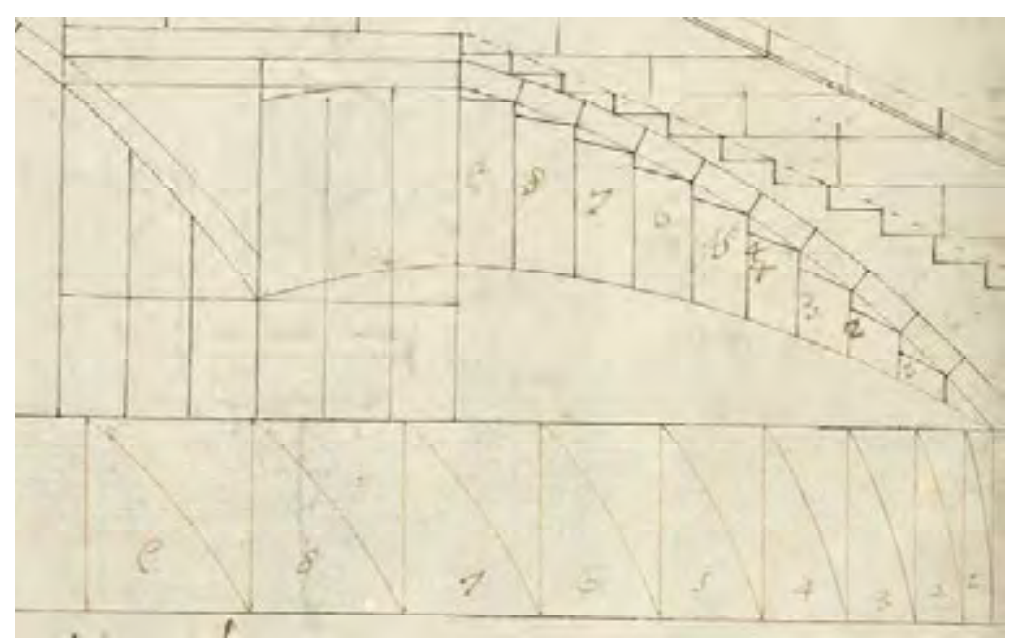



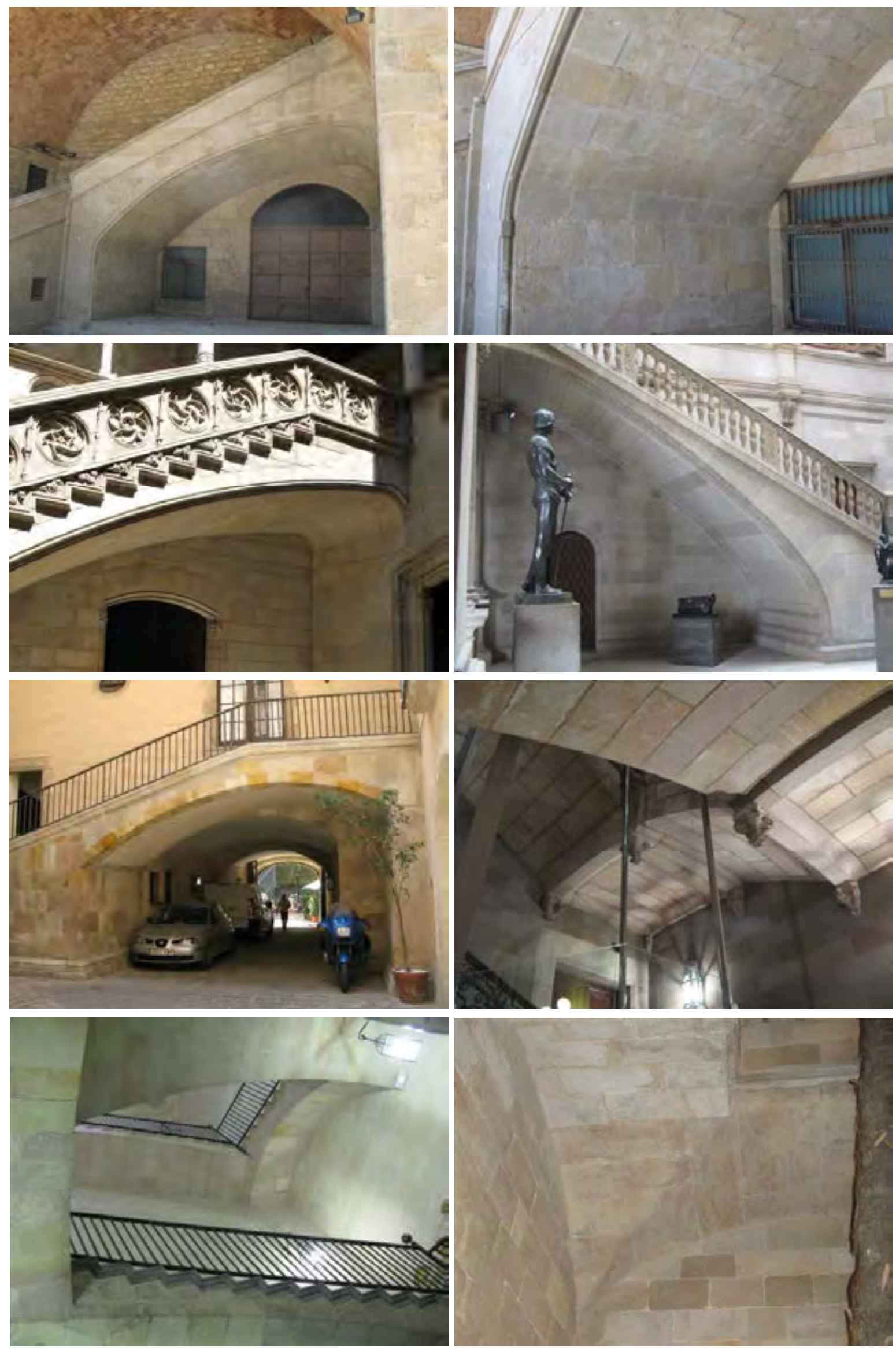

Fig. 9.12. Hospital de la Santa Creu, Barcelona (A y B), Palau de la Generalitat, Barcelona; Casa de la Ciutat, Barcelona; Palau Fivaller (1517), Barcelona; Palau del Parlament de Catalunya, Barcelona; Casa de Convalescència, Barcelona; Casa en Leída . Fotos del autor. 

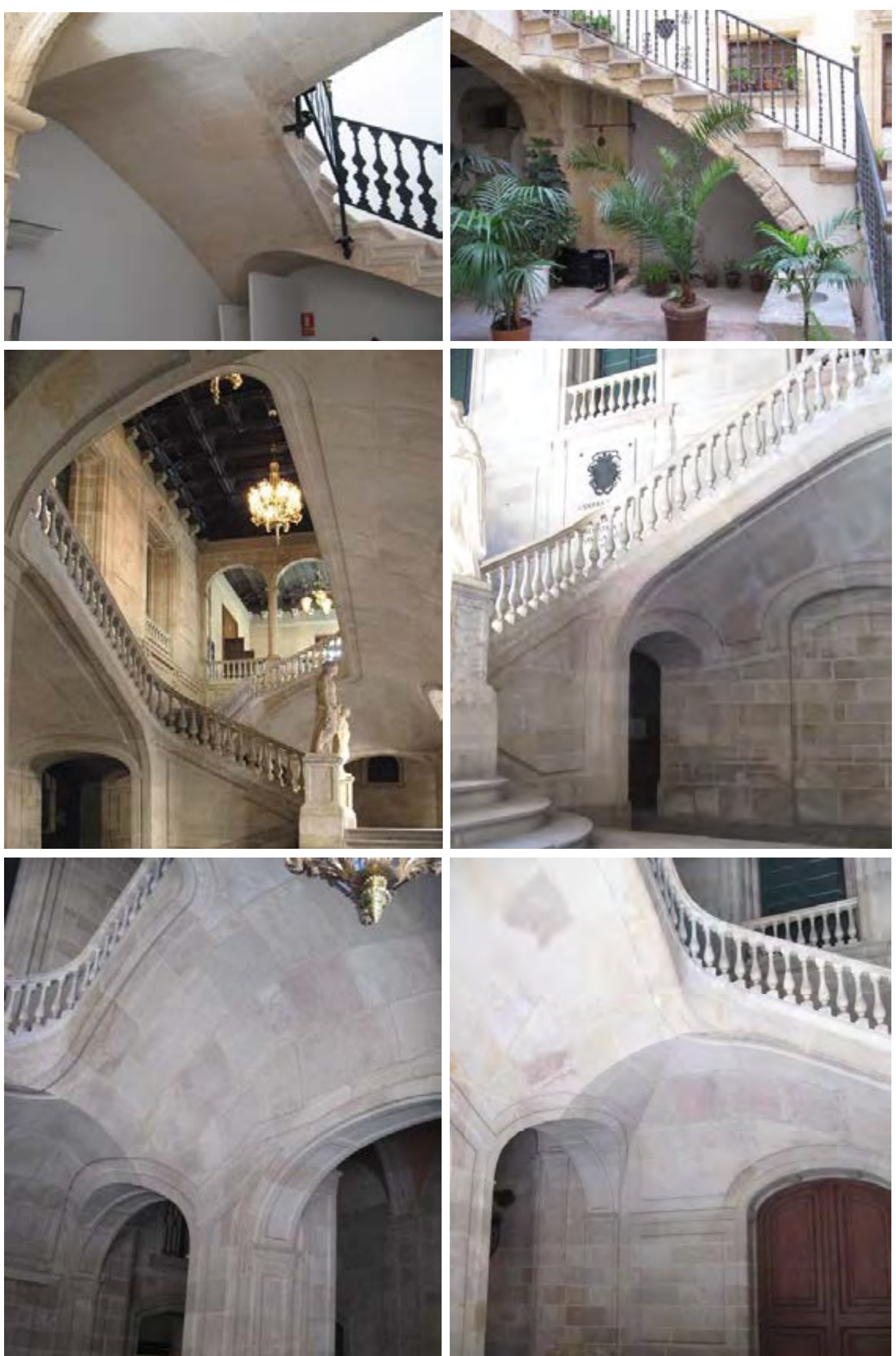

Fig. 9.13. Sant Antoni Abad, Palma de Mallorca; Casa en Tarragona; Lonja de Mar de Barcelona (C, D, E, F) 


\subsection{Vis de Saint Gilles}

La vis de Saint Gilles (Fig. 9.14) es una de las trazas más emblemáticas de la estereotomía por su complejidad. Aunque no sea presente en el Llibre de trasas, se considera oportuno recogerla en este capítulo por su interés en la esfera del estudio del corte de piedras y por relativa difusión en el ámbito mediterráneo. Esta escalera tiene planta circular y en el medio se levanta un muro concéntrico a la caja que funge de alma de la escalera. El espacio entre los dos muros está cubierto por una bóveda de canon helicoidal aparejada en piedra que sostiene los peldaños. El intradós de la bóveda viene determinado geométricamente por el desplazamiento de un arco de medio punto sobre una hélice. Este tipo de traza podría formar una agrupación distinta de las otras escaleras por la particularidad constructiva, centrada en el problema de la bóveda de revolución en espiral y no en el peldaño. Toma su nombre de la abadía de Saint Giles, en del sur de la Francia donde se encuentra lo que es considerado el primer modelo europeo, aunque se considera que sus orígenes sean del mediterráneo oriental.

La escalera cubierta con bóveda helicoidal es una tipología conocida en Cataluña, aunque se conservan pocos ejemplos: existen toscos ejemplares del románico con bóvedas en material incoherente y dovelaje más o menos definido y el modelo en vis de Saint-Giles completo de finales del siglo XIV ${ }^{16}$ que se encuentra en el Portal de Sant'lu de la Catedral de Barcelona. La escalera tiene 136 peldaños de $92 \mathrm{~cm}$ de ancho y la bóveda está resuelta con 7 hiladas de dovelas de la cual una está adosada al husillo central, detalle que ha permitido asociarla a la escalera del Castel Maniace ${ }^{17}$ en Siracusa, Sicilia.

De las muestras Románicas en Cataluña con bóveda de material incoherente, la escalera de la iglesia de San Pere Galligans en Girona ${ }^{18}$ tiene un aparejo más cuidado respecto a los otros ejemplos de la época. Esta escalera, de dirección dextrógira, tenía probablemente una dúplice función: de conexión a la capilla alta de Sant Miquel, que se encuentra en el transepto justo bajo el nivel del techo, y una función defensiva, garantiendo acceso a las muras de la ciudad que transitaban en esa posición. La ejecución de las dovelas todavía no es clara y precisa, sin embargo, especialmente en el primer tramo de la escalera, hay un claro intento de ordenar las dovelas en sillares paralelos y con juntas regulares. La construcción es todavía empírica pero quizás coadyuvada de un soporte geométrico rudimental.

16 F. Carreras Candi, "Les Obres de La Catedral de Barcelona," Boletín de La Real Academia de Buenas Letras de Barcelona 7 (1913), describe la presencia de esta escalera:

"Los dos campanarios se empezaron hacia 1386, aunque el de las campanas se acabó en el siglo XVI. La escalera de caracol de éste último está fechada en mayo del mismo 1386; intervino en la decoración de los capiteles el alemán Francesc Mulner. La torre del reloj, sobre la puerta de San Ivo, tiene un colosal caracol construido hacia 1387-1389".

17 Maria Mercedes Bares, "La Scala Dell'Imperatore: Una Vis de Saint-Gilles Nel Castello Maniace Di Siracusa," in Actas Del Sexto Congreso Nacional de Historia de La Construcción, Valencia 2009, ed. S. Huerta et al., vol. 1 (Instituto Juan de Herrera, 2009): 153-62.

18 . San Pere de Galligans, en localidad de Girona, se empezó a construir en 1130, consta de tres naves con crucero y cuatro ábsides construidos con un claro aparejo de sillares en piedra dispuestos en vuelta de horno. En esta iglesia además es muy interesante la capilla a las que conduce esta escalera, caracterizada por cuatro trompas cónicas. En 1362 el monasterio fue incluido en la cinta muraría de la ciudad y la torre del campanario fue reformada para darle una función más defensiva, característica que ha seguramente determinado la dirección de la espiral. 


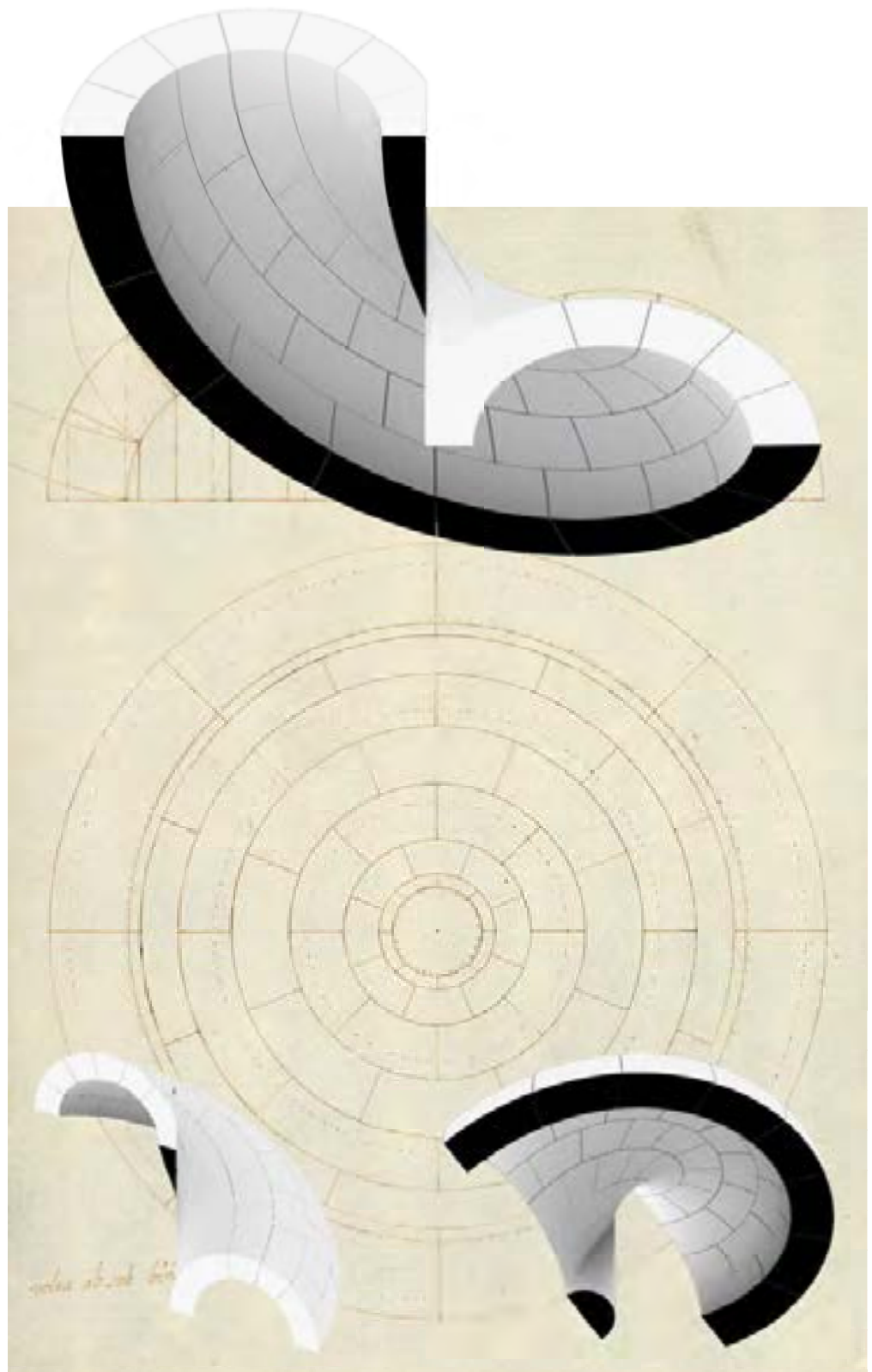

Fig. 9.14. Hipotético modelado virtual de una Vis de Saint Gilles sobre la bóveda anular del Llibre de Trasas
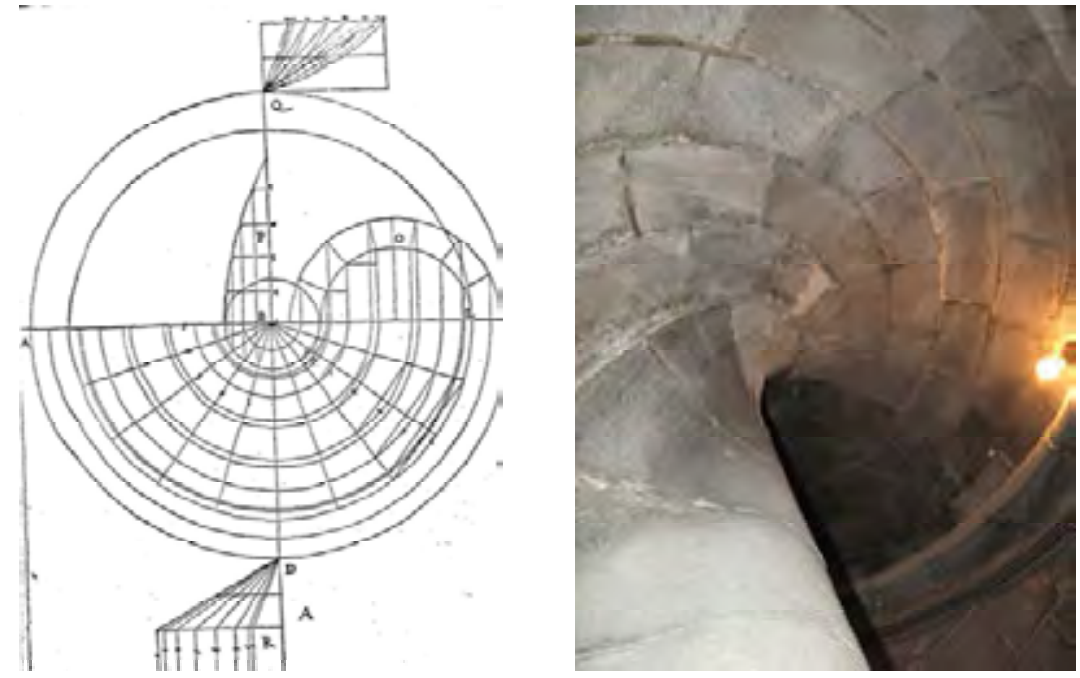

Fig. 9.15. Vis de Saint Gilles en Philiber de L'Horme; escalera en bóveda continua la Catedral de Barcelona. Foto del autor. 

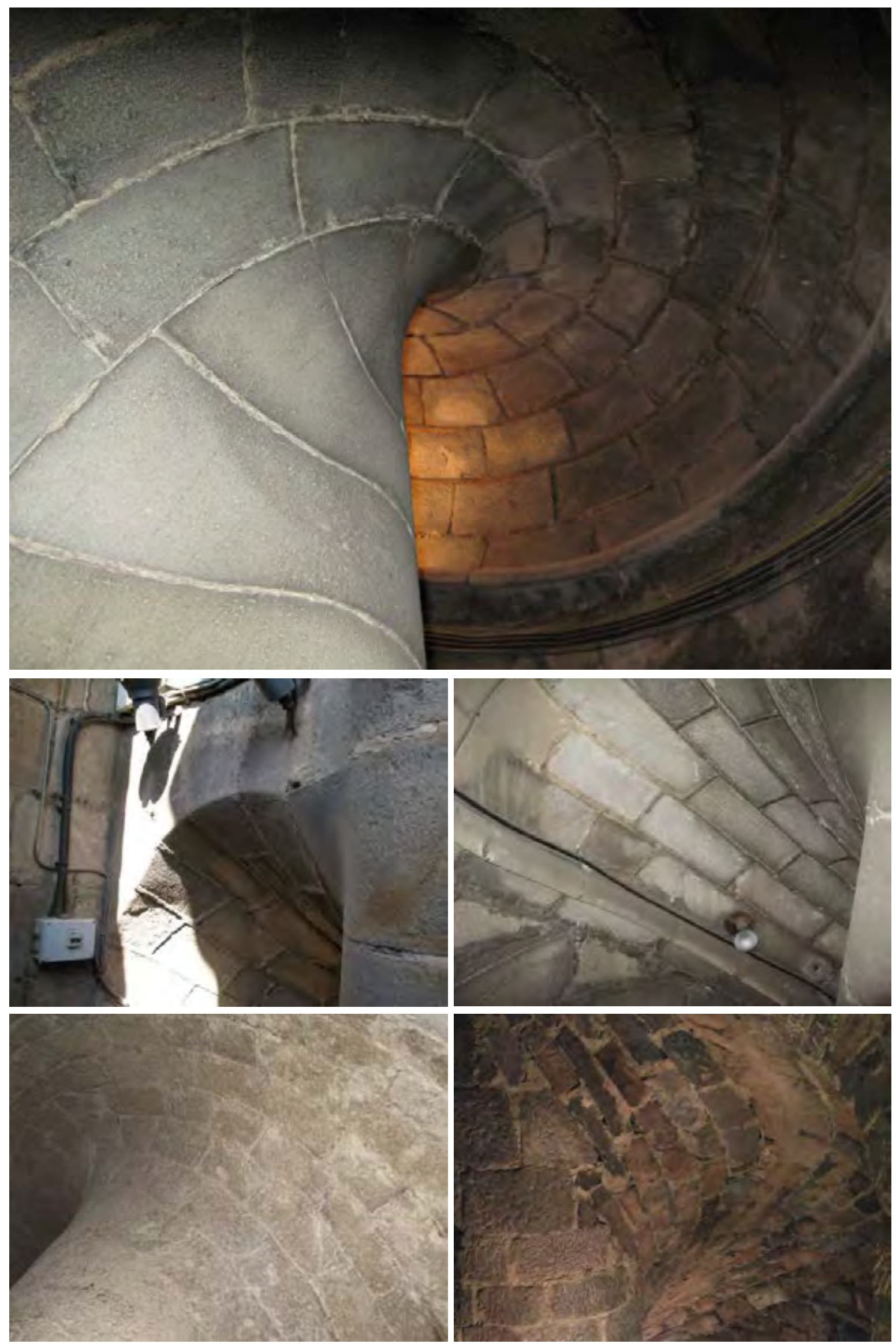

Fig. 9.16. Escalera en bóveda continua la Catedral de Barcelona (A, B, C); Sant Pere de Galligans, Girona; Castillo de Cardona. Fotos del autor. 
En la Catedral de Tarragona, relacionada con la Capilla de los Sastres, se encuentra un formidable caracol abovedado (Fig. 9.16) de finales del tercer cuarto del siglo XIV ${ }^{19}$. La superficie de la bóveda es constituida con tramos de bóveda de cañón inclinada adyacentes en planta de sector circular, como si fueran las hojas de una palmera. Aunque no sea propiamente una Vis de Saint Gilles, el intradós que se va a conformar es aparentemente helicoidal.

Como hemos visto anteriormente en el capítulo dedicado a las bóvedas con la Volta ab sub biño (Bóveda en patio redondo, traza 50), una bóveda anular yace sobre un plano y se desarrolla a lo largo de una directriz circular. Si la directriz fuera una espiral, la bóveda se desarrollaría también en altura, conformando un tipo el aparejo denominado en la tratadistica como vis de Saint-Giles. ¿Podría Ribes haber visto la traza de la bóveda de Sint Gilles y no haberla copiada correctamente? Se ha podido constatar como Ribes no haya entendido totalmente la traza de la Volta ab sub biño por el hecho que se equivoca en representar el desarrollo de la cara de intradós de las dovelas. El dibujo es incompleto y lo que Ribes enseña es solo el principio de lo que parece ser el desarrollo de las dovelas, como si la sección de la superficie tórica de la bóveda anular fuera la sección de una media esfera. Ya se ha avanzado la hipótesis que Ribes haya copiado alguna traza de otros tratados, por ejemplo, conoce la Bolta per aresta que las filadas Rrodan de los folios 57-58 del Llibre de trasas, presente solo en el tratado de L'Horme (la voûte en éventail) y otra parecida del tratado de Alonso de Guardia. También en el manuscrito de Hernán Ruiz $^{20}$ aparece una traza de una bóveda suspensa en planta circular que no presenta la pendiente de las dovelas y que se podría considerar como si fuera bóveda anular y no caracol abovedado. A diferencia de Ribes, a favor de la tesis que la traza de Hernán Ruiz sea una escalera, es el hecho que en el mismo manuscrito existe la traza completa de un caracol abovedado sobre planta cuadrada.

En el Castelnuovo de Nápoles, en territorio relacionado con Cataluña, se ha encontrado una escalera con bóveda de Saint Gilles de ojo abierto desarrollada alrededor de un pozo ${ }^{21}$.
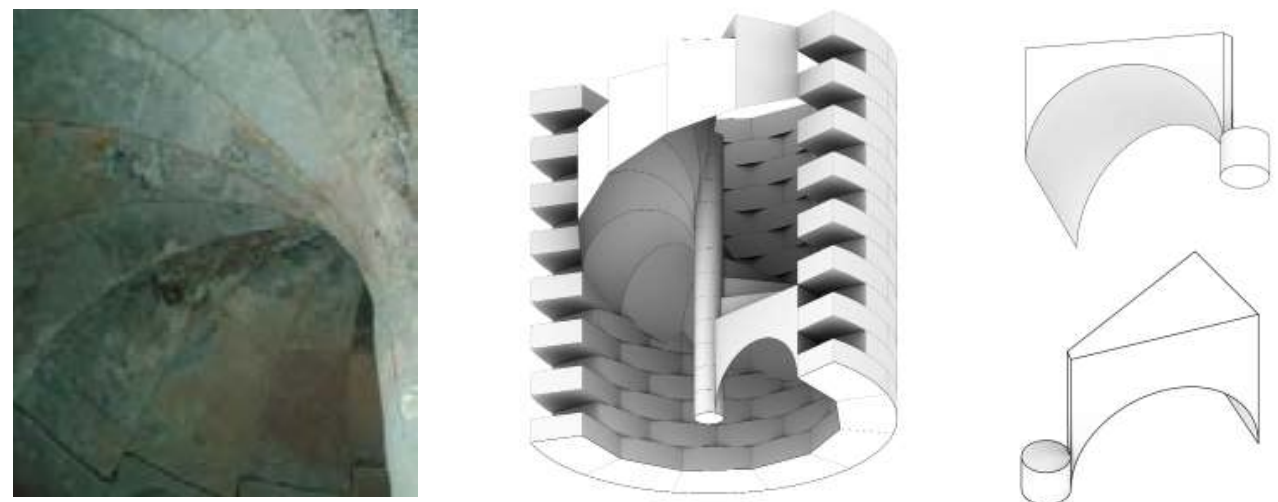

Fig. 9.16. Bóveda de la escalera en la Catedral de Tarragona (foto de Arturo Zaragozá Catalán) y modelado virtual. Dibujo del autor.

\footnotetext{
19 Arturo Zaragozá Catalán, "La Escalera de Caracol Tipo Vis de Saint-Gilles," in LEXICON: Storie e Architettura in Sicilia, 2007: 10.

20 Manuscrito conservado en la ETSAM, R31 (sin nombre), fol 151r.

21 como observada por Pérez de los Ríos y Enrique Rabassa en: Carmen Pérez de los Ríos, "Aspectos Formales y Constructivos En La Obra de Guillem Sagrera: El Uso de Las Plantillas” (Tesis Doctoral, 2016): 352.
} 


\section{Capiteles pinjantes}

Los capiteles pinjantes tienen una presencia importante en el repertorio estilístico de los patios de los palacios de Barcelona por su originalidad y notable estereotomía. Al momento este tema es actualmente carente de bibliografía y estudios dedicados y por esta razón, aunque este elemento no venga representado en el manuscrito de Ribes, se considera oportuno describirlo en esta tesis, enfocándose en el análisis de la estereotomía y técnica constructiva de los capiteles pinjantes del episodio catalán.

La búsqueda de lo insólito y de lo inesperado en Arquitectura ha perdurado desde hace siglos y se ha manifestado con diferentes enfoques y expresiones: en algunas circunstancias se ha actuado sobre el sistema estructural del edificio, disimulando y falsificando ciertos elementos arquitectónicos. Otras veces se ha conseguido el asombro del espectador quitando los soportes estructurales, de manera casi ilógica, desde posiciones aparentemente necesarias para garantizar la estabilidad de la fábrica.

Estos alardes se manifiestan todavía con más fuerza en las construcciones en piedra de cantería ya que, a diferencia de las construcciones con estucos o en carpintería, el sistema estructural es perceptiblemente más claro y evidente, como más perceptible es también el efecto de la gravedad y el peso de la piedra. En este ámbito pueden situarse los capiteles pinjantes, que son un recurso compositivo/estructural que produce el efecto de suspensión de las claves o de las impostas de un arco, empleados también para solucionar aspectos funcionales, como por ejemplo garantizar un paso más cómodo en una abertura de ancho determinado por un intercolumnio existente.

Los casos más tempranos se caracterizaron por la supresión del fuste de la columna que debería haberse encontrado por debajo de la imposta de dos arcos consecutivos, dejando de esta forma solo un capitel suspendido en el aire. Sucesivamente fueron incluidos en sistemas abovedados más complejos como bóvedas de crucería o galerías porticadas.

La lógica del sistema estructural era ocultada meticulosamente a través de un cuidado dibujo y corte de las dovelas que componen los arcos, poniendo así de manifiesto los conocimientos estereotómicos de su constructor.

Su construcción abarca un extendido ámbito geográfico y temporal: encontramos arcos con claves suspendidas en los portales de las iglesias y de los monasterios románicos; se aprecian en las tracerías de los grupos escultóricos del gótico de origen flamígero; aparecen expresados en las bóvedas de crucería del gótico y tardo gótico de Francia, Inglaterra y del área Germánica; fueron parte de los alardes estereotómicos del barroco francés; hasta caracterizaron con exquisitos ejemplos las arquitecturas coloniales hispanoamericanas ${ }^{1}$.

\footnotetext{
1 En particular recordamos las obras de Francisco Guerrero y Torres, activo en Ciudad de México a finales del siglo XVIII
} 
La traza del capitel pinjante fue descrita en sus dos formas, ya sea cuando el capitel viene colocado sobre arcos consecutivos o parte de una bóveda de crucería, en los tratados de estereotomía y cuadernos de apuntes de Villard de Honnecourt, Philibert de l'Orme, Joseph Gelabert, Claude François Milliet-de-Chales, Tomás Vicente Tosca y en los análisis constructivos de los elementos arquitectónicos de la arquitectura francesa de Viollet-le-Duc y de las bóvedas góticas inglesas de Robert Willis² (Fig. 10.1).

Un sistema constructivo afín aparece también en la arquitectura islámica asociado a los portales con muqarnas, consecuente a la transmutación en piedra de los motivos formales basados en yeso y ladrillo ${ }^{3}$.

En particular, podemos destacar como el uso de los capiteles pinjantes ha sido muy apreciado en la arquitectura gótica y tardo gótica de Cataluña, en particular en Barcelona, caracterizando los patios de sus palacios y casas particulares, y posteriormente siendo reproducidos durante el periodo barroco y modernista, testimonios de un arraigado gusto debido al interés que despertaban.
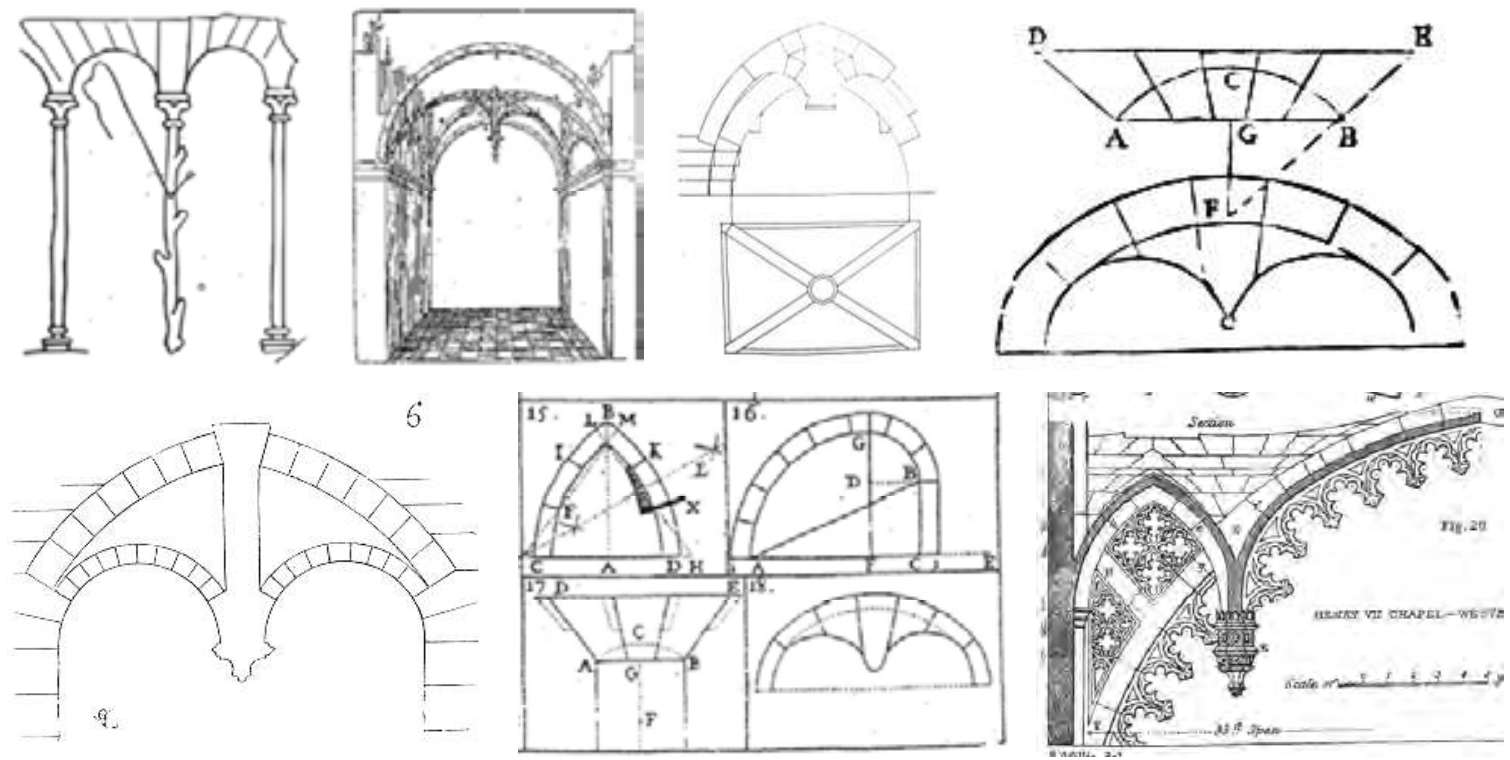

Fig. 10.1. Capiteles pinjantes en los tratados de Villard de Honnecourt, Philibert de l'Orme, Joseph Gelabert, Claude François Milliet-de-Chales, Tomas Vincente Tosca, Viollet le Duc, Robert Willis

\footnotetext{
2 - La construcción de un capitel pinjante (Par ce moyen on taille une voussure pendant) viene descrita por primera vez en el cuaderno de apuntes de Villard de Honnecourt (c. 1235, fol. 20 v), dedicado a la construcción de catedrales góticas, en el cual recopila varios temas de construcción en piedra, incluyendo armaduras de madera y bocetos de carácter escultórico. Los otros ejemplos aparecen en:
}

Philibert De L'Orme: D'une voute à croisée d'ogives, ayant une clef suspendue (De L'Orme, 1567: 111);

Para Joseph Gelabert ver Rabasa, 2012: 392;

PROPOSITIO XIII Problema De Arcu in lineam rettam degenerante (Milliet de Chales, 1674, vol 2: 629); - Tosca (Tosca, 1797: folio 108, imagen 18) dibuja un arco con capitel pinjante similar al modelo de Viollet-leDuc y Claude François Milliet de Chales;

- Viollet-le-Duc (Viollet-le-Duc, 1854: Vol. 3, 300);

- Robert Willis (Willis, 1842: 36) describe los aspectos constructivos de las claves suspendidas en las bóvedas de crucería inglesas;

consta también la existencia de un dibujo de capitel pinjante en un texto didáctico manuscrito de título Tratado VIII: De la arquitectura civil de 1778 de Claudio Martel, ahora conservado en la biblioteca del Colegio Oficial de Arquitectos de Madrid. Quizás corresponde a una copia del Curso Matemático de Pedro de Lucuze de 1739 impartido en la Real Academias de Matemáticas de Barcelona. Para más informaciones consultar (Montaner, 1990: 153 y 821) y (Galindo, 2008: 465-482).

3 Recordamos el primer ejemplo en la madrasa Al-Nuriyya al-Kubra, construida en Damasco en 1168 (Tabbaa 2011, 137-149) 

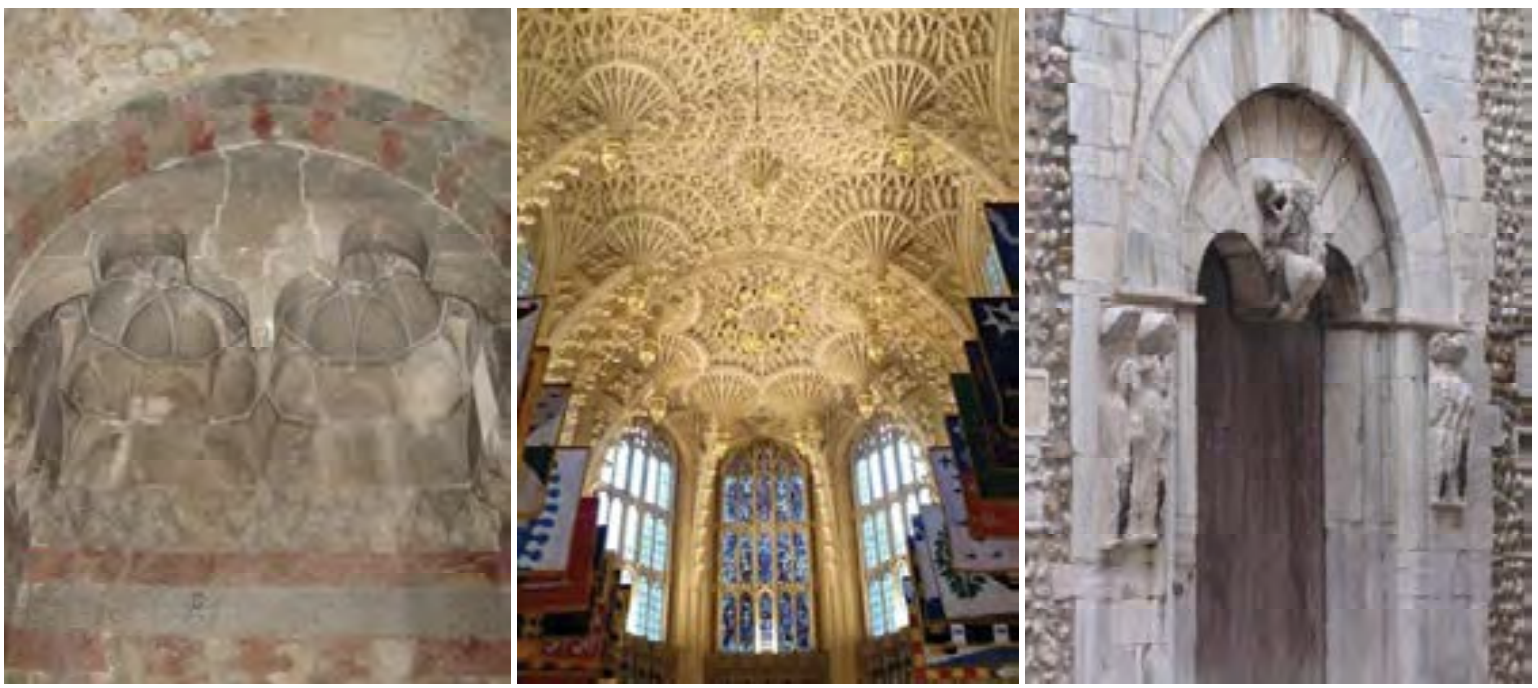

Fig. 10.2. Madrasa Al-Dawadariyya, Jerusalén; Henry VII Chapel, Westmister Abbey, London (foto de Khan Academy https://images.app.goo.gl/XHL3i6Mw69So6BCb6); Catedral de Perpiñan. Fotos del autor.
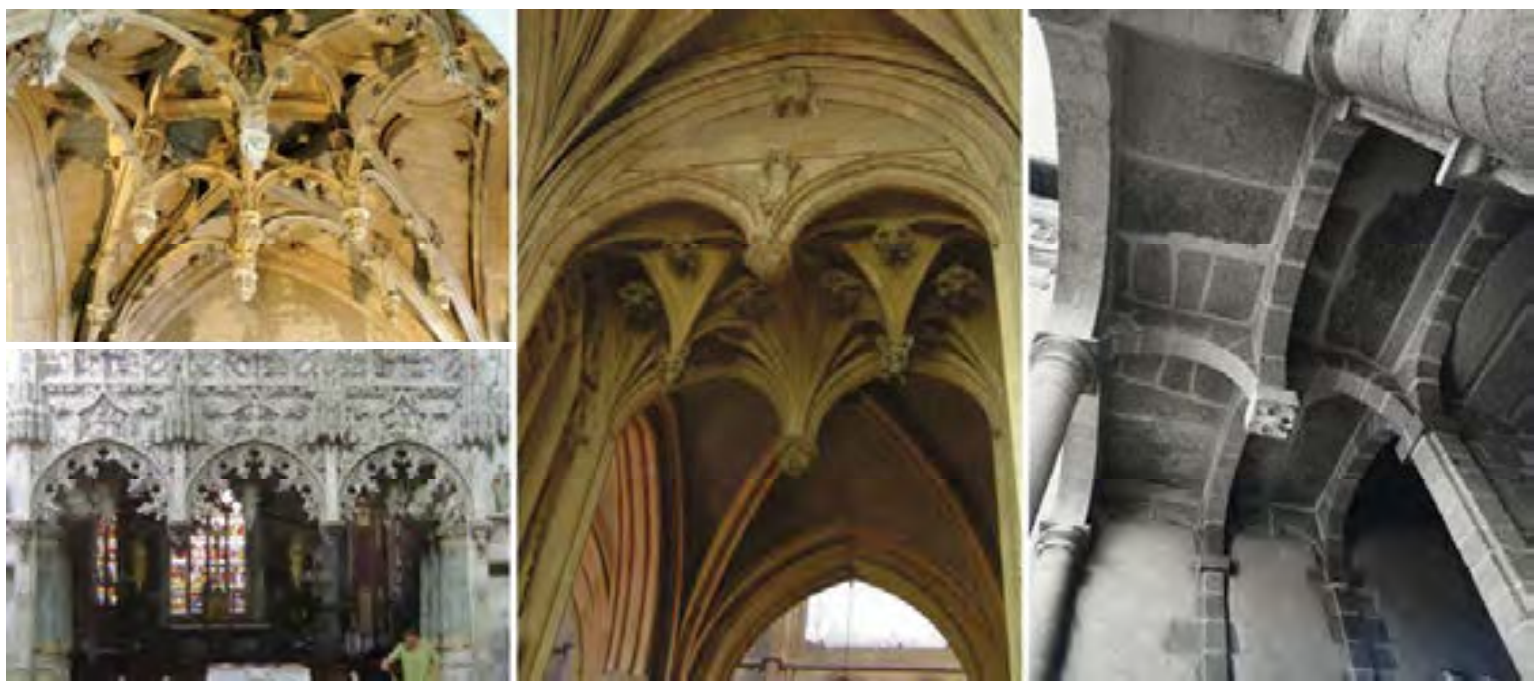

Fig. 10.3. Iglesia Ste. Madeleine, Troyes; Catedral de Lyon, Chapelle des Bourbons; Hotel Maldert de Feytiat

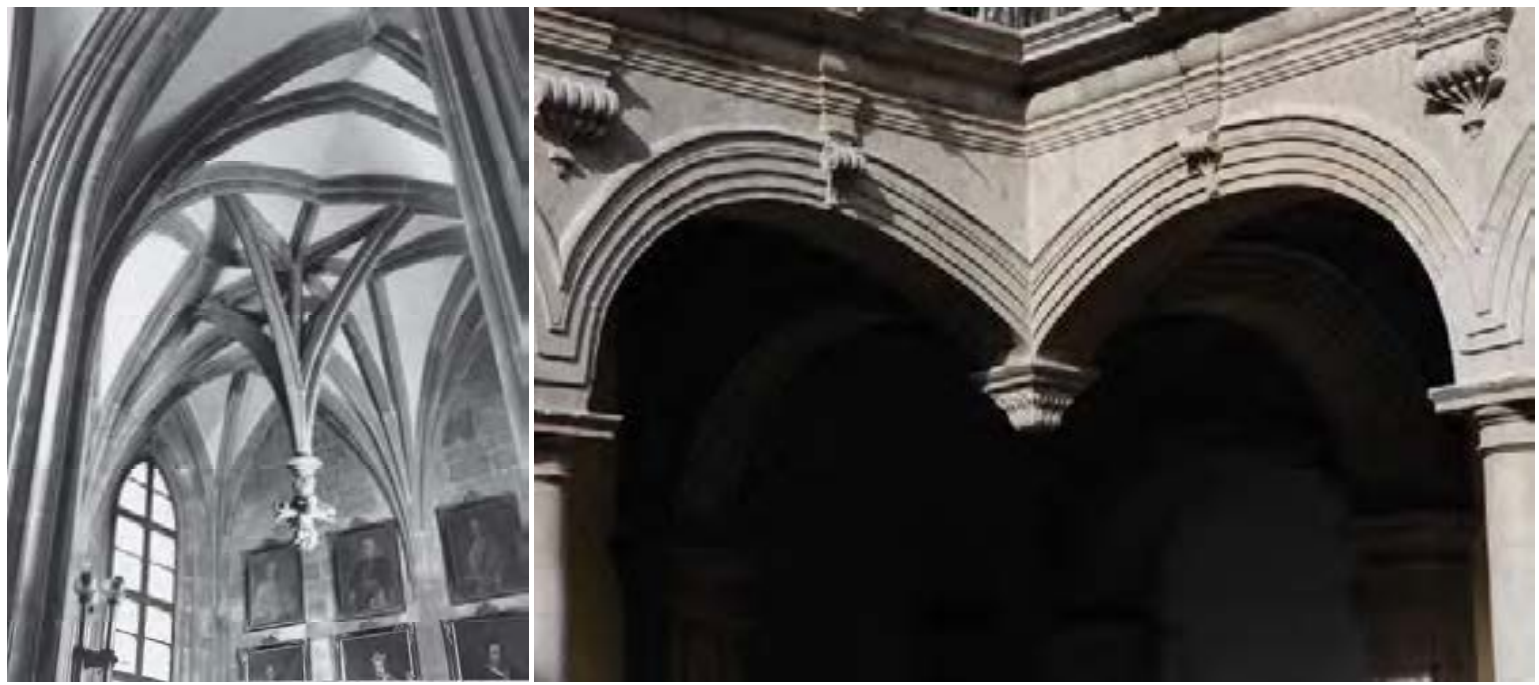

Fig. 10.4. Catedral de San Vito, Praga; Antiguo Palacio de la Inquisicion, Cludad de Mexico 


\subsection{Clasificación geométrica}

A fin de una catalogación geométrica de los ejemplos analizados, se han reconocido dos tipologías de aparejos adovelados con capitel pinjante (Fig. 10.5): el primero tiene el perfil de intradós conformado como dos arcos sucesivos que se delinean sobre un plano (una pared vertical) con capitel suspendido entre los dos arcos; el segundo se origina por la intersección de dos arcos o de dos series de arcos sucesivos pertenecientes a dos planos perpendiculares entre ellos y tiene el capitel suspendido en el punto de encuentro de los dos planos. En cada caso se pueden presentar variaciones geométricas que van a complicar notablemente la traza, como por ejemplo el número de arcos sucesivos que resultan ser suspendidos, la inclinación y los peraltes de los arcos o las asimetrías de los elementos.
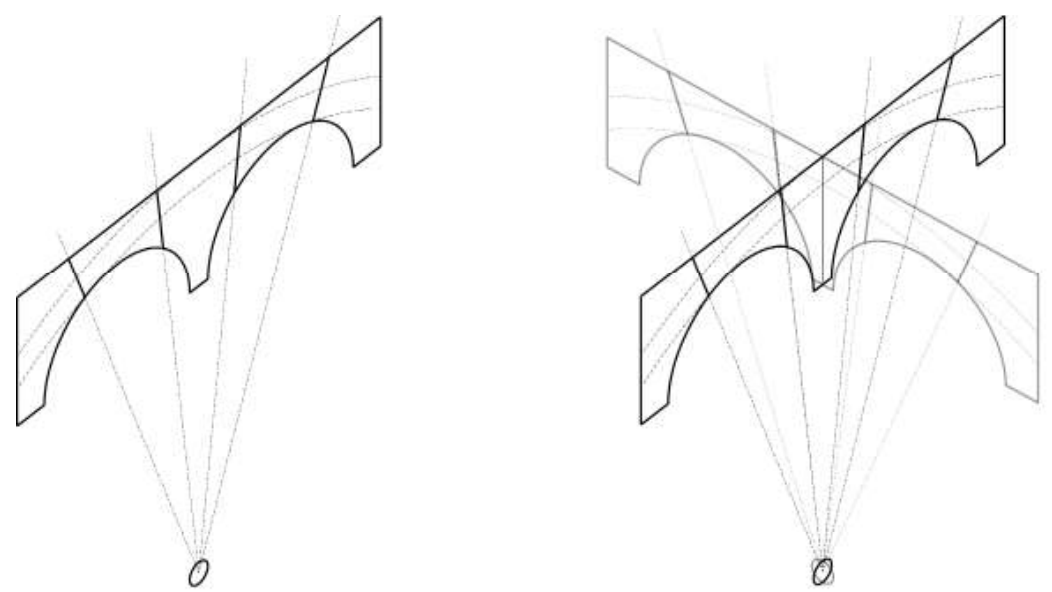

Fig. 10.5. A la izquierda el capitel pinjante se encuentra entre dos arcos yacentes en el mismo plano, a la derecha se coloca en la intersección de arcos sobre dos planos perpendiculares. Dibujo del autor.

\subsection{Capitel pinjante entre arcos sucesivos}

Los capiteles pinjantes no fueron introducidos en Cataluña recalcando literalmente la distintiva traza de Villard de Honnecourt, prototipo del portal románico de la iglesia de Sant Joan el Vell de Perpiñán ${ }^{4}$ y de otros ejemplos construidos en España ${ }^{5}$. En los monasterios cistercienses catalanes de Santes Creus y del Poblet se empleó un original aparejo adaptado a la traza de las ventanas geminadas con hueco romboidal en el tímpano, a las cuales fue removido el mainel, dejando así la dovela central colgada (Fig. 10.6). El arco que delimita la bífora en la parte de arriba tiene las dovelas medianas adecuadamente talladas para recibir el elemento suspendido, conformado como pieza en "L" girada 45 grados (Fig. 10.7), y se apoya únicamente en ellas. Las direcciones de las juntas de las dovelas que conforman los huecos concurren en el centro del arco de medio punto que delimita la bífora, asegurando así la firmeza del conjunto. El diferente espesor de las juntas alrededor de la dovela suspendida, más anchas respecto a las otras, podría hacer suponer que la línea de carga, favorablemente, se distribuya principalmente en la parte superior del arco, aliviando así la tensión en la pieza en "L".

\footnotetext{
4 atribuida a Ramon de Bianya (1219)

5 Recordamos: la puerta norte de la Catedral de Lugo; la portada sur de la iglesia de Santiago del Burgo, Zamora; entrada trasera a la Catedral de Santiago de Compostela, ahora tienda de la Catedral
} 

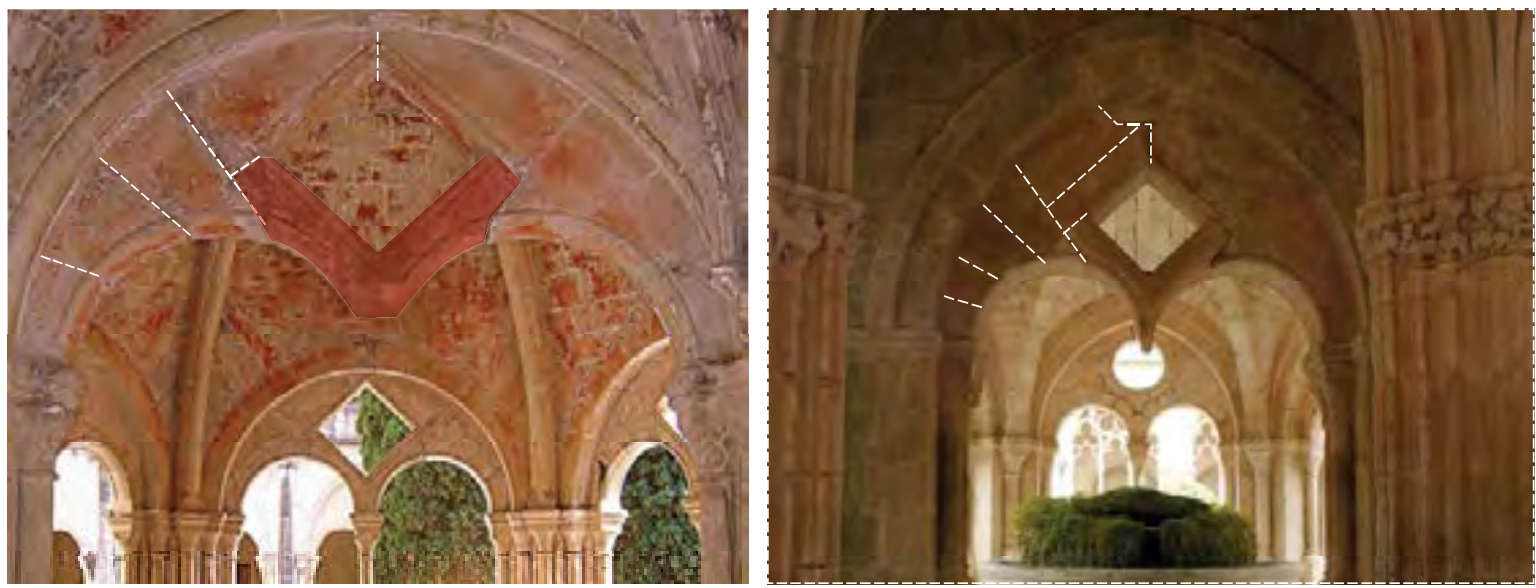

Fig. 10.6. Lavatorio del Monasterio del Poblet. Foto de Jordi de Castelldefelds (http://creativecommons.org/licenses/by/2.0), via Wikimedia Commons; Monasterio de Santes Creus, Tarragona

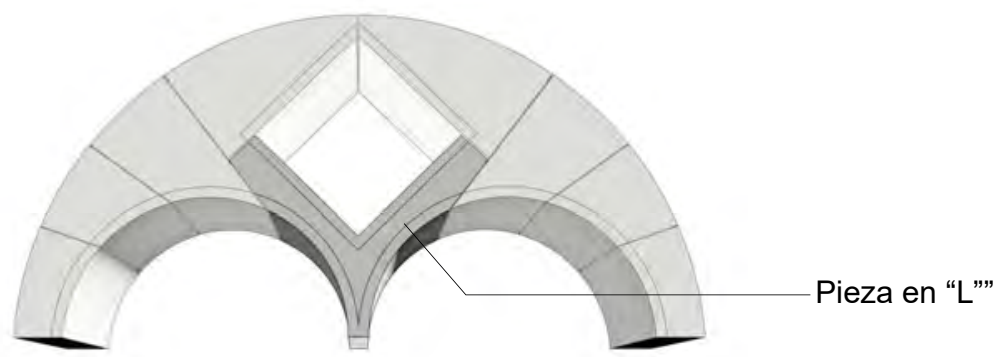

Fig. 10.7. La bífora con clave suspendida del acceso al Lavatorio del Monasterio del Poblet. Dibujo del autor.

El Monasterio de Santes Creus (Tarragona) alberga dos ejemplos de este característico aparejo convertido aquí en toda una seña de identidad, uno en la puerta de acceso a la Sala Capitular y otro en el Lavatorio. El acceso a la Sala capitular se produce a través de una puerta flanqueada por otros dos arcos de igual altura con antepecho bajo, formando una triple arcada de bíforas semejantes, en la cual cada una tiene un parteluz a excepción de la central. El uso de este aparejo viene justificado por una cuestión funcional a la vez que estética, pues permite ampliar el ancho del paso entre dos vanos manteniendo la misma traza y proporción que los otros huecos de la arcada. Igual ocurre en el caso del Lavatorio, cinco de los seis lados del templete se caracterizan por arcos partidos con un mainel en el centro, mientras que el acceso a la fuente se realiza quitando el soporte central a uno de ellos. Este arco, con mismas proporciones y traza, pero diferente despiece de dovelas respecto a los otros cinco, se queda con la dovela central suspendida, manteniendo la unidad formal y la armonía del espacio.

El Monasterio de Poblet (Tarragona) también cuenta con un Lavatorio en la parte central del claustro, construido entre los siglos XII y XIII, y sigue la misma disposición que el Monasterio de Santes Creus: un templete hexagonal en el que se produce el acceso en la cara adyacente al pasillo del claustro mediante un arco con dovela central suspendida. En este monasterio se puede apreciar la microarquitectura del aparato escultórico del Sepulcro de Martí l'Humà, del siglo XVI: de fondo de escena aparece una arcada a la cual se han eliminado las columnas de soporte de los arcos y se han dejado los capiteles suspendidos. 
Aparte los ejemplos cistercienses, en Cataluña se pueden enumerar otras muestras de capiteles pinjantes con un despiece de dovelas formalmente más similar al ejemplo clásico de dos arcos consecutivos, como es representado por Villard de Honnecourt y recogido en la tratadística española por Padre Tosca ${ }^{6}$ (Fig. 10.1F). En este aparejo, las dovelas están unidas entre sí conformando un arco en su extradós, con las juntas convergentes hacia un centro para garantizar el enlace, mientras que la forma del intradós se traza con perfil de dos arcos de circunferencia, determinando el característico hueco bipartido, con las dovelas que se prolongan hasta rellenar el vacío entre que queda extradós e intradós. Gracias a la disposición de las juntas y la longitud de las dovelas, partes de estas pueden quedar sin aparente soporte y crear el efecto de suspensión del aparejo, sin embargo, la resistencia estructural del conjunto queda garantizada por la porción superior del arco, sólida y continua, en la cual se distribuye la línea de empuje como en el caso de un arco de medio punto o escarzano. La gran longitud relativa de las dovelas que conforman la clave suspendida permite que éstas no se deslicen y se encajen en el sistema estructural por su parte superior, mientras que su porción inferior sobresalga hacia abajo creando la impresión de suspensión, algunas veces presentando la extremidad entallada como un capitel.

Recordamos aquí dos ejemplos notables, uno de ellos desaparecido, en los cuales se ha conformado un claustro entero con la sucesión de capiteles pinjantes tendidos entre dos columnas.

Uno era el Convento de Santa Madrona (Fig. 10.8), localizado donde actualmente se encuentra la Plaza Real de Barcelona, fue reconstruido varias veces desde 1619 y sufrió su demolición definitiva en 1835. En las acuarelas de Joaquin Mosteyrin del siglo XIX se aprecia como los arcos de la galería de la primera planta estaban subdivididos por una intercesión de arcos con capitel pinjante.

Otro ejemplo se encuentra en el claustro barroco del Convent dels Dominics de Vic (ca. 1720), obra de Jacint Morató, en el cual destaca la galería porticada de la planta baja, constituida también en este caso por una alternancia de columnas y capiteles pinjantes (Fig. 10.8). No podemos afirmar con seguridad cual es el despiece de las dovelas de este ejemplo porque el muro está revestido por una capa de revoco que deja visible solo la piedra de la moldura de los arcos. Sin embargo, reconociendo en las molduras las juntas reales y mirando su dirección, se podría suponer que la construcción se compone de 7 piezas, con la dovela central de mayor tamaño para conformar el capitel suspendido (Fig. 10.9); esta hipótesis, de toda forma, queda por comprobar.

Hay otros ejemplos catalanes que se pueden recoger en la tipología de arcos con capitel pinjante posicionado entre dos arcos consecutivos ${ }^{7}$, pero de entre todos destacan, por su valor estereotómico, los ejemplares a los cuales se han aplicado deformaciones geométricas y asimetrías, como en el caso de arcos pertenecientes a cuerpos de escaleras.

\footnotetext{
6 Tosca los define así: "arcos pendientes, cuyos pies de una parte se juntan en uno que no llega al suelo, quedando al parecer entrambos arcos pendientes en el ayre"

7 A parte los ejemplos descritos anteriormente y a continuación en el texto de esta tesis se han podido localizar en Cataluña: el arranque de la escalera con dos columnas truncadas de Ca'n Ramona i Maynés en Vilanova i la Geltrú, un ejemplo incluido en el pórtico de la Plaza Mayor de Solsona, otros en arranques de escaleras en Sant Ramón (Segarra) y Santa Maria Magdalena de Vergós Guerrejat
} 

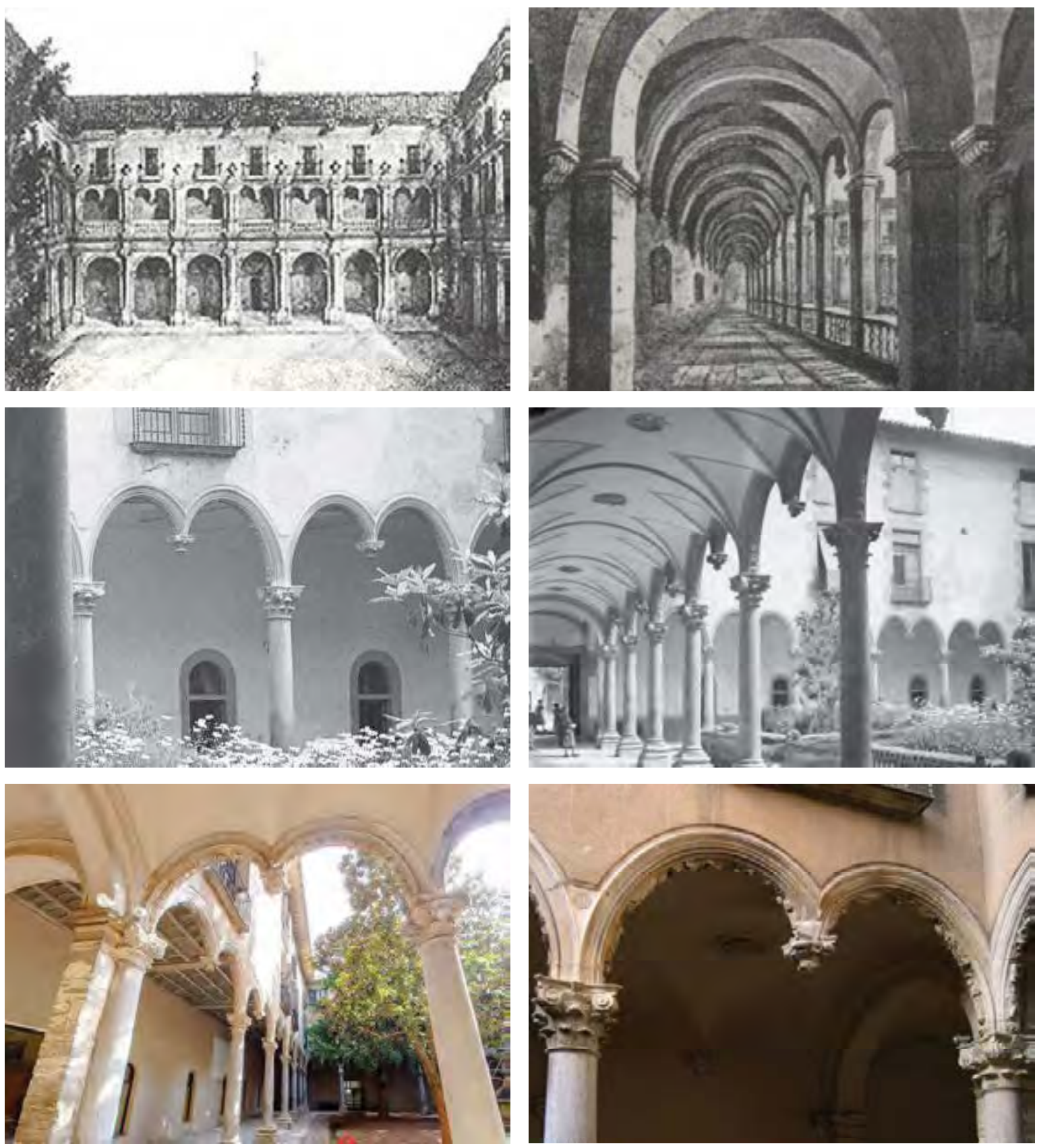

Fig. 10.8. Claustro del Convento de Santa Madrona, Barcelona (demolido en 1835); claustro del Convent de Sant Domènec de Vic. Fotos de www.monestirs.cat.

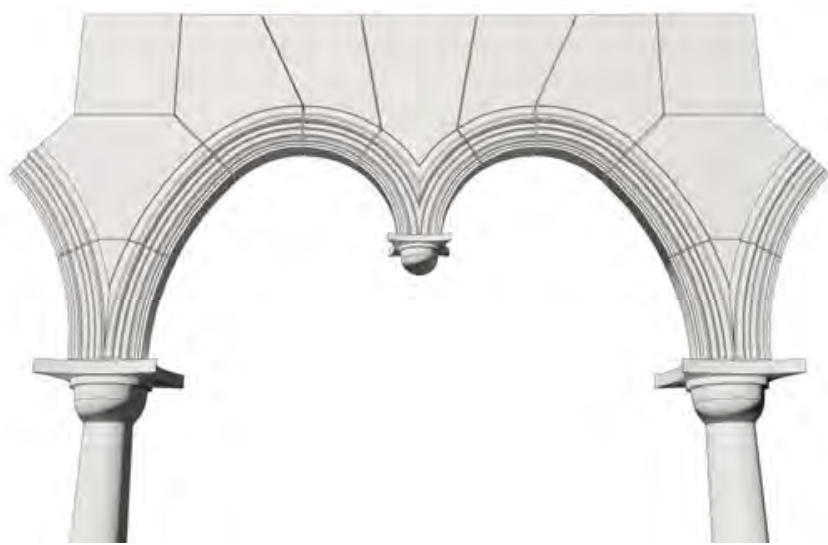

Fig. 10.9. Despiece del arco con capitel pinjante del Convent dels Dominics de Vic. Dibujo del autor. 

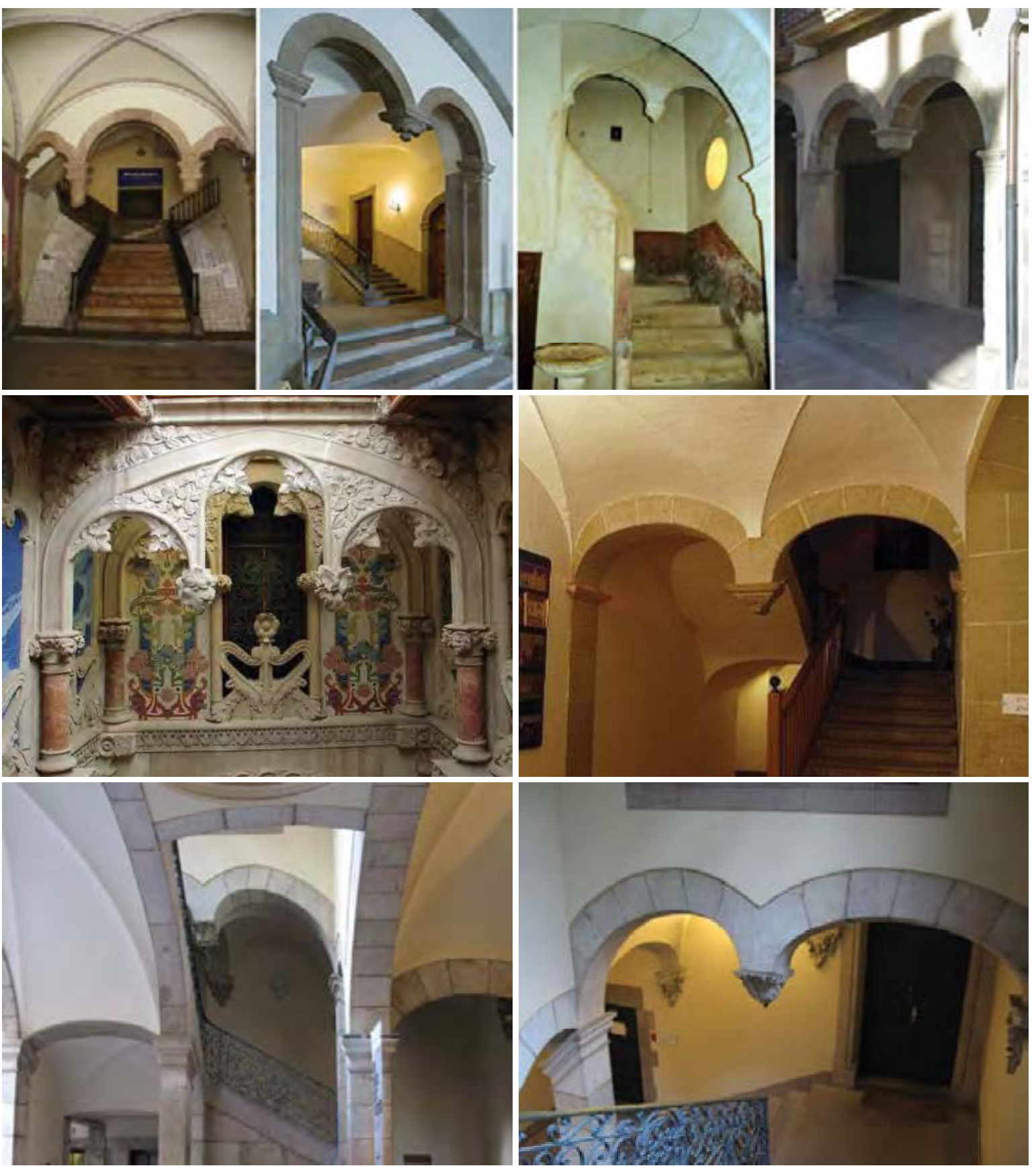

Fig. 10.10. Casa Ramona y Maynes, Vilanova i la Geltru; Palacio Episcopal, Solsona (Siglo XVIII); Iglesia parroquial de Santa Maria Magdalena de Vergos Guerrejat; Plaza Mayor, Solsona; Casa Navas, Reus; Sant Ramon, Palau de la Virreina, Barcelona. Fotos del autor. 
En el Palacio Episcopal de Solsona, por ejemplo, los dos arcos que encabezan el arranque de la escalera tienen un peralte: el perfil de una testa está a una cota diferente de la otra, proponiendo, en su forma «suspendida», una traza de arco muy común en Barcelona.

Las variaciones geométricas más notables de esta tipología se encuentran asociadas a los arcos que cubren las bóvedas de las escaleras claustrales de las casas nobles catalanas. De hecho, para acompañar la pendiente de la escalera, se utilizan arcos rampantes, a veces deformados con peraltes o en decenda de cava $^{8}$, que vienen normalmente suportados por columnas esbeltas. Los motivos decorativos y las molduras se adaptaban a la pendiente de la rampa, aplicándose también a los capiteles y las bases de columnas que resultarán deformadas en directriz oblicua, haciendo propias, o quizás desarrollando de manera independiente, las teorías arquitectónicas teorizadas por Juan Caramuel y Lobkowitz (Arquitectura civil recta y oblicua, Vigevano 1678).

En algunas de estas escaleras se ha removido el soporte central de los arcos de la galería, dejando un capitel pinjante suspendido entre dos arcos rampantes, a los cuales están frecuentemente asociados arcos con juntas discontinuas de despieces muy curiosos para mejorar el anclaje de las dovelas. En Barcelona hay varios ejemplos conocidos: El Palau Mercader, descrito a continuación por su mayor complicación; la Casa Josep Martí i Fàbregas, situada en la calle Portaferrissa 17, del siglo XVIII y reformada en 1864; la fábrica de Portaferrissa 7, parecido al ejemplo recién descrito; y por último el Palau de la Virreina en las Ramblas (Fig. 10.10, 11), construido entre 1772-1778, que se distingue por su escalera principal de doble rampas simétricas que se conjuntan en su parte superior con un pequeño puente, y por el capitel colgante con adorno, suspendido entre dos arcos rampantes y en descenda de cava de luz distinta.

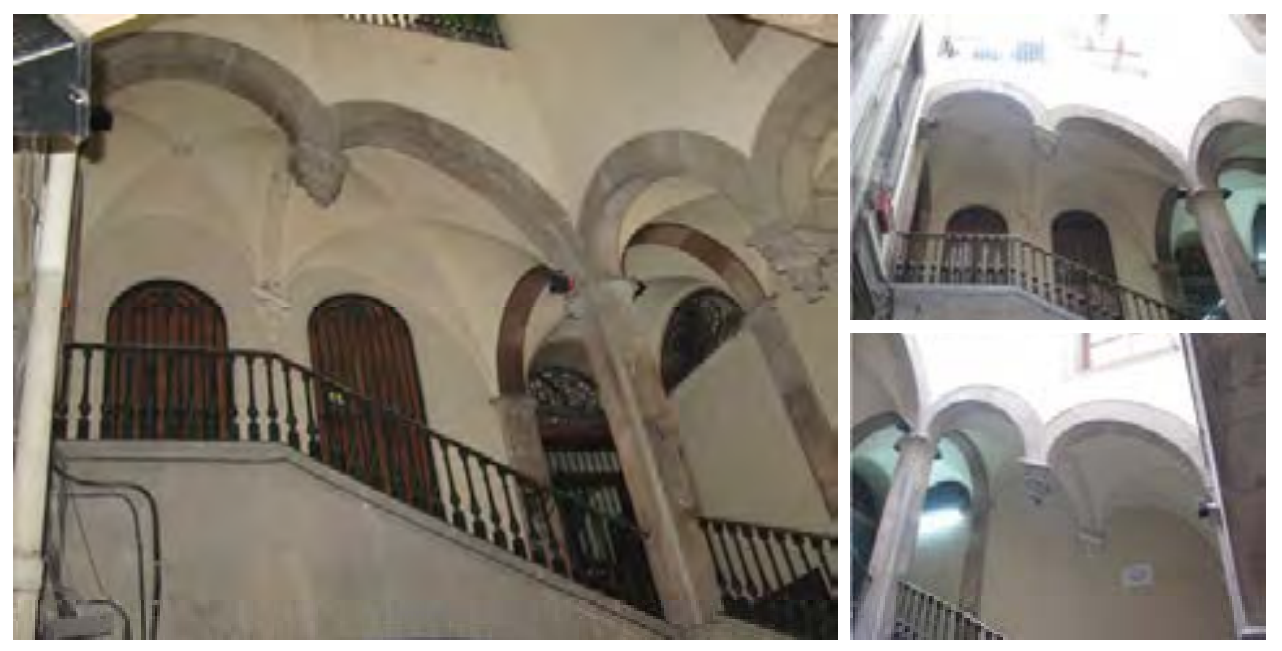

Fig. 10.11. Casa Arti i Fabregues, Portaferrissa 17, Barcelona. Fotos del autor.

\footnotetext{
8 Arcos peraltados o arcos en descenda de cava son trazas muy características en los cuerpos de escaleras en Barcelona, y vienen descritas en los capítulos a seguir de esta tesis
} 


\subsection{Capitel pinjante entre arcos perpendiculares}

Los modelos que se describen a continuación son los capiteles pinjantes que se colocan en la intersección de arcos yacentes sobre dos planos ortogonales. En estos casos el dibujo de las claves se complica, pasando de ser un sistema adovelado bidimensional (un arco con perfil de intradós conformado con arcos consecutivos) a un aparejo tridimensional, en el cual la intersección de dos sucesiones de arcos, es decir el encuentro de cuatro arcos, se resuelve con una clave pinjante. Cuando el sistema es simétrico, como por ejemplo las claves pinjantes de algunas bóvedas de crucería, el dibujo de las piezas no se complica demasiado, ya que la misma traza se puede repetir en las otras direcciones; cuando el sistema es asimétrico, como en las escaleras de los patios de Barcelona, se requiere un atento estudio de la estereotomía de las dovelas.

El manuscrito de cantería del mallorquín Joseph Gelabert contiene la traza de una bóveda de crucería con capitel pinjante ${ }^{9}$. La clave está colgada desde los arcos diagonales de la bóveda de crucería que se bifurcan en dos tramos: el superior sujeta la clave y el inferior se apoya en la parte más baja de la clave. Esta viene conformada adecuadamente con apoyos para recibir los nervios. Es una traza relativamente sencilla y por su dibujo regular y simétrico requiere determinar los ángulos y planos de corte de uno solo de los nervios. Hay una bóveda semejante en el convento de Santo Domingo en Valencia, construida por Francesc Baldomar (1425-1463), y se caracteriza por tener los nervios que se apoyan en la clave pinjante aislados en el aire, sin contacto con la cáscara de la bóveda, dejando vista la longitud de la clave.

Un ejemplo catalán que se puede relacionar a la traza de Gelabert, caso único en el territorio, se encuentra en la Capilla del Roser (Fig. 10.12), construida en el siglo XV en la Catedral de Tortosa. Se trata de una bóveda de crucería con planta rectangular de proporción dupla (2:1), compuesta por la yuxtaposición de dos bóvedas estrelladas de planta cuadrada. En el punto medio, los espinazos (o rampantes) forman una cúspide ligeramente apuntada hacia abajo, conformando una cáscara discontinua y convexa. El encuentro de los rampantes viene rematado con una clave pinjante acampanada.
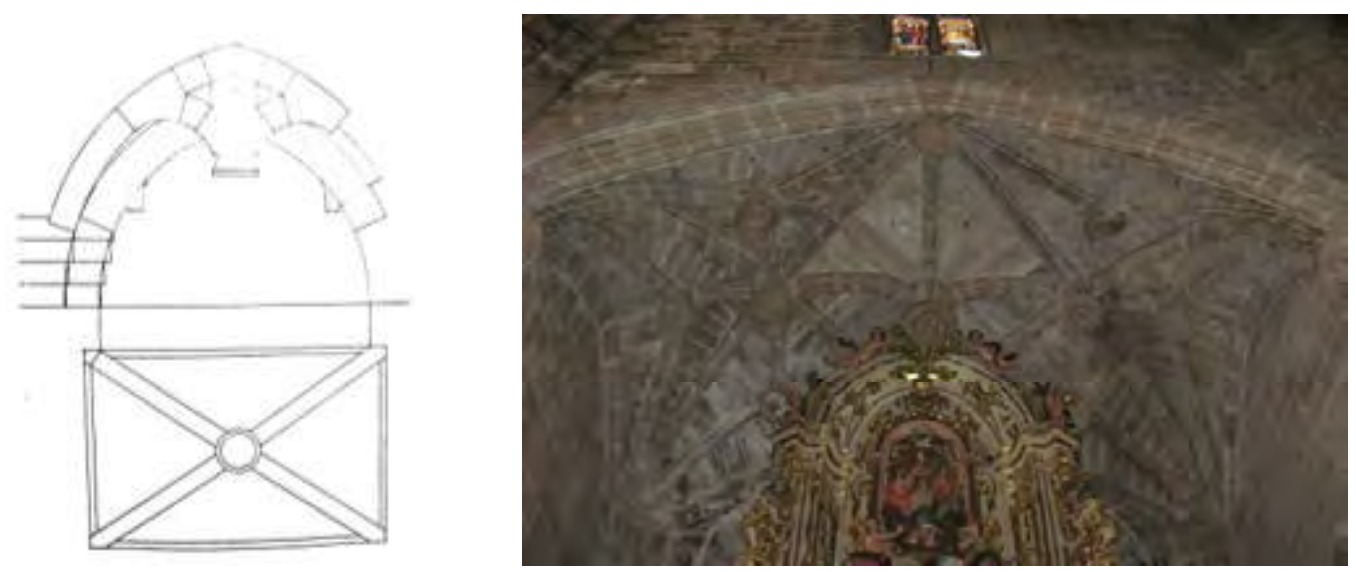

Fig. 10.12. Clave suspendida en Gelabert; Capilla del Roser (siglo XV) en la Catedral de Tortosa . Foto del autor.

\footnotetext{
9 la Capella perllongade ab una clau penjant o Capilla rectangular con clave pinjante, (Rabasa, 2012: 392)
} 


\subsubsection{Palau de la Generalitat}

En Cataluña, los sistemas asimétricos de capiteles pinjantes suspendidos entre arcos perpendiculares son formalmente muy distintos de los ejemplos de bóvedas de crucería que se acaban de describir. Caracterizándose por una estereotomía muy compleja, se materializan al remover los soportes de las esquinas de los patios ${ }^{10}$ y sin duda alguna constituyen los ejemplos catalanes más emblemáticos. Entre ellos, el más antiguo y conocido de todos se encuentra en el patio gótico del Palau de la Generalitat de Barcelona, que fue realizado durante una reforma del siglo XVI eliminando una columna de esquina de la existente galería gótica, correspondiente al desembarque de la escalera (Fig. 10.13). Como resultado de esta intervención el paso se hizo más cómodo, ganando en solemnidad, pero también haciendo más visible la portada de la capilla de Sant Jordi, situada en este mismo lado en la primera planta. Al remover la columna de esquina se ha cambió completamente el sistema estructural de esta parte de la galería (Fig. 10.15). Anteriores a la intervención, los dos arcos carpaneles de perfil muy rebajado, perpendiculares entre sí, eran necesarios para contrarrestar los empujes de la fachada y arrancaban de la esquina correspondiente a la llegada de la escalera, extendiéndose hasta el muro interior de la galería. Ahora, al quitar la columna de esquina han sido construidos con diferente despiece de dovelas preservando aproximadamente la forma del intradós y las formas originales de la arcada, y se extienden desde las dos columnas próximas a la esquina hasta el muro interior de la galería.

Los dos arcos se encuentran entre ellos a la altura de la esquina que ahora está privada de soporte, materializando en el cruce el capitel pinjante.
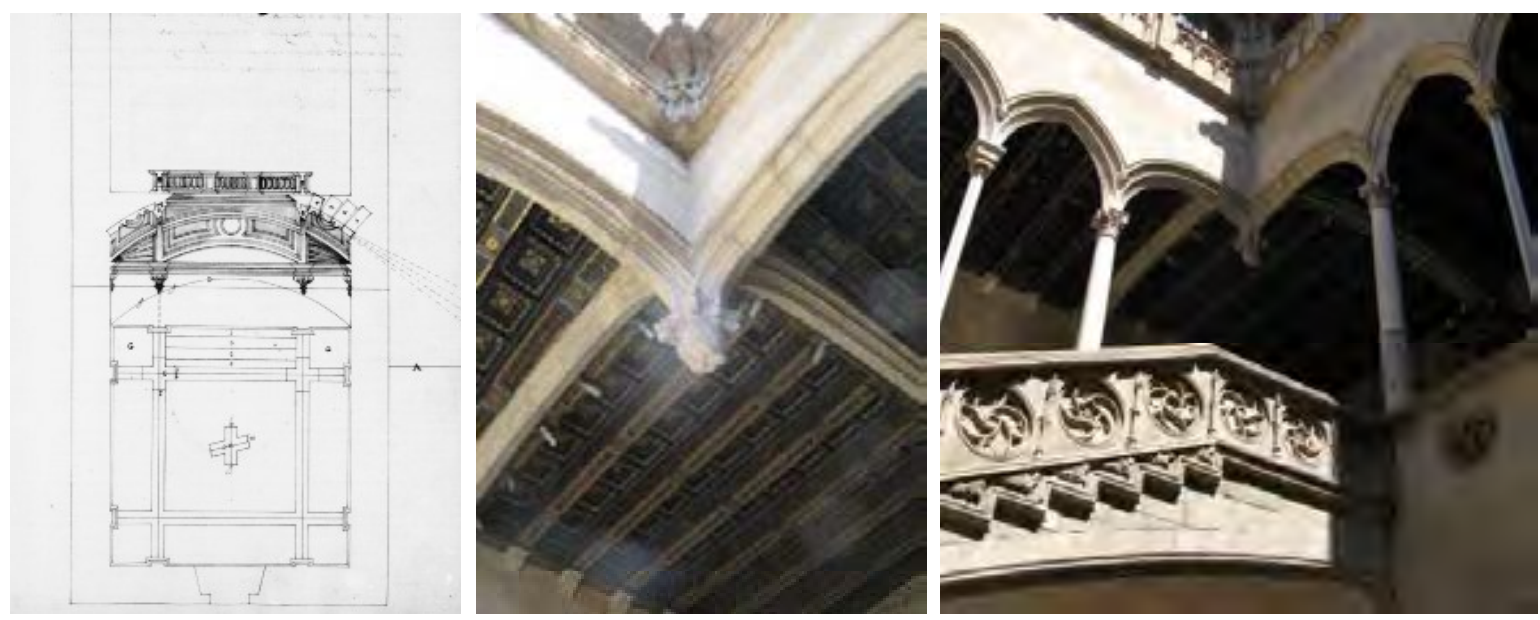

Fig. 10.13. Vandelvira, patio sin columnas; detalle del patio gótico del Palau de la Generalitat de Barcelona. Fotos del autor.

10 Se podría recordar la analogía con el Patio sin columnas cuadrado del tratado de Vandelvira, el cual justifica la remoción de los pies derechos para que no dificulten el paso (Palacios, 2003). 
Numerosas dovelas de los paramentos sustentados por los arcos de la galería han sido sustituidas por otras dovelas con juntas discontinua para asegurar el trabado y la estabilidad de conjunto y a su vez, debido a la necesidad de soportar el incremento de las cargas, las dos columnas desde las cuales salen los arcos han sido sustituidas por otras de mayor diámetro. El sistema estructural se caracteriza entonces por dos arcos rebajados con intradós poligonal que se apoyan en las columnas que encuadran el paso en esquina de la escalera y se extienden hasta las paredes interiores de la galería, produciendo en el cruce el capitel pinjante. El despiece de las dovelas y las juntas de estos dos arcos (estructuralmente se pueden considerar dos, pero por su extradós son conformados como cuatro) tiene en cuenta de la mayor longitud y de la necesidad de encontrarse en una única pieza, el capitel pinjante, que se convierte en la dovela que conecta las dos hiladas de arcos.

Es curioso observar como en correspondencia con las dovelas de junta discontinua haya una cierta libertad en el dibujo y orientación de las juntas, las cuales no convergen exactamente hacia un único centro como habría que esperar al observar los dibujos de los tratados y los aparejos de capiteles pinjantes más sencillos. El cambio de dirección de las juntas se nota en la proximidad de la clave pinjante, se puede entonces constatar que para los maestros de obra de la época las dovelas de junta discontinua eran un componente muy importante para la estabilidad del arco que, conjuntamente a la considerable altura de la clave, no requerían orientar las líneas de junta del arco a un único centro. Se puede apreciar el intento de su constructor de ocultar el sistema estructural entallando en la piedra vista del muro la continuación de las juntas y el despiece tradicional de los arcos adyacentes.

Además de este magnífico ejemplo, el Palau de la Generalitat contiene otras instancias de capiteles pinjantes. En la ampliación de la capilla de Sant Jordi de 1738 se realizó una cubierta compuesta por una bóveda de media naranja sustentada por arcos que continúan dos capiteles suspendidos. Otra serie de capiteles suspendidos, de fecha mucho más reciente, se encuentra en la actual sala de conferencias, situada bajo el patio de los Naranjos: durante la rehabilitación de Carles Solsona i Piña en 1993 fueron truncadas las columnas y sustentadas a través de un sistema estructural metálico oculto encima de las bóvedas, dando como resultado otros seis capiteles pinjantes (Fig. 10.14).
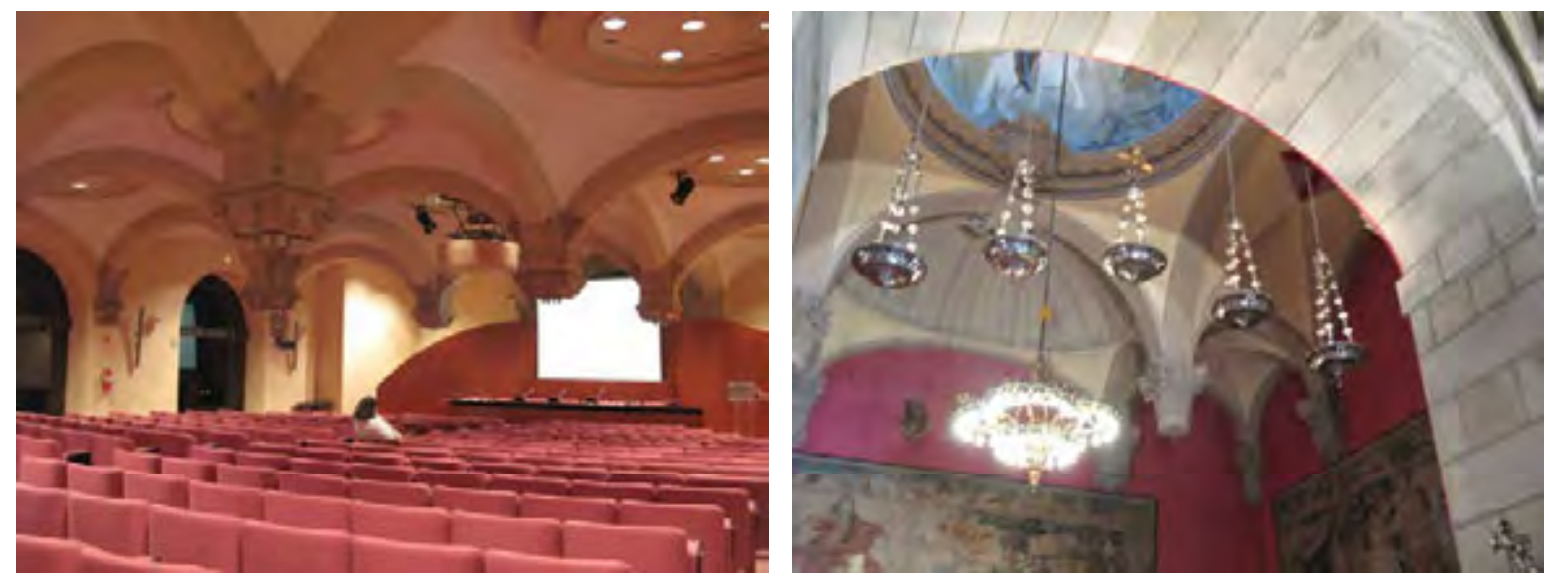

Fig 10.14. Palau de la Generalitat de Barcelona, rehabilitación de Carles Solsona i Piña (1993); ampliación de la Capilla de Sant Jordi (1738) 

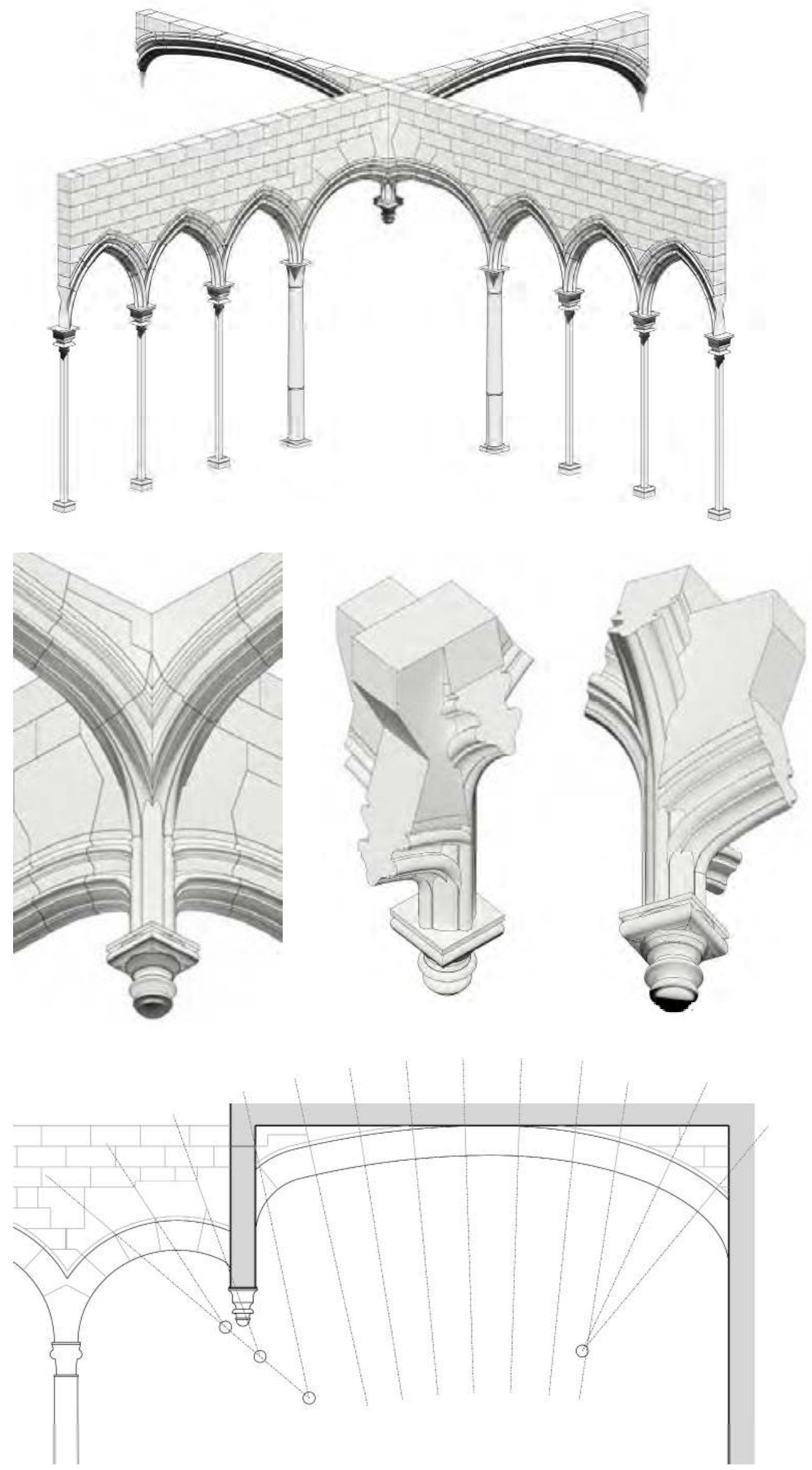

Fig 10.15. Axonometría del sistema estructural del patio gótico del Palau de la Generalitat de Barcelona. Dibujo del autor. 


\subsubsection{Palau Mercader}

En el patio de acceso del Palau Mercader, un edificio barroco localizado en la Calle de Lledó 11 de Barcelona, se encuentra un impresionante ejemplo de escalera de dos tramos cubierta por una galería abovedada con dos capiteles pinjantes, uno de ellos colocado en la esquina y otro en el segundo tramo de la rampa (Fig. 10.16).

Al remover el soporte de la esquina se crea un sistema estructural de arcos cruzados, escondidos en el paramento vertical del patio, que se tienden entre el muro que delimita la escalera y el muro del lado opuesto del patio y suben con la pendiente de la rampa. El perfil de intradós de dichos arcos está conformado por una sucesión de arcos rampantes en correspondencia de las rampas y arcos rebajados en decenda de cava en correspondencia del descansillo a los cuales se han quitado los soportes verticales, dando así la impresión de que estas sucesiones de arcos estén suspendidas en el aire (Fig. 10.17, 18).

Por encima del tramo más largo de la escalera se encuentra otro capitel pinjante, colocado en el punto de encuentro de las impostas de los dos arcos rampantes. Afortunadamente este muro no tiene revoco y es posible observar con exactitud el despiece de las dovelas, ocultas entre las falsas juntas del muro para simular los sillares paralelos de un muro de piedra tradicional. Las dovelas están cortadas y ajustadas de manera que una vez colocadas en su sitio, la misma gravedad del conjunto pueda asegurar el trabado y enlace suficiente para garantizar la estabilidad: las juntas concurren en un único centro, pero, como se ha notado el Palau de la Generalitat, hay un cambio en el punto de convergencia para los tramos de arcos sucesivos cuando vienen separados por el capitel pinjante. Aunque los centros estén muy próximos, los resaltes o dinteles en los bloques de piedra impiden su deslizamiento hacia abajo. En el conjunto se aprecia en particular el tamaño y la longitud de la clave central, aquella que por debajo tiene un adorno en forma de capitel y columna truncada de directriz oblicua. La sensación de pesadez de los grandes elementos de piedra y la propia estabilidad de la estructura quedan aparentemente en entredicho debido a la tensión visual producida por la ausencia de soportes.
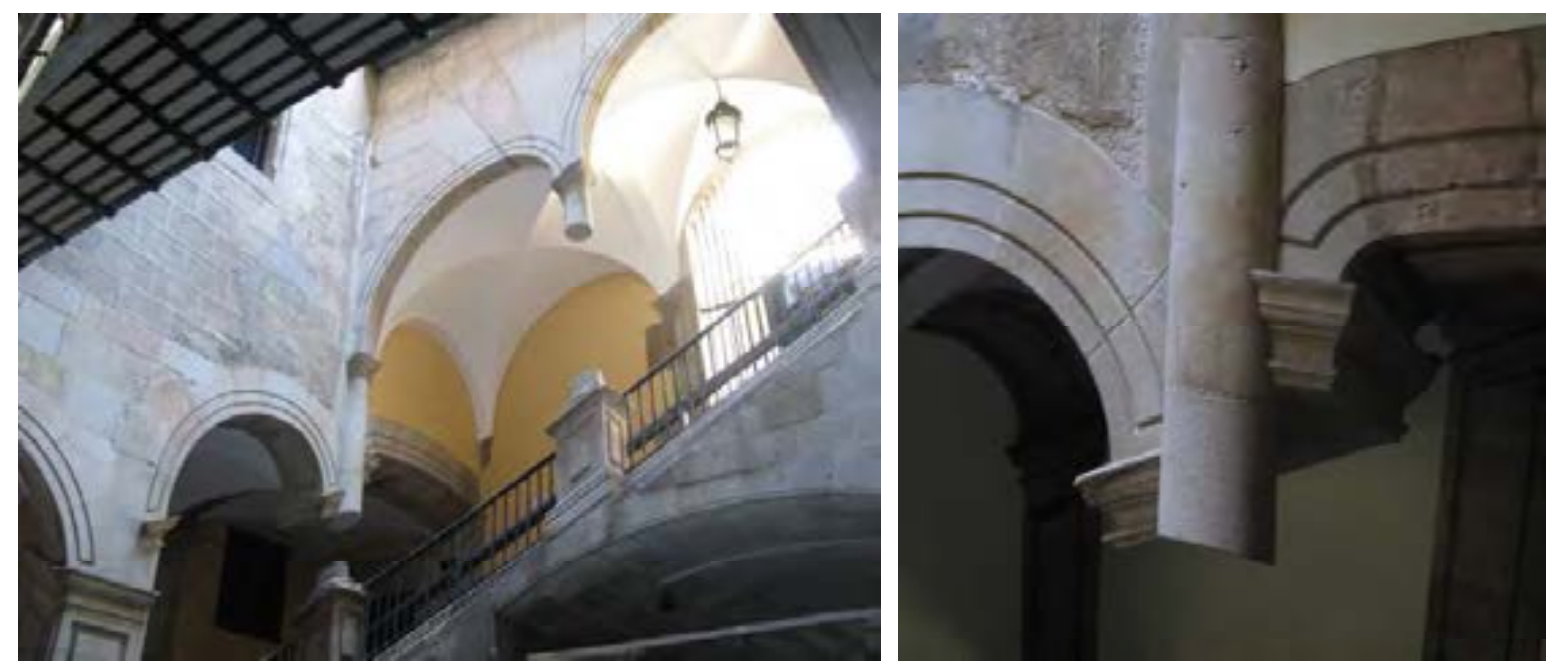

Fig. 10.16. La escalera de Palau Mercader. Fotos del autor. 

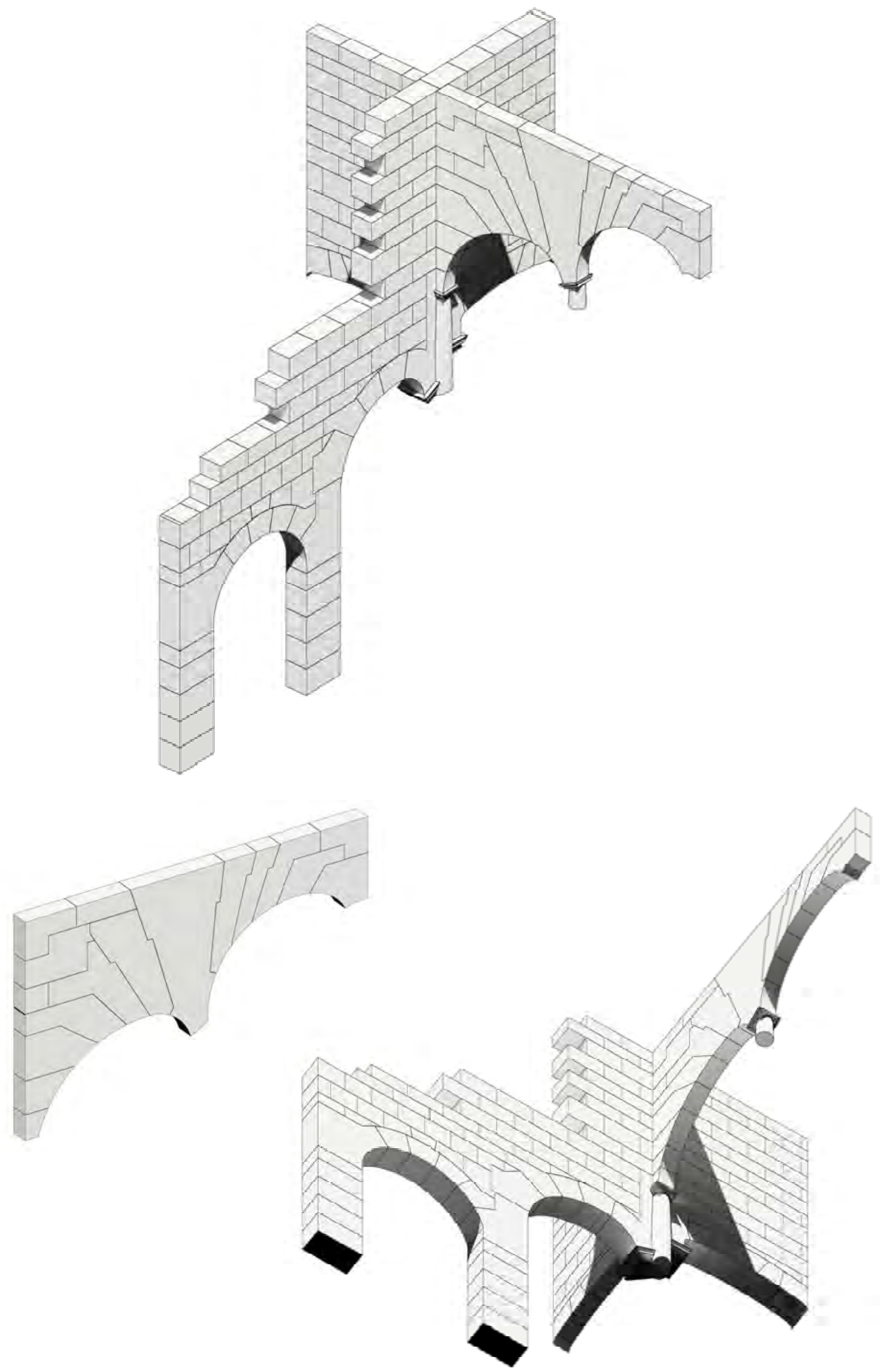

Fig. 10.17. Axonometría del sistema de arcos cruzados y capiteles pinjantes del Palau Mercader. Dibujo del autor. 

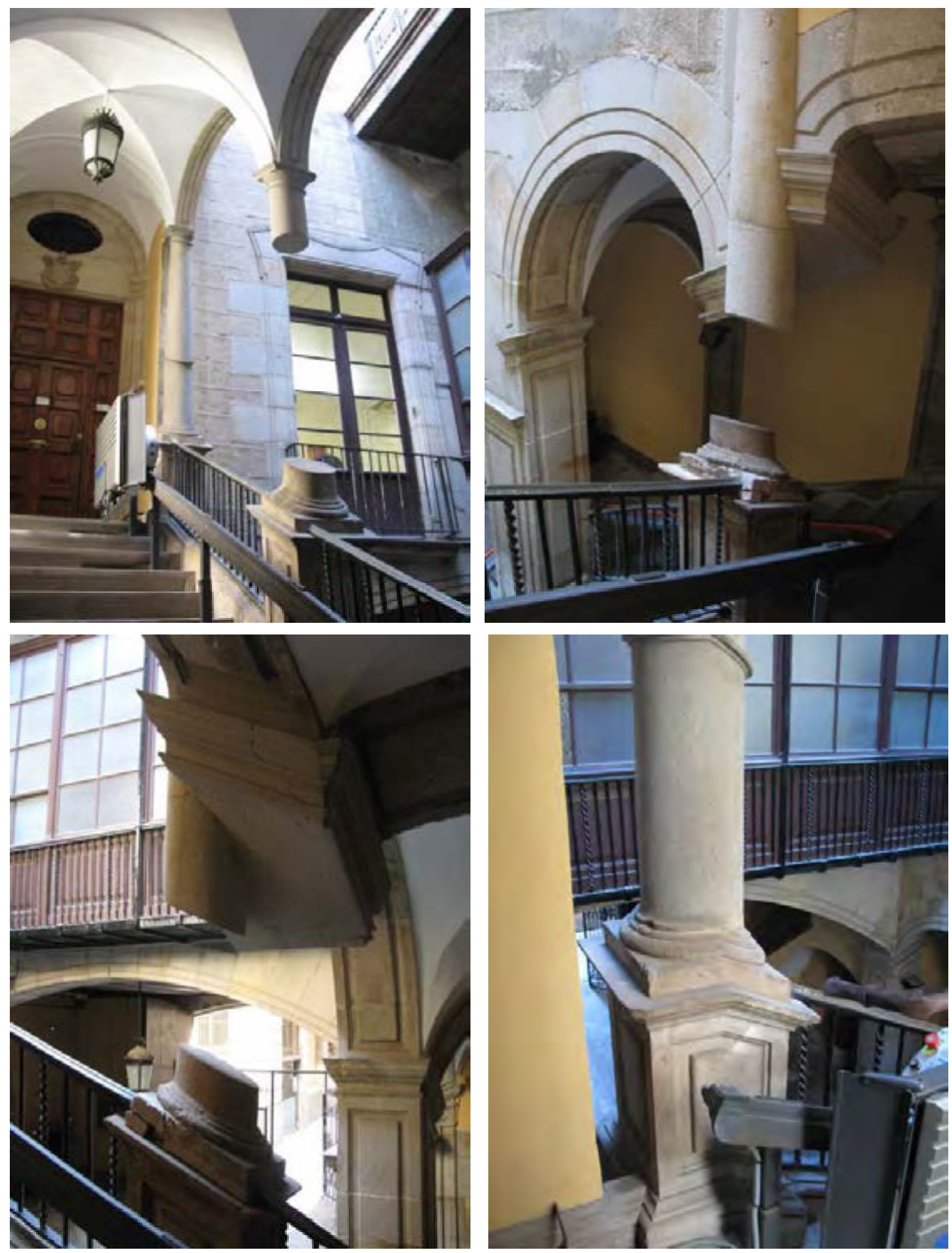

Fig. 10.18. capiteles pinjantes y molduras oblicuas en el Palau Mercader, Barcelona. Fotos del autor. 


\subsubsection{Ca la Mercè y Casa Amatller}

Los dos casos a continuación son otra variación sobre el tipo de capitel pinjante colocado en la intersección entre dos planos ortogonales, sin embargo, en esta instancia uno de los arcos solo arranca de la clave pinjante y no continúa cruzando la serie de arcos consecutivos como en los casos anteriores. En la Ca la Mercè, localizada en Calle Avinyó 44 de Barcelona, encontramos este ejemplo al principio de la escalera cubierta por bóvedas inclinadas. Su geometría es interesante por la completa asimetría del aparejo: la clave pinjante se interpone a los dos arcos sobrestantes el arranque de la escalera, uno rebajado y otro en descenda de cava, y recibe perpendicularmente otro arco rampante que soporta la bóveda de la rampa (Fig 10.19). No sabemos si es una intervención original del siglo XVII como el edificio o de reformas posteriores.

Otro ejemplo se puede encontrar en la Casa Amatller (1898-1900) en la cual Puig i Cadafalch reinterpreta arquetipos propios de la arquitectura gótica catalana. En este caso el capitel pinjante se coloca en uno de los arcos transversales de las caballerizas, justo en correspondencia del punto de terminación de una hilada de arcos perpendiculares al primero.

\subsection{Un episodio catalán}

En Cataluña, encontramos principalmente el capitel pinjante integrado en el conjunto arquitectónico del edificio, creando un sistema cohesivo con los otros elementos estructurales que requieren una cuidada estereotomía de las piezas. Son limitados los casos donde el capitel pinjante sobrevive como motivo ornamental, como por ejemplo en el Palau del Parlament de Catalunya (de estilo clasicista y reformado en 1889) y en el modernista Palau del Baró de Quadras (1904-1906) colgado por debajo de las escaleras. El interés por los capiteles pinjantes no desaparece a lo largo de los siglos y el legado arquitectónico del capitel del Palau de la Generalitat ha llegado hasta nuestros días ${ }^{11}$. Aunque sea difícil estimar la datación y autenticidad de numerosos edificios del Barri Gótic de Barcelona (ya que muchas obras de estilo gótico son en realidad restauraciones, reformas o nuevos proyectos realizados durante el siglo XX y finales del XIX) debido a la transformación del centro histórico mediante la reconstrucción de las formas medievales ${ }^{12}$, el número de capiteles pinjantes y su difusión geográfica confirman la fascinación por este elemento arquitectónico en el territorio catalán.

\footnotetext{
11 Su construcción ha persistido hasta el siglo XX: por ejemplo, en la intervención en la sala de conferencias del Palau de la Generalitat, mencionada anteriormente, o en su reinterpretación en clave contemporánea en la casa del escultor catalán Xavier Corberó.

12 Agustín Cócola estudia la transformación del Barrio Gótico de Barcelona y su reconstrucción con formas medievales. Agustín Cócola Gant, "El Barrio Gótico de Barcelona: Planificación Del Pasado e Imagen de Marca" (Tesis Doctoral, 2010).
} 

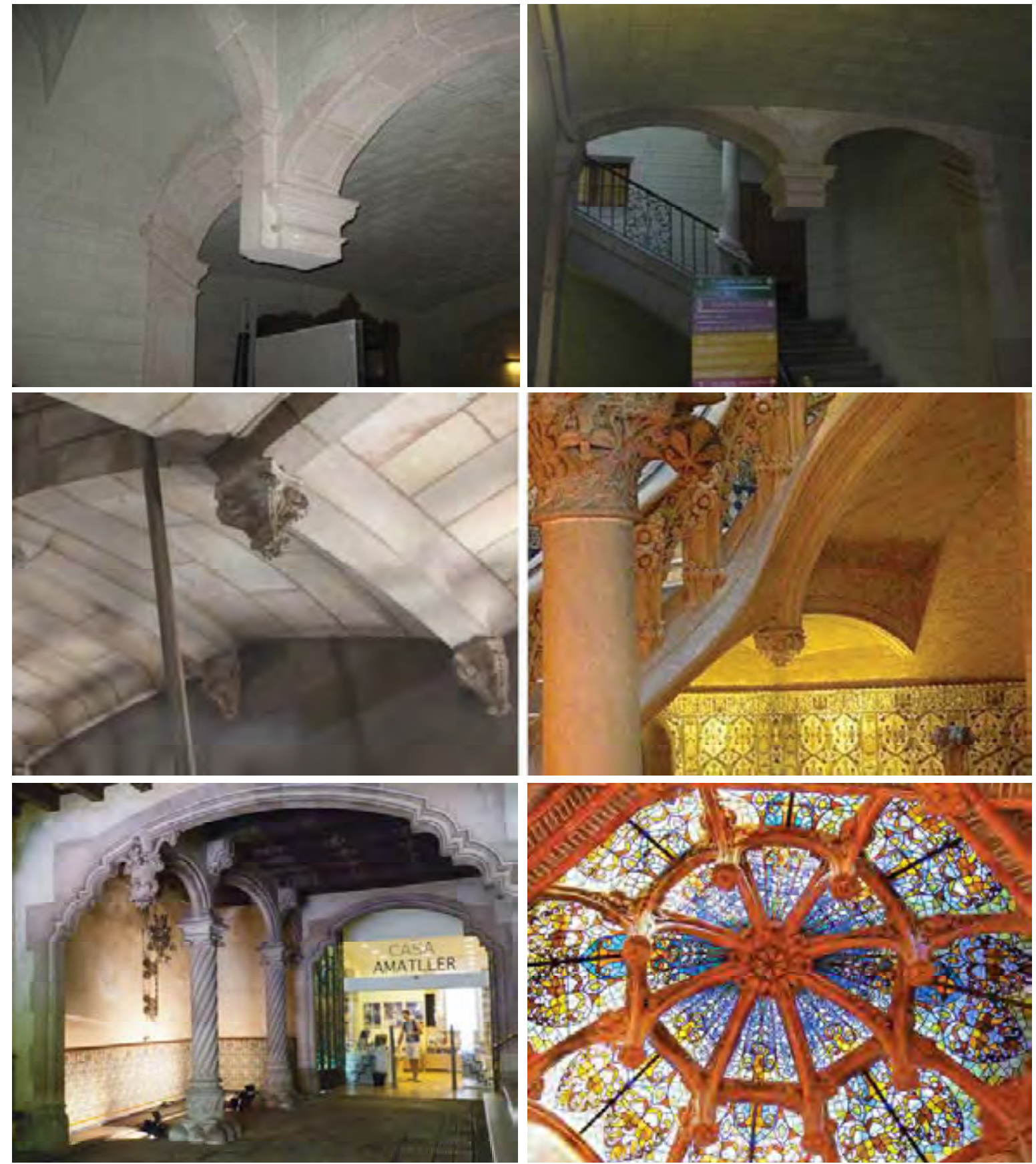

Fig. 10.19. Capiteles pinjantes en Barcelona: Ca la Mercè (A y B); Palau del Parlament de Catalunya; Palau del Baró de Quadras; Casa Amatller (Puig i Cadafalch, 1898-1900); Hospital de la Santa Creu i Sant Pau (Domènech i Montaner, 19011930). Fotos del autor. 


\section{Construcción de una bóveda de crucería del Llibre de trasas}

La singularidad y casi la extravagancia del dibujo en red de la volta ab dotsa claus (Figura 14) que hemos mencionado anteriormente es la razón que justifica el exhaustivo estudio realizado sobre esta bóveda, el cual ha incluido la construcción de un modelo real de 3 metros de lado en el marco de la asignatura del Taller de Construcción Gótica de la Escuela Superior de Arquitectura de Madrid durante el Año Académico 2013-14, que se ha también repetido con la construcción de otra bóveda igual durante el Summer School del mismo año. Esta experiencia de extraordinario interés ha podido estudiar y testar los métodos de dibujo y construcción góticos.

\subsection{Influencias del gótico alemán}

El gótico alemán fue crucial en la renovación del gótico español en la segunda mitad del siglo XV. Tres siglos más tarde, la pequeña bóveda de Ribes nos conecta nuevamente con el gótico centroeuropeo con una bóveda en red. La red, es un diseño de crucerías poco usado en la península lbérica, mucho más apegada una contundente división por tramos en los que instalar una bóveda estrellada aislada. No obstante, hubo dos excepciones a la norma verdaderamente colosales: Juan de Álava en el reino de Castilla y Joao del Castillo en Portugal. La obra de estos dos gigantes está llena de formidables ejemplos de sofisticadas y complejas bóvedas en red. Joseph Ribes en la Barcelona de comienzos del XVIII vuelve a manifestar interés por este tipo de bóvedas e incluye en su tratado un interesante ejemplo que ha dado pie para llevar a cabo un interesante ejercicio académico del que se desprenden las reflexiones de esta investigación.

\subsection{Hipótesis de trazado}

La volta ab dotsa claus (Traza 70 del Llibre de trasas) se caracteriza por su simetría axial, carece de nervios diagonales y tampoco clave central, la cúspide de la bóveda se cierra con cuatro claves, a partir de la cual, se originan la retícula de los nervios. La traza en planta de la bóveda se inicia con el cuadrado que forman las cuatro claves centrales, equidistantes del centro (Fig. 11.1), y de las diagonales y las ligaduras que las conectan las claves entre sí. Para determinar la geometría que define la posición de las otras claves, se procede trazando una línea que, pasando por dos claves contiguas, (clave 3 y W), se prolongue hasta cortar el borde del cuadrado $(\mathrm{T}) \mathrm{y}$, desde este punto, se traza otra línea perpendicular al mismo borde. La intersección de esta línea con la diagonal del cuadrado determina la posición de la clave de la diagonal (clave 1). Trazando desde esta clave una línea paralela al borde del cuadrado hasta encontrar la línea de prolongación de las claves centrales previamente trazada, se obtiene la posición de la clave próxima a la ligadura (clave 2). 
Para completar el dibujo de la retícula basta con conectar las dos claves que se acaban de definir (claves 1 y 2) con los puntos medios de los dos lados del cuadrado (claves 5 y 6 ), que serian la cúspide de los arcos formeros. Se obtiene entonces el dibujo de un cuarto de la bóveda que, por simetría, es suficiente para determinar el dibujo completo de la planta. Como acabamos de ver, la distancia de las cuatro claves centrales con el centro de la bóveda determina de manera univoca la posición de las otras claves; por tanto, al variar este parámetro, las demás claves adoptan otra posición definida geométricamente por el método de traza, El diseño en planta de la bóveda está sujeto a una ley geométrica que define paramétricamente la posición de cada clave, de tal modo que, cualquier variación de una de ellas, conlleva el cambio de posición del resto. Como acabamos de exponer, las bóvedas en red, al contrario que las bóvedas estrelladas, carecen de clave central. Se construyen con una red de nervios que forman una retícula de geometría más o menos compleja. Este tipo de bóvedas alcanzan el máximo de su expresividad en las iglesias en planta de salón, es decir, con las naves a la misma altura. En este tipo de iglesias, el diseño de la red va conectando todos los tramos entre sí hasta extenderse a la totalidad del templo. En Alemania, este tipo de bóvedas se construían con un solo arco. Por compleja que fuera la red, un sólo arco y por tanto una única dovela, permitía construir toda la bóveda. Conseguir construir toda la red con un solo arco, el arco principal, requería estar en posesión de ciertas habilidades geométricas; requería conocer un método típicamente germánico para el trazado de bóvedas, que permitía determinar las alturas de las claves de forma que toda la bóveda pudiera construirse con un solo arco. Este método se conoce por el nombre: Prinzipalbogen ${ }^{1}$. Aunque parece muy improbable que Joseph Ribes conociera este método, la construcción de esta bóveda ha sido llevada a cabo usando esta herramienta geométrica, con objeto de conocer de forma más profunda las consecuencias que plantea el singular diseño de esta traza. Por tanto, en nuestro estudio, nos hemos distanciados de la reconstrucción literal de la bóveda tal y como aparece descrita en el tratado, es decir, con su con intradós perfectamente esférico y con los todos los nervios de distinta curvatura.

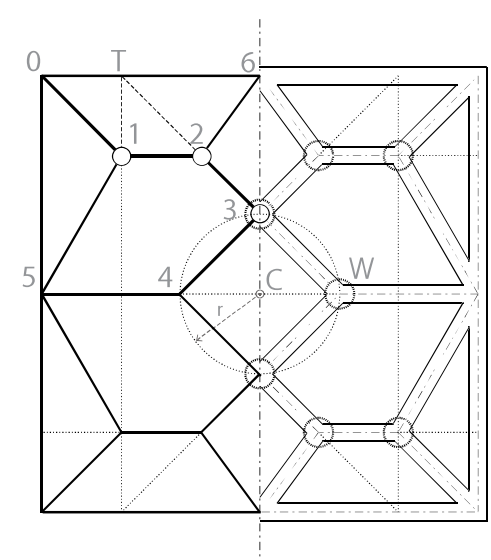

Fig. 11.1. Geometria de la boveda de Ribes. Dlbujo del autor.

\footnotetext{
1 El diseño y trazado de bóvedas en el ámbito germánico ha sido ampliamente estudiado por Werner Müller, Grundlagen Gotischer Bautechnik: Ars Sine Scientia Nihil (München: Deutscher Kunstverlag, 1990). Uno de los métodos enumerado por Müller, y sin duda el más peculiar, se trata del método del arco principal o Prinzipalbogen, en alemán.
} 


\subsection{Método de dibujo alemán: El Prinzipalbogen}

El diseño y trazado de bóvedas en el ámbito germánico ha sido ampliamente estudiado por Werner Müller (1990). A través de fuentes documentales, Müller logró identificar tres procedimientos para determinar las curvaturas de los arcos.

En el primer caso se utiliza una superficie regular - cilindro recto o esfera - sobre la cual proyectar los nervios trazados en la planta, los arcos resultantes tendrían distinta curvatura. En el segundo método (Fig. 11.2A) se parte también de una superficie esférica o cilíndrica sobre la cual proyectar, en este caso, solo los puntos de cruce de los nervios. Una vez obtenidas las cotas de las claves, una simple operación geométrica permite definir la longitud de los arcos en verdadera magnitud, y se trazan todos iguales, con la misma curvatura del arco principal que corresponde a la media diagonal del cuadrado.

El tercer método enumerado por Müller (Fig. 11.2B) es sin duda el más peculiar, se trata del método del arco principal o Prinzipalbogen, en alemán. En este caso, toda la bóveda se traza con el mismo arco y la altura de las claves se determina por un recorrido que el arquitecto elige siguiendo el trazado de los nervios en la proyección horizontal de la bóveda, desde el arranque hasta su punto más alto. Este método tiene la particularidad de que la altura de las claves y por tanto la forma de la bóveda puede variar en función del recorrido. La suma de las longitudes de cada tramo del recorrido en planta, se usa como radio de un gran arco que es precisamente el arco principal. Este gran arco de medio punto determina las alturas de las claves y la forma de los diferentes arcos. Este método se basa en la vinculación directa entre planta y volumetría y permite estandarizar las curvaturas de los arcos definiendo un protocolo de talla y ejecución de piezas claro y sencillo, facilitando enormemente la organización de la ésta.

El Prinzipalbogen es un sistema muy riguroso y a la vez dúctil que permitía al arquitecto medieval adaptar la bóveda a según su gusto estético siempre bajo una rigurosa racionalidad constructiva. Los resultados podían ser entonces bóvedas de crucerías muy diferentes, caracterizadas por enjarjes de nervios que parten a alturas distintas y claves, o más bien, a cruces de arcos que se intersecan a distintas alturas, dando origen a los característicos nervios superpuestos del gótico alemán. En el proceso de replanteo de la bóveda de Ribes, el modelado virtual nos ha permitido apreciar las diferentes configuraciones que habría podido adoptar la bóveda en función del recorrido elegido para determinar el arco principal (Fig. 11.4).
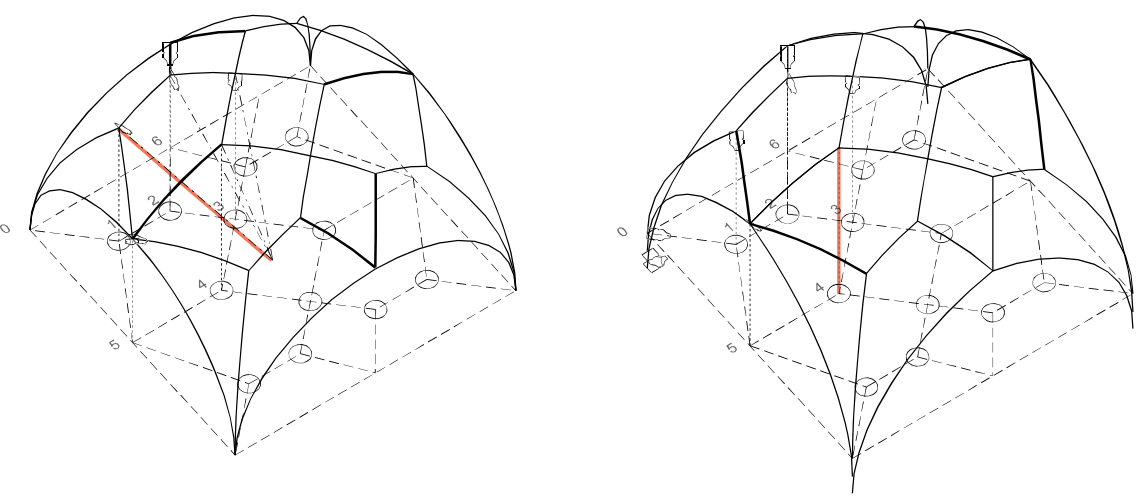

Fig. 11.2. Metodos de medida del Prinzipalbogen. Dlbujo del autor. 

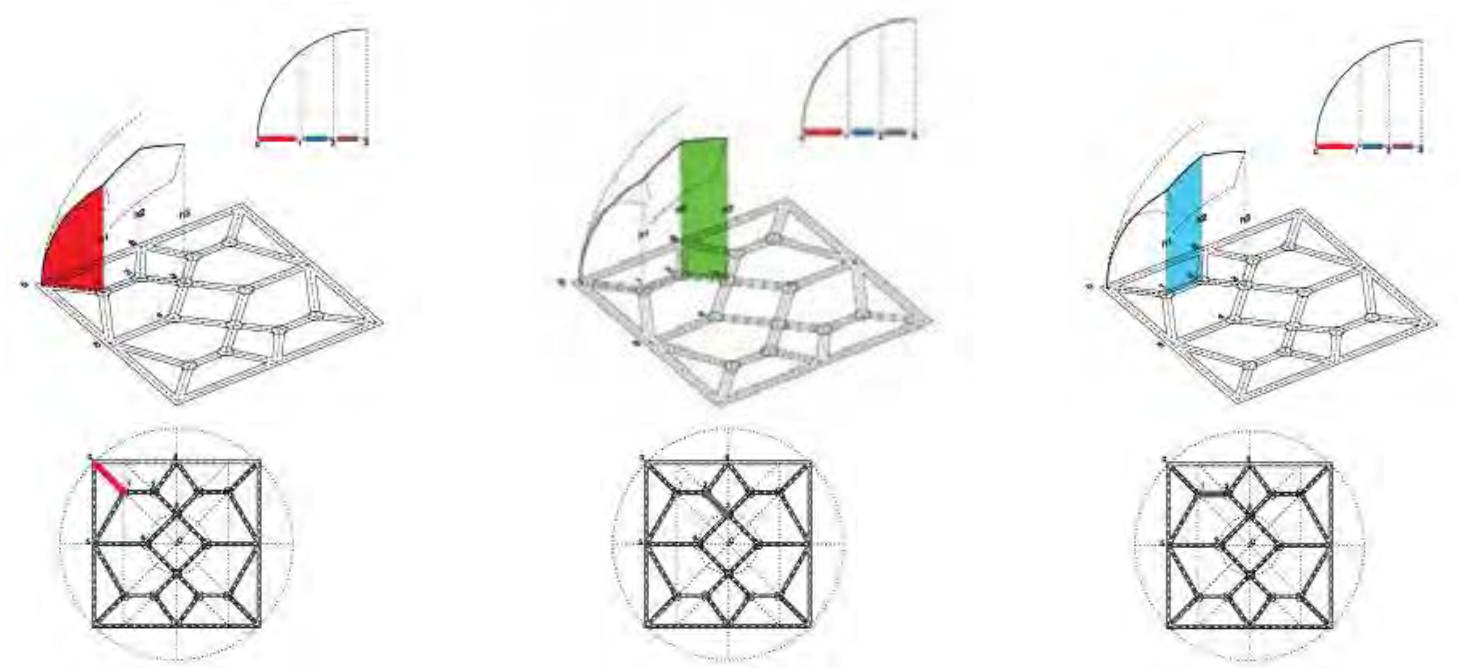

Fig. 11.3. Prinzipalbogen: recorrido del arco. Dlbujo del autor.

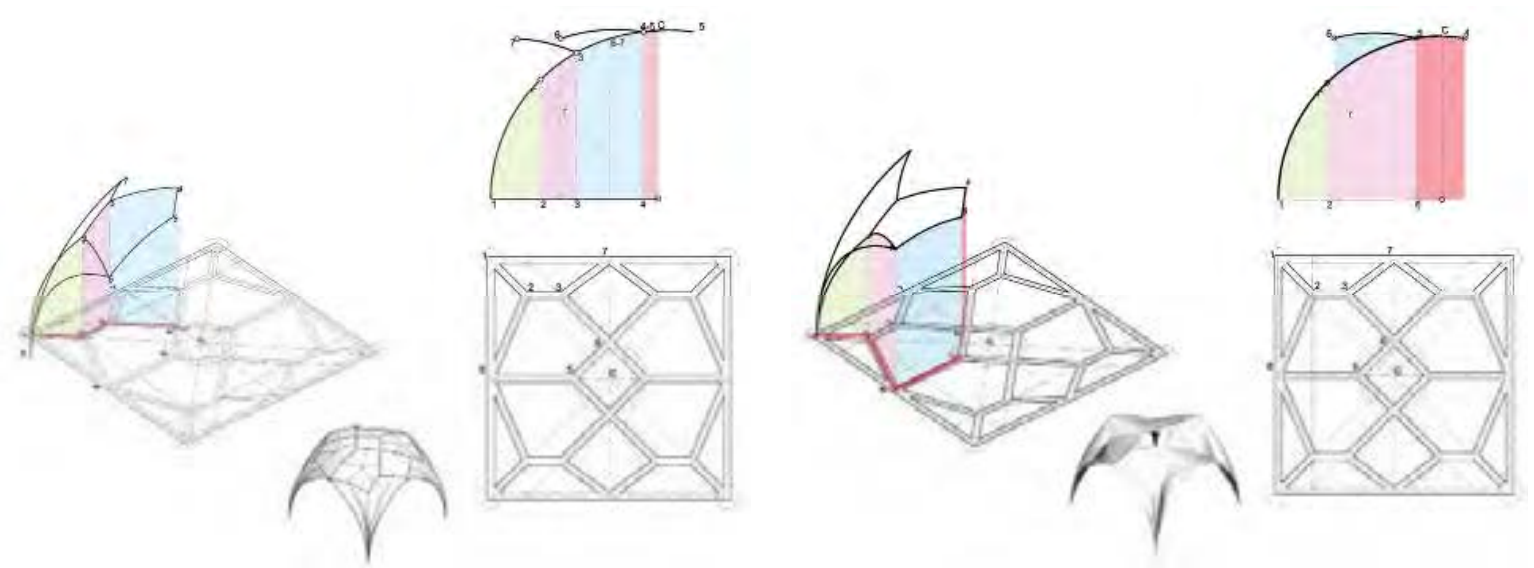

Fig. 11.4. Prinzipalbogen: recorrido del arco (A y B). Dlbujo del autor.
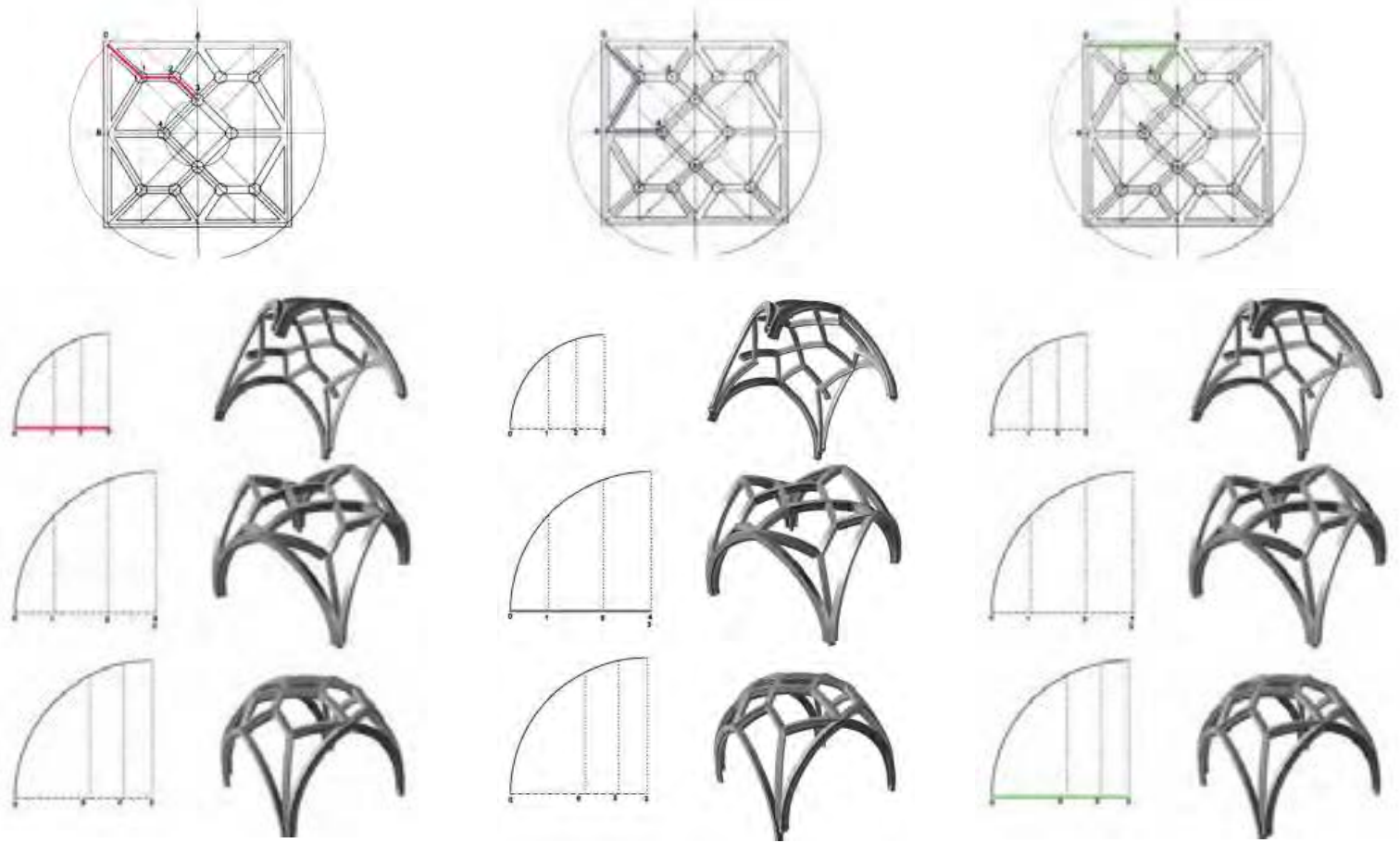

Fig. 11.5. Prinzipalbogen: estudios volumetricos de la boveda en funcion del recorrido del arco. Dibujo del autor. 


\subsection{La Montea}

Utilizando este procedimiento se comienza por dibujar la montea, es decir los dibujos a tamaño natural de la bóveda, tanto en planta como en alzado. Toda la bóveda se traza con el mismo arco y la altura de las claves se determina en función de un recorrido que el arquitecto elige siguiendo el trazado de los nervios en la proyección horizontal de la bóveda, desde el arranque hasta su punto más alto. Este método de traza, el Prinzipalbogen, tiene la particularidad de que la altura de las claves y por tanto, la forma de la bóveda puede variar en función del recorrido. La suma de las longitudes de cada tramo del recorrido en planta, se usa como radio de un gran arco que es precisamente el arco principal. Este gran arco de medio punto determina las alturas de las claves y la forma de los diferentes arcos. El método establece una vinculación directa entre planta y volumetría y permite estandarizar las curvaturas de los arcos definiendo un protocolo de talla y ejecución claro y sencillo, facilitando enormemente la organización de la ésta.

El Prinzipalbogen es un sistema muy riguroso y a la vez dúctil que permitía al arquitecto medieval adaptar la bóveda a según su gusto estético siempre bajo una rigurosa racionalidad constructiva. Los resultados podían ser entonces bóvedas de crucerías muy diferentes, caracterizadas por enjarjes de nervios que parten a alturas distintas y claves, o más bien, a cruces de arcos que se intersecan a distintas alturas, dando origen a los característicos nervios superpuestos y a otras faltas de concordancias tan llamativas en el gótico alemán². Para construir esta bóveda, se escogió un recorrido y, en consecuencia, un arco principal con el que construir una volumetría armoniosa y más bien redondeada, como quería Joseph Ribes. Las claves, es decir, el punto en que se intersecan entre sí los arcos, lo hacen a la española, es decir, en un punto. Las jarjas de esta bóveda, aunque el arco diagonal parte a distinta altura, son también próximas a la estética de la bóveda española, caracterizadas por un claro plano de imposta.

El arco principal se determina por la suma de las distancias en planta entre las claves del recorrido que parte del punto 0 , pasa por las claves 1 y 2, hasta alcanzar la clave 3 (Figura 11.7). En nuestro caso, con la intención de crear un intradós redondeado, hemos supuesto que la clave 4 está a la misma cota de la clave 3 . A continuación se irán colocando en línea las distancias anteriormente mencionadas y, usando la suma de todas ellas como radio, se trazará un arco de medio punto que es, precisamente el arco principal; todos los arcos de la bóveda son iguales y tiene esta misma curvatura. A partir de aquí se procede a ciertos ajustes, por ejemplo, para determinar el nervio 5-0 y mantener la tangencia con las jarjas se ha rebajado el plano de imposta de toda la bóveda, resultando en un peralte del arranque del nervio 0-1. También se ha procedido a inclinar los nervios 1-5 y 2-6 con el fin de evitar un cruce de arcos superpuestos. Siguiendo el dibujo de Ribes todas las claves de la bóveda han sido orientadas hacia el centro de la bóveda; es decir, son claves radiales. El resultado obtenido puede apreciarse en la Figura 11.9.

\footnotetext{
2 Es por tanto interesante señalar que el método del Prinzipalbogen no es un método rígido en absoluto. Dependiendo del recorrido que se escoja en el dibujo en planta de la bóveda, la longitud final, es decir el radio del arco, va a variar notablemente. Una variación de esta longitud, conlleva un importante cambio en la curvatura del arco y, como consecuencia, en la forma de la bóveda; además, una variación del arco principal, va a provocar importantes cambios en las jarjas, en las que los arcos partirán a alturas diferentes y en el cruce de los arcos, las claves, en las que los cruces de los arcos pueden variar de altura considerablemente.
} 

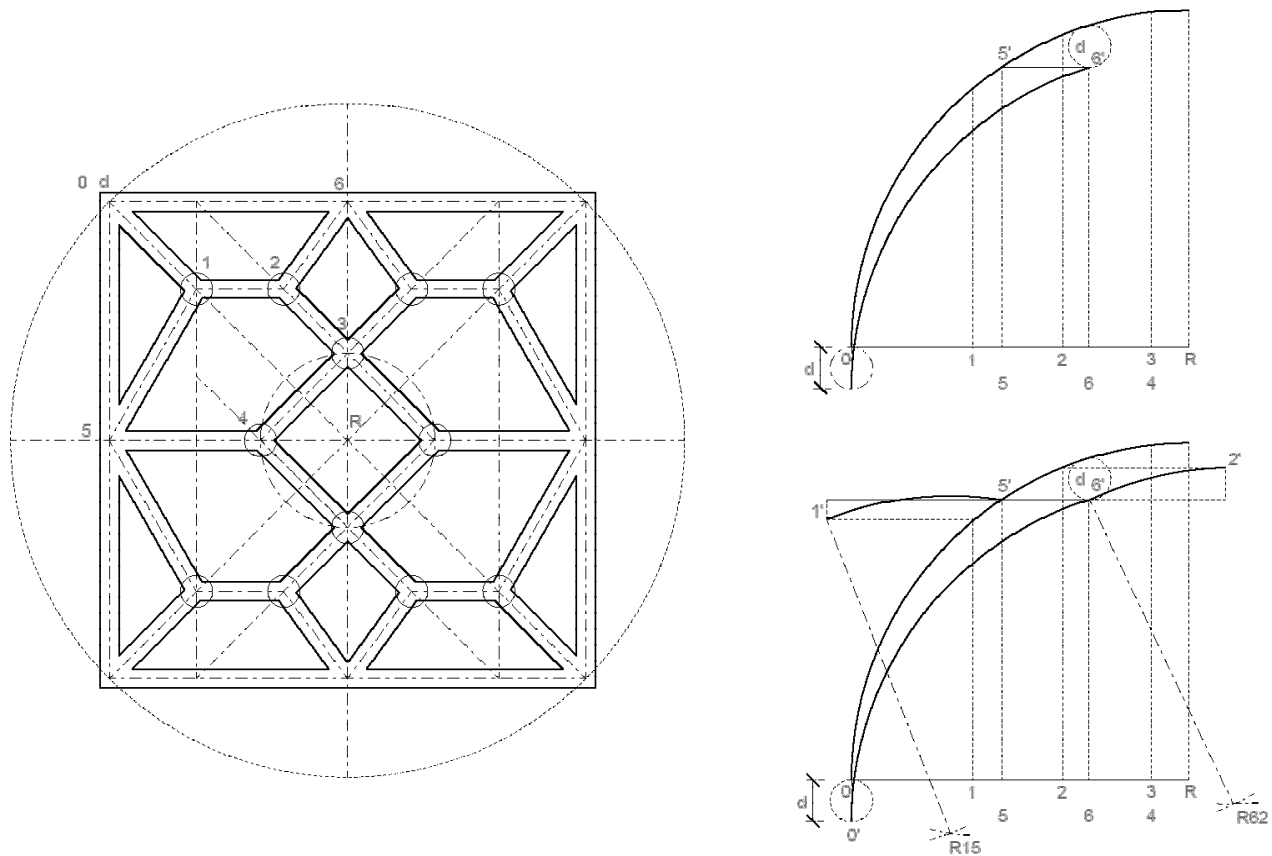

Fig. 11.6. Montea de la bóveda de Ribes según el método del Prinzipalbogen. Dlbujo del autor.
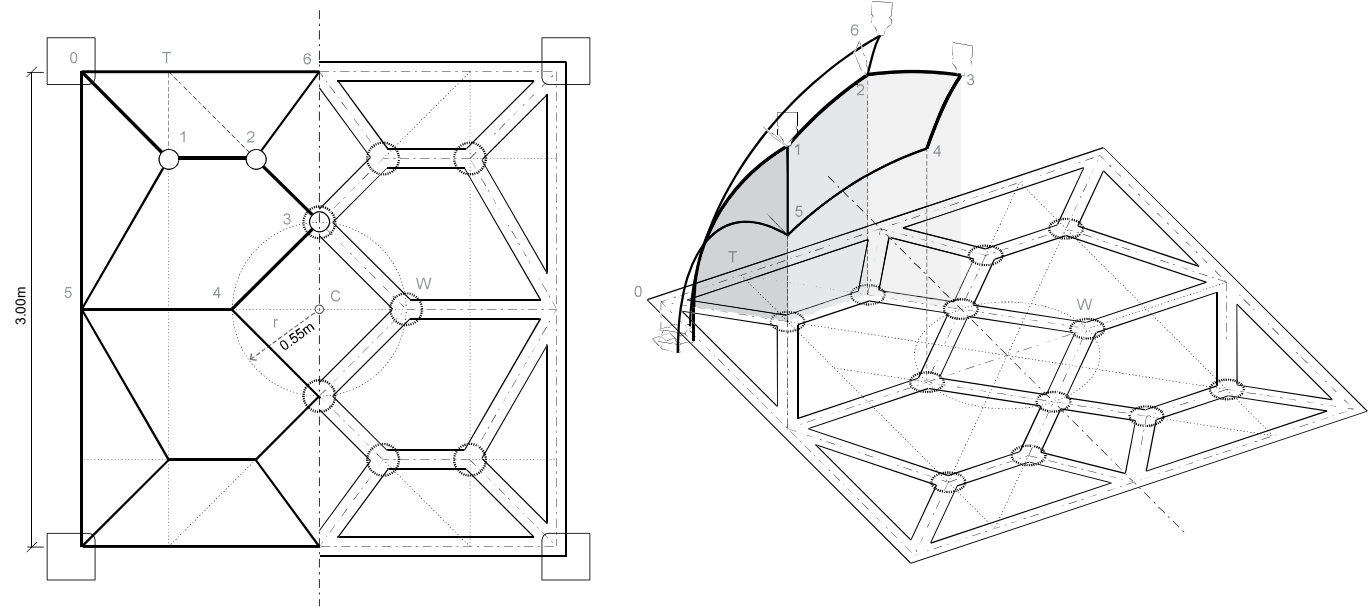

Fig. 11.7. Recorrido de los arcos en el espacio según el método del Prinzipalbogen. Dlbujo del autor.

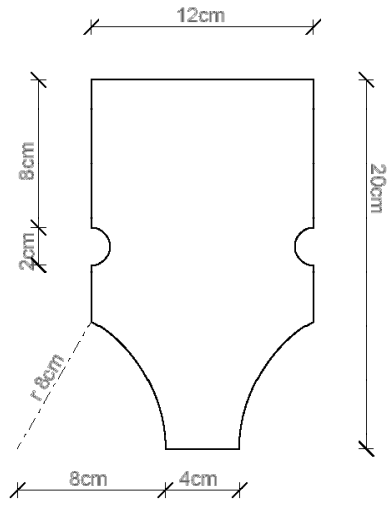

Fig. 11.8. Plantilla de los nervios.

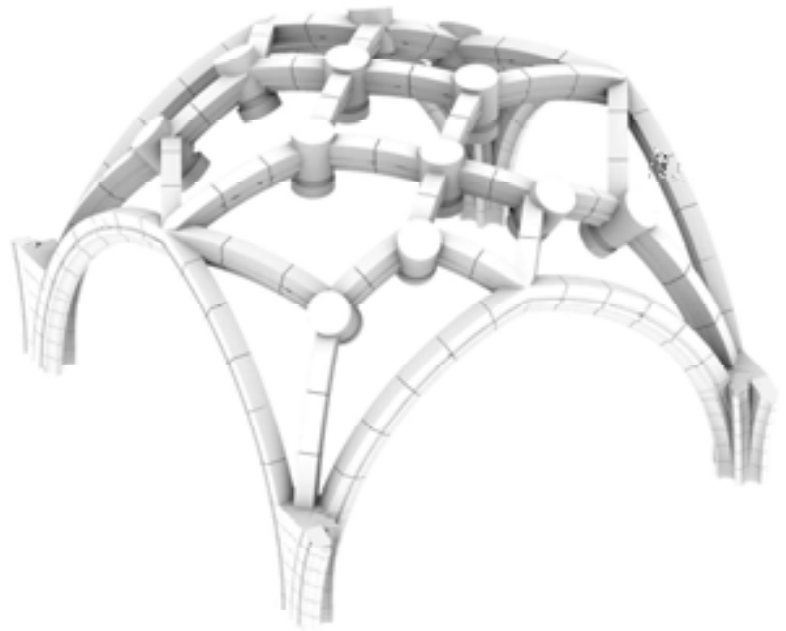

Fig. 11.9. Axonometria de la boveda de Ribes. Dlbujo del autor. 


\subsection{La labra de los nervios}

A partir la montea se dibuja y fabrica el baibel, que es una herramienta imprescindible para controlar la talla de las dovelas. Es una escuadra de dos brazos no articulados, uno de ellos cortado con la curvatura del intradós del arco y el otro recto, orientado hacia el centro geométrico del arco (Fig. 11.10).

Con la ayuda del baibel, se procede a tallar las dovelas con la certeza que su curvatura interior y la inclinación de sus lechos de apoyos se atienen con total precisión al Prinzipalbogen.
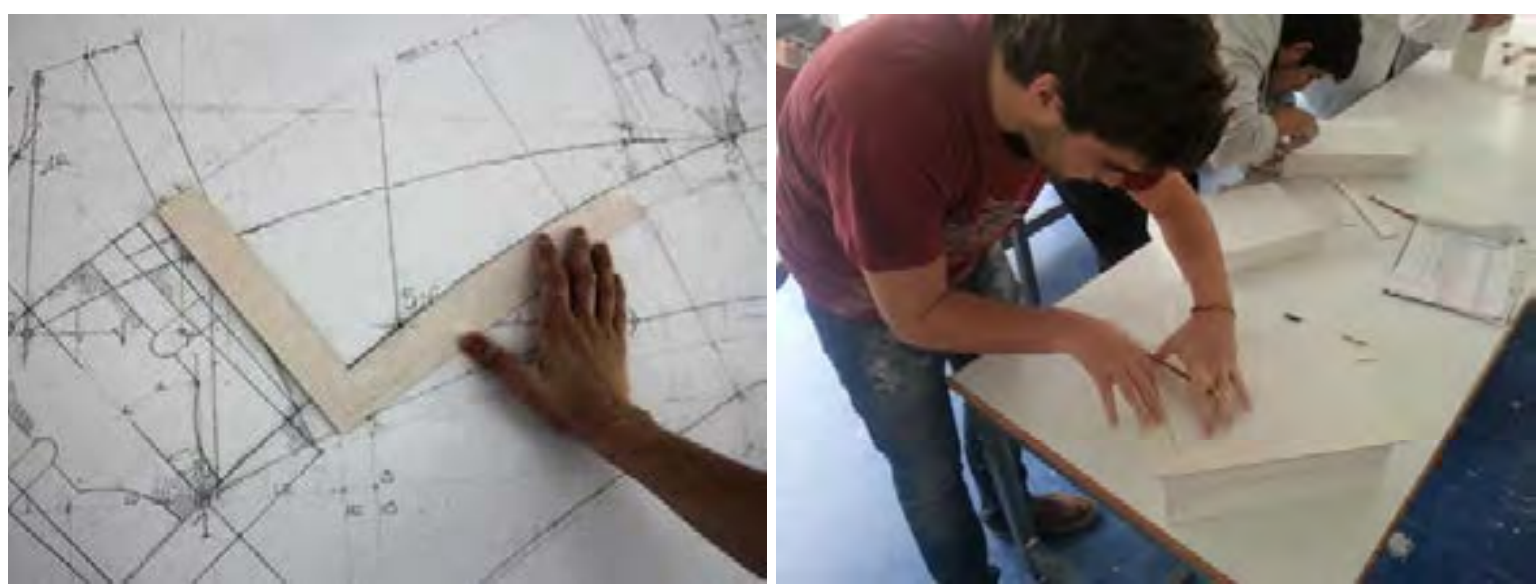

Fig. 11.10. Baibel y labra de las dovelas. Foto del autor.

\subsection{Las jarjas}

Para el apoyo de los nervios y el contrarresto de los empujes, la bóveda requiere de la construcción de unas sólidas jarjas. Las jarjas o salmeres de la bóveda son los arranques de la misma. Sabemos que en una bóveda de crucería las jarjas deben llegar hasta el punto en que los arcos que concurren en un arranque se independizan unos de otros. Para la construcción de las jarjas recurrimos de nuevo a la montea (Figura 11.11).

Sobre la sección se van dibujando los planos horizontales que se consideren oportunos $y$, en la planta, se van dibujando las proyecciones horizontales resultantes en cada nivel.
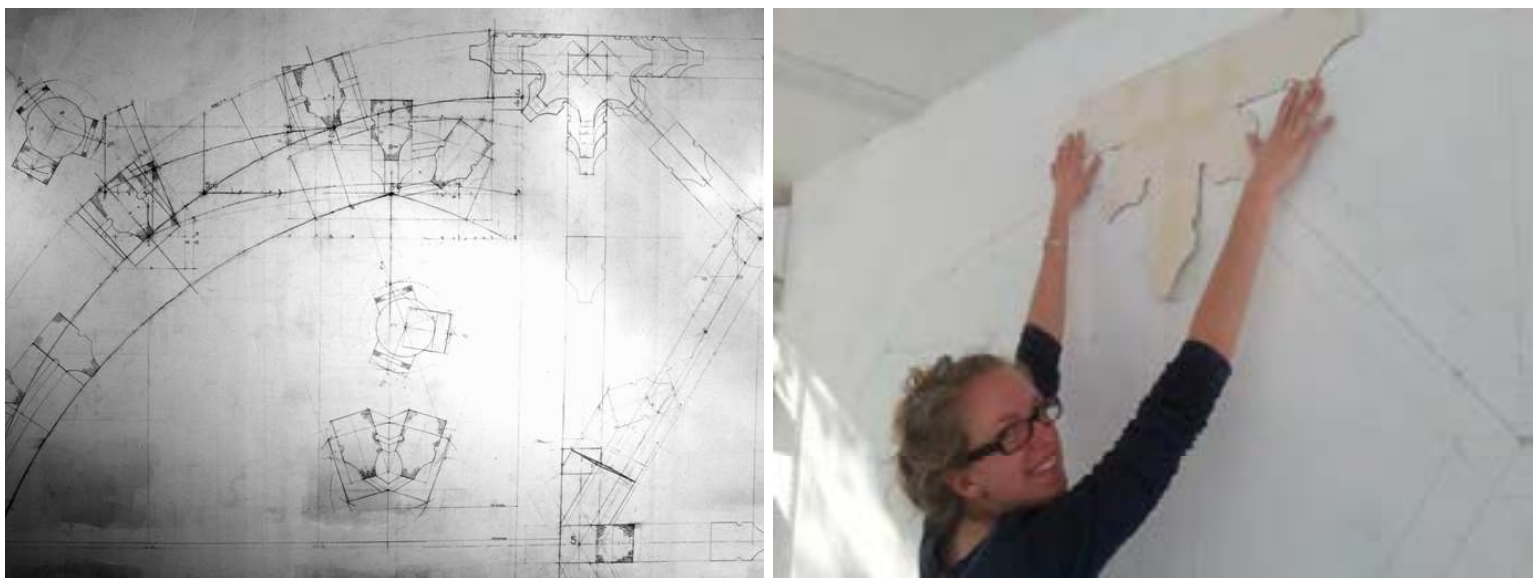

Fig. 11.11. Montea y dibujo de las jarjas. Foto del autor. 
Con estas secciones se dibujan una serie de plantillas que permitirán tallar las piezas que forman cada lecho; la plantilla inferior se calca en el plano inferior del sillar elegido y, con la plantilla superior se hace lo mismo sobre la cara superior; posteriormente se procede a la labra enlazando una cara con la otra.

La última jarja recibe los arcos y ha de tallarse con la inclinación necesaria que pide cada uno de ellos, dato éste que de nuevo ha de extraerse de la montea. Como mencionamos anteriormente, en nuestra bóveda, el nervio diagonal esta peraltado respecto al plano de imposta, es decir, que arranca a diferente altura que el formero, lo cual añade cierta dificultad a la labra de los bloques de las jarjas. El mismo baibel es suficiente para tallar también la curva del perfil de las jarjas.

\subsection{Las claves}

Como mencionado anteriormente, las claves de todas las bóvedas de crucería estudiadas por Ribes son radiales. Las claves radiales o inclinadas, aparecen en las bóvedas españolas y portuguesas en el siglo XVI y quizás sean una característica específica del gótico de la península ibérica. La talla de una clave inclinada, con sus correspondientes brazos de conexión, implica pasar de la proyección vertical de las claves tradicionales, a la proyección sobre el plano tangente; todo un logro geométrico de la cantería gótica. La clave inclinada, contrariamente a lo que sucede con la clave vertical que se talla con ayuda de su proyección horizontal, se talla a partir de su proyección sobre el plano tangente ${ }^{3}$.

\subsection{Las cimbras}

La cimbra se ha llevado a cabo siguiendo las pautas que aconsejaba Rodrigo Gil de Hontañón ${ }^{4}$, el cual, recomendaba en primer lugar la construcción de una plataforma de madera a la altura del nivel superior de las jarjas (Fig. 11.12). Sobre ella habría de dibujarse de nuevo la montea horizontal de la bóveda a tamaño natural. En las intersecciones de las líneas, es decir, en los puntos en que se sitúan las claves, se colocarían pies derechos
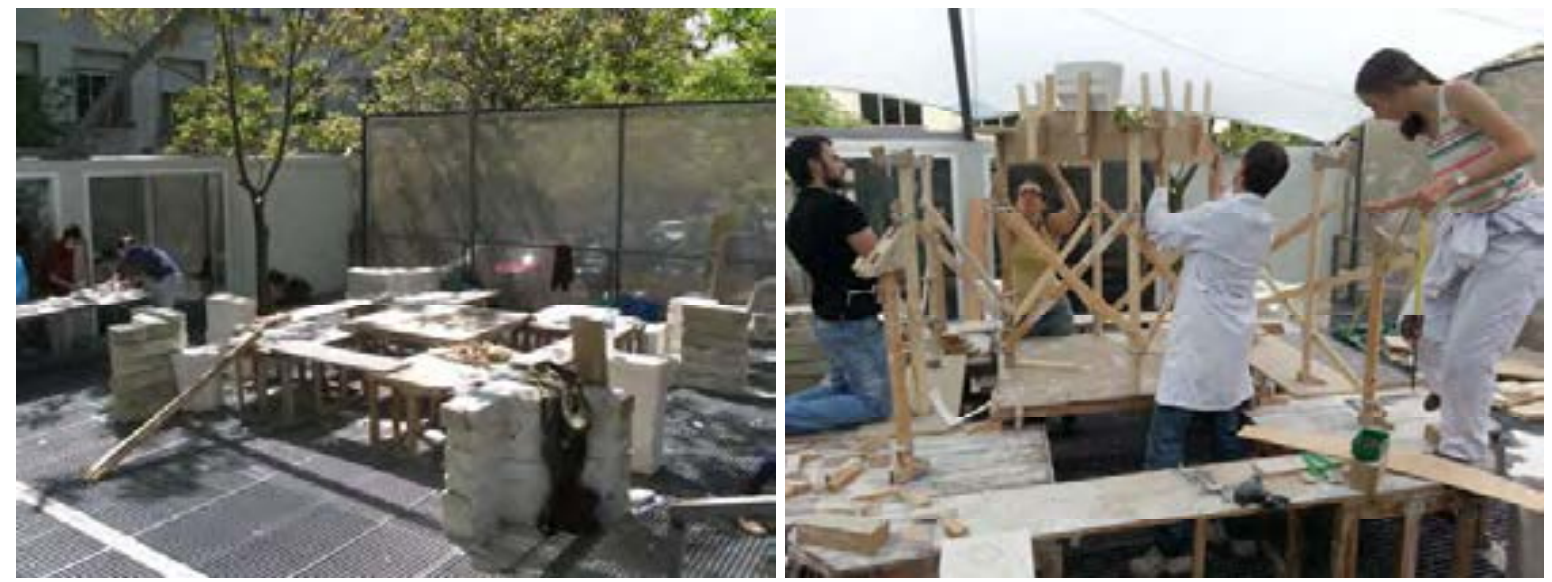

Fig. 11.12. Plataforma y pies derechos verticales. Foto del autor.

3 Palacios Gonzalo y Tellia, 2015.

4 Simón Garcia, Compendio de Architectura y Simetria de Los Templos Conforme a La Medida Del Cuerpo Humano [1681] (1681; repr., Valladolid: Colegio Oficial De Arquitectos De Valladolid, 1991). 
con la altura adecuada; este dato, una vez más, se extrae de la montea. Entre estos pies derechos se colocan las cimbras curvas de los arcos, atando unos con otros y estabilizando el conjunto. Con objeto de facilitar el descimbrado, los pies derechos de las cuatro claves situadas en el centro de la bóveda se han situado, a su vez, sobre una plataforma más pequeña alzada sobre un sistema de cuña que, al extraerse, las cuatro claves centrales descenderán a la vez, de manera que toda la bóveda entrará en carga al mismo tiempo.

\subsection{La construcción y el descimbrado}

Con las cimbras ya acabadas, se pueden ir colocando en primer lugar las claves sobre los pies derechos verticales (Fig. 11.13) y a continuación las dovelas. Es ésta una operación que requiere gran habilidad: para conseguir un correcto alineamiento de las dovelas; éstas se colocan separadas unas de otras mediante juntas de mortero, con el que se consigue que los errores de talla en los lechos de contacto no se vayan trasladando de unas a otras y, además, asegurará un perfecto contacto entre las dovelas mismas.

Terminada esta fase es posible apreciar por primera vez el singular diseño de la bóveda de Ribes (Fig. 11.14). La retirada de la cimbra de una bóveda es siempre un momento apasionante, durante ese proceso, las cargas dejarán de transmitirse verticalmente para hacerlo, a través de los arcos, hacia sus apoyos laterales ${ }^{5}$. En este crítico instante se genera el empuje horizontal que producen todas las bóvedas y que habrá de contrarrestarse mediante los contrafuertes, el precio a pagar por mantener las piedras suspendidas en el aire. Ahora la bóveda exenta del armazón de madera que la sujetaba se muestra en toda su belleza.
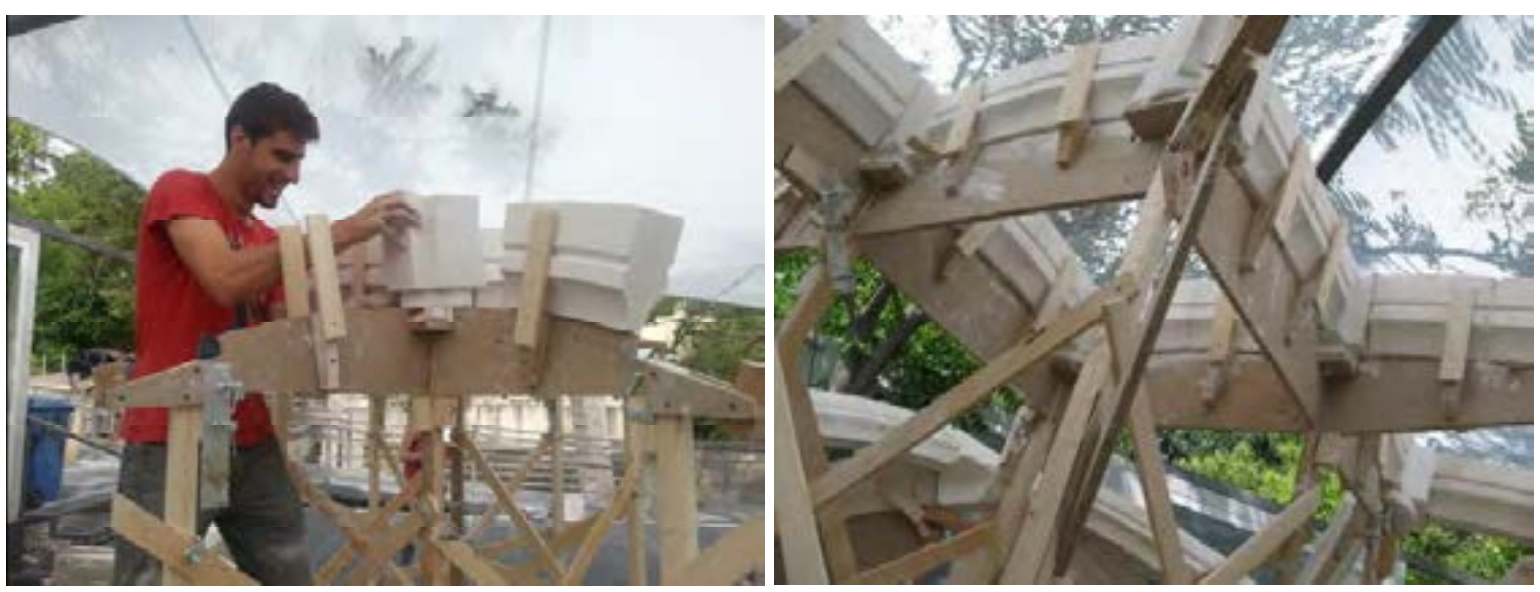

Fig. 11.13. Construcción de los nervios. Foto del autor.

\footnotetext{
5 José Carlos Palacios Gonzalo y Fabio Tellia, "Descimbrado de Una Bóveda de Crucería Gótica de Josep Rives," YouTube Video, YouTube, November 7, 2014, https://www.youtube.com/watch?v=WfBRtVNs8Dc. Fecha de acceso: 23 jun. 2015
} 

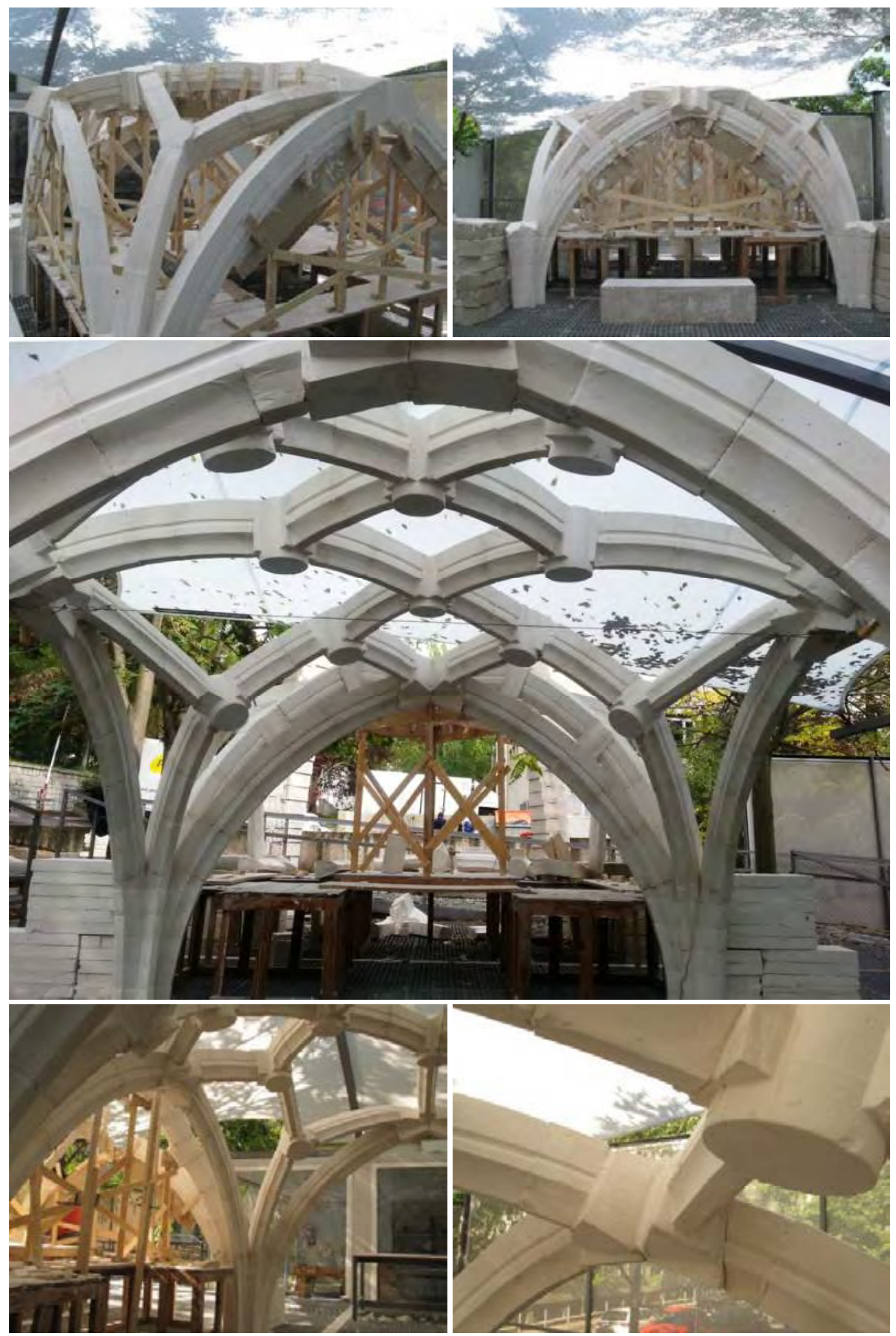

Fig. 11.14. La bóveda de Ribes. Foto del autor. 

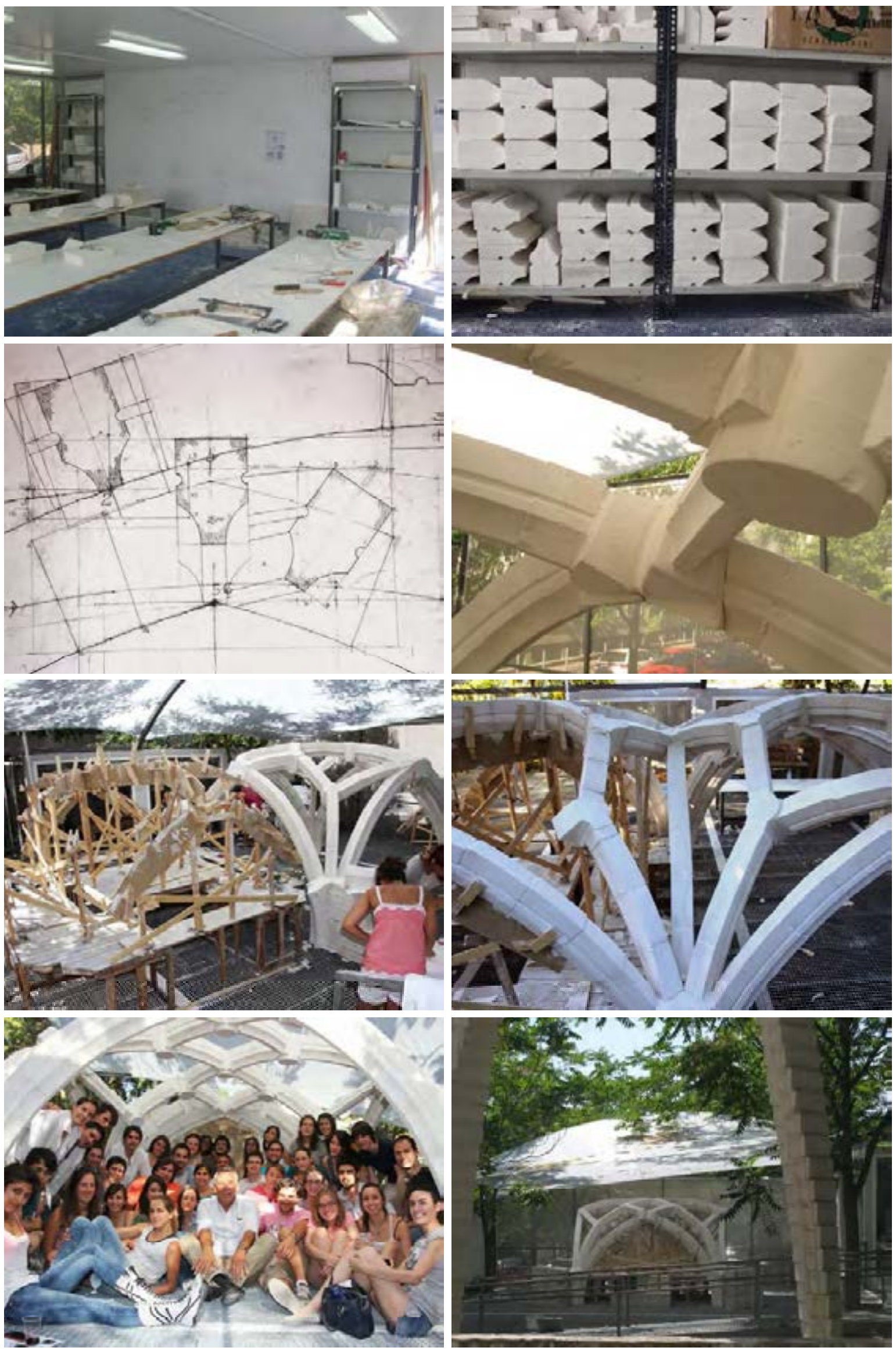

Fig. 11.15. La bóveda de Ribes: Sala de trazas; almacenamiento dovelas estandarizadas; detalle de la montea; las claves inclinadas; construcción de la segunda bóveda; encuentro de las bóvedas; el equipo; la bóveda en la ETSAM. Foto del autor. 


\subsection{Estudio paramétrico de la volta ab dotsa claus}

El estudio de las particulares características geométricas del diseño de la bóveda ab ab dotsa claus nos permiten reconocer un algoritmo generativo de su diseño y la relación paramétrica entre la posición de las llaves. Es posible establecer un parámetro para determinar la distancia de una de las cuatro claves centrales del centro de la bóveda que al cambiar de valor crea una la variación en la posición de las otras claves y del volumen de la bóveda. A través de Grasshopper, un lenguaje de programación visual que corre dentro de la aplicación CAD Rhinoceros, se ha recreado este algoritmo en un ambiente informatizado para visualizar y estudiar las posibles variaciones que esta traza permite alcanzar (Fig. 11.16).

En esta tesis, se quiere introducir el estudio paramétrico de las geometrías de la arquitectura gótica y de su interpretación como una primordial arquitectura algorítmica ${ }^{6}$, que contribuiría no solo a la historia de la construcción, pero también al ámbito proyectual.

Otros estudios anteriores se pueden relacionar a esta visión. Camillo Trevisan buscó relaciones paramétricas en la traza de la trompe d'Anet de Philiber de L'Horme interpretando el trait cual fuera un algoritmo. Sus estudios produjeron una aplicación informática ${ }^{7}$ para la generación de modelos tridimensionales y crear las plantillas al variar de los parámetros de planta y sección de una trompa. La pioneristica investigación de Giuseppe Fallacara se ha dedicado al desarrollo de la estereotomía en época contemporánea, proponiendo aparejos tradicionales y nouvelles invenciones basadas en la actualización de las técnicas estereotómicas. Este estudio fue introducido en su tesis doctoral, donde planteó un estudio paramétrico de la disciplina entre los desarrollos futuros de su investigación.

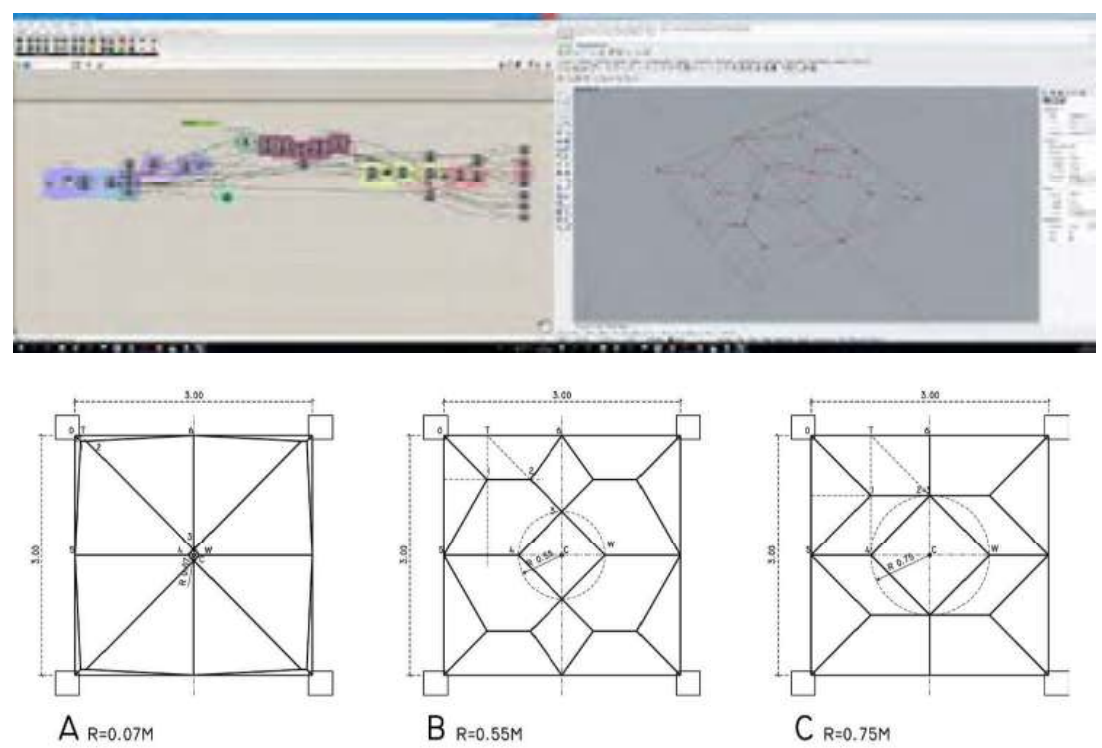

Fig. 11.16. Estudio parámetrico del algoritmo geométrico de la bóveda de Ribes con Grasshopper y Rhinos: tres variaciones del dibujo de los nervios al variar un solo parámetro Dibujo del autor.

\footnotetext{
6 Estos conceptos han sido introducidos por el autor en conferencias al master IE en Londres y al Queens University de Belfast y en la publicación Stereotomy and architectural design at Foster+Partners.

7 - Camillo Trevisan, "La Trompe Di Anet e Le Sue Variazioni Ottenute Mediante II Programma TROMPE," 1997, http://www.camillotrevisan.it/stereo/anet.pdf.

- Camillo Trevisan, "Sulla Stereotomia, II CAD e Le Varie Trompe d'Anet," in Geometria e Architettura, Strumenti Del Dottorato Di Ricerca in Rilievo e Rappresentazione, ed. Riccardo Migliari (Roma: Gangemi, 2000): 27-53.
} 


\section{ESPAÑA $\cdot$ Madrid}

\section{El saber secreto de las bóvedas}

Un protesor de Arquitectura aplica los arcanos de la técnica medieval

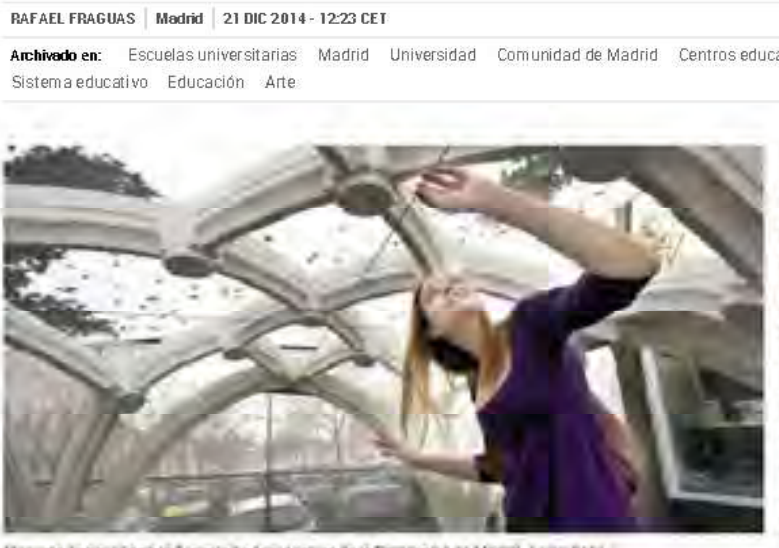

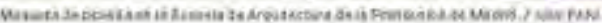
Superior de Anquitecruna de Madrid guarda un preciado tesoro. Se trata de un libro cuyo texto, escrito hace cuat ro siglos por el vistago de un genisl alarife, Andres de Vandelvin (Aleariz, Albacete, 1509 Jaén, 1575), revela los secretos de un arte prodigioso, la estereotomía: el arte de cortar ia piedra, clave para la constracción de edificios, que alcanzó esplendor en las catedrales gbticas y su culme日, en las bovedas de cruceria y en los arteponados.

Hace siete años, el arquitecto y yrofesor titular del Departameato de Construcéón de le Bseuel. madrileña, José Carlos Palacios Gonzalo, a sabiendas del valor incalculable de aquel libro, se aventurb a aplicar su contenido a los estudios prícticos de la Arquitectura. Ideb una asignatura especifica con la que ensefiaría a los futuros arquitectos a construir bóvedas góticas, mudéjares, renacentistas o neoclásicas, tras desvelarles los secretos del arte constructivo más complejo y grato: complejo, por garantizar el milagro de sujetar - durante siglos - arcos de piedra de ancha luzy decenas de toneladas de peso en un desafio a la ley de la gravedad; grato, porque tal sujecín lograba un milagro imposible.

José Carlos Palacios se propuso reproducir en un taller adjunto a la ETSAM los procesos materiales que guiaran hacia su meta. Su asignatura fue programada como optativa. Bl profesor contaba con su entusiasmo y con el de un yañado de estudiantes hartos como el de tanto saber tebrico sepultado en libros sin salida práctica, $y$ anhelantes de un conocimiento tan tangible como el que su profesor les brindaba. Bnfrascados en los misterios de la piedra, lograron transcribir a escala y reproducir en escayola los elementos básicos - piedras, dovelas y jarjas-, que configuran los nervios y componentes de las cúpulas de claustros y catedrales. Se aplicaron pues a construir por sus manos con el apoyo de la robótica para el costoso corta dasjie piezas di éscigsila-bovedas de crucería y

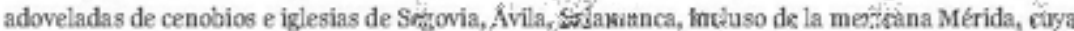
documentación era acopiada por alumnos autore de tesis especificas; śregrados en el grupo.

Una de las bovedas reconstruidas fue la sexpartita del monasterio cisterciense soriano de Santa Maria de Huerta, cuya hechura supuso un reto formidable. Constaba de seis gajos. Tal como el libro de Vandelvira prescribía, era preciso trazar previamente un plano a tamaño natural, llamado montea, donde figuraran los elementos de la bóveda deseada. Mediante un baibel, artificio biangular de dos ejes perpendiculares unidos, combado el inferior con la curvatura deseada para el arco, se construía en madera una cimbra o soporte sobre el cual la bóveda, propiamente dicha, se asentaría. En el centro se situaba un madero vertical, la clave. La observación de la montea señalaba luego el camino para disponer cada pieza pétrea del entramado curvo. Bn los extremos de las piezas combadas, los estribos recobraban la verticalidad.

Profesor y alumnos asisten Bl milagro de las bóvedas, la contencion de un enorme peso arquèdo sin con unción al descimbrado desplomarse, cabía contemplarlo en el descimbrado de la pieza entera,

Fig. 11.17. La bóveda de Ribes publicada en El Pais 


\section{Conclusiones}

El desarrollo de esta tesis ha llevado a la descripción y análisis del manuscrito de Joseph Ribes. Se ha podido apreciar su valor como fuente documental y evaluar su contribución a la historia de la estereotomía, abriendo un camino inédito en Cataluña.

\subsection{Análisis del Llibre de trasas de viax y muntea}

Los resultados obtenidos a través de la análisis historiográfica y geométrica del Llibre de trasas han alcanzado los objetivos propuestos al principio de la investigación.

Dese el punto de vista histórico, el problema originario fue verificar la confiabilidad de la fecha del manuscrito para las consecuencias que ello habría implicado. Si la fecha de 1708 es correcta, se identifican importantes resultados sobre los conocimientos históricos normalmente asimilados. Otro aspecto es que no tenemos constancia documental de tratados de estereotomía catalanes originales del ' 700 , podemos recordar solo otro de procedencia española. Los que nos han llegado son copias o reediciones de trabajos de otros autores precedentes. Para estos factores se había inicialmente pensado que la fecha escrita en la portada del manuscrito había sido añadida posteriormente y que el tratado fuera en realidad anterior. Mi primera preocupación ha sido entonces de comprobar la exactitud de la datación. Analizando el papel, en particular la filigrana, he podido llegar a la conclusión que el papel remonta efectivamente a esa temporada y entonces la fecha de 1708 es aceptable. Esta conclusión mía ha sido verificada por la Biblioteca Nacional de Catalunya, que es la propietaria del documento.

La autenticidad de la fecha permite además de afirmar con certidumbre que la influencia del gótico se ha extendido más allá de lo que se consideraba ser sus límites temporales. Tradicionalmente se pensaba que el gótico terminara en el siglo XVII, mientras que se puede afirmar que el interés para los abovedamientos góticos extiende su vida hasta el siglo XVIII.

La verifica de la fecha del manuscrito permite también atribuir a Ribes las primeras trazas de un capialzado de Marsella en un tratado de estereotomía español, que vienen desarrolladas en el Llibre de trasas sistemáticamente y en numerosas variaciones. La historiografía atribuía este primado al tratado de padre Tosca (1727), que copió el capialzado de Marsella del tratado francés de Milliet-Deschales. Existe una semejanza de una traza del manuscrito de Alonso de Guardia (1598) con dicho capialzado, pero representado en una forma primitiva. El hecho que Ribes escriba este tratado en un momento difícil para Cataluña, cuando estaba progresivamente perdiendo poder y autonomía, hasta perderlo totalmente con la llegada de los Borbones, testimonia la persistencia de una tradición constructiva vernácula y un contexto cultural dinámico que pulsaban no obstante la situación política desfavorable. 
El análisis de las trazas ha permitido evidenciar algunos aspectos originales o de notable interés en la obra de Ribes.

En particular:

- Se ha señalado la caracterización del gótico con claves inclinadas.

- Desde el punto histórico proporciona informaciones valiosas sobre el nivel de conocimiento técnico de los maestros de obra de Barcelona, en línea con los del resto de España, pero con posibles influencias de la escuela francesa.

- Se han decodificado los dibujos de Ribes, representándolos en manera que también un lector sin conocimientos avanzados de geometría pueda entenderlos.

- Se ha marcado la originalidad de algunas trazas, cuales arcos, trompas, capialzados y bóvedas de crucería.

- Se ha reconocido la posibilidad de una influencia del tratado de Philibert de L'Orme por compartir una traza única a este tratado.

- En comparación con otros tratados y manuscritos de estereotomía se han reconocido similitudes e influencias.

- Se ha empezado un inventario de obras de estereotomía en Cataluña, coadyuvada de una campaña fotográfica original.

- Se ha comprobado el gusto estético de las composiciones de Ribes a través de la construcción de una de sus bóvedas de crucería.

- Se ha averiguado que era el tratado de un constructor y no una mera especulación teórica porque conserva apuntes prácticos para preparar cal y enlucir claves.

- Al resguardo de las Baleares, se han identificados numerosos aparejos estereotómicos difundidos en las islas de Mallorca y Menorca.

- Se ha comprobado como algunos elementos en corte de piedra que caracterizan las islas no han tenido éxito en Cataluña y viceversa.

Eligiendo tomar como objeto de estudio el manuscrito, hasta ahora muy poco conocido y objeto solo de una única citación de un histórico del arte, sucesivamente recuperada en dos adicionales referencias de otros historiadores, me puse el objetivo de hacer conocer y valorizar un documento a mi pensar importante para la historia de la estereotomía que va a llenar un vacío documental que respeta la arquitectura catalana. De hecho, mientras existen numerosos estudios dedicados a la estereotomía de las otras regiones de España y de los territorios que habían sido culturalmente y políticamente conectados a España, ningún estudio, a mío conocimiento, ha profundizado el tema de la estereotomía en Cataluña. Con esta investigación considero de haber contribuido a llenar esta laguna. Se ha podido entonces poner de relieve el papel que ha tenido Cataluña en el desarrollo y en la transmisión de la estereotomía en España. 
Se señala lo que aporta esta tesis al conocimiento de la estereotomía:

1. El descubrimiento de una nueva fuente

2. Datación de la misma

3. Descripción y análisis grafico del contenido

4. Delineación de las particularidades de las trazas de Ribes

5. Conocimiento e identificación de la estereotomía catalana

\subsection{Nuevas vías de investigación}

Esta tesis doctoral pretende ser el íncipit de un más amplio estudio sobre la estereotomía catalana, que requeriría la continuación y proyección al entero ámbito mediterráneo, relacionándose por ejemplo con Sicilia y los territorios de ultramar de la Corona de Aragón, para inscribirse en los actuales estudios del Gótico Mediterráneo.

El estudio de la estereotomía catalana, hasta esta tesis y a parte los artículos desarrollados por el autor, ha sido carente de artículos y publicaciones, sin embargo, la producción de análisis históricos y estructurales hechas por los estudiosos catalanes ha sido muy rica y detallada. Por esta razón, se piensa que posibles líneas de investigación futuras podrían relacionar los estudios históricos existentes sobre arquitecturas y mestres de obra, con nuevos análisis enfocados a la estereotomía, geometría y el aspecto constructivo en corte de piedras. Algunos edificios analizados se han revelado abundantes de aparejos estereotómicos y no cabe duda de que necesitarían un estudio monográfico que relacione las investigaciones históricas con el corte de piedras. Por ejemplo, las bóvedas del Palau de la Generalitat de Cataluña o de la Lonja de Mar de Barcelona, vienen mencionadas en artículos y textos de carácter históricos, pero están todavía pendientes de un estudio constructivo detallado.

Sería necesario abordar el estudio de las bóvedas utilizando sistemas de medición precisos, como la estación total o el escáner laser, complementados con software de fotogrametría, y mirados a identificar la exacta concreción geométrica de los elementos constitutivos, como por ejemplos la curvatura arcos, los ángulos de imposta de los nervios, la superficie de las cáscaras, el despiece y tamaño de las dovelas, la estandarización, etc...

Para el estudio de las fábricas del Gótico Catalán, del cual ya hay tomas de datos avanzadas de los edificios más importantes, haría falta integrar los análisis existentes (de levantamiento y estructurales) con estudios geométricos y constructivos mirados a las técnicas del corte de piedras, y extender el estudio a numerosos edificios eclesiásticos de gran interese patrimonial que se encuentran en las comarcas más alejadas de las poblaciones principales.

En esta tesis se han observado también las arquitecturas de las Baleares, riquísimas de arquitecturas estereotómicas en Mallorca y Menorca, pero más pobre de ejemplos en Ibiza. Se han podido observar linajes típicos de cada isla que quedan todavía para catalogar. En 
particular, la Mola de Menorca requeriría estudios atentos dedicados a la estereotomía de sus bóvedas.

Se ha desarrollado el tema de los capiteles pinjantes en Cataluña, pero se ha observado la portada europea ${ }^{1}$ de este recurso estilístico que, según el autor de esta tesis, no ha sido reconocida suficientemente.

Durante la fase de investigación inicial y de toma de datos, se ha observado una componente estereotómica muy fuerte en la arquitectura modernista de Barcelona, de Palma de Mallorca y en la obra de Gaudí, que podrían ser objeto de futuras investigaciones.

En esta tesis se ha introducido el estudio de las crucerías góticas a través de programas informáticos paramétricos. Se cree que un estudio dedicado podrá revelar interesantes reflexiones.

\footnotetext{
1 En realidad, el fenómeno transciende el área europea y Mediterránea. Por ejemplo, en el Templo de Veerabhadra (India, siglo XVI) se encuentra una entera columna suspendida, conocida como Aakaasa Sthambha.
} 


\section{Bibliografía}

El estudio bibliográfico ha sido muy extenso, se ha visitado y consultado textos del Arxiu historico de la Biblioteca Nacional de Catalunya, la sala manuscritos de la Biblioteca Nacional de España en Madrid, las bibliotecas del ETSAB y de la ETSAM, la British Library en Londres, la Columbia University de New York y el MIT de Boston.

Se han consultado numerosas "bibliotecas virtuales" en las cuales es posible descargar artículos en formato digital, como el "raco de revistes catalanes", y otras que conservan las copias digitales de textos antiguos, como por ejemplo la Biblioteca Nacional de Francia o la Biblioteca Nacional de Austria. Debido a mi residencia afuera de España, se quiere señalar su utilidad porque han permitido llevar a cabo una tesis doctoral a distancia y todavía poder analizar las fuentes históricas originales.

La bibliografía consultada ha sido muy amplia, se han leído textos de estereotomía no necesariamente enfocados a esta tesis y se han producido trabajos y artículos en paralelo a la tesis, como por ejemplo el estudio de la estereotomía en New York y la comparación de los sistemas constructivos góticos con los métodos utilizados en la arquitectura High Tech, que ha producido una serie de conferencias al resguardo.

Otros textos consultados incluyen nociones de geometría, historia, tratados y documentos originales, artículos de historia de la construcción contemporáneos y del comienzo del siglo pasado, archivos fotográficos históricos de la ciudad de Barcelona en la búsqueda de elementos estereotómicos desaparecidos, hasta obviamente a los textos específicos de estereotomía estrictamente relacionados con esta tesis.

En particular se han querido recordar aquí los libros que han sido imprescindibles:

-José Carlos Palacios: Trazas y cortes de cantería en el Renacimiento Español (publicada en 1990, procedente de la tesis doctoral Invención y Convención en las técnicas constructivas del Renacimiento Español, 1987) y Arquitectura gótica son los textos de referencia para entender la construcción geométrica de las trazas y la metodología constructiva de la estereotomía renacentista a partir del tratado de Alonso de Vandelvira y de la cantería gótica a partir del análisis geométrico/constructivo de las bóvedas de crucería españolas. -Enrique Rabasa Díaz: Construcción y forma en piedra (2000). Libro de referencia que colecciona algunos textos inéditos y artículos antecedentes, necesario para adquirir una visión global de la materia y para entender las peculiaridades geométricas que caracterizan cada traza.

-Giuseppe Fallacara: Il paradigma stereotomico nell'arte del costruire (tesis doctoral, 2003), sucesivamente editada con el título Verso una progettazione stereotomica, ofrece un catálogo exhaustivo de aparejos estereotómicos como aparecen en diferentes tratados representados a través de infografías 3D.

-José Calvo López: tesis doctoral, texto de referencia para identificar construcciones y singularidades geométricas de las trazas de arcos. 
-Arturo Zaragozà: Arquitecturas del Gótico Mediterráneo, libro que recorre e impulsa el carácter regional de la estereotomía valenciana y el concepto del gótico mediterráneo.

-Marià Carbonell i Buades: el artículo De Marc Safont a Antoni Carbonell: la pervivencia de la arquitectura gótica en Cataluña describe la arquitectura y el contexto histórico y cultural de la Barcelona tardo-gótica.

\subsection{Bibliografía de referencia}

Agusti, David. Historia Breve de Cataluña. 2002. Reprint, Madrid: Silex, 2009.

Almuni i Balada, Victòria. La Catedral de Tortosa Als Segles Del Gòtic. Barcelona Fundació Noguera, 2007.

Anónimo. Tratado Octavo. De La Arquitectura Civil. Vol. Mss. No. XIX-82. Biblioteca del Colegio de Arquitectos de Madrid, n.d.

Arranz Herrero, Manuel. "Los Profesionales de La Construcción En La Barcelona Del Siglo XVII." Tesis Doctoral, 1981.

Arranz, Manuel. La Menestralia de Barcelona Al Segle XVIII : Els Gremis de La Construcció. Barcelona: Proa, 2001.

—. Mestres d'obres i Fusters : La Construcció a Barcelona En El Segle XVIII. Barcelona: Col•legi D’aparelladros I Arquitectes Técnics, 1991.

Bails, Benito. Diccionario de Arquitectura Civil. Madrid: Viuda de Ibarra (Ed. facsimilar Oviedo, Colegio de Aparejadores, 1973), 1802.

Elementos de Matemática. Vol. IX. Madrid: en la impreta de la viuda de D. Joaquin Ibarra, 1796. http://www.cervantesvirtual.com/obra/elementos-dematematica---tomo-ix.

Ball, Philip. Universe of Stone : A Biography of Chartres Cathedral. New York: Harper, 2008.

Barbé-Coquelin De Lisle, Geneviève. El Tratado de Arquitectura de Alonso de Vandelvira. Madrid: Confederación Española de Cajas de Ahorros, 1977.

Bares, Maria Mercedes. "La Scala Dell'Imperatore: Una Vis de Saint-Gilles Nel Castello Maniace Di Siracusa." In Actas Del Sexto Congreso Nacional de Historia de La Construcción, Valencia 2009, edited by S. Huerta, R. Marín, R. Soler, and A.

Zaragozá, 1:153-62. Instituto Juan de Herrera, 2009.

Bassegoda i Nonell, Juan. "La Construcción de Las Bóvedas Góticas Catalanas." Boletín Académico, no. 11 (1989): 30-38.

Bassegoda Nonell, Juan. La Catedral de Barcelona : Su Restauración, 1968-1972.

Barcelona: Técnicos Asociados, 1973.

Bayard, Jean-Pierre. La Tradition Cachée Des Cathédrales. Saint-Jean-de-Braye: Edition Dangles, 1995. 
Böker, Johann Josef. Architektur Der Gotik : Bestandskatalog Der Weltgrößten Sammlung an Gotischen Baurissen (Legat Franz Jäger) Im Kupferstichkabinett Der Akademie Der Bildenden Künste Wien : Mit Einem Anhang Über Die Mittelalterlichen Bauzeichnungen Im Wien Museum Karlsplatz = Gothic Architecture : Catalogue of the World-Largest Collection of Gothic Architectural Drawings (Bequest Franz Jäger) in the Collection of Prints and Drawings of the Academy of Fine Arts Vienna : With an Appendix of the Medieval Construction Drawings in the Wien Museum Karlsplatz. Akademie Der Bildenden Künste Wien. Kupferstichkabinett. Salzburg ; München: A. Pustet, Cop, 2005.

Bonet Correa, Antonio. "Le Scale Imperiali Spagnole." In Atti Del Convegno Internazionale Di Studi, 631-45. Genova: S.N, 1975.

Bucher, F, ed. Architector: The Lodge Books and Sketchbooks of Medieval Architects. New York: Abaris Books, 1979.

Bucher, François. Medieval Architectural Design Methods : 800-1560. Boston: International Center Of Medieval Art, 1972.

Calbo y Caldés, Pascual. Obras Didácticas. Manuscrito. Museo de Mahón, 1790. 17901817.

Calvo López, José. "Cerramientos y Trazas de Montea de Ginés Martínez de Aranda." Tesis Doctoral, 2000.

Calvo López, José. "Estereotomía de La Piedra." Upct.Es, 2013. https://doi.org/84-8988220-07.

Calvo López, José. "La Literatura de La Cantería: Una Visión Sintética." In El Arte de La Piedra Teoría y Práctica de La Cantería. Cuadernos de Investigación, Vol. Número 01. CEU Ediciones, 2009. Número 01.

Caracciolo, Marella, y Francesco Venturi. Casas Señoriales de Mallorca. Londres: Cartago, 2004.

Carbonell i Buades, Marià. "De Marc Safont a Antoni Carbonell: La Pervivencia de La Arquitectura Gótica En Cataluña." Artigrama, no. 23 (2008): 97-148. . "L'arquitectura a l'època Del Barroc." In L'època Del Barroc i Els Bonifàs : Actes de Les Jornades d'Història de l'Art a Catalunya, Valls, 1, 2 i 3 de Juny de 2006, edited by Bonaventura Bassegoda, Joaquim Garriga, and Jordi Paris. Barcelona: Universitat De Barcelona, 2007.

Carbonell i Buades, Mariá. "Marc Safont ( ca. 1385-1458 ) En l' Arquitectura Barcelonina Del Segle XV. Documents per a Un Esbós Biogràfic." Estudis Històrics $i$ Documents Dels Arxius de Protocols 21 (2003): 181-226.

Carbonell i Buades, Marià, ed. The Palau de La Generalitat de Catalunya, 600 Years -- Art and Architecture. Museu Nacional D'art De Catalunya. Barcelona: Generalitat De Catalunya, 2005.

Carrasco Hortal, José, y Antonio Millán Gómez. La Estructura Gótica Catalana : Sobre Los Conceptos de Medida y Espacio : El Problema de La Forma En La Cubierta. Barcelona: Upc, 2006. 
Carreras Candi, F. "Les Obres de La Catedral de Barcelona." Boletín de La Real Academia de Buenas Letras de Barcelona 7 (1913).

Chueca Goitia, Fernando. Historia de La Arquitectura Española : Edad Antigua y Edad Media. Madrid: Editorial Dossat, 1965.

Cirici, Alexandre, y Jordi Gumí. L'art Gòtic Català : L'arquitectura Als Segles XV i XVI. Barcelona: Edicions 62, 1979.

Cócola Gant, Agustín. "El Barrio Gótico de Barcelona: Planificación Del Pasado e Imagen de Marca." Tesis Doctoral, 2010.

Conrad, Dietrich. Kirchenbau Im Mittelalter : Bauplanung Und Bauausführung. Leipzig: Seemann, 2011.

De La Rue, Jean-Baptiste. Traité de La Coupe Des Pierres, Où Par Une Méthode Facile \& Abregée, I'on Peut Aisément Se Perfectionner En Cette Science. Par J.B. de La Ruë, ... Paris: L'imprimerie Royale, 1728.

Derand, François. L'Architecture Des Voûtes, Ou l'Art Des Traits, et Coupe Des Voûtes: Traicté Tres-Util, Etc. Sebastien Cramoisy: Paris, 1643.

Ecochard, Michel. "Notes d'archéologie Musulmane. Stéréotomie de Deux Portails Du XIle Siècle: La Médersa Maqaddamiya d'Alep, Un Portail Au Château de Sayhun." Bulletin d'études Orientales de I'Institut Français de Damas T.VII-VIII (1937): 83111. République arabe syrienne.

Erlande-Brandenburg, Alain. Quand Les Cathédrales Étaient Peintes. Paris: Gallimard, 2009.

Fallacara, Giuseppe. "For a History of Modern Stereotomy: 1951-2011." In Stereotomy. Stone Architecture and New Research. Paris: Press des Ponts, 2012. "Il Paradigma Stereotomico Nell'arte Del Costruire." Tesis Doctoral, 2003. . Stereotomia Ri-Composta. L'evoluzione Di Una Disciplina Che Insegna a Costruire Lo Spazio. Roma: Aracne, 2012.

Fallacara, Giuseppe, Claudio D'amato, Marco Stigliano, y Richard A Etlin. Stereotomy : Stone Architecture and New Research. Paris: Presses Des Ponts, DI, 2012.

Fitchen, John. The Construction of Gothic Cathedrals : A Study of Medieval Vault Erection. 1961. Reprint, Chicago: University Of Chicago Press, 1997.

Fitchen, John. The Construction of Gothic Cathedrals : A Study of Medieval Vault Erection. Oxford: Clarendon Press, 1967.

Fiteé i Llevot. "L'alberg i l'inventari Patrimonial de Rotllí Gautier, Escultor i Mestre d'obra de La Seu de Lleida (1442)." Seu Vella: Anuari d'història i Cultura, no. 3 (2001): 123-50.

Frankl, Paul. Gothic Architecture. Harmondsworth: Penguin Books, 1962.

Frézier, Amédée François. La Théorie de La Pratique de La Coupe Des Pierres et Des Bois, Pour La Construction Des Voûtes et Autres Parties de Bâtiments Civils et Militaires Ou Traité de Stéréotomie À l'usage de l'architecture. Strasbourg ; Paris, 1737. 
Galindo Díaz, Jorge. "La Enseñanza de La Perspectiva Como Parte de La Fortificación En EI Siglo XVIII: EI Caso de La Real Academia de Matemáticas de Barcelona." Varia Historia 24, no. 40 (December 2008): 465-82. https://doi.org/10.1590/s010487752008000200008.

Gallet, Yves. "Une Voûte à Clef Pendante Du XIIle Siècle à Saint-Urbain de Troyes." Bulletin Monumental 171, no. 1 (2013): 11-21. https://doi.org/10.3406/ bulmo.2013.9519.

Garcia, Simón. Compendio de Architectura y Simetria de Los Templos Conforme a La Medida Del Cuerpo Humano [1681]. 1681. Reprint, Valladolid: Colegio Oficial De Arquitectos De Valladolid, 1991. estudios introductorios de Antonio Bonet Correa y Carlos Chanfón Olmos.

Gayoso Carreira, Gonzalo. "Apuntes Para La Historia Papelera de Las Provincias de Tarragona, Baleares y Canarias." In Investigaciones y Tecnica Del Papel, 675. Madrid, 1974.

Gelabert, Joseph. De l'art de Picapedrer, Manuscrito Facsímile. [1653]. 1653. Reprint, Palma de Mallorca: Diputación, 1977.

Genin, Soraya. "Les Voûtes Manuelines de João Del Castilho. Histoire et Conservation," 2014.

Georg, Otto. The Gothic Cathedral : Origins of Gothic Architecture and the Medieval Concept of Order. Princeton: Princeton University Press, 1989.

Gómez Martínez, Javier. El Gótico Español de La Edad Moderna: Bóvedas de Crucería. Universidad Valladolid: Secretariado De Publicaciones e Intercambio Científico, 1998.

Gómez-Moreno, Manuel. El Libro Español de Arquitectura : Discurso. Madrid, 1949.

Guardia, Alonso de. Manuscrito de Cantería. Ubicación: Biblioteca Nacional de España, Madrid. Signatura: ER/4196, 1598.

Harvey, John. The Gothic World, 1100-1600. Batsford, 1950.

Herráez Cubino, Guillermo. Catalanismos En El Léxico de Los Canteros Del

Renacimiento Español. Biblioteca Virtual Miguel de Cervantes. Alicante: Biblioteca Virtual Miguel de Cervantes, 2008. https://doi.org/https://dialnet.unirioja.es/servlet/ dcart?info=link\&codigo $=5511118$ \&orden $=1$.

Honnecourt, Villard de. Album de Villard de Honnecoutexts Album de Villard de Honnecourt, Architecte Du XIIle [i.e., Triezième] Siècle; Reproduction Des 66 Pages et Dessins Du Manuscrit Français 19093 de La Bibliothèque Nationale. Edited by Henri Omont. Paris: Fréres, 1858.

Huerta, Santiago. Arcos, Bóvedas y Cúpulas: Geometría y Equilibrio En El Cálculo Tradicional de Estructuras de Fábrica. Vol. Vol 97, No 3. Madrid: Instituto Juan de Herrera, 2004.

Hughes, Robert. Barcelona. New York Vintage, 1999.

Iborra Bernard, Federico, y Vicente García Ros. "La Lonja Que No Fue. Reflexiones e Hipótesis Sobre El Proyecto Inicial de La Lonja de Valencia." Anales de Historia Del Arte, August 20, 2012. 
Jean Baptiste Rondelet. Traité Theorique et Pratique de l'art de Batir. Paris: Auteur, 1817. 1802-1817.

Jiménez Martín, Alfonso. La Catedral Gótica de Sevilla : Fundación y Fábrica de La Obra Nueva. Sevilla: Universidad De Sevilla, Secretariado De Publicaciones, Vicerrectorado De Investigación, 2007.

Jousse, Mathurin. Le Secret d'architecture Decouvrant Fidelement Les Traits Geometriques, Couppes et Derobements Necessaires Dans Les Bastimens. La Fleche: Georges Griveau, 1642.

Kubler, George. Arquitectura de Los Siglos XVII y XVIII En España. Madrid, 1957.

L' Horme, Philibert de. Le Premier Tome de l'Architecture. Vol. Livre III. Paris: Federic Morel, 1567.

Lavedan, Pierre. L'Architecture Gothique Religieuse En Catalogne, Valence et Baléares. Paris: Henri Laureen, 1935.

Lluis i Ginovart, J. "Geometría y Traza de Escaleras Góticas. Las Escuadras Como Ábacos En La Construcción de Los Caracoles de La Catedral de Tortosa." Informes de La Construcción 68, no. 541 (2012): 132. http:// informesdelaconstruccion.revistas.csic.es/index.php/informesdelaconstruccion/ article/view/4672/5433.

L'Orme, Philibert de. Le Premier Tome de l'Architecture. 1567. Reprint, Paris: Facsimilar de la principe, Leonce Laget, 1988.

Luis, Antonio. El Proyecto Renacentista En El Tratado de Arquitectura de Hernán Ruiz. Sevilla: Secretariado De Publicaciones, Universidad De Sevilla, 2002.

Martínez de Aranda, Gines. Cerramientos y Trazas de Montea. Facsimilar. Madrid: CEHOPU, 1986.

Mateos, Agustí. Llotja Oberta : Rehabilitació de l'edifici de La Llotja de Mar, 1996-2002. Barcelona: Rqp Arquitectura, 2002.

Matthäus Roritzer, y August Reichensperger. Das Büchlein von Der Fialen Gerechtigkeit : Nach Einem Alten Drucke Aus Dem Jahr 1486 in Die Heutige Mundart Übertragen Und Durch Anmerkungen Erläutert. Trier: Lintz, 1845.

Mercedes Bares, María. "La Scala Dell'Imperatore: Una Vis de Saint-Gilles Nel Castello Maniace Di Siracusa." In Actas Del Sexto Congreso Nacional de Historia de La Construcción, Valencia 2009, Vol. I:153-62. Madrid: Instituto Juan de Herrera, 2009.

Migliari, Riccardo, y Cinzia Conti. II Disegno e La Pietra. Roma: Gangemi, 2000.

Milliet De Chales, Claude-François. Cursus Seu Mundus Mathematicus. Tomus Secundus. Lyon, 1674.

Mira, Eduard, Marco Rosario Nobile, y Arturo Zaragozá Catalán. Una Arquitectura Gótica Mediterránea : [Exposición, Museo de Bellas Artes de Valencia, 2003]. 2. Valencia: Generalitat Valenciana. Consorci De Museus De La Comunitat C, 2003.

Mira, Eduardo, y Arturo Zaragozá Catalán, eds. Una Arquitectura Del Gótico Mediterráneo. Catálogo de La Exposición. Valencia: Generalitat Valenciana. Conselleria de Cultura i Educació, 2003. 
Mojados Ramos, Eduardo. Nociones de Estereotomia. Madrid: Libr. Impr. Y Bibliot. Militar, 1883.

Montaner, Josep Maria. La Modernització de l'utillatge Mental de l'arquitectura a Catalunya (1714-1859). Barcelona: Institut D'estudis Catalans, 1990.

Müller, Werner. Grundlagen Gotischer Bautechnik : Ars Sine Scientia Nihil. München: Deutscher Kunstverlag, 1990.

Müller, Werner, and Norbert Quien. Virtuelle Steinmetzkunst Der Österreichischen Und Böhmisch-Sächsischen Spätgotik : Die Gewölbeentwürfe Des Codex Miniatus 3 Der Österreichischen Nationalbibliothek in Wien. Petersberg: Michael Imhof Verlag, 2005.

Navarro Fajardo, Juan Carlos. Bóvedas de La Arquitectura Gótica Valenciana : Traza y Montea. Valencia: Publicacions De La Universitat De València, 2006.

. "Bóvedas Valencianas de Crucería de Los Siglos XIV AI XVI: Traza y Montea." Tesis Doctoral, 2004.

Navascués Palacio, Pedro. "El Libro de Arquitectura de Hernán Ruiz. Introducción Histórica - Archivo Digital UPM." Oa.Upm.Es, 2011. https://doi.org/http://oa.upm. es/7636/.

Nussbaum, Norbert. German Gothic Church Architecture. New Haven: Yale University Press, 2000.

Nußbaum, Norbert, y Sabine Lepsky. Das Gotische Gewölbe : Eine Geschichte Seiner Form Und Konstruktion. Darmstadt: Wiss. Buchges, 1999.

Palacios Gonzalo, Jose Carlos. "Invención y Convención En Las Técnicas Constructivas Del Renacimiento Español." Tesis Doctoral, 1987.

Palacios Gonzalo, José Carlos. La Cantería Medieval : La Construcción de La Bóveda Gótica Española. Madrid: Munilla-Lería, 2009.

—. La Estereotomía En Las Construcciones Abovedadas. Madrid: Cuaderno del Instituto Juan de Herrera de la ETSAM, 1999.

- Taller de Construcción Gótica I: Workshop on Building Gothic Methods I. Madrid: Munilla-Lería, 2015.

—. Trazas y Cortes de Canteria En El Renacimiento Español. Madrid: Ministerio De Cultura, Instituto De Conservación Y Restauración De Bienes Culturales, 1990.

Palacios Gonzalo, José Carlos, y Sandra C Bravo Guerrero. "Diseño y Construcción de Las Bóvedas Por Cruceros En España Durante EI Siglo XVI.” Informes de La Construcción 65, no. Extra-2 (October 14, 2013): 81-94. https://doi.org/10.3989/ ic.13.022.

Palacios Gonzalo, José Carlos, y Rafael Martín Talaverano. "Complejidad y Estandarización En Las Bóvedas Tardogóticas." Anales de Historia Del Arte, no. 22 (August 20, 2012): 375-87.

Palacios Gonzalo, Jose Carlos, y Rafael Martín Talaverano. "La Construcción de Una Bóveda de Crucería En La Escuela Técnica Superior de Arquitectura de Madrid." Informes de La Construcción 61, no. 515 (September 14, 2009): 49-58. https://doi. org/10.3989/ic.08.058. 
Palacios Gonzalo, Jose Carlos, y Fabio Tellia. “Aplicación Del 'Prinzipalbogen' Al Estudio de Una Bóveda 'Libre de Trasas' de Joseph Ribes." In 1514 Arquitectos Tardogóticos En La Encrucijada, edited by Begoña Alonso Ruiz, Juan Clemente, Alfonso Jiménez Martín, and Begoña Laguna Paul, 571-84. Sevilla: Editorial Universidad De Sevilla, 2016.

Palacios Gonzalo, José Carlos, y Fabio Tellia. "Descimbrado de Una Bóveda de Crucería Gótica de Josep Rives." YouTube Video. YouTube, November 7, 2014. https:// www.youtube.com/watch?v=WfBRtVNs8Dc.

Palacios Gonzalo, Jose Carlos, and Fabio Tellia. "Inclined Keystones in Spanish Late Gothic." In Proceedings of the Fifth International Congress on Construction History in Chicago, June 3rd-7th, (Chicago 2015). Chicago, 2015.

Perelló Ferrer, Antonia Maria. L'arquitectura Civil Del Segle XVII a Barcelona. Barcelona L'abadia De Montserrat, 1996.

Perello Ferreŕ, Maria. Esglésies Dels Segles XVII i XVIII a Ciutat de Mallorca : Influències Tendències i Tipologies Artístiques. Palma De Mallorca: Moll, 1985.

Pérez de los Ríos, Carmen. "Aspectos Formales y Constructivos En La Obra de Guillem Sagrera: El Uso de Las Plantillas." Tesis Doctoral, 2016.

Perouse de Montclos, Jean-Marie. "La Vis de Saint Gilles et l'escalier Suspendu Dans l'architecture Française Du Xvi Siécle." In L'escalier Dans l'architecture de La Renaissance. Paris: Picard, 1985.

Pérouse De Montclos, Jean-Marie. L'architecture À La Française : XVI-XVII-XVIII Siècles. Paris: Librarie La Porte Etroite, 1982.

Ponte y Blanco, Francisco. Manual Práctico de Estereotomía: Aplicaciones Al Corte de Piedras, Maderasy Hierros. La Coruña: Ferrer, 1904.

Ponz y Aguilar, Antonio. Viaje a España. Madrid: por la viuda de D. Joaquin Ibarra, 1794. http://www.bibliotecavirtualdeandalucia.es/catalogo/es/catalogo_imagenes/grupo. cmd?path=158256.

Portor i Castro, Juan. Cuaderno de Arquitectura. Madrid: Biblioteca Nacional, Ms. 9114, 1708.

Portor y Castro, Juan de. Cuaderno de Arquitectura de Juan de Portor y Castro [Manuscrito]. Bdh.Bne.Es, 1708.

Potié, Philippe. Philibert de L'Orme : Figures de La Pensée Constructive. Marseille: Editions Parenthèses, 1996.

Rabasa Díaz, Enrique. "Construcción de Una Bóveda de Crucería En El Centro de Oficios de León." In Actas Del Cuarto Congreso Nacional de Historia de La Construcción. Cádiz, 27 - 29 de Enero de 2005. Madrid: Instituto Juan de Herrera, 2005. El Manuscrito de Cantería de Joseph Gelabert : Titulado Vertaderas Tra-Ces Del Art de Picapedrer : Transcripción, Traducción Anotación e llustración Del Texto y Los Trazados. [Ms. 1653]. Madrid: Fundacion Juanelo Turriano, 2011. Forma y Construcción En Piedra : De La Cantería Medieval a La Estereotomía Del Siglo XIX. Madrid: Akal Ediciones, 2000. . "Los Arcos Oblicuos En La Traza de Cantería." Revista de E.G.A., no. 2 (1994): 145-54. 
Rabasa Díaz, Enrique, José Calvo López, y Rafael Martín Talaverano. "Bóvedas de Crucería Que Se Proyectan En Planta Según Una Matriz de Estrellas. Transmisión de Conocimiento Técnico En El Tardogótico Europeo." In Actas Del Décimo Congreso Nacional y Segundo Congreso Internacional de Historia de La Construcción : Donostia-San Sebastián, 3 a 7 de Octubre 2017, edited by Santiago Huerta, Paula Fuentes, and Ignacio J. Gil Crespo. Madrid: Instituto Juan De Herrera, 2017.

Ribes, Joseph. Llibre de Trasas de Vias y Muntea. Barcelona: Ms. Biblioteca Nacional de Catalunya, 1708.

Rovira y Rabassa, Antoni. Estereotomía de La Piedra. Barcelona: Provincial de la Caridad, 1897.

Sabater Rebassa, Tina. "Guillem Sagrera, Arquitecto y Escultor." In Llonja de Palma. Palma de Mallorca: Govern Balear, 2003.

Sakarovitch, Joël. Épures d'architecture : De La Coupe Des Pierres À La Géométrie Descriptive, XVIe - XIXe Siècles. Basel ; Boston ; Berlin: Birkhäuser, 1998.

Sakarovitch, Joel. "Gèomètrie Practique, Gèomètrie Savante. Du Trait Des Tailleurs de Pierre à La Gèomètrie Descriptive." In Géométrie, Mesure Du Monde, edited by Thierry Paquot, 45-60. Paris: La Découverte, 2005.

Saltamacchia, Martina. Costruire Cattedrali : Il Popolo Del Duomo Di Milano. Genova: Marietti, 2011.

Salvat, Juan. El Escudo de Armas de La Ciudad de Tarragona. Tarragona: Ayuntamiento, 1975.

Sanabria, Sergio Luis. The Mechanization of Design in the 16th Century : The Structural Formulae of Rodrigo Gil de Hontañón. S.L.: Princeton University, Society Of Architectural Historians, 1982.

Sanjurjo, Alberto. "La Escalera de Caracol En Los Tratados de Estereotomía Españoles." Tesis Doctoral, 2016.

Senent Domínguez, Rosa. "La Deformación Del Tipo. Construcción de Bóvedas NoCanónicas En España (Siglos XVI-XVIII).” Tesis Doctoral, 2016.

Shelby, Lonnie R. Gothic Design Techniques : The Fifteenth-Century Design Booklets of Mathes Roriczer and Hanns Schmuttermayer. Carbondale: Southern Illinois University Press, 1977.

Talaverano, Rabasa, y Calvo-López. "Bóvedas de Crucería Que Se Proyectan En Planta Según Una Matriz de Estrellas. Transmisión de Conocimiento Técnico En El Tardogótico Europeo." In Actas Del II Congreso Hispanoamericano de Historia de La Construcción, 2017. 
Tellia, Fabio. "El Tratado de Estereotomía de Joseph Ribes, 1708." In Actas Del Séptimo Congreso Nacional de Historia de La Construcción, Santiago de Compostela, 2629 Octubre de 2011, edited by Santiago Huerta Fernández, 2:1413-20. Madrid: Instituto Juan de Herrera, 2011.

"Las Bóvedas de Crucería En El Llibre de Trasas de Viax y Muntea de Joseph Ribes." In Actas Del Octavo Congreso Nacional de Historia de La Construcción. Madrid, 9-12 de Octubre de 2013, edited by Santiago Huerta and Fabián López Ulloa, 1017-25. Madrid: Instituto Juan de Herrera, 2013. https://doi.org/10.5565/ rev/locus.235.

- "Stereotomy and Architectural Design at Foster+ Partners." Nexus Network Journal 20, no. 3 (May 15, 2018): 605-26.

Tellia, Fabio, y Garcia Ares, Jose Antonio. "Some Instances of Arch and Vaulting Construction at the New York Public Library." In Proceedings of the First Construction History Society Conference, Queen's College, University of Cambridge 11th-12th April 2014, edited by James W P Campbell. Ascot: Construction History Society, 2014.

Tellia, Fabio, y Miquel Bibiloni Terrasa. "Características Geométrico-Constructivas de Los Capiteles Pinjantes En Cataluña." In Actas Del Décimo Congreso Nacional y Segundo Congreso Internacional Hispanoamericano de Historia de La Construcción. Donostia-San Sebastián, 3 - 7 Octubre 2017, edited by Santiago Huerta, Paula Fuentes, and Ignacio J. Gil Crespo, 3:1615-24. Madrid: Instituto Juan de Herrera, 2017.

Tellia, Fabio, y José Carlos Palacios Gonzalo. "Las Bóvedas de Crucería Del Manuscrito Llibre de Trasas de Viax y Muntea, de Joseph Ribes." Locus Amoenus, 2015. "The Squinch Vaults in Joseph Ribes, Libre de Trasas De Viax y Muntea." In 4th International Congress on Construction History. 3-7 Julio 2012, edited by Valérie Nègre, Joël Sakarovitch, André Guillerme, and Robert Carvais, 647-54. Paris: Picard, 2012.

Torres Balbás, Leopoldo. "Los Teorias Sobre La Arquitectura Gótica y Los Bóvedas Do Ojivas." Las Ciencias, no. 1 (1939).

Tosca, Tomás Vicente. Tratado de La Montea y Cortes de Cantería. Madrid: Imprenta de Antonio Mar, 1797.

Trevisan, Camillo. "La Trompe Di Anet e Le Sue Variazioni Ottenute Mediante II Programma TROMPE," 1997. http://www.camillotrevisan.it/stereo/anet.pdf. . "Sulla Stereotomia, II CAD e Le Varie Trompe d'Anet." In Geometria e Architettura, Strumenti Del Dottorato Di Ricerca in Rilievo e Rappresentazione, edited by Riccardo Migliari, 27-53. Roma: Gangemi, 2000.

Triadó Tur, Joan-Ramón, y Francesc Català-Roca. L'Epoca Del Barroc, s. XVII - XVIII. Història de l'art català. Vol. 5. Barcelona: Edicions 62, 1984.

Valls i Subirà, Oriol. Paper and Watermarks in Catalonia. Amsterdam: Paper Publications Society, 1970. 
Vandelvira, Alonso de. Libro de Cortes de Cantería de Alonso de Vandelvira, Arquitecto.

Sacado a Luz y Aumentado Por Philipe Lázaro de Goiti, Arquitecto, Maestro Mayor de Obras Dela Santa Iglesia de Toledo, Primada de Las Españas, y de Todas Las de Su Arçobispado. Dirigido a Su Ilustrisimo Cabildo [s.I.]: [Manuscrito], [15881591]. Edited by Felipe Lazaro de Goiti, 1646. Biblioteca Nacional de España, Madrid. Signatura: Mss/12719.

Vidal Franquet, J. "Els Dos Testaments Coneguts de Petit Joan Sarnoto. Edició i Notes." RACBASJ. Butlletí XXIII-XXIV (2009).

Viollet-Le-Duc, Eugène-Emmanuel. Dictionnaire Raisonné de l'architecture Française Du Xle Au XVIe Siècle. Tomo III. Vol. Tomo III. Édition Bance-Morel, n.d.

Wilkinson, Catherine. "La Calahorra and the Spanish Renaissance Staircase." In L'Escalier à La Renaissance, edited by A. Chastel and J. Guillaume, 153-60. Paris, 1985.

Willis, Robert. Transactions of the Royal Institute of British Architects of London. London: Longmans, 1842. Reprinted from the Transactions of the Royal Institute of British Architects. Vol. 1, part 2. London: Royal Institute of British Architects.

Yasser, Tabbaa. The Transformation of Islamic Art during the Sunni Revival. London: I.B. Tauris, 2001.

Yeguas, Joan. “Obres Al Convent de Bellpuig (1507-1535)." Urtx: Revista Cultural de l'Urgell 17 (2004). Tàrrega: Museu Comarcal de l'Urgell.

Zaragozá Catalán, Arturo. "A Propósito de Las Bóvedas de Crucería y Otras Bóvedas Medievales." Anales de Historia Del Arte, 2008.

. Arquitectura Gótica Valenciana, Siglos XIII-XV. Valencia: Generalitat Valenciana, Conselleria De Cultura, Educació I Ciència, Direcció General De Patrimoni Artístic, 2000.

. El Arte de Corte de Piedras En La Arquitectura Valenciana Del Cuatrocientos : Un Estado de La Cuestión: Discurso de Ingreso Del Académico Electo IImo. Sr. D. Arturo Zaragoza Catalán, Leído En El Salón de Actos de La Academia El Día 29 de Enero de 2008. Valencia Real Academia De Bellas Artes De San Carlos De Valencia, 2008.

. "La Escalera de Caracol Tipo Vis de Saint-Gilles." In LEXICON: Storie e Architettura in Sicilia, 8-14, 2007.

. "Las Escaleras Con Bóveda Continua de Piedra: Técnicas y Significados. El Episodio Valenciano de La Edad Moderna." In Le Scale in Pietra a Vista Nel Mediterraneo, edited by Giuseppe Antista and María Mercedes Bares. Palermo: Caracol, 2013.

Zaragozá Catalan, Arturo, y Maria Gomez-Ferrer Lozano. Pere Comte, Arquitecto. Generalitat Valenciana, 2007.

bovedasgoticasdecruceria.com, 2011. https://bovedasgoticasdecruceria.com/ .

Monestirs.cat, 2013. https://monestirs.cat/.

Rutas con Historia. https://www.rutasconhistoria.es/. 
